Agatha Frischmuth

\title{
NICHTSTUN \\ ALS POLITISCHE \\ PRAXIS
}

Literarische Reflexionen von Untätigkeit in der Moderne

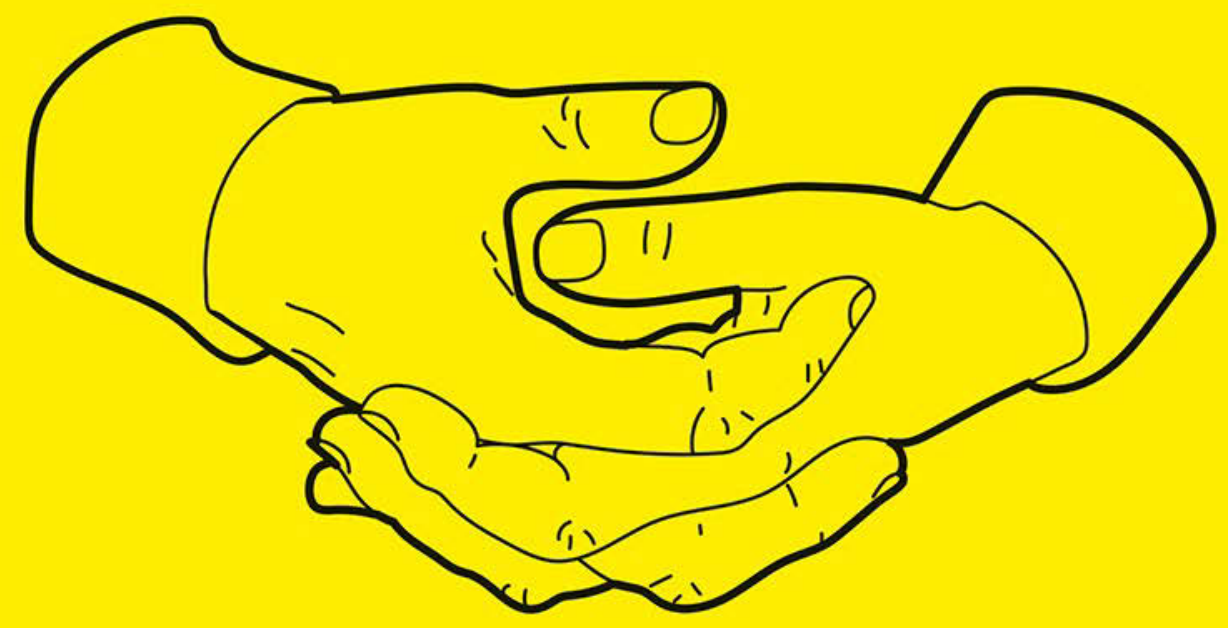

[transcript] $\begin{aligned} & \text { S)TUDIEN DER K)ULTURWISSENSCHAFTLICHEN } \\ & \text { G)ESELLSCHAFT }\end{aligned}$ 
Agatha Frischmuth

Nichtstun als politische Praxis

Studien der Kulturwissenschaftlichen Gesellschaft | Band I 


\section{Editorial}

Die Studien der Kulturwissenschaftlichen Gesellschaft versammeln innovative Beiträge, die aus theoretisch-programmatischer oder empirischer Perspektive kulturwissenschaftlichen Fragestellungen nachgehen. Die Buchreihe nimmt Sammelbände und Monographien auf, die vornehmlich den einzelnen Sektionen der Kulturwissenschaftlichen Gesellschaft (KWG) entstammen und folgende thematische Bereiche umfassen: Materielle Kulturen, Kulturphilosophie und Kulturtheorie, Kulturwissenschaftliche Ästhetik, Kulturwissenschaftliche Border Studies, Medienkulturen, Naturen/Kulturen, Sprache und kommunikative Praktiken, Transkulturelle Lebenswelten, Raum und Kultur, Wissenskulturen und Kritische Methodologie. Über die Arbeiten der KWG hinaus begrüßt die Reihe Forschungsarbeiten, die zur Stärkung methodischer, theoretischer und anwendungsorientierter Ansätze im Umgang mit kulturellen Praktiken beitragen.

Die Reihe wird herausgegeben von Thomas Metten, Giulia Pelillo und Teresa Pinheiro.

Agatha Frischmuth, geb. 1986, lebt in Berlin, wo sie an der Freien Universität in Allgemeiner und Vergleichender Literaturwissenschaft promovierte. Für Ihre Doktorarbeit »Nichtstun als Praxis« erhielt sie 2020 den Dissertationspreis der Kulturwissenschaftlichen Gesellschaft. 
Agatha Frischmuth

\section{Nichtstun als politische Praxis}

Literarische Reflexionen von Untätigkeit in der Moderne 
Dieses Buch ist eine überarbeitete Fassung der Dissertation »Nichtstun als Praxis«, die von 2014 bis 2019 am Peter Szondi-Institut der Freien Universität Berlin entstanden ist und von Georg Witte und Michael Gamper betreut wurde. Ihre Entstehung wurde ermöglicht durch ein Promotionsstipendium der FriedrichNaumann-Stiftung für die Freiheit.

Der Druck wurde gefördert durch die Ernst-Reuter-Gesellschaft der Freunde, Förderer und Ehemaligen der Freien Universität Berlin e.V. und die digitale Publikation wurde ermöglicht durch eine Ko-Finanzierung für Open-Access-Monografien und -Sammelbände der Freien Universität Berlin.

\section{Bibliografische Information der Deutschen Nationalbibliothek}

Die Deutsche Nationalbibliothek verzeichnet diese Publikation in der Deutschen Nationalbibliografie; detaillierte bibliografische Daten sind im Internet über http://dnb.d-nb.de abrufbar.

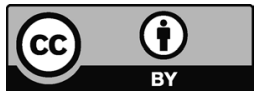

Dieses Werk ist lizenziert unter der Creative Commons Attribution 4.o Lizenz (BY). Diese Lizenz erlaubt unter Voraussetzung der Namensnennung des Urhebers die Bearbeitung, Vervielfältigung und Verbreitung des Materials in jedem Format oder Medium für beliebige Zwecke, auch kommerziell. (Lizenztext: https://creativecommons.org/licenses/ by/4.0/deed.de)

Die Bedingungen der Creative-Commons-Lizenz gelten nur für Originalmaterial. Die Wiederverwendung von Material aus anderen Quellen (gekennzeichnet mit Quellenangabe) wie z.B. Schaubilder, Abbildungen, Fotos und Textauszüge erfordert ggf. weitere Nutzungsgenehmigungen durch den jeweiligen Rechteinhaber.

\section{Erschienen 2021 im transcript Verlag, Bielefeld (c) Agatha Frischmuth}

Umschlaggestaltung: Maria Arndt, Bielelfeld

Druck: Majuskel Medienproduktion GmbH, Wetzlar

Print-ISBN 978-3-8376-5739-5

PDF-ISBN 978-3-8394-5739-9

https://doi.org/10.14361/9783839457399

Gedruckt auf alterungsbeständigem Papier mit chlorfrei gebleichtem Zellstoff. Besuchen Sie uns im Internet: https://www.transcript-verlag.de

Unsere aktuelle Vorschau finden Sie unter www.transcript-verlag.de/vorschau-download 


\section{Inhalt}

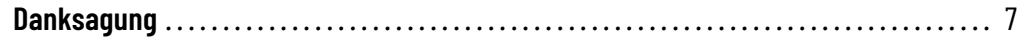

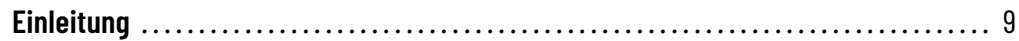

Philosophische Überlegungen: Nichtstun als politische Praxis .............. 23

Handlung und Geschichte .......................................... 24

Überwindung der Zweck-Mittel-Relation ............................. 26

Ereignis und Geschichte ....................................... 32

Rekonzeptualisierung des Handelns ............................. 35

Gemeinschaft .................................................... 40

Gemeinschaft durch Tätigkeit und Arbeit .......................... 41

Gemeinschaft 2.0: Werklosigkeit ................................ 46

Bartleby: kollektive Distanz, reine Potenz ......................... 51

Herrschaft ...................................................... 57

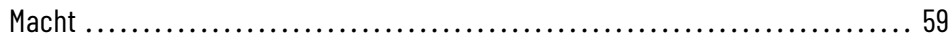

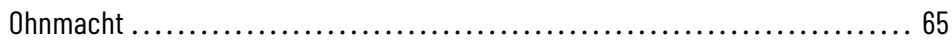

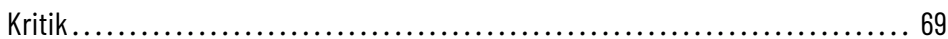

Poetische Überlegungen: Binäropposition und Uneigentlichkeit .............. 73

Binäropposition ............................................ 74

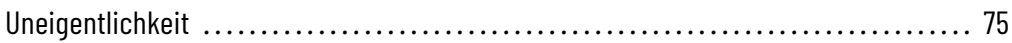

Arbeit vs. Muße................................................. 81

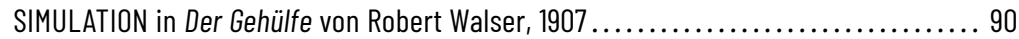

Unverhältnismäßigkeiten der Arbeit ..............................91

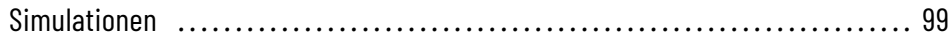

Ostentative, unechte Muße ............................ 100

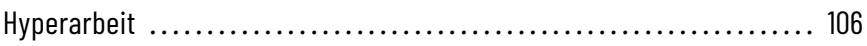


\Ostı/Inaktiv vs. ১Westı/Aktiv .................................... 131

PROJEKTION in Der Zauberberg von Thomas Mann, 1924 ....................... 141

১Orientalisiertes Nichtstun ................................ 142

Inaktivität begehren ................................ 144

Angst vor dem Osten................................. 154

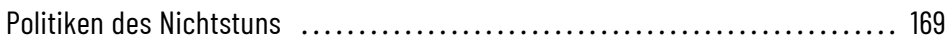

$»$ Regieren«: Herrschaft durch Nichtstun ....................... 169

»Politischer Faktor « - Gemeinschaft statt Politik ................ 180

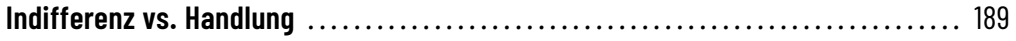

PRÄTENTION in Un homme qui dort von Georges Perec, 1967 .................... 194

Rund um das Handlungsparadigma 1968 .......................... 195

Das Projekt Indifferenz ................................... 200

Performativer Widerspruch ................................. 205

Indifferenz als Kritik .................................. 211

Handlung und geschichtsphilosophische Fremdbestimmung ..............215

Nichtstun als geschichtliche Selbstbestimmung ................. 223

Kontrollverlust und Herrschaftsphantasie .................... 228

Aufgabe der Indifferenz und Rückkehr in die Gemeinschaft ...............241

Sprechen vs. Handeln ............................................ 249

KOMPENSATION in Bombel von Mirosław Nahacz, 2004 ...................... 254

Dorf und Bushaltestelle: Räume praktischen Nichtstuns ............... 255

Erzählen ..................................................261

Arbeit, eine Lüge ................................... 272

Fortschrittsillusion .................................... 277

Biopolitik vs. Organische Gemeinschaft ......................... 281

Kontrolle des inaktiven Körpers ............................. 284

Gemeinschaft der Nichtstuer............................ 290

Fazit und Ausblick ........................................ 297

Literaturverzeichnis......................................... 309 


\section{Danksagung}

\section{Dank gilt}

Georg Witte für sein Vertrauen, kritisches Fragen, und gute Laune Meinen Eltern Kurt und Bożena für ihre Güte, Großzügigkeit und die Freiheit, die sie mir ließen

Meinem Vater für die unschätzbar wertvolle redaktionelle Hilfe vor der Abgabe Meinem Mann Maximilian für das Schaffen einer humorvoll-harmonischen

Welt außerhalb dieser Arbeit

Elisa Leroy, Thomas Erthel, und Clemens Günther für stets produktives

$$
\text { Mitdenken }
$$

Markus Krumm für Foucault und seine Freundschaft

Christina Färber und Therese Hoy für ihre Kameradschaft

Ruth Signer für ihr Lektorat und Annett Kamke für das Korrekturlesen

Der Stabi-Gang für lustige Pausen

Dem Doktorandenkolloquium für die dort praktizierte Ehrlichkeit

Meinen Studierenden für ihr Engagement

Dirk Linowski für seine Hilfe bei der Stipendiumsbewerbung

Michael Gamper, Alfrun Kliems, Kathrin Busch und Leonie Achtnich für ihren Zuspruch und ihr Interesse an dieser Arbeit. 



\section{Einleitung}

Liest man ein Buch wie Georges Perecs Un homme qui dort (1967), dessen Erzähler - ein junger Student - davon berichtet, nicht zu seiner Abschlussprüfung zu gehen, dann wirft das Fragen auf. Obwohl die Hauptfigur ohne Unterlass wiederholt, dass sie nichts tut, liegt die Sache nicht so eindeutig, wie man meinen möchte. Denn ist nicht schon der Bericht über eine solche NichtBegebenheit von einer bezeichnenden Ambiguität geprägt?

Plus tard, le jour de ton examen arrive et tu ne te lèves pas. Ce n'est pas un geste prémédité, ce n'est pas un geste, d'ailleurs, mais une absence de geste, un geste que tu ne fais pas, des gestes que tu évites de faire. [...] Ton réveil sonne, tu ne bouges absolument pas, tu restes dans ton lit, tu refermes les yeux. ${ }^{1}$

Später kommt der Tag deiner Prüfung, und du stehst nicht auf. Es ist kein vorbedachtes Handeln, es ist übrigens gar kein Handeln, sondern ein Nichthandeln, ein Handeln, das du unterlässt, das du vermeidest. [...] Dein Wecker läutet, du rührst dich überhaupt nicht, du bleibst im Bett liegen, du machst die Augen wieder zu. ${ }^{2}$

Die Bewegungslosigkeit, das Liegen, das Schließen der Augen, all das mag tatsächlich wie Nichthandeln anmuten. Doch es regen sich gleichzeitig Zweifel. Denn spricht der Erzähler nicht jemanden an, indem er wiederholt »tu« sagt? Selbst wenn er mit sich selbst spricht, ist nicht auch so ein Sprechen eine Handlung? Nicht zuletzt gibt der Begriff »geste« Rätsel auf: wird hier die Anwesenheit einer Handlung verneint, oder die Lesbarkeit einer Geste? Ist

1 Georges Perec: Un homme qui dort. Paris: Éditions Denoël (1967), 23.

2 Georges Perec: Ein Mann der schläft. Übers. v. Eugen Helmlé. Zürich: Diaphanes (2012), 14. 
entscheidend, ob die Handlung "prémédité« ist, ja ist nicht die Vermeidung oder Unterlassung einer Handlung auch eine Tätigkeit?

Das Thema des Nichtstuns verlangt es von der literaturwissenschaftlichen Forschung, sich mit solchen Fragen zu beschäftigen. Eine kann ich schon vorab beantworten: Der Student ist tätig, trotz seiner Behauptung, nichts zu tun. Ein in der Literatur dargestelltes Nichtstun, das ist die Prämisse dieses Buches, ist in den meisten Fällen mit Tätigkeit verbunden. Nichtstun ist also kein negatives, sondern ein positives Phänomen. Obwohl das einige Studien ganz anders sehen und das Nichtstun hauptsächlich als Mangel darstellen, ${ }^{3}$ ist die Idee des Nichtstuns als positives Phänomen in der Literaturwissenschaft nicht neu. Leonhard Fuest, Autor der bislang umfangreichsten Studie zur Poetik des Nichtstuns im deutschen Raum, sieht dies ähnlich: "So wie also in der Passivität das Schreiten [frz. "pas« bedeutet dt. »Schritt«] noch anwesend ist, ist zumindest auch das Nichtstun nie frei von allem Tun «. ${ }^{4}$ So wie Fuest zufolge im Nichtstun noch ein Tun enthalten ist, betrachten Barbara Gronau und Alice Lagaay das Nichtstun als gleichbedeutend mit einem Tun, indem sie behaupten, dass Nichtstun und Nichtsprechen mit John L. Austins Konzept des performative speech auch als Sprechakt angesehen werden müssen. »Muss ein Denken des Performativen nicht so angelegt sein, dass nicht nur das Handeln, sondern vielmehr auch das Unterlassen von Handlungen performativ wirksam werden kann? ${ }^{5}$ Aus ihrer Perspektive ist ein Nichtstun (bzw. ein >Nichttun`) nicht weniger performativ als jedes andere Tun. Über

3 Demgegenüber stehen eine Reihe von Studien, die das Nichtstun wirklich im Sinne einer Abwesenheit untersuchen, so wie Schaffner in ihrer Motivgeschichte der Erschöpfung derselben tatsächlich »apathy«, »paralysis and inaction« zuschreibt. Anna K. Schaffner: Exhaustion. A History. New York: Columbia UP (2016), 13, 26. Studien anderer Fachrichtungen tendieren ebenfalls dazu, das Nichtstun als ein negatives Phänomen, d.h. nur in Bezug auf seinen >Mangel z zu verstehen. So zum Beispiel bei dem Soziologen Alain Ehrenberg, der einen psychopathologischen Zusammenhang zwischen dem Nichtstun und den dominanten Tätigkeitsansprüchen der zeitgenössischen Gesellschaft festgestellt. Ansprüche wie hohe Arbeitsleistung und Selbstoptimierung in einer Welt, in der prinzipiell alles möglich sein soll, provozieren Überforderung und Erschöpfung. Aus dieser Spannung heraus entwickele sich die Depression, die gekennzeichnet sei von der »Unfähigkeit zu handeln«. Alain Ehrenberg: Das erschöpfte Selbst. Depression und Gesellschaft in der Gegenwart. Übers. v. Manuela Lenzen u.a. Frankfurt a.M.: Campus (2004), 157.

4 Leonhard Fuest: Poetik des Nicht(s)tuns. Verweigerungsstrategien in der Literatur seit 1800. München: Fink (2008), 15.

5 Barbara Gronau u. Alice Lagaay: Performanzen des Nichttuns. Wien: Passagen (2008), 11. 
das literarische Motiv der Gelassenheit sagt Thomas Strässle, es bedeute zwar »Sein über Tun « (und komme so einem Nichtstun nah), das hieße aber »nun nicht, dass die Gelassenheit mit Tatenlosigkeit zu verwechseln wäre ${ }^{6}$ Im Gegenteil: »In allen Fällen bezeichnet das Lassen eine Form des Handelns «. ${ }^{7}$

Betrachtet man das Nichtstun als ein Tun, stellt sich eine Folgefrage: Was für eine Art des Tuns spielt sich in diesem und durch dieses Nichtstun ab? Welchen Status hat es im Vergleich mit anderen menschlichen Tätigkeiten? Auch auf diese Frage gibt es in der Forschung bereits einige Antworten. Die Literaturwissenschaft, die das Nichtstun in all seinen verschiedenen Formen und Begriffen untersucht - als Müßiggang, Melancholie, Muße, Langeweile, Ennui und anderen - kommt in der Frage, inwiefern diese Phänomene Tätigkeit aufweisen, oft auf zwei Ideen zurück: geistige Beschäftigung und kreatives Schaffen (im Gegensatz zu einer Leistung mit greifbarem Produkt, oder einer Arbeit). »Wie der Müßiggang kann die Melancholie eine Voraussetzung für Denken und Dichten sein «, schreibt Gisela Dirschner. ${ }^{8}$ Ulrich Schnabel behauptet, dass sich der menschliche Einfallsreichtum direkt aus der Muße speise. ${ }^{9}$ Auch Byung-Chul Han argumentiert aus der Perspektive des Kulturwissenschaftlers, dass ein Abrücken von Hyperaktivität und das Zulassen von Langeweile notwendig sind für den »kreativen Prozess «. ${ }^{10}$ Dieser kreative Prozess wird in den Literaturwissenschaften nicht zufällig häufig als literarische Produktion verstanden. Wer unter Ennui leide, so Reinhard Kuhn, der werde dadurch $\mathrm{zu}$ einem »creative act « literarischer Art verleitet - »if there is one trait that most victims of boredom have in common, it is the desire to express in writing their state of mind «. ${ }^{11}$ Wenn es der Literaturwissenschaft also nicht um die Darstellung eines denkenden Subjekts geht, so entzünden sich am Topos des Nichtstuns Fragen über das Schreiben, Konzepte der Au-

6 Thomas Strässle: Gelassenheit. Über eine andere Haltung zur Welt. München: Hanser (2013), 50.

7 Strässle: Gelassenheit, 21.

8 Cisela Dischner: Melancholie und Müßiggang - Eine Zustandsbeschreibung. In: Ökonomie des Clücks. Muße, Müßiggang und Faulheit in der Literatur. Hg. v. Mirko Gemmel u.a. Berlin: Ripperger \& Kremers (2014), 7.

9 Vgl. Ulrich Schnabel: Muße. Vom Clück des Nichtstuns. München: Blessing (2010).

10 Byung-Chul Han: Müdigkeitsgesellschaft. Berlin: Matthes \& Seitz (2010), 26.

11 Reinhard C. Kuhn: The Demon of Noontide. Ennui in Western Literature. Princeton: UP (2017), 4. 
torschaft und nach der Beschaffenheit von Kunst. ${ }^{12}$ Dass so auch der Begriff der »Technik « eines Nichtstuns aufkommt, ist nicht verwunderlich. ${ }^{13}$

Doch ich glaube, dass Nichtstun als literarisches Motiv mehr darstellen kann als das Denken, und mehr zu reflektieren vermag als künstlerische Kreativität. In diesem Buch geht es darum, dass Nichtstun auch Praxis sein kann eine andere Art der Praxis jedoch, die sich nicht auf eine Tätigkeit beschränkt, die wie die literarische Produktion mit körperlicher Untätigkeit und einer gewissen Welt-Entzogenheit assoziiert ist. Im Gegenteil: Indem es normale Aktivitäten unterbricht, verweigert, und verändert, zieht es die Art der tätigen Gestaltung des menschlichen Lebens prinzipiell in Zweifel. Es eröffnet damit die Möglichkeit, sich zu fragen, ob Dinge auch anders getan werden können - nicht nur, ob man etwas anderes tun könnte, sondern ob Tun und Handeln anders gedacht werden können. So stellt sich in Georges Perecs Un homme qui dort nicht nur die Frage, warum der Student nicht zu seiner Prüfung geht, sondern auch, ob und warum Prüfungen notwendig sind. Oder, um noch einen Schritt weiter zu gehen, warum man überhaupt die Universität besuchen sollte, ob sie im Frankreich der 1960er-Jahre eine sozial gerechte Institution ist, ob die Gesellschaft von ihrer Existenz profitiert - ob dieses Tun also überhaupt auf sinnvolle Weise gestaltend in die Gesellschaft eingreift. Wo ein Nichtstun dargestellt wird, provoziert es ethische und politische Grundsatzfragen: Sind die Tätigkeiten, denen wir konventionellerweise nachgehen, die besten Tätigkeiten? Wollen wir so unser politisches Leben gestalten? Welche Handlungen sind dafür relevant, welche nur scheinbar?

Für genau solche Fragen habe ich mich interessiert. Ich bin letztlich $\mathrm{zu}$ dem Schluss gekommen, dass das Nichtstun eine politische Tätigkeit ist, und dass seine literarische Darstellung Reflexionsprozesse über das Politische abbildet.

12 Robert Krause führt aus, dass »Muße in der Moderne« als ein »Schlüsselkonzept für die Ausbildung von Subjektivitäts-, Kunst- und Autorenentwürfen « fungiere. Robert Krause: Muße und Moderne. Zur Einführung. In: Muße und Moderne. Hg. v. Dems. u.a. Tübingen: Mohr Siebeck (2018), 3.

13 Claudia Lillge u.a. verweisen auf einen aus dem 18. Jahrhundert stammenden Wörterbucheintrag zum Begriff »Müßiggang«, der denselben nicht nur als »unthätige Unterlassung der pflichtmäßigen Arbeit« definiert, sondern auch als »die Fertigkeit dieser Unterlassung «. Darauf aufbauend heißt es später: »Muße und Müßiggang werden von den Romantikern auf vielfältige Weise als entscheidende Selbsttechniken der romantischen Existenzweise reflektiert und praktiziert.«Claudia Lillge u.a.: Arbeit und Müßiggang in der Romantik. Eine Einführung. In: Arbeit und Müßiggang in der Romantik. Hg. v. Ders. u.a. Paderborn: Fink (2016), 17, 28. Beide Herv. meine. 
Aus dieser These leiten sich auch die zwei Kernbegriffe dieses Buches ab: Nichtstun und Praxis. Ich definiere das Nichtstun als Abwesenheit nicht allen Tuns, sondern eines als >wichtig konnotierten Tuns. Es stellt eine kontextuell, historisch oder diskursiv als >mangelhaft، ausgewiesene Tätigkeit dar. Eine Tätigkeit, die einem (beliebig) gesetzten Standard, einer bestimmten Erwartung, einer gesellschaftlichen Konvention nicht genügt. Man muss es immer neu definieren, indem man den Rahmen bestimmt, gegen den es im jeweiligen Kontext gesetzt ist. Dabei stellen sich viele Fragen immer neu: Fragen der Wertigkeit und Wertschätzung (Bringt es Glück oder Leid?), der sozialen Akzeptanz (Wird es gefeiert oder verdammt?), des historischen Kontextes (Hat es - beispielsweise - ein Krieg ausgelöst, oder die Arbeitslosigkeit?), der Freiwilligkeit (Ist es selbstgewählt oder aufgezwungen?), des Zeitgeistes (Könnte es ein Problem der Moderne sein?), des intellektuellen oder spirituellen Ursprungs (Kommt es aus der Religion, der Philosophie, oder gar der Pädagogik?), einer möglichen Pathologie (Ist es Ausdruck einer Depression?), der Absolutheit des Nichtstuns (Ist wirklich die Abwesenheit jeglicher Tätigkeit gemeint, geistig wie körperlich? Ist es eine Umschreibung des Todes?). In vielen Fällen ist heute beispielsweise der Standard, an dem sich die Wertschätzung des Nichtstuns orientiert, die Arbeit. Weil in der Neuzeit die Arbeit und das Herstellen - beide Begriffe werden im Folgenden genauer herzuleiten sein - zu den am meisten geschätzten Tätigkeiten avanciert sind, bezieht sich der Mangel im Nichtstun so oft, wenn auch nicht ausschließlich, auf das Fehlen einer Arbeit oder eines Produktes. Meine Definition des Nichtstuns als eine Tätigkeit, die aus der Konvention heraustritt und außerhalb von üblicherweise wertgeschätzten Tätigkeitsmodellen situiert ist, nähert sich an Brian O'Connors Verständnis von »idleness« an:

idleness [...] encapsulates a form of experience that places us outside the norms or conventions of societies like ours. It is not only a state of not working, though that is a key marker. It involves a departure from a range of values that make us the kinds of people we are supposed to be in order to live well. $^{14}$

Ebenso wie O'Connor »idleness« als Abweichung von einem gesellschaftlich als >richtig< verstandenen Lebensmodell ansieht, verstehe ich das Nichtstun als Normabweichung. Eine Normabweichung, die infrage stellt, ob normale bzw. normative Tätigkeiten wirklich zu dem guten Leben führen (»to live 
well«), welches sie angeblich ermöglichen sollen. Die Frage nach einem guten Leben, die sich so im Nichtstun stellt, führt zu dem zweiten in diesem Buch wichtigen Begriff: dem der Praxis. Ich benutze den Begriff Praxis laut Aristoteles, wie ihn Richard Bernstein zusammenfasst:

Aristotle [...] uses »praxis« to designate one of the ways of life open to a free man, and to signify the sciences and arts that deal with the activities characteristic of man's ethical and political life. [...] These disciplines, which require knowledge and practical wisdom, can be contrasted with »theoria « because their end is not knowing or wisdom for its own sake, but doing - living well. ${ }^{15}$

Der Begriff Praxis bezieht sich auf die ethischen und politischen Tätigkeiten des menschlichen Lebens. Die Praktiken lassen sich dabei danach bewerten, inwiefern sie dem Gesamtziel der bestmöglichen Lebensweise dienen. Basierend auf diesen Definitionen ergibt sich eine weitere für die von mir sogenannte Praxis des Nichtstuns: diese bezeichnet den Versuch, durch die und mit der Abwesenheit normativer Tätigkeiten eine bestmögliche Lebensgestaltung zu erreichen - sei es im Sinne eines Ethos für das gesamte Leben, oder einer politischen Stellungnahme oder Aktion. ${ }^{16}$

Ich habe auch deswegen den Begriff des Nichtstuns gewählt, weil mein Erkenntnisinteresse sich auf die ethische und politische Dimension von Handlung und Nicht-Handlung richtet: Er enthält das »Tun« und verweist somit explizit auf den Tätigkeitsaspekt dieses Phänomens, sodass es sich ohne Probleme auf das politische Handeln, die politische und ethische Praxis im Sinne Aristoteles' rückbeziehen lässt. Während das Nichtstun mein zentraler Begriff

Richard ]. Bernstein: Praxis and Action. Contemporary Philosophies of Human Activity. Philadelphia: University of Pennsylvania Press (1971), ix-x.

16 Der Begriff der Praxis oder Praktik taucht in Verbindung mit dem Nichtstun bereits in der Forschungsliteratur auf, jedoch nicht in Verbindung mit dem Politischen, sondern mit individuellen Erfahrungen und Tätigkeiten. Bianca Blum spricht z.B. von der Handarbeit u.Ä. als »Mußepraktiken«, die, ähnlich dem Handwerk in Walter Benjamins Erzähler-Aufsatz, das Tagträumen und Phantasieren befördern. Vgl. Bianca E. Blum: »Meiden Sie Untätigkeit, sie ist die Mutter aller Laster... -Zu Muße und Weiblichkeit in der russischen Literatur des 19. Jahrhunderts. Hamburg: Kovac (2019), 13. Gimmel und Keiling sprechen von einer »Praxis der Achtsamkeit«. Vgl. Jochen Gimmel u. Tobias Keiling: Konzepte der Muße. Tübingen: Mohr Siebeck (2016), 32. Andrea Erwig bezieht sich auf eine institutionelle Praxis, wenn sie den Topos des Wartens mit den Begriff Praxis und Technik beschreibt; sie meint damit klinische und psychoanalytische >Anwendungen des Wartens. Vgl. Andrea Erwig: Waiting Plots. Paderborn: Fink (2018), 19. 
ist, verwende ich `Untätigkeit< oder `Inaktivität gelegentlich synonym. Ich benutze diese Begriffe, wie diskursiv etabliert, als Gegensätze zu >Tun ‘ und >Tätigkeit - um diesen Gegensatz aber im Laufe meiner Ausführungen immer wieder aufzuheben. Ich verwende den Begriff des Handelns ausschließlich im Sinne Hannah Arendts (wie er im Folgenden ausgeführt wird).

Die Praktiken des Nichtstuns, die in dieser Arbeit beschrieben werden, haben auch eine kritische Funktion, insofern sie normative Ethiken und Politiken abzulösen versuchen. »So kann ein Nicht/Handeln die Sinn- und Wirkungslosigkeit etablierter Praktiken anzeigen«, schreibt Theo Jung, »und so bestehende Strukturen symbolisch infrage stellen. ${ }^{17}$ O'Connor bezieht eine ähnliche Position: »idleness is not mindless: no less than non-idle behavior, it contains conceptual components and judgments «, »[it is] implicitly dissatisfied with the usual social arrangements «. ${ }^{18}$ Die Kritik dieser Praktiken des Nichtstuns in diesem Buch richtet sich gegen verschiedene Tätigkeitsparadigmen der Moderne: die große Wertschätzung der Arbeit, die Fetischisierung von Produktivität, und die Idee eines geschichtlichen Fortschritts durch menschliche Aktivität. Die kritische Funktion des Nichtstuns ist dabei durchaus ernst gemeint: Literarische Darstellungen des Nichtstuns entfalten die Fähigkeit, die Tätigkeitsparadigmen der Moderne auf ihre inneren Widersprüche, Bedingtheiten und Beschränkungen hin zu untersuchen und damit auf die Kontingenz der Abgrenzung zwischen Tun und Nichttun hinzuweisen. Das Nichtstun, das sie darstellen, erweist sich in diesem Sinne als Praxis, und die Praxis der Texte selbst als Kritik gesetzter Paradigmen des Tuns. Anders gesagt: Nichtstun wird in der Philosophie wie in der Literatur zur Handlung umgedeutet, was insgesamt die Auflösung der im westlichen Denken fest verankerten Binäropposition zwischen Handlung und Nichthandlung, Tun und Nichtstun befördert.

Die Analyse der Paradigmen des Tuns hat in Hannah Arendts Denken, welches meinen Fokus wesentlich bestimmt hat, viel Raum eingenommen. In Vita activa (1958) drückt Arendt ein Unbehagen darüber aus, dass seit der Neuzeit Tätigkeiten wertgeschätzt werden, die dem Wohl der Menschheit und der Welt abträglich sind. Sie problematisiert das große Interesse an der Arbeit und dem Herstellen von Dingen, und fokussiert stattdessen - in Anlehnung an xeologie des Nicht/Handelns. In: Zwischen Handeln und Nichthandeln. Unterlassungspraktiken in der europäischen Moderne. Hg. v. Dems. Frankfurt a.M.: Campus (2019), 23. 
die Aristotelische Praxis - das Handeln als soziale Interaktion, durch das die Welt gemeinschaftlich gestaltet werden kann. ${ }^{19}$ Hannah Arendt vermisst eine solche Form der Tätigkeit, die ihr zufolge von der Arbeit und dem Herstellen ersetzt worden ist. Ausgehend von dieser Beobachtung habe ich mich gefragt (sowohl theoretisch als auch anhand von literarischen Texten), ob die Tätigkeitsform des Handelns die Form eines Nichtstuns annehmen kann. Diesen Gedanken beschrieb Arno Baruzzi bereits in den 1990er-Jahren: Wenn in der Neuzeit das, was in der Antike Praxis bzw. Handeln war, mit Arbeit gleichgesetzt wird, so kann eine Rückkehr zur tatsächlichen Praxis nur erfolgen, indem man ein »wirkliches Nichtstun« bzw. »Nichttun« vollzieht. ${ }^{20}$ Der Praxisbegriff, so Baruzzi, müsse um das Nichtstun erweitert werden, weil »im Nichttun ein wesentliches Tun sich abspielt «. ${ }^{21}$ Arendt und Baruzzi differenzieren ihrerseits also zwei Formen der Tätigkeit, die sie unterschiedlich bewerten: (1) Die in der Neuzeit auf Arbeit beschränkte Tätigkeit, der gegenüber alle anderen Tätigkeiten als Nichtstun abgewertet werden. Und (2) eine andere Tätigkeit, eine sechte Praxis`, welche soziale Kollektivität hervorbringt. Diese andere Tätigkeit könnte sich im neuzeitlichen Paradigma des Tätigseins, welches auf Arbeit beschränkt ist, in dem als dessen Gegensatz definierten Nichtstun bzw. »Nichttun« (Baruzzi) verbergen. Es würde so die Beschränkung der als Arbeit definierten Tätigkeit kritisch in Frage stellen und eine Alternative dazu formulieren. Das vorliegende Buch widmet sich der Erörterung dieses neuen ethischen Interesses am Nichtstun, und supplementiert so die Forschung der letzten Jahrzehnte, die sich dem Nichtstun eher in Form einer Apologie genähert hat - die jedoch keiner ethischen Re-Evaluierung des gesellschaftlichen Stellenwerts von Arbeit und Tätigkeit, sondern >nur der notwendigen Re-Konzeptualisierung des Arbeitsmarktes im späten 20. und frühen 21. Jahrhunderts Rechnung trägt. ${ }^{22}$

19 Vgl. Hannah Arendt: Vita activa oder Vom tätigen Leben. München: Piper (2016), 278f. Für den Begriff der >Welt< bei Arendt vgl. den Abschnitt »Binäropposition und Uneigentlichkeit« in diesem Buch.

Vgl. Arno Baruzzi: Machbarkeit. Perspektiven unseres Lebens. Freiburg i.Br.: Alber (1996), 173-207, zit. 203.

21 Baruzzi: Machbarkeit, 203.

22 Eine Tendenz zur gesellschaftlichen Rehabilitierung des Nichtstuns lässt sich seit dem späten 20. Jahrhundert feststellen. Dies ist sicherlich auch eine Antwort auf die seit den 1980er-Jahren verstärkt diskutierte Krise der Arbeitsgesellschaft. Zentrale Zeugnisse dieser Debatte finden sich in Joachim Matthes (Hg.): Krise der Arbeitsgesellschaft? Verhandlungen des 21. Deutschen Soziologentages in Bamberg 1982. Frankfurt a.M.: Campus (1983). Der mit dem Wirtschaftswachstum einhergehende Wegfall von Arbeitsplät- 
Der erste Teil dieses Buches widmet sich der Ausführung dieses Gedankens ausgehend von Hannah Arendts Vorstellung des passiven Widerstands und von Walter Benjamins Konzept des Streiks. Er beschäftigt sich anhand philosophischer und politischer Diskurse mit der Möglichkeit, dass sich im Nichtstun eine neue, ethische Form der Gemeinschaft bilden könne. Er rekurriert zu diesem Zweck auf französische und italienische Gemeinschaftsphilosophien von Jean-Luc Nancy, Maurice Blanchot, Gilles Deleuze und Giorgio Agamben aus den 1980er-Jahren, die auf verschiedene Ideen des Nichtstuns zurückgreifen, um eine neue, gewaltfreie Gemeinschaftsethik zu umreißen. Zuletzt erkundet das Kapitel auch die Konnotation des Nichtstuns im Topos des Herrschens, und inwiefern sich in dieser Verbindung Macht, Ohnmacht, oder Kritik ausdrückt. Dabei zeichnet sich bereits ab, dass die philosophische Handlungstheorie und analoge Theorien des Nicht-Handelns eine »Neubewertung des Verhältnisses von Aktivität und Passivität« durchführen, wie Kathrin Busch feststellt. ${ }^{23}$ Beide Begriffe werden von einer scheinbaren Opposition auf verschiedene Weise in eine Dynamik gebracht, in der sie nur miteinander und durch einander gedacht werden können.

Der zweite Teil dieses Buches widmet sich der Analyse des Untätigkeitsparadigmas in vier europäischen Romanen des 20 . und frühen 21. Jahrhunderts: Der Gehülfe (1907) von Robert Walser, Der Zauberberg (1924) von Thomas

zen, so die häufig formulierte Sorge, zwinge Menschen in die >Berufsunfähigkeit<, die schmerzlich als Identitätsverlust empfunden werde. In einer Gesellschaft, in der nichts so wichtig ist wie die Arbeit, während doch keine zu haben ist, sei man als Nichtstuer ein >überflüssiger Mensch, so schreibt Ilija Trojanow. Vgl. Ilija Trojanow: Der überflüssige Mensch. München: DTV (2015). Man müsse deshalb, so Wolfgang Engler, das lange als dominant gesetzte >Recht auf Arbeit< umdenken in ein >Recht auf Einkommen <und damit die Idee normalisieren, dass die Hauptbeschäftigung des Menschen eben nicht die Arbeit ist. Vgl. Wolfgang Engler: Bürger, ohne Arbeit. Für eine radikale Neugestaltung der Cesellschaft. Berlin: Aufbau (2005). Im Zuge dieser Bemühungen haben viele der Publikationen über das Nichtstun den impliziten Anspruch, der Verzweiflung über diese so empfundene >Überflüssigkeit< eine positive Vision der Arbeitsfreiheit entgegenzusetzen. So ist Eberhard Straubs Vom Nichtstun (2004) um eine motivgeschichtliche Beweisführung darüber bemüht, dass die »Befreiung von übermäßiger Arbeit« keine Verdammung des Menschen bedeute, sondern seine Befreiung, die ihm die Celegenheit verschafft, »in freier Zeit sein Inneres zu bilden und seine personale Würde zu entfalten. "Eberhard Straub: Vom Nichtstun. Leben in einer Welt ohne Arbeit. Berlin: Wjs (2004), 118.

23 Kathrin Busch: Elemente einer Philosophie der Passivität. In: Theorien der Passivität. Hg. v. Ders. u.a. München: Fink (2013), 16. 
Mann, Un homme qui dort (1967) von Georges Perec, und Bombel (2004) von Mirosław Nahacz. Diese vier Romane weisen die Neuaushandlung der Opposition zwischen Nichtstun und Handlung bzw. Arbeit nicht nur als Marker ihres jeweiligen Entstehungs- und Publikationskontextes, sondern als für die Moderne prägendes Phänomen aus. Während man darüber streiten kann (und sollte), was genau >Moderne in diesem Zusammenhang bedeutet, so scheint es ausreichend, darauf zu verweisen, dass aus heutiger Sicht die Moderne als ideengeschichtliche Kategorie mit einer enorm hohen Arbeitswertschätzung einhergeht. Dies hat, wie literaturgeschichtlich längst bekannt ist, eine ganze Reihe von künstlerischen Gegenbewegungen herausgefordert, die den absoluten Wert der Arbeit infragestellen. Die in diesem Buch analysierten Romane verweisen alle auf spezielle Entstehungskontexte und nationale Konfliktlagen, die sie verhandeln, und die ihnen einen besonderen politischen Impetus verleihen. Ihre Protagonisten praktizieren ein Nichtstun in dem Sinne, wie es oben beschrieben wurde. Sie wenden sich auf verschiedene Arten und Weisen von konventionellen Tätigkeiten ab - vornehmlich der Arbeit und der Ausbildung -, um die politischen und sozialen Möglichkeiten innerhalb des Nichtstuns auszuloten. Sie versuchen, Gemeinschaften auf der Basis des Nichtstuns zu gründen, probieren im Nichtstun Herrschaftskonzepte aus, und experimentieren mit dem Nichtstun als einer neuen Form von Handlung. Die literarischen Texte nehmen die Dynamisierung des Zusammenhangs zwischen Konzepten des Handelns und des Nichtstuns, die in der Literaturtheorie und Philosophie nachvollzogen wird, auf, und reagieren darauf mit literarischen Verfahren, welche in den Lektüren genauer bestimmt werden. Dabei zeichnen sich zwei zentrale Gemeinsamkeiten aller untersuchten Texte ab:

(1) Alle Texte interessieren sich für das Phänomen des sozialen Ausschlusses, das potentiell mit dem Nichtstun einhergeht. Die Lektüren verfolgen daher häufig das Ziel, die Handlungsphilosophie Hannah Arendts mit den Überlegungen von Michel Foucault zur gesellschaftlichen Exklusion anomischen Verhaltens zu kombinieren. ${ }^{24}$ Die Lektüren befragen deshalb die Romane auch auf die gesellschaftlichen Inklusions- und Exklusionsmechanismen hin,

24 Die Verbindung zwischen Arendt und Foucault wurde bereits 1995 von Giorgio Agamben gemacht, der behauptet, die thematische Überschneidung der beiden PhilosophInnen sei weder von ihnen selbst realisiert, noch von der Forschung erarbeitet worden. Dabei verbinde sie der Umstand, dass der »homo laborans und mit ihm das biologische Leben zunehmend ins Zentrum der politischen Bühne der Moderne« gerückt sei. Giorgio Agamben: Homo sacer. Die souveräne Macht und das nackte Leben. Übers. v. Hubert Thüring. Frankfurt a.M.: Suhrkamp (2002), $13 f$. 
denen das Nichtstun in ihren Diegesen unterliegt. Dass gesellschaftlicher Ausschluss in allen Romanen eine Rolle spielt, zeigt sich an einer poetischen Gemeinsamkeit der Texte: sie alle stellen das Nichtstun in einem Modus der Uneigentlichkeit dar, der die gesellschaftliche Ablehnung des Nichtstuns reflektiert. Mit Uneigentlichkeit ist dabei der Versuch gemeint, das Nichtstun zu verstecken, oder, wiederum anders, etwas durch das Nichtstun zu verschleiern. Jede der vier Lektüren ist nach dem Verfahren der Uneigentlichkeit benannt, mit dem der jeweils analysierte Roman operiert: Simulation, Projektion, Prätention und Kompensation. Jedes von ihnen bezeichnet eine vom jeweiligen Roman vorgestellte Weise, das Nichtstun nie direkt und absolut darzustellen - sondern als Kehrseite, Verhüllung, als das Andere einer Aktivität, die in seinem Hintergrund stattfindet, ohne dass beide Pole der Opposition sich gegenseitig ausschließen würden.

(2) Jeder der Romane verfolgt eine Destabilisierung bekannter Binäroppositionen wie Aktivität/Inaktivität, Arbeit/Muße usw., in denen das Nichtstun im Verhältnis zum gesetzten Standard von wertvoller Tätigkeit eine Abwertung erfährt, laut der es den schwächeren, untergeordneten, und den vermeintlich gesellschaftlich bedeutungslosen Teil der Opposition einnimmt. Die thematische Einleitung des jeweiligen Kapitels zeigt an, welche Norm von wertvoller Tätigkeit hinterfragt und wie diese mit einem als ihr Gegenteil imaginierten Nichtstun dynamisch in Verbindung gebracht wird. Dabei ermöglichen die literarischen Werke auf ihre je eigene Weise, diese Dynamisierung zweier scheinbar entgegengesetzter Pole von Nichtstun und Handlung zu verfolgen, ohne dass sie - wie im politischen oder philosophischen Diskurs selbst - eine endgültige Wertung oder Erkenntnis zum Ergebnis haben müssten, aus der sich dann eine ethische oder politische Handlungsanweisung ableiten ließe. Die Uneigentlichkeit der Darstellungsverfahren ermöglicht, die Protagonisten als zugleich tätige und untätige wahrzunehmen.

Die Lesbarkeit dieser Verfahren hängt dabei in höchstem Maß von der diskursiven Situierung des Nichtstuns der jeweiligen Romane ab. Die Notwendigkeit dieser kontextuellen Einordnung ist in der Forschung schon mehrfach bemerkt worden. »Jedes Nichttun[...] erhält seine Anerkennung und Relevanz nur im Rahmen der jeweiligen historischen Situation ${ }^{25}$ schreiben Gronau und Lagaay. Die Bedeutung des Nichtstuns, so sagt auch Theo Jung über seinen Begriff des Nicht/Handelns, ist nicht autonom, sie konstituiert sich »immer erst im Kontext des jeweils gegebenen gesellschaftlichen Interessengefü-

25 Gronau u. Lagaay: Performanzen des Nichttuns, 12. 
ges «. ${ }^{26}$ Auch vor diesem Hintergrund erklärt sich die Verwendung des Begriffes Nichtstun in diesem Buch: in der Reihe anderer Begriffe ähnlicher Art Faul- oder Trägheit, Muße, Müßiggang, Acedia, Langeweile, Ennui, Melancholie, Apathie u.v.m. - erweist er sich als der allgemeinste. Weil er keine nennenswerte Begriffsgeschichte aufweist, und unabhängig von Entstehungsoder Verwendungskontexten ist, lässt er sich gerade als neutraler heuristischer Begriff an die unterschiedlichen historischen Kontexte anlegen, die den Romanen als Hintergrund dienen. So erlaubt er eine offene und weitreichende Befragung der Phänomene, die er zu beschreiben versucht. Um der jeweiligen historischen Bedeutung des Nichtstuns in den vier ausgewählten Romanen interpretativ gerecht $\mathrm{zu}$ werden, weisen ihre Leküren eine anteilige diskursanalytische Ausrichtung auf, die mit zahlreichen close readings kombiniert und abgeglichen wird.

Auch das Nichtstun in Georges Perecs Un homme qui dort (1967) ist nur in Anbetracht seines historischen Entstehungskontexts in seiner vollen Bedeutung zu erfassen. Das zeigt sich im Vergleich mit Leonhard Fuests Lektüre des Romans. Dessen fast ausschließlich auf den Romantext fokussierte Arbeit sieht in Un homme qui dort den Spiegel einer selbstreflexiven Moderne, ein Echo poststrukturalistischer Theorie, übersieht darüber aber die Gesellschaftskritik, die der Protagonist formuliert. So glaubt Fuest, dem Nichtstun fehle politische Unterfütterung, während man unter Einbezug der Vorgeschichte der Studierendenproteste im Mai 1968 in Paris klar erkennen kann, dass der Protagonist sich durch sein Nichtstun gegen etablierte Tätigkeitsmodelle wehrt und so einen neuen Modus der Handlung beginnt. Was Fuest als "Nutzlosigkeit der Verweigerung « bezeichnet, ${ }^{27}$ ist tatsächlich eine Rückkehr zum Sozialen über den Weg des Nichtstuns.

Diese historische Scharfstellung hat also weitreichende Folgen für die Deutung der Darstellung des Nichtstuns, auch für die anderen drei Romane. Dabei zeigt sich beispielsweise, dass Robert Walsers Der Gehülfe (1907) durch die Verbindung von Muße und Arbeit den Grenzverlauf zwischen den gesellschaftlichen Klassen im frühen 20. Jahrhundert aufzeigt und in Frage stellt. Eine Einbettung des Nichtstuns im Kontext des Orientalismus hingegen demonstriert, dass Der Zauberberg (1924) von Thomas Mann die etablierte Dominanz des aktiven >Westens über den inaktiven >Osten Das Nichtstun in Bombel (2004) von Mirosław Nahacz formuliert, so wird im

26 Jung: Bartleby und das Unterlassen, 19.

27 Fuest: Poetik des Nicht(s)tuns, 244. 
Kontext des EU-Beitritts Polens sichtbar, eine Kritik an der Fetischisierung von Arbeit in der noch jungen Dritten Republik. All diese Lektüren fördern eine konkrete politische Dimension in der Darstellung des Nichtstuns zu Tage, und räumen so mit dem Diktum snutzlosen Nichtstuns auf, ohne seine Wirkungskraft auf den Bereich kreativen oder intellektuellen Schaffens zu reduzieren. Das Potential des Nichtstuns als politische Praxis wird erkennbar. 



\section{Philosophische Überlegungen: Nichtstun als politische Praxis}

Das Phänomen des Nichtstuns hat im 20. und 21. Jahrhundert eigentümlicherweise ein Denken über das Politische vorangetrieben. Gesellschaftlich betrachtet gilt weiterhin die Vorstellung, Nichtstun sei eine wertlose, dysfunktionale Abweichung, aber parallel dazu hat sich ein gegenläufiger Diskurs entwickelt. Aus dem Bereich der Kunst, Literatur und Philosophie kommen Impulse für eine andere Deutung des Nichtstuns: man versteht es zunehmend als genuin politischen Akt. Dieses Verständnis bricht jedoch mit der europäischen Ideengeschichte, die das Nichtstun seit jeher als unpolitisch wahrgenommen hat - schließlich bedeutete die Muße in der Antike (griech.: scholé, lat.: otium) nicht nur die Abwesenheit von Sorge und Mühsal, sondern auch »Freiheit von politischer Tätigkeit «; ${ }^{1}$ und auch andere, weniger genussvolle Formen des Nichtstuns weisen in der herkömmlichen Sicht einen $\mathrm{zu}$ großen Grad von Isolation oder Nonkonformität auf, um als politisches Agieren zu gelten. Doch die moderne Politisierung des Nichtstuns konzentriert sich gerade auf das anomische Element des Nichtstuns, und zeigt, dass Politik aus einer Abweichung heraus gedacht werden kann. Das Denken über das Nichtstun im 20. Jahrhundert interessiert sich für die Möglichkeit, Politik nicht elitär, exklusiv, oder an bestimmte Tätigkeitsformen gebunden zu denken, sondern als eine unkonventionelle Praxis, die keiner vorangegangen Art politischer Führung oder Partizipation gleicht. In diesem Kontext wird das Nichtstun deshalb auch mindestens als Kritik oder Störung, und sogar als eine aktive Veränderung des politischen Status quo verstanden.

Dieser Teil des Buches widmet sich drei verschiedenen Möglichkeiten, Nichtstun als politische Praxis zu denken. Im ersten Theoriekapitel wird Nichtstun als eine Handlung im Sinne Hannah Arendts betrachtet, die ein 
Ereignis darstellt, und damit sowohl gesellschaftliche Veränderung generieren kann als auch die zukünftige geschichtliche Entwicklung zu beeinflussen vermag. Im zweiten Theoriekapitel wird das Nichtstun als Voraussetzung zur Bildung einer neuen Gemeinschaft betrachtet, die sich üblichen sozialen Normen verweigert. Im dritten Theoriekapitel geht es, abweichend von den ersten beiden, um die Korrelation zwischen Nichtstun und Herrschaft, die sowohl Macht als auch Ohnmacht bedeuten kann. In allen drei Fällen wird das Nichtstun als eine Praxis betrachtet, die entweder Konventionen bricht, neue Ethiken etabliert oder einfach neue Perspektiven auf das Politische eröffnet.

\section{Handlung und Geschichte}

Nichts zu tun heißt, zu handeln. Es ist ein Ereignis, und beeinflusst die Geschichte. Dem Nichtstun als Idee und als literarisches Motiv wohnt ein hartnäckiges Paradox inne. Und zwar, um die Leibniz'sche Frage umzuformulieren, dass Nichtstun überhaupt etwas ist, und nicht etwa nichts. Damit wird gefragt, ob das Nichtstun, ebenso wie das Tun, Wirkungen in der Welt produzieren kann. Daran knüpfen sich zwei Ideen, die eng miteinander verbunden sind. Zum einen, dass diese Wirkungen als politische Handlungen verstanden werden können, dass also Nichtstun zu einem der wesentlichsten menschlichen Tätigkeitsbereiche gehört: der Politik. Zum anderen, dass das Nichtstun ein Ereignis produziert, und damit auch die Geschichte beeinflussen kann. Der Zusammenhang zwischen diesen beiden Begriffen - Handlung und Ereignis als Teil einer Praxis des Nichtstuns ist Thema dieses Kapitels.

Dass das Nichtstun eine Handlung, und damit gar politisch und geschichtlich relevant ist, suggerieren verschiedene Handlungs- und Geschichtsphilosophien des 20. Jahrhunderts. Einen zentralen Hinweis liefert Hannah Arendt. In ihrer Handlungsphilosophie umreißt sie grob zwei Arten des Nichtstuns. Zum einen meint sie damit - und zwar aus der Perspektive der Vita activa heraus - das Denken. Es sei »reine Tätigkeit des Geistes in Verbindung mit völliger Unbeweglichkeit des Körpers «. ${ }^{2}$ Diese Art des Nichtstuns hält Arendt nicht für eine Handlung, weil man ohne körperliche Aktivität nicht in der Welt und mit Menschen zusammen sein kann - ihr 
Handlungsbegriff aber setzt beides voraus. Es gäbe allerdings noch eine andere Form des Nichtstuns, so Arendt, die trotz körperlicher Untätigkeit eine Handlung darstellen könne. Diese Ausnahme von der Regel ihrer Handlungsphilosophie wird in den Ausführungen zum Verhältnis von Macht und Gewalt in Vita activa formuliert. Im Kontext einer Gewaltherrschaft könne nämlich, so Arendt, der passive Widerstand durchaus eine Handlung darstellen:

So können auch Volksaufstände gegen die materiell absolut überlegenen Gewaltmittel eines Staates eine fast unwiderstehliche Macht erzeugen, und zwar gerade, wenn sie sich selbst der Gewalttätigkeit enthalten, in der sie ohnehin die Unterlegenen wären. Dies mag man den »passiven Widerstand « nennen, aber man sollte sich bewusst sein, daß dieser Name im Ernstfall nicht ohne Ironie ist. Denn der passive Widerstand auf seinem Höhepunkt, auf dem er der Gewalt nicht weicht, gehört zweifellos zu den aktivsten und wirksamsten Formen des Handelns, die je ersonnen worden sind, und zwar gerade, weil er sich nicht einem Kampf stellt, dessen Resultat die Niederlage oder der Sieg wäre, und man ihm daher im Prinzip nur durch einen organisierten Massenmord begegnen kann, der für den Sieger ein Pyrrhus-Sieg ist, weil ja niemand über Tote herrschen kann. ${ }^{3}$

Die These Arendts lautet, dass durch ein Nichtstun in Form des passiven Widerstands Macht entstehen kann. Dieser Gedanke ist nicht unbedingt naheliegend. Man würde eigentlich eher davon ausgehen, dass Nichts zu tun im Rahmen einer Gewaltherrschaft einem Todesurteil gleichkäme. Wenn in sozialdarwinistischer Manier das Recht des Stärkeren gilt, dann gehen zuallererst diejenigen zugrunde, die nicht für ihr Leben kämpfen. Doch Arendt sieht gerade darin ein Machtpotential, denn: Indem man auf Gewaltmittel verzichtet, hebelt man die Aktionslogik des Gegners aus, und vermag ihn so $\mathrm{zu}$ bezwingen. ${ }^{4}$ Das englische Original vermittelt dies besonders pointiert.

4 Dabei muss man betonen, dass in Arendts Verständnis das Machtpotential des Nichtstuns nicht nur, aber auch auf seiner kollektiven Demonstration gründet. Der passive Widerstand ist an sich eine Handlung. Macht entsteht aber erst dann, wenn es sich um eine Aktion vieler Menschen handelt, denn Pluralität ist für Arendt eine Voraussetzung für Macht: »Macht entspricht der menschlichen Fähigkeit, nicht nur zu handeln oder etwas zu tun, sondern sich mit anderen zusammenzuschließen und im Einvernehmen mit ihnen zu handeln. Über Macht verfügt niemals ein Einzelner; sie ist im Besitz einer Gruppe«. Hannah Arendt: Macht und Gewalt. Übers. v. Gisela Uellenberg. München: Piper (2017), 45. 
Dort liest man, "passive resistance« sei eben deswegen »one of the most active and efficient ways of action ever devised, because it cannot be countered by fighting «. ${ }^{5}$ Wer nicht kämpft, der kann nicht besiegt werden, auch wenn er/sie im Falle eines Kampfes unterlegen gewesen wäre. Man kann also aus der Perspektive des Gewaltinhabers das Nichtstun nicht `kontern<, ihm nichts entgegensetzen, weil es - immer schon - außerhalb des Handlungsparadigmas situiert ist, in dem Gewalt entstehen kann. Das Nichtstun ist dennoch ein wichtiger Bestandteil des Aufstandes, weil es einen Bruch mit der Norm darstellt, durch den die bis dahin geltende Gewalt des Staates von der Macht des Volkes abgelöst werden kann. Daraus erklärt sich auch die Tatsache, dass Arendt dem passiven Widerstand Handlungscharakter zuspricht. Zu handeln heißt ihr zufolge nämlich konkret, »etwas Neues Anfangen «, ${ }^{6}$ womit sie auch andeutet, dass Handlungen überkommene gesellschaftliche Prozesse (wie genau ein Staat geführt, Staatsgewalt durchgesetzt wird usw.) unterbrechen und ersetzen können. Und das Nichtstun, wenn es die Form eines passiven Widerstandes annimmt, könne dies eben auch. Seine genaue Funktionalität lässt sich als Überwindung des Zweck-Mittel-Verhältnisses nachvollziehen.

\section{Überwindung der Zweck-Mittel-Relation}

Das Nichtstun, vor allem die Form des passiven Widerstands, macht auf ein ethisches Problem aufmerksam. Dieses Problem ergibt sich Arendt zufolge aus der Veränderung des Handlungsverständnisses in der Neuzeit. Wenn man heute von Handlung spricht, dann sind daran generell drei Dinge notwendig beteiligt: Ein verantwortliches Subjekt, ein Wille, und ein Ziel. Arendt kritisiert vor allem die Tendenz, das letzte Element, also das Ziel im Sinne des Ergebnisses einer Handlung zu ernst zu nehmen. Und tatsächlich ist das Ergebnis auch in den Handlungstheorien des 20. Jahrhunderts in der Regel nicht relevant. Es geht dort zumeist um die Feststellung und Feststellbarkeit einer inneren Tendenz - wie man sie auch nennen mag: Grund, Intention, Wille, Motivation, Neigung usw. - zur Handlung bevor sie stattfindet, denn erst diese Tendenz macht ein Geschehen zur Handlung. ${ }^{7}$ An

\footnotetext{
Hannah Arendt: The Human Condition. Chicago: University of Chicago Press (1998), 201. Arendt: Vita activa, 215.

Jochen Gimmel summiert als die drei zentralen Strukturmerkmale des Handlungskonzeptes in den dominanten Handlungstheorien von Donald Davidson (Analytische Philosophie) und Max Weber (Soziologie): 1. den Akteur, 2. seine Intention, und 3. die Rationalität der Handlung, die ihre Erklärbarkeit garantiert. Jochen Gimmel: Zum Begriff
} 
der Relation zwischen der Motivation und dem Zustand nach der Handlung, dem Ergebnis, ist die Handlungstheorie eher nicht interessiert. Das gilt auch für Hannah Arendt, die, antike Positionen rezipierend, davon ausgeht, dass Handlung zwar Motiven folge, aber nicht über ihr Ergebnis definiert werden kann - Handlung ist Selbstzweck. ${ }^{8}$ "Handeln und Sprechen sind Vorgänge," so Arendt, »die von sich aus keine greifbaren Resultate und Endprodukte hinterlassen. 9

Hierin entzweit sich die theoretische Position von einer praktischen, lebensweltlichen, denn im Alltag ist nicht nur von Interesse, wer handelt, oder ob jemand gehandelt hat, sondern auch, ob die Handlung erfolgreich war. Diese vor allem im Bereich der Wirtschaft relevante Frage widmet sich gerade dem Ziel, dem Ergebnis, dem Produkt von Handlungen. Arendt fürchtet, dass dieses Interesse in der Neuzeit dominiert, sodass nun Handlung nicht mehr als Selbstzweck, sondern als Produktionsprozess wahrgenommen wird. Das Produkt jedoch gehört Arendt zufolge nicht zum Handeln, sondern zum Herstellen:

Der durchschlagende Erfolg der Umwandlung des Handelns in eine Form des Herstellens ließe sich leicht an der uns selbstverständlich gewordenen Terminologie politischer Theorie und des praktisch-politischen Denkens erweisen. Sie macht es nämlich nahezu unmöglich, über Fragen der Politik auch nur zu sprechen, ohne uns der Zweck-Mittel-Kategorie zu bedienen. Vielleicht noch überzeugender für diesen Tatbestand ist die Einstimmigkeit, mit der uns die volkstümlichen Sprichwörter und Redensarten aller lebendigen Sprachen sagen, daß wer A gesagt hat, auch B sagen müsse, daß der Zweck die Mittel heilige, daß »he who wants an end must also want the means « oder daß »on ne fait pas d'omelette sans casser des oeufs«. Vielleicht hat

des Nicht/Handelns und der Hoffnung, Geschichte zum Stillstand bringen zu können. In: Zwischen Handeln und Nichthandeln, 296.

8 Hannah Arendt situiert das Handeln außerhalb der Mittel-Zweck-Kategorie, gesteht aber dennoch ein, dass Handlungen in der Regel interessengeleitet und zielgerichtet sind. Wichtig sei für Arendt jedoch, dass sich der Bereich des Politischen nicht ausschließlich durch diese Interessen und Ziele definiert, so James Knauer: »Political action involves motives and goals but is not determined by them. And in transcending these specific concerns, action transcends purely instrumental categories.« James $\mathrm{T}$. Knauer: Motive and Coal in Hannah Arendt's Concept of Political Action. In: American Political Science Review 74 (3), 1980, 729.

9 Arendt: Vita activa, 225. 
keine Generation vor uns so reichlich Gelegenheit gehabt, sich von den mörderischen Konsequenzen dieser Vorstellungen zu überzeugen, denen zufolge alle Mittel, sofern sie wirksam sind, berechtigt sind, wenn sie nur einem Zweck dienen, der sie zu rechtfertigen imstande ist. [...] Solange wir uns einbilden, daß wir im Politischen uns im Sinne der Zweck-Mittel-Kategorie bewegen, werden wir schwerlich imstande sein, irgend jemand davon abzuhalten, jedes Mittel zu benutzen, um anerkannte Zwecke zu verfolgen. ${ }^{10}$

Das von Arendt beschriebene Problem bezieht sich explizit auf die Verbrechen gegen die Menschlichkeit im Nationalsozialismus. Sie behauptet, dass das Denken und die Realisierung von Politik über die Zweck-Mittel-Kategorie gefährlich ist, weil so die Möglichkeit entsteht, die Grenzen der Moral im Einzelnen zu überschreiten (d.h. unmoralische Mittel einzusetzen), um einen vermeintlich moralischen Zweck zu erfüllen bzw. ein moralisches Ziel zu erreichen. Die enge Verbindung zwischen Mittel und Zweck kreiert in der Folge die Illusion, die so erfolgte Handlung sei im Ganzen moralisch. Im Bereich des Herstellens funktioniere das allerdings sehr wohl, dort seien die Mittel (des Herstellens) immer durch den Endzweck (die Produktion bestimmter Dinge) legitimiert: »Der Zweck rechtfertigt die Gewalt, die der Natur angetan wird, wenn man Material aus ihr gewinnen will, wie das Holz das Fällen des Baumes rechtfertigt, wie der Tisch schließlich die nochmalige Zerstörung des Materials, das Zersägen des Holzes, rechtfertigt. «" ${ }^{11}$ Doch - und darin liegt der Unterschied zwischen Herstellen und Handeln - man kann mit Menschen nicht wie mit der Natur verfahren, da kein Zweck Gewalt am Menschen rechtfertigen könne. Genau dies kann aber geschehen (weil es bereits in der Vergangenheit geschehen ist), wenn man die Politik grundsätzlich als vom Zweck-Mittel-Verhältnis abhängig begreift. Wenn man Politik primär als Zweck-Mittel-Verhältnis versteht, so erklärt James Knauer das Argument Arendts, dann verhindere man die Wahrnehmung und Diskursivierung von politischem Verfall: »to define politics in terms of the nature of its purposes makes it impossible to talk about instrumentalizing the public realm. And it is exactly this kind of perversion of politics that concerned Arendt and that she sought to warn us against. ${ }^{12}$

\footnotetext{
10 Arendt: Vita activa, 291.

11 Arendt: Vita activa, 181f.

12 Knauer: Motive and Coal, 730.
} 
Weil innerhalb der pervertierenden Zweck-Mittel-Logik kein Widerstand möglich ist, stellt das Nichtstun - in seiner konkreten Form des passiven Widerstands, wie oben beschrieben - für Arendt eine Möglichkeit dar, die Unterbrechung einer solchen Zweck-Mittel-Politik zu denken. Denn dieses Nichtstun weicht gewissermaßen von den bekannten Skripten politischer Interaktion und Konfliktaustragung ab. Es disqualifiziert sein Gegenüber, indem es etwas anderes tut als dieses, nämlich gar nichts. Der passive Widerstand stellt sich gerade nicht einem Kampf, »dessen Resultat die Niederlage oder der Sieg wäre« (s.o.), ${ }^{13}$ er entzieht sich der Möglichkeit eines Resultats überhaupt, und damit auch seiner eigenen Zweckhaftigkeit.

Dieser von Arendt formulierte Vorschlag des passiven Widerstands als Gegenentwurf zu einer pervertierten Gewaltpolitik ist ein dominantes Thema in der Philosophie des Nichtstuns, die sich im 20. Jahrhundert in Europa entwickelt hat. Ein weiterer bedeutender Referenzpunkt für dieses Denken ist die Ausführung zum Streik in Walter Benjamins Aufsatz »Zur Kritik der Gewalt « (1921). In diesem Text, der Arendts Denken wesentlich beeinflusst haben muss, ${ }^{14}$ kritisiert Benjamin die Tatsache, dass das ZweckMittel-Verhältnis das »elementarste Grundverhältnis jeder Rechtsordnung« darstellt, ${ }^{15}$ weil dieses Verhältnis die Funktionalität des Rechts missbrauchsanfällig macht. Denn obwohl im Idealfall Rechtsmittel wie Rechtszwecke >gerecht s sind, kann es passieren - Benjamin geht sogar davon aus, dass das immer der Fall ist -, dass ungerechte Mittel durch die Gerechtigkeit der Zwecke gerechtfertigt werden, oder dass umgekehrt durch die »Berechtigung der Mittel« die »Gerechtigkeit der Zwecke« fälschlich garantiert wird. ${ }^{16}$ Auch hier lautet die Befürchtung, dass die Koppelung von Mittel und Zweck ein gegenseitiges Alibi ermöglicht, in der die so womöglich entstehende Gewalt legitimiert wird. Diese Verschränkung von Recht und Gewalt ist für Benjamin problematisch, weil sich dadurch ein hermetisches System bildet, in das man nicht durch Handlung eingreifen, und in dem auch keine Gerechtigkeit durchgesetzt werden kann. »Was Benjamin im Grunde beklagt, « so schreibt

Arendt: Vita activa, 253.

Es fällt auf, dass Arendt sich in ihren Ausführungen zur Cewalt nicht auf Benjamin stützt, obwohl es signifikante Ähnlichkeiten zwischen ihren Ansätzen gibt. Vgl. hierzu Christopher ]. Finlay: Hannah Arendt's Critique of Violence. In: Thesis Eleven 97 (1), 2009, insb. 38-42. 
Jürgen Brokoff, »ist das Fehlen einer über dem Recht stehenden Instanz, die zur Kritik fähig ist. « ${ }^{17}$ Es fehlt also ein >Außen des Systems. Die Frage, die sich in Benjamins Aufsatz stellt, ist die nach der Möglichkeit einer solchen äußeren, kritischen Instanz. Die Antwort ist wesentlich mit dem Nichtstun verbunden.

Das Recht ist Benjamin zufolge ein von Gewalt durchzogener Bereich, der durch verschiedene Formen dieser Gewalt entweder gestützt oder erneuert wird - er spricht von >rechtserhaltenden mitteln. ${ }^{18}$ Doch wie auch immer das Recht durch diese Gewalten modifiziert wird, so bleibt es doch immer im Kern eine unbegründete, gewalttätige Kraft, die es Benjamin zufolge um der Gerechtigkeit willen $\mathrm{zu}$ unterbrechen gilt. Diese Unterbrechung kann nur - und hier wechselt Benjamin das Register, von der Rechtsphilosophie in die politische Theologie - durch eine gänzlich andere Form der Gewalt vollzogen werden, die er "göttliche reine Gewalt» nennt. ${ }^{19}$ Sie vermag, das Rechtssystem zu stören, denn: im Gegensatz zu den anderen Gewaltmitteln verfolgt sie keinen Zweck (ist also reines Gewaltmittel), und wirkt deswegen weder >rechtserhaltend oder >rechtssetzend $\mathrm{k}$, sondern rechtszerstörend.

Entscheidend für die politische Wirkkraft des Nichtstuns ist nun folgendes: Während Benjamin diese >reine` Gewalt als göttliche Intervention denkt, so glaubt er dennoch daran, dass sich diese Intervention auch auf menschlicher Ebene realisiert, und zwar durch den Streik (genauer: den proletarischen Generalstreik). ${ }^{20}$ Der Streik als die »Unterlassung von Handlungen, ein Nicht-Handeln« kann dort, wo er nicht Mittel zum Zweck ist (zum Beispiel als Druckmittel in der Verhandlung für bessere Arbeitsbedingungen), gerade aufgrund seiner Zwecklosigkeit zur (zer)störenden Kraft werden. Wo er, so Benjamin, einem »Abbruch von Beziehungen gleichkommt, « da ist er

17 Jürgen Brokoff: Die apokalyptische Vernichtung des Rechts. Zur politischen Theologie Walter Benjamins. In: Apokalypse und Erinnerung in der deutsch-jüdischen Kultur des frühen 20. Jahrhunderts. Hg. v. Dems. u.a. Göttingen: Vandenhoeck \& Ruprecht (2002), 49.

18 Benjamin: Gewalt, 190.

19 Benjamin: Gewalt, 200. Den polito-theologischen Aspekt, insbesondere das Thema des Messianischen, wurde bereits von Agamben umfangreich bearbeitet, vgl. Giorgio Agamben: The Messiah and the Sovereign: the Problem of Law in Walter Benjamin. In: Ders.: Potentialities. Collected Essays in Philosophy. Hg. v. Daniel Heller-Roazen. Stanford: UP (1999), 160-174.

Benjamin gebe, so Brokoff, den proletarischen Ceneralstreik als »die unmittelbare Manifestation der apokalyptischen und reinen Gewalt Gottes durch den Menschen aus«. Brokoff: Die apokalyptische Vernichtung des Rechts, 54. 
ein »völlig gewaltloses, reines Mittel ${ }^{21}$ das die salte` Ordnung des Rechts ablehnt, ohne ein konkretes Interesse an der Gründung einer neuen Ordnung zu haben: "Dieser Generalstreik bekundet ganz deutlich seine Gleichgültigkeit gegen den materiellen Gewinn der Eroberung, indem er erklärt, daß er den Staat aufheben will ${ }^{22}$ Benjamin verankert das Nichtstun konkret im Bereich des Politischen. Da üblicherweise jedes, und besonders politisches Handeln interessengeleitet, und damit zweckhaft ist, bricht die zwecklose »NichtHandlung « mit der Norm. Die Hoffnung, auf die auch Benjamin anspielt, ist die, dass dieser Normbruch nicht gekontert, d.h. auch nicht gekittet werden kann.

Die Idee, dass dieses »Nicht-Handeln« im Streik kein Ergebnis produzieren und so auch nicht zweckhaft sein kann, ist bei Benjamin auch auf der Ebene der göttlichen Intervention beschrieben. Das messianische Element in seinem Denken, so die Auslegung Giorgio Agambens, fundiere ebenso auf der Idee einer Zwecklosigkeit, einer Resultat- und Ergebnislosigkeit: »the Messiah fulfills every historical event, [...] the reign of God is not goal but end. ${ }^{23}$ Die grausame Kausalität von Mittel und Zweck kommt in Benjamins Denken zu einem Ende - auf der Ebene der politischen Theologie durch den Messias, auf der Ebene der Rechtsphilosophie durch den Streik, das »Nicht-Handeln«, d.h. das Nichtstun. Giorgio Agamben, dessen Philosophie der Arbeit Benjamins und Arendts zu großen Teilen verpflichtet ist, nimmt diesen Gedanken auf: indem er den Protagonisten aus Herman Melvilles "Bartleby, The Scrivener« zu eben der göttlichen Symbolfigur einer neuen Rechtsordnung macht - den Nichtstuer Bartleby, der zentralen Figur der literarischen Motivgeschichte des Nichtstuns in der Moderne. Bartleby, der Schreiber hört auf, zu schreiben (»stop[s] copying«) gibt seine Arbeit auf (»give[s] up his work «), ${ }^{24}$ und zeigt durch dieses Nichtstun die Befreiung von der alten Ordnung an, wie Benjamin sie beschrieben hat. Bartlebys »renunciation of copying is also a reference to the Law, a liberation from the >oldness of the letter $«$, ${ }^{25}$ und ist in seiner Unnachgiebigkeit, die ihn in den Tod führt, so absolut, dass sie für Agam-

21 Benjamin: Gewalt, 184.

22 Benjamin: Gewalt, 194.

23 Agamben: Walter Benjamin and the Demonic: Happiness and Historical Redemption. In: Ders.: Potentialities, 144. Herv. meine.

24 Agamben: Bartleby, or On Contingency. In: Ders.: Potentialities, 268.

25 Agamben: Bartleby, 270. 
ben eine göttliche Intervention darstellt. Bartleby, der Nichtstuer ist »a new Messiah«, »the new savior «, ${ }^{26}$ der ultimativ Streikende.

Melvilles Bartleby wird spätestens seit der Lektüre Agambens als Figur betrachtet, die passiven Widerstand leistet. Während er in der Kurzgeschichte selbst eine »challenge to capitalist, corporatist ideologies « darstellt, ${ }^{27}$ fungiert er in anderen Kontexten als symbolischer Hoffnungsträger einer neuen Politik im Allgemeinen. So heißt es auch bei Michael Hardt und Antonio Negri: »[Bartleby's] refusal of work and authority, or really the refusal of voluntary servitude, is the beginning of a liberatory politics. ${ }^{28}$ Das Nichtstun kommt einer Befreiung gleich.

\section{Ereignis und Geschichte}

Die Aushebelung der Zweck-Mittel-Relation bei Arendt und Benjamin bringt auch mit sich, dass das Nichtstun geschichtliche Bedeutung erlangt. Hannah Arendt hält Handlung im Allgemeinen für geschichtlich relevant, sie bedeutet, etwas Neues anzufangen: »Dem Handeln ist es eigentümlich [...], einen neuen Anfang zu setzen, etwas Neues zu beginnen, die Initiative zu ergreifen [...] die Menschen [sind], solange sie handeln können, das Unwahrscheinliche und Unberechenbare zu leisten imstande ${ }^{29}$ Die Möglichkeit, etwas Neues und Unwahrscheinliches zu tun, macht das Handeln für Arendt ereignishaft; der »Geschichtsprozess « sei ihr zufolge aus "menschlichen Initiativen entstanden « und wird »durch neue Initiativen dauernd durchbrochen ${ }^{30}$

Während für Arendt der passive Widerstand nur eine von vielen Möglichkeiten für ein ereignishaftes Handeln darstellt, ist bei Benjamin der Streik nicht eins unter vielen möglichen Ereignissen, sondern er ist das eine Ereignis. In der Ereignisphilosophie wird das Ereignis gemeinhin als einzigartig und unvorhersehbar betrachtet, und ist deshalb nicht nur Teil der Geschichte, sondern bewirkt eine historische Zäsur. Ein Ereignis ist, in den Worten

\footnotetext{
26 Agamben: Bartleby, 270.

27 Jane Desmarais: Preferring not to. The Paradox of Passive Resistance in Herman Melville's »Bartleby«. In: Journal of the Short Story in English 36 (Spring), 2001, 1 [Absatzzahl].

28 Michael Hardt u. Antonio Negri: Empire. Cambridge: Harvard UP (2000), 204.

29 Hannah Arendt: Was ist Politik? Fragmente aus dem Nachlaß. Hg. v. Ursula Ludz. München: Piper (2015), 34f.

30 Arendt: Was ist Politik?, 33. Zum Thema Ereignishaftigkeit vgl. ebd. 23 u. Arendt: Vita activa, 216.
} 
Slavoj Žižeks, eine "rupture in the normal run of things «, ${ }^{31}$ ein radikaler Einschnitt in den normalen Verlauf der Dinge. Es bewirkt so eine phänomenologische Verschiebung, erzwingt geradezu einen neuen Wahrnehmungsmodus: "[A]t its most elementary, event [sic!] is not something that occurs within the world, but is a change of the very frame through which we perceive the world and engage in it «. ${ }^{32}$ Genauso versteht auch Werner Hamacher den Streik im Benjaminschen Sinne, den er ein »afformatives Ereignis« nennt - und dadurch in Kontrast setzt zu dem handlungsspezifischen, "performative[n] Akt «. ${ }^{33}$ Der Begriff des Afformativen ${ }^{34}$ drückt die Unbestimmtheit des Nicht-Handelns und seiner Folgen aus; er beschreibt, dass sich darin eben nichts >formieren kann, schon gar nicht Affirmation oder Negation. Der Streik ist ein Widerstand, der die Politik, den Staat, das Recht weder erhalten noch umgestalten will, sondern zunächst einmal vollkommen außer Kraft setzt. Damit wird, so argumentiert Hamacher, eine Umkehrung der Perspektive klassischer politischer Theorie vollzogen, indem sie Politik nicht in Bezug auf affirmative, sondern auf subversive Konfrontationen mit den Imperativen der Produktion definiert:

31 Slavoj Žižek: Event. Philosophy in Transit. London: Penguin (2014), 38. Dieses Verständnis orientiert sich an dem Konzept des Ereignisses, wie es nicht nur, aber insbesondere in der französischen Philosophie des 20. Jahrhunderts dominant ist. Vgl. hierzu Marc Rölli: Einleitung: Ereignis auf Französisch. In: Ereignis aufFranzösisch. Von Bergson bis Deleuze. Hg. v. Dems. München: Fink (2004), 7-40. Die Abwertung des Ereignis-Konzepts in der Ceschichtswissenschaft, zum Beispiel im Rahmen der Annales Schule, ist in diesem Kontext irrelevant.

32 Žižek: Event, 10.

33 Werner Hamacher: Afformativ, Streik. In: Was heißt »Darstellen«? Hg. v. Christiaan L. Hart Nibbrig. Frankfurt a.M.: Suhrkamp (1994), 359.

34 Hamacher kommentiert die linguistische Grundlage für diesen Neologismus nicht. Wahrscheinlich ist, dass er eine Doppelkonnotation erwirken will: einerseits suggeriert das doppelte »f« eine Nähe zum Begriff des Affirmativen, andererseits suggeriert er durch das Alpha privativum eine Negation der Form, und damit des Performativen. Diese Doppeldeutigkeit verleiht der Tatsache Ausdruck, dass Hamacher den Streik zwar als negierende Unterbrechung denkt, aber eben auch als positiven Neuanfang, der sich jedoch von den positiven Setzungen des Performativen abhebt. So schreibt Jan Sieber: »Für eine Theorie des Passiven ist der Begriff des Afformativen insofern interessant, als dass er es ermöglicht, die strikte Dichotomie von passiv und aktiv zu überwinden und zugleich Passivierung als Voraussetzung von Aktivierung zu denken.«Jan Sieber: Schweigen, Streiken, Vergessen. Zur Aktivierung durch Passivierung bei Walter Benjamin. In: Theorien der Passivität. Hg. v. Kathrin Busch u.a. München: Fink (2013), 228. 
Im Unterschied zur historisch-transzendentalen Pragmatik, die es auf die geschichtlichen Formen sprachlichen und gesellschaftlichen Handelns absieht, ist Benjamins Skizze einer Politik der reinen Mittel eine Theorie nicht der setzenden, herstellenden und darstellenden, der formierenden und transformierenden Handlung, sondern eine Theorie ihrer Unterlassung; sie ist, wenn man will, eine Theorie des transzendentalen Streiks, der die Bedingungen historischen Handelns freilegt, seine bisherigen Formen suspendiert und eine andere Geschichte eröffnet, die nicht mehr von Formen der Setzung und der Arbeit, der Darstellung und der Herstellung und nicht mehr von Formen beherrscht wäre. Also eines Streiks, der noch die Form des Transzendentals, die Form reiner paradigmatischer Formen selber und damit die Möglichkeit seiner Erkenntnis betrifft. ${ }^{35}$

In dieser Passage zeigt Hamacher eine neue Dimension des Benjamin'schen Streik-Konzepts auf. Der Streik eröffne »eine andere Geschichte«, weil er die bis dahin unvorstellbare Abweichung von einer Norm darstellt, die danach nicht mehr restituiert werden kann. Der Konnotation eines geschichtlichen Endes der Geschichte, die durch das messianische Element in Benjamins Text zustande kommt (und auch in den Interpretationen Agambens stark betont wird), fügt Hamacher noch die eines Anfangs der Geschichte hinzu. Das Nichtstun im Sinne des Streiks ist also ein paradoxes Phänomen. Es ist gleichermaßen Ende und Anfang der Geschichte; es bezeichnet das Ende des Handelns und eröffnet zugleich »die Möglichkeit eines anderen sittlichen Handelns «. ${ }^{36}$ Für Benjamin kann Geschichte also nur dort »gemacht«« werden, so resümmiert Jochen Gimmel, »wo sich Menschen dem geschichtlichen Handlungszwang durch eine Strategie der Stillegung und Unterbrechung entziehen. «37

Dieser Gedanke ist im höchsten Maße ungewöhnlich, da in den dominanten westlichen Geschichtsphilosophien das Nichtstun lediglich mit dem Ende der Geschichte korreliert, selten aber mit ihrem Wechsel oder Neubeginn. So sieht Karl Marx die klassenlose Gesellschaft im Kommunismus als das Ende der Arbeit an, der geschichtsfördernden Aktivität überhaupt; ${ }^{38}$ Alexandre

\footnotetext{
35 Hamacher: Afformativ, 357f. Herv. meine.

36 Sieber: Schweigen, Streiken, Vergessen, 226.

37 Gimmel: Zum Begriff des Nicht/Handelns, 315.

38 Die Revolution habe, so Arendt, nach Marx »nicht etwa die Aufgabe, die arbeitende Klasse zu emanzipieren, sondern die Menschen von der Arbeit zu befreien. «Aus dem Kapital zitierend schreibt sie weiter: »das Reich der Freiheit beginnt in der Tat erst da,
} 
Kojève spricht von Hegels Vollendung der Geschichte als dem »Beenden aller >Aktion« «; 39 Arnold Gehlen beschreibt das (von ihm begründete) Posthistoire als das Ende eines »unmittelbaren Handelnkönnen[s]«. ${ }^{40}$ Die Vorstellungen eines historischen Endes gehen in vielen Fällen auch mit dem Ende des Handelns einher, vor allem dort, wo Geschichte als von menschlicher Handlung gemacht verstanden wird. Seit diese Prämisse mit Adorno und Horkheimers Dialektik der Aufklärung (1944) aus der Geschichtsphilosophie verbannt wurde, ${ }^{41}$ ist die Verbindung von Nichtstun und Geschichte zwar weniger überraschend, aber dennoch kaum beschrieben worden. Dieser Umstand hat vielfach zur Abwertung des menschlichen Agens geführt, ${ }^{42}$ selten aber zur historischen Aufwertung des Nichtstuns. Dabei kann, wie Jochen Gimmel richtig bemerkt, gegenüber der Idee einer Geschichte als Handlungsaufforderung an den Menschen (die natürlich nicht wenig Druck erzeugt), "gerade Nicht/Handeln zur eigentlich geschichtlichen Tat und Ermöglichung einer Freiheit werden ${ }^{4}{ }^{43}$

\section{Rekonzeptualisierung des Handelns}

Die von Arendt identifizierte neuzeitliche Reduktion des Handlungsbegriffs durch die Zweck-Mittel-Relation hat mehrere ethische Komponenten, die auch das Nichtstun jeweils in ein anderes Licht rücken. Mitte und Ende des 20. Jahrhunderts haben Arendt und Benjamin, ebenso wie Agamben und andere, eine mögliche Wende zur Gewalt im Handeln fokussiert - in ihrem

wo das Arbeiten, das durch Not und äußere Zweckmäßigkeit bestimmt ist, aufhört.« Arendt: Vita activa, 123.

»[L]a cessation de l'Action«. Alexandre Kojève: Introduction à la lecture de Hegel. Hg. v. Raymond Queneau. Paris: Callimard (1947), 435. Übersetzung bei und von Hans U. Gumbrecht in: Präsenz. Hg. v. Jürgen Klein. Berlin: Suhrkamp (2016), 12.

Arnold Gehlen: Über kulturelle Kristallisation. In: Ders.: Studien zur Anthropologie und Soziologie. Neuwied: Luchterhand (1963), 324.

41 Vgl. hierzu auch Cumbrecht: Präsenz, $12 \mathrm{f}$.

42 »Die Annahme, dass man Ceschichte in die Hand nehmen und entscheiden könne, ob man jetzt in Richtung rechts oder links geht, war eine Überschätzung, die auf der einen wie auf der anderen Seite zu skandalösen totalitären Konsequenzen geführt hat. Man sollte die menschliche agency nicht so überschätzen«. Fernando Esposito u. Hans U. Gumbrecht: Posthistoire Then. Ein Gespräch mit Hans Ulrich Gumbrecht über »unsere breite Gegenwart«. In: Zeitenwandel. Transformationen geschichtlicher Zeitlichkeit nach dem Boom. Hg. v. Fernando Esposito. Göttingen: Vandenhoeck \& Ruprecht (2017), 271. Gimmel: Zum Begriff des Nicht/Handelns, 310. 
Denken hebelt das zweckfreie Nichtstun bestehende Logiken des Handelns aus, es ist eine rettende Nicht-Handlung. Agamben widmet diesem Gedanken die Textsammlung Mezzi senza fine (1996), in der er die Zweckfreiheit (er nennt es »reine Mittelbarkeit«) zum idealen Standard des Politischen erhebt:

Politik ist die Darbietung einer Mittelbarkeit, das Sichtbarmachen eines Mittels als solchem. Sie ist weder die Sphäre eines Zwecks an sich, noch die Sphäre der einem Zweck untergeordneten Mittel, sondern die einer reinen Mittelbarkeit ohne Zweck als Feld des menschlichen Handelns und Denkens. $^{44}$

Doch in den heutigen zeitgenössischen Philosophien liegt, auch durch den größeren zeitlichen Abstand zu den Weltkriegen, der Fokus auf einem anderen Problem. Man fürchtet nicht die Vorstellung der Zweck-Mittel-Relation aufgrund ihrer möglichen Legitimation von Gewalt, sondern vielmehr den Wegfall einer grundsätzlichen ethischen Motivation des Handelns im Fall einer Auflösung der Zweck-Mittel-Relation. Dieses mit der Postmoderne assoziierte Problem hat Jean-Luc Nancy 2016 in Que faire? beschrieben. In der Essaysammlung, die denselben Titel trägt wie eine programmatische Schrift Lenins aus dem Jahr 1902, ${ }^{45}$ behauptet er, dass zwar »)tun untrennbar ist von sexistieren «, doch dass heute sowohl das Tun »fragilisiert« als auch die Wirklichkeit »destabilisiert« worden sei. ${ }^{46}$

Die Fragilisierung des Praktischen ergibt sich für Nancy aus einem epistemischen Problem: Die kontinuierliche Erweiterung des menschlichen Wissens verunsichere die Vorhersehbarkeit der Ergebnisse des eigenen Handelns, wie sie konventionellerweise durch das Zweck-Mittel-Modell suggeriert wird. Weil Wissen nicht mehr überschaubar sei, könne man Mittel und Zwecke

44 Ciorgio Agamben: Mittel ohne Zweck. Noten zur Politik. Übers. v. Sabine Schulz. Zürich: Diaphanes (2006), 101. Guilia Pelillo-Hestermeyer wies mich zum einen darauf hin, dass der Originaltitel Mezzi senza fine eine Anspielung auf und zugleich eine provokative Verdrehung des italienischen Sprichwortes »il fine giustifica i mezzi« ist, zu deutsch »das Ziel rechtfertigt die Mittel«. Zum anderen, dass Agamben damit natürlich auch Hannah Arendts Bemerkung über die ideologische Prägung volkstümlicher Sprichwörter bestärkt, die durch die Rechtfertigung der Mittel zum Erreichen entsprecher Zwecke den Wert des serfolgreichen Abschlusses < einer Handlung über den Wert der Handlung selbst stellen. Ich danke ihr für den entsprechenden richtigen Hinweis.

45 Vladimir I. Lenin: Was tun? Brennende Fragen unserer Bewegung. Berlin: Dietz (1971).

46 Jean-Luc Nancy: Was tun? Übers. v. Martine Hénissart u.a. Zürich: Diaphanes (2017), 47, 71. 
nicht mehr vernünftig koppeln: Man kennt zu viele, kleinteiligste Zwecke, weiß aber nicht, mit welchen Mitteln sie erreicht werden können, oder ob sie nicht vielmehr zu neuen Mitteln für unliebsame Zwecke werden. Es sei in einer solchen Welt geradezu unmöglich, eine Ethik aufrechtzuerhalten. Deshalb sei die ethische Frage überhaupt, Was tun?, in unserer Zeit »nur noch undeutlich zu hören«, weil man

nicht mehr an die geringste wirkliche Antwort glaubt, auch wenn alle möglichen Zeitungen überquellen vor informierten Analysen und kundigen Ratschlägen. Der Gipfel unserer Verunsicherung ist, dass wir nicht einmal mehr wagen, die Frage zu stellen. [...] [N]ichts erlaubt uns [...], eine Frage zu stellen, deren Begriff uns bereits entgeht: die eines Handelns, das mit verfügbaren Mitteln zu einem bestimmten Ziel führt. ${ }^{47}$

Bei Nancy hallt die Idee der »kulturellen Kristallisation« wieder, die Arnold Gehlen Anfang der 1960er vorgebracht hatte: ein Zustand der Verfestigung aller Wissens- und Operationsbereiche, der das Ende eines »unmittelbaren Handelnkönnen[s] « bedeute. ${ }^{48}$ Im Gegensatz zu Gehlen, der dies als neutrale Zeitdiagnose formulierte und damit das Denken des Posthistoire einleitete, ist Nancys Beobachtung jedoch von einem besorgten Ton und einer ethischen Verunsicherung geprägt. Wenn Mittel und Zweck nicht mehr kausal miteinander verknüpft sind, wie will man dann noch etwas tun - und warum sollte man überhaupt? Nancy reißt also ein anderes Problem an als Benjamin und Arendt: Wenn man, wie es Nancy zufolge üblich ist, Handlung als die Verwendung eines Mittels zu Erreichung eines bestimmten Zwecks versteht, dann ist Handlung nunmehr unmöglich, weil Zwecke und Mittel nicht mehr zugeordnet werden können - das Resultat ist ein Nichtstun. Doch Nancys Verständnis des Nichtstuns ist ein anderes als bei Benjamin und Arendt. Es ist keine rettende, ergreifende Handlung, sondern Resignation. Es ist nicht der Anfang einer neuen Ethik, sondern das Ende von Ethik überhaupt. Mit der Setzung des Nichtstuns als Problem will Nancy den Zeitgeist beschreiben, der ihn zu der Publikation von Que faire? motiviert hat: Die Menschen sheute haben das

\footnotetext{
47 Nancy: Was tun?, gf.

48 Gehlen: Über kulturelle Kristallisation, 324. Dabei handelt es sich bei Nancys und Gehlens Ansätzen um zwei völlig verschiedene Modi der Problembetrachtung. Gehlen geht im Gegensatz zu Nancy nicht von einer Überforderung des Menschen durch den wissenschaftlichen Fortschritt aus, sondern von einer Art >Vorentschiedenheit< aller Handlungsergebnisse, wegen der nichts Neues mehr getan werden kann.
} 
Gefühl, nichts mehr tun zu können, und schweben deshalb in Gefahr, tatsächlich nichts mehr zu tun. Die Gefahr, die Nancy darin sieht, ist nicht nur eine mögliche aktive Hinwendung zur Gewalt, sondern auch ein passives Hinnehmen der schlechten Zustände auf der Welt, eine resignative Akzeptanz ihrer Verwahrlosung.

Dennoch geht Nancys Idee, wie dieses Dilemma zu lösen ist, in eine ähnliche Richtung wie bei Arendt und Benjamin. Er schlägt vor, die Trennung von Zweck und Mittel nicht als die Verunmöglichung von Handlung im Nichtstun zu denken, sondern diese Trennung als konstitutiv für eine neue Form der Handlung zu setzen (ohne sie jedoch als Nichtstun zu beschreiben):

Wenn Was tun? bisher mal auf das Anstreben eines Endziels, mal auf die Bestimmung der richtigen Mittel orientiert war, so erfährt nun das Tun selbst eine Wendung, die vielleicht genauso charakteristisch ist wie jene, die es ins Rampenlicht der Geschichte und des Denkens treten ließ. Die Sache des Tuns wird nicht mehr nur auf der Ebene des Projekts verfolgt, auch nicht nur auf derjenigen des Kampfes (die Frage war zwischenzeitlich gerade aus dem Sinn der militanten Aktion entsprungen, die ihre Akteure opfert). Sie wird also nicht mehr in der Perspektive einer zumindest tendenziellen Einstellung der Mittel auf die Ziele verfolgt. Es gilt vielmehr dem Tun eine nie dagewesene Distinktion zuzuerkennen. Auf die Dehiszenz zwischen Theorie und Praxis und auf den Willen, ihren Abstand zu beseitigen in der Verwirklichung des Projekts, folgt eine Befragung über das Tun selbst. ${ }^{49}$

Nancy hebt in diesem Passus hervor, dass man das Handeln nicht mehr als Mittel-Zweck-Relation verstehen dürfe. Die Verstandesoperation, die der Mensch zur Wahl der richtigen Mittel für die gewünschten Endziele vollziehen müsse, sei nicht durchführbar - vollständiges Wissen ist keine ausreichende Voraussetzung für das Handeln mehr. Nancy markiert so den Unterschied seines Denkens zu dem Lenins, den er im Titel referenziert: Lenins Idee einer expertokratisch geführten Arbeiterbewegung, die dieser in Was tun? (1902) gegen die Vorstellung einer durch spontanes Handeln hervorgebrachten Umwälzung verteidigte, ist für Nancy heute nicht mehr denkbar. Die Folge für Nancy ist jedoch nicht die Glorifikation eines posthistorischen Nichtstuns, wie man es zum Beispiel in Kojèves Hegel-Auslegung liest. ${ }^{50}$

\footnotetext{
49 Nancy: Was tun?, 63.

50 Das Ende der Ceschichte in Hegels Denken impliziere natürlich auch das Ausbleiben weiterer Veränderung. Kojève spricht vom »Beenden aller >Aktion« im Sinne einer po-
} 
Er propagiert vielmehr die Abschaffung des Zweck-Mittel-Verhältnisses im Verständnis des Handelns.

Dieses neue, aktualisierte Verständnis des Handelns weist zwei Beziehungen zum Nichtstun auf: es stellt zum einen eine Überwindung des apathischen, unethischen Nichtstuns im Sinne Nancys dar; aber zum anderen entspricht es dem streikenden, rechtszerstörenden Nichtstun im Sinne von Benjamin und Arendt. Nancy etabliert, wenn auch aus einer anderen Situation heraus, dasselbe Verständnis von Handlung wie Benjamin und Arendt: eine Handlung, die die Struktur eines Nichtstuns annimmt, und die gerade dadurch eine neue Potenz erlangt.

Nancy bedient sich hier allerdings anderer Termini: Theorie und Praxis (statt Mittel und Zweck). Er verweist dabei jedoch auf dasselbe Prinzip: das eines Handelns, das den Abläufen des Herstellens folgt. Der Herstellungsprozess ist Arendt zufolge nämlich in materieller Hinsicht von der »Zweck-Mittel-Kategorie bestimmt« (zum Herstellen eines Produkts braucht man ein bestimmtes Material, bestimmte Werkzeuge), ${ }^{51}$ aber immateriell auch von der Existenz einer theoretischen Vorstellung des Endprodukts im Denken des Herstellenden. »Die eigentliche Herstellung nun vollzieht sich stets unter Leitung eines Modells, dem gemäß das herzustellende Ding angefertigt wird. Ein solches Modell mag dem inneren Blick des Herstellenden nur vorschweben ${ }^{52}$ Dieses Verhältnis wird von Nancy, wie umgangssprachlich üblich, als die Verknüpfung von Theorie und Praxis bezeichnet. Die Lösung ist ihm zufolge die Aufhebung dieser Verknüpfung, das heißt also die Re-Konzeptualisierung des Handelns im Allgemeinen als ein Tun ohne vorausgehendes Modell und ohne die Erwartung eines vorab vorstellbaren Ergebnisses.

Das Fazit, das Nancy zieht, ähnelt dem von Arendt und Benjamin. Ihre Kritiken der handlungsspezifischen Zweck-Mittel-Relation kommen alle $\mathrm{zu}$ demselben Ergebnis: Handlung muss als zweckfrei re-konzeptualisiert werden, Praxis muss von der Theorie getrennt sein. Bemerkenswert dabei ist, dass gerade das Nicht-Handeln, der Streik, der passive Widerstand, also das

sitiven Stabilisierung, die das Clück des Menschen ermögliche. Praktisch bedeute das Beenden aller Aktion nämlich: »das Verschwinden von Kriegen und blutigen Revolutionen. [...] Alles andere aber kann unendlich aufrechterhalten werden: die Kunst, die Liebe, das Spiel usw.; kurz: alles, was den Menschen glücklich macht.«Zit. n. Gumbrecht: Präsenz, 12f.

51 Arendt: Vita activa, 168.

52 Arendt: Vita activa, 166. 
Nichtstun zum Inbegriff dieser neuen Handlung wird. Es steht für die Umgehung und Auflösung einer moralischen Verirrung im Handeln, und - auch wenn Nancy es nicht ebenso konkret benennt wie Arendt und Benjamin -,53 es ebnet den Weg für eine realistische, zu bewältigende zeitgenössische Ethik. Eine, die sich nicht daran abarbeite, dass jede Handlung ein ganz bestimmtes Ergebnis produzieren muss. Man kann so im 20. Jahrhundert, wenn nicht einen epistemischen Bruch, so doch zumindest eine diskursive Spaltung erkennen: auf der einen, konventionellen Seite ist Handlung ohne Zweck keine Handlung, sondern erfährt eine Abwertung zum Nichtstun. Auf der anderen, hier untersuchten Seite ist eine Handlung ohne Zweck im positiven Sinn ein Nichtstun, das aufgrund seiner Abwendung vom konventionellen Handlungsmodell eine neue Art der Handlung etabliert. Einer Handlung im Arendt'schen Sinne, denn: »Handeln und Sprechen sind Vorgänge, die von sich aus keine greifbaren Resultate und Endprodukte hinterlassen.« Arendts Handlungskonzept zeichnet sich, auch wenn sie selbst dies nicht expliziert, dadurch aus, wesentliche Eigenschaften des Nichtstuns als politisch wirksamer Tätigkeit aufzuweisen. ${ }^{54}$ Weil es keinem bestimmten Plan folgt und auch nicht an der Produktion eines bestimmten Ergebnisses interessiert ist sondern die Möglichkeiten von Handlung selbst jenseits der Zweck-MittelRelation, und der damit möglicherweise einhergehenden Gewalt, freilegt.

\section{Gemeinschaft}

Nichtstun schafft Gemeinschaft. An die Idee des Nichtstuns ist auch die Hoffnung geknüpft, dass sich auf seiner Grundlage eine neue Art der Gemeinschaft bilden könnte - wobei ich unter Gemeinschaft eine soziale Bindung zwischen mehreren Menschen unter Rückbezug auf geteilte Werte oder Eigenschaften verstehe. Die Koppelung des Nichtstuns mit Gemeinschaftlichkeit ist allerdings nicht selbstverständlich. Zwar gibt es

53 Nancy hat allerdings in seiner Gemeinschaftstheorie das Konzept der >Werklosigkeit< vorgestellt, und folgt darin derselben Logik wie Arendt: Gemeinschaft kann nicht produziert werden. Dieses Element seines Werks, das im folgenden Kapitel diskutiert wird, zeigt seine Zugehörigkeit zu diesem Denken an.

54 Finlays Analyse ist zu entnehmen, dass der Zusammenhang von Arendts Politikverständnis mit Benjamins Nicht-Handlung als reines Mittel sich nicht nur auf das Ereignis einer Revolution, eines geschichtlichen Umbruchs bezieht, sondern auf Politik im Allgemeinen. Vgl. Finlay: Hannah Arendt's Critique of Violence, 42. 
in der Literaturgeschichte einige Hinweise auf diese Assoziation, so zum Beispiel Vergils Arkadien-Utopie, die er in den Hirtengedichten (Eclogae) entwirft. Darin dominiert, in Manfred Kochs Worten, die Vorstellung des "musisch beflügelten Gemeinschaftslebens« eines von beschwerlicher Arbeit verschonten Hirtenvolks, das sich mit Vorliebe dem Flötenspiel widmet. ${ }^{55}$ Es ist sicher auch kein Zufall, dass die deutsche Romantik einerseits dazu tendierte, »das >Andere des tätigen Lebens (neben dem Müßiggang auch den Schlaf, die Muße und Faulheit) auf[zu]werten «, ${ }^{56}$ und andererseits ihre Gemeinschaftsphilosophien nicht nur an Natur, Gefühl und Religion ausrichtete, sondern auch über den expliziten Ausschluss zweckrationalen Handelns definierte. ${ }^{57}$ Doch von solchen Ausnahmen abgesehen ist die Idee der Gemeinschaft in der Motivforschung zum Nichtstun bisher nicht von allzu großem Interesse gewesen, weil die bekanntesten Nichtstuer-Figuren gerade nicht gemeinschaftlich orientiert, sondern vielmehr Einzelgänger sind.

\section{Gemeinschaft durch Tätigkeit und Arbeit}

Die These dieses Kapitels lautet, dass Nichtstun als Fundament eines neuen Gemeinschaftstyps verstanden werden kann, der sich gegen übliche Gemeinschaftsvorstellungen richtet. Gemeinschaft wird gemeinhin entweder als durch Immanenz oder Tätigkeit hergestellt verstanden. Die Idee einer sich auf Immanenz gründenden Gemeinschaft bezieht sich auf die den Mitgliedern gegebenen, unveränderlichen Eigenschaften - dazu gehören zum Beispiel Gender, Alter, Ethnie, Geburtsland, Muttersprache, Sexualität usw. Hingegen die Idee einer auf Tätigkeit basierenden Gemeinschaft, die unter anderem von Hannah Arendt vertreten wird, fokussiert die Aktivität ihrer Mitglieder.

55 Manfred Koch: Faulheit. Eine schwierige Disziplin. Springe: zu Klampen (2012), 38.

56 Lillge u.a.: Arbeit und Müßiggang in der Romantik, 21.

57 »Mit Leidenschaft wandten romantische Denker sich gegen Hobbes und alle Theorien, welche die staatliche Gemeinschaft aus einer zweckrationalen Vertragsübereinkunft ausgehen ließen. « Juliane Spitta: Cemeinschaft jenseits von Identität? Über die paradoxe Renaissance einer politischen Idee. Bielefeld: transcript (2013), 139. Die in diesem Kapitel diskutierten Gemeinschaftstheorien, die sich um den Begriff der Werklosigkeit zentrieren (von Maurice Blanchot und Jean-Luc Nancy), weisen ebenfalls Bezüge zur deutschen Romantik auf. Dies zeigt Leslie Hill anhand von Blanchots und Nancys früher Theoretisierung der romantisch idealisierten literarischen Form des Fragments als >werklos` (»l'œuvre de l'absence d'œuvre«). Leslie Hill: Nancy, Blanchot. A Serious Controversy. London: Rowman \& Littlefield International (2018), $29 f$. 
Sie ist, kurz gesagt, nicht vom Sein, sondern von dem Handeln der Menschen abhängig. Arendt schreibt:

Handeln[...] ist in Isolierung niemals möglich; jede Isoliertheit, ob gewollt oder ungewollt, beraubt der Fähigkeit zu handeln. So wie das Herstellen der Umgebung der Natur bedarf, die es mit Material versorgt, und einer Umwelt, in der das Fertigfabrikat zur Geltung kommen kann, so bedarf das Handeln und Sprechen der Mitwelt, an die es sich richtet. [...] das Handeln und Sprechen vollzieht sich in dem Bezugsgewebe zwischen den Menschen, das seinerseits aus Gehandeltem und Gesprochenem entstanden ist, und muß mit ihm in ständigem Kontakt bleiben. ${ }^{58}$

Wer in diesem Verständnis nichts tut, der zieht sich von anderen Menschen zurück, und kann auch nicht Teil einer Gemeinschaft sein. Auch außerhalb von Arendts Verständnis gehört das Nichtstun nicht zum Kanon der Konditionen zur Gemeinschaftsbildung: es ist weder eine gültige immanente Eigenschaft, noch wird es als gemeinschaftskonstituierende Tätigkeit wahrgenommen. Die heute oft angeführte antike Auffassung, die Republik könne davon profitieren, wenn manche Individuen ein kontemplatives Leben zurückgezogen von der Öffentlichkeit führen, ${ }^{59}$ ist mit neuzeitlichen Gemeinschaftsideen nicht kompatibel. Besonders in und seit der Aufklärung wird das Nichtstun als unwürdig empfunden, da es den sozialen Möglichkeiten des Menschen nicht gerecht wird. Das Denken der Aufklärung erlaubte den Menschen, so Brian O'Connor,

to realize themselves individually as autonomous beings and, collectively, as a rational community. Idleness, in this light, is a denial of Enlightenment. It

\footnotetext{
58 Arendt: Vita activa, 234.

59 O'Connor nennt als Beispiel Seneca, der in De Otio behauptet, »that studious contemplation, and a leisurely withdrawal from civic life, can lead to an enhancement of the republic. «O'Connor schließt ebenfalls eine Begründung dafür an, dass diese Sichtweise heute nicht allgemeingültig sein kann: »In this essay, Seneca posits the idea of a republic that is not reducible to the existing arrangements of the state. He is speaking about the kinds of ideal political actor that we may sometimes be able to become only when we have the freedom to spend our time in philosophical reflection. We can be theorists when we no longer have to compromise our principles to meet the needs of everyday politics. «O'Connor: Idleness, $34 \mathrm{f}$.
} 
amounts to a refusal to meet the challenge of taking responsibility for oneself and the institutions of the state. ${ }^{60}$

Gemeinschaft wird also als Ergebnis der Aktualisierung durch Handlung verstanden, die sich bis auf die Staatsebene vollzieht. Im sogenannten >Westen ist seit dieser Zeit bis heute die Idee einer tätigen Gemeinschaft besonders prävalent. Dabei gibt es unterschiedliche Vorstellungen, wie genau diese Tätigkeit beschaffen sein soll und muss. Für Arendt besteht diese Tätigkeit idealerweise im zweckfreien Handeln. Doch für die westliche Gesellschaft des 20. und 21. Jahrhunderts ist ein solches Handeln nicht so relevant wie die Arbeit einerseits, und das Herstellen andererseits. In der Neuzeit, so behauptet auch Arno Baruzzi, wird »Arbeit eine Praxis genannt«, als stelle sie ein Handeln dar. ${ }^{61}$ Die Tätigkeitsformen Arbeit und Herstellen genießen sogar eine wesentlich größere Wertschätzung als das Handeln, sodass sie nun auch für das Konzept von Gemeinschaft konstitutiv sind. ${ }^{62}$

Besonders die Arbeit ist bekanntermaßen in den letzten Jahrhunderten von einer Lebensnotwendigkeit zu einem der wichtigsten gesellschaftlichen Werte avanciert. »Die Neuzeit hat im siebzehnten Jahrhundert damit begonnen, theoretisch die Arbeit zu verherrlichen, «schreibt Arendt, »und sie hat zu Beginn unseres Jahrhunderts damit geendet, die Gesellschaft im Ganzen in eine Arbeitsgesellschaft zu verwandeln. ${ }^{63}$ Damit ist sie auch zum zentralen Merkmal der Gemeinschaft im 20. Jahrhundert geworden - wobei gerade im Fall der Arbeit Gesellschaft und Gemeinschaft gleichbedeutend zu sein scheinen. Folgt man der gesellschaftlichen Erwartung, zu arbeiten, so die Logik, kann man immer und überall Gemeinschaft finden. Tut man es nicht, fällt man sowohl aus der Gesellschaft wie aus der Gemeinschaft heraus. Bildeten also in früheren Gemeinschaftsphilosophien noch Sprache, Religion, Natur oder gar Ethnie den gemeinsamen Fixpunkt, so ist es im späteren 20. Jahrhundert die Arbeit. Sigmund Freud drückt es 1930 in Das Unbehagen in der Kul-

60 O'Connor: Idleness, 38f. Herv. meine. Für eine Diskussion der Asozialität des Nichtstuns bei Kant vgl. ebd. 43-45.

61 Baruzzi: Machbarkeit, 187.

62 Ein gutes Beispiel hierfür ist das von Lave und Wenger etablierte Konzept der »Community of Practice«, das sich vornehmlich auf professionelle Cruppierungen bezieht und eine Gemeinschaft über den gemeinsamen Nenner der Arbeit postuliert. Jean Lave u. Etienne Wenger: Situated Learning. Legitimate Peripheral Participation. Cambridge: UP (1991), 98-100.

63 Arendt: Vita activa, 12. 
tur wie folgt aus: »Keine andere Technik der Lebensführung bindet den einzelnen so fest an die Realität als die Betonung der Arbeit, die ihn wenigstens in ein Stück der Realität, in die menschliche Gemeinschaft sicher einfügt. « ${ }^{64}$ So wird Arbeit im Denken des Gemeinschaftlichen zum neuen Gegenbegriff des Nichtstuns.

Das heißt im Rückschluss natürlich auch, dass jedes Subjekt, das nicht arbeitet, aus eben dieser Gemeinschaft, die die größte ihrer Art darstellt, ausgeschlossen ist. Das zeigt sich besonders in den starken Arbeiterbewegungen des frühen 20. Jahrhunderts: »Die Proletarier formieren sich zur Klasse, die Vagabunden [d.h. Nicht-Arbeitenden] nicht. ${ }^{65}$ Erstere streben ins Kollektiv, Letztere zum Individualismus. Die Gemeinschaftslosigkeit der Nichtstuer besteht allerdings auch außerhalb des Klassenkampf-Kontextes. Denn, so schreibt beispielsweise Wolfgang Lepenies im Hinblick auf die soziologische Betrachtung der Melancholie im 20. Jahrhundert, Nichtstun ist eine Abweichung von konventionellen Verhaltensweisen, also Anomie, und "per definitionem können Anomie Praktizierende nicht Gesellschaft bilden. « ${ }^{66} \mathrm{Im}$ Rückbezug auf Robert King Mertons Sozialtheorie argumentiert Lepenies, die Gesellschaftsunfähigkeit sei zentrales Element der Handlungsenthaltung. Er schreibt:

Das Rückzugsverhalten unterliegt gesellschaftlicher Verdammung, weil es Gesellschaft in Frage stellt, ohne sie anzugreifen: das Abweichen beruht auf purer Passivität. Nach Merton schaffen sich die »Abweichler« (deviants), die im wirklichen Leben verdammt werden, ihre Kompensation in der Phantasie. Immer aber bleiben sie vereinzelt. Die Passivität ihrer Reaktion gestattet ihnen kein Gruppen -, sondern nur ein privates, singuläres Dasein. ${ }^{67}$

\footnotetext{
64 Sigmund Freud: Das Unbehagen in der Kultur. Frankfurt a.M.: Fischer (2009), 46.

65 Walter Fähnders: »Generalstreik das Leben lang!«. Arbeit, Arbeitsverweigerung und Vagabondage. In: Arbeit und Protest in der Literatur vom Vormärz bis zur Gegenwart. Hg. v. luditha Balint u.a. Würzburg: Königshausen \& Neumann (2015), 78.

Wolf Lepenies: Melancholie und Cesellschaft. Frankfurt a.M.: Suhrkamp (1998), 10. Als Beleg hierfür zieht er auch Ralf Dahrendorf heran, der in Bezug auf die deutsche Gesellschaft nach Wilhelm II. von einer »Un-Gesellschaft «spricht, die durch einen andauernden »Zustand tendentieller Anomie«, d.h. also durch die »Abwesenheit von Handeln überhaupt«charakterisiert sei. Die ersten beiden Zitate stammen aus Dahrendorfs Cesellschaft und Demokratie in Deutschland (1965), zit. n. Lepenies, das dritte Zitat von Lepenies selbst.

67 Lepenies: Melancholie und Cesellschaft, 11.
} 
Der gesellschaftliche Ausschluss, den Lepenies beschreibt, ist in der Forschung eine gängige Annahme. Meine These vertritt die gegenteilige Annahme eines gemeinschaftsstiftenden Nichtstuns. In der üblichen, von Lepenies dargestellten Position kann es eine Ko-Existenz von Nichtstun und Gemeinschaft jedoch allerhöchstens in der Imagination geben. Eine der wenigen denkbaren Relationen zwischen Nichtstun und Gemeinschaft ist also die von Lepenies diagnostizierte "Kompensation in der Phantasie«der Nichtstuer kann sich ausmalen, Teil einer Gemeinschaft zu sein. Ein Beispiel hierfür findet sich in einer modernen Urszene des Nichtstuns, in Iwan Gontscharows Oblomow, dessen Protagonist sich die Aufhebung seiner Isolation wünscht, ohne jedoch sein Nichtstun aufgeben zu müssen. Seine Vorstellung des idealen Lebens umfasst nicht nur das Nichtstun, denn dies lebt er, der die meiste Zeit allein auf seinem Diwan zubringt, bereits vom Beginn der Fiktion an. Er träumt im Gegenteil von einer sozialen Version dieses Nichtstuns, aus der eine Sehnsucht nach »unverdorbener Natürlichkeit« und "Empfindsamkeit « spricht, ${ }^{68}$ die dem romantischen Gemeinschaftsdenken in Deutschland ähnlich ist. Der Teil der Gesellschaft, von dem Oblomow sich distanziert, ist nämlich nicht nur von einer ungesunden Erfolgslust getrieben, sondern leidet auch an einer daraus resultierenden sozialen Kälte. Nach seinem Dafürhalten wird das Nichtstun, welches im Übrigen nur den finanziell abgesicherten vergönnt ist, diese Kälte überwinden, und »Gastfreundschaft«, »Güte« und »Sympathie« zwischen den Menschen wieder aufleben lassen. ${ }^{69}$ Ein ideales Leben, so beschreibt Oblomow seinem besten Freund, dem arbeitsamen Stolz, verlebe man ohne viel Tätigkeit in einer ländlichen Idylle mit guter Gesellschaft:

Jetzt kommen die Gäste, zum Beispiel Du mit Deiner Frau. [...] Dann noch zwei, drei Freunde, immer dieselben Gesichter. Wir setzen das gestrige, unvollendete Gespräch fort; es wird gescherzt oder es tritt auch ein beredtes Schweigen, eine Nachdenklichkeit ein - nicht infolge des Verlustes eines Amtes oder einer Angelegenheit im Senat, sondern infolge der Fülle verwirklichter Wünsche - das Sinnen des Clückes. [...] In den Augen der Anwesenden sieht man Sympathie, beim Scherz hört man ein aufrichtiges, gutmütiges Lachen ... Alles kommt von Herzen! ${ }^{70}$

\footnotetext{
68 Spitta: Cemeinschaft, 105, 141.

69 Iwan Gontscharow: Oblomow. Übers. v. Clara Brauner. Frankfurt a.M.: Fischer (2009), 227.

70 Contscharow: Oblomow, 233.
} 
Die Imagination einer solchen Gemeinschaft stellt also zumindest eine der »inneren Aktivität[en]« dar, von denen Andrea Erwig sagt, dass sie mit der »äußeren Passivität« korrespondieren. Die »gesteigerte[...] Imaginationskraft «, ${ }^{71}$ die man Nichtstuern gemeinhin nachsagt, mag Bilder und Vorstellungen von Gemeinschaft produzieren, und auch Zeugnis vom kreativen Potential des Nichtstuns ablegen. In der Realität jedoch bleiben sie weiterhin allein, und sind oft einsam.

\section{Gemeinschaft 2.0: Werklosigkeit}

In den 1980er und 1990er-Jahren hat sich in der politischen Philosophie (vordergründig in Frankreich) allerdings eine andere Gemeinschaftstheorie herausgebildet, die Gemeinschaft und Nichtstun miteinander verknüpft. Die Philosophen Jean-Luc Nancy, Maurice Blanchot, Gilles Deleuze und auch Giorgio Agamben entwerfen in dieser Dekade Gemeinschaftsideen, die weder auf Immanenz noch auf Tätigkeit basieren. Sie definieren die ideale Gemeinschaft als einen offenen sozialen Raum, der jede Form der menschlichen Existenz akzeptiert, ohne sie zu verstoßen. Diese Gemeinschaft verlangt von ihren Mitgliedern keinerlei Form der Gleichartigkeit in Eigenschaften (Immanenz) oder Handlungsweisen (Tätigkeit).

Bei den frühen Texten zu diesem Thema ist hierfür der Begriff des »désœuvrement« (Werklosigkeit) maßgeblich, den Nancy in La communauté désœuvreé (1982) etabliert. ${ }^{72}$ Dort äußert er fundamentale Kritik am Gemeinschaftsdenken der Moderne: Die an Entfremdung und ideologischer Zersplitterung leidende Gesellschaft neige dazu, ${ }^{73}$ sich nach einer >ursprünglichen und 'wahren Gemeinschaft zu sehnen. In ihr, so hofft sie, gäbe es einige wesentliche Elemente, die all ihre Mitglieder auf eine eindeutige Art vereine, und damit eine Identität schaffe. Dieses Schaffen ist das, was Nancy mit dem Begriff »oeuvre« meint. Das Werk der Gemeinschaft ist ihre Kohäsion. Nancy vertritt jedoch die Auffassung, dass eine Gemeinschaft ein solches Werk nicht

\footnotetext{
71 Erwig: Waiting Plots, 8.

72 Vgl. Jean-Luc Nancy: Von einer Cemeinschaft, die sich nicht verwirklicht. Übers. v. Esther von der Osten. Wien: Turia + Kant (2018).

73 »Among others, the impending collapse of communism in the Eastern bloc, the contradictory resurgence of religious belief and beliefs throughout much of the world, war in the Middle East, social conflicts and civil disobedience in France and elsewhere, and the increasingly rampant phenomenon of technological globalisation[...] could not do other than add to the urgency of Nancy's agenda.« Hill: Nancy, Blanchot, 6.
} 
schaffen kann. Sein Hauptanliegen dabei ist, darauf hinzuweisen, dass der Versuch, eine solche Gemeinschaft zu etablieren, potentiell gewaltsam ist wobei ihm die in der NS-Ideologie zentrale Idee der >Volksgemeinschaft stets als negativer Richtwert dient. ${ }^{74}$ Gleichzeitig übt er Kritik an der modernen Erwartung, dass alle gesellschaftlichen Prozesse ein Produkt hervorbringen müssen. Damit kritisiert er im weiteren Sinne auch die Vorstellung, dass die Gemeinschaft als Produkt der arbeitenden Bevölkerung angesehen wird. ${ }^{75}$ Tatsächlich aber entstehe Gemeinschaft gerade aus dem, was nicht geschaffen, nicht erwirkt, nicht erarbeitet wird. Die folgende, aus Nancys Vorwort zur englischen Erstausgabe des Aufsatzes stammende Passage zeigt dies in aller Deutlichkeit:

community is made or is formed by the retreat or by the subtraction of something: this something, which would be the fulfilled infinite identity of community, is what I call its »work. «All our political programs imply this work: either as the product of the working community, or else the community itself as work. But in fact it is the work that the community does not do and that it is not that forms community. ${ }^{76}$

Gemeinschaft, so Nancy, ist jenseits von Identität und einer möglichen totalitären Gleichmachung angesiedelt: sie ist und greift dort, wo es Distanz, Unterschiede, und Singularitäten gibt. ${ }^{77}$ Ebensowenig ist sie »the product of

74 Hill zufolge ist diese Verbindung logisch motiviert; die 1980er Jahre, in denen Nancy verstärkt an seiner Cemeinschaftsphilosophie arbeitet, weisen ähnliche Krisenherde auf wie die späten 1930er-Jahre: » politics once more seemed to be facing a similar sense of exhaustion and crisis as in the 1930s «. Hill: Nancy, Blanchot, 10.

So schreibt Hole: »Nancy, along with Blanchot, is concerned with refiguring community in such a way that it no longer leads to some property that we would possess or an essence that we would produce in common. It cannot be defined in terms of function or the productive value generated by its members. « Kristin Hole: The Ethics of Community: Nancy, Blanchot, Esposito. In: Angelaki 18 (3), 2013, 106. Jean-Luc Nancy: The Inoperative Community. Übers. v. Peter Connor u.a. Hg. v. Dems. Minneapolis: University of Minnesota Press (1991), xxxviiif.

77 In der Philosophie Jacques Rancières gibt es einen ähnlichen Gedanken, der jedoch umgekehrt (durch Gleichheit statt durch Unterscheidung) beschrieben wird. In Le partage du sensible (2000) schreibt Rancière, das ästhetische Regime der Künste hebe alle Unterschiede, die in der polizeilichen Ordnung der Mächte aufrechterhalten werden, auf-darunter fällt auch der Gegensatz zwischen »Aktiv/Passiv«. Stattdessen wird eine »Politik der Gleichgültigkeit« begründet, die Rancière zufolge ebenfalls einen »Gemeinsinn« begründet. Jacques Rancière: Die Aufteilung des Sinnlichen. Die Politik der 
the working community«, sie existiert abseits der Ideologie, die Arbeit als Voraussetzung zur Teilhabe an der Gemeinschaft postuliert. Hierbei bezieht sich Nancy, dessen philosophisches Werk sich nicht selten an die Handlungsphilosophie Hannah Arendts anlehnt, auch auf Arendts Urteil über die Arbeit als gesellschaftliche `Gleichstellungsmaschine «: »Antipolitisch an diesen, von der Arbeit bedingten, gesellschaftlichen Bildungen ist die Verschmelzung der Vielen in ein Kollektiv, also die Aufhebung der Pluralität; dies ist der genaue Gegensatz jeglicher Gemeinschaft «. ${ }^{78}$

Das Nichtstun ist in zweifacher Hinsicht bedeutsam in diesem Kontext. Zum einen ist die mit ihm verbundene Anomie kein Ausschlusskriterium für die Gemeinschaftszugehörigkeit, die dadurch entstehende Abweichung von der Norm der Tätigkeit ist vielmehr konstitutives Merkmal einer >guten $<\mathrm{Ge}$ meinschaft. Nancys Ansatz hat eine klare ethische Dimension: Es gilt, Andersheiten und Uneindeutigkeiten auszuhalten, sie als Teil der Welt, in der man lebt, zu akzeptieren. Eine Haltung, ${ }^{79}$ die man als Gelassenheit bezeichnen kann, da sie von einer, in den Worten Strässles, »existentielle[n] Offenheit für das, was einem begegnen kann« zeugt. ${ }^{80}$ Zum anderen definiert Nancy das Tätigkeitsparadigma der Gemeinschaft neu, indem er es - in Arendts Terminologie - von Arbeit und Herstellen weg und in die Nähe zum Handeln rückt, d.h. auch zur Ergebnisoffenheit und Zweckfreiheit. Kristin Hole beschreibt dies wie folgt:

For Nancy, then, ethics becomes a matter of what he terms »making sense.« The meaning of our being here is precisely undecided and undecidable. »Making sense « is a matter of conducting oneself so as to maintain and heed that responsibility. But conduct as a kind of ethics must be understood

Kunst und ihre Paradoxien. Übers. v. Jürgen Link. Hg. v. Maria Muhle. Berlin: b_books (2008), 15.

78 Arendt: Vita activa, 272.

79 Die ohne Zweifel bestehende konzeptuelle Relation zwischen Nichtstun und Haltung bedürfte genauerer Erörterung. Ein guter, wenn auch nur knapp ausgeführter Ansatz findet sich bei Frauke A. Kurbacher. Im Rahmen ihrer Ausführungen zu »Haltungen zwischen Aktivität und Passivität« schreibt sie in Anlehnung an Aristoteles, Haltung sei »in sich ruhende, befriedete Tätigkeit, die ihren Zweck in sich selbst trägt«, und zieht ebenfalls Parallelen zu Hannah Arendts Handlungsbegriff. Frauke A. Kurbacher: Zwischen Personen. Eine Philosophie der Haltung. Würzburg: Königshausen \& Neumann (2017), 373.

80 Strässle: Celassenheit, 13. 
in a much more passive form than it may seem to imply. Here it is a question of living with the question, refusing to stabilize its meaning or fix an answer, but maintaining that question in all of its messiness as it impacts the way we are in the world. In fact, Nancy is careful to distinguish conduct (Handeln) from production, making ethics, like community, unproductive or désoeuvrée[...]. ${ }^{81}$

Hole betont, dass die Ethik der Gemeinschaft in gewissem Sinne passiv ist. Diese Passivität ist Teil der Gelassenheit, bei der es ja gerade nicht darum geht, seine Umwelt zu kontrollieren, sondern sich selbst, um die Anderen sein zu lassen. ${ }^{82}$ Doch obwohl das Seinlassen, so Strässle, in »allen Fällen« eine »Form des Handelns « bezeichnet, ${ }^{83}$ so wirkt es Hole zufolge aufgrund der Abwesenheit eines Produkts wie eine reduzierte Tätigkeit. Man könnte sagen, das Handeln als die Tätigkeitsform der idealen Gemeinschaft sei, den Maßstäben heute herkömmlicher Gemeinschaftsvorstellungen nach zu urteilen, ein relatives Nichtstun.

$\mathrm{Zu}$ einem ähnlichen Ergebnis kommt Maurice Blanchot, der in Antwort auf Nancy nur ein Jahr später ebenfalls eine Gemeinschaftsphilosophie in La communauté inavouable (1983) skizziert. Er übernimmt von Nancy den Begriff des »désœuvrement« als den Kern der Gemeinschaft, und stellt ihn damit ebenfalls implizit in Opposition zur Arbeitsgesellschaft. Eine Gemeinschaft könne nicht durch Arbeit gemacht oder produziert werden, noch nicht einmal insoweit, sich selbst als Gemeinschaft begreifen oder benennen zu können. Deshalb ist >wahre Gemeinschaft »inavouable« - uneingestehbar. Sie formiere sich nur ungeplant und spontan, und folge keinem Konzept. Ein (reales oder bevorstehendes) Ereignis, das zu dieser spontanen Formierung beiträgt, sei Blanchot zufolge der Tod. Nur im Angesicht des Todes könne sich eine >wahre Gemeinschaft bilden, die kein anderes Ziel habe, als die Einsamkeit der Todesnähe gemeinsam zu ertragen:

Im Unterschied zu einer sozialen Zelle untersagt sie [die Cemeinschaft], ein Werk zu schaffen, und sie hat keinerlei Produktionswert zum Ziel. Wozu dient sie? Zu nichts, wenn nicht dazu, den Dienst am Anderen bis in den

81 Hole: The Ethics of Community, 108.

82 Vgl. Strässle: Gelassenheit, 28.

83 Strässle: Gelassenheit, 21. 
Tod hinein gegenwärtig zu halten, damit der Andere nicht einsam zugrunde geht. $^{84}$

Ebenso wie Nancy entwickelt Blanchot eine ausdrückliche Gemeinschaftsethik, die sich in seinem Fall nicht nur an Akzeptanz des Anderen, sondern auch an der Sorge um ihn ausrichtet. ${ }^{85}$ Dieses Verhältnis schließt jede Hierarchie aus; die ideale Gemeinschaft existiert immer in Distanz zur Macht. ${ }^{86} \mathrm{Als}$ Beispiel führt Blanchot den Trauerzug zum Gedenken an die Opfer des Massakers an, das sich 1962 in der Metrostation Charonne ereignete. Die Menge, die sich versammelt hatte, um den Toten zu gedenken, die bei einer Demonstration gegen den Algerienkrieg durch Polizeigewalt ums Leben gekommen waren, sei als Volk (»people«) zu begreifen, das sich auszeichne durch seine »instinktive[...] Weigerung, irgendeine Macht auszü̈ben, in seinem absoluten Mißtrauen, sich in eine Macht zu verwickeln«, und letztlich durch seine »Erklärung der Machtlosigkeit«. Blanchot meint mit »Machtlosigkeit« jedoch keinesfalls Ohnmacht, sondern vielmehr die aktive Entscheidung, keine Macht auszuüben, obwohl man es vielleicht könnte. Blanchot schreibt, wieder in Bezug auf den Trauerzug: »Gegenwart des »Volkes« in seiner grenzenlosen Macht, die, um sich nicht zu begrenzen, auf sich nimmt, nichts zu tun« ${ }^{87}$ Auch in der Philosophie Blanchots ist die Tätigkeit innerhalb der Gemeinschaft an die Abweichung von konventionellen Tätigkeiten geknüpft, an ein Nichtstun

84 Maurice Blanchot: Die uneingestehbare Cemeinschaft. Übers. v. Gerd Bergfleth. Berlin: Matthes \& Seitz (2007), 25.

85 Man erkennt hier Blanchots Verbundenheit zur Levinas'schen Ethik. Vgl. Hill: Nancy, Blanchot, 7.

86 Diese Dynamik ist auch in Roland Barthes' Vorlesung Comment vivre ensemble zu finden. Darin imaginiert er eine ideale soziale Form, die sich weder im isolierenden Individualismus noch in der Massengesellschaft verliert. Er sucht, so sagt er, nach einer »mittleren, utopischen, paradiesischen, idyllischen Form «, und findet als Antwort die »Idiorrhythmie«- eine Lebensweise, die zwischen Isolation und Rückkehr in die Cemeinschaft oszilliert. Roland Barthes: Wie zusammen leben. Simulationen einiger alltäglicher Räume im Roman. Vorlesung am Collège de France 1976-1977. Übers. v. Horst Brühmann. Hg. v. Éric Marty. Frankfurt a.M.: Suhrkamp (2007), 47. Zentral dabei ist ihre Machtferne; es geht darum, ein Leben individuell zu gestalten und keinem »Apparat« zu unterwerfen, d.h. »die Macht ablehnen, der Macht widerstehen« (ebd. 68). Dabei handelt es sich, wie im Folgenden mehrfach ausgeführt wird, um eine Handlung bzw. ein Ereignis, die bzw. das Barthes mit dem Begriff der Anachorese beschreibt: „gegründet auf einen aktiven Bruch[...], eine Handlung, eine Markierung, das Überschreiten einer Schwelle« (ebd. 68).

87 Blanchot: Die uneingestehbare Cemeinschaft, 57. 
also, das trotz und wegen dieser Abweichung als Handlung figuriert. Es knüpft damit auch an das von Walter Benjamin und Hannah Arendt herausgehobene Nichtstun des Streiks und des passiven Widerstands als revolutionäres Moment an.

\section{Bartleby: kollektive Distanz, reine Potenz}

Die Koppelung der >neuen (Gemeinschaft an das Nichtstun hat in den späten 1980ern noch eine Steigerung erfahren, zu der der Protagonist von Herman Melvilles »Bartleby, The Scrivener« zur exemplarischen Gründungsfigur berufen wurde. So tut es Gilles Deleuze in seinem Aufsatz »Bartleby, ou la formule« (1989). Deleuze attestiert der Formel »I would prefer not to« eine von ihm so genannte "Agrammatikalität ${ }^{88}$ die den Sprecher Bartleby aus der Struktur der Sprache und des Gesellschaftlichen zugleich heraushebt:

Würde Bartleby verweigern, könnte er noch als Rebell oder als aufsässig ausgemacht werden und in dieser Eigenschaft noch eine gesellschaftliche Rolle übernehmen. Doch die Formel entschärft jeden Sprechakt, zur gleichen Zeit, wie sie aus Bartleby einen reinen Ausgeschlossenen macht, dem keinerlei gesellschaftliche Stellung mehr zuerkannt werden kann. ${ }^{89}$

Bartlebys Nichtstun ist für Deleuze bezeichnend, weil es kein allgemein anerkanntes Verhältnis zu seiner Umwelt etabliert. Es bedeutet weder Scheitern, noch Anpassung, auch ahmt es nichts nach, und lehnt nichts ab. Sein Verhalten ist nicht am Bekannten orientiert. Bartleby ist ein »Original«: seine Aktionen gehorchen nicht den »allgemeinen Gesetzen«, es kennzeichnet ihn eine »extreme und rationalitätslose Logik «. ${ }^{90}$ Dieser Austritt aus der Rationalität, der in einem von der Aufklärung informierten Denken auch die Abkoppelung von der Gemeinschaft bedeutet, ${ }^{91}$ ist für Deleuze hingegen ein Zeichen für deren Neubildung. Er sieht in Bartleby einen neuen Menschen, der abseits der Gesellschaft und ihrer gängigen Gesetze spricht und agiert, aber von dessen Art es mehrere geben muss, denen eben diese Transzendenz gemeinsam

88 Gilles Deleuze: Bartleby oder die Formel. Übers. v. Bernhard Dieckmann. Berlin: Merve (1994), 21.

89 Deleuze: Bartleby, 20.

90 Deleuze: Bartleby, 42.

91 Die Ausführungen O'Connors zum Verhältnis von Nichtstun, Vernunft, und Gemeinschaft bei Kant sind in dieser Hinsicht sehr erhellend. Vgl. O'Connor: Idleness, 37-57. 
ist: eine »Gesellschaft von Brüdern«, eine »Gemeinschaft anarchistischer Individuen $\ll .{ }^{92}$ Er stellt es sich vor wie die ersten >Siedler in Amerika, die sich vom Vater - dem Gesetz - abkapselten und

gegen die europäische Moral des Heils und der Nächstenliebe eine Moral des Lebens [etablieren], in der die Seele sich nur erfüllt, indem sie den Weg ohne weiteres Ziel einschlägt, [...] ohne andere Vollendung als die Freiheit und stets bereit, sich zu befreien, um sich zu vollenden. ${ }^{93}$

In Deleuzes Vorstellung ist, anders als bei Nancy und Blanchot, keine ethische Komponente verankert. Die Figur Bartleby steht für die Überwindung aller Gesetze, die das Handeln des Menschen leiten wollen. Durch sein Nichtstun befreit er sich von diesen Gesetzen, erlangt also »Freiheit« im Sinne von Souveränität, ${ }^{94}$ die Deleuze zur quasi-genetischen Verbindungslinie zwischen Brüdern stilisiert, ${ }^{95}$ die sich in der absoluten Andersheit des Nichtstuns endgültig vom gemeinsamen Vater emanzipieren. Ihre Gemeinschaft beruht lediglich auf der gemeinsamen »Zugehörigkeit zur Distanz «, ${ }^{96}$ nicht aber in einer gegenseitigen Abhängigkeit.

Giorgio Agambens La comunità che viene (1990) knüpft an die vorhergegangenen Gemeinschaftsphilosophien an. Er übernimmt zwei mit dem Nichtstun

92 Deleuze: Bartleby, 48f.

93 Deleuze: Bartleby, 54.

94 Man muss hier anmerken, dass der Aspekt der Souveränität (im Sinne von Unabhängigkeit), den Deleuze betont, nicht unbedingt mit den anderen in diesem Kapitel beschriebenen Gemeinschaftskonzepten übereinstimmt. Hannah Arendt zum Beispiel, deren Handlungskonzept hier prinzipiell mit dem Nichtstun in eine Linie gesetzt wird, hält Handlung zwar für gemeinschaftsstiftend, versteht Souveränität allerdings als Widerspruch zur Idee der Gemeinschaft. Arendt hält die - schon im Stoizismus geltende-Cleichsetzung von Freiheit und Souveränität für einen Irrtum, da letztere als »unbedingte Autonomie und Herrschaft über sich selbst, der menschlichen Bedingtheit der Pluralität widerspricht«, d.h. das soziale Element des Menschseins ignoriert. Arendt: Vita activa, 299.

95 Ein »Sinn der Brüderlichkeit«, so Tristan Garcia, kann das Gefühl eines höheren » Wir«« erzeugen: »Wir Brüder < ist die stärkste Intensität, die man einer politischen Person geben kann. >Unsere Brüder s spielen wie >unsere Genossen pastorale Rolle: Wenn man den Kreis eines >Wir des Glaubens, der Ideen und Werte nachzeichnet, muss man in einen gemeinsamen Schoß zurückbringen, was sich in individuellen Identitäten und partikularen Sekten zerstreut hat.« Tristan Garcia: Wir. Übers. v. Ulrich Kunzmann. Berlin: Suhrkamp (2018), $32 f$.

96 Carcia: Wir, 59. Carcia spricht ebenfalls über Cemeinschaftsbildungen jenseits anderer, größerer Gemeinschaften. 
in engster Verbindung stehende Elemente seiner Vorgänger: Zum einen stellt auch er Bartleby, den Schreiber, in den metaphorischen Dienst für seine Vorstellung von Politik. ${ }^{97}$ Zum anderen gilt auch sein Interesse dem Prinzip der ,Werklosigkeit<, das er jedoch als "Impotenz« neu definiert. Ein Kommentar zu seinem Verständnis dieser Begriffe findet sich in Homo sacer (1995):

Das Thema des désœuvrement als Figur der Fülle des Menschen am Ende der Ceschichte, das zum ersten Mal in Kojèves Rezension von Queneau auftaucht, ist von Blanchot und Nancy wiederaufgenommen worden; letzterer hat es ins Zentrum seines Buches La Communauté désœuvrée gestellt. Hier hängt alles davon ab, was man unter désœuvrement versteht. Es kann weder die einfache Absenz des Werks [opera/œuvre] sein noch (wie bei Bataille) eine souveräne und untätige [senza im-piego] [...] Form der Negativität. Die einzige kohärente Auffassung von désœuvrement wäre die einer unbestimmten Existenz der Potenz, die sich nicht (wie die individuelle Tätigkeit oder die kollektive Haltung, die als Summe der individuellen Tätigkeiten begriffen wird) in einem transitus de potentia in actum erschöpft. ${ }^{98}$

Agamben ist davon überzeugt, dass »désœuvrement« nicht nur Unproduktivität oder souveräne Untätigkeit bedeutet, sondern Impotenz. Diese Impotenz, oder besser: die Potenz eines >Nicht-zu<, ist jedoch nicht das Gegenteil der Potenz, sondern ein ihr wesentlicher Bestandteil. Damit knüpft Agamben an das Argument Nancys an: er hält den gesellschaftlichen Ausschluss dessen, was gemeinhin als negativ empfunden wird, für problematisch. Die Gemeinschaft, die Agamben sich als kommende vorstellt, darf keine eingeschränkte Vorstellung des menschlichen Wirkens haben, da jede Einschränkung automatisch Abweichungen ausschließt, verstößt, oder sich gar von ihnen bedroht fühlt und sie vernichtet. Das Tian'anmen-Massaker von 1989 ist stetiger Referenzpunkt in La comunità che viene. Die Figur Bartleby symbolisiert für Agamben jene Negativität, die zum gesellschaftlichen Ausschluss anregt, aber tatsächlich Teil des gesamten Spektrums dessen ist, was der Mensch sein und tun kann. Dieses gesamte Spektrum nennt Agamben >Potenz«, und versichert nachdrücklich, dass es einerseits die Möglichkeit eines Werdens und Handelns einschließt, aber auch die ebenso wahrscheinliche Möglichkeit eines Nicht-Werdens und Nicht-Handelns. Es gehört zum Wesen des Menschen,

97 Vgl. das Kapitel »Bartleby« in Giorgio Agamben: Die kommende Gemeinschaft. Übers. v. Andreas Hiepko. Berlin: Merve (2003), 37-40.

98 Agamben: Homosacer, $72 \mathrm{f}$. 
so Agamben, dass er eben nicht nur zum Tun, sondern auch zum Nichtstun befähigt ist: "The greatness - and also the abyss - of human potentiality is that it is first of all potential not to act «. ${ }^{99}$ Bartleby macht durch sein NichtSchreiben eben darauf aufmerksam, und ist reine Potentialität:

As a scribe who has stopped writing; Bartleby is the extreme figure of the Nothing from which all creation derives; and at the same time, he constitutes the most implacable vindication of this Nothing as pure, absolute potentiality. ${ }^{100}$

Durch sein Nichtstun repräsentiert Bartleby ein >Nichts $<$, in dem sich absolut alles ereignen und verwirklichen kann. Auch hier erscheint, ähnlich wie in der oben erwähnten Oblomow'schen Phantasie, das Nichtstun als eine kreative Tätigkeit. Agamben versteht Bartleby als Metapher für eine ethische Gemeinschaft, in der nichts bestimmtes passieren muss, sondern potentiell alles - und eben auch nichts - passieren kann. Das Anerkennen einer »absolute potentiality«, die sich im Nichtstun offenbart, habe, so die Implikation, in einer neugegründeten Gemeinschaft das Ende von Gewalt zur Folge.

Diese Philosophien der Gemeinschaft, die sich in den 1980ern bis in die 1990er-Jahre entwickelt haben, verstehen das Nichtstun als einen Weg zu einer neuen, besseren, humaneren Gesellschaft. Ob sich die Gemeinschaft mit dem Nichtstun bereits realisiert oder, wie Michael Hardt und Antonio Negri behaupten, nach dem passiven Widerstand erst noch als "new social body« kreiert werden muss, ${ }^{101}$ ist letztlich ungeklärt geblieben und unterliegt der Interpretation. Ersichtlich ist nur, dass diese Philosophien dezidiert keine 'Gemeinschaft der Nichtstuer skizzieren, die mit Vergils Arkadien vergleichbar wäre. Es geht nicht um die Kreation einer luxuriösen, weil arbeitsfreien Idylle. Vielmehr steht eine gemeinsame Unterminierung dominanter Tätigkeitsparadigmen im Vordergrund. Gegenüber Ordnungen, in denen Handeln auf Gewalt, Arbeit oder Herstellen reduziert wird, ist das Nichtstun ein Gegenentwurf, der ein anderes Handeln und eine neue Form der Gemeinschaft denkbar macht. Die oft bemerkte Nähe zum Tod, die das Nichtstun - besonders der passive Widerstand Bartlebys - aufweist, ${ }^{102}$ und von der man behaupten kann, dass sie sowohl der Bildung einer neuen Politik als auch

99 Agamben: On Potentiality. In: Ders.: Potentialities, 181.

100 Agamben: Bartleby. In: Ders.: Potentialities, 253f.

101 Hardt u. Negri: Empire, 204.

102 Vgl. z.B. Desmarais: Paradox of Passive Resistance, 12. 
der Formierung einer neuen Gemeinschaft entgegensteht, ist dabei von großer symbolischer Bedeutung. Timothy J. Deines schlägt vor, mit besonderem Blick auf Nancys Gemeinschaftsphilosophie, dass ein abstraktes Verständnis des Todes "constitutes the presupposition of every humanist formation $",{ }^{103}$ wenn man ihn als ständige Neuverhandlung von Identität begreift. Versteht man den Tod also metaphorisch als ein Abdanken vormals festgeschriebener Bedeutungen von Gemeinschaft (vor allem solcher, unter denen Menschen leiden mussten), so ermöglicht der Tod in dieser Hinsicht eine humanistische Neukonstitution von Gemeinschaft.

Dieses Denken ist nicht zufällig in einer Zeit entstanden, als der Wert der Arbeit - zum Beispiel im Rahmen der Debatte um die >Krise der Arbeitsgesellschaft - begann, hinterfragt zu werden. Seit den 1980er-Jahren wurde deshalb die Idee populär, dass die vom Wert der Arbeit so durchdrungene Gesellschaft selbst gar keine richtige Gemeinschaft bilden kann, weil sie sich zu sehr auf marktwirtschaftliche Dynamiken konzentriert. Axel Honneth zufolge bestehe einer der zentralen "Mißstände der kapitalistischen Arbeitswelt « darin, im Arbeitsmarkt »Effizienzsteigerung « statt "Sozialintegration « anzustreben. ${ }^{104}$ Mit dem Begriff »Sozialintegration « meint Honneth auch die für sein philosophisches Gesamtwerk konstitutive soziale Anerkennung, die dem (in diesem Fall) arbeitenden Individuum das Gefühl »allgemeiner Wertschätzung « vermittelt. ${ }^{105}$ Um das zu erfüllen, müsse der Markt zwei Dinge schaffen: einmal zur Absicherung seiner Angestellten einen Mindestlohn einführen, und zweitens »den vollzogenen Tätigkeiten eine Gestalt« geben, die sie »als Beiträge zum allgemeinen Wohl erkennbar sein läßt. « ${ }^{106}$ Das Beitragen zum allgemeinen Wohl ist für Honneths Argument zentral. Es sei, so behauptet er im Rückgriff auf Hegels Rechtsphilosophie, eines der schlagenden Argumente gegen das Nichtstun. Betrachtet man den kapitalistischen Markt

103 Timothy ]. Deines: Bartleby the Scrivener, Immanence and the Resistance of Community. In: Culture Machine 8, 2006.

104 Axel Honneth: Das Ich im Wir. Studien zur Anerkennungstheorie. Berlin: Suhrkamp (2010), 95, 101. Vgl. im Besonderen den ganzen Aufsatz »Arbeit und Anerkennung «, 78-102. »Ein wachsender Teil der Bevölkerung kämpft überhaupt nur noch um den Zugang zu Chancen subsistenzsichernder Beschäftigung, ein anderer Teil vollzieht Tätigkeiten unter rechtlich kaum mehr geschützten, stark deregulierten Verhältnissen, ein dritter Teil schließlich erfährt im Augenblick die rapide Entberuflichung und Entbetrieblichung ihrer vormals noch statusmäßig gesicherten Arbeitsplätze.« (Ebd. 78) 
nämlich, wie Hegel es tut, als Form der Befriedigung der Bedürfnisse aller Gesellschaftsmitglieder, dann impliziere es eine moralische Aufforderung an den Einzelnen, "persönliche Neigungen des Müßiggangs abzustreifen und durch eigene Arbeit zum allgemeinen Wohl beizutragen. « ${ }^{107}$ Wenn die angemessene Gegenleistung - die Sicherung der eigenen Subsistenz zum einen, die gesellschaftliche Anerkennung zum anderen - ausbleibt, ist die Folge eine Unsicherheit der Lohnarbeit, aber auch das Fehlen einer »Solidarität, die nötig ist, um auch moderne Gesellschaften zu integrieren «. ${ }^{108}$ Die Konsequenzen für den Diskurs des Nichtstuns sind ebenfalls weitreichend. Honneth versichert zwar, dass es trotz dieser Missstände nicht zu einem »Relevanzverlust der Arbeit in der gesellschaftlichen Lebenswelt « gekommen ist. ${ }^{109}$ Doch es ist auch das genau Entgegengesetzte geschehen: Die Tatsache, dass die Aufgabe des Müßiggangs nicht die notwendigen sozialen Ergebnisse gezeitigt hat, hat einer neuen Legitimation des Nichtstuns Raum gegeben. Und das nicht nur im Bereich der präferierten Tätigkeiten. Vor allem konnte sich in diesem $\mathrm{Zu-}$ sammenhang die Idee entwickeln, dass die fehlende Solidarität der Arbeitsgesellschaft woanders zu finden sein könnte, nämlich in einer Gemeinschaft, die auch das Nichtstun als Wirkungsprinzip anerkennt.

Viele Formen der Passivität, so attestierte jüngst Theo Jung, weisen eine »ausgeprägte symbolische Dimension« auf, die vor allem im sozialen Bereich große Tragkraft entwickelt hat. ${ }^{110}$ Nichtstun markiere so zum Beispiel "performativ ein widerspenstiges Heraustreten aus der konventionellen Ordnung, ein >ich nicht<, das für Subjektivierungs- und Gruppenbildungsprozesse konstitutiv werden kann «. ${ }^{111}$ Der Tatsache, dass die Idee einer Gemeinschaft der Nichtstuer heute populärer ist denn je, trägt auch der 2014 gegründete, gemeinnützige Berliner Verein Haus Bartleby Rechnung. Der Verein tritt in öffentlichen Diskussionsrunden, Performances und Publikationen als revolutionäre Gruppe auf, die der durch Arbeit perpetuierten kapitalistischen Ausbeutung ein Ende setzen will. Viele ihrer Mitglieder haben für die Vereinsarbeit ihre Karrieren beendet, und rufen in ihrer ersten Essaysammlung gemeinsam zum »lebenslangen Generalstreik« auf. ${ }^{112}$ Sie teilen die Überzeu-

\footnotetext{
107 Honneth: Das Ich im Wir, 89.

108 Honneth: Das Ich im Wir, 97.

109 Honneth: Das Ich im Wir, 79.

110 Jung: Bartleby und das Unterlassen, 24.

111 Jung: Bartleby und das Unterlassen, 24. Herv. meine.

112 Haus Bartleby (Hg.): Sag alles ab! Plädoyers für den lebenslangen Generalstreik. Hamburg: Edition Nautilus (2015), 9.
} 
gung, dass sie durch die Abwendung von der Arbeit zur Entwicklung einer egalitären Gesellschaft beitragen, und nennen sich deshalb die »Conjuration des Ėgaux «, die »Verschwörung der Gleichen «. ${ }^{113}$ Unter dem Banner der Bartleby'schen Verweigerung versteht sich das Haus Bartleby als eine Gemeinschaft, ${ }^{114}$ die über das Mittel des Nichtstuns Gerechtigkeit schaffen und propagieren will - ebenso wie Benjamin es für den Streik, das reine Mittel, angedacht hatte.

\section{Herrschaft}

Herrscher tun nichts, deshalb herrschen Nichtstuer. Die dritte Praxis des Nichtstuns, die ich hier vorstellen möchte, unterscheidet sich wesentlich von den beiden vorhergehenden. Die zuvor diskutierten philosophischen Ansätze schlagen eine ernsthafte Theorie des Nichtstuns als echte Handlung in der Welt vor. In diesem Kapitel hingegen wird der Topos >Nichtstun als Herrschen nicht unbedingt als reale Praxis, sondern eher als diskursives bzw. literarisches Konstrukt betrachtet, an dem sich Fragen sozialer und politischer Handlungsfähigkeit in einer nichtstuerischen Isolation entzünden. Im Kontext der Herrschaft kann das Nichtstun auch eine fundamental andere Rolle einnehmen als hier zuvor besprochen wurde. Während sich beim Streik und dem passiven Widerstand (ebenso wie bei der Gemeinschaft) das Nichtstun als Gegenentwurf zu einem bestehenden Handlungsparadigma entpuppt und so ein neues, gerechteres gesellschaftliches System begründet, kann ein Nichtstun auch in das Gegenteil dieser positiven Visionen umschlagen. Die Abkoppelung von bestehenden Handlungs- und Gesellschaftsstrukturen im Nichtstun kann nicht nur mit Handlung und Gemeinschaft, sondern im Gegenteil auch mit einem Ohnmachtsgefühl einhergehen. Dieses Ohnmachtsgefühl, so suggerieren die späteren Lektüren in diesem Buch, ist

113 Haus Bartleby: Generalstreik, 10.

114 Die durch das Nichtstun sich konstituierenden Gemeinschaften müssen allerdings daraufhin befragt werden, ob sie die Paradigmen, die sie zu transzendieren suchen, nicht doch aus Versehen fortführen. Leslie Hill gibt dies bei der Verwendung des Begriffs >Gemeinschaft< in der Philosophie von Nancy und Blanchot zu bedenken: sie können »rethink, rearticulate, even deconstruct what the term implied, [but] it [the term >community ] also represented a danger, which was that, by using the word, one would be simply reiterating, rather than overcoming, its often disturbing, frequently compromised political past.«Hill: Nancy, Blanchot, 18. 
häufig eng mit einer vorhergehenden Imagination von Macht, einer Eigenwahrnehmung als Herrscher verbunden, die nach gewisser Zeit kollabiert. Das vorliegende Kapitel widmet sich möglichen diskursiven Vorläufern dieser semantischen Engführung, die den Stoff für die Imagination von Nichtstuern liefern, wie sie zuvor bei Gontscharows Oblomow gezeigt wurde. Es hat zum Ziel, das Denken über das Nichtstun um die Dimension des Herrschens zu erweitern, um damit zu zeigen, dass das Nichtstun nicht nur ein Phänomen sozialer Exklusion nach >Unten< darstellt, sondern dass es sich ebenso im gesellschaftlichen >Oben $<$ manifestiert - und, nicht zuletzt, dass sich in dieser Verbindung eine ungewöhnliche Dynamik zwischen `Unten` und ১Oben ausbilden kann. In anderen Worten: in diesem Abschnitt wird Nichtstun nicht philosophisch zur politischen Handlung umgedeutet, sondern es wird ein Panorama möglicher, teils widersprüchlicher Deutungen des Verhältnisses von Nichtstun und Herrschaft entfaltet. Dazu gehören auch negativ konnotierte Verhältnisformen des Nichtstuns zum Bereich des Politischen. Wie man später in den Lektüren sehen wird, werden eben diese negativen Konnotationen häufig literarisch aufgegriffen und verschieden verarbeitet. So verfallen die nichtstuenden Protagonisten zum Teil selbst dem (imaginären) Herrschaftspotential des Nichtstuns, um es entweder zugunsten der positiven Auslegung von Nichtstun als kritischer, politischer Handlung zu verwerfen, oder aber auch, um das Projekt Nichtstun als Handlung ganz scheitern zu lassen.

Das zeitgenössische Verständnis eines politischen Nichtstuns, welches oben im Detail beschrieben wurde, klammert in der Regel die seit langem bestehende Verbindung zwischen Nichtstun und Herrschaft aus. Dass diese Verbindung bis in die Antike zurückreicht, zeigt Wolfgang Lepenies am Beispiel einer spezifischen Form des Nichtstuns: der Melancholie. ${ }^{115}$ In Aristoteles' Problemata Physica läge »das Paradigma verborgen«, welches »als Prototyp des Melancholikers den Herrscher sieht«, d.h. also Herrschaft im Kontext des Nichtstuns einbettet. ${ }^{116}$ Dieser Zusammenhang funktioniere in

115 Hartmut Böhme beschreibt den Melancholiker als einen Praktiker des Nichtstuns ganz im Sinne dieser Arbeit. Ein Melancholiker sei der, der »nicht dazugehört, nicht von den kodifizierten Zielen des Handelns - Gottgefälligkeit, Glück, Erfolg, Reichtum - getragen scheint«, habe aber nichts mit einer »handlungsgehemmten Apathie zu tun«; er hält sich in »Distanz zur gesellschaftlichen Praxis«, aber »er ist produktiv«. Hartmut Böhme: Natur und Subjekt. Frankfurt a.M.: Suhrkamp (1988), 259, 272. 
beiden Richtungen, so Lepenies, indem einerseits bestimmte Herrscherfiguren als Inbegriff der Melancholie gelten (Kierkegaard wählte hierfür zum Beispiel Nero), aber auch andersherum. So zitiert er den Leibarzt Heinrichs IV. André du Laurens, der behauptet, dass der Melancholiker davon träume, Herrscher zu sein: »If an ambitious man become melancholike, he straightway dreameth that he is a King, an Emperor, a Monarke. «117

Diese Verbindung ist in der Motivforschung, von wenigen Ausnahmen abgesehen, bisher kaum gewürdigt worden. Auch sie ist, wie es beim Denken eines Nichtstuns als Handlung und beim Nichtstun als Gemeinschaftskonstituens der Fall ist, nicht naheliegend. Üblicherweise kann weder derjenige herrschen, der nichts tut, noch kann ein Herrscher als Nichtstuer bezeichnet werden. Nichtsdestotrotz besteht diese Verbindung; sie findet sich in verschiedenen literarischen Texten, philosophischen Ausführungen und wissenschaftlichen Analysen. Man kann sie in drei Kategorien unterteilen: 1. Nichtstun als Zeichen der Macht eines Herrschenden; 2. Nichtstun als Zeichen der Ohnmacht eines Regenten; 3. Die Zuschreibung des Nichtstuns zum Zweck der Herrschaftskritik. Diese Kategorien schließen sich allerdings keineswegs untereinander aus, in manchen Fällen sind zwei, oder sogar alle drei zutreffend.

\section{Macht}

Eine zentrale Korrelation zwischen Nichtstun und Herrschen gründet in christlich religiösen Vorstellungen göttlicher Herrschaft. Gott als der Herrscher über das von ihm Geschaffene ist ein in der Bibel vielthematisiertes Motiv. In den sogenannten >Königspsalmen des Alten Testaments zum Beispiel heißt es: "Der HERR ist König«. ${ }^{118}$ Das Motiv des Nichtstuns ist, zumindest als Teil dieser Herrschaft, in der Bibel allerdings nicht prävalent. Der göttliche Herrscher ist vielmehr ein Alles-Tuer: »Ich bin Gott, und sonst keiner mehr, ein Gott, dem nichts gleicht. [...] Ich sage: Was ich beschlossen habe, geschieht, und alles, was ich mir vorgenommen habe, das tue ich. «119 Das Element des Nichtstuns weist eine andere Abstammung auf: es kommt

117 Lepenies: Melancholie und Gesellschaft, 47. Herv. meine. Lepenies fährt in diesem Kapitel allerdings fort, die Langeweile des Adels zu beschreiben anstelle der Melancholie des Herrschers. Auch hier wird, bis auf diese kurz zitierten Anmerkungen, das Potential des Zusammenhangs Herrschen-Nichtstun nicht ausgeschöpft.

118 Ps 10,16, LU. Ebenso in: Ps 93,1; 97,1; 99,1.

119 Jes 46,9-11, LU. 
mithin nicht aus biblischen Texten, sondern aus der Theologie und ihren Versuchen, die Existenz Gottes zu beweisen. Diese Beweise weisen zwei Tendenzen auf: Sie suchen erstens nach dem Ursprung von allem Seienden, und zweitens beschreiben sie diesen Ursprung mit Eigenschaften, die von denen des Seienden zum Teil wesentlich abweichen, also als ihr >Anderes verstanden werden können. $\mathrm{Zu}$ diesen Abweichungen gehört auch eine in bestimmter Weise reduzierte, oft als geistig ausgewiesene >Tätigkeit<, die man mit dem Motiv des Nichtstuns zumindest in eine grobe Verbindung bringen kann. Zu beachten ist, dass zwar eine Abwesenheit oder Andersheit ausgedrückt wird, die allerdings nicht - wie im konventionellen Verständnis des Nichtstuns Gang und Gäbe ist - Zeichen eines Mangels, sondern von Allmacht ist.

So zum Beispiel bei Thomas von Aquin. In der Summa theologica führt er mehrere Argumente für einen Gottesbeweis an, die alle Gott als den Ursprung des Seienden darstellen. Der Fokus des ersten Arguments liegt auf der Bewegung: Was sich auf der Welt in Bewegung befinde, müsse erst in Bewegung gebracht werden, und zwar ursprünglich von etwas bzw. jemandem, der sich dezidiert nicht bewegt - ein erstes Bewegendes, »das von keinem bewegt ist $« .{ }^{120}$ Diese Stelle ist eine der Kernreferenzen der philosophischen Idee des unbewegten Bewegers - der Vorstellung also, dass Gott zwar die Quelle jeder Bewegung sei, ohne sich selbst jedoch zu bewegen. Diese Idee ist bereits bei Aristoteles ausgeführt. Es gebe eine Seinswesenheit, heißt es in der Metaphysik, die, »selber nicht in Bewegung, (anderes) in Bewegung setzt «. ${ }^{121}$ Aristo-

120 Die entsprechende Stelle in Gänze lautet: »Wenn demnach das, wovon etwas seine Bewegung erhält, selbst auch in Bewegung ist, so muß auch dieses wieder von einem anderen bewegt sein, und dieses andere wieder von einem anderen. Das kann aber unmöglich so ins Unendliche fortgehen, da wir dann kein erstes Bewegendes hätten. Denn die späteren Beweger bewegen ja nur in Kraft des ersten Bewegers, wie der Stock nur insoweit bewegen kann, als er bewegt ist von der Hand. Wir müssen also unbedingt zu einem ersten Bewegenden kommen, das von keinem bewegt ist. Dieses erste Bewegende aber meinen alle, wenn sie von »Gott« sprechen. «Thomas von Aquin: Summa theologica. Die deutsche Thomas-Ausgabe. Bd 1. Cottes Dasein und Wesen. Übers. v. Dominikanern u. Benediktinern Deutschlands u. Österreichs. Hg. v. Katholischen Akademikerverband. Salzburg: Anton Pustet (1934), 45 (Teil 1, Frage 2, Artikel 3).

Aristoteles: Metaphysik. Übers. v. Hans Günter Zekl. Würzburg: Königshausen \& Neumann (2003), 348 (XII, Kap. 7, 1072a). Der Vollständigkeit halber verweise ich darauf, dass die hier angenommene Idee, Aristoteles stelle den unbewegten Beweger mit Gott gleich, auch angefochten worden ist. Vgl. hierzu Michael Bordt: Why Aristotle's God is Not the Unmoved Mover. In: Oxford Studies in Ancient Philosophy 40, 2011, 91-109. 
teles postuliert konkrete Unterschiede zwischen der Aktivität der Bewegung und der ihrer Impulsgebung: Was in Bewegung ist, sei in »wirkender Tätigkeit«, der unbewegte Beweger jedoch sei in »tätiger Wirklichkeit« begriffen. ${ }^{122}$ Der Akt des Beginnens weist also eine Veränderung des Tätigkeitsgrades auf, von >wirklich $<\mathrm{zu}$ >wirkend . Zudem wird das göttliche Prinzip mit dem »Denken, rein für sich « gleichgesetzt. ${ }^{123}$ Diese Verbindung zwischen Unbewegtheit und dem Denken gibt es im Übrigen auch in Arendts Konzeption der vita contemplativa, also des unpolitischen Nichtstuns: das Denken sei »reine Tätigkeit des Geistes in Verbindung mit völliger Unbeweglichkeit des Körpers « ${ }^{124}$ »die Unbewegtheit ist die eigentliche[...] Hauptforderung der Vita contemplativa«. ${ }^{125}$ Im Gegensatz zu dem von Arendt aufgegriffenen historischen Verständnis des körperlich untätigen Denkens, dessen Haupteigenschaften eine "Distanzierung vom Handeln $\ll^{126}$ und eine »Unsichtbarkeit ${ }^{127}$ in der Welt der Erscheinungen darstellen, ist Gott als der unbewegte Beweger gleichermaßen mehr und weniger tätig als die restliche Bewegung des Seienden. Gott ist das Denken, und damit nicht bewegt, und bewegt doch alles. Der unbewegte Beweger ist Nichtstuer und Allestuer zugleich. Dass in und seit der Antike »das Verlangen nach dem leichten, von Mühe und Arbeit befreiten, göttergleichen Leben« besteht, schließt gedanklich an diese Assoziation an. ${ }^{128}$

Diese paradoxe Verbindung von Allmacht, Denken und Bewegungslosigkeit scheint auf einige menschliche Herrschaftskonzeptionen transponiert worden zu sein. In einer Analogie zum göttlichen Prinzip des unbewegten Bewegers werden Herrscher überhöht, indem ihnen Macht zugesprochen wird, ohne dass sie körperliche Kraft anwenden müssen (sie unterstehen den Gesetzen der Logik nicht - das macht sie unberechenbar); und nicht zuletzt bedeutet es die privilegierte Enthebung des Herrschers aus `normalen Tätigkeitszusammenhängen: er muss nicht arbeiten, er darf nichtstun. Ein Zeugnis dafür findet sich in einer Monographie des Historikers Lothar Kittstein über die preußische Politik um 1800, die sich auf die Regentschaft von Friedrich Wilhelm III. bezieht, der ab 1797 regierte. Kittstein zitiert aus einer Schrift des damaligen Beamten Christian von Massenbach, in der ebenfalls die Idee eines

122 Aristoteles: Metaphysik, 348 (XII, Kap. 7, 1072a).

123 Aristoteles: Metaphysik, 349 (XII, Kap. 7, 1072b).

124 Arendt: Vom Leben des Ceistes, 127.

125 Arendt: Vita activa, 386.

126 Arendt: Vom Leben des Geistes, 97.

127 Arendt: Vom Leben des Ceistes, 77.

128 Arendt: Vita activa, 12. 
passiven und trotzdem wirkmächtigen Herrschers ausgeführt wird. Massenbach, der an der politischen Einheit Preußens interessiert war, behauptet, diese sei nur möglich, wenn der König in ihrem Zentrum stünde und nicht durch »konkretes Wirken«, sondern nur durch seinen Blick diese Einheit stiftete. ${ }^{129}$ Kittstein schreibt, diesen Gedanken ausführend:

Die Untätigkeit des Monarchen, der den Dingen lediglich zusah, war das Prinzip. Der bloße Zusammenhang, den der königliche Blick stiftete, würde aktives Zusammendrängen in Einheit und Energie erzeugen. Nicht Machtausübung, nicht Organisation bestimmte die Vision, sondern das Vertrauen auf aktives Drängen nach Einheit, das der ideale herrscherliche Überblick erzeugte. $^{130}$

Die hier geschilderte Vorstellung, der König könne durch reines Nichtstun nur durch einen Blick, dem keine Tat folgen sollte - eine Aktivität in seinem Staat bewirken, ähnelt strukturell der Idee eines unbewegten Bewegers als göttlichem Herrscher. Die Aktivität, die der Monarch hier bewirken können soll, ist das Zusammendrängen des Staates in eine Einheit. Der konkrete politische Kontext suggeriert jedoch, dass es sich hier bei dem Motiv des Nichtstuns nicht unbedingt um ein Zugeständnis von Macht handelt, sondern vielleicht um den Versuch, dem Monarchen ein Nichtstun aufzunötigen, um ihn zu entmachten. Immerhin entstand in Preußen unter Friedrich Wilhelm III. 1808 erstmals eine Ministerregierung, was die Macht des Königs zumindest geringfügig einschränkte (ohne, dass die absolutistische Staatsform jedoch tatsächlich verändert oder in Gefahr gebracht worden wäre). Vielleicht stellt das Nichtstun-Motiv im Herrschaftsverständnis ein frühes Zeichen einer Machtverlagerung dar, eine Kritik der als zu umfassend empfundenen Autorität des Monarchen. ${ }^{131}$

129 Lothar Kittstein: Politik im Zeitalter der Revolution. Untersuchungen zur preußischen Staatlichkeit 1792-1807. Stuttgart: Steiner (2003), 559. Vgl. hierzu auch die in der ZauberbergAnalyse ausgeführte Verbindung zwischen Herrschaft und Blick im Abschnitt »>Regieren<: Herrschaft durch Nichtstun«.

130 Kittstein: Politik, 559.

131 Ein Herrscher, der nach außen hin zwar als stark gilt, aber innerhalb seines Hofes praktisch nicht in Regierungsgeschäfte involviert ist, gibt immer Macht frei, über die andere glauben verfügen zu können. So ähnlich erzählt es Stephen Greenblatt über die Darstellung von politischer Macht in Shakespeares King Henry VI: »[T]he nobles [...] actually prefer a weak ruler[...]. The power vacuum at the center gives the rivals space to 
Die Vorstellung, dass gerade das Nichtstun als Mittel der Machtausübung gelten könnte, stellt außerdem eine zentrale Aussage des Tao-Tê-Kings dar. Die aus dem 4. Jahrhundert vor Christi stammende chinesische Spruchsammlung ist der Gründungstext des Taoismus - eine chinesische Philosophie und Religion, die von einer unabänderlichen kosmischen Ordnung ausgeht, in die aktives Handeln gar nicht einzugreifen vermag. Der Taoismus formuliert deswegen die >Handlungsmaxime des Nichtstuns. Der Anwendungsbereich des Tao-Tê-King als Anleitung zur Lebensführung umfasst allerdings nicht nur den ethischen, sondern auch den politischen Bereich. Denn der Text skizziert auch eine Staatslehre, die von dem Staatsoberhaupt verlangt, nicht zu intervenieren. ${ }^{132}$ So wenig wie möglich zu tun, das sei die Voraussetzung für eine gute Herrschaft zum Wohl der Beherrschten. »Wessen Regierung recht zurückhaltend,/dessen Volk kommt recht empor«, so schreibt Lao-tse. ${ }^{133}$ Das Nichtstun ist ein häufig wiederkehrendes Motiv im Tao-Tê-King, und nimmt dort vor allem im politischen Kontext eine zentrale Rolle ein:

Tao ist ewig Nicht-Tun,

und doch bleibt nichts ungetan.

Wenn Fürsten und Könige (es) zu halten vermögen,

werden alle Wesen von selbst sich umwandeln. ${ }^{134}$

Im staatlichen Führungsmodell des Taoismus steht das Nichtstun im Vordergrund, und die Tatsache, dass der ideale Herrscher eine unbewegte, neutrale Person ist, dient im Wesentlichen dem Machterhalt des Herrschers. Seine Interessenlosigkeit hat eine wichtige Vorbildfunktion für das Volk, welches ihm nacheifern und so das Aufkommen von Konflikten verhindern soll, die an-

maneuver and to plot against one another. «Stephen Greenblatt: Tyrant. Shakespeare on Power. London: The Bodley Head (2018), 24f.

132 Hans-Georg Moeller zufolge wurde das Tao-Tê-King in seiner Entstehungszeit und lange hernach spezifisch als Herrschaftsanleitung gelesen: »[T]he Laozi was used by this group [the cultural elite] as a guideline for the exercise of social power«, und »[i]nsofar as the Laozi was a text about rulership, it was just as much a guidebook for political leaders as many other sphilosophical writings in China were at that point. "HansCeorg Moeller: The Philosophy of the Daodejing. New York: Columbia UP (2006), 2, 57.

133 Lao-tse: Tao-Tê-King. Übers. v. Victor von Strauß. Hg. v. Willy Y. Tonn. Zürich: Manesse (1959), 137 (LVIII). Unsichtbarkeit gehört zur idealen Erscheinungsform von Herrschaft: »Von den großen Herrschern wußten/die Untertanen kaum,/daß sie da waren.« (Ebd. 77, XVII)

134 Lao-tse: Tao-Tê-King, 104 (XXXVII). 
sonsten vielleicht die Autorität des Herrschers in Frage stellen könnten. So erklärt der Sinologe Hans-Georg Moeller:

The ruler certainly does not encourage people to "participate in government. « He himself has no intentions to actively govern and no ambitions to steer the people in a particular direction-and the last thing he wants is to encourage the people to become political agents themselves. The ideal of government is certainly not »democratic. «Even the ruler refrains from ruling and from forming a political will. One important function of his restraint is that it prevents his people from developing ambitions and the corresponding »political « means for getting their interests recognized at the cost of others. Once the political arena is opened, the scheming among the people will begin and they will use all sorts of cunning and deceitful behavior to gain power or influence. ${ }^{135}$

Moellers Ausführungen entbergen, anders als es bei Aristoteles der Fall ist, eine realpolitische Komponente des Nichtstuns, die auch plausibel zeigt, warum Nichtstun eine Voraussetzung von Macht sein kann. Erhebt man die Abwesenheit von und den Unwillen zur Veränderung zur Tugend, und lebt sie seinem Volk vor, so macht man damit die eigene Absetzung unwahrscheinlich - und sichert so den eigenen Machterhalt.

Der Taoismus ist seit dem 19. Jahrhundert in Europa mit viel Interesse studiert worden. Unter den Zeugnissen dieses Interesses finden sich viele Erklärungen des taoistischen Denkens, um es den unerfahrenen Europäern nahezubringen. Dabei scheinen zum Zwecke der Nachvollziehbarkeit einige Anleihen in der europäischen Geistesgeschichte getätigt worden zu sein. In einer solchen, von Ernst Fuhrmann in den frühen 1920er Jahren verfassten, Erklärung fällt beispielsweise auf, dass sie die Beschreibung des taoistischen Regierens um Elemente erweitert, die zwar nicht im Tao-Tê-King vorkommen, dafür aber dem europäischen Denken des nichtstuenden Herrschers eigen sind. Fuhrmann schreibt:

In diesem Sinne werden schließlich Heilige und Herrscher identisch. [...] und so bleibt dem Herrscher in China nach den rituellen Vorschriften fast nichts zu tun: In die Kleinigkeiten der praktischen Regierung soll er sich nicht einmischen, sondern er soll sich in das tiefste Wissen der Zusammenhänge versenken, und es ist dem Orientalen dann sicher, daß das ganze Reich die wohl-

135 Moeller: The Philosophy of the Daodejing, 61f. Herv. meine. 
tätigen Einflüsse dieses reinen Denkens und Lernens erfahren wird. [...] Wer Anstrengungen macht, versucht immer nur das Unmögliche, aber wer unbedingt gehorcht und sich tun läßt, ohne selbst zu tun, der ist selbst ein Zentrum, das nun zentrifugal auf die Umwelt wirkt in kleinen oder großen Kreisen, je nach der Weite seiner Erkenntnisse, und so kann er am Ende seinen Einfluß aufein ganzes Reich ausdehnen. [...] Wie der Polarstern steht also der Kaiser regungslos in der Welt. ${ }^{136}$

Auch Fuhrmann übernimmt, ganz in der Art, wie man es bei Kittsein auch gesehen hat, die Vorstellung eines unbewegten Bewegers, indem er sagt, dass der Herrscher »ohne selbst zu tun«, »zentrifugal auf die Umwelt wirkt « und so seinen »Einfluß auf ein ganzes Reich« ausdehnt. Die hier erläuterte Idee, der Herrscher sei zugleich ein absoluter Ruhepol - wie »der Polarstern steht also der Kaiser regungslos ist der Welt « - und der energetische Ursprung und Beeinflusser der restlichen Welt, ist nicht unbedingt nur Wiedergabe des taoistischen Denkens, sondern möglicherweise auch ein Echo westlicher Gottesvorstellungen. Auch die von Fuhrmann ins Zentrum gerückte Auffassung, der Herrscher widme sich dem Denken und Lernen, ist europäisch geprägt. In Lao-Tses Darstellung ist der Herrscher nämlich weder Denker noch Gelehrter, sondern vielmehr »ausgeleert « und »verwirrt «. ${ }^{137}$ Die Tatsache, dass Fuhrmanns Erklärungen des Tao so viele Transponierungen enthalten, zeigt vor allem eins: die Idee, dass Nichtstun Allmacht und Herrschaftsfähigkeiten konnotieren - sei es in der theologischen Konzeption des unbewegten Bewegers, oder in der politischen Annahme eines nichtstuenden Herrschers - ist ein griffbereites Konzept der europäischen Geistesgeschichte.

\section{Ohnmacht}

Doch das Nichtstun in Herrschaftszusammenhängen besteht nicht nur aus Privilegien. Häufig geht es auch mit zum Teil heftigen Entbehrungen einher, die die Macht des Monarchen in Ohnmacht umwandeln. ${ }^{138}$ Herr-

136 Ernst Fuhrmann: China. Das Land der Mitte. Hagen i.W.: Folkwang-Verlag (1921), 15f. Herv. meine.

137 Lao-tse: Tao-Tê-King, 80 (XX).

138 Ein besonders schöner Verweis auf die Entbehrung durch das Nichtstun findet sich in der populären Netflix-Serie The Crown, in der Queen Mary ihre Enkelin und neue Regentin Elisabeth II. über die Schwere der königlichen Aufgabe aufklärt, die letztlich im Nichtstun besteht: »To do nothing is the hardest job of all. And it will take every 
schaftskonzeptionen, in denen Herrscherfiguren eine Verbindung zu Gott aufrechterhalten sollen, sind dafür besonders anfällig. Denn von Gott eingesetzte Monarchen sind effektiv keine autonomen Agenten, sondern Medien. Das Narrativ dieser Herrschaftskonzeption versteht Monarchen als von einem göttlichen Willen durchflossen, was einerseits Omnipotenz suggeriert, andererseits aber auch impliziert, dass Monarchen nur Marionetten sind und selbst nichts tun. In der Funktion des Mediums ist der Monarch nämlich lediglich ausführender Helfer des göttlichen Willens, und handelt so nicht. Denn er selbst - als Mensch, nicht als Monarch - ist handlungsunfähig, da er durch seine Funktion als Medium an einen anderen Willen als seinen eigenen gebunden ist. Diese Instrumentalisierung von Herrscherfiguren habe es, so behauptet Hajo Eickhoff, zum Beispiel schon im Alten Ägypten gegeben. Dessen Könige seien - und das nicht nur metaphorisch - weitestgehend an ihren Thron gefesselt gewesen, als eine Art lebendes Opfer an die Götter. Das Opfer des Königs läge

in der Begrenzung und Untätigkeit infolge des Sitzens. Der Cewinn, den eine Gemeinschaft aus der Tötung eines Menschen zieht, währt nur eine begrenzte Zeit, doch im thronenden König, dem die Ruhigstellung und Sitzhaltung spirituelle Fähigkeiten verleiht, verfügt eine Cemeinschaft über ein permanentes Opfer. ${ }^{139}$

Auch Eickhoff spricht über den Dualismus von Macht und Ohnmacht, der in der Figur des Königs zusammenkommt. Seine Attribute gründen »nicht allein in seiner Macht und Stärke, " schreibt er, »sondern gleichermaßen in seiner Ohnmacht. ${ }^{140}$ Diese physische Restriktion sollte der Ausbildung geistiger, und hier speziell »spiritueller « Fähigkeiten Vorschub leisten. ${ }^{141}$ Die Funktion

ounce of energy that you have. To be impartial is not natural, not human. People will always want you to smile or agree or frown. And the minute you do, you will have declared a position. A point of view. And that is the one thing as sovereign that you are not entitled to do. «Act of God. In: The Crown. Staffel 1, Episode 4. 2016. Regie: Julian Jarrold. Drehbuch: Peter Morgan. GB/USA: Left Bank Pictures/Sony Pictures Television. Fassung: Netflix 2016.

139 Hajo Eickhoff: Thronen als Denken und Meditieren. Die Medialität von Thron und Stuhl. In: Möbel als Medien. Beiträge zu einer Kulturgeschichte der Dinge. Hg. v. Sebastian Hackenschmidt u.a. Bielefeld: transcript (2014), 35.

140 Eickhoff: Thronen, 33.

141 Vgl. Arendt: Vom Leben des Ceistes, 127. 
des passiven Königs war es, zu meditieren. Er sollte so zum »Medium« werden, das »Menschen und Götter verbindet ${ }^{142}$ Seine Aufgabe war es, selbst nichts zu tun, er >wurde getan`. Man kann dem Monarchen also auch eine Opferrolle zuschreiben. Er erfüllt eine religiöse und staatliche Aufgabe, die wörtlich zu nehmen ist: er bzw. sie gibt sich auf, um den Anforderungen an die Rolle des Monarchen gerecht zu werden.

Herrschaft hat, so könnte man sagen, auch eine eingebaute Falle: Mit der Macht, die sie verleiht, geht eine Verantwortung einher, die die Privatperson, die den Titel trägt, gleichzeitig ohnmächtig macht. Sie wird nicht immer unbedingt als problematisch empfunden, doch diese Macht-OhnmachtÜberlagerung kann, so lernt man aus Shakespeares King Richard II, auch zum Untergang eines Monarchen beitragen. Richard ist, der politischen Theologie des Mittelalters folgend, durch göttliche Bestimmung König von England, und fühlt sich deshalb unangreifbar:

Not all the water in the rough rude sea

Can wash the balm off from an anointed king;

The breath of worldly men cannot depose

The deputy elected by the Lord: ${ }^{143}$

Niemand, so Richard, könne ihm seinen Titel streitig machen, da er der rechtmäßige Monarch sei - er ist immerhin der Stellvertreter Gottes, der »deputy elected by the Lord«. Diese Überzeugung allerdings ist einer der Gründe seines Niedergangs durch seinen Cousin, Henry Bolingbroke, der ihn später vom Thron stoßen wird. Überzeugt davon, dass er aufgrund seiner Erwählung durch Gott nichts Falsches tun kann - und damit auch nicht bestimmtes tun muss - unterlässt Richard es, die Adeligen in seinem Umfeld mit genügend Kalkül zu behandeln, und bringt sie gegen sich auf. Die Sicherheit, die er durch die göttliche Bestimmung empfindet, hindert ihn daran, einen eigenen Agens auszubilden, der ihn vielleicht retten könnte. Selbst als er von dem Komplott gegen sich erfährt, verweist er auf die Übermacht Gottes, die ihn retten wird:

And though you think that all, as you have done,

Have torn their souls by turning them from us,

And we are barren and bereft of friends,

142 Eickhoff: Thronen, 34.

143 William Shakespeare: King Richard II. Arden Shakespeare Third Series. Hg. v. Charles R. Forker. London: Bloomsbury (2002), 3.2, 54-57. 
Yet know: my Master, God omnipotent, Is mustering in His clouds on our behalf Armies of pestilence, and they shall strike Your children, yet unborn and unbegot, ${ }^{144}$

Seine Gegner mögen glauben, dass er nichts mehr tun könne, da seine Ressourcen für das Handeln nun erschöpft seien - »you think that [...] we are barren and bereft of friends« - doch sein Herr (»my Master, God omnipotent«) bereite Armeen im Himmel vor, wo sie auf Erden fehlen, und diese werden nicht nur seine Gegner, sondern auch alle ihre Nachfahren vernichten. Diese Stelle zeigt den König selbst als handlungsunwillige Figur, die für Ihre Wirkmacht auf die Kraft Gottes vertraut - die sich jedoch nicht wie gewünscht manifestiert. Diese Spaltung zwischen ohnmächtigem König und allmächtigem Gott hat Ernst H. Kantorowicz in seiner Studie The King's Two Bodies (1957) beschrieben. In der »Theology of Kingship« des englischen Mittelalters wurde der König als Einheit zweier Körper betrachtet: Dem konkreten physischen Körper (»body natural«) und dem symbolischen politischen Körper (»body politic«). ${ }^{145}$ Die tatsächliche Macht liegt in letzterem, dem »body politic «, ${ }^{146}$ er überdauert die materielle Existenz der Regenten, die körperlich rein menschlich, also ohne jede besondere Macht ausgestattet sind. Die Ohnmacht der Regenten offenbart sich allerdings nur selten, da sie zu ihren Lebzeiten von der Macht des »body politic« verdeckt wird. Im Fall Richards II., der sich selbst sentkrönen muss und so als abgespaltener »body natural « zurückbleibt, zeigt Shakespeare jedoch die Schwachstelle der doppelten königlichen Körperlichkeit, die ohne Hoffnung auf göttliche Hilfe zu einem resignierten Nichtstun zusammenfällt. »Gone [...]«, so Kantorowicz, »is the fiction of royal prerogatives of any kind, and all that remains is the feeble human nature of a king «. ${ }^{147}$

144 Shakespeare: King Richard II, 3.3, 82-89.

145 Ernst H. Kantorowicz: The King's Two Bodies. A Study in Mediaeval Political Theology. Princeton: UP (1957), 16, 7.

146 Der »body politic« wird auch als eine Art perfekter Handlungsträger bezeichnet. Kantorowicz schreibt, er sei »incapable of doing wrong«. Kantorowicz: The King's Two Bodies, 4. Zit. n. Sir William Blackstones Commentaries on the Laws of England (1765).

147 Kantorowicz: The King's Two Bodies, 30. 


\section{Kritik}

Das Phänomen des Nichtstuns bedeutet: eine Tätigkeit, der etwas (aber nicht alles) fehlt. Eine Tätigkeit, die einem (beliebig) gesetzten Standard, oder einer bestimmten Erwartung nicht genügt. Man muss es immer neu definieren, indem man den Standard bestimmt, zu dem es im jeweiligen Kontext in Kontrast gesetzt wird. In vielen Fällen ist heute dieser Standard die Arbeit. Für ein Verständnis des Herrschens als mangelhafte Tätigkeit, d.h. als Nichtstun, gelten allerdings andere, spezifischer auf das Politische ausgerichtete Standards. In der politischen Philosophie Hannah Arendts zum Beispiel ist das Grundelement des Politischen das menschliche Handeln. In ihrem Sinne bedeutet Handeln »etwas Neues Anfangen ${ }^{148}$ Es zeichnet sich zudem darin aus, sozial zu sein, es vollzieht sich »im Bezugsgewebe zwischen den Menschen «, und ist »in Isolierung niemals möglich «. ${ }^{149}$ Das Herrschen jedoch erfüllt diese beiden Voraussetzungen für das Handeln nicht.

Der politische Standard, den Arendt in ihrer Philosophie etabliert, steht im Einklang mit republikanischen, auch demokratischen Vorstellungen. Das Prinzip des Herrschens, dessen >Reinform Staatsform zugerechnet werden kann, geht mit diesem Ideal natürlich nicht konform. Herrschen ist für Arendt so eine politisch mangelhafte Tätigkeit, und wird deshalb zu einer Form des Nichtstuns abgewertet, die im Gegensatz zum oben ausgeführten passiven Widerstand keine ethische Handlungsform darstellt. Arendt tut dies im Rückgriff auf den Dialog über den »Staatsmann«, in dem Plato das Handeln in zwei Stadien (das anfangende und das durchführende Stadium) teilt. ${ }^{150}$ Der Herrscher (bei Arendt: der Führer) zeichne sich dadurch aus, nur der Anfänger, nicht aber der Vollzieher der von ihm angefangenen Handlung zu sein. Diese Teilung zwischen >beginnen und `vollenden s sei im Begriff der Handlung zwar in einigen Sprachen angelegt (so im Griechischen und Lateinischen), doch wenn sie nicht nur im Denken, sondern auch auf funktionaler Ebene realisiert würde - z.B. in der Aufgabenteilung zwischen Herrscher (er fängt an) und Untertan (er vollendet) - dann würden »weder der Befehlende noch die Vollstreckenden je wirklich handeln. « ${ }^{151}$ Hinzu kommt, dass das Herrschen auch der für

148 Arendt: Vita activa, 215.

149 Arendt: Vita activa, 234.

150 Vgl. Arendt: Vita activa, 281.

151 Arendt: Vita activa, 236. 
das Handeln konstitutiven sozialen Komponente entbehrt. Indem er nur die Initiative ergreift, die Ausführung jedoch anderen überlässt, isoliert sich der Herrscher. Deshalb sagt Arendt über den Herrscher, dass er »sich von eigentlichem Handeln fernhält und in Distanz bleibt von denen, die seine Befehle empfangen, so daß er, "praktisch" gesprochen, nichts tut. ${ }^{152}$ Sie entkräftet damit ebenfalls die (durchaus plausible) Vorstellung, dass solch ein Herrscher mächtig sei. Wer in Alleinherrschaft ohne die Absprache mit anderen so agiere, der übe nur Gewalt aus, verfüge aber nicht über Macht. Die Ausübung von Gewalt, so Arendt, ist immer ein Zeichen von Ohnmacht. ${ }^{153}$

Arendt kritisiert die Idee der Alleinherrschaft, indem sie der Figur des Herrschers das Nichtstun vorwirft. Damit ist sie nicht allein. Eine solche Funktionalisierung dieses Motivs für politische Zwecke hat im europäischen Denken Tradition. Montesquieus Skepsis gegenüber den absolutistischen Regenten der Bourbonen bewegte ihn dazu, 1748 in De Lesprit des Lois die Gewaltenteilung zu propagieren. Um die französische Monarchie nicht direkt $\mathrm{zu}$ kritisieren, beschrieb Montesquieu in Anlehnung an Aristoteles die Figur des >orientalischen $<$ Despoten, und stattete ihn mit all den Eigenschaften aus, die er bei Ludwig XIV. und Ludwig XV. für problematisch hielt. ${ }^{154}$ Dabei standen, wie auch in der oben ausgeführten Stelle von Arendt, Isolation und Untätigkeit im Vordergrund. Der Despot sei von seinen Untertanen abgeschottet und lebe "ganz eingeschlossen «, ohne Kontakt zur Öffentlichkeit. ${ }^{155}$ Diese Abgeschnittenheit vom Rest der Gesellschaft befördert eine solipsistische Charakterentwicklung, die auch erkläre, warum der Despot »naturgemäß faul« ist: Wer, wie er, denkt, »er sei alles und alle anderen nichts«, der krümmt keinen Finger, um Ansehen zu erlangen oder seine Situation zu verbessern, da er sich schon an der Spitze der sozialen Hierarchie befindet. ${ }^{156}$

Kritik am Herrschen, wie sie hier durch die Charakterisierung als Nichtstun geübt wird, taucht auch, aber in umgedrehter Weise, in der Literatur auf.

\section{Arendt: Vita activa, 282. Herv. meine.}

153 Arendt: Macht und Cewalt, 55.

154 Für die detaillierte Erklärung dieser in der Montesquieu-Forschung gängigen These siehe u.a. Joan-Pau Rubiés: Oriental Despotism and European Orientalism: Botero to Montesquieu. In: Journal of Early Modern History 9 (1), 2005, 109-80. Montesquieu: Vom Ceist der Cesetze. Bd 1. Übers. v. Ernst Forsthoff. Tübingen: H. Laupp'sche Buchhandlung (1951), 86 (5/14).

156 Montesquieu: Vom Geist der Gesetze, 31 (2/5). Herv. meine. Es heißt zudem: »Bildet die Furcht das Prinzip, so ist die Ruhe das Ziel der despotischen Regierung« (ebd. 88; 5/14). Herv. meine. 
Es mag sicher literarische Texte geben, die gelangweilte oder faule Herrscherfiguren darstellen. Doch bezeichnend scheint ebenfalls, dass im Gegenteil das literarische Motiv des Nichtstuns mit herrschaftlichen und sogar despotischen Eigenschaften ausgestattet, und so kritisiert wird. ${ }^{157}$ Ein gutes Beispiel hierfür findet sich im ersten Teil von Marcel Prousts À la recherche du temps per$d u$ (1913). Dort heißt es über die Figur Tante Léonie, die aufgrund einer mehr oder weniger imaginierten Krankheit ihr Zimmer nicht verlässt, dass sie eben solche Eigenschaften entwickele:

eine alte Dame in der Provinz, wenn sie nur hemmungslos ihren Launen und einer aus Muße gezeugten Bosheit folgt, ohne daß sie dabei jemals an Ludwig XIV. gedacht hat, es erleben kann, daß ihre unbedeutendsten täglichen Beschäftigungen, die mit ihrem Aufstehen, ihrem Mittagessen, ihrer Ruhe zusammenhängen, durch ihren despotischen Eigenwillen etwas von dem Interesse bekommen, wie es dem innewohnte, was Saint-Simon den >Mechanismus< des Lebens in Versailles genannt hat. ${ }^{158}$

In diesem sehr bezeichnenden Passus zeigt sich die Isolation und Abgeschiedenheit, die sowohl Arendt als auch Montesquieu als Problem der Herrscher und Despoten ausweisen. Ohne soziale Kontrolle steht es Tante Léonie frei, ihren »Launen« freien Lauf zu lassen. Dabei präge sich in ihrem Verhalten, ohne dass sie sich dessen im Geringsten bewusst ist, in ihrer freien Zeit (ihrer "Muße «) eine Bosheit aus, ${ }^{159}$ die als despotisch bezeichnet wird.

Diese Verbindung, wie Proust sie expliziert, findet sich in vielen literarischen Texten über das Nichtstun. Die Lektüren in den folgenden Kapiteln zeigen diese Prävalenz exemplarisch auf. Die Genese der nichtstuerischen Herrschaft folgt dabei in vielen Fällen der thematischen Reihenfolge dieses Kapitels: Zunächst entsteht bei den Nichtstuern ein Gefühl von Macht, das

157 Eine ähnliche Dynamik beschreibe ich in diesem Buch in der Zauberberg-Analyse im Abschnitt » Regieren«: Herrschaft durch Nichtstun« sowie bei Un homme qui dort im Abschnitt »Kontrollverlust und Herrschaftsphantasie«.

158 Marcel Proust: Aufder Suche nach der verlorenen Zeit. In Swanns Welt. Übers. v. Eva RechelMertens. Frankfurt a.M.: Suhrkamp (1997), $159 f$.

159 Aleida Assmann hat bereits vor Längerem die literarische Verbindung zwischen Einsamkeit und Bosheit erörtert, noch dazu anhand der Monarchen-Figur in Shakespeares Richard III. Aleida Assmann: Die Einsamkeit des Bösen. In: Einsamkeit. Hg. v. Ders. u.a. München: Fink (2000), insb. 129-133. Ein Verweis auf die Rolle der Muße bzw. des Nichtstuns (die im Band an anderer Stelle als einsamkeitsrelevant in den Fokus gerückt wird) mit den Topoi Bosheit und Herrschen bleibt allerdings aus. 
$72 \quad$ Nichtstun als politische Praxis

sich im weiteren Verlauf ihrer Geschichte als Illusion entpuppt und in eine Ohnmacht umkehrt, die letztlich ebenfalls eine Kritik impliziert. Der kritische Impetus der Texte funktioniert in beiden Richtungen: Prinzipien des Herrschens werden durch die Zuschreibung des Nichtstuns ebenso kritisiert, wie das Nichtstun, das durch den Modus des Herrschens problematisiert wird. 


\section{Poetische Überlegungen: Binäropposition und Uneigentlichkeit}

Nachdem die politischen Dimensionen des Nichtstuns ausgeleuchtet worden sind, bedürfen die nun folgenden Analysen literarischer Werke einer klaren Einordnung als von der philosophischen Reflexion auf Untätigkeit eindeutig unterschiedene künstlerische Verfahren. Das philosophische Verständnis des Nichtstuns als der Beginn von etwas Neuem und als realem Phänomen mit Handlungscharakter, das bisher entfaltet wurde, ist eine Theorie. Sie ermöglicht, Nichtstun als Handlung zu denken. Sie kann so als Ausgangspunkt für eine literaturwissenschaftliche Analyse dienen, nicht aber als Anleitung, wie etwa eine These - Nichtstun ist Handlung - deduktiv aus den Texten herzuleiten wäre.

Tatsächlich kann auch nur einer der Romane als affirmative Inszenierung einer Theorie des Nichtsuns als Handlung beschrieben werden. Lediglich in dem 1967 publizierten kurzen Roman Un homme qui dort von Georges Perec wird das Nichtstun als passiver Widerstand, als Streik gegen die bestehende Ordnung inszeniert, in der es in Wirklichkeit keine sechten< Handlungen oder Ereignisse gibt, weil man, nur scheinbar handelnd, lediglich vorgefertigten Lebensentwürfen folgt. Hier erscheint das Nichtstun des namenlosen Protagonisten tatsächlich als neue Praxis, als sechte Handlung. Die anderen Analysen hingegen weichen von diesem >Idealtypus $<$ ab: sie sind nicht explizit als Formen des Widerstands markiert, das in ihnen entwickelte Nichtstun ist auf der Ebene der Diegese nicht immer eine neue Art der Handlung, die alte Konventionen durch ein Nicht-Agieren überwindet. 


\section{Binäropposition}

Dennoch verleihe ich jeder der in den Romanen gestalteten Formen des Nichtstuns das Attribut der Praxis. Der Grund dafür liegt nicht etwa in einer genauen Analogie zu dem Theorem des Streiks bzw. des passiven Widerstands, sondern vor allem in der Tatsache, dass jeder dieser Romane die Binäropposition zwischen Nichtstun und vermeintlicher Handlung erschüttert. Indem sie das tun, stellen die Romane die Frage neu, was überhaupt als Handlung gelten darf.

In jedem Roman bildet eine Binäropposition den Ausgangspunkt, die die Geschichte maßgeblich strukturiert. Diese Opposition nimmt immer die Form >Nichtstun vs. Handlung an, wobei >Nichtstun` und >Handlung jeweils idiosynkratisch ausgedeutet und benannt sind. In Der Gehülfe steht Muße gegen Arbeit, in Der Zauberberg >Ost//Inaktiv gegen >West/Aktiv, in Un homme qui dort opponieren Indifferenz und Handlung, im Bombel Sprechen und Handeln. Während all diese Oppositionen in den Romanen etabliert werden, diegetisch vielleicht sogar Vertreter haben, die sie immer wieder $\mathrm{zu}$ performieren und zementieren versuchen (so wie Settembrini im Zauberberg für den aktiven >Westen/Aktiv), oder von den Erzählern selbst aufgerufen werden, so setzen die Romane jeweils spezifische literarische Verfahren ein, um dieser Ausgangslage eine klare Destabilisierung der Nichtstun-Handlungs-Opposition entgegenzusetzen.

So wird sich in Walsers Gehülfen zeigen, dass dort Muße nicht das Gegenteil der Arbeit ist, sondern dass Muße eine andere Form von Arbeit darstellt, die ich Hyperarbeit nenne. Im Gegenzug folgt daraus, dass als Arbeit gekennzeichnete Tätigkeiten gleichzeitig auch müßig sein können. Im Zauberberg Thomas Manns zeigt sich, dass sich der topographische Grundgegensatz des Romans zwischen einem mit der Inaktivität assoziierten >Osten nem mit Aktivität verbundenen >Westen $`$ nicht aufrechterhalten lässt. Mittels Projektionsverfahren weist der Roman den Osten als aktiv aus, während er den Westen als inaktiv konnotiert. In Georges Perecs Un homme qui dort wird die Inaktivität, die sich zunächst prätentiös als Indifferenz präsentiert, zum zentralen Vehikel eines Streiks, und damit - zumindest zeitweise - gleichbedeutend mit Handlung. Konventionelle Formen des Protests hingegen werden als sinnlos entlarvt. In Mirosław Nahaczs Bombel entpuppt sich ein zunächst als wahnsinnig konnotiertes Sprechen aus dem Nichtstun heraus als ein kompensatorischer, kritischer Sprechakt, und damit als ein Versuch, die bestehende Ordnung durch Sprachhandlungen zu verändern. Die Kritik und 
vermeintliche Aktion von anderen Figuren innerhalb der Diegese erscheinen in diesem Licht viel eher wie Wahnsinn und sinnlose Tätigkeit als das Nichtstun des Protagonisten-Erzählers.

Jenseits der jeweils verschiedenen Ausgestaltung der Oppositionsterme ist den Romanen gemein, dass sie die Dekonstruktion der Binäropposition über Wege vornehmen, die sich als Verfahren der Uneigentlichkeit beschreiben lassen.

\section{Uneigentlichkeit}

Von dem Strukturmerkmal der Binäropposition ausgehend lässt sich auch eine interessante Ableitung für die Darstellung des Nichtstuns in der Literatur feststellen. Geht man von einer übergeordneten Opposition >Nichtstun vs. Handlung a aus, so stellt das Nichtstun aufgrund seiner gesellschaftlichen Verachtung seit der Moderne immer den schwächeren Term dar. Diese Schwäche führt dazu, dass sich die literarische Darstellung des Nichtstuns durch den Modus der Uneigentlichkeit auszeichnet. Damit ist eine Art der Darstellung gemeint, die von Ambiguität geprägt ist, weil sie das Motiv des Nichtstuns nicht sdirekt< und sals solches darstellt, sondern gleichzeitig auch als etwas anderes. In den Romanen, die im Folgenden analysiert werden, wird das Nichtstun als vermeintlich schwächeres Paar der Binäropposition versteckt, als etwas anderes getarnt, oder dient selbst als Deckung, um etwas anderes zu verbergen. Diese Verschiebungen lassen sich allesamt als Verfahren der Uneigentlichkeit definieren. Dieses Buch behandelt vier solcher Verfahren: Simulation, Projektion, Prätention, und Kompensation.

Diese Darstellungsverfahren sind in besonderer Weise mit dem Motiv des Nichtstuns verknüpft, denn während sie dem Nichtstun zum Erscheinen verhelfen, stellen sie stets eines der zentralen Probleme des Nichtstuns mit dar: die Möglichkeit seines öffentlichen Erscheinens. Um diese Problematik näher zu betrachten, lohnt sich ein weiterer Blick auf die Handlungsphilosophie Hannah Arendts. Arendt schreibt der Öffentlichkeit eine wichtige Rolle zu, da sich erst dort eine mit anderen Menschen geteilte, gemeinsame >Wirklichkeit konstituiere. Das Wort ’öffentlich bedeute, so schreibt sie,

daß alles, was vor der Allgemeinheit erscheint, für jedermann sichtbar und hörbar ist, wodurch ihm die größtmögliche Öffentlichkeit zukommt. Daß etwas erscheint und von anderen genau wie von uns selbst als solches wahr- 
genommen werden kann, bedeutet innerhalb der Menschenwelt, daß ihm Wirklichkeit zukommt. Verglichen mit der Realität, die sich im Gehört- und Gesehenwerden konstituiert, führen selbst die stärksten Kräfte unseres Innenlebens - die Leidenschaften des Herzens, die Gedanken des Geistes, die Lust der Sinne - ein ungewisses, schattenhaftes Dasein. ${ }^{1}$

Nur was in der Öffentlichkeit erscheint, so Arendt, unterliegt dem gemeinsamen Wirklichkeitsverständnis der Menschen. In der Öffentlichkeit, von der auch als »Erscheinungsraum « die Rede ist, können allerdings nur einige der menschlichen Tätigkeitsformen erscheinen. ${ }^{2}$ Ursprünglich seien es das Handeln und das Sprechen gewesen, in der Neuzeit habe sich aber auch die Arbeit zu einer öffentlich vollzogenen Tätigkeit entwickelt. ${ }^{3}$

In diesem Kontext betrachtet ist das Nichtstun vor ein Problem der Wahrnehmbarkeit gestellt. Da es sich zumeist dadurch auszeichnet, außerhalb dominanter Tätigkeitsformen wie der Arbeit zu stehen, und deswegen zum Teil abgewertet wird, ist das Nichtstun in Gefahr, nicht gesehen und gehört, das heißt öffentlich zu werden. Das gilt Arendt zufolge zum Beispiel für Formen des Nichtstuns, die sich auf körperliche Untätigkeit beschränken, wie es bei geistigen Tätigkeiten der Fall ist. Über das Denken sagt Arendt, es gehe mit »völliger Unbeweglichkeit des Körpers « einher, ${ }^{4}$ und zeichne sich durch eine »Distanzierung vom Handeln $\aleph^{5}$ aus - weshalb eine seiner Haupteigenschaften »Unsichtbarkeit « sei. ${ }^{6}$ Im Bereich der geistigen Tätigkeit ist die Unsichtbarkeit des Subjekts in der Regel nicht problematisch, da die Personen, die sich der Vita contemplativa zuwenden, Arendt zufolge nicht unbedingt das »Bedürfnis« haben, »als tätiges [Ich] zu erscheinen «. ${ }^{7}$ Bei anderen Formen des Nichtstuns kann diese Unsichtbarkeit allerdings ein Problem darstellen. Bei solchen Subjekten nämlich, denen die Möglichkeiten, Anlagen oder Fähigkeiten zu einem Erscheinen in der Öffentlichkeit fehlen, obwohl sie ein Bedürfnis danach empfinden; oder die auf eine andere Weise erscheinen möchten, als es der öffentliche Raum zulässt, und die vielleicht den öffentlichen Raum durch

Arendt: Vita activa, 63. Herv. meine.

Arendt: Vita activa, 251.

Arendt: Vita activa, 61.

Arendt: Vom Leben des Ceistes, 127.

Arendt: Vom Leben des Geistes, 97.

Arendt: Vom Leben des Geistes, 77.

Arendt: Vom Leben des Geistes, 77. 
das Nichtstun selbst umgestalten wollen, es aber aufgrund ihrer Unsichtbarkeit nicht können.

Wer nichts tut und so auch nicht in der Welt erscheinen kann, befindet sich in einem Zustand der »Weltlosigkeit «. ${ }^{8}$ Rahel Jaeggi, die Hannah Arendt als Sozialphilosophin der Exklusion versteht, weist diesen Zustand nicht als statisches Faktum, sondern als dynamischen Prozess aus. Das vom öffentlichen Leben und der Gestaltung der Welt ausgeschlossene Prekariat, so Jaeggi, akzeptiere diese Exklusion nicht, sondern befinde sich in einem »Kampf[...] um Sichtbarkeit «. ${ }^{9}$ Texte, die sich mit dem Nichtstun literarisch auseinandersetzen, bilden diesen Kampf um Sichtbarkeit ab - indem sie zeigen, wie ein Nichtstun versteckt oder inszeniert werden muss, damit es (und die Person, die es praktiziert) in der Welt erscheinen kann.

In der ersten Lektüre geschieht dies durch eine Simulation von Arbeit. Sie soll den Luxus der Muße legitimieren, dem sich die Protagonisten aus Robert Walsers Der Gehülfe (1907) hingeben wollen. Die Simulation ist eine sowohl von der Muße als auch von der Arbeit unterschiedene, dritte Tätigkeitsform, ein Nichtstun, das gesellschaftlich nicht legitimiert ist und das sich durch den Anschein einer anderen, svollwertigen Tätigkeit kaschieren will. In der zweiten Lektüre zeigt sich, dass das Nichtstun auch durch Projektion versteckt werden kann. In Thomas Manns Der Zauberberg (1924) soll von einem seuropäischen Nichtstun, das dem >westlichen Ideal des Fortschritts zuwiderläuft, abgelenkt werden - und zwar indem das Nichtstun als genuin rasiatisches Phänomen deklariert wird. Um selbst nicht unter der Verurteilung des verachteten Nichtstuns zu leiden, schreiben es die Protagonisten des Romans in einem orientalistischen Modus dem >Osten $\mathrm{zu}$ - um als der im Gegensatz aktive >Westen zu erscheinen. Die dritte Lektüre exemplifiziert, dass dieses Spiel auch umgekehrt, und zwar als Prätention funktioniert. Der Erzähler-Protagonist aus Georges Perecs Un homme qui dort (1967) gibt vor, er würde wegen seiner Indifferenz der Welt gegenüber nichts tun. Tatsächlich ist ihm die Welt alles andere als gleichgültig. Er hält nur die bestehenden Handlungsmodelle für sinnlos. Er will als Nicht-Erscheinender erscheinen, um zu testen, ob die Welt und ihre Handlungsmodelle so verändert werden können. In der letzten Lektüre zeigt sich die Kompensation als Mittel der Überblendung eines gesellschaftlich verurteilten Nichtstuns. Der Protagonist aus Mirosław Nahaczs Bombel (2004) kompensiert die Erniedrigung, die er als arbeitsloser

8 Arendt: Vita activa, 139.

9 Rahel Jaeggi: Wie weiter mit Hannah Arendt? Hamburg: Hamburger Edition (2008), 22. 
>Penner erleiden muss, durch exzessives Sprechen. Er will so in einer anderen, neuen Rolle erscheinen: als Entertainer, als Chronist und Geschichtenerzähler, und auch als Kritiker bestehender Verhältnisse - eine Rolle, in der er durch sein Sprechen aktiv die bestehenden Verhältnisse verändern möchte.

Diese literarischen Texte stellen die gesellschaftliche Problematisierung des Nichtstuns mit dar. Denn sie signalisieren, dass dem Nichtstun aufgrund seiner gesellschaftlichen Ablehnung ein uneigentliches Sprechen (der Protagonisten, der Erzähler, der Romane im Ganzen) eignet. Dabei handelt es sich um ein Sprechen, das von etwas anderem ablenken, und seine eigentliche öffentliche Erscheinung bewirken, beeinflussen und manipulieren will. Dieses uneigentliche Sprechen ist darin dem Schauspiel ähnlich. Durch das Schauspiel kann das Nichtstun als etwas anderes (meist Aktives) erscheinen, und wirkt dadurch wie eine öffentlich legitime Tätigkeit (Handeln oder Arbeit), während es gleichzeitig sein eigenes Schauspiel entlarvt und sich als Nichtstun zu erkennen gibt. Im gleichen Zug, in dem diese Geschichten das Nichtstun zu einem Versteckspiel funktionalisieren, legen sie das offen, was versteckt werden soll. Diese Geschichten sind in diesem Sinne keine Rätsel, die es aufzulösen gilt. Sie zeigen vielmehr sehr offensichtliche Sachverhalte und Beziehungen, um sie dann von den nichtstuenden Charakteren verzerren zu lassen, was komische, aber auch tragische Effekte produziert. Ohne dominante Diskurse der Auf- oder Abwertung des Nichtstuns zu übernehmen, gelingt es der Literatur mittels dieser Verfahren die Paradoxien, die Handeln und Nichtstun miteinander verbinden, offenzulegen und beide Pole in neuer Weise miteinander ins Spiel zu bringen.

Die Literatur, die sich mit dem Nichtstun beschäftigt, zeichnet sich so dadurch aus, den Gegensatz zwischen Nichtstun und Handeln aufzulockern, indem sie beide Tätigkeiten gleichzeitig abbildet. Sie wirft damit auch eine wichtige Frage auf: Wenn legitime Tätigkeiten gespielt und nachgestellt werden können, kann man dann ein durch uneigentliches Sprechen überspieltes Nichtstun überhaupt von sechter Handlung oder sechter Arbeit unterscheiden? Folgt man nämlich der Logik von Arendt, so kann diese Art des uneigentlichen Erscheinens nicht unbedingt von dem Erscheinen durch eine >legitime Tätigkeit unterschieden werden. Dies leitet sich aus der Theater-Metapher ab, die Arendts Werk durchzieht, und in der sie eine Parallelität zwischen dem Handeln und dem Schauspielern bzw. dem Theater feststellt. Das Erscheinen des Subjekts in der Welt sei, so Arendt, mit einer »Aufführung« im Theater 
vergleichbar. ${ }^{10} "$ Handelnd und sprechend offenbaren die Menschen jeweils, wer sie sind, zeigen aktiv die personale Einzigartigkeit ihres Wesens, treten gleichsam auf die Bühne der Welt«, ${ }^{11}$ schreibt sie. Aus der Behauptung einer solchen Relation drängt sich eine Vermutung auf, die Arendt in ihrem Werk kaum berücksichtigt hat: dass die auf das Handeln übertragene Metapher des Theaters auch umgekehrt funktioniert, dass also Handlung einerseits nur gespielt werden kann, und dass das Schauspiel allein aufgrund seines Erscheinens ebenfalls eine Handlung darstellt. ${ }^{12}$

Es ist also einerseits möglich, das Nichtstun als Tätigkeit zu beschreiben, die dem Schauspiel verwandt ist, und andererseits das Schauspiel im Nichtstun auch als Handlung zu betrachten. Die Verfahren der Uneigentlichkeit, die in der Literatur zur Darstellung des Nichtstuns funktionalisiert werden, bilden so nicht nur seine gesellschaftliche Problematisierung ab. Die Uneigentlichkeit wird außerdem zum Anker einer möglichen Relativierung zwischen Tun und Nichtstun. Sie zeigt, dass sich das Nichtstun produzieren und etwas anfangen muss, um zu erscheinen. Damit ist es nicht weniger produktiv als die Arbeit, und prägt den Erscheinungsraum ebenso wie das Handeln. Sie suggeriert auch, dass Tätigkeiten, die gesellschaftlich als `legitim^ und >vollwertig، kodiert sind, ebenso schauspielerische Elemente enthalten können, weil auch sie auf der »Bühne der Welt« (s.o.) erscheinen.

Die Literatur bildet das Verhältnis zwischen Nichtstun und >richtigem Tun nicht als Opposition ab, sondern stellt es als eine komplexe Dynamik dar. Die literarischen Texte hinterfragen diesen oft als unauflösbar wahrgenommenen Gegensatz, ähnlich wie die philosophischen Betrachtungen des Nichtstuns, die im vorangegangenen Kapitel vorgestellt wurden.

\footnotetext{
10 Arendt: Vita activa, 233.

11 Arendt: Vita activa, 219.

12 Arendt geht grundsätzlich davon aus, dass Handlung nicht mit Täuschungen operiert, da sich der Mensch im Handeln und Sprechen als der zeigt, der er wirklich ist. Vgl. Arendt: Vita activa, 219. Doch andererseits identifiziert sie das Lügen als genuine Handlung. Vgl. Hannah Arendt: Wahrheit und Lüge in der Politik. Zwei Essays. München: Piper (2016), 73.
} 



\section{Arbeit vs. Muße}

Die Simulation von Arbeit, wie sie im nächsten Abschnitt untersucht wird, stellt nicht nur ein literarisches Phänomen dar. Die Tendenz zur Simulation von Arbeit hat sich aus der historischen Veränderung der Arbeit, und ihrer Wahrnehmung in der Gesellschaft entwickelt - und wird in der Literatur als solche aufgegriffen. Dabei sind zwei Faktoren besonders relevant: Zum einen die Aufwertung von Arbeit in der Neuzeit und die Tatsache, dass sie sich dadurch an die Muße annähert. Zum anderen die Verknappung der Arbeit im 20. Jahrhundert und die daraus resultierenden Beschäftigungsmaßnahmen. Diese beiden Faktoren, die im Folgenden weiter ausgeführt werden, tragen zu einer Art ssimulativer Umwertung< von Arbeit bei.

\section{Annährungen}

Ein Grund, Arbeit überhaupt zu simulieren, liegt in der großen gesellschaftlichen Wertschätzung, die ihr seit einigen Jahrhunderten zukommt. Im Zuge ihrer Aufwertung hat sich ein dominanter Diskurs entwickelt, der der Arbeit einen ähnlichen Genusswert zuschreibt wie der Muße. Diese Nähe von Muße und Arbeit, die auch bei Robert Walser durchscheint, ist historisch betrachtet ein relativ neues Phänomen. Blickt man zurück zu den Anfängen der europäischen Kultur, so stellt man eine strenge Trennung zwischen Arbeit und Muße fest. In der griechischen Antike wurde Arbeit (ponos) als die Befriedigung von Grundbedürfnissen verstanden, und als minderwertige Tätigkeit angesehen. So schreibt Hannah Arendt, dass alle Beschäftigungen, die »nicht um ihrer selbst willen unternommen wurden, sondern um die Lebensnotwendigkeiten herbeizuschaffen«, dem »verachteten Stand der Arbeit gleichgestellt« wurden. ${ }^{1}$ Die Muße (scholé) hingegen war eine hochgeachtete Tätigkeit, gerade weil sie die Freiheit von der Arbeit bedeutete: 
Die griechische $\sigma \times 0 \lambda \eta ́$ [scholé] wie das lateinische otium bedeuten nicht so sehr Muße als Freiheit von politischer Tätigkeit; allerdings werden beide Worte auch gebraucht, um Freiheit von Arbeit und den Lebensnotwendigkeiten zu bezeichnen. In jedem Fall handelt es sich nicht primär um Freizeit, sondern um eine von Sorge und Mühe freie Lebenslage. ${ }^{2}$

Muße im antiken Sinne meint gerade einen Rückzug von dem Tätigkeitsprinzip der Notwendigkeit, was sie im Gegensatz zur einfachen Arbeit zu einer hochkultivierten Tätigkeitsform machte: »Muße bildet [...] die Voraussetzung des bios theoretikos (Aristoteles) eines Philosophen als der vornehmsten antiken Lebensform und des otium cum dignitate « der römischen Nobilität, die mit dem niederen labor, der Werkarbeit, nichts zu tun hatte. ${ }^{3}$ Muße, Müßiggang, Freizeit, Nichtstun und alle anderen Termini, die sich in diese Reihe einfügen lassen, bilden seit der Antike und mindestens bis ins späte Mittelalter einen positiven Gegenbegriff zur negativ konnotierten Arbeit als Tätigkeit aus der Sphäre der Notwendigkeit.

Doch in der Neuzeit ändert sich diese Relation drastisch, weil Arbeit nunmehr als etwas Gutes wahrgenommen wird. Im Gegensatz zur Korrelation der Arbeit mit Sorge und Mühe, wie Hannah Arendt sie für die Antike beschreibt, entstand in der Neuzeit ein Diskurs, in dem Arbeit zu einer Möglichkeit umgedeutet wird, das eigene Leben selbstständig verbessern zu können. Zum einen verbreitet sich durch die theoretische Arbeit von John Locke ab Ende des 17. Jahrhunderts die Erkenntnis, dass Arbeit zur Akkumulation von Eigentum führen kann. ${ }^{4}$ Adam Smith postulierte knapp hundert Jahre später, dass sich daraus auf nationaler wie auf individueller Ebene Reichtum erwirtschaften lässt. ${ }^{5}$ Für den arbeitenden Menschen der Neuzeit war dies in vielerlei Hinsicht eine segenreiche Kehrtwende: lange eingeschnürt in das Korsett des Frondienstes und ähnliche Abhängigkeiten, versprach eine Aufwertung der Arbeit für ihn auch eine Befreiung aus rigiden Beschäftigungssystemen und die Möglichkeit eines sozialen Aufstiegs. Erfolgreiche Berufsarbeit, so heißt es

\footnotetext{
2 Arendt: Vita activa, 418.

3 Johannes Engels: Merces auctoramentum servitutis - Die Wertschätzung bestimmter Arbeiten und Tätigkeiten durch antike heidnische Philosophen. In: Arbeit im Mittelalter. Vorstellungen und Wirklichkeiten. Hg. v. Verena Postel. Berlin: Akademie (2006), 60.

4 Vgl. John Locke: The Second Treatise of Government. Hg. v. Thomas P. Peardon. New York: Liberal Arts Press (1952).

5 Adam Smith: An Inquiry into the Nature and Causes of the Wealth of Nations. Hg. v. Jonathan B. Wight. Petersfield: Harriman House (2007), 293.
} 
bei Aßländer und Wagner, vermochte es angeblich, "Stand und Herkunft als klassische gesellschaftliche Stratifikationsmerkmale« abzulösen. ${ }^{6}$

Es entwickelte sich zudem die Idee, dass der Mensch die ihm gegebenen Möglichkeiten erst in der Arbeit vollkommen realisieren könne. Während im Mittelalter noch eine große Skepsis gegenüber technisierter und industrieller Arbeit vorherrschte, so hielt man sie in der Neuzeit zunehmend für den Beweis des menschlichen Erfindungsgeistes. Der arbeitende Mensch ist in dieser Perspektive ein schöpferisches Wesen, und die Arbeit Manifestation seiner weltbildenden "Naturbeherrschung " und der Innovation seines Denkens. ${ }^{7}$ Den Höhepunkt dieses "glänzende[n] Aufstieg[s] der Arbeit von der untersten und verachtetsten Stufe zum Rang der höchstgeschätzten aller Tätigkeiten«, so Hannah Arendt, ist im Denken von Karl Marx erreicht, in dessen Einschätzung die Arbeit nicht nur die »Quelle aller Produktivität« ist, sondern auch »Ausdruck der Menschlichkeit des Menschen selbst.$^{8}$ Diese und andere Würdigungen bilden seit dem 17. Jahrhundert einen Diskurs der ArbeitsIdealisierung aus, der nachteiligere Beurteilungen der Arbeit in nicht unwesentlichem Maße verdrängt hat. In diesem Diskurs ist Arbeit nicht mehr mit "Sorge« und "Mühe« verbunden, wie Arendt es für die Antike beschreibt im Gegenteil. Mithilfe der eben genannten Vorteile der Arbeit - Eigentum, Reichtum, sozialer Aufstieg, Innovation, Weltbildung - operiert dieser Diskurs mit der Suggestion, Arbeit sei nicht nur produktiv und nützlich, sondern auch angenehm. Ebenso angenehm, so die Implikation, wie die Muße, die die Arbeit doch eigentlich erst ermöglichen soll.

\section{Arbeit als Zeichen}

Diese Idee einer angenehmen, genussvollen Arbeit hat jedoch eine Kehrseite: die positive Umwertung der Arbeit birgt nicht nur Vorteile für Arbeiter, sondern ist auch von kapitalistischen Machtinteressen geleitet. Das verleitet zu der Annahme, dass die Vorstellung, Arbeit sei eine angenehme Tätigkeit, in gewisser Hinsicht nur eine Täuschung ist, die zu der tatsächlich weiterhin mühseligen Arbeit animieren soll.

6 Michael S. Aßländer u. Bernd Wagner: Einführung: Arbeit und Philosophie. In: Philosophie der Arbeit. Texte von der Antike bis zur Gegenwart. Hg. v. Dens. Berlin: Suhrkamp (2017), 11.

7 Georg Jochum: Arbeit als Grundlage menschlicher Existenz: Zur historischen Entwicklung des Verständnisses von Arbeit. In: Handbuch Arbeitssoziologie. Hg. v. Fritz Böhle u.a. Wiesbaden: VS Verlag für Sozialwissenschaften (2010), 99. 
Obwohl Arbeit bis heute einen hohen gesellschaftlichen Stellenwert inne hat, wurde dieser Wert doch zugleich sausgehöhlt‘. David Graeber zufolge hat sich nämlich die in der zweiten Hälfte des 20. Jahrhunderts häufig getroffene Prognose über die Zukunft der Arbeit nicht bewahrheitet. Diese Prognose, für die Jeremy Rifkins The End of Work (1995) als exemplarisch zu lesen ist, beinhaltete die Behauptung, dass der technologische Fortschritt in großem Ausmaß Arbeitsplätze im Industrie-, Landwirtschafts- und Dienstleistungssektor überflüssig machen würde. ${ }^{9} \mathrm{Da}$ in Folge nur wenige Menschen Arbeit haben würden, so stellten sich Rifkin und andere vor, müsse sich die Gesellschaft organisatorisch auf Arbeitslosigkeit einstellen. Diese Voraussage ist Graeber zufolge nur zum Teil eingetroffen, denn während einige Sektoren Arbeitsplätze abbauen mussten, haben sie sich in anderen schlagartig vermehrt. Diese zusätzlich geschaffenen Arbeitsplätze seien allerding sinnlos, so die These Graebers, da sie dem kapitalistischen Diktum der Effizienz zuwiderlaufen. Es mag heute keinen Mangel an Arbeitsplätzen geben, doch bei vielen von ihnen handele es sich um »jobs that don't seem[...] to really do much of anything «. ${ }^{10}$ Er schreibt:

the same period that saw the most ruthless application of speed-ups and downsizing in the blue-collar sector also brought a rapid multiplication of meaningless managerial and administrative posts in almost all large firms. It's as if businesses were endlessly trimming the fat on the shop floor and using the resulting savings to acquire even more unnecessary workers in the office upstairs. ${ }^{11}$

Graebers Begründung für diese Entwicklung ist vielschichtig, operiert aber im Kern mit Machtargumenten: jemanden viel Gehalt für eine Tätigkeit zu zahlen, die demjenigen sinnlos erscheint, hält er für eine Form der Unterdrückung. Insbesondere wenn sozial wertvolle Arbeit (Graeber spricht von "social value«, und nennt dafür KindergärtnerInnen, ÄrztInnen usw. als Beispiele) viel geringer entlohnt wird. ${ }^{12}$

The answer clearly isn't economic: it's moral and political. The ruling class has figured out that a happy and productive population with free time on

9 Jeremy Rifkin: The End of Work. The Decline of the Global Labor Force and the Dawn of the Post-Market Era. New York: C. P. Putnam's Sons (1995).

10 David Graeber: Bullshit Jobs. A Theory. London: Allen Lane (2018), xiii.

11 Graeber: Bullshit Jobs, 18.

12 Graeber: Bullshit Jobs, 12. 
their hands is a mortal danger. [...] the feeling that work is a moral value in itself, and that anyone not willing to submit themselves to some kind of intense work discipline for most of their waking hours deserves nothing, is extraordinarily convenient for them. ${ }^{13}$

Graeber argumentiert, dass Arbeit zum Selbstzweck avanciert ist. »We have become a civilization based on work - not even "productive work« but work as an end and meaning in itself. ${ }^{14}$

Ähnlich argumentierte bereits vierzig Jahre zuvor Jean Baudrillard. Baudrillard leitet seine medientheoretische Idee einer simulierten Realität (er nennt dies Hyperrealität), um die es später noch gehen wird, nämlich aus einer post-marxistischen Betrachtung moderner Arbeitsmarktentwicklung ab. Schon Marx hätte erkannt, heißt es da, „daß das Kapital dazu tendierte, die Arbeitskraft zu reduzieren, wenn nicht gar vollständig aus seinem Prozeß auszuschalten, und sie durch eine riesige Menge toter Arbeitskraft zu ersetzen. ${ }^{15}$ Anstelle des von Marx erhofften Schwindens der Herrschaft des Kapitals, so argumentiert Baudrillard, hätte sich diese stote Arbeit‘ von der »Produktivkraft« $\mathrm{zu}$ einem »Produkt « gewandelt: $^{16}$

Denn die Arbeit ist keine Kraft mehr, sie ist Zeichen unter Zeichen geworden. [...] Früher bezeichnete die Arbeit die Realität der gesellschaftlichen Produktion, eines gesellschaftlichen Ziels, Reichtum anzuhäufen. [...] Die Arbeit war in jedem Fall von einer Zweckbestimmung durchzogen - [...] Heute gilt das nicht mehr: Die Arbeit ist nicht mehr produktiv, sie ist zur Reproduktion der Arbeitsanweisung geworden. ${ }^{17}$

Daraus folgt die These, Arbeit leiste nichts als die Kreation eines Abbilds ihrer selbst. Sie sei damit eine Funktion des Imaginären: »[S]ie ist nur noch der Spiegel der Gesellschaft, ihr Imaginäres, ihr phantastisches Realitätsprinzip «. ${ }^{18}$

Die Vorstellung, dass auch nur einige Arten von Arbeit zum Selbstzweck avanciert sind, bricht mit allen Arbeitskonzepten, die in den letzten Jahrtausenden erdacht worden sind. Hannah Arendt argumentiert, dass Arbeit

\footnotetext{
13 Graeber: Bullshit Jobs, xvi-xvii.

14 Graeber: Bullshit Jobs, xxiv.

15 Jean Baudrillard: Der Symbolische Tausch und der Tod. Übers. v. Gerd Bergfleth u.a. München: Matthes \& Seitz (1982), 62.

16 Baudrillard: Der Symbolische Tausch und der Tod, 50.

17 Baudrillard: Der Symbolische Tausch und der Tod, $23 \mathrm{f}$.

18 Baudrillard: Der Symbolische Tausch und der Tod, 28.
} 
immer einen konkreten Zweck verfolgt, und zwar »Lebensnotwendigkeiten herbeizuschaffen«. Man arbeitet, um zu überleben: für Essen, Wärme und Unterkunft. Diese Zweckgerichtetheit war in der griechischen Antike zu einem solchen Maße etabliert, dass alle Beschäftigungen als Arbeit galten, "sobald sie nicht um ihrer selbst willen unternommen wurden ${ }^{19}{ }^{19}$ In der Neuzeit sei die Zweckhaftigkeit der Arbeit sogar noch erweitert worden, indem man ihr die Erzeugung eines Produktes nachsagte - eine Anschauung, die Arendt nicht teilt. Ihrer Ansicht nach zeichnet sich die Arbeit dadurch aus, »daß sie nichts objektiv Greifbares hinterläßt, daß das Resultat ihrer Mühe gleich wieder verzehrt wird «. ${ }^{20}$ Tatsächlich sei aber gerade die Vermischung von Arbeiten (homo laborans) und Herstellen (homo faber) einer der Gründe für die große Wertschätzung der Arbeit in der Moderne. Arendt schreibt:

Denn ausschlaggebend für die neuzeitliche Rangerhöhung der Arbeit war gerade ihre »Produktivität«, und Marx' blasphemisch gemeinte Formulierung, daß die Arbeit (und nicht Cott) den Menschen erschaffen habe oder daß die Arbeit (und nicht die Vernunft) ihn von allen anderen Tieren unterscheide, spricht nur in schockierender Radikalität aus, worüber sich die gesamte Neuzeit im Crunde einig war. ${ }^{21}$

Graeber geht davon aus, dass in diesem über Jahrhunderte verfestigten Kontext eine Feststellung wie die, Arbeit sei nicht mehr zweckhaft, und schon gar nicht mehr produktiv, problematisch sein könnte. Selbstzweck kann vor diesem Hintergrund kein anerkanntes Element von Arbeit sein; ihre gesellschaftliche Wertschätzung beruft sich weiterhin auf ihre produktive, und nicht auf ihre selbstreflexive Kraft. Diese Diskrepanz erfordere Graeber zufolge eine Täuschung, insofern man sich als ArbeitnehmerIn dazu gezwungen sähe, so zu tun, als ob die eigene Arbeit tatsächlich sinnhaft ist:

Bullshit jobs are not just jobs that are useless or pernicious; typically, there has to be some degree of pretense and fraud involved as well. The jobholder must feel obliged to pretend that there is, in fact, a good reason, why her job exists, even if, privately, she finds such claims ridiculous. There has to be some kind of gap between pretense and reality. ${ }^{22}$

\footnotetext{
19 Arendt: Vita activa, 101.

20 Arendt: Vita activa, 104.

21 Arendt: Vita activa, $103 \mathrm{f}$.

22 Graeber: Bullshit Jobs, 8.
} 
Aus Graebers Arbeit lassen sich also zwei wichtige Feststellungen ableiten. Zum einen liegt damit ein Hinweis darauf vor, dass nicht nur die Arbeit verschiedentlich in den Bereich der Freizeit (bzw. der Nicht-Arbeit) eindringt, sondern auch andersherum. Die beiden Tätigkeitsbereiche opponieren demnach weit weniger als bisher angenommen. Zum anderen scheint das Eindringen des Nichtstuns in den Bereich der Arbeit einer ähnlichen Maskierungsnotwendigkeit zu unterliegen, wie es anders herum der Fall ist. So wird Arbeit, die man freiwillig in der eigenen Freizeit verrichtet, zum Beispiel als Selbstverwirklichung getarnt, oder als Errungenschaft einer flexiblen Arbeitszeitenregelung. Analog dazu ist es konstitutiv für zwecklose Arbeit, dass sie von denen, die sie verrichten, nicht offen als solche gekennzeichnet wird. Im Gegenteil: sie täuschen anderen, besonders ihren Arbeitgebern, vor, dass ihre Arbeit einen externen Zweck erfüllt, dass sie sinnvoll ist. Ironisch daran ist, dass diese Täuschung selbst, der Arbeit in vielerlei Hinsicht gleich, eine spezialisierte Tätigkeit ist. Annalisa Fischer argumentiert entsprechend, die Fälschung (»forgery« - die ja mit der Täuschung eng verwandt, wenn nicht mit ihr identisch ist), müsse als »autonomous mimetic method of creation« verstanden werden. ${ }^{23}$ Die Tatsache also, dass die topologische Verschiebung des Nichtstuns in den Bereich der Arbeit wiederum mit einer anderen Art von Arbeit verdeckt wird, suggeriert, dass eine zentrale, weil reale, Praxis des Nichtstuns im Bereich der Arbeit stattfindet.

Diese Tendenz, die strikte Opposition von Arbeit und Nichtstun aufzulösen, hat auch literarischen Niederschlag gefunden. In der Literatur über das Nichtstun tauchen immer wieder Texte auf, die eine komplexere und vor allem engere Beziehung zwischen Arbeit und Nichtstun etablieren, und in denen sich diese vermeintlich diametral entgegengesetzten Tätigkeitsformen Nichtstun und Arbeit räumlich, strukturell und semantisch überlagern. Melvilles Bartleby zum Beispiel hört auf als Schreiber zu arbeiten, bleibt aber doch im Büro und wird weiterhin bezahlt. In Robert Musils Der Mann ohne Eigenschaften dreht sich alles um die Arbeit an der >Parallelaktion<, die allerdings nie ein Ergebnis zu produzieren vermag, und deren Arbeitstreffen nicht viel mehr sind als ein genussvoller Salon. ${ }^{24}$ In Kafkas Das Schloss ist K. im

23 Annalisa Fischer: Preface. In: Faking, Forging, Counterfeiting. Discredited Practices at the Margins of Mimesis. Hg. v. Ders. u.a. Bielefeld: transcript (2018), 8.

24 Über das Ziel der >Parallelaktion<heißt es dort bezeichnenderweise: »Es dürfe nicht nur praktisch, es müsse eine Dichtung sein«- womit die Grenze zwischen Arbeit, Politik und Ästhetik verunklart wird. Robert Musil: Der Mann ohne Eigenschaften. Erstes Buch. Hg. v. Adolf Frisé. Reinbek bei Hamburg: Rowohlt (2014), 178. 
Arbeitsauftrag als Landvermesser unterwegs, kann jedoch wegen der Unerreichbarkeit des Verwaltungsapparats nicht wirklich tätig werden - was ihn jedoch nicht davon abhält, weiter an seinem Arbeitsort zu verweilen. ${ }^{25}$ Robert Walsers Romane, die nicht zuletzt wegen ihres Einflusses auf Kafkas Werk bekannt geworden sind, zeigen eine ähnliche, noch weitreichendere Überlagerung, die sich ganz konkret im Bereich des Tuns als solchem ansiedelt, und so die traditionelle Trennung zwischen Arbeit und Muße aufhebt.

Walser tut dies, indem er der Opposition zwischen Arbeit und Nichtstun das vermittelnde Element der Simulation hinzufügt. Diese eröffnet die Möglichkeit zu denken, dass die Arbeit zwar Genuss nur simuliert, diese Simulation aber genussreich sein kann. Arbeit zu simulieren kann also seinerseits Gefallen hervorrufen. Dass Arbeit mit Genuss auf eine verschobene Weise in Verbindung steht, besagt auch Sigmund Freuds These der Triebsublimierung. In Das Unbehagen der Kultur (1930) schreibt er:

Die Möglichkeit, ein starkes Ausmaß libidinöser Komponenten, narzißtische, aggressive, und selbst erotische, auf die Berufsarbeit und auf die mit ihr verknüpften menschlichen Beziehungen zu verschieben, leiht ihr einen Wert, der hinter ihrer Unerläßlichkeit zur Behauptung und Rechtfertigung der Existenz in der Cesellschaft nicht zurücksteht. Besondere Befriedigung vermittelt die Berufstätigkeit, wenn sie eine frei gewählte ist, also bestehende Neigungen, fortgeführte oder konstitutionell verstärkte Triebregungen durch Sublimierung nutzbar zu machen gestattet. ${ }^{26}$

Arbeit, so Freud, hat also das Potential, den Menschen auf ebenso befriedigende Weise zu beschäftigen, wie die Tätigkeiten, die dem Lustprinzip ohne Umschweife folgen. Er impliziert, dass sie diese Triebregungen produktiv umlenken und damit zumindest zeitweilig ersetzen kann. Indem Freud das Angenehme und Lustvolle, dem sich der Mensch normalerweise in der Zeit der Muße widmet, idealtypisch der Arbeit zuschreibt, vollzieht sein Denken

25 Die Aufhebung von Grenzen - zwischen privat und öffentlich, bekannt und unbekannt, Institution und Mensch -, für die Kafkas Werk bekannt ist, gilt auch für das Paar Arbeit/Nicht-Arbeit. Dies wird z.B. durch Funktionsvertauschungen dargestellt: K. will mit dem Beamten Klamm, der ihn über seine Arbeit unterrichten soll, »als Privatmann « sprechen, während er stattdessen mit seiner Wirtin, die ihm nichts über seine Arbeit mitteilen kann, über seine Stelle spricht. Franz Kafka: Das Schloß. Frankfurt a.M.: Fischer (2012), 98.

26 Freud: Das Unbehagen in der Kultur, $46 \mathrm{f}$. 
eine Integration von Muße und Arbeit, die ihre ursprüngliche Trennung aufhebt. Diese konzeptuelle Aufhebung bleibt bis ins 21. Jahrhundert relevant. So schreibt Svenja Flaßpöhler mehr als 80 Jahre später: »Arbeit ist für uns heute nicht mehr nur Mühsal. Wir, die wir unsere Arbeit gern tun und uns in ihr verausgaben auch über das erforderliche Maß hinaus, sind keine Pflichtarbeiter im herkömmlichen Sinne mehr, sondern Genussarbeiter. «7 Die Ansätze von Freud und Flaßpöhler lassen sich beide mit dem Begriff der Simulation in Verbindung bringen. Wenn die Arbeit eine »Befriedigung (Freud), einen "Genuss« (Flaßpöhler) simulieren kann, dann kann auch die Simulation von Arbeit wiederum Befriedigung und Genuss bringen.

27 Svenja Flaßpöhler: Wir Genussarbeiter. Über Freiheit und Zwang in der Leistungsgesellschaft. München: DVA (2011), 9. Flaßpöhler benutzt den Begriff der Simulation nicht, hält aber den Cenuss von Arbeit für kulturell kodiert (eher als in der Tätigkeit selbst angelegt), und deshalb auch für problematisch. 


\section{SIMULATION in Der Gehülfe von Robert Walser, 1907}

Die folgende Lektüre setzt sich mit einem Phänomen auseinander, das-zumindest vordergründig-in einem offensichtlichen Widerspruch zum Nichtstun steht: die Arbeit. In diesem Kapitel wird gezeigt, dass Arbeit auch eine Praxis des Nichtstuns sein kann, und zwar wenn sie nicht einfach gemacht, sondern spielerisch simuliert wird, und sich damit der Muße annähert. Anhand von Robert Walsers Der Gehülfe (1907) wird diese Simulation von Arbeit untersucht, die einem Lustprinzip folgt, dabei allerdings aus gesellschaftlichen Gründen als Arbeit kodiert werden muss.

Im zweiten Roman Robert Walsers, Der Gehülfe, ${ }^{28}$ verschwimmt die in der europäischen Geistesgeschichte so prävalente Trennung von Arbeit und $\mathrm{Mu}$ ße. Die Geschichte erzählt von einem Angestellten, Joseph Marti, der im Haus seines Vorgesetzten, des Ingenieurs Karl Tobler, sowohl arbeitet als auch lebt. Im Haus gibt es zwei Bereiche, die unterschiedlich konnotiert sind: Im Büro wird gearbeitet, im Rest des Hauses ist man frei, müßig zu sein (neben Tobler arbeitet niemand sonst in der Familie). Schon früh im Text kündigt sich allerdings an, dass diese Bereiche nicht ganz strikt voneinander getrennt sind:

Das Toblersche Haus war überdies noch zweiteilig, es bestund aus einem Wohnhaus sowohl wie aus einem Geschäftshaus, und Josephs Pflicht und Schuldigkeit war, beide Sorten Häuser ergründen zu lernen. Wo Familie und Ceschäft so nah beieinander sind, daß sie sich, man möchte sagen, körperlich berühren, kann man das eine nicht gründlich kennen lernen und zugleich das andere übersehen. (C 27)

Die Nähe zweier so unterschiedlicher Räume - einer, in dem das Geschäftliche erledigt wird, der andere, in dem man mit dem Rest der Familie müßig sein darf - ist so groß, dass man von einem In-Eins-Fallen sprechen kann. Aus dieser Nähe geht das paradoxe Motiv des praktischen Nichtstuns in der Form >müßiger Arbeit hervor. Das zeige ich in drei Schritten. Im folgenden, ersten Unterkapitel (Unverhältnismäßigkeiten der Arbeit) erörtere ich, dass der Topos der Arbeit durch eine Reihe von Unverhältnismäßigkeiten umkodiert wird in eine Tätigkeit, die der Muße nähersteht als die Arbeit, die damit eigentlich denotiert werden soll. Im zweiten Unterkapitel (Simulationen) führe 
ich zwei verschiedene Simulationen aus. Zum einen die ostentative, unechte $\mathrm{Mu-}$ ße (Ostentative, unechte Muße), die als Auszeichnung bürgerlicher und aristokratischer Lebensentwürfe die am höchsten wertgeschätzte Tätigkeitsform der Diegese darstellt. Die beiden Protagonisten Tobler und Marti setzen alles daran, so müßig wie möglich zu leben - der erste, um aus Eitelkeit seinen Wohlstand öffentlich zu beweisen, der zweite, um indirekt an diesem Wohlstand teilhaben zu können, den er selbst nie erreichen wird. Um dies zuwege zu bringen, wird Muße in ihrer Auslebung regelrecht inszeniert. Die Arbeit hingegen ist nicht etwa Grundlage dieser Muße, indem sie ihr die finanziellen Mittel bereitstellt, sondern wird stattdessen Teil der Inszenierung. Diese Art der semantischen Aushöhlung des Arbeitsbegriffs wird um ein weiteres Phänomen ergänzt, das ich in Anlehnung an Jean Baudrillard Hyperarbeit nenne: die Arbeit, die Marti als Angestellter notgedrungen ausführen muss, wird in Muße umgewandelt, indem er die Arbeit nicht seinfach so a ausführt, sondern sie ebenfalls inszeniert wie ein Theaterspiel (Hyperarbeit). Die Semantik der Arbeit kommt also nicht tatsächlich, sondern nur als Zeichen zum Ausdruck, welches wiederum für die Legitimierung kostspieligen Müßiggangs funktionalisiert wird: Weil es so aussieht, als ob gearbeitet wird, wird angenommen, dass genug Geld da ist, um Feste zu feiern, gut zu essen usw. Im dritten und letzten Unterkapitel (Gemeinschaft und Illusion) zeige ich, dass sowohl die ostentative Muße als auch die Hyperarbeit mit einer Vorstellung von Gemeinschaft korrespondiert, die Arbeit grundsätzlich ausschließt, aber aufgrund ihrer gesellschaftlich hohen Stellung als Zeichen immer mittragen muss.

Es zeigt sich also insgesamt, dass Arbeit so eng mit der Muße verschränkt ist, dass ihr eigentlicher Referent in den Hintergrund tritt, und zeitweise vollkommen verschwindet. Im Gehülfen ist der Topos der Arbeit, so die These, nur mehr eine vom Nichtstun bzw. der Muße usurpierte Tätigkeitsform, die nur in ihrer Darstellung, als Zeichen, als Spiel, als Theater wichtig ist.

\section{Unverhältnismäßigkeiten der Arbeit}

Der Roman Der Gehülfe von Robert Walser zeichnet sich durch eine merkwürdige Ambivalenz aus: obwohl sein zentrales Thema die Arbeit ist, ${ }^{29}$ scheint es

29 Rüsch schreibt, dem Roman sei die »klare thematische Begrenzung« des Angestelltenverhältnisses gegeben. Lukas Rüsch: Ironie und Herrschaft. Untersuchungen zum Verhältnis von Herr und Knecht in Robert Walsers Roman »Der Cehülfe«. Königstein/Ts.: Forum Academicum (1983), 15. 
dennoch, als würde niemand darin wirklich arbeiten. Zwar ist die Geschichte voll von Arbeitsdarstellungen, doch diese weichen in vielerlei Hinsicht von einer konventionellen Vorstellung von Arbeit ab - es kommt dabei zu einer regelrechten >Aushöhlung< des Arbeitsbegriffs. Diese >Aushöhlung<wird im Folgenden anhand von verschiedenen Unverhältnismäßigkeiten beschrieben, bevor im nächsten Kapitel die Gründe für diese >Aushöhlung und die jeweils zur Anwendung kommenden performativen Strategien als Praktiken des Nichtstuns ausgewiesen werden.

Der Roman beschreibt ein Angestelltenverhältnis - sein Beginn ist durch den Eintritt des Protagonisten Marti in die Stelle des Gehülfen, das Ende durch seinen Stellenaustritt markiert. Anstellung findet er bei dem kürzlich selbstständig gewordenen Ingenieur Tobler, dessen Büro in seinen Familiensitz integriert ist, die »Villa Abendstern« im Dorf Bärenswil. Den Erwerb der Villa und die finanziellen Mittel zur Eröffnung seines Geschäftes verdankt Tobler einer Erbschaft. Als >Gründer < ist Tobler ehrgeizig, auch zeichnet er sich, zumindest vordergründig, durch seine Arbeitsamkeit aus, der eine Reihe von Erfindungen Rechnung trägt: Neben seinen >Hauptwerken $<$ - der ReklameUhr und des Schützenautomaten (ein mit Münzen betriebener Munitionsspender) - zählen zu seinen Geräte-Konzeptionen eine Bohrmaschine (G 141), ein patentierter Krankenstuhl ( $G$ 141), und ein Dampfapparat (G 50). Für die optimale Unterstützung dieser Schaffensfreude wünscht er sich einen geeigneten Mitarbeiter. Einen, wie es Tobler beim ersten Gespräch Marti gegenüber ausdrückt, »Kopf als Angestellten«, eine »Intelligenz, eine selbstständig arbeitende Kraft« (G 10). Da ihm jener, zwar etwas umständlich, aber affirmativ, antwortet: »Was mich betrifft, ich glaube und hoffe des bestimmtesten, daß ich jederzeit dasjenige zu leisten imstande sein werde, was Sie glauben werden, von mir verlangen zu dürfen « (G 10) - so ist hier, auf den ersten Blick, ein fleißiges Arbeitsmilieu umrissen, in welchem ein fordernder Vorgesetzter und dienstwilliger Angestellter zur idealen Übereinkunft kommen. Doch Martis umständliche Versicherung gibt Anlass zur Verwunderung: $\mathrm{Zu}$ viel und $\mathrm{zu}$ komplex wird hier gesprochen, als dass es mit einem einfachen $>\mathrm{Ja}<$, was hier verlangt wird, gleichgesetzt werden könnte. Es handelt sich dabei um das erste Anzeichen einer für diesen Roman charakteristischen semantischen Unverhältnismäßigkeit, die den Topos der Arbeit im Fundament definiert. Der sprachliche Überfluss in der eben zitierten Rede Martis, deren Aussage ungleich kleiner ist als ihr Sprachvolumen, ist nur ein Beispiel für die Reihe von Unverhältnismäßigkeiten, die im Weiteren auch materielle und finanzielle Aspekte der Diegese markiert. 
Toblers Wortwahl - seine Idee vom »Kopf als Angestellten« - enthält einen ersten Hinweis auf die unverhältnismäßige Beschaffenheit seines Unternehmens. Diese ausbuchstabierte Metonymie dreht die übliche Hierarchie vieler Staatsmetaphern (wie Hobbes' Leviathan) um, in denen der Kopf das lenkende Oberhaupt, nicht aber das ausführende Organ ist. Diese Umkehrung ist nicht nur komisch, sondern auch aufschlussreich. Tobler, der sich rasch als ahnungsloser Geschäftsmann herausstellt und »nur einen sehr vagen Begriff von seinem Unternehmen hat «, ${ }^{30}$ sucht nicht nur nach einer Arbeitskraft, sondern nach jemandem, der die Aufgabe des Chefs (also Toblers eigene Aufgabe) übernimmt. Die harmonische Balance, die zunächst zwischen Tobler und Marti herrscht, wird schnell von diesen Unverhältnismäßigkeiten verdrängt. Aus interpretativer Sicht hat dies zwei Konsequenzen: Zum einen wird dadurch die Seriosität der Arbeit in Frage gestellt - darauf gehe ich im Folgenden ein. Zum anderen - ich komme später darauf zurück - deuten diese Unverhältnismäßigkeiten darauf hin, dass die Arbeit im Roman nicht nur unseriös ist, sondern überhaupt nur gespielt, nachgestellt und geschauspielert wird. Denn die Arbeit, die die zwei Protagonisten verrichten, zeigt ein größeres Interesse am (Schau-)Spiel als an den Grundvoraussetzungen eines erfolgreichen Geschäfts wie Leistung und Fleiß. Am Romantext zeigt sich eindeutig, dass innerhalb der Diegese nicht gearbeitet, sondern dass Arbeit inszeniert wird.

Zunächst allerdings zur >Unseriosität , der Arbeit im Roman. Diese zeigt sich schon zu Beginn der Geschichte. In der nachfolgenden Passage wird die Arbeit als dem Hause und Geschäft Tobler unwesentlich etabliert, da während einer Besichtigung des Büros die ungenügende Beschaffenheit des zukünftigen Arbeitsplatzes Martis herausgestellt wird:

Nach dieser Rücksprache wies der Vorgesetzte dem Untergebenen den Platz an, woran er schreiben »könne«. Es war dies ein etwas zu enges, schmales und zu niedrig gebautes Sitzpult mit einer Schieblade, worin sich die Markenkasse und einige kleinere Bücher befanden. Der Tisch, denn nur ein solcher war's und gar kein wahrhaftiges Pult, stand dicht an einem Fenster und an der Gartenerde. (G 10)

Das hervorgehobene »könne«" wird durch die Anführungszeichen modalisiert. Könnte man einen Satz wie >Hier können Sie arbeiten.く ohne weiteres 
als Einweisung verstehen, markiert die Hervorhebung zusätzlich die Abwesenheit eines Imperativs (>Hier müssen Sie arbeiten.८) oder zumindest die feste Annahme eines zukünftigen Tätigseins (>Hier werden Sie arbeiten.८). Vielmehr ist impliziert, dass hier lediglich die Möglichkeit gegeben ist, zu arbeiten - ein Zwang aber besteht nicht. Mit der Beschreibung des zu engen, zu schmalen und zu niedrigen Sitzpults ist sogleich eine weitere Destabilisierung des Arbeits-Topos angedeutet, da das Pult - oder vielmehr der »Tisch« - Marti nicht ausreichend Platz zum Arbeiten bietet. Dem Verweis auf diesen Mangel geht, im Kontrast dazu, eine üppige Mahlzeit vorweg, die ahnen lässt, dass im Hause Tobler andere Bereiche durchaus großzügig ausgestattet sind:

»Setzen Sie sich. Irgendwo, das ist ganz egal. Und essen Sie, bis Sie satt sind. Hier ist Brot. Schneiden Sie soviel davon ab wie Sie wollen. Genieren Sie sich nur nicht. Schenken Sie nur mehrere Tassen ein. Kaffee ist genug da. Und da ist Butter. Die Butter ist zum Zugreifen da, wie Sie sehen. Und da haben Sie auch Konfitüre, falls Sie ein Liebhaber davon sind. Wollen Sie Bratkartoffeln dazu essen?«(G 9)

Im Gegensatz zu dem in alle Richtungen begrenzten Arbeitsplatz sind am Esstisch der Familie scheinbar unzählige Sitzmöglichkeiten gegeben; der dadurch bezeichnete Raum ist so groß, dass die Platzzuweisung nicht genau bestimmt werden muss (»[i]rgendwo«). Zusätzlich zu diesem (konventionell zwar üblichen, aber dennoch stark markierten) Größenunterschied steht den knappen Maßen des Arbeitspultes und den darin befindlichen »kleineren« Büchern die regelrecht maßlose Zurverfügungstellung guter Lebensmittel gegenüber. So deutet sich durch diesen quantitativen Unterschied bereits auf den ersten Seiten des Romans ein Ungleichgewicht zwischen der - die Erzählung vermeintlich bestimmenden - Arbeit auf der einen, und dem (in diesem Fall lukullischen) Genuss auf der anderen Seite an. Die Darstellung des Arbeits-Topos ist hier durch quantitative Unverhältnismäßigkeiten geprägt, die sich gegenseitig überlagern, und so den Status der Arbeit und ihrer Gestalt verunsichern.

So wird die Arbeit im vorangegangenen Beispiel durch die verschiedenen Tisch-Dimensionen und die Größenunterschiede zwischen Arbeitsmaterialien und Viktualien abgewertet, während im Umfeld der Villa bemerkenswert viel gearbeitet wird - nur nicht von Marti und Tobler. Stattdessen werden unzählige Aufträge an die Handwerker und Kauflaute der Umgebung verteilt: für maßgeschneiderte Kleider, die Lieferung von Zigarrenstumpen, die Errich- 
tung einer Feengrotte (d.h. eines extravaganten Gartenunterschlupfes), oder die festliche Ausrichtung des Schweizer Nationalfeiertags am 1. August. Wie die Festvorbereitung für Letzteres zeigt, liegt das Interesse Toblers vielmehr darin, arbeiten zu lassen, als selbst zu arbeiten:

Leute stellten sich plötzlich ein, um an der Dekorierung des Hauses zu helfen, Leute, die einfach mit einmal da waren, und so begann man, überall an Gesimsen und Nischen, an Borden und Fenstern und Gittern Fähnchen zu befestigen und Lampen anzubringen. [...] Wie glücklich sah Tobler aus. Das war etwas für ihn. Für Feste und deren schöne Inszenierung schien er wie kaum ein zweiter geschaffen zu sein. Beständig trat er vors Haus hinaus, um da oder dort noch etwas anzuordnen oder selber einen Draht mit der Zange zu krümmen, eine schief hängende, elektrische Lampe gerade zu drehen oder um bloß dem Ding zuzuschauen. Seine Reklame-Uhr schien er vergessen oder wenigstens verschoben zu haben. (G 60)

Dieser Passus zeigt, ebenso wie das vorangegangene Beispiel, die Prioritätenverteilung Toblers, der das Vergnügen der Anleitung dem Aufwand der Eigen-Arbeit (an der »Reklame-Uhr«) vorzieht. Tobler erscheint hier als Dirigent einer etwas unordentlichen Arbeits-Komposition, in der er nur punktuell optimierende Handgriffe vornimmt, womit parodistisch auf die Adam Smith'sche Metapher der »invisible hand« angespielt wird. Anstatt, wie von Smith spekuliert, durch (1) die Unterstützung heimischer Gewerbe (»support of domestic industry «) (2) seine eigenen wirtschaftlichen Interessen zu verfolgen (»direct that industry that its produce may be of the greatest value«) und damit (3) ungewollt der Gesellschaft im Ganzen, wie von einer unsichtbaren Hand geleitet, $\mathrm{zu}$ Wohlstand zu verhelfen (»promote the public interest«), weichen Toblers Ziele in jedem Fall geringfügig davon $a b:^{31}$ (1) Seine Aufträge

31 Die korrespondierende Stelle in Wealth of Nations (1776) lautet wie folgt: »As every individual, therefore, endeavours as much as he can, both to employ his capital in the support of domestic industry, and so to direct that industry that its produce may be of the greatest value; every individual necessarily labours to render the annual revenue of the society as great as he can. He generally, indeed, neither intends to promote the public interest, nor knows how much he is promoting it. By preferring the support of domestic to that of foreign industry, he intends only his own security; and by directing that industry in such a manner as its produce may be of the greatest value, he intends only his own gain; and he is in this, as in many other cases, led by an invisible hand to promote an end which was no part of his intention. «Smith: Wealth of Nations, 293. 
unterstützen zwar theoretisch die lokale Wirtschaft, doch sein schnell voranschreitender Konkurs lässt diese unbezahlt und schwächt somit Handel und Handwerk im Dorf eher, als sie voranzutreiben; (2) die Vernachlässigung seines Geschäfts kombiniert mit der exorbitanten Verausgabung für ein Feiertagsfest läuft seinen wirtschaftlichen Interessen dezidiert zuwider; und (3) entgegen der Smith'schen These trennt Tobler den Arbeitsdiskurs von der Idee des nationalen Wohlstandes, indem er behauptet, man sei es nicht wert, ein schönes Vaterland zu haben, wenn man »nur noch die ganze Zeitlang auf seinem Beruf und Geldschrank hocke« (G 61). Im zuletzt genannten Umstand ist die ungewöhnliche Assoziation des Festefeierns mit einer Art staatsbürgerlichen Ethik zu beobachten, an der sich der hohe Stellenwert des Müßiggangs in Toblers Weltbild ablesen lässt. So wird auch über Marti gesagt, er sei in der Festnacht »ein Angestellter im Namen des großen, heiligen Vaterlandes« ( $G$ 66)..$^{32}$

Tobler, so stellt sich bald heraus, ist ein miserabler Geschäftsmann. Das zeigt sich im ungleichen Verhältnis seiner Festaufwendungen zu seinen Arbeitsbemühungen. So zum Beispiel beim Aufsetzen einer Zeitungsannonce für potentielle Investoren: er wendet sich dort ganz allgemein an »Kapitalisten!«, und preist mit einem Minimum an Informationen ein »[g]ewinnbringendes, absolut risikofreies Unternehmen « (G 47) an - und demonstriert damit seine Ignoranz gegenüber der Notwendigkeit detaillierten Wissens, der unabdingbaren Voraussetzung für ökonomisches Handeln. An der Ernsthaftigkeit seines Wunsches, dies möge funktionieren, mag nicht zu zweifeln sein, dennoch schimmert auch hier die Unverhältnismäßigkeit seiner Aufwendungen für Spiel und Arbeit durch - immerhin zeigt sich an der zwei

32 Hier ist die Frage des Verhältnisses zwischen Nationalidentität und Tätigkeit interessant. Während das Volksfest als müßige Tätigkeit in der Schweiz um die Jahrhundertwende in einigen Fällen bezüglich der nationalen Identität als bedeutsam wahrgenommen wurde, so zeigt zum Beispiel Matthias Agethen die Bedeutung der Arbeit für die Idee der nationalen Cemeinschaft auf. Matthias Agethen: Vergemeinschaftung, Modernisierung, Verausgabung. Nationalökonomie und Erzählliteratur in der zweiten Hälfte des 19. Jahrhunderts. Göttingen: V\&R unipress (2018), 32. VgI. zum Thema des Volksfestes bei Walser auch Karl Wagner: Herr und Knecht. Robert Walsers Roman »Der Gehülfe«. Wien: Wilhelm Braumüller (1980), 112. Es ist ebenfalls möglich - bedarf allerdings noch einer weiterführenden Untersuchung -, dass diese hier so stark akzentuierte Verbindung zwischen Patriotismus und dem Festefeiern ein parodistischer Fingerzeig auf die leere Prunkhaftigkeit der vergangenen Gründerzeit ist. Vgl. Richard Hamann u. Jost Hermand: Epochen deutscher Kultur von 1870 bis zur Gegenwart. Bd. 2. Naturalismus. München: Nymphenburger Verlagshandlung (1976), gf. 
Sätze langen Annonce, im Vergleich zur Organisation des August-Festes, ein verschwindend geringer Einsatz für das Geschäft.

Eine weitere Unverhältnismäßigkeit des Romans besteht darin, dass Tobler zwar gern andere für sich arbeiten lässt, dass jedoch die Figur Marti eine ambivalente Beziehung zur Arbeit hat. So wie das Sitzpult im Büro eigentlich zu klein zum Arbeiten ist, so fehlt Marti auch das rechte Talent zum Arbeiten. Wiederholt artikuliert sich im Roman seine Schwierigkeit, ein »rechter Mensch zu werden«, was in Martis Fall eine gewisse Unfähigkeit bezeichnet, ein arbeitender Mensch zu bleiben. In der Vergangenheit haben ihm seine fehlenden betriebswirtschaftlichen Kenntnisse die Anstellung in einer Fabrik gekostet (vgl. G 24-26), und seine problematische Beziehung zur Disziplin während des Militärdienstes führte zu mehrtägigem Karzer-Arrest ( $G$ 204), ${ }^{33}$ auch war er vor der Anstellung bei Toblers lange »stellenlos« gewesen (G 15). Die Unterminierung seiner Pflichten deutet nicht nur auf Unfähigkeit hin in diesen Instanzen zeigt sich auch die Skepsis gegenüber einer Überhöhung der Arbeit, die er mit Tobler zu teilen scheint. ${ }^{34}$ Bezüglich seiner Anstellung bei Tobler ergeben sich drei weitere Elemente der Infragestellung des Werts seiner Leistungen.

Erstens wird mehrfach auf Martis ambivalentes Verhältnis zur Arbeit hingewiesen, was auch den starken Zweifel über seine eigene Leistungsfähigkeit miteinschließt. Nach dem eingangs beschriebenem Treffen mit Tobler (er brauche eine »Intelligenz « usw.) beispielsweise, nachdem er in die "geschäftlichen Unternehmungen kurz eingeweiht und mit den Pflichten, die er zu erfüllen hatte, im allgemeinen vertraut gemacht « wurde, überkommt ihn das Gefühl, inadäquat zu sein: »Es ging ihm dabei eigentümlich, er verstand nur die Hälfte. Was denn nur mit ihm sei, dachte er und machte sich Vorwürfe: »Bin ich ein Betrüger, ein Schwätzer? Will ich Herrn Tobler hintergehen?

33 Überhaupt wird der Militärdienst als ein unglückliches Tätigkeitsfeld dargestellt: »Die Diensterfüllungen kamen nicht einem jeden so glatt gelegen, wie vielen andern, die aus den Diensterfüllungen sogar ein Lebens- und Wertgeschäftchen zu machen wußten, indem sie sich auf Staatskosten unterhalten und beköstigen ließen. Manchem riß der Dienst ein unangenehmes Loch in die Laufbahn, [...] nicht einen jeden nahmen dann Kontor und Fabrik oder Werkstätte sogleich wieder auf, sondern er mußte oft lange warten, bis er wieder zu dem Kreis arbeitender, lernender, erwerbender und zielbewußter Menschen gehörte.« ( $($ 210) Damit ist auch Martis Distanzierung vom Sozialismus zu erklären (vgl. Abschnitt »Gemeinschaft und Illusion«später in diesem Kapitel). 
Er verlangt einen >Kopf und ich, ich bin heute absolut kopflos.«(G 12) Martis Umgang mit diesen wiederkehrenden Zweifeln an seiner Eignung gleicht einer Selbstgeißelung - sogar der Verzehr des »ausgezeichnet[en]« Mittagessens, das seiner Einarbeitung folgt, wird sogleich durch seinen Minderwertigkeitskomplex bestraft: »Werde ich diesen unverschämten Appetit durch entsprechende Leistungen rechtfertigen?« $(G$ 12) So ist die Diegese von einer dualen Unwirtschaftlichkeit geprägt: Auf der einen Seite durch die Verschwendung Toblers, die er zwar für rentabel hält, die es aber tatsächlich nicht ist. Auf der anderen Seite durch Martis Unsicherheit, ob sich das Anstellungsverhältnis auch für seinen Arbeitgeber >lohnt‘, ob es ökonomisch ist, obwohl er die grundlegenden Voraussetzungen für diesen Beruf nicht mitzubringen scheint.

Die zweite Infragestellung seines Arbeitswerts ergibt sich wie folgt: Marti zweifelt zwar zu Recht an der Wirtschaftlichkeit des Geschäfts, ist selbst aber nicht der eigentliche Grund für dessen Mängel. Zwar unterlaufen Marti immer wieder kleinere Fehler, dennoch erfüllt er seine Pflichten - zugegeben recht banale, wie Postgänge, Einkäufe, kleinere Schreibarbeiten - im Großen und Ganzen gewissenhaft. Misslingt ihm etwas, so sind auch andere daran schuld; ist Tobler unzufrieden, so liegt es nicht minder an dessen cholerischem Gemüt. Dennoch ist Marti explizit nicht an der Produktion von Gewinn beteiligt. Im Gegenteil gleicht fast jede Aufgabe einem Eintrag in die Soll-Spalte des Tobler'schen Geschäftsbuches: Jedes Mal, wenn er beim Tabakwarenhändler 500 Zigarrenstumpen oder beim Buchbinder Gebrauchsgegenstände besorgt, »indem er's >ins Buch aufschreiben ließ« (G 153) wächst der Schuldenberg Toblers, den Marti auch mit den Anschreiben, in denen er um Fristverlängerungen für die Rückzahlungen bittet, nicht abbauen kann. Dabei zeigt sich auch der Charakter der Schrift und des Schreibens im Roman: Sowohl die von Marti produzierten Schriftstücke als auch die Schrift des Romans selbst bilden allesamt Verschuldung ab, obwohl die diegetische Intention Wohlstandsakkumulation ist - so wird angeschrieben statt gutgeschrieben.

Drittens: Natürlich ist Martis eigene Existenzabsicherung eng mit der Toblers verbunden. Sein Vorgesetzter versorgt ihn zwar - auf Kosten seiner Schuldiger - mit Kost und Logis, zahlt ihm allerdings kein Gehalt (vgl. G 146). Anstatt dessen bezieht er zuweilen nebst einer "gute[n], deutsche[n] Zigarre« lediglich » fünf Mark Taschengeld« (G 32), bleibt aber bis zum Ende seiner Anstellung ohne Entlohnung. Seine Leistungen sind demnach von einem kon- 
kreten, allgemein anerkannten Wert abgekoppelt, was ihre Bedeutung selbstverständlich enorm unterminiert.

Daraus ergibt sich eine dreifache Unterminierung des titelgebenden Arbeitsverhältnisses: (1) Der Angestellte denkt, er kann seine Aufgaben nicht bewältigen, er besitze nicht genug »Kopf«; (2) das schwache Geschäftsmodell seines Arbeitgebers zeigt, dass er gar nicht erfolgreich arbeiten kann, weil jener selbst über zu wenig »Kopf « verfügt; (3) auch beflissene Tätigkeit zahlt sich nicht aus, weil die Entlohnung jeder wirtschaftlichen Basis entbehrt. Weder Tobler noch Marti arbeiten tatsächlich, im Sinne einer Tätigkeit, die materielle Lebensgrundlagen absichert. Die Romangeschichte kreist vielmehr um einen Aktionismus, der die Arbeit als vordergründig wichtigste Tätigkeit der erzählten Welt immer wieder neu entwertet, und damit als Praxis des Nichtstuns erscheint.

Diese Verschränkung von Arbeit und Nichtstun produziert im Romantext zwei weitere Unverhältnismäßigkeiten. Zum einen werden konventionelle und logische Verhältnisse von Arbeit und Muße umgekehrt, sodass es zu einer strukturellen Unverhältnismäßigkeit kommt. Dieses, vor allem Tobler betreffende, Phänomen zeigt sich an der >ostentativen Darstellung von >Muße<, die den gesellschaftlichen Status des arbeits-aversiven Ingenieurs sichern soll, aber nicht kann. In dieser Unverhältnismäßigkeit offenbart sich das fehlende ökonomische Fundament der Muße-Ostentation. Zum anderen kommt es, komplementär zur Muße-Inszenierung, zu einer hyperbolischen Zurschaustellung von Arbeitsabläufen, die jedoch kein Produkt herstellen oder Gewinn produzieren. Dabei handelt es sich um eine semiotische Unverhältnismäßigkeit insofern hier das Zeichen >Arbeit von seinem kulturell bestimmten Referenten abgetrennt wird - ein Phänomen, das ich in Anlehnung an die Theorie Baudrillards >Hyperarbeit< nenne.

\section{Simulationen}

Die im vorherigen Abschnitt aufgezeigten Unverhältnismäßigkeiten werfen eine Reihe von Fragen auf. Wenn Arbeit im Roman kein ernstzunehmender Wert ist, warum steht sie dann überhaupt im Vordergrund der Geschichte? Die Antwort liegt in der Bedeutung von Arbeit für die soziale Identität der Protagonisten. Als Variation von >Herr $<$ und >Knecht< repräsentieren sie, wie Michel Serres treffend sagt, die gesellschaftlichen Klassen, zu denen sie gehö- 
ren. ${ }^{35}$ In Walsers Roman treffen zwei Männer aufeinander, die einer höheren Klasse angehören wollen als die, in der sie sich befinden. Tobler gehört dem Bürgertum an, während er eigentlich zum Adelsstand gehören möchte. Marti ist Angestellter, und befindet sich damit in einer mittleren Position zwischen Arbeiterklasse und Bürgertum, will aber von ersterer nichts wissen und sich stattdessen in ein bürgerliches Leben einfügen. Beide Protagonisten leiden unter dem gleichen Problem: ihre tatsächliche gesellschaftliche Stellung erfordert von ihnen, dass sie arbeiten, während in ihrer erwünschten Stellung die Arbeit auf andere Personen ausgelagert oder - zumindest teilweise - von materiellem Luxus und freier Zeit ersetzt werden könnte. Die folgenden zwei Unterkapitel zeigen, dass beide Protagonisten dieselbe Lösung für ihr Problem wählen: sie versuchen, die Anforderungen der Realität und die Verheißungen ihrer Wünsche miteinander zu integrieren, d.h. gleichzeitig zu bewältigen bzw. zu genießen. Dabei ist die Arbeit meist das Medium, während eigentlich Muße im Vordergrund steht: Sie simulieren Arbeit, um ihre Muße zu rechtfertigen; gelegentlich machen sie sogar ihre Arbeit zu einem müßigen Spiel. Die Romangeschichte offenbart jedoch die Kurzlebigkeit dieser Praktiken des Nichtstuns, indem sie das Fehlen ihres ökonomischen Fundaments durch den Niedergang von Toblers Geschäft in den Vordergrund rückt.

\section{Ostentative, unechte Muße}

Eine signifikante Eigenschaft Toblers ist sein verdrehtes Verständnis des Verhältnisses, in dem Muße und Arbeit zueinander stehen. Bevor er sich durch eine Erbschaft selbstständig machen und eine bürgerliche Identität annehmen konnte, war er, ebenso wie Marti, einfacher Angestellter. Innerhalb dieser Beschäftigungsklasse ist das Verhältnis zwischen Arbeit und Muße klar definiert: sie halten sich die Waage. Oder, in den Worten Hannah Arendts: »Der Segen der Arbeit ist, daß Mühsal und Lohn einander [...] [im] regelmä-

35 Michel Serres zufolge ist das Verhältnis zwischen Herr und Knecht immer ein repräsentatives, in dem auch das Machtverhältnis zwischen den Klassen gespiegelt wird. Es sei »grundfalsch, das Verhältnis zwischen Herr und Knecht als ein Verhältnis zwischen zwei einzelnen darzustellen[...]; ihr Verhältnis ist zumindest das zwischen dem einen und den vielen, wenn nicht gar das zwischen dem einen und der Quasi-Totalität«. Michel Serres: Der Parasit. Übers. v. Michael Bischoff. Frankfurt a.M.: Suhrkamp (1987), 9of. Walsers Cehülfe weicht von diesem Machtverhältnis nur insofern ab, als Marti und Tobler ähnliche Aufstiegssehnsüchte haben, was sie einander annähert und so die übliche Distanz zwischen Herr und Knecht wesentlich mindert. 
Bigen Rhythmus folgen «. ${ }^{36}$ Tobler, nun ins Bürgertum aufgestiegen, verwirft dieses Verhältnis in Folge und widmet sich verstärkt nicht der mühseligen Arbeit, sondern fast ausschließlich dem genussvollen Müßiggang. Er unterliegt damit einem konzeptionellen Missverständnis, denn das Bürgertum, obwohl es in der Klassengesellschaft eine Stufe über den Angestellten steht, zeichnet sich nicht weniger durch die Ausführung von Arbeit aus. »The creation of a culture of work has been, arguably, the greatest symbolic achievement of the bourgeoisie as a class«, wie Franco Moretti postuliert. ${ }^{37}$ Tobler, vielleicht aus dem Minderwertigkeitskomplex des 'nur< Neureichen heraus, ignoriert dies, scheut sich vor der Arbeit und schwelgt im Luxus - als wäre er nicht nur eine, sondern gleich zwei Gesellschaftsstufen aufgestiegen und lebe nun als Aristokrat.

Für die Aristokratie gilt nämlich ein anderes Verhältnis zwischen Muße und Arbeit: Die Muße ist von der Arbeit losgelöst - zumindest von der eigenen Arbeit; der Wohlstand ermöglicht das Ausleben von Muße ohne vorherige Erarbeitung der dafür notwendigen finanziellen Mittel. Dieser Zusammenhang wird 1899 - nur wenige Jahre vor der Veröffentlichung des Gehülfen von Thorstein Veblen beschrieben. Die »superior pecuniary class «, ${ }^{38}$ erklärt dieser, zeichnet sich durch die Ablehnung von Arbeit zugunsten von Muße aus: "Abstention from labour is the conventional evidence of wealth and is therefore the conventional mark of social standing; and this insistence on the meritoriousness of wealth leads to a more strenuous insistence on leisure. « 39 Tobler hat also offensichtlich ein Abgrenzungsproblem, da er das Leben eines Adeligen mit den Mitteln eines nicht-arbeitenden Bürgers zu bestreiten versucht. Der Roman spiegelt mit dieser fälschlichen Identifikation ein historisches Phänomen, das Wolfgang Lepenies bereits ins 18. Jahrhundert datiert: eine Spannung zwischen den Lebensnotwendigkeiten und Wünschen eines neu entstandenen Bürgertums. Es »stoßen gerade im achtzehnten Jahrhundert, das - in Deutschland - den ökonomischen und politischen Aufstieg des Bürgertums einleitet, der Wunsch und die Sehnsucht, den Adel nachzuahmen, mit der Notwendigkeit zusammen, zu arbeiten, um erst einmal die Grundlagen für hinreichende gesellschaftliche »Entlastung« zu schaffen«. ${ }^{40}$

36 Arendt: Vita activa, 126.

37 Franco Moretti: The Bourgeois. Between History and Literature. London: Verso (2014), 43.

38 Thorstein Veblen: The Theory of the Leisure Class. An Economic Study of Institutions. New York: Random House (1934), 36.

39 Veblen: Leisure Class, 41.

40 Lepenies: Melancholie und Gesellschaft, 70. 
Tobler widmet sich nicht der Grundlagenschaffung für die müßige »Entlastung«, sondern der Nachahmung des Adels. Für diese Priorisierung, und die Bequemlichkeit eines finanziell abgesicherten Lebens im Allgemeinen, steht im Roman regelmäßig der Topos des Spiels ein. So berichtet der Erzähler von der Mode des Kartenspielens, die bei den "sogenannten besseren« Frauen angekommen sei, "nämlich bei solchen, die nicht gar so streng zu arbeiten brauchten, den Tag über, und das gerade sind ja die Besseren.« ( $G$ 48) Für Marti wird in der Anstellung bei Tobler das »recht[e]« Leben ganz von einem arbeitsamen in ein freizeitliches umgewertet - »Joseph müsse das Kartenspiel auch lernen, hieß es, es sei einer kein rechter Mann, wenn er dieses Spiel nicht verstehe. ( $G$ 87, Herv. meine)

Doch das Spiel ist nicht der einzige Ausdruck, den die von Veblen postulierte leisure annimmt, denn der Adelsstand zeichnet sich nicht nur durch ein bequemliches Leben aus, sondern auch durch soziales Ansehen, das er außerhalb der Berufsarbeit erlangen und erhalten muss. Zu diesem Zweck übernimmt der finanziell abgesicherte Adlige unter anderem politische Aufgaben: »The normal and characteristic occupations of the [leisure] class [...] are government, war, sports and devout observances. ${ }^{41}$ Tobler würde auch dies gern tun, doch es ist ihm nicht möglich. Als neu Hinzugezogener ist es ihm nicht erlaubt, sich im Dorf politisch zu engagieren, um seinen pseudo-aristokratischen Status zu performieren. ${ }^{42}$ Zudem wird die Gegend um Bärenswil vom handwerklichen Stand bewohnt, der den kapitalistischen Erfinder für suspekt hält. Das zeigt sich unter anderem daran, dass die Bewohner des Dorfes »an die gesunde Basis seiner technischen Unternehmungen nicht so recht glauben wollen« (G 71). So kann Tobler durch seine tatsächliche bürgerliche Stellung und die Beschäftigung, der er in ihrem Rahmen nachgeht, kein Ansehen erreichen. Die aristokratische Stellung, die er gerne einnehmen würde, kann er auch nicht durch politisches Handeln performieren, da ihn das Gesetz vorerst davon abhält. Er nutzt schließlich andere Möglichkeiten,

41 Veblen: Leisure Class, 40. Herv. meine.

42 Diese Beschränkung war in der Bundesverfassung von 1848 (Art. 41-42) festgelegt. Die Niederlassung in einem neuen Kanton (wie der Kauf der Villa Abendstern sie wahrscheinlich erforderte) zog einen Ausschluss von der Partizipation in Cemeindeangelegenheiten für bis zu zwei Jahren mit sich. Vgl. Regula Argast: Staatsbürgerschaft und Nation. Ausschließung und Integration in der Schweiz 1848-1933. Göttingen: Vandenhoeck \& Ruprecht (2007), 106. Lokale Politik erforderte eine langjährige lokale Verwurzelung, die Tobler als Zugezogener nicht aufweisen kann. 
um seinem Geltungsdrang nachzukommen: das Zurschaustellen von Muße, und die Auslagerung von Arbeit an andere.

Es ist charakteristisch für die Art des Wohlstandes, die Tobler zu imitieren versucht, diesen nicht im Geheimen zu genießen, sondern ihn nach außen zu präsentieren. »In order to gain and to hold the esteem of men it is not sufficient merely to possess wealth or power[...] «, so Veblen, »[t]he wealth or power must be put in evidence, for esteem is awarded only on evidence. « ${ }^{43} \mathrm{Er}$ prägte hierfür den Terminus der conspicuous leisure, einer auffällig-ostentativen Muße, die unübersehbar ist. ${ }^{44}$ Diese Sichtbarkeit wird auf zwei Arten produziert: Zum einen durch die Zurschaustellung des eigenen Müßiggangs. So veranstaltet Tobler, wie im ersten Abschnitt bereits beschrieben, zum Beispiel gleich zu Beginn des Romans ein großes Fest, um den Schweizer Nationalfeiertag am 1. August zu feiern. Ein zentrales Anliegen Toblers bei diesem Fest (sowie all den anderen, die er im Verlauf der Geschichte organisiert) ist es, gesehen zu werden. Der Höhepunkt dieses Festes ist ein großes Feuerwerk, bei dem es Tobler wichtig ist, früher und mehr »Raketen«, »Feuerteufel« und »Glutschlangen« in den Himmel zu schicken als »[d]ie im Dorf« (G 66), die er als »Schlappschwänze« bezeichnet (G 67). Ähnlich aufwendig lässt Tobler, schon längst in einer finanziell schwierigen Lage, für »tausendfünfhundert Mark, eine Summe, wie man sie in der Villa Tobler schon seit langer Zeit nicht mehr beisammen gesehen hatte ( $G$ 172), eine sogenannte Feengrotte in seinem Garten errichten - eine Art aufwendig produzierte Laube (»ein höhlenartiges, mit Zement ausgeschlagenes und tapeziertes Ding«, G 172). Ihre Fertigstellung nimmt er zum Anlass, erneut ein Fest zu feiern, bei dem er seinen letzten Wein auftischt, und mit aller Mühe versucht, sich nicht anmerken zu lassen, dass ihm das Geld ausgeht (vgl. G 173-175).

Neben diesen Festen, den häufigen Wirtshausbesuchen und Freizeitaktivitäten seiner Familie, mit denen Tobler ostentativ seinen Reichtum und Erfolg zur Schau stellen will, verfolgt er noch eine weitere Strategie: Er zeigt ebenfalls ostentativ, dass er es sich leisten kann, andere Leute für sich arbeiten zu lassen. Auch das gehört Veblen zufolge zum angemessenen Verhalten eines "gentleman of leisure«: »he should find some means of putting in evidence the leisure that is not spent in the sight of the spectators", zum Beispiel durch »the labour performed for the gentleman of leisure by handi-

43 Veblen: Leisure Class, 36. Herv. meine.

44 Vgl. Veblen: Leisure Class, 35-67. 
craftsmen and servants in his employ ${ }^{45}$ Die ostentative Muße des Adels, die Tobler nachzuahmen versucht, ist also eng mit der Auslagerung von Arbeit an Dritte verbunden - an den Gärtner, die Köchin, die Handwerker, die die Feengrotte errichten und die Helfer, die beim Augustfest bei der »Dekorierung des Hauses (G 60) mitwirken. So zeigt Tobler nicht nur Reichtum und unproduktiven Zeitvertreib, wie es dem Adelsstand angemessen ist, sondern funktionalisiert auch die Kontrolle fremder Arbeitskraft für die Darstellung seiner Überlegenheit. Die Ausrichtung des Feiertagsfests und der Bau der pompösen Feengrotte tragen seiner Verfügungsgewalt über Arbeitskräfte, d.h. seiner Macht, Rechnung. Er schart arbeitende Helfer um sich, um »sein maßloses Geltungsbedürfnis zu befriedigen, um nach außen einen Reichtum zur Schau zu stellen, über den er in Wirklichkeit gar nicht verfügt. « ${ }^{46}$ Die Einstellung des Gehülfen ist ebenfalls ein wichtiger Teil dieser indirekten MußeDarstellung durch die Arbeit anderer. Deswegen wird er auch bei scheinbar jeder Gelegenheit »in seiner Eigenschaft als »mein Angestellter« den Leuten vorgestellt« (G 54). ${ }^{47}$ Seine Anwesenheit bestätigt den mehrfach erwähnten »wohlhabenden Eindruck« (G 104) der Villa Abendstern.

Doch Martis Anstellung soll nicht nur Toblers Wunsch nach einer aristokratischen Auslagerung von Arbeit befriedigen, und damit der indirekten Darstellung von Muße dienen. Dieser wünscht sich nämlich den Respekt der Gemeinschaft im Dorf Bärsenswil, die zwar nicht aus Aristokraten besteht, allerdings einen durch Arbeit erwirtschafteten Reichtum aufweist. »In diesen Gegenden«, so heißt es im Roman, ist »der stolze Gewerbefleiß wirklich zum alten Land- und Stadtadel zu zählen« (G 71). Durch die Anstellung Martis will Tobler nicht nur Reichtum beweisen, sondern auch, dass sein Geschäft in Sachen »Gewerbefleiß« (G 71) der Dorfgemeinschaft in nichts nachsteht. Marti erfüllt so eine Doppelfunktion: Er attestiert nicht nur einen pseudoaristokratischen Wohlstand, sondern auch den Fleiß seines Vorgesetzten als Vertreter des Bürgertums. Dieses Attest stellt sich jedoch, wie bereits angekündigt, als Fälschung heraus. Denn diesem »wohlhabenden Eindruck« (s.o., $G$ 104), der durch Toblers exorbitante Aufwendungen hervorgebracht wird, fehlt »die gesunde ökonomische Basis, die bürgerlicher Repräsentation eigen

45 Veblen: Leisure Class, 43f. Herv. meine.

46 Rüsch: Ironie und Herrschaft, 34.

47 In Marti hat Tobler eben - in seiner Eigenschaft als mäßiger, aber stolz präsentierter Angestellter, wie Marti selbst sagt - einen zwar »nicht ganz tüchtigen, wohl aber brauchbaren und schmiegsamen Menschen« gefunden ( $C$ 201). 
ist. $\aleph^{48}$ Die Erfolge des Tobler'schen Unternehmens bleiben nämlich gänzlich aus und stehen damit in frappantem Gegensatz zu seiner behaupteten Geschäftigkeit. Den Respekt der anderen Bürger des Dorfes verdient er dadurch nicht. Auch wenn seine ostentative Muße für sie zeitweilig Zerstreuung bedeutet, so spricht sich doch schnell herum, dass er seine Rechnungen nicht begleichen kann. Da sie ihn noch dazu selbst nie arbeiten sehen, halten sie ihn für »prahlerisch« und »lächerlich « ( $G$ 174), für eine Fälschung eben. Toblers Muße-Inszenierungen - vom Fest bis zum Angestellten - sind Ausgaben, für die es an Einnahmen fehlt, sodass sich notgedrungen ein wirtschaftliches Ungleichgewicht ergibt: Es fließt stets mehr Kapital aus dem als in den Haushalt. Die Aufrechterhaltung dieses Ungleichgewichts anstelle seiner Behebung auf der auch die dekadente Entwicklung des Romans gründet, der über die rasant anwachsenden Schulden der zahlungsunfähigen Familie das Scheitern des Ingenieursunternehmens erzählt -zeigt, wie wichtig die conspicuous leisure für Toblers Selbstbild ist. Für dieses ökonomisch desaströse Festhalten an einer Muße, die man sich nicht leisten kann, hat Veblen ebenfalls einen Begriff gefunden: er nennt sie »spurious« leasure, eine gefälschte, unechte Muße. ${ }^{49}$ Während in Veblens Sicht dieser Fehler nur dem abgestiegenen Adel unterläuft, der sich nicht von seinen lange gepflegten Gewohnheiten und Werten trennen kann, zeigt der Roman anhand von Tobler, dass dies auch jemandem passieren kann, der nie zum Adel gehört hat, sondern sich nur an seine Stelle wünscht.

Durch die Figur Tobler wird im Roman eine Abweichung von dem Modell des homo oeconomicus generiert: Er ist kein idealtypischer »Unternehmer, der alle Märkte und Börsen im Kopf vereinigt und sämtliche Entschlüsse an diesem Wissen orientiert; der vollständig informierte, durch und durch rationale Mensch $«,{ }^{50}$ sondern ein Unternehmer, der maßlos Geschäftserträge öffentlich zur Schau stellt, die er sich wünscht, tatsächlich aber gar nicht verbucht. Die Idee des homo oeconomicus ist zwar von Ralf Dahrendorf (wie von anderen) als unrealistisch verworfen worden, ${ }^{51}$ dennoch ist es eine Tat-

\footnotetext{
48 Wagner: Herr und Knecht, 90.

49 Veblen: Leisure Class, 42.

50 Ralf Dahrendorf: Homo Sociologicus. Wiesbaden: VS Verlag für Sozialwissenschaften (2006), 19.

51 Dahrendorf spricht vom homo oeconomicus nicht als realistischem Menschenbild, sondern als einem »höchst problematische[n] «, dem »wir in der Wirklichkeit unserer Alltagserfahrung kaum je begegnen dürften.« Dahrendorf: Homo Sociologicus, 19. Auch Bauer verweist auf die Fiktionalität und Simplifizierung, die dem Modell des vollkom-
} 
sache, dass das ihm zugeschriebene wirtschaftliche Verhalten in vielerlei Hinsicht dem der bürgerlichen Gesellschaft des frühen 20. Jahrhunderts eignet. So verhält sich der Bürger Tobler durch die Priorisierung und Ostentation der Muße nicht-klassenkonform - er ist vielmehr ein ökonomischer Parasit, wie ihn Michel Serres beschreibt. ${ }^{52}$ Anstatt selbst zu produzieren, lebt er von dem, was von anderen produziert wird. Das schließt eine gewisse Form des Reichtums zwar nicht aus - bei »den Parasiten ist der Tisch stets gedeckt«, schreibt Serres - ${ }^{53}$ jedoch ist dieser durch das ewige Abhängigkeitsverhältnis nicht nur prekär, sondern eben auch endlich. Diese Endlichkeit wird zudem durch Toblers Verausgabung verstärkt, die Georges Bataille zufolge den reichen Klassen vorbehalten ist. Die bürgerliche Gesellschaft, der Tobler ja tatsächlich angehört, tendiere eigentlich dazu, ihren Reichtum für sich zu behalten und bewahren - sie zwinge sich »in bezug auf die Verausgabung zur Sterilität«, »ihrer buchführenden Vernunft gemäß «. ${ }^{54}$ Nur die reichen Klassen seien zur Verausgabung, d.h. zum Luxus, geneigt, ja, geradezu verpflichtet: »der ostentative Verlust [ist] überall mit dem Reichtum verbunden als seine eigentliche Funktion.« Der soziale Rang, der mit dem Reichtum einhergeht, so Bataille, sei immer geknüpft an die Bedingung, „daß das Vermögen teilweise für unproduktive soziale Ausgaben geopfert wird wie Feste, Schauspiele und Spiele. ${ }^{55}$ Am Topos der Muße im Roman zeigt sich also eine Inkongruenz zwischen dem, was Tobler ist, und dem, was er sein möchte. Diese klassenspezifische Inkongruenz zwingt ihn geradezu zu dem, was bis hierhin als Praxis des Nichtstuns beleuchtet wurde: der Wunsch, sozial anerkannt zu werden, bringt ihn dazu, etwas darzustellen, was er nicht sein kann. Er simuliert eine Muße, an deren Stelle eigentlich Arbeit stehen muss, weil seine gesellschaftliche Stellung ihm das Nichtstun nicht erlaubt.

\section{Hyperarbeit}

Der Gehilfe Toblers, Joseph Marti, unterliegt im Prinzip demselben parasitären Problem wie sein Vorgesetzter. Veblen hat in seiner Studie die »servants«

men rational wirtschaftenden Menschen zugrunde liegen. Manuel Bauer: Ökonomische Menschen. Literarische Wirtschaftsanthropologie des 19. Jahrhunderts. Cöttingen: V\&R unipress (2016), 26-28.

52 Serres: Der Parasit, 14.

53 Serres: Der Parasit, 13.

54 Georges Bataille: Die Aufhebung der Ökonomie. Übers. v. Cerd Bergfleth. München: Rogner und Bernhard (1975), 24.

55 Bataille: Die Aufhebung der Ökonomie, 21. 
der "gentleman of leisure « nicht viel beachtet, ${ }^{56}$ doch auch sie sind nicht dagegen immun, Muße nicht nur als angenehm, sondern auch als Merkmal einer hohen sozialen Stellung zu verstehen. Die Literaturgeschichte zeigt eine Neigung des Dieners, die Verhaltensweisen ihrer Herren zu übernehmen das gilt auch und vor allem für deren Nichtstun. ${ }^{57}$ Roland Barthes vermerkte in seiner Vorlesung »Comment vivre ensemble« aus den 1970er-Jahren zum Verhältnis zwischen Herren und Bediensteten, es handele sich dabei um eine "Struktur der Nachbildung, Nachahmung, Anamorphose, Verdoppelung: die Herren kehren in den Domestiken wieder, jedoch in unvollständiger Gestalt, als Karikatur. ${ }^{58}$ Und tatsächlich schätzt Marti die Muße nicht weniger wert als Tobler; man könnte sogar sagen, er wird von Tobler diesbezüglich in die Schule genommen - die Einschätzung der Toblers, Marti würde nur durch das Kartenspiel ein »rechter Mann« (G 87) werden, bezeugt dies.

Dass Marti Lust und Freude an dieser parasitären ${ }^{59}$ Muße empfindet, liegt nicht nur daran, dass er durch seine Stellung als Gehilfe Glück vornehmlich durch Muße finden kann, wie Nietzsche in seinen Überlegungen zur Herren- und Sklavenmoral vermutet. Zum Thema Agens innerhalb dieser Hierarchie führt Nietzsche aus, dass die aktive Tat nur den Herren zuzuordnen ist, während dem Unterlegenden (dem »Sklaven«) eine passive Verhaltensweise eignet, er sei höchstens im reaktiven Sinne >tätlichく. Das Tätigsein würde bei den Herren »mit Notwendigkeit ins Glück hineingerechnet«, im Gegensatz dazu trete das Glück »auf der Stufe der Ohnmächtigen [...] wesentlich als Narkose, Betäubung, Ruhe, Frieden, »Sabbat«, Gemüts-Ausspannung und Gliederstrecken, kurz p a s s i v i s c h auf «. ${ }^{60}$ Glaubt man dieser These in Bezug auf Marti, so ließe sich seine generelle Affinität zur Muße (die »umfangreiche Portion Ruhe«, mit der er geboren wurde, G 55) aus seiner Stellung heraus erklären. Doch der Roman bildet eine kompliziertere Konstellation ab: Martis Muße-Genuss ist sicher durch seine gesellschaftlich niedrige Stellung als Angestellter determiniert, doch im selben Zug verehrt er die Arbeit, die das Bürgertum notwendigerweise definiert. Denn er erkennt, dass »work has

56 Veblen: Leisure Class, $43 \mathrm{f}$.

57 Man denke an Sachar in Contscharows Oblomow, oder Soliman, den Diener Arnheims in Musils Der Mann ohne Eigenschaften.

58 Roland Barthes: Wie zusammen leben, 138.

59 Vgl. neben Serres' Der Parasit auch Bauer: Ökonomische Menschen, 274.

60 Friedrich Nietzsche: Sämtliche Werke. Bd. VII. Zur Cenealogie der Moral. Stuttgart: Kröner (1964), 265. 
become the new principle of legitimation of social power «, ${ }^{61}$ wie Franco Moretti über die Bourgeoisie sagt.

Er sieht, zumindest zu Beginn des Romans, dass Tobler als arbeitender, bürgerlicher Ingenieur im Dorf Respekt entgegengebracht wird. Er selbst bewundert ihn schließlich auch - für seine »stattliche Figur« (G 15), sein »stattliches Haus« $(G$ 27) und seine "Bürgersfrau von echtester Abstammung« ( $G$ 28). Diese soziale Anerkennung färbt auf ihn als seinen Mitarbeiter ab. Er will arbeiten und etwas leisten, um sich diese Annehmlichkeiten ehrlich zu verdienen. »Dulde du nur keine Trägheit in dir«, sagt er sich selbst, »[m]an spaziert nicht immer, man leistet auch einmal etwas« (G 141). Diese Verehrung der Arbeit, die ihm den Verbleib in einem bürgerlichen Haus garantiert, mischt sich im Roman allerdings mit einer Nachahmung der aristokratischen spurious leisure, die sein Chef Tobler ihm vorlebt. In dessen inszenierter MußeIllusion ist die Unterstützung des Ingenieur-Büros durch den Gehilfen eigentlich nicht nötig, weil es dort aufgrund von Toblers eigener Untätigkeit gar keine Arbeit zu verrichten gibt. Die Hilfe, die der Gehilfe geben soll, ist nicht selten selbst müßig - zum Beispiel, als Tobler ihn auffordert, er »soll kommen und ihm helfen, den Rest Rotwein noch auszutrinken« ( $G 46)$.

So sieht sich Marti einerseits mit der Erwartung konfrontiert, irgendetwas zu arbeiten, um Toblers gewünschte Außenwirkung zu erzielen, während er gleichzeitig die Möglichkeit hat, seine Zeit ebenfalls müßig zu gestalten. Das verleitet ihn dazu, Arbeit und Muße auch selbstständig zusammenzulegen: Angenehme Tätigkeiten wie das gelegentliche Rasensprengen oder das Begleiten der Familie auf Gondelfahrten (G 49-54) legt er sich als Arbeit aus. Die wenige Arbeit hingegen, die im Büro zu erledigen ist, betrachtet er als Spiel. So findet er in jedem Fall einen Weg, stets sowohl zu arbeiten als auch müßig zu sein. Darin bewahrheitet sich die von Betiel Wasihun über Jakob von Gunten getroffene Feststellung auch in Bezug auf den Gehülfen: »ein vollkommener Diener muss die Kunst des Schauspiels beherrschen. ${ }^{62}$ Er wird implizit nur deshalb beschäftigt, um denselben Schwindel wie Tobler zu treiben.

\footnotetext{
61 Moretti: The Bourgeois, 30.

62 Betiel Wasihun: Nichtstun und dennoch Haltung beobachten - Robert Walser und Samuel Beckett. In: Muße-Faulheit-Nichtstun: Fehlende und fehlschlagende Handlungen in der russischen und europäischen Literatur seit der Aufklärung. Hg. v. Sonja Koroliov u.a. Frankfurt a.M.: Peter Lang (2017), 223.
} 
Analog zur Toblers > unechter $<$ Muße ist Martis Arbeit keine >wirkliche Arbeit. Auch sie wird nicht reinfach so vollzogen, sondern inszeniert, d.h. sie ist durch den Modus des als ob charakterisiert. Darin zeigt sich die semiotische Unverhältnismäßigkeit im Topos der Arbeit: Das >Lebenserhaltende in der Semantik des Arbeitsbegriffs kommt nicht tatsächlich zur Geltung (in Form von Lohn bzw. Gewinn), sondern wird nur als Zeichen verwendet, das den Anschein eines wohlhabenden, funktionierenden Haushalts aufrechterhalten und weitere luxuriöse Ausgaben legitimieren soll. Normalerweise stehen, wie oben bereits ausgeführt, in der Klasse der Angestellten wie auch im Bürgertum Arbeit und Muße in einem bestimmten Verhältnis zueinander: ersteres bedingt letztes, und diese Kausalität kann nicht aufgehoben werden. Ebenso wenig können diese beiden in einer Tätigkeit zusammenfallen; die gängigen Arbeitstheorien, so schreibt Arendt, würden »nahezu einstimmig die Arbeit im Gegensatz zum Spiel definieren «. ${ }^{63}$ Während diese beiden Tätigkeitsformen - Arbeit und Spiel bzw. Muße - normalerweise entweder Antipoden darstellen oder mindestens durch eine abwechselnde Abfolge ihre Gleichzeitigkeit ausgeschlossen ist, fallen Arbeit und Spiel in diesem Roman jedoch zusammen. Dieser Zusammenfall ist zum Beispiel durch die semantische Überlagerung von Schreib- und Küchentisch angezeigt, deren unverhältnismäßige Größe ich eingangs beschrieben habe. ${ }^{64}$ Nach der Eingewöhnungsphase Martis im Hause Toblers (nach ungefähr einem Drittel der Erzählung) wird sein Sonntag wie folgt beschrieben:

Später ging er ins Bureau hinunter. Es war ja nicht viel zu machen da unten, aber er setzte sich trotzdem, angezogen von einem beinahe lieblichen Gewohnheitsgefühl, an den Schreibtisch, der wie ein Küchentisch aussah, und korrespondierte. Ach, es war heute das reine Tändeln mit der sonst so ernsthaften Feder. Das Wort »telephonische Unterredung « erschien ihm ebenso sonntäglich geputzt wie das Wetter und die Welt draußen. Die Redewendung »und gestatte ich mir« war blau wie der See zu Füßen der Villa Tobler, und das »hochachtungsvoll« am Schluss des Schreibens schien nach Kaffee, Sonne und Kirschenmarmelade zu duften. (G 90, Herv. meine)

In dieser Passage wird die gegenseitige Abhängigkeit von Arbeit und Muße deutlich. Für jemanden in Martis Stellung kann es ideell keinen Genuss ohne Arbeit geben. Doch die alltägliche Arbeit in Toblers Büro ist ja bereits durch

63 Arendt: Vita activa, 151.

64 Vgl. den Abschnitt »Unverhältnismäßigkeiten der Arbeit« in diesem Kapitel. 
einen häufigen Genuss definiert, zum Beispiel wenn Marti zum Kartenspielen angehalten wird, die Familie mit einer Gondel über den See fährt (vgl. G 49f.), oder wenn er Zigarrenstumpen bei der Arbeit raucht. Im Umkehrschluss wird deshalb seine freie Zeit mit der Arbeit verschränkt: Er geht auch am Sonntag ins Büro, empfindet die vormals als unterschiedlich groß beschriebenen Tische (zum Arbeiten respektive Dinieren) als einander ähnlich, und verbindet synästhetisch den Anblick seiner Schreibarbeit mit dem Duft eines GartenFrühstücks.

Diese Verschränkung von Arbeit und Muße als Praxis des Nichtstuns erklärt auch die Festigkeit der gegenseitigen Bindung zwischen Tobler und Marti trotz der kuriosen Ausklammerung der Lohn- und Leistungsthematik. Als Parasiten in gegenseitiger Abhängigkeit profitieren sie vielfach voneinander. Marti genießt die Verhaltensweise, die sich aus der Überlagerung von Arbeit und Nichtstun ergibt, und die man Arbeits-Spiel nennen könnte - d.h. nicht $\mathrm{zu}$ arbeiten, sondern sich so zu verhalten, als ob er arbeiten würde, während er tatsächlich nichts tut. Im Romantext ist dieses Spiel zu erkennen, weil die Reflexionen über die Arbeit, ebenso wie die Konditionen ihrer Verrichtung, mehr Erzählraum einnehmen als die Arbeit selbst:

Im Bureau! Erst ein bißchen auf und ab gehen, das gehörte doch schließlich zur Sache, so fing einer immer an, wenn er zu arbeiten sich vornahm. Gehörte Joseph zu den Menschen, die mit Ausschnaufen ein Geschäft beginnen und erst nach Beendigung desselben, das heißt, nach halber Beendigung energisch werden, das heißt wiederum, nur dazu energisch, um sich über irgendeinen billigen Cenuß herzumachen? Er zündete langsam einen der wohlbekannten Stumpen an, die ihm jeweilen den Gedanken an die beginnende Arbeit so sehr versüßten, und rauchte drauf los wie das Mitglied eines Rauchklubs. Und dann setzte er sich wieder einmal an seinen Schreibtisch, und fing an, sich nützlich zu erweisen. (G 144, Herv. meine)

Der Beginn »Im Bureau! « wirkt wie eine Regieanweisung, und verleiht der Situation eine theatrale Note. Wie diese Passage zeigt, ist der Eintritt in das Büro bzw. auf die Bühne nicht mit einem sofortigen Beginn der Arbeit verbunden, sondern mit einem Gedankenmonolog, der sich liest wie die Überlegungen eines Schauspielers, der nach einer Geste sucht, die am besten den Beginn der Arbeit konnotiert. Bemerkenswert ist bereits hier, dass Marti nur auf ein Zeichen (= das Rauchen) fokussiert, was auf die Arbeit verweist, nicht jedoch auf die Arbeit selbst, von der er selbst nur ungenau spricht. Die grammati- 
sche Unbestimmtheit der Versicherung, es gehöre »zur Sache« (welcher?), und dass »einer" (wer?) immer so anfange, »wenn er zu arbeiten sich vornahm", markiert eine Distanz zur Arbeit. Der Gedankengang offenbart, dass Martis Verhalten Gehabe ist, und mehr mit der Darstellung von Arbeit beschäftigt als mit der Arbeit selbst.

Dieses Phänomen wird in fast jeder Szene, die im Büro spielt, irgendwie abgewandelt erzählt. Marti scheint immer nach passenden Gesten oder den richtigen Worten zu suchen, um sich selbst als genuin arbeitend darzustellen. Wenn Tobler etwas sagt, wovon er nichts versteht, so antwortet er dennoch: »natürlich! als sei er bereits jahrelang im Geschäft tätig gewesen«, weil er es für »passend« ( $G$ 62) hält. Der Text offenbart immer wieder, dass Martis Verhalten im Büro zu großen Teilen dem Kalkül folgt, arbeitend auszusehen. Im Roman werden so Zeichen geschaffen, die zwar auf Arbeit und ein florierendes Geschäft verweisen, ohne diese innerhalb der Diegese jedoch tatsächlich >ehrlich zu bezeichnen. Die Gleichung lautet also so: Die Kombination von a) Abneigung gegen die Arbeit (von sowohl Marti als auch Tobler) mit b) der Unterminierung der geleisteten Arbeit Martis ergibt nicht einfach c) eine Negation, sondern eher d) eine Simulation derselben. Im Modus des Spiels simulieren beide Arbeit, indem sie kompensatorische, prokrastinierende Aktivitäten theatralisch aus- bzw. auf führen. ${ }^{65}$

65 Es gibt bereits ähnliche Argumentationslinien bei Jochen Greven und Karl Wagner, allerdings unter der (mir unverständlichen) Ausklammerung der Arbeit. Wagner schreibt zum Beispiel, Marti würde mit »seinen körperlichen Aktivitäten« wie dem Rasensprengen sein »Versagen« und »seine permanente Kopflosigkeit« kompensieren. Wagner räumt zwar ein, dass Marti den "Sinn der Büroarbeit gar nie begriffen hat und auch gar nicht begreifen konnte«, lastet das aber der fehlenden Intelligenz Martis an, anstatt darin eine strukturelle Beschaffenheit der Arbeit zu sehen, die sich eben grundlegend durch müßige Handlungen definiert. Wagner: Herr und Knecht, 44f. Creven hingegen argumentiert ganz anders, und zwar sieht er in den Kompensationeninsbesondere in den Hausarbeiten, dem Rasensprengen sowie dem Schwimmen und Spazierengehen - eine Flucht vor der eigenen, mit Vorwürfen überladenen Selbstreflexion und den Versuch, sich so »wirklich mit seiner Umwelt [dem »real Seienden «] zu verbinden «. Jochen Greven: Existenz, Welt und reines Sein im Werk Robert Walsers. Versuch zur Bestimmung von Crundstrukturen. Paderborn: Fink (2009), 57. Greven hat insofern Recht als Marti das Schauspiel der hyperbolischen und anderen Verhaltensweisen im Büro für Tätigkeiten unterbricht, die dem Funktionieren des Haushaltes dienen (und durch die Entlohnung der Haushälterin Pauline auch mehr geschätzt werden), und damit dem tatsächlichen Wunsch, etwas zu leisten, Ausdruck verleihen. Wiederholt wird versucht, die Illusion (des scheinbaren Leistens) zur Realität (eines wirklichen Leistens) 
Mit dieser >Theatralität ` geht eine Statusveränderung einher, d.h. es wird für den Bereich der Handlung vollzogen, was John L. Austin in Bezug auf Sprechakte einen Szenenwechsel (»sea-change«) nennen würde: Marti agiert wie ein Schauspieler, und das, was er tut, ist »in a peculiar way hollow or void if said by an actor on the stage ${ }^{66}$ Austin beschreibt den Modus solcher Inszenierungen als erkennbar unernst und parasitär, in stetiger Abhängigkeit von ihrem Wirt - der seigentlichen Bedeutung der gesprochenen Worte oder vollzogenen Handlungen. Umgekehrt beschreibt auch Michel Serres in Le parasite das Parasitäre als »Störung der Kommunikation«, die nur aufgrund ihrer Abhängigkeit zur Kommunikation (ohne die sie nicht wahrnehmbar wäre) existiert. ${ }^{67}$ Die Verschränkung von veränderter, entrückter Kommunikation und dem Parasitären nähert diese Art des theatralen Verhaltens und Sprechens, die man bei Marti beobachten kann, auch prinzipiell der Figur des Nichtstuers (/Müßiggängers/Taugenichts/Faulpelzes etc.) an. Von dieser behauptet Manuel Bauer nämlich, sie habe »zwangsläufig eine Stellung zum Wirtschaftsleben, die sich aber zumeist nur ex negativo erschließt [...] und in vielen Fällen in parasitärem Egoismus mündet «. ${ }^{68}$

Marti arbeitet, wie gesagt, eben nicht selbst, lebt aber davon, dass andere dies tun (so die Händler, die Tobler unbezahlt weiter beliefern und die Familie ernähren) - und ebenso verhält es sich mit seiner >Performance<. Martis Handlung in diesem Passus verweist lediglich auf das Ritual des Arbeitsbeginns, ohne dass sich tatsächliche Arbeit anschließt. Man erfährt nämlich nicht, wie sich Marti »nützlich« erweist, sondern nur vom Eintreten Toblers, der, selbst nicht arbeitend, auch Marti von der Arbeit ablenkt und so erneut seine Unfähigkeit zur Geschäftsführung beweist. Beschwingt von vornächtlicher Zecherei trifft er spät im Büro ein, verwickelt Marti in ein Gespräch dazu noch über sein bisher ausbleibendes Gehalt - , nur um ihm Faulheit vorzuwerfen:

So zeigen Sie auch, Teufel noch einmal, daß Sie imstande sind, etwas zu leisten. Bis jetzt habe ich noch wenig davon bemerkt. Ein großes Maul macht noch keine nennenswerte Leistung, haben Sie das verstanden? (G 145)

umzukehren, doch dafür fehlt der Organisation (des Ceschäfts und der Familie) die wirtschaftliche Grundlage. vard University in 1955. Oxford: Clarendon Press (1962), 22.

67 Serres: Der Parasit, 11.

68 Bauer: Ökonomische Menschen, 273. 
Trotz des offensichtlichen Widerspruchs, der zwischen Toblers Benehmen und seinen Erwartungen besteht, benennt er dennoch die programmatische Losung der Gehülfen-Geschichte - das "große Maul« ohne »nennenswerte Leistung«. Oder eben »Zeichen« ohne »Referenten«, analog zu Baudrillards Vorstellung einer simulierten Realität. »La simulation n'est plus [...] d'un être référentiel, d'une substance« erklärt dieser; »[e]lle est la génération par les modèles d'un réel sans origine ni réalité : hyperréel.«"9 Unter dieser »Hyperrealität« versteht Baudrillard die Kopie von etwas Realem, was von der >tatsächlichen Realität losgelöst ist, und als >neue Realität wahrgenommen wird. ${ }^{70}$ Diese Theorie verkompliziert unweigerlich die Idee eines Wahrheitsgehalts, denn die Kopie bezeichnet >Uneigentliches`, ist also in gewisser Weise Lüge. Es sei damit »unmöglich geworden«, führt er an anderer Stelle aus, »daß ein Sinn zurückverfolgt werden kann. ${ }^{71}$ Ganz ähnlich verhält es sich mit der Unbestimmtheit des »so fing einer immer an, wenn er zu arbeiten sich vornahm«: Marti imitiert hier nicht direkt eine Arbeit, sondern die Vorstellung einer Arbeit, deren Ursprung vollkommen unklar ist. Somit kann die Sinnhaftigkeit des Auf-und-Ab-Gehens als Arbeitsbeginn nicht (mehr) nachvollzogen werden. Auch Tobler agiert so; er habe, wie seine Frau kurz vor dem Bankrott sagt, "nur den Ton dieser pfiffigen und schlauen [Geschäfts-]Leute angenommen, das äußere Betragen, die Manieren, nicht aber zugleich die Fähigkeiten.«(G 246, Herv. meine)

Die im Roman beschriebenen shyperrealen Handlungen, die Arbeit auf diese Art und Weise simulieren, können analog dazu als Hyperarbeit verstanden werden. Das hier entwickelte Konzept der Hyperarbeit ist im Kern bereits bei Baudrillard angelegt, da er den Simulationsmechanismus - wie im einleitenden Abschnitt dieses Kapitels bereits beschrieben wurde - überhaupt erst aus einer post-marxistischen Betrachtung moderner Arbeitsmarktentwicklung herleitet: Anstelle des von Marx erhofften Schwindens der Herrschaft des Kapitals hätte sich Arbeit von einer »Produktivkraft« zu einem »Produkt«

69 Jean Baudrillard: Simulacres et simulation. Paris: Calilée (1981), 10.

70 Fred Jameson führt als Beispiel für das Simulacrum - der individuelle Baustein der allgemeinen Hyperrealität - den Photorealismus der 1960er und 70er Jahre an, deren Bilder (z.B. jene von Chuck Close) keine >Realien<, sondern Photographien als Referenten hatten. Die reale Welt, so Jameson, ist »transformed into images, of which the »realism« of the photorealist painting is now the simulacrum«. Fredric Jameson: Postmodernism, or, The Cultural Logic of Late Capitalism. Durham: Duke UP (1991), 31. (1990), 9. 
gewandelt, es ist nur mehr ein "Zeichen unter Zeichen ${ }^{72}{ }^{72}$ Daraus folgt die in bezeichnender Weise auf Walsers Gehülfen von 1907 ebenso wie auf den frühen Postmoderne-Diskurs Baudrillards zutreffende - These, Arbeit leiste nichts als die Kreation eines Abbilds ihrer selbst. Sie sei damit eine Funktion des Imaginären: »[S]ie ist nur noch der Spiegel der Gesellschaft, ihr Imaginäres, ihr phantastisches Realitätsprinzip «. ${ }^{73}$

Natürlich gelten im Roman andere Prämissen als die von Baudrillard beschriebenen: Der Grund für die Hyperarbeit liegt weder in der gesteigerten Effektivität industrieller Produktion, die menschliche Arbeitskraft abwertet, noch liegt ihr Ziel in der politischen Drosselung gesellschaftlicher Kräfte, die durch >tote Arbeit< (oder »bullshit jobs « in David Graebers Terminologie) ${ }^{74}$ beschäftigt und ermüdet werden. Im Gehülfen überspielt Hyperarbeit zunächst lediglich ein dysfunktionales System (Toblers Unternehmen), indem sie einen Abstand zu diesem System schafft und sich darin theatralisch produziert. Eben wegen dieser >Entrücktheit< und der gesellschaftlichen Kritik, die sie auch impliziert, sollte man die Hyperarbeit, die aus dieser Simulation entsteht, nicht nur als simple Kopie betrachten. Die Simulation als Verfahren im Roman kopiert die Arbeit immerhin nicht perfekt, sondern zeigt Abweichungen und Störungen auf, die sich mit normaler Arbeit gar nicht vereinbaren lassen. Dabei entsteht nicht nur eine zweite, andere Arbeit, sondern eine Arbeit anderer Ordnung. Die Simulation als parasitäre Kommunikation im Sinne Serres' bringt also ein neues Phänomen hervor, sie ist eine »Störung, welche die Ordnung verändert«: »Die neue Ordnung erscheint durch den Parasiten, der die Nachricht stört. Er verwirrt die alte Reihe, die Folge, die Botschaft, und er komponiert eine neue. ${ }^{75}$

Diese Hyperarbeit, die normale Arbeit simuliert und sich dabei von ihr entfernt, zeigt Ambivalenzen innerhalb des Gegensatzes zwischen Muße und Arbeit im Gehülfen auf. Das obige Beispiel illustriert die angenehme Seite der Hyperarbeit: Das `Simulations-Spiek eröffnet den Arbeitsdiskurs, und legitimiert damit zum Beispiel den Genuss des Rauchens, da die Zigarren Toblers Anweisung gemäß nur »während der Arbeit« (G 13, Herv. meine) geraucht wer-

\footnotetext{
72 Baudrillard: Der Symbolische Tausch, 50, 23.

73 Baudrillard: Der Symbolische Tausch, 28.

74 Graeber: Bullshit Jobs, xvi.

75 Serres: Der Parasit, $282 f$.
} 
den dürfen. ${ }^{76}$ Dieser positiv konnotierte Aspekt wird im Laufe der Erzählung immer wieder aufgegriffen, besonders gehäuft aber zu Beginn des Arbeitsverhältnisses. Da bereitet Marti das Spielen der Rolle des Angestellten, trotz der Ahnung eines Problems, noch große Freude:

Was hatte es zu bedeuten, daß zwei Wechsel zu je vierhundert Mark nicht bezahlt wurden. Man schob den Verfalltag dieser Billetts einfach auf einen Monat hinaus, es war sogar riesig nett für Joseph, an den Aussteller der Akzepte schreiben zu dürfen: »Bitte, haben Sie noch Ceduld. Die Finanzierung meiner Patente läßt nur noch kurze Zeit auf sich warten. Bis dahin wird es mir möglich geworden sein, die fälligen Verpflichtungen prompt einzulösen.«

Er hatte mehrere solcher Briefe zu schreiben, und er freute sich über die Leichtigkeit, mit der er den gesamten kaufmännischen Stil beherrschte. ( $G$ 31f.)

Das Simulationsphänomen ist allerdings nicht ausschließlich lustvoll, insofern es nicht selten bei der Überbrückung heikler Situationen hilft, so zum Beispiel bei der Interaktion Martis mit einem der vielen Gläubiger Toblers. Dort zeichnet sich die Arbeitssimulation Martis, der den Gläubigern nichts entgegenzusetzen hat, durch überschüssige Bewegungen aus, die diese Unfähigkeit kaschieren sollen:

Der Kassenbote der Bärenswiler Sparbank trat ein.

»Natürlich ein Wechsel«, dachte Joseph. Er stand von seinem Platz auf, nahm das Formular in die Hand, besah es von allen Seiten, schüttelte es hin und her, prüfte es auf das Genaueste, machte ein zugleich nachdenkliches und wichtiges Gesicht und sagte dann zu dem Boten, es sei gut, man werde vorbeikommen.

Der Mann nahm den Wechsel wieder zu sich und ging, Joseph nahm sogleich die Feder zur Hand, um brieflich den Aussteller des Wechsels zu ersuchen, noch einen Monat Geduld zu haben. (C 74)

Das Entgegennehmen des Wechsels könnte natürlich auch durch einen einzigen Handgriff erledigt werden. Stattdessen vollzieht er, wie schon Tobler, die Darstellung großer Gesten, die überschüssig wirken, weil ihre Funktion

76 Dazu gehört ebenso die im Zitat vorgenommene Abwertung der Gewohnheit, sich erst nach der Arbeit »irgendeine[m] billigen Genuß« als Belohnung hinzugeben, anstatt sich vor der Arbeit dadurch auf sie einzustimmen. 
uneindeutig ist. In diesem Fall sind sie verantwortlich für die Aufrechterhaltung der Illusion, Toblers Geschäft sei einerseits liquide - was das Aufkommen eines Wechsels unwahrscheinlich oder zumindest selten macht - und andererseits ökonomisch, d.h. in beiden Fällen hochmotiviert zur genauesten Prüfung eines Wechsels. Die Übertriebenheit dieser Gesten - das Besehen, das Hin-und-Her-Schütteln, das genauste Prüfen, die mehrdeutige Mimik produziert eine Komik, an der sich die Verschleierungs-Taktik abzeichnet, die den Misserfolg Toblers verdecken soll. Beide Anstrengungen Martis, die Begleichung der Schuld um jeweils einen Monat zu verschieben, verweisen auf leere Referenten: Eine erfolgreiche, finanziell uneingeschränkte Zukunft. Ohne ernstzunehmende Hoffnungsträger ist dies nichts als eine Wunschvorstellung, und der Verweis darauf wird damit gleichsam Simulation.

Die logische Konsequenz aus einer konstanten Arbeits-Simulation, die sich im Text durchgängig nachweisen lässt, ist Baudrillard zufolge die Gleichsetzung der Arbeit mit ihrem Gegenteil, der Nicht-Arbeit bzw. dem Nichtstun. Da die Arbeit »keine Kraft« mehr ist, sondern nur »Zeichen unter Zeichen«, lässt sie sich »mit der Nicht-Arbeit, der Freizeit vertauschen, mit der sie völlig äquivalent ist, sie läßt sich verwandeln in alle anderen Teilbereiche des Alltagslebens«; sie ist, »wie die meisten Tätigkeiten, nur noch ein Ensemble von Beschreibungsvorgängen. « ${ }^{77}$ Dies bedeutet aber gerade nicht die erwartete Ausklammerung der Leistungsthematik, wie sie sich in dem oben beschriebenen Diskurs über Martis Leistungsunfähigkeit andeutet.

Tatsächlich ist Marti selbst sehr auf die Qualität seiner Leistung bedacht. Nur bezieht sich dieser Fokus mehr auf die Abbildung von Leistungsbildern, als auf das tatsächliche Leisten. Dabei gilt in analoger Weise, was Bourdieu und Passeron über Studenten schreiben, die sich den Habitus des Intellektuellen aneignen, ohne bereits selbst intellektuell zu arbeiten: Gerade die »Verrichtung von Tätigkeiten « in der »Art des >So-tun-als-ob« ist »eine der Bedingungen für die Übernahme der Werte«, die die intellektuelle Welt beherrschen - oder eben die Welt der Arbeit. ${ }^{78}$ Auch das So-tun-als-ob funktioniert

77 Baudrillard: Der Symbolische Tausch, 23.

78 Pierre Bourdieu u. Jean-Claude Passeron: Die Erben. Studenten, Bildung und Kultur. Übers. v. Stephan Egger u.a. Konstanz: UVK (2007), 62. Die Autoren gehen soweit, das »Erlernen « eines solchen »Spiels und doppelten Spiels« als »Vorbereitung auf den Beruf « zu betrachten, da so relevante »Techniken« erworben werden können (ebd.) nicht zu vergessen ist dabei, dass Bourdieu und Passeron in dieser Schrift die Universität als eine Institution kritisieren, die Scheinhaftigkeit belohnt. 
im Gehülfen im Rahmen der von Weber postulierten protestantischen Leistungsethik. ${ }^{79}$ Der springende Punkt in Webers Verständnis der Arbeitsethik sei nämlich, so Matthew Finkin, dass sich diese Ethik unabhängig davon entwickelt, worin diese Arbeit besteht. »Manche Arbeit ist für sich schon Belohnung, « schreibt er weiter, »Spiel oder Freude für die, die sie leisten ${ }^{80}{ }^{80}$ Man kann es auch leicht verschoben betrachten: eine Arbeit, die nur zum Spiel gemacht wird, kann ebenso belohnend sein und zum Mehr-Leisten anregen wie eine sechte< Arbeit.

\section{Gemeinschaft und Illusion}

Die im vorherigen Kapitel beschriebenen Simulationen - die ostentative, unechte Muße ebenso wie die Hyperarbeit - sind im Roman ohne Zweifel als >lustvolk konnotiert. Sie bereiten den Protagonisten Freude, weil sie luxuriöse Verausgabung und müßiges Schauspiel involvieren, und weil sie einen Lebensstandard vortäuschen, den sie sich eigentlich nicht leisten können. Für Marti hat dieses schöne Leben auch einen großen sozialen Wert, denn er findet in der Familie Tobler eine bedeutsame Bindung und ein Zugehörigkeitsgefühl, das ihm lange abhandengekommen war. Er ist, so sagt er selbst, »erschreckt [...] darüber, daß ihm einfachere und näherliegende Beziehungen vollständig mangeln« ( $G$ 93). Die Familie Tobler gleicht diesen Mangel aus. Die These, Marti würde die unbezahlte Anstellung im Tausch für eine quasiMitgliedschaft bei der Familie Tobler hinnehmen, ist in der Walser-Forschung bereits etabliert. ${ }^{81}$ Diese versteht, in Anlehnung an eine Passage vom Beginn des Romans, Marti als >Heimatlosen<, der in der Familie Tobler eine neue Heimat zu finden sucht. ${ }^{82}$ Tatsächlich werden in Marti durch die Familie Tobler

79 Werner Deich stellt nach der Auswertung von fast 70 Angestelltenromanen aus dem deutschsprachigen Raum um die Jahrhundertwende (den Cehülfen inbegriffen) fest, dass sich diese Berufsgruppe in ihrer literarischen Darstellung durch ein stark ausgeprägtes Leistungs- und Pflichtbewusstsein auszeichnet. Vgl. Werner Deich: Der Angestellte im Roman. Zur Sozialgeschichte des Handlungsgehilfen um 1900. Köln: Grote (1974), 176-178.

80 Matthew Finkin: Arbeit, Arbeitsrecht und Wissenschaft. Webers Frage. Übers. v. Rudolf Buschmann. In: Arbeit und Recht 55 (12), 2007, 410.

81 Vgl. Rüsch: Ironie und Herrschaft, 128f.; Wagner: Herr und Knecht, $33 \mathrm{f}$.

82 So werden die Blicke der Kinder, als sie Marti das erste Mal sehen, wie folgt beschrieben: »Diese ungeniert fragenden und forschenden Blicke entmutigten ihn. Solche Blicke erinnern eben an die Angeflogenheit an etwas Fremdes, an die Behäbigkeit dieses Fremden, das für sich eine Heimat darstellt, und an die Heimatlosigkeit desjenigen, 
Erinnerungen an sein eigenes »bürgerliche[s] Familienhaus« (G 102) geweckt. Auch seine Familie befand sich in einer »Misere« (G 102) - in was für einer, weiß man nicht. Auch seine Mutter ist, wie Frau Tobler, häufig krank und schwach, aber dennoch gütig und schön (vgl. G 101f. und G 227f.). Doch Marti assoziiert seine Familie, trotz dieser Probleme, vor allem mit der Muße und dem Spiel aus seiner Kindheit, die er bei der Familie Tobler wieder aufnehmen kann. Im Roman wird Martis Kindheit nur wenige Male erwähnt, immer jedoch in Momenten der Muße und des Genusses. Das erste Mal erinnert sich Marti, wenige Tage nach seinem Einzug bei den Toblers, beim Trinken des Nachmittagskaffees, eines seiner liebsten Genussmittel: »Warum denke ich an $\mathrm{zu}$ Hause, an die Kindheit, wenn ich diesen sonderbaren Kaffee trinke?« ( $G$ 29). Eine weitere, bezeichnende Erinnerung überkommt Marti ebenfalls in einem besonders von Muße bestimmten Moment. An einem Sonntagsspaziergang nach einem Bad im See legt er sich in eine moosbewachsene Schlucht und tagträumt von einem ähnlichen Tag seiner Jugendzeit: »Es war auch an einem Sommersonntag[...]. Die Kinder waren vorausgesprungen, Spiele erfindend und betreibend, hinterher kamen die Eltern « (G 100, Herv. meine).

Der Protagonist Marti verbindet seine Kindheit mit dem Spiel, und nimmt die Toblers als Ersatzfamilie her, weil er sich dort fast vollständig dem Spiel widmen darf, sei es am Kartentisch oder im Büro. Die Muße, die Marti bei Toblers genießt, ermöglicht diese gedankliche Verbindung auch erst. So schreibt Gaston Bachelard über die Träumerei, sie entstehe aus der Muße, in der man nicht denken muss: »c'est moi qui suis heureux de rêver ma rêverie, c'est moi qui suis heureux du loisir où je n'ai plus la tâche de penser «. ${ }^{83}$ Die zumindest zeitweilige Befreiung von Anstrengungen, die Marti im Hause Tobler zum ersten Mal in seiner elenden Karriere erlebt, führt ihn direkt in seine Kindheit zurück - »'enfance [...], l'archétype du bonheur simple«, schreibt Bachelard -, ${ }^{84}$ in der er ähnlich befreit war.

Die Vorstellung einer idealen Gemeinschaft, die sich in der Geschichte an der Figur Marti abbildet, ist die einer im Spiel und Muße begriffenen Familie. Diese Art der Gemeinschaft wird im Roman in einen scharfen Kontrast zu

der nun so dasitzt und die Pflicht hat, sich möglichst rasch und guten Willens in das behagliche fremde Bild heimatlich einzufügen.« $(G 13)$

83 Gaston Bachelard: La Poétique de la Rêverie. Paris: Presses Universitaires de France (1960), 20. Herv. meine. Bachelard möchte in dieser Passage auf die Bewusstheit des Tagträumens hinaus.

84 Bachelard: La Poétique de la Rêverie, 106. 
solchen Gemeinschaftsformen gesetzt, deren Fundament die Arbeit ist. Diese andere Art der Gemeinschaft wird durch den Sozialismus versinnbildlicht, den Marti ideologisch entschieden ablehnt. ${ }^{85}$ Diese Ablehnung bezieht sich auf die sozialistische Idealisierung von Arbeit, auf die sich seiner Meinung nach keine Gemeinschaft aufbauen lässt. Die Idee einer sozialistischen Arbeitergemeinschaft wird im Roman im Rahmen eines Wiedersehens zwischen Marti und seiner Jugendfreundin Klara demontiert. Beide hätten zwar einmal an den Sozialismus geglaubt, heißt es dort, hätten diesen Glauben jedoch aufgegeben, da diese Bewegung nichts als Schall und Rauch gewesen sei:

Es war damals eine sonderbare Welt und Zeit gewesen. Unter dem Namen »Sozialismus« hatte sich, einer üppigen Schlingpflanze ähnlich, eine zugleich befremdende und anheimelnde Idee in die Köpfe und um die Körper der Menschen[...] geworfen[...]. Die Arbeiter und ihre Interessen nahm man damals allgemein mehr geräuschvoll als ernst. Es wurden häufig Umzüge veranstaltet, an deren Spitze auch Frauen schritten, blutigrote oder schwarze Fahnen hoch in der Luft daherschwenkend. Was nur immer mit den Verhältnissen und Ordnungen der Welt unzufrieden war, schloß sich dieser leidenschaftlichen Gedanken- und Gefühlsbewegung hoffnungsvoll und zufrieden an, und was die Abenteuerlust einer gewissen Sorte von Schreibern, Krakeelmachern und Schwätzern vermochte, die Bewegung einesteils prahlerisch hochzuheben und anderteils in die Cemeinheit des Tages herabzuziehen, das bemerkten die Feinde dieses »Cedankens« mit einer Art vergnüglichen Hohnlächeln. Die ganze Welt, Europa und die übrigen Erdteile, so hieß es damals unter den jungen und halbreifen Geistern, verbände und vereinige diese Idee zu einer fröhlichen Menschenversammlung, aber nur wer arbeite, sei berechtigt usw.

Joseph und Klara waren damals ganz und gar von diesem vielleicht edlen und schönen Feuer ergriffen worden[...]. Sie liebten beide, wie es damals Mode war, die »Menschheit«. (G 134f., Herv. meine)

85 Der Sozialismus war in der Schweiz des späten 19. und frühen 20. Jahrhunderts sowieso von einer gemäßigteren Ausprägung und insgesamt weniger populär als im Rest Europas. Die Gründe für diese historische Entwicklung lagen in der Stärke und Etabliertheit der repräsentativen Demokratie, die Interessenverbünde von Arbeitern zwar nicht überflüssig, aber zumindest weniger notwendig machten. Vgl. Volker Reinhardt: Ceschichte der Schweiz. München: Beck (2014), $104 \mathrm{f}$. 
Die Hervorhebung der Worte, die auf den Sozialismus oder seine Kerngedanken hinweisen (»Sozialismus«", »Gedankens«", »Menschheit«) markiert ein zitierendes, d.h. distanziertes Sprechen, welches das sozialistische Programm nicht ernsthaft in Erwägung zieht. Dies zeigt sich ebenfalls in der skeptischen Formulierung des Erzählers, bei der Leidenschaft für diese Idee handele es sich um ein nur »vielleicht edle[s] und schöne[s] Feuer« (s.o., Herv. meine). Damit wird die emphatische Gutheißung dieses Projekts, ganz abseits von der Legitimität der sozialistischen Agenda, in Frage gestellt. Als Grund für diese Infragestellung dient die Scheinhaftigkeit der Bewegung: die Anteilnahme an den Lebensumständen der ArbeiterInnen sei nur oberflächlich, denn sie werde »mehr geräuschvoll als ernst« genommen. Der Sozialismus postuliere ein anderes, überhöhendes Verständnis von Arbeit, wodurch er es verfehle, die Lebensrealität der Arbeitenden zu erfassen. Er stellt somit lediglich eine Illusion dar.

Die sozialistische Ideologie fungiert hier demnach nicht weniger als hyperreales Zeichen als die Arbeit Martis, beide sind eine >Waise ohne Referenten. Die »Krakeelmacher[...] und Schwätzer[...]« heben die Bewegung prahlerisch hoch - ganz getreu der oben erwähnten Tobler'schen Losung >großes Maul ohne Leistungく ( $G$ 145). Den Grund dafür, dass sowohl Klara als auch Marti den "Sozialismus« letztlich ablehnen, lernt man implizit aus diesem Verweis auf die >Falschheit< seiner Proklamationen. Die, so kann man annehmen, die Arbeit als Art der Mitgliedschaftskondition anpreisen und damit auch idealisieren, ohne jedoch die unverhältnismäßigen Belastungen der Arbeit wirklich beseitigen zu wollen. Klaras Äußerung, sie sei »jetzt öfters unwohl und unfähig, das Erwerbsleben, das sie so lange geführt habe, zu ertragen«, und dass sie »zu schwach geworden« sei (G 137), ist wichtigstes Ausschlusskriterium für ihre Mitwirkung im »Sozialismus« «, denn »nur wer arbeite, sei berechtigt, usw«. Zudem habe sie, als alleinerziehende Mutter, ihre Aufmerksamkeit von der Masse auf das Einzelwesen gerichtet bzw. richten müssen: »[v]on da an liebte sie nicht mehr die »Menschheit«, sondern sie betete ihr Kind an.« (G 136)

Die oben zitierte Passage zeigt klar den Standpunkt Martis zum Thema Gemeinschaft: Die Teilnahme und -habe an der Gemeinschaft darf nicht an die Voraussetzung der Arbeit gekoppelt sein. Zum einen zerstört sie den Körper und macht den Menschen, wie Klara selbst sagt, schwach. Dies war Hannah Arendt zufolge für die längste Zeit die hauptsächliche Konnotation der Arbeit: die Bedeutung des Wortes schließe »seit eh und je »Mühe und Plage«, 
Anstrengung und Schmerz, ja eine Verunstaltung des Körpers « ein. ${ }^{86}$ Eine so herbeigeführte Schwäche kann der Gemeinschaft nicht zuträglich sein, sie würde dem Menschen nur die soziale Energie rauben. Zum anderen scheint die Arbeit eine zu allgemeine Gemeinsamkeit zu sein, als dass man darauf eine Gemeinschaft gründen könne. Da fast jeder Mensch arbeitet oder arbeiten muss, bestünde eine solche Gemeinschaft aus der ganzen Menschheit - und das ist sowohl für Klara als auch für Marti nicht zu schaffen. Beide lehnen diese große Gemeinschaft ab. Über Joseph heißt es, er spräche »kein Wort mehr von der »Menschheit«. Das war längst vorüber. Je schwerer es einem wurde, ein »rechter Mensch« $\mathrm{zu}$ werden, desto weniger mochte man große Worte in den Mund nehmen, und schwer war es, »recht « zu bleiben, das empfand man jeden Tag deutlicher.« ( $G$ 137, Herv. meine) Am Beispiel Klaras erkennt man, dass das große Wort »Menschheit « und die große Gemeinschaft zugunsten einer greifbaren Realität abgewählt werden: der Familie. Ihre Liebe richtet sich kurz auf die Menschheit, dann nur noch auf ihr Kind. Gemeinschaft, so wird hier mit größter Stärke suggeriert, kann mit der Arbeit selbst nichts zu tun haben.

Aus diesem Zusammenhang ergibt sich die besondere Ironie, dass Marti den Sozialismus und seine Fixierung auf die Arbeit ablehnt, weil dessen humanistische und gemeinschaftsstiftende Funktion nur Illusion sei, obwohl seine Gemeinschaft mit Toblers rund um den simulierten Luxus ebenso illusorisch ist. Wie durch die Phänomene der ostentativen Muße und der Hyperarbeit verdeutlicht ist, sind Martis Arbeits- und Freizeittätigkeiten fundamental von illusionsbildenden Prozessen abhängig. Der Umstand, dass Marti den Sozialismus ablehnt, obwohl er prinzipiell die Stärkung der arbeitenden Bevölkerung zum Ziel hat, deutet darauf hin, dass Marti selbst einer Illusion im Marx'schen Sinne erliegt - der Illusion nämlich, es gehe ihm gut. Marx verwendet den Begriff der Illusion sowohl für ein durch Religion produziertes, >falsches` Glück, das den Menschen an der Verbesserung seiner Lebensumstände hindere, ${ }^{87}$ als auch im Sinne einer ideologischen Regressivität der herrschenden Klasse, die sich an die geschichtlich bedingte, gesellschaftliche

86 Arendt: Vita activa, 6of.

87 »Die Aufhebung der Religion als des illusorischen Clücks des Volkes ist die Forderung seines wirklichen Glücks. Die Forderung, die Illusionen über seinen Zustand aufzugeben, ist die Forderung, einen Zustand aufzugeben, der der Illusionen bedarf. Die Kritik der Religion ist also im Keim die Kritik des Jammerthales, dessen Heiligenschein die Religion ist.« Karl Marx: Zur Kritik der Hegelschen Rechtsphilosophie. In: Deutsch-Französische Jahrbücher. Hg. v. Dems. u.a. Paris: Bureau der Jahrbücher (1844), 72. 
Veränderung geistig noch nicht anpassen konnte. ${ }^{88}$ Aus Marx' Sicht ist die Überwindung solcher Illusionen und eine kritische Betrachtung der Welt und damit die Bewusstwerdung über die Wirklichkeit - eine zentrale Voraussetzung für die Befreiung der Arbeit und die Etablierung des Kommunismus. ${ }^{89}$ Die Aufgabe des Sozialismus ist die Dekonstruktion dieser Illusion. Die Tatsache, dass die sozialistische Bewegung von Marti selbst als Illusion kritisiert wird, obwohl sie sich als Instanz sieht, die eigentlich die Kritik an anderen illusorischen Zuständen befördern will, zeugt von Martis eigener illusorischer Gefangenheit.

Das passt zu der Inkompatibilität von Angestelltenschaft und der marxistischen Ideologie, die Siegfried Kracauer 1929/30 beschrieben hat. "Es ist eine der Pointen von Kracauers Studie«, so Michael Gamper, »dass sie zu zeigen vermochte, wie Arbeitssituation und soziale Lage der Angestellten sich allmählich denjenigen des Proletariats annäherten, die Betroffenen aber kein dieser Deklassierung entsprechendes Bewusstsein entwickelten. «" Schon 1912 betonte der Soziologe Emil Lederer, die Privatangestellten befänden sich in einer "Zwischenstellung, zwischen den Klassen «. ${ }^{91}$ Kracauer setzte dem hinzu, die Angestellten »möchten Unterschiede bewahren, deren Anerkennung ihre Situation verdunkelt; sie frönen einem Individualismus, der dann allein sanktioniert wäre, wenn sie ihr Geschick noch als einzelne

88 》]e mehr die normale Verkehrsform der Cesellschaft und damit die Bedingungen der herrschenden Klasse ihren Gegensatz gegen die fortgeschrittenen Produktivkräfte entwickeln, je größer daher der Zwiespalt in der herrschenden Klasse selbst und mit der beherrschten Klasse wird, desto unwahrer wird natürlich das dieser Verkehrsform ursprünglich entsprechende Bewusstsein [...], desto mehr sinken die früheren überlieferten Vorstellungen dieser Verkehrsverhältnisse[...] zu bloß idealisierenden Phrasen, zur bewußten Illusion, zur absichtlichen Heuchelei herab.«Karl Marx u. Friedrich Engels: Historisch-Kritische Cesamtausgabe. 1. Abt., Bd. 5. Deutsche Ideologie. Hg. v. Vladimir Adoratskij. Glashütten: Auvermann (1970), 271.

89 Richard Bernstein bemerkt zu Marx' Position:»[C]riticism [...] has the power not of delineating some utopian ideal which is to be striven for, but of revealing to men a critical understanding of what they are suffering. «Bernstein: Praxis and Action, 54.

90 Michael Gamper: Masse lesen, Masse schreiben. Eine Diskurs- und Imaginationsgeschichte der Menschenmenge 1765-1930. München: Fink (2007), 488f. Wagner zufolge sei der Wirtschaftsgeist der späten Schweizer Gründerzeit so ausgeprägt, dass es zu einer regelrechten »Proletarisierungsangst des Kleinbürgertums« kam. Wagner: Herr und Knecht, 98.

91 Emil Lederer: Die Privatangestellten in der modernen Wirtschaftsentwicklung. Tübingen: Mohr Siebeck (1912), 25. 
gestalten könnten. «"2 Obwohl Kracauers Analyse mehr als 20 Jahre nach dem Erscheinen von Der Gehülfe entsteht, erklärt sie den Grund für die Verblendung Martis passgenau. Die Parallelen zu Martis Situation sind evident: Martis Abneigung gegen die »Menschheit«, ebenso wie Klaras neu verlagerter Fokus von eben dieser auf ihr eigenes Kind, verleihen der Sehnsucht nach einer individuell gestalteten Erfahrung anstelle einer Zugehörigkeit zur Masse Ausdruck. Die abwertende Haltung spiegelt geradezu Gustave Le Bons negatives Urteil über die Masse in Psychologie der Massen (1895), in dem der Masse sowohl der Verlust von Individualität als auch Unvernünftigkeit attestiert wird. ${ }^{93}$ Was die Masse in Le Bons und Martis Denken symbolisiert, passt nämlich gar nicht zusammen mit der inhärenten Sehnsucht nach Bürgerlichkeit, die Kracauer den Angestellten unterstellt, ${ }^{94}$ und die sich in Martis Fall so deutlich an der enthusiastischen Imitation des Tobler'schen Habitus in ostentativer Muße und Hyperarbeit abzeichnet. Im Vergleich $\mathrm{zu}$ den Aktivitäten des Proletariats ist Toblers Habitus nämlich hochindividuell, und wenn auch nicht per se vernüftig, so imitiert er immerhin vernünftige Wesenszüge des Bürgertums. Dass Marti daran glaubt, einer höheren Klasse anzugehören, bringt ihn auch dazu, sich im Gegensatz zu der Köchin, die zur Arbeiterklasse gehört, von der Familie Tobler ausbeuten zu lassen:

Pauline erhielt ihren Lohn regelmäßig ausbezahlt, dagegen setzte man beim Gehülfen Verständnis und Takt genug voraus, die Lage zu begreifen, wortlos, und sich in dieselbe zu schicken. Joseph war ein Mann, Pauline ein unberechenbares Kind aus dem Volk. Einem Mann durfte man Entsagungen

92 Siegfried Kracauer: Die Angestellten. Aus dem neuesten Deutschland. Frankfurt a.M.: Suhrkamp (1971), 279f.

93 »In der Gemeinschaftsseele verwischen sich die Verstandesfähigkeiten und damit auch die Persönlichkeit der einzelnen. [...] Eben die Vergemeinschaftlichung der gewöhnlichen Eigenschaften erklärt uns, warum die Massen niemals Handlungen ausführen können, die eine besondere Intelligenz beanspruchen.« Gustave Le Bon: Psychologie der Masse. [Übers. v. Rudolf Eisler.] Stuttgart: Kröner (1953), $15 f$.

94 Kracauer spricht von »spießbürgerlich[en] « Idealen junger, weiblicher Angestellter und von der Neigung, sich »durch irgendeinen Rang von der Menge abzuheben«, die eine »im bürgerlichen Deutschland ausgeprägte Sucht«sei. Kracauer: Die Angestellten, 268f., 281. Auch Werner Deich postuliert, dass der Angestelltenroman um die Jahrhundertwende von der Erwartung geprägt gewesen sei, dass ein Angestellter aufsteigen und sich selbstständig machen, d.h. bürgerlich werden wird. Vgl. Deich: Der Angestellte im Roman, 178-182. 
zutrauen, einem Kind aus den niederen Schichten des Volkes niemals, und der Angestellte begriff das. ( 6 164f.)

Die Verwendung des Verbs >begreifen ist hier sarkastisch. Marti begreift ja gerade nicht, dass seine Arbeitssituation der des Proletariats nicht nur näher rückt, sondern sich bereits in einem schlechteren Zustand befindet. Dass er die Ungerechtigkeit der Situation als angemessen `begreift<, unterstreicht nur die von Gamper hervorgehobene Tatsache, dass er über »kein dieser Deklassierung entsprechendes Bewusstsein« (s.o.) verfügt.

Doch obwohl Krakauers Hypothese klar auf Marti zutrifft, gibt es dennoch einen grundlegenden Unterschied zwischen den jeweiligen Situationen: ihre Illusionen haben nicht den gleichen Ursprung. Krakauer zufolge produziere die Unterhaltungsindustrie diese Illusionen, und unterstütze damit die Grenzziehung der Angestellten zum Proletariat. Die Partizipation an Massenkulturphänomenen wie Sportveranstaltungen oder Kinovorstellungen sei eine Kompensationsmethode der Angestellten, in der sie »durch äußere Ablenkung die innere Leere« zu zerstreuen suchten. ${ }^{95}$ In seinem Verständnis schafft insbesondere das Kino einen schönen Schein, der prekäre Realitäten überspielen soll. Filme der Gegenwart, so Kracauer, sind zwar »Spiegel der bestehenden Gesellschaft«, doch sie »färben die schwärzesten Einrichtungen rosa und sind deshalb letztlich »Blendungsversuche«. ${ }^{96}$ Zwar sei auch die Arbeiterklasse anfällig dafür, doch der Gegenwartsfilm bündele viele gerade für »Angestellte produzierte[...] Illusionen «. ${ }^{97}$

Martis Illusion allerdings hat einen anderen Ursprung: die Arbeit. Er geht nicht ins Kino, doch eine geradezu filmische Illusion gibt es in seinem Leben trotzdem: die, die er selbst in der Hyperarbeit >erspielt<. Durch das `Spielen` von Arbeit simuliert er, selbst bürgerlich, oder gar affluent zu sein. Auch Nagi Naguib spricht in dieser Hinsicht von Martis »Schauspielern[...] mit sich selbst «. ${ }^{98}$ Der Unterschied zu Kracauers These ist freilich, dass der von ihm

\footnotetext{
95 Camper: Masse lesen, 490.

96 Siegfried Kracauer: Die kleinen Ladenmädchen gehen ins Kino. In: Ders.: Das Ornament der Masse: Essays. Frankfurt a.M.: Suhrkamp (1977), 279, 280, 281.

97 Kracauer: Die Angestellten, 220. Bezeichnenderweise publiziert Freud im selben Jahr, 1930, einen Aufsatz, der ebenfalls die Illusion des Kunstwerks als Abwehrmechanismus des Menschen ausweist. Dort heißt es, die Realität sei »die Quelle alles Leids«, von der der Mensch sich durch Illusionen unabhängig macht, die er aus seiner Phantasie oder den »Werken der Kunst«schöpft. Vgl. Freud: Das Unbehagen in der Kultur, 47. 
beschriebe »GlanZ« nicht an der Zerstreuung haftet, sondern an der Arbeit, jedoch ohne dass Marti von dem Glauben abrückt, »dass ein zerstreutes Dasein zugleich das höhere sei.«99 Immerhin heißt es ja, dass die Zerstreuung des Kartenspiels, in welches Marti bei Tobler eingeführt wird, den »sogenannten besseren « vorbehalten sei, »die nicht gar so streng zu arbeiten brauchten den Tag über« (s.o., G 48); außerdem fallen, wie oben gezeigt wurde, in Martis Angestelltentätigkeit Arbeit und Freizeit meistens zusammen. So zum Beispiel in der Gondelfahrt-Episode, in der er als "richtiger Mann für alles« ( $G$ 49) sowohl rudert als auch die »Genugtuung« der spätabendlichen Stille genießt und sich seinen »Einbildungen« überlässt ( $G$ 53f.). Klassenfragen beiseite genommen, kann man bei Walsers Gehülfen von einer doppelten Illusion sprechen: Die Hyperarbeit, die den Müßiggang legitimiert einerseits; der Müßiggang andererseits, der den »Schein wahre[...], zur bürgerlichen Gesellschaft zu gehören «, ${ }^{100}$ obwohl es dafür überhaupt keine ökonomische Grundlage gibt. Die Illusion Martis gewinnt also an Festigkeit, weil sie an einer mit Muße verschmolzenen Arbeit hängt. Weil die spielerische Arbeit und die unechte Muße ihm außerdem die Gemeinschaft bieten, die er sich wünscht, und sich zusätzlich wie ein Klassenaufstieg ausnehmen, denkt Marti gar nicht daran, sich diese Illusion nehmen zu lassen. Die Beschuldigung des Sozialismus als Illusionsmaschine ist eine Strategie, die ihn von seiner eigenen Illusion abzulenken versucht. Es ist eine Projektion seines eigenen Problems auf einen anderen Sachverhalt, der ebenfalls die Arbeit im Zentrum hat. Der Roman zeigt mit Marti eine Hauptfigur, die mit allen Kräften für die Aufrechterhaltung ihrer Illusion kämpft.

Doch obwohl Marti aufgrund eben dieser starken Illusionsbindung in der Walser-Forschung fehlendes Klassenbewusstsein und dem Roman die Inszenierung einer ausbleibenden Dialektik des historischen Materialismus attestiert wurde, ${ }^{101}$ gibt es in der Geschichte auch Momente, in denen sich der

Kracauer: Die Angestellten, 289. Folgt man Nietzsches Ausführungen zur Herren- und Sklavenmoral aus Jenseits von Gut und Böse, die für die Dynamik zwischen Tobler und Marti einschlägig ist, so ist Martis affirmative Haltung zur Muße bzw. zum Müßiggang symptomatisch für »das Verlangen nach Freiheit « und den »Feinheiten des FreiheitsGefühls«, die »notwendig zur Sklaven-Moral« gehören. Friedrich Nietzsche: Sämtliche Werke. Bd. VII. Jenseits von Gut und Böse. Stuttgart: Kröner (1964), 204. 
Simulationscharakter der Muße wie der Arbeit auch Marti aufdrängt und ihn an der >Echtheit< seiner Anstellung zweifeln lässt. So fragt sich Marti zuweilen recht unvermittelt, ob er seine Rolle als Angestellter korrekt ausführt, oder ob er überhaupt dafür geeignet ist. Zum Beispiel bei der oben kurz skizzierten Szene, in der Marti souverän auf Toblers Aussagen im Büro reagieren möchte, ohne diese allerdings zu verstehen. Nachdem er auf dessen Erzählung zwei Mal »natürlich!« und dann »selbstverständlich!« geantwortet hatte, weil es ihm »passend« erschien, "gutmütige Töne und Gebärden an den Tag zu legen«, stellt er die so angezeigte wohlwollende Eingeweihtheit ins Geschäft in Frage: »Glaube ich eigentlich an das, was ich da sage? « (G 62f.) Diese sorgende Frage begleitet die Arbeitssimulation Martis fast von Beginn der Geschichte an, und gibt Anlass zu langen Gedankenmonologen, in denen die Nähe von Muße und Arbeit reflektiert und problematisiert wird:

»Was leiste ich eigentlich? Ich kann mich da, wenn ich will, sogleich ungestört zu Bett legen, um in einen sehr wahrscheinlich gesunden und tiefen Schlaf zu versinken. Ich bekomme in Biergärten Bier zu trinken. Ich kann mit Frau und Kindern Gondel fahren, ich habe zu essen. Die Luft hier oben ist eine ausgezeichnete, und was die Behandlung betrifft, so wäre ich ein Lügner, wenn ich sie tadelte. Licht und Luft und Gesundheit. Aber was gebe nun ich dafür? Ist das etwas Reelles und Cewichtiges, was ich zu bieten vermag? Bin ich klug und gebe ich das Maß meiner Klugheit auch wirklich voll her? Was sind das für Dienste, die ich bis zum heutigen Tage Herrn Tobler bereits geleistet habe? Alles was recht und gut ist, aber ich bin felsenfest davon überzeugt, daß mein Herr und Meister noch wenig Nutzen durch mich davongetragen hat. Sollten mir der Schneid, die Initiative, die Begeisterungsfähigkeit fehlen? Das ist möglich, denn in der Tat, ich bin mit einer merkwürdig umfangreichen Portion Ruhe ausstaffiert zur Welt gekommen. Aber schadet denn das etwas? Freilich schadet es, denn die Unternehmungen Toblers verlangen leidenschaftliche Anteilnahme, und die Ruhe der Seele ähnelt bisweilen der trockenen Gleichgültigkeit. Das Schicksal der Reklame-Uhr zum

tu Warszawskiego (1980), 51. Marti, der sich selbst als gleichgültig beschreibt (vgl. C 55) weise Hong zufolge so gar keine Tendenz zur gesellschaftlichen Umwälzung auf, sodass er auch die »Geschichte « nicht vorantreiben könne. Kil-Pyo Hong: Selbstreflexion von Modernität in Robert Walsers Romanen »Ceschwister Tanner«, »Der Cehülfe« und »]akob von Cunten«. Würzburg: Königshausen \& Neumann (2002), 156. Wer wie Marti Ausbeutung widerstandslos hinnimmt, der kann nicht zum Revoluzzer werden, lautet die marxistische Deutung. 
Beispiel, hat es mich wirklich auch an allen Fasern meines Ichs angepackt? Bin ich davon erfüllt? Ich muß gestehen, ich denke nur allzu oft an ganz andere Dinge. Das aber, mein bester Herr Cehülfe, ist Verrat. Tauche jetzt endlich mal stramm unter in die Angelegenheiten Fremder, du ißt ja auch Fremder ihr Brot, gehst mit Fremder ihren Frauen und Kindern auf dem See schiffahren, liegst in Fremder Kissen und Betten und trinkst Fremder Rotwein aus. Kopf hoch jetzt, und vor allen Dingen den Kopf sauber gehalten. Ich meine, wir sind hier bei Toblers nicht deshalb, daß wir es nur schön haben. Es ist eine Ehre, es sich auch ein bißchen sauer zu machen. Hopp!« ( $G 55 f$.)

In dieser in Gänze zitierten Passage grübelt Marti über das Phänomen der Kongruenz von Muße und Arbeit nach. Der Umstand, dass im Hause Tobler "Mühsal und Lohn einander « gerade nicht im »regelmäßigen Rhythmus folgen ${ }^{102}$ wie Hannah Arendt die Tätigkeit der Arbeit beschreibt, ruft in ihm Zweifel an seinem Verhalten hervor. Er zählt all die Aspekte der Muße und Freizeit auf, die er genießt - "gesunden und tiefen Schlaf«, in »Biergärten Bier zu trinken«, »mit Frau und Kindern Gondel fahren«, »ausgezeichnete [...] Licht und Luft und Gesundheit « - und zweifelt daran, ob er diesen »Lohn« auch durch »Mühsal« erarbeitet hat, weil so gut wie jeder Aspekt seines Lebens ihm wie "Lohn« erscheint. »Aber was gebe nun ich dafür? Ist das etwas Reelles und Gewichtiges, was ich zu bieten vermag?«, fragt er. Der Begriff des »Reellen« in seinem Monolog deutet darauf hin, dass er den Spielcharakter seiner Arbeit erahnt, auch wenn er ihn nie erkennt. Anstatt diese Ahnung jedoch zum Anlass zu nehmen, seine Illusion zu durchbrechen, spornt sie ihn dazu an, sich noch tiefer in sie zu versteigen.

Der simulative Charakter seiner Arbeit verleitet ihn dazu, sie konzeptuell anzuzweifeln. Das führt ihn allerdings nicht zu einer Entlarvung Toblers als Regisseur dieser umfassenden Muße- und Arbeitssimulation, sondern im Gegenteil dazu, sich selbst als das Problem zu betrachten. Die Frage, ob auch wirklich »alle Fasern« seines Ichs angepackt wurden, ob sein Ich von der Arbeit erfüllt sei, die Aufforderung, "stramm« in die "Angelegenheiten Fremder« unterzutauchen, und die Versicherung, es sei »eine Ehre, es sich auch ein bißchen sauer zu machen « - all diese Gedanken zeigen eine unverhältnismäßige Fixierung auf die Arbeit an, die das Übergewicht der Muße im Hause Tobler kompensieren soll. Weil Marti in der Hyperarbeit keine »Mühsal« haben kann, schafft er sie sich in Gedanken, und bemüht sich zudem 
umso mehr um die Gunst von Herrn und Frau Tobler. Dies passiert in besonderem Maße dann, wenn er auf seine Ausbeutung aufmerksam wird. So zum Beispiel, wenn der Verwalter des Stellenvermittlungsbüros, durch den Marti seine Anstellung bekommen hat, ihn nach seinem Gehalt fragt. Marti gesteht ihm, dass er noch kein Gehalt ausbezahlt bekommen hat, und dass dies zu den »Punkten« gehört, die ihm »nicht recht gefallen« (G 185). Auf diese Punktierung seiner Illusion hin reagiert er allerdings nicht mit Entrüstung oder Selbstbehauptung. Er wirft sich stattdessen in die Arbeit - die Hausarbeit, denn sie ist wegen der Stasis im Ingenieursbüro die einzige Möglichkeit zur Beschäftigung -, sodass sich Frau Tobler über seinen »feurigen Diensteifer« ( $G$ 187) wundert. Er steigert sich mit einer Obsession in die Arbeit rein, die ein Rezensent der englischen Übersetzung des Gehülfen als »as zealous as a religious fanatic's « bezeichnet, "even though no hint of religion appears in the text «. ${ }^{103}$ Die Verbindung zur Religion, die hier etabliert wird, verweist einmal mehr auf eine Art von Verblendung, die auch Karl Marx beschäftigt hat, der die Religion bekanntlich als »illusorische[s] Glück « bezeichnet hat. ${ }^{104}$ Nur ist Martis Opium eben nicht die Religion, sondern die Arbeit selbst, die Marx so heilsgeschichtlich aufgeladen hat.

Martis Illusion wird am Ende des Romans - allerdings nur vermeintlich aufgehoben. Am Bankrott von Toblers Geschäft zeigt sich, dass Martis Vorstellungen von einer Gemeinschaft, die nur auf Freiheit, Spiel und Muße aufbaut, mit der Realität nicht kompatibel sind. Das Scheitern des Geschäfts und der Familie, die Martis neue >Heimat‘ sein sollten, bewegt ihn dazu, eine Gemeinschaft durch Arbeit erneut in Betracht zu ziehen. Dies ergibt sich aus einer Begegnung mit dem ehemals bei Tobler angestellten Herr Wirsich. Dieser wurde aufgrund von Alkoholismus entlassen, kehrt allerdings immer wieder zurück, um weiterhin, ebenfalls parasitär, am Wohlstand der Toblers teilzuhaben. Marti entwickelt zum Ende des Romans eine Freundschaft zu dem lange stellenlosen und trinkfreudigen Wirsich, der ebenso große Schwierigkeit mit der Arbeit hat wie Tobler und Marti. Sobald er wieder eine Stelle hat, kommt er Marti besuchen und schlägt vor, »in die nächstbeste Wirtschaft zu treten und eins auf den Durst hinauf zu nehmen« ( $G$ 253), und verliert die Stelle dann geradewegs wieder. Innerhalb dieser Freundschaft zeigt Marti eine neugefundene Solidarität mit dem »Kollegen« (G 289). Denn nachdem

103 John McCormick: Review: Ambiguous Immediacy. The Assistant by Robert Walser. In: The Sewanee Review 116 (4), 2008, Ixxxviii.

104 Marx: Zur Kritik der Hegelschen Rechtsphilosophie, 72. 
er den Tag vor seiner Kündigung (er kündigt, nicht Tobler ihm) mit Wirsich trinkend und redend verbracht hat, koppelt er sich gedanklich von seiner bisherigen Situation, und damit auch von der Gemeinschaft der Nichtstuer ab. Als er, Wirsich im Schlepptau, am Abend zuhause einkehrt, bezeichnet er sich Frau Tobler gegenüber als »Arbeiter « (G 287) des Hauses, wohingegen er vorher im Roman immer als »Angestellter « bezeichnet wurde und auch selbst von sich als »Angestelltem« sprach. Dies weist auf eine veränderte Selbstwahrnehmung hin, und darüber hinaus auf eine Bewusstwerdung des Rechts auf eine gerechte Behandlung. Denn im Romanverlauf kommt die Eigenbezeichnung als "Arbeiter« sonst nur ein einziges Mal vor, und zwar als er bei einer früheren Auseinandersetzung mit Tobler darauf besteht, respektvoll behandelt zu werden. Als er trotz ausbleibenden Lohns zum Dank für seine angenehme Kost und Logis angehalten wird, wehrt er sich wie folgt:

Was muten Sie mir zu, wenn Sie glauben, Ursache zu haben, mir den natürlichen Aufenthalt und Genuß, den ich hier oben bei Ihnen habe, in einem fort vorwerfen zu müssen? Bin ich ein Bettler oder ein Arbeiter? Ruhig, Herr Tobler. Bitte, ich mache hier keine Szene, ich setze ganz einfach etwas für unser gegenseitig notwendiges Verständnis auseinander. Ich möchte festgestellt haben dreierlei. Erstens weiß ich Ihnen für alles, was Sie mir >bieten<, Dank, zweitens wissen Sie das, denn Sie konnten das meinem bisherigen Betragen ruhig entnehmen, und drittens leiste ich etwas, ein Beweis für dieses Letztere ist die Tatsache, daß mein Gewissen und Ihre Klugheit mich immer noch hier beschäftigt sehen. (G 146f., Herv. meine)

Im Gegensatz zu einigen anderen zentralen Stellen im Roman, in denen Marti sich ungeeignet fühlt, oder, wiederum anders, vollkommen in der Vorstellung aufgeht, seine Rolle perfekt zu spielen, zeigt sich an dieser Stelle eine sehr realistische Einschätzung seiner Situation, die allerdings nicht verstetigt wird, sondern sofort wieder hinter der Illusion zurücktritt. Am Ende des Romans kündigt sich jedoch eine Rückkehr dieser Haltung an, wenn Marti sich wieder als einen »Arbeiter ( $G$ 287) sieht. Gleich darauf fordert er von Tobler die Auszahlung seines "versprochenen Lohns« ( $G$ 291), kündigt nach der Ablehnung desselben und verlässt zusammen mit Herrn Wirsich die Familie.

Was durch die Verwendung des Wortes "Arbeiter « und das Bestehen auf seine Rechte aussieht wie eine Re-Solidarisierung mit der Arbeiterschaft, und damit mit dem Sozialismus, ist jedoch nichts weiter als eine Fortführung der Illusion Martis. Denn Wirsich fühlt sich genauso wenig als Arbeiter wie Mar- 
ti, er wünscht sich nur den »angenehmen Lebensaufenthalt« ( $G$ 254) in einem bürgerlichen Haushalt, und möchte eigentlich »den halben und den ganzen Tag betrunken" sein (G 284). Auch er ist im Grunde ein Nichtstuer, der keine Arbeit halten kann und auf der Suche nach Muße ist. Das ist der eigentliche Grund, aus dem Marti sich mit ihm verbündet: um eine neue Gemeinschaft der Nichtstuer zu gründen, nun, da der alten das Geld ausgegangen ist. Am Schluss des Romans scheint Marti so an die Idee der humanen Kollektivität in der Sozialismus-Episode anzuknüpfen - einer "fröhlichen Menschenversammlung « voller Menschheitsliebe ( $G$ 135) - ist aber immer noch nicht geneigt, wirklich zu arbeiten. Er übernimmt nur die auf Arbeit basierende Gruppenidee, um sie allerdings mit Muße zu füllen, so wie er es zuvor mit dem Angestelltenverhältnis zu Tobler mittels der Hyperarbeit auch gemacht hat. Der Roman zeichnet so das Bild einer Gesellschaft, in der eine Gemeinschaft ohne die Grundlage der Arbeit undenkbar ist, sodass alle Gemeinschaften auch die, die auf anderen Werten (wie dem Nichtstun) beruhen - nur unter dem Deckmantel der Arbeit existieren können. 


\section{ऽOstı/Inaktiv vs. 'Westı/Aktiv}

Zunächst lohnt sich ein Blick in die Geschichte: Die Zuschreibung des Nichtstuns hat sich im Laufe der Jahrhunderte europäischer Kolonisation vor allem in Bezug auf den so allgemein bezeichneten `Osten<, >Asien` oder >Orient< gebildet. ${ }^{1}$ Der passive >Orient steht hier fast immer dem aktiven >Okzident gegenüber. Der Diskurs des Orientalismus ist in Deutschland, und nicht nur dort, lange ganz wesentlich von dieser Unterscheidung geprägt gewesen, und nimmt damit auch in der Ideengeschichte des Nichtstuns einen großen Raum ein. Schon im frühen 19. Jahrhundert, so schreibt Ludwig Ammann, sei der Vorwurf der Untätigkeit ein zentrales Merkmal des Denkens über den >Orient gewesen. Es habe eine »kleine Anzahl immer wiederkehrender verallgemeinernder Urteile über den Orient und den Orientalen [gegeben], zumeist verurteilender Natur«, die sich auf »drei Formeln« bringen lassen: die Despotie, die Leidenschaftlichkeit und die Indolenz. ${ }^{2}$ Was Ammann hier der Übersichtlichkeit halber ordentlich trennt ist aber eigentlich aufs Engste miteinander verbunden, denn diese Urteile konnotieren sich alle gegenseitig. Tatsächlich liegt dem gesamten Orientalismus-Diskurs in Deutschland eine Idee des Nichtstuns zugrunde, wie ich im Folgenden zeigen werde.

$1 \quad$ Im Folgenden bezeichne ich diesen Diskurs als >orientalistisch<, auch wenn es streng genommen nicht an allen diesbezüglichen Punkten um den Orient selbst geht, sondern um Asien, Russland, oder sogar Afrika. Meine Intention ist es, ähnliche Abwertungspraktiken - vor allem jene, die mit der Zuschreibung des Nichtstuns operieren aus verschiedenen Zeiten und Regionen unter einem bekannten Schlagwort zu bündeln, um ihre diskursive Verwandtschaft zu betonen.

2 Ludwig Ammann: Östliche Spiegel. Ansichten vom Orient im Zeitalter seiner Entdeckung durch den deutschen Leser, 1800-1850. Hildesheim: Georg Olms (1989), 25. 


\section{Despotie}

Ein eindrückliches Beispiel für den Zusammenhang zwischen Despotie und Nichtstun findet sich bereits in Montesquieus De L'esprit des Lois (1748), der das Denken über den 〉Orient « in ganz Europa bis ins 20. Jahrhundert hinein maßgeblich geprägt hat. Montesquieu entwickelt hier die Theorie, dass ein warmes Klima - das, so die Implikation, überall im `Orientく vorherrscht auf den Menschen eine physisch und moralisch schwächende Wirkung ausübt. Diese Schwäche bedinge eine leichte >Unterwerfbarkeit«: Frau und Sklave unterwerfen sich deshalb dem Mann, dieser sich wiederum dem despotischen Herrscher, da keiner von ihnen die Kraft zu einer abwehrenden Tat aufbringen kann. Der Despot selbst ist ihnen nur durch seine soziale Stellung überlegen, teilt aber ihre Handlungsunfähigkeit. Die Untätigkeit der Untertanen definiert diese als solche, und ihre Untätigkeit erzeugt Herrschaft, die wiederum eine andere Form von Untätigkeit erzeugt. Der Despot bilde in seiner Isolation von seinem Volk eine Ich-Erhöhung, und infolgedessen einen untätigen Solipsismus heraus, und sei deshalb ein »Mensch, dem seine fünf Sinne unaufhörlich sagen, er sei alles und alle anderen nichts«, was erkläre, warum er »naturgemäß faul « ist. ${ }^{3}$ Diese ideelle Verbindung von Despotismus und >Orient< besteht schon seit der Antike, doch während bei Aristoteles der Grund dieser Funktionalität in der >sklavischen Natur der »Barbaren Asiens « liegt, macht Montesquieu ganz konkret die Faulheit kausallogisch dafür verantwortlich - und rückt damit das Nichtstun ins Zentrum der Vorstellung politischer Unfähigkeit im >Orient $<.{ }^{4}$ Eine Unfähigkeit, die durch das Bild untätiger Herrscher wie Untertanen ausgedrückt wird.

\section{Leidenschaftlichkeit}

Die Leidenschaftlichkeit der >Orientalen` (wie auch anderer Fremder), ist ein vielschichtiges Phänomen, bei der die Untätigkeit nicht in jeder Hinsicht ein relevanter Faktor ist. Häufig denotiert die Leidenschaftlichkeit ein promiskes Verhalten, ${ }^{5}$ das auf europäische Kolonisatoren gleichsam angenehm und

3 Montesquieu: Vom Ceist der Gesetze, 31 (2/5). Herv. meine. »Bildet die Furcht das Prinzip, so ist die Ruhe das Ziel der despotischen Regierung «, heißt es außerdem an anderer Stelle $(88 ; 5 / 14)$. Herv. meine.

4 Aristoteles: Werke. Bd. 9. Politik. Übers. v. Eckart Schütrumpf. Hg. v. Hellmut Flashar. Berlin: Akademie (1991), 77 [1285a 18-22].

5 Diese Zuschreibung hat viele verschiedene Ursprünge, die Südseereisen des 18. Jahrhunderts sind dabei besonders prominent. Vgl. hierzu die beispielreiche Aufarbeitung von Christiane Kuechler Williams: Die Entdeckung des erotischen Paradieses. Eine Untersu- 
(aufgrund des ungewohnten sexuellen Agens der Frau) bedrohlich wirkte. ${ }^{6}$ Die Sexualisierung des Fremden hat jedoch auch eine Kehrseite, bei der die Untätigkeit eine wichtige Rolle spielt. Dabei will ich zwei verschiedene Aspekte hervorheben.

(1) Den >Orient< als leidenschaftlich zu bezeichnen heißt zum einen, ihn als faul und arbeitsscheu auszuweisen, und damit als kulturell unterlegen. Denn: im europäischen Denken schließen sich die Topoi `Sex und >Arbeit< größtenteils gegenseitig aus. Der historische Beginn der Arbeit, so lautet eine von Georges Batailles anthropologischen Überlegungen in L'Érotisme (1957), kann nur unter der Bedingung eines eingeschränkten Sexualtriebs stattfinden. ${ }^{7}$ Um dies zu verdeutlichen, konstruiert Bataille das Bild einer >Urgesellschaft<, in der Sex im Vordergrund der tätigen Lebensgestaltung steht, dann allerdings irgendwann von der Arbeit abgelöst wird. Dieses Bild ist tief in der europäischen Vorstellung der Vergangenheit verwurzelt, die man in den vormals sogenannten >Urgesellschaften $\prec$, auf karibischen Inseln, dem Orient, ebenso wie in Fernostasien, wiedergefunden zu haben glaubte. Bataille benutzt es, um die Verdrängung der Erotik aus dem gesellschaftlichen Diskurs zu erklären. Doch europäische Reisende, Kolonisatoren und Wissenschaftler haben es über Jahrhunderte funktionalisiert, um die Rückständigkeit dieser Gesellschaften zu beweisen. An der Eigenschaft der Leidenschaftlichkeit hängt eben die massive Implikation, dass nicht gearbeitet wird. Und da Arbeit einer der zentralsten Werte der europäischen Fortschrittsideologie und ihrer Vorstellung von Zivilisation darstellt, ist die Zuschreibung der Leidenschaftlichkeit gleichbedeutend mit dem Etikett des Nichtstuns, und suggeriert damit geschichtliche Zurückgebliebenheit.

(2) Den >Orient $<$ als leidenschaftlich zu bezeichnen heißt weiterhin, ihn als seinnehmbar zu deklarieren. Denn: das Urteil der Leidenschaftlichkeit der >orientalischen unbedingt) promisken Aktivismus, sondern Passivität im Sinne des Zulassens, und damit der widerspruchslosen Zugänglichkeit. Diese Passivität gilt im übertragenen Sinn auch für die Geographie der fremden Länder. So wird

chung der europäischen Südseerezeption im 18. Jahrhundert. Dissertation. Evanston: Northwestern University (2001), insb. 148-203.

6 Williams spricht zum Beispiel von der Kastrationsangst, die durch eine »sexuell unersättliche Partnerin«hervorgerufen wird. Williams: Entdeckung des erotischen Paradieses, 161.

7 Vgl. Ceorges Bataille: Die Erotik. Übers. v. Gerd Bergfleth. Berlin: Matthes \& Seitz (1994), 41-51. 
Land(schaft) in kolonialen Kontexten - auch solchen, die nicht den >Orient betreffen - häufig als passiv/weiblich dargestellt, um eine vermeintlich natürliche >Bereitschaft‘ zur Eroberung auszudrücken. Ein prominentes Beispiel hierfür in der bildenden Kunst ist der in den späten 1580er-Jahren entstandene Kupferstich Jan van der Straets (Stradanus), der Amerigo Vespuccis Entdeckung Amerikas allegorisch darstellt. Darin trifft der stehende, vollbekleidete und mit allerhand technischem Gerät ausgestattete Mann Vespucci auf eine nackte, in einer Hängematte liegende Frau.

Abbildung 1: Jan van der Straet: »Allegory of America«, ca. 1587-89.

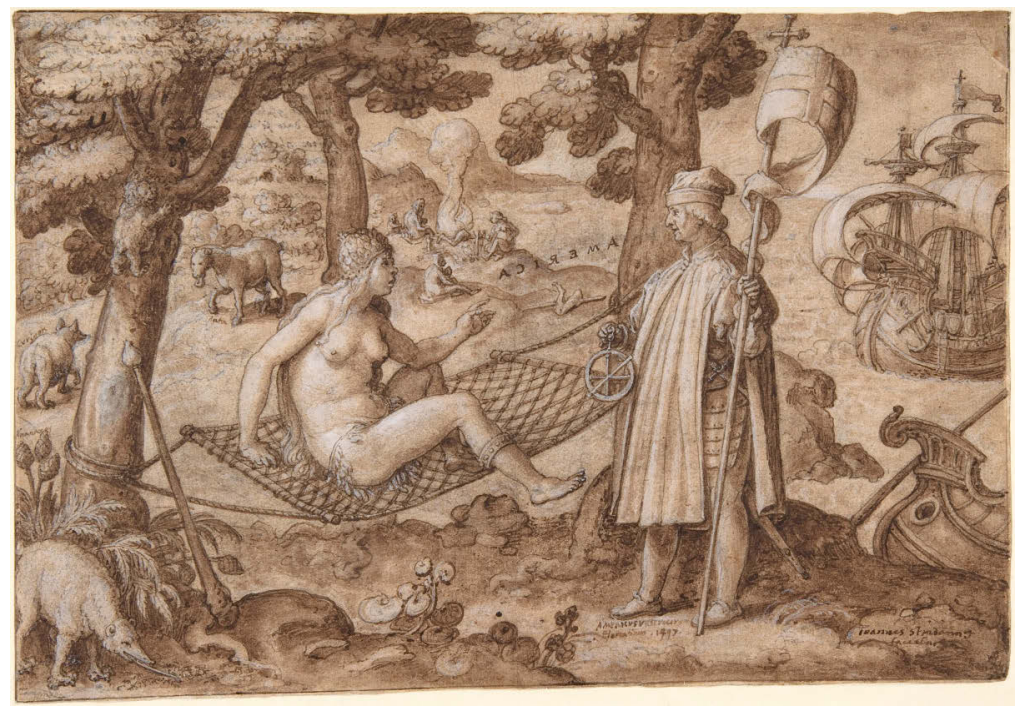

Die geschlechtliche wie positionelle Differenzierung der alten und neuen Welt zeigt nicht nur den im kolonialen Bestreben inhärenten Eros, sondern auch, wie zentral das Motiv der Stagnation und des Stillstandes in diesem Kontext ist, die in der Untätigkeit der Frau (ebenso wie beispielsweise in der Abbildung des in Amerika heimischen Faultiers) Ausdruck finden. »Land is named as female as a passive counterpart to the massive thrust of male technology«, so lautet die akkurate Beschreibung dieser Dynamik durch 
Peter Hulme. ${ }^{8}$ Es ist eben diese weibliche Untätigkeit, die einen Mangel an Sinn impliziert, der durch den männlichen Kolonisator ausgeglichen werden >muss $\triangleleft,{ }^{9}$ wie Anne McClintock schreibt:

The myth of the virgin land is also the myth of the empty land, involving both a gender and a racial dispossession. Within patriarchal narratives, to be virgin is to be empty of desire and void of sexual agency, passively awaiting the thrusting, male insemination of history, language and reason. Within colonial narratives, the eroticizing of »virgin « space also effects a territorial appropriation, for if the land is virgin, colonized peoples cannot claim aboriginal territorial rights, and white male patrimony is violently assured as the sexual and military insemination of an interior void. ${ }^{10}$

Die jungfräuliche Reinheit, von der McClintock spricht, kodiert über die Verfügbarkeit des Körpers der Frau eine geopolitische Verfügbarkeit von Land. Die ihr zugeschriebene Untätigkeit verleugnet damit einerseits ihre sexuelle Selbstbestimmung, und andererseits die Handlungsfähigkeit der Kolonisierten im Allgemeinen. Die oben erwähnte beunruhigende sexuelle Rolle der >orientalischen bzw. >fremden Frau in der Begegnung mit dem Kolonisator bedeutet eine rhetorische Schwächung des 〉Orients〈 bzw. des >Fremden`, die auch seine Unterwerfung legitimieren kann.

\section{Indolenz}

Das Urteil der Indolenz in >Reinform « meint »in seiner einfachsten und häufigsten Verwendung « vor allem eine »mindere Arbeitstätigkeit und überhaupt eine niedere Leistungsbereitschaft «, schreibt Ammann. ${ }^{11}$ Darin steckt eine

8 Peter Hulme: Polytropic Man. Tropes of Sexuality and Mobility in Early Colonial Discourse. In: Europe and Its Others. Hg. v. Francis Barker u.a. Colchester: University of Essex (1985), 18.

9 Gregor Thum nimmt im osteuropäischen Kontext für diesen >Ausgleich eines Sinnmangels« das Bild der tabula rasa her: manche sahen »im Osten Rückständigkeit und Barbarei, vielleicht auch die zivilisatorische tabula rasa, die nach der Hand des deutschen Kolonisten rief«. Diese Idee des unbeschriebenen Blatts, das beschrieben werden kann, findet eine Entsprechung im unbewegten Körper, der bewegt werden kann. Gregor Thum: Ex Oriente lux - ex Oriente furor. Einführung. In: Traumland Osten. Deutsche Bilder vom östlichen Europa im 20. Jahrhundert. Hg. v. Dems. Göttingen: Vandenhoeck \& Ruprecht (2006), 8.

10 Anne McClintock: Imperial Leather. Race, Gender and Sexuality in the Colonial Contest. New York: Routledge (1995), 30.

11 Ammann: Östliche Spiegel, 28. 
moralische Verurteilung, die eine wichtige Rolle in einer weiteren kolonial motivierten Legitimierungsstrategie spielt: der Organisation von Zwangsarbeit. War die lokale Bevölkerung auf kolonialem Gebiet nicht als Arbeitskraft zu gewinnen - zum Beispiel, weil sie eigenen Berufen nachging, Lohnarbeit im Prinzip nicht kannte oder zu weit weg vom Ort der Arbeit wohnte -, so wurde sie mit verschiedenen Maßnahmen dazu genötigt, und das immer im Rückbezug auf ihre vermeintliche Trägheit. Ania Loomba beschreibt dies sehr genau im Hinblick auf die kurze britische Kolonialherrschaft in Südafrika:

After acquiring land, colonists needed to recruit labour. >Chiefs< were also used to spersuade Africans to enter the labour force, and these measures were defended on the grounds that they would eliminate sidleness and vices among the local population. Thus the imperial mission, based on a hierarchy of races, coincided perfectly with the economic needs of the colonists. ${ }^{12}$

Diese Art der politischen Funktionalisierung des Nichtstuns durch die Hervorhebung seiner Lasterhaftigkeit (»idleness and vice«) kommt in den meisten kolonialen Kontexten vor, auch den deutschen. Sebastian Conrad beschreibt eine nahezu identische Situation in einer der afrikanischen Kolonien des Deutschen Reiches, in der das Aufeinandertreffen verschiedener Erwartungen an die Arbeitsorganisation zu Konflikten und schließlich auch zu der Auffassung führte, die kolonialen Subjekte wären arbeitsscheu, weil sie anders arbeiteten als in Europa üblich:

Die Ansprüche der Kolonialherren stießen bei den Afrikanern häufig auf Unverständnis und brachten vielfältige Formen des Widerstands hervor. Die ständigen Beschwerden über die »notorische Indolenz und Faulheit« der Afrikaner lassen die Grenzen erkennen, welche der Verfügung über die einheimischen Untertanen gesetzt waren. ${ }^{13}$

Die Indolenz ist also ein konstanter Faktor in der Abwertung des >Anderen Neben der auf Arbeit bezogenen, moralischen Verurteilung gibt es auch noch eine weitere Problematisierung: diese Art des Nichtstuns ist nutzlos, wenn es um das Vorantreiben der Geschichte geht. In Europa herrscht damals wie heute die Überzeugung vor, dass menschliches Tätigsein eine Voraussetzung für den Fortschritt ist, eine Bedingung für Zivilisation. Das Nichtstun kann

12 Ania Loomba: Colonialism/Postcolonialism. Abingdon, Oxon: Routledge (2015), 133. Herv. meine.

13 Sebastian Conrad: Deutsche Kolonialgeschichte. München: Beck (2008), 59. 
dies nicht leisten. Als Eigenschaft des >Anderen steht es im krassen Gegensatz zu der als genuin europäisch empfundenen Tätigkeit. Die Indolenz sei, so Ammann, ein "grob vereinfachender Ausdruck der Irritation, welche der Europäer als Vertreter einer modernen, [...] dem Fortschritt ergebenen Zivilisation in der Lebenswelt einer traditionellen Gesellschaft verspürt, deren Zeit so viel langsamer vergeht, daß allem Anschein nach nie ein Wandel stattfindet. $\ll^{14}$

Es ist diese Abwesenheit von geschichtlichem Wandel durch das Nichtstun, die den deutschen Orientalismus besonders beeinflusst hat. Sie wurde in der Forschung vieler verschiedener Disziplinen aufgegriffen, so zum Beispiel in der Religionswissenschaft. August Schlegel behauptet dementsprechend, das Christentum wäre »im Orient entstanden«, hätte dann aber seine »wesentlichsten und auffallendsten Wirkungen durchaus im Abendlande geäußert«. Während es sich im Abendland als »energisches und bildendes Prinzip « ausgedrückt habe, sei es im Orient stagniert. ${ }^{15}$ Auch sein Bruder Friedrich suggeriert, dass es im >Orient، eine Art verstärkter Erdanziehungskraft gebe, die statt eines senergischen Prinzips nur die Ausbildung von Philosophien bzw. Religionen zulasse, die die Trägheit des Menschen fördern. So bemerkte Friedrich Schlegel zum Beispiel 1808 in Über die Sprache und Weisheit der Indier, dass der menschliche Geist in der >orientalischen< Philosophie am tiefsten im Pantheismus »herabgesunken« sei, da dieser, vornehmlich im Buddhismus, alle Dinge für gleich gültig erkläre, was »dem Eigendünkel des Menschen ebensosehr als seiner Trägheit [schmeichelt] «. ${ }^{16}$ Die Betonung einer Stagnation durch Trägheit findet sich auch in Hegels geschichtsphilosophischen Überlegungen, in denen er behauptet, dem >Orient< mangele es aufgrund fehlender Handlungsfähigkeit an der Möglichkeit zur Ausbildung einer echten Geschichte. Indiens Entwicklung sei nichts als »eine stumme,

14 Ammann: Östliche Spiegel, 28.

15 August W. Schlegel: Über das Mittelalter. Eine Vorlesung, gehalten 1803. In: Deutsches Museum. Bd. 2. Hg. v. Friedrich von Schlegel. Wien: Camesina (1812-13), 436.

16 Friedrich Schlegel: Über die Sprache und Weisheit der Indier [1808]. In: Ders.: Kritische Friedrich-Schlegel-Ausgabe. Bd. 8. Studien zur Philosophie und Theologie. Hg. v. Ernst Behler u.a. München: Ferdinand Schöningh (1975), 253. Herv. meine. Bezüglich Schlegels allgemeinem Urteil über den `Orient < kommentiert Murti: »This then is the Orient that emerges from Schlegel's writings: fatalistic, apathetic, passive, excessive [...], all without structure yet perversely contained within a rigid system that does not allow for progress. « Kamakshi P. Murti: India. The Seductive and Seduced »Other« of German Orientalism. Westport: Greenwood (2001), 16. Herv. meine 
tatlose Verbreitung, d.h. ohne politische Handlung «, in China fehle indessen jegliche »Reflexion über die Natur der Handlung «. ${ }^{17}$ Über eben diese Schriften des deutschen Orientalismus sagt Nina Berman zurecht, sie »dokumentieren die europäische Expansion durch das deutliche Bemühen, Sprach-, Kulturoder Weltgeschichte in einer Weise zu interpretieren, welche die Legitimation der Herrschaft Europas über den Rest der Welt ermöglicht. « ${ }^{18}$

Die vielfache Verbindung >Orient $\iota=$ Nichtstun, die ich hier in aller Kürze skizziert habe, hat sich über die Zeit zu einer geradezu axiomatischen Assoziation entwickelt. Meine These lautet, dass ihre kulturelle Verfestigung sich daran erkennen lässt, dass sie auch umgekehrt funktioniert (d.h. Nichtstun $=>$ Orient $\varsigma$ ), wie sich an literarischen Texten über das Nichtstun aus und in Europa ablesen lässt. Die europäische Literatur des Nichtstuns zeigt, insbesondere im 19. Jahrhundert, bemerkenswert viele Verbindungen zu einer >orientalischen Motivik - und kombiniert dabei häufig die Untätigkeit mit einer ebenfalls als genuin >orientalisch empfundenen Maßlosigkeit.

Ein gutes Beispiel findet sich beim titelgebenden Protagonisten in Iwan Gontscharows Oblomow (1859). Oblomow ist träumerisch und faul, isst ohne Maß und Vernunft, kann kaum von seinem Diwan aufstehen - und ist asiatisch konnotiert. All diese Eigenschaften lassen es nicht $\mathrm{zu}$, dass er sich um seinen Lebensunterhalt kümmern kann. Er kommt aus einem der »entlegensten Gouvernements, beinahe in Asien« und trägt »einen Schlafrock aus persischem Stoffe, einen echten morgenländischen Schlafrock - ohne die geringste Anlehnung an Europa «. ${ }^{19}$ Auch Gustave Flauberts Roman L'Éducation sentimentale (1869) - der im Übrigen auch Thomas Manns Zauberberg beeinflusste,$-{ }^{20}$ bringt diese Interrelation auf den Plan: Der in eine verheiratete Frau verliebte Frédéric Moreau oszilliert aus Verzweiflung über seine aussichtslose Situation zwischen Apathie und »dem schrankenlosesten Müßiggang ${ }^{21}{ }^{21} »[E] \mathrm{r}$ tat nichts, er unternahm nichts, die Furcht vor dem Mißerfolg

17 Georg W. F. Hegel: Werke. Bd. 12. Vorlesungen über die Philosophie der Ceschichte. Hg. v. Eva Moldenhauer u.a. Frankfurt a.M.: Suhrkamp (1970), 178, 162.

18 Nina Berman: Orientalismus, Kolonialismus und Moderne. Zum Bild des Orients in der deutschsprachigen Kultur um 1900. Stuttgart: Metzler (1997), 31.

19 Gontscharow: Oblomow, 73, 10.

20 „Castorp ist ein Vetter von Frédéric Moreau«. André Banuls: Thomas Mann und die französische Literatur. In: Thomas-Mann-Handbuch. Hg. v. Helmut Koopmann. Stuttgart: Kröner (2001), 227.

21 Gustave Flaubert: Die Erziehung des Herzens. Ceschichte eines jungen Mannes. Übers. v. Emil Alphons Rheinhardt. Zürich: Diogenes (1980), 35. 
lähmte ihn«, stattdessen erträumt er sich einen luxuriösen, >orientalischen< Rückzugsort: »Frédéric wiederum richtete sich einen maurischen Palast ein, um darin, auf Kaschmirdiwans liegend, dem Murmeln der Springbrunnen lauschend, von Negerknaben bedient, sein Leben zu verbringen. ${ }^{22}$ Auch im wenige Jahre später erschienenen Roman À rebours (1884) von Joris-Karl Huysmans findet sich in der Vielzahl intellektueller, künstlerischer und kultureller Referenzen auch ein Orient-Motiv. Der Protagonist Des Esseintes zieht sich in ein Haus zurück, das er, »erschöpft vom Leben« und »überwältigt von unendlicher Müdigkeit", nicht mehr verlässt, und zu seiner Unterhaltung (oder eher: nervlichen Stimulation) mit vielen teuren, exotischen Gegenständen füllt. ${ }^{23}$ Das Herzstück seiner ästhetizistischen Bemühungen bildet eine mit Edelsteinen besetzte Schildkröte (die an den Folgen dieser Verzierung stirbt), die er einzig und allein anschafft, um sie auf einen "schimmernden Orientteppich « zu setzen, um die »Lebendigkeit« seiner Farben - »das aladingelbe und pflaumenviolette Wollgewebe - noch verstärken zu können. ${ }^{24}$ Diese Texte zeigen exemplarisch, dass vor allem bestimmte Gegenstände wie der Teppich und der Diwan zu Referenzpunkten der literarischen Imagination über den >Orient « werden. Madeleine Dobie hält dieses selektive Aufgreifen für ein Zeichen dafür, dass die damit assoziierten Zustände (bequemes Sitzen oder Liegen) den Aspekt der Stagnation (wie auch der Erotik) aufgreifen:

It seems reasonable to propose that the ascription of Oriental names to comfortable reclining chairs reflects not simply Europeans' primitive knowledge of Oriental furnishings and domestic habits, but also a wide-spread association of Oriental culture with indolent behavior and pervasive eroticism. In the nineteenth century, Oriental furniture, notably the Turkish divan, a word that signifies both council and sofa, would in fact become a leading metaphor for the passivity and stagnation of Oriental culture. ${ }^{25}$

Das Nichtstun steht also im Zentrum einer ganzen Reihe verschiedener Prozesse: Konflikte mit dem Anderen, Fremden und vor allem auch dem `Östlichen ren, das sich auf das Land und seine BewohnerInnen richtet. Dabei ist schon

22 Flaubert: Erziehung des Herzens, 37, 78.

23 Joris-Karl Huysmans: Gegen den Strich. Übers. v. Brigitta Restorff. München: DTV (2015), 85.

24 Huysmans: Gegen den Strich, $55 f$.

25 Madeleine Dobie: Foreign Bodies. Gender, Language, and Culture in French Orientalism. Stanford: UP (2001), 101. 
häufig festgestellt worden, dass die dem Fremden zugeschriebenen Eigenschaften - sei es die Despotie, die Leidenschaft, die Indolenz oder sonst etwas - nur Konstrukte sind, die mehr über das Selbstbild und die Wünsche der Europäer aussagen, als über die Beschaffenheit der Anderen. Das Nichtstun wurde in diesem Kontext bisher lediglich in seiner legitimierenden Funktion verstanden: Am Nichtstun konstruiert der kolonial interessierte bzw. der orientalistische Diskurs den Gegensatz zwischen Eigenem und Fremdem, und zwar, um die aktive Übernahme, also die Befriedigung des eigenen Begehrens zu legitimieren. Tatsächlich ist jedoch die Beziehung zwischen Nichtstun und Begehren unter Umständen weitaus komplizierter.

Das Beispiel für diese Analyse ist Der Zauberberg (1924) von Thomas Mann. Anhand dieses im Kontext des Ersten Weltkrieges verfassten Romans werde ich im Folgenden zeigen, dass sich das europäische Begehren in der Literatur auch auf das Nichtstun selbst richten kann - und somit das Narrativ einer europäischen Dominanz subvertiert. Das vorliegende Kapitel zeigt den Einfluss dieses Gedankens einer schwindenden ‘westlichen $<$ genauer: deutschen Macht noch in einer weiteren Figuration des Nichtstuns: im Zauberberg wird der >Osten als untätig konnotiert, während der Roman jedoch den >Westen als untätig inszeniert, dem `Osten « hingegen Macht zuschreibt. Das Nichtstun fungiert so ebenfalls als Projektion einer reigenen (d.h. deutschen bzw. europäischen) Schwäche, die sich aus der Wahrnehmung kolonialen Misserfolgs und politischer Niederlage speist. Die Verfahren der Verschiebung und Dekonstruktion etablierter Oppositionen mittels des Motivs der Inaktivität werden im Folgenden als orientalistische Praxis des Nichtstuns untersucht. 


\section{PROJEKTION in Der Zauberberg von Thomas Mann, 1924}

Diese Lektüre weicht in einem wesentlichen Punkt von den drei anderen LiteraturAnalysen ab. Sie fokussiert nicht nur auf die Darstellung eines praktizierten Nichtstuns und seiner politischen Bedeutung, sondern auch auf die Zuschreibung des Nichtstuns als Eigenschaft des Anderen, wie sie seit Jahrhunderten im orientalistischen Diskurs praktiziert wird. Anhand von Thomas Manns Der Zauberberg (1924) wird diese Zuschreibung unter anderem als europäische Projektion einer gefühlten Handlungsunfähigkeit verhandelt, die Aussagen über das Eigene im politischen Sinne enthält.

Der dritte große Roman Thomas Manns, Der Zauberberg, ${ }^{26}$ erzählt die Geschichte des jungen, kurz vor dem Abschluss seiner Ausbildung stehenden Schiffsingenieurs Hans Castorp. Der dreiwöchige Besuch, den er seinem Vetter Joachim im Sanatorium »Berghof « abstattet, dehnt sich auf einen sieben Jahre langen Aufenthalt aus - erst der Ausbruch des Ersten Weltkrieges veranlasst Castorp, wieder ins »Flachland «, und damit ins Leben zurückzukehren. Der Roman greift die Topographie des orientalistischen Diskurses, der oben skizziert wurde, auf, indem er das Flachland als >westlich aktiv, den »Berghof « allerdings als >östlich

Im ersten Unterkapitel (`Orientalisiertes $<$ Nichtstun ) wird gezeigt, dass Castorps langer Aufenthalt im Roman als eine Hinwendung zum >östlichen Nichtstun beschrieben und aufgrund der damit einhergehenden Unterwanderung der normativen, hierarchischen Opposition >Ost//inaktiv und >West</aktiv problematisiert wird. Der Roman gestaltet diese Unterwanderung mit Blick auf die spezifische politische Position Deutschlands vor und nach dem Ersten Weltkrieg aus, und zeigt im Zuge dessen die Paradoxien des orientalistischen Diskurses auf. Denn darin vermischen sich sowohl ein auf östliche Kolonien gerichtetes Begehren (Inaktivität) als auch Ängste vor einem erstarkenden >Osten`, dessen Bevölkerung die europäische Wirtschaft und dessen Philosophien die europäische Kultur infiltrieren könnten (Angst vor dem Osten). Die Angst vor dem Osten findet Ausdruck in der Projektion eines nunmehr als >westlich< empfundenen Nichtstuns auf den Osten - eine Verschiebung der ursprünglichen >Ost//inaktiv - >West//aktiv Opposition, die im Roman inszeniert wird. Damit setzt der Roman eine orientalistische

26 Thomas Mann: Der Zauberberg. Große kommentierte Frankfurter Ausgabe. Bd. 5,1. Hg. v. Heinrich Detering u.a. Frankfurt a.M.: Fischer (2002). Wird nachfolgend mit der Sigle $Z$ und der Seitenzahl im Text zitiert. 
Tradition des 19. Jahrhunderts fort, denn auch dort sind ähnliche Projektionsdynamiken feststellbar, die das Nichtstun als Motiv funktionalisieren.

Das zweite Unterkapitel (Politiken des Nichtstuns) widmet sich den politischen Modellen, die im Zauberberg anhand des Nichtstuns gegeneinander ausgespielt werden. Die Frage einer >östlichen von Castorps nichtstuerischer Denkpraxis des »Regierens« verhandelt - ein Motiv, das im selben Zuge aber auch einen swestlichen greift und parodiert (»Regieren« : Herrschaft durch Nichtstun). Die fortlaufende Doppeldeutigkeit der >Ost $</>$ West $<$-Konnotation des »Regierens « subvertiert die Grundopposition des Romans weiter. Im letzten Abschnitt (»Politischer Faktor« - Gemeinschaft statt Politik) zeigt sich, dass Castorps >östliches Nichtstun auch als Ausdruck seiner Abwendung von den zwei dominanten politischen Ideologien des >Westens seiner Zeit gelesen werden kann (die beide mit Arbeit in Verbindung gebracht werden) - vom konservativen Monarchismus auf der einen und der progressiven Demokratie auf der anderen -, und zwar zugunsten einer Gemeinschaftsform, die sich durch Werklosigkeit und die gemeinsame Nähe zum Tod auszeichnet.

\section{`Orientalisiertes` Nichtstun}

Im Zauberberg geht es immer wieder um den 〉Osten $<$, den >Orient $<$ und >Asien $\prec$ Diese oft ohne besondere Trennschärfe ${ }^{27}$ verwendeten Begriffe werden, vor allem in den Ausführungen Settembrinis, in Opposition zum Thema >Europa gebracht. Diese topographische Ordnung wird unter anderem durch die Opposition Aktivität/Inaktivität semantisiert. Die Inaktivität gehört dem

27 Diese Begriffe haben im Deutschen natürlich sehr unterschiedliche, historisch bedingte Bedeutungen, siehe dazu Berman: Orientalismus, 16f. Berman weist allerdings ebenfalls darauf hin, dass trotz und neben diesen Bedeutungsunterschieden um die Jahrhundertwende herum in Deutschland »besonders in theoretischen Texten dieser Periode gleichzeitig jene Dichotomisierung von >Orient< und `Okzident< [existiere], die den gesamten asiatischen und nordafrikanischen Raum respektive das Gebiet Europas und Nordamerikas zu homogenen Gebieten verschmelzen lässt.« (Ebd. 17) Gollwitzer bemerkt, dass diese semantische Zusammenballung `östlicherく, sasiatischer « und `orientalischer Inhalte im frühen 20. Jahrhundert typisch war: »Häufig genug warfen die Literaten und Journalisten des Zeitalters die Begriffe » russisch«, »tatarisch«, »asiatisch « in einen Topf«. Heinz Gollwitzer: Die gelbe Gefahr. Geschichte eines Schlagworts. Studien zum imperialistischen Denken. Göttingen: Vandenhoeck \& Ruprecht (1962), 36. 
>Osten $<$ an, und ist der >westlichen Aktivität entgegengesetzt. Das Nichtstun wird damit zum zentralen Element des sogenannten sasiatischen Prinzips

Nach Settembrinis Anordnung und Darstellung lagen zwei Prinzipien im Kampf um die Welt: die Macht und das Recht, die Tyrannei und die Freiheit, der Aberglaube und das Wissen, das Prinzip des Beharrens und dasjenige der gärenden Bewegung, des Fortschritts. Man konnte das eine das asiatische Prinzip, das andere aber das europäische nennen, denn Europa war das Land der Rebellion, der Kritik und der umgestaltenden Tätigkeit, während der östliche Erdteil die Unbeweglichkeit, die untätige Ruhe verkörperte. Gar kein Zweifel, welcher der beiden Mächte endlich der Sieg zufallen würde,- es war die der Aufklärung, der vernunftgemäßen Vervollkommnung. (Z 240, Herv. meine)

Bei dieser semantischen Verschränkung des `Ostens` mit der >Inaktivität (»das Prinzip des Beharrens«, »die Unbeweglichkeit, die untätige Ruhe«) handelt es sich um eine weitere Praxis des Nichtstuns. Im Gegensatz zu den vorangegangenen Beispielen, in denen diese Praktiken auf der diegetischen Ebene von nichtstuenden Akteuren ausgeführt werden, handelt es sich hier um eine auf historische Diskurse bezogene Praxis. Sie besteht darin, so die These, das Motiv der Inaktivität durch seine >Veröstlichung`zum Träger eines Kommentars über die zeitgenössische politische Situation des Deutschen Reiches zu machen, und speziell seines Verhältnisses zu Osteuropa und Asien. Die Topologie des Romans steht im Dienst dieses Kommentars: die diegetische Welt ist in Flachland und Bergland aufgeteilt, wobei das unten gelegene Flachlach als >westlich und aktiv konnotiert ist, und das sich oben befindende Bergland als >östlich und inaktiv.

Mit diesem Zugang strebe ich an, die zumeist intradiegetisch fokussierten und philosophisch informierten Zauberberg-Interpretationen ${ }^{28}$ dezidiert um eine historische Analyse des Motiv-Paars `Osten/Inaktivität zu erweitern.

28 Zu diesem Komplex zählt u.a. auch die bekannte Schopenhauer-Auslegung des Zauberbergs durch Kristiansen, der in Castorps Ceschichte einen Übergang von der Form (empirische Realität) über die Unform (Tod, Krankheit, Metaphysik) zur Überform (asketische Verneinung des Lebenswillens) sieht. Vor diesem Hintergrund versteht er das `Asiatische، schlicht als Element der Unform; es vertrete eine »Wirklichkeitssphäre«, die sich mit der Realität, also mit »der Welt der Sprache und der Gesellschaft als unvereinbar erweist«. Børge Kristiansen: Unform - Form - Überform. Thomas Manns Zauberberg und Schopenhauers Metaphysik. Kopenhagen: Akademisk Forlag (1978), 198. 
Dieses Verhältnis ist, wie sich zeigen wird, ambivalent. Die >östlicheく Untätigkeit als Motiv signalisiert einerseits ein koloniales Begehren von Seiten des Deutschen Reiches im Vorfeld des Ersten Weltkrieges. Allerdings kommt es im Roman zu einer teilweisen Inversion von Settembrinis Gegenüberstellung, sodass nicht der >Osten<, sondern vielmehr der >Westen « als untätig konnotiert wird. Diese Inversion spiegelt die Tatsache, dass seit dem späten 19. Jahrhundert der >Osten $\ll$ nicht nur mit Begehren, sondern auch ob seiner wachsenden wirtschaftlichen Kraft mit Angst betrachtet wird. Die nichtsdestotrotz anhaltende fiktionale Charakterisierung dieses faktisch erstarkenden >Ostens als untätig und unbeweglich durch Settembrini ist, so die These dieses Kapitels, eine Projektion der eigenen (d.h. deutschen bzw. europäischen) wahrgenommenen Schwäche, die sich auf ältere deutsche Orientalismusdiskurse stützt. Auch sie funktionalisierten Inaktivität als Hauptbeschreibungsmerkmal fremder und begehrenswerter Kulturen, um die fehlende koloniale Involviertheit Deutschlands zu kompensieren. Das Erschreiben einer globalen Topographie der Untätigkeit ist deswegen eine Praxis des Nichtstuns, weil sie die Untätigkeit im Eigenen offenbart, gerade indem sie sie durch das $\mathrm{Zu-}$ Schreiben des Fremden zu bannen versucht.

\section{Inaktivität begehren}

In Der Zauberberg, der fast vollständig im Sanatorium Berghof in den Alpen spielt, wird ein semantischer Raum entworfen, der in mehrfacher Hinsicht als >östlich konnotiert ist. Eine dieser Konnotationen ergibt sich aus den vielen >östlichen $<$ - vor allem slawischen - PatientInnen im Berghof (es gibt zwei sogenannte »Russentisch[e]« $(Z$ 67), keine andere Nationalität bekommt so viel $>$ Raum in der Geschichte). Ein spezifisch >östliches`, kolonial gefärbtes Begehren von Seiten des deutschen >Westens $<$ ergibt sich aus der Liebeshandlung, die der Roman beschreibt: der deutsche Protagonist Castorp ist in die Russin Clawdia Chauchat verliebt, die durch ihre Nationalität sowie durch ihre »leicht asiatisch[...] « (Z 350) sitzenden Augen dem `Osten zugeordnet ist. Damit ist, wie schon im 12 Jahre zuvor erschienenen Tod in Venedig, wieder Osteuropa die »site of sexual desire « in Manns Werk, wie Todd Kontje bemerkt hat. ${ }^{29}$ Dieses Begehren, und vor allem die ablehnende Haltung des begehrten Objekts, bildet die vergebliche deutsche Sehnsucht nach einer umfassenderen Kolonialherrschaft Richtung Osten ab. 
Die Sehnsucht nach kolonialer Herrschaft wirkt im Kontext des frühen 20. Jahrhunderts etwas anachronistisch - die Blütezeit des europäischen Kolonialismus ist längst vergangen -, doch das liegt am späten Einstieg des Deutschen Reiches ins Kolonialgeschäft. Während England und Frankreich schon im 16. bzw. im 17. Jahrhundert mit dem Ausbau ihrer kolonialen Herrschaft begannen, erwarb das Deutsche Reich erst ab 1884 seine ersten Kolonien. Allerdings konnte es nicht annähernd so viel Gewinn daraus ziehen wie seine Nachbarn. »Für den deutschen Staat war das Kolonialreich ein $\mathrm{Zu}$ schußgeschäft«, schreibt Sebastian Conrad. »Kaum eines der Gebiete konnte sich wirtschaftlich selbst tragen. « $^{30} \mathrm{Um}$ diesen Verlust auszugleichen, nahm das Reich seit der Jahrhundertwende einen zunehmend aggressiven kolonialen Akquisitions-Kurs auf (nur wenige Jahre, nachdem Bernhard von Bülow 1897 das bekannte Verlangen nach einem »Platz an der Sonne« in einer Reichstagsdebatte formuliert hatte). ${ }^{31}$ Dabei entstand ein innereuropäischer Konkurrenzkampf, der später den Ersten Weltkrieg mitverursachen würde, und der ebenfalls im Zauberberg abgebildet ist - und zwar anhand des Motivs eines >östlichen« Nichtstuns.

Im Roman spielt sich dieser Wettkampf am Körper der rasiatischen $<$ Clawdia Chauchat ab; Castorp, und damit Deutschland, zieht dabei meist den Kürzeren. Mehr Glück hat sein Gegner Hofrat Behrens, der medizinische Leiter des Sanatoriums, der ebenfalls ein Auge auf Chauchat geworfen hat. Behrens Position ermöglicht ihm einen einzigartigen `Zugang $\mathrm{zu}$ ihr: als Arzt untersucht und röntgt er sie regelmäßig, außerdem ist er Hobbymaler und lässt sie für ein Porträt Modell sitzen. Was Behrens' ganz direkt erfährt, ist Castorp nur indirekt zugänglich, und zwar über den Kontakt mit Abbildungen von

30 Weiter heißt es: »Lediglich die kleinsten und ökonomisch unbedeutendsten Kolonien, Samoa und Togo, wiesen in den letzten Jahren ein ausgeglichenes Budget auf. Auch wenn private Gesellschaften Cewinne machten, profitierte das Reich kaum davon. Angesichts hoher Ausgaben für die Verwaltung sowie für die Kriege, vor allem in Südwestafrika und China, waren die Reichszuschüsse für drei Dekaden Kolonialreich enorm.« Conrad: Deutsche Kolonialgeschichte, 61.

31 »[T]he post-1900 phase of German overseas expansion was chiefly characterized by her penetration pacifique [sic!] - in Turkey and the Euphrates valley, in Latin America, in the Dutch East Indies, and in the Belgian and Portuguese colonies in Africa, all of which appeared to offer greater economic rewards than the formal Cerman colonial empire itself.« Paul M. Kennedy: The Rise of the Anglo-German Antagonism. 1860-1914. London: Ceorge Allen and Unwin (1982), 413. 
ihr: er kommt in den Besitz eines ihrer (in Glas gefassten) Röntgenbilder (»Innenporträt «, $Z$ 527); er darf das Portrait von Chauchat in Behrens' Wohnung besichtigen. In beiden Fällen ist sein Zugang zu dem Objekt seiner Begierde nur medial möglich. Castorp versucht, diese Distanz zu Chauchat durch physischen Kontakt mit diesen Medien zu kompensieren, was jedoch nur lächerliche Effekte produziert - so, als er besagtes Portrait in Behrens' Wohnung abhängt und während der Führung durch dieselbe mit sich herumträgt ( $Z$ 393-396). Die Konkurrenz Castorps mit Behrens, gepaart mit der Unerreichbarkeit der >östlichen`Chauchat, ist eine Metapher auf die deutsche pénétration pacifique - den Versuch des Deutschen Reiches, in bereits von Russland, England und Frankreich dominierten Regionen des Vorderen Orients mittels wirtschaftlichen Engagements einzudringen (z.B. durch die Beteiligung am Bau der Bagdadbahn). Die pénétration, obwohl stellenweise erfolgreich, kam doch eher einer Rundreise durch bereits von anderen Europäern besetzte und deshalb unantastbare Gebiete gleich. Nicht nur Castorps Umgang mit Chauchats Portrait, sondern die Gesamtsituation in Behrens Wohnung legt diese Deutung nah: dieser besitzt noch eine Reihe anderer >östlicher Dinge - eine »orientalisch ornamentierte[...] Messingplatte« zum Beispiel, auch eine pornographisch verzierte »Kaffeemühle [...] indischer oder persischer[...] Herkunft« (Z 396f.) - die Castorp, wie das Portrait Chauchats, nur bewundern darf, aber nicht selbst besitzen kann. Kenneth Weisinger weist darauf hin, dass diese Gegenstände, die in Behrens >orientalisch eingerichteten Räumen mitsamt ihrer Herkunft (Indien, Persien, China und Ägypten) beschrieben werden, geographisch allesamt dem englischen Kolonialreich zugehören, sodass der Eindruck entsteht, Behrens' Raum sei »a representation of the growing German desire to expand its own colonies along the lines of Britain's already established empire ${ }^{32}$ Todd Kontje argumentiert entsprechend, dass über den östlich konnotierten sexuellen Diskurs auch die Dynamiken westlicher Nationen im Kampf um globale Imperialansprüche inszeniert werden:

The Oriental trappings of Behrens's smoking alcove not only point to the >Asiatic appeal of Chauchat's sexuality, but also to the competition between Germany and Great Britain to control this realm. Behrens offers Castorp indirect access to Chauchat, but also stands in his way as a potential rival [...] (1999), 195. 
pointing simultaneously to a realm of unbridled sensuality in the East and to the Western imperialist efforts to tame and exploit this realm. ${ }^{33}$

In diesem durch die sexuelle Spannung transportierten Motiv des kolonialen Begehrens spielt auch die eingangs beschriebene sasiatische< Eigenschaft der Inaktivität eine große Rolle, die als rhetorische Legitimierung zur Penetration fungiert. Dieser Zusammenhang ist jedoch in der Thomas Mann-Forschung bisher weitestgehend unerkannt geblieben.

Die Figuration des `faulen oder >untätigen Asiaten ist, wie eingangs erläutert, ein wiederkehrendes Motiv des europäischen Orientalismus (welcher diese Zuschreibung wohlbemerkt auch an anderen Staaten durchgespielt hat). Zur genauen Lektüre des Romans empfiehlt sich eine detaillierte Analyse der Gestalten und Dynamiken, die diese Projektion des Nichtstuns annimmt. Die Synonymreihe »Faulheit/Untätigkeit/Inaktivität/Apathie« bildet ein Beschreibungsparadigma für das Fremde schlechthin. Dafür gibt es (unter Anderem) drei Gründe:

(1) Zum einen kristallisiert sich an dieser Zuschreibung, wie Edward Said herausgestellt hat, eine idealisierte Selbstwahrnehmung Europas heraus. Ania Loomba beschreibt sie wie folgt:

Said shows that this opposition is crucial to European selfconception: if colonised people are irrational, Europeans are rational; if the former are barbaric, sensual, and lazy, Europe is civilisation itself, with its sexual appetites under control and its dominant ethic that of hard work; if the Orient is static, Europe can be seen as developing and marching ahead; the Orient has to be feminine so that Europe can be masculine. ${ }^{34}$

(2) Die von Said und Loomba beschriebene Semantisierung der Räume >Europa und `Orientく spiegelt die oben zitierte Opposition Settembrinis, erweitert sie aber um die Gegenüberstellung männlich/weiblich. Wie bereits in den Bemerkungen zum Orientalismus zu Beginn dieses Kapitels ausgeführt wurde, werden dem kolonialisierten Raum Merkmale zugeordnet, die ebenso dem stereotypen Vokabular der Beschreibung von Weiblichkeit zugehören - und damit sowohl Herablassung als auch Begehren konnotieren. Die Passivität des kolonialen Objekts wiederum spielt in seiner erotischen Besetzung eine zentrale Rolle, weil sie die Möglichkeit einer Inbesitznahme durch den

33 Kontje: German Orientalisms, $155 \mathrm{f}$.

34 Loomba: Colonialism/Postcolonialism, 63f. 
männlichen Kolonisator impliziert. ${ }^{35}$ In diesem Diskurs bzw. in dieser Tradition ist der männliche Liebhaber, so Loomba, der »active discoverer of the female body, and desires to explore it in the same way as the European radventurer who penetrates and takes possession of lands which are seen as passive, or awaiting discovery. ${ }^{36}$ Dementsprechend wird in Bildnissen von Neulandentdeckungen- und Inbesitznahmen eben jenes Land oft durch eine liegende Frau allegorisiert. ${ }^{37}$ Castorp nimmt dieselbe Position ein, wenn er sagt, Frauen seien »reaktive Geschöpfe, ohne selbstständige Initiative, lässig im Sinne von passiv« ( $Z$ 911), da nicht sie ihre Männer wählen, sondern im Gegenteil immer gewählt werden. Eine Frau »wird zum wählenden Subjekt der Liebe erst auf Grund der Wahl des Mannes« ( $Z$ 911). Damit beschreibt Castorp implizit die Funktionalität der Erotik im Diskurs kolonialer Aneignung: Die Zuschreibung der erotischen Inaktivität legitimiert die Inbesitznahme von Land wie Frau auch deshalb, weil beide vor der Aneignung nur Objekte sind und erst mit dem spenetrierenden< Eingreifen der europäischen Siedler zu Subjekten werden können. Koloniale Inbesitznahme ist ein Akt der sinnstiftenden Vervollkommnung - ermutigt und ermöglicht durch die Passivität des begehrten Objekts.

(3) Drittens legitimiert die Behauptung einer passiven Neigung fremder Völker nicht nur die ländliche Inbesitznahme, sondern auch die ihr folgenden Herrschaftsstrategien. Insbesondere die Sehnsucht nach wirtschaftlicher Rentabilität der kolonialen Projekte führte vielerorts zu Zwangsrekrutierungen lokaler Arbeiter. Es war gängige Praxis, das ökonomische Eigeninteresse dieser Zwangsmaßnahmen zu verschleiern, indem man hierfür ideologische Motivation vorgab, z.B. die moralische Erziehung der >faulen kolonisierten Völker zur Arbeit. Alle Kolonialmächte Europas haben, wie bereits beschrieben, die moralisch zu verurteilende Indolenz in dieser Weise für ihre Zwecke funktionalisiert. Auch das erst spät kolonialpolitisch aktiv gewordene Deutsche Reich legitimierte die Kolonisation durch »die Vorstellung von Deutsch-

35 Vgl. hierzu die Ausführungen Dobies über Montesquieus Bild der >orientalischen<Frau: das "portrait of the passivity of Oriental women is reinforced by the assertion that the enclosure of women in the seraglio contradicts the very spirit of slavery because harems are in reality experienced by women as »delightful places« (»lieux de délices«) in which they are at liberty to indulge their natural indolence«. Dobie: Foreign Bodies, 42. Herv. meine.

36 Loomba: Colonialism/Postcolonialism, 84. Herv. meine.

37 Vgl. das Beispiel von Stradanus' Kupferstich, der Vespuccis Entdeckung Amerikas allegorisch darstellt, in der Einleitung zu diesem Kapitel. 
lands zivilisatorischer Mission«, in deren Zentrum auch die »Erziehung zur Arbeit « stand. ${ }^{38}$

Die Behauptung, Untätigkeit sei fremden Völkern eigentümlich, ist also mit verschiedenen Arten des Begehrens verknüpft. Einerseits mit dem, sich selbst dem in Europa so hoch geschätzten Wert versichern zu können: dem Prinzip der "gärenden Bewegung, des Fortschritts [...] und der umgestaltenden Tätigkeit« (s.o., Z 240) zu folgen, wie Settembrini es formuliert. Andererseits mit dem Begehren, zu besitzen und zu beherrschen. Die Verknüpfung von >Untätigkeit< mit den Topoi >Sexualität und >Weiblichkeit<, die sich im Zauberberg an Castorps Interesse für Clawdia Chauchat zeigt, ist daher nicht beliebig, sondern führt den von Said identifizierten Diskurs eines kolonial geprägten europäischen Orientalismus fort.

Doch diese bekannte koloniale Metapher wird im Roman nicht einfach reproduziert, sondern an zwei sehr entscheidenden Punkten umgewandelt. Die Zuschreibungen des untätigen >Ostens und tatkräftigen >Westens`, obwohl sie koloniale und orientalistische Diskurse akkurat spiegeln, lassen sich im Roman nicht wie üblich kartieren. Zum einen wird die sasiatische Chauchat zwar begehrt, weist aber keine klar begehrenswerten Eigenschaften auf. Castorp selbst sieht in seiner Zuneigung selbst nur

ein Ferienabenteuer, das vor dem Tribunal der Vernunft - seines eigenen vernünftigen Gewissens - keinerlei Anspruch auf Billigung erheben konnte: hauptsächlich deshalb nicht, weil Frau Chauchat ja krank war, schlaff, fiebrig und innerlich wurmstichig, ein Umstand, der mit der Zweifelhaftigkeit ihrer Cesamtexistenz nahe zusammenhing (Z 220).

38 Neben Handelsinteressen, der Ansiedlung auslandsdeutscher Gemeinschaften, und der Hoffnung, durch die Kolonialpolitik innerdeutsche Konflikte in den Hintergrund zu drängen, nennt Conrad folgende kulturelle Gründe für die Kolonisation: »Die »Hebung « der Kolonisierten war ein Vorhaben, das unterschiedliche Kreise zusammenführen und Gruppierungen für das koloniale Unterfangen begeistern konnte, die ihm sonst ferngestanden hätten: Es konnte sich wahlweise auf Bildung, Christianisierung oder die »Erziehung zur Arbeit« richten. Auch wenn häufig die Überzeugung von einer besonderen »Sendung « des Deutschen Reiches mitschwang, etwa in Abgrenzung von England und Frankreich, war dies doch eine Cemeinsamkeit aller Kolonisatoren, gespeist von einer spezifischen Melange aufklärerischer Emanzipationsversprechen und sozialdarwinistischer Hierarchien. «Conrad: Deutsche Kolonialgeschichte, 25f. Und: »Die »Arbeiterfrage« galt als der wichtigste Gegenstand aller kolonialen Politik.« (Ebd. 57) 
Natürlich ist es gerade die »Zweifelhaftigkeit ihrer Gesamtexistenz« (s.o.), die Castorp anziehend findet. Diese kommt unter anderem in ihrer koketten Unterwanderung bürgerlicher Verhaltensstandards zum Ausdruck, wie beispielsweise im Zuschlagen der Speisesaaltür, die Castorp als »verdammte Schlamperei!« $(Z$ 72) bezeichnet. Ihr Körper hingegen hat nicht den gleichen Reiz wie ihre sozialen »Ungezogenheiten« $(Z$ 347). Er wird als »krank«, »wurmstichig«, »fiebrig«, und als durch die Untätigkeit verkommen beschrieben. In der Darstellung Settembrinis sind sowohl ihr Körper als auch der Osten »weich und zur Krankheit geneigt«, weshalb asiatische Charaktere das Sanatorium »so ausgiebig beschick[en]« $(Z$ 370). Das am meisten für Chauchat verwendete Adjektiv ist »schlaff« (s.o.). Ihrem untätigen Körper fehlt, wie diskursgeschichtlich üblich, Spannung und Kontrolle, sodass Frau Chauchat jegliche Haltung abgeht:

Frau Chauchat saß zusammengesunken und schlaff, ihr Rücken war rund, sie ließ die Schultern nach vorne hängen, und außerdem hielt sie auch noch den Kopf vorgeschoben, so daß der Wirbelknochen im Nackenausschnitt ihrer weißen Bluse hervortrat. (Z 191)

Wenn auch einige ihrer Körperteile im weiteren Romanverlauf als schön und »verlockend « bezeichnet werden (z.B. ihre Arme, $Z$ 197) und Castorp »das Mark bezaubern« (ihre Augen, $Z$ 350), so symbolisiert dieser kranke und »schlaffe« Körper Clawdia Chauchats nicht, wie im orientalistischen Diskurs üblich, den erhofften Reichtum einer neuen Kolonie. ${ }^{39}$ Dieser Umstand weist auf die zweite, wesentlich extremere Abweichung hin, und zwar auf Castorps eigene Inkompatibilität mit der Semantisierung des >Westens $<$. Die Tatsache, dass der weibliche, untätige Körper der Asiatin krank ist, könnte darauf hindeuten, dass das faule >Asien « weder Heilung noch Aktivität allein organisieren kann und dafür erst den Kolonisator braucht, wie eben beschrieben. Doch Castorp kann und will nicht den aktiven Kolonisator spielen. Anstatt sich dazu anzuschicken, Frau Chauchat irgendwie zu erobern oder zu dominieren, kopiert er ihre passive Schlaff- und Nachlässigkeit - und findet sogar Gefallen daran. »Er versuchte«, heißt es,

wie es sei, wenn man bei Tische zusammengesunken, mit schlaffem Rücken dasäße, und fand, daß es eine große Erleichterung für die Beckenmuskeln

39 »[T]he sexual promise of the woman's body indicates the wealth promised by the colonies«. Loomba: Colonialism/Postcolonialism, 84. 
bedeute. Ferner probierte er es, eine Tür, durch die er schritt, nicht umständlich hinter sich zu schließen, sondern sie zufallen zu lassen, und auch dies erwies sich sowohl als bequem wie als angemessen ( $Z$ 348).

Castorp gefällt sich in der Rolle des Passiven, er empfindet sie als »Erleichterung « und hält die damit korrespondierende Laxheit für »angemessen«. Diese Rolle entspricht auch seinem Charakter, wie er zu Beginn des Romans beschrieben wird. Dort wird ihm eine ungewöhnlich stark ausgeprägte Tendenz zur Untätigkeit zugeschrieben. Schon lange vor seiner Ankunft im Berghof habe Castorp, so führt der Erzähler aus, die Arbeit zwar achten, aber nicht lieben können,

und zwar aus dem einfachen Grunde, weil sie ihm nicht bekam. Angestrengte Arbeit zerrte an seinen Nerven, sie erschöpfte ihn bald, und ganz offen gab er zu, daß er eigentlich viel mehr die freie Zeit liebe, die unbeschwerte, an der nicht die Bleigewichte der Mühsal hingen (Z 56f.).

Castorp entspricht von Anfang an nicht den ideellen Maßstäben, die Settembrini an den ,Westen anlegt. Doch im Flachland, das in der Topologie des Romans dem ,Westen< entspricht, konnte er dieser Neigung nicht nachgeben. Erst das `östlich konnotierte Sanatorium ermöglicht es ihm, der bekömmlicheren »untätigen Ruhe« (s.o.) offen zu frönen. Dies äußert sich besonders markant an seiner Begeisterung für die »Liegekur $(Z$ 109), die neben üppigen Mahlzeiten den Kern der Therapie bildet. Die Liegekur sei »das Beste hier «, soweit er sehe, sagt Castorp gleich zu Beginn seines Aufenthalts: »Ich wollte, ich läge schon wieder auf meinem vorzüglichen Stuhl.« (Z 109) Dass Castorp den Großteil des Tages in diesem Liegestuhl zubringt, ist ein klares Zeichen dafür, dass er nicht an der »umgestaltenden Tätigkeit« (s.o.) des ,Westens teilhat. Zwar behauptet Castorp, den Liegedienst auch für wissenschaftliche Zwecke zu nutzen (v.a. im Kapitel »Forschungen«), sodass man meinen könnte, er sei zumindest durch seine geistige Tätigkeit am Projekt der »Aufklärung, der vernunftgemäßen Vervollkommnung« (s.o., $Z$ 240) involviert, das Settembrini zufolge den `Sieg< über den inaktiven `Osten< davontragen wird. Doch dieses sStudium< ist nur ein Vorwand für eine sinnliche Träumerei. Der darin angedeutete aufklärerische Impetus wird mehrmals enttäuscht, was zum Beispiel im Krankenbesuch Settembrinis während Castorps erster Bettruhe zum Ausdruck kommt: 
LS: »Guten Abend, Ingenieur! Ist es erlaubt, sich nach Ihnen umzusehen? Wenn ja, so bedarf es dazu des Lichtes, — verzeihen Sie meine Eigenmächtigkeit!« sagte er, indem er die kleine Hand schwunghaft zur Deckenlampe emporwarf. »Sie kontemplierten, — ich möchte beileibe nicht stören. Neigung zur Nachdenklichkeit wäre mir ganz begreiflich in Ihrem Fall[...].

HC: [...] Sie stören mich keine Spur. Ich lag da und sinnierte, — sinnieren ist schon zu viel gesagt. Ich war einfach zu faul, das Licht anzudrehen. (Z 295)

Die »Nachdenklichkeit«, die Settembrini erwartet, wird von Castorp mit Witz enttäuscht. Während Settembrini kommt, um ihn aufzuklären - das Motiv des Lichts ist schließlich das Symbol der Aufklärung -, taugt Castorp nicht mal zur Minimaltätigkeit des Sinnierens, und ist für die Erleuchtung - in doppeltem Sinne - zu faul.

Castorps Unterwanderung des >westlichen Prinzips wird noch verstärkt durch den erotischen Diskurs in der längsten Liegekur-Episode im Kapitel "Forschungen«, in dem er vielfach als devote Figur gezeichnet wird. So zum Beispiel in dem sexuellen Traum, der ihn dort überkommt: Ihm erscheint »irgendwo im Raume, entrückt und doch sinnennah, der Leib, der Körper « ( $Z$ 419) Frau Chauchats - sie ist nicht namentlich erwähnt, aber an den »Augen, die eine Varietät der Lid-hautbildung schief erscheinen ließ« (ebd.) erkennbar - ${ }^{40}$ die sich über Castorp neigt, bis »er auf seinen Lippen die feuchte Ansaugung ihres Kusses « $\left(Z\right.$ 434) fühlt. ${ }^{41}$ Hier ist im Gegensatz zu der herkömm-

40 In einem früheren Cespräch mit Hofrat Behrens erklärt dieser Castorp: »Die Lidspalte, sagen Sie, ist geschlitzt, schief. Das scheint Ihnen aber nur so. Was Sie täuscht, ist der Epikanthus, das heißt eine Varietät, die bei gewissen Rassen vorkommt und darin besteht, daß ein Hautüberschuß, der von dem flachen Nasensattel dieser Leute herrührt, von der Deckfalte des Lides über den inneren Augenwinkel hinabreicht.« (Z 39of.) Es ist typisch für den Mann'schen Schreibstil, einmal gewählte Formulierungen für eine Idee im Laufe des Romans beizubehalten, sodass das Vorkommen der Begriffe »erscheinen«, »Varietät«, »Lid« und »Haut« zweifelsfrei auf Clawdia Chauchat verweist.

41 Diese ganze Episode verweist im Übrigen auf das Orient-Motiv in Schlegels Lucinde. Dort konstatiert Julius: »Cleich einem Weisen des Orients war ich ganz versunken in ein heiliges Hinbrüten und ruhiges Anschauen der ewigen Substanzen, vorzüglich der Deinigen und der meinigen. [...] [N]ur die im Orient verstehen zu liegen; wo hat sich aber der Geist zarter und süßer gebildet als in Indien?« Friedrich Schlegel: Lucinde. Mit: Friedrich Schleiermacher. Vertraute Briefe über Schlegels >Lucinder. Hg. v. Ursula Schröder. Frankfurt a.M.: Ullstein (1980), 31, 33. Heide Volkening weist darauf hin, dass der Schlusssatz dieser Betrachtung (»Anschauen der ewigen Substanzen, vorzüglich der deinigen und meinigen «, Herv. meine) eine sexuelle Konnotation enthält. Vgl. Heide Volkening: Über Europäische Arbeit und die Orientalische Kunst der Passivität. Friedrich 
lichen Aktivitätsverteilung der >Ost $</$ West $<$ Opposition Castorp als $>$ Westler passiv, und wird von der aktiven >Ostlerin « verführt. Die Verbindung von Passivität und Sexualität kommt im selbigen Kapitel häufiger vor. So zum Beispiel im Vorgang des parasitären Befalls eines passiven menschlichen Organismus, den Castorp in seinen Forschungen nachvollzieht, und der sich Elisabeth Strowick zufolge als »erotisches Geschehen " gestaltet. ${ }^{42}$ Kurz vor der eben beschriebenen Kuss-Szene ist die Rede von »besonders üppige[n] Gewebsformen -, hervorgerufen durch das Eindringen fremdartiger Zellen in einen Organismus, der sich für sie aufnahmelustig erwiesen hatte", und der ihnen »berauscht, [...] in Hochtemperatur, mit wogendem Busen « unterliegt ( $Z$ 431f., Herv. meine). Der untätige Castorp wird hier als unterwürfiger Charakter beschrieben, der sich sexuell daran berauscht, der Schwächere zu sein.

Dies lässt freilich die kolonialen bzw. orientalistischen Verweise, die oben diskutiert wurden, in neuem Licht erscheinen. Es ist nicht der tatkräftige Deutsche aus dem >Westen<, der die untätige >Asiatin< begehrt und sich ihren Körper aneignet; er selbst ist der Untätige, zudem Liegende, der imaginiert, von der stehend sich über ihn neigenden >Asiatin< ergriffen zu werden. Dieser Rollenwechsel ist nicht zuletzt ein Hinweis auf das homoerotische Interesse Castorps, der an Clawdia Chauchat ja auch deshalb interessiert ist, weil sie ihn an seinen ehemaligen Mitschüler erinnert, in den er (wenn auch unbewusst) verliebt gewesen war: den Kirgisen Pribislav Hippe (vgl. $Z$ 188f.). Castorps Sehnsucht nach Untätigkeit - und die damit einhergehende Abwendung von der swestlichen< Idee einer dominanten männlichen Sexualität - subvertiert die Machtdynamik heteroerotischer Imagination, die den imperialen Diskurs in Europa über Jahrhunderte hinweg mitgeformt hat. Dass in diesem Fall dennoch der >Orient zum Ort dieser Subversion geworden ist, verweist auf die homoerotische Komponente im europäischen Orientalismus, auf deren lange übersehene Bedeutsamkeit Joseph Allen Boone aufmerksam gemacht hat. Der so oft als sexuell zügellos beschimpfte `Orient diente nämlich auch den

Schlegels »Idylle über den Müßiggang«. In: Arbeit und Müssiggang in der Romantik, 124. Die Studienepisode im Liegestuhl kopiert die Wortwahl Schlegels ebenso wie dessen ironische Auflösung der >orientalischen`Meditation: Die 15 Seiten umfassende Episode im Kapitel »Forschungen«, in der Hans Castorp die Frage »Was war das Leben?« ( $Z$ 416) anhand von naturwissenschaftlicher Fachliteratur zu beantworten sucht, enthält das Wort »Substanz« (bei Schlegel: »ewige[...] Substanzen«) ganze 11 mal (von nur 14 Vorkommnissen im ganzen Roman). Elisabeth Strowick: Sprechende Körper-Poetik der Ansteckung. Performativa in Literatur und Rhetorik. München: Fink (2009), 266. 
Europäern als Möglichkeit, der rigiden sexuellen Ordnung des >Okzidents` zu entkommen und homoerotisches Interesse auszuleben. ${ }^{43}$ Castorps Tendenz zur Passivität ist also auch Ausdruck eines sexuellen Eskapismus, der im `Orient einen idealen Nährboden findet.

Die von Settembrini postulierte Hierarchie ist somit auf jeden Fall aufgebrochen: der >Westen $<$ ist zur Untätigkeit verkommen, und scheint die Dominanz durch den Osten geradezu herbeizusehnen. Diese Umkehrung des kolonialen Eros steht natürlich im Gegensatz zu der These, dass dem Motiv des `Ostens $\prec$ bzw. des `Orients das koloniale Begehren des Deutschen Reichs nach Besitz und Dominanz eingeschrieben ist. Tatsächlich begehrt Castorp nicht die untätige Frau, sondern die Untätigkeit selbst; nicht als Objekt will er sie sich aneignen, sondern als Eigenschaft.

\section{Angst vor dem 0sten}

Die im vorherigen Unterkapitel herausgestellte Diskrepanz zeigt, dass Der Zauberberg als literarischer Text mit dem Motiv der >östlichen` bzw. sasiatischen Untätigkeit bestehende Diskurse - wie die des kolonialen Begehrens aufgreift. Nicht aber, um sie zu reproduzieren, sondern um sie zu destabilisieren.

Tatsächlich verrät Castorps >Lagerwechsek $<$ - topologisch von $>$ West $<$ nach >Ost<, vom Flachland ins Bergland, semantisch von der Aktivität zur Inaktivität - dass Settembrinis Opposition >Ost</Inaktivität und >West</Aktivität nicht, wie orientalistische Diskurse zumeist suggerieren, einen wahrgenommenen Ist-Zustand darstellt, sondern ein unbedingt zu etablierendes Ideal. Die Tatsache, dass Castorp diesem >westlichen $<$ Ideal nicht entspricht und sich stattdessen dem des >Ostens` verschreibt, stellt in den dergestalt in Settembrinis Rede semantisch besetzen Räumen des Romans eine ereignishafte Grenzüberschreitung dar. ${ }^{44}$ Dies versetzt Settembrini in Panik. Nicht zufällig beginnt nur wenige Seiten, nachdem Castorps Verliebtsein in Chauchat zum ersten Mal explizit gemacht wird ( $Z$ 349), eine Verlagerung seiner Rhetorik. Er äußert eine andere, den Ton des pädagogischen Kursus verschärfende Empfindung: die Angst vor >Asien . Anstatt, wie bisher, Castorp aus Prinzip

\footnotetext{
43 Vgl. Joseph A. Boone: The Homoerotics of Orientalism. New York: Columbia UP (2015), xxi.

44 Vgl. die strukturale Erzähltheorie Lotmans. Jurij M. Lotman: Die Struktur literarischer Texte. Übers. v. Rolf-Dietrich Keil. München: Fink (1972), 336.
} 
(d.h. mit dem Verweis auf seine seuropäische< Natur) zur Rückkehr ins Flachland und damit in den $>$ Westen und zur Tätigkeit zu drängen, ${ }^{45}$ behauptet er plötzlich die Omnipotenz >Asiens`, gegen die sich Europa zur Wehr setzen muss:

[»]Asien verschlingt uns. Wohin man blickt: tatarische Gesichter.« Und Herr Settembrini wandte diskret den Kopf über die Schulter. »Dschingis-Khan«, sagte er, „Steppenwolfslichter, Schnee und Schnaps, Knute, Schlüsselburg und Christentum. Man sollte der Pallas Athene hier in der Vorhalle einen Altar errichten, - im Sinne der Abwehr. (Z 366, Herv. meine)

Diese Angst vor einem nun plötzlich doch aktiven >Osten`, die Settembrini artikuliert, war im frühen 20. Jahrhundert ein europäisches Phänomen, mit ganz verschiedenen Ursachen und Ursprungsländern. ${ }^{46}$ Der Zauberberg nimmt konkret auf zwei Diskurse Bezug: einerseits bezieht sich der Roman implizit auf die in Deutschland weit verbreitete Wahrnehmung einer wirtschaftlich-politischen Übermacht `Asiens‘; andererseits bezieht sich der Roman explizit auf eine historisch kaum nachweisbare Angst vor einer gedanklichen Kontamination mit rasiatischer Philosophie über das Nichtstun. Obwohl Settembrini den >Osten zuvor als inaktiv charakterisiert hatte, bezieht sich die hier genannte Angst tatsächlich auf die ihm in mehrerer Hinsicht neu zugeschriebene Handlungsfähigkeit.

Der Eindruck einer wirtschaftlich-politischen Übermacht >Asiens` ergibt sich aus dem Zusammenspiel vieler historischer Ereignisse. Ein wahrgenommener Krisenherd war Russland, das (spätestens) ${ }^{47}$ seit den Revolutionen 1905

45 Das passiert übrigens auch in Abgrenzung zu anderen Topoi wie der Psychoanalysesie sei schlecht »insofern sie die Tat verhindert, das Leben an den Wurzeln schädigt, unfähig, es zu gestalten « (Z 338, Herv. meine) - und der Musik - sie sei ein Opiat, welches »Dumpfsinn, Beharrung, Untätigkeit, knechtischen Stillstand«schaffe (Z175, Herv. meine).

46 Wie bereits zu Beginn des Kapitels erwähnt werden im Zauberberg die Begriffe >Osten<, >Asien « und >Russland « nicht klar voneinander unterschieden, vielmehr handelt es sich dabei um Konglomerate verschiedener Ideen. Ein Grund dafür ist Gollwitzer zufolge die allgemein ängstliche Beschaffenheit der damaligen Bevölkerung, die Cefahrvon vielen verschiedenen Ländern ausgehen sah; es habe eine »nervöse und hektische Geistesverfassung der Bevölkerung moderner Großstaaten « gegeben, die anfällig war »für stets wechselnde, sensationell und aufputschend formulierte Denksurrogate«. Gollwitzer: Die gelbe Gefahr, 37.

47 Gollwitzer schreibt, »die Vorstellung einer »russischen Gefahr« oder einer »Gefahr aus dem Osten« selbst« habe es schon vor dem 20. Jahrhundert gegeben, sie führe 
und 1917 als Bedrohung empfunden wurde, was sich auch vielfach im literarischen Schaffen der Zeit äußerte. ${ }^{48}$ Die Angst, von russischen Kräften irgendwie >überwältigt‘ $\mathrm{zu}$ werden, wurde außerdem durch massenhafte Migrationsbewegungen aus Osteuropa Ende des 19. und Anfang des 20. Jahrhunderts weiter verstärkt. Mehr als 4 Millionen Deutsche waren im Laufe des 19. Jahrhunderts ausgewandert - hauptsächlich nach Amerika - und der gesteigerte Bedarf an Arbeitskraft in den industriellen Zentren Deutschlands führte zu einer sprunghaft gestiegenen Immigration. Aufgrund der expansiven deutschen Außenpolitik nach Osteuropa kamen die meisten Einwanderer von dort. So ließen sich gut 500000 Polen dauerhaft im Rheinland und Ruhrgebiet nieder (die sog. Ruhrpolen), mehrere hunderttausend polnische Gastarbeiter befanden sich zeitweise hier, und mehr als 5 Millionen Osteuropäer durchquerten Deutschland auf ihrem Weg zum Atlantik, um nach Amerika zu reisen - alles noch vor dem 1 . Weltkrieg. ${ }^{49}$

»über das napoleonische Zeitalter bis zu Montesquieu zurück«. Collwitzer: Die gelbe Gefahr, 41. Folgt man Nina Bermans konzisem Abriss der »ökonomischen und politischen Interdependenz « zwischen Deutschland und dem `Osten« seit dem Mittelalter, so findet man auch viele Hinweise auf weiter zurückliegende Ängste vor dem Osten (Berman thematisiert zum Beispiel die »anhaltende Furcht vor dem expandierenden Osmanischen Reich«im 17. Jahrhundert), die sich im deutschen Ceschichtsbewusstsein verfestigt haben mögen. Berman: Orientalismus, 18-35, hier 18 und 26. In der Wahrnehmung dieser Geschichte darf natürlich nie vergessen werden, dass es in Europa immer auch, und das nicht in geringerem Maße, Interesse, Begeisterung und gar »Euphorie« für den `Orient « gegeben hat - ganz im Sinne der unauflöslichen Verbindung von Begehren und Angst, Eros und Thanatos im Blick auf den Osten. Berman: Orientalismus, 30 .

48 Edward Engelberg führt dies aus: »The fear of the East was widespread among »Western«writers, especially after the Russian Revolution.«Edward Engelberg: Ambiguous Solitude. Hans Castorp's Sturm und Drang nach Osten. In: A Companion to Thomas Mann's The Magic Mountain, 107. Weiter heißt es: »Yeats placed unflattering »vague Asiatic immensities « in contrast to Phidian »measurement«; Eliot envisioned »hooded hordes« threatening Western civilization; Hesse asserted that The Brothers Karamazov was the »cause« of Europe's »Untergang«; and, in The Magic Mountain, Mann plays out the contrast in so many ways that the subject commands attention. (Ebd. 98)

49 Diese Migrationsbewegungen, insbesondere das Recht vieler Polen auf die deutsche Staatsbürgerschaft, wurde in der deutschnationalen Presse als Invasion dargestellt, die aufgrund von angeblicher interkultureller Inkompatibilität negativ bewertet wurde. Als besonders bedrohlich wurde die Einwanderung von Juden aus Russland beschrieben, als eine quasi apokalyptische >Flut von Osten`, was einen enormen Antisemitismus schürte. Hier wurden unter anderem Ängste vor politisch radikalen Kräften, Krankheiten und Epidemien genährt - und anti-semitische Stereotype verbanden sich 
Auch von China und Japan schien Gefahr auszugehen. Der sogenannte Boxeraufstand von 1900, bei dem sich in China anti-imperialistische Ressentiments in einer Auflehnung gegen deutsche (und andere) Kolonisatoren entluden, hatte die Angst der Deutschen ursprünglich entfacht. Hatte man diese Unruhen noch »verhältnismäßig mühelos niedergeschlagen, so zeigte der Sieg Japans über Rußland 1904/05, daß im Fernen Osten eine sehr ernstzunehmende militärische Kraft entstanden war «. ${ }^{50}$ Doch es war nicht nur die Angst vor einer nunmehr umgedrehten Kolonisierung durch China oder Japan, ${ }^{51}$ die die Deutschen umtrieb, sondern die wirtschaftliche Kraft dieser Länder, die sich an der rasant wachsenden Produktion und den großen Zahlen verhältnismäßig billiger Arbeitskräfte ablesen ließ. Die Mitte der 1890er Jahre von der Preußischen Regierung geprüfte Idee, große Gruppen chinesischer Arbeiter (die sogenannten Kulis) zu simportieren um die ausgewanderten Deutschen zu sersetzen < - die übrigens massive, nationalistisch motivierte Proteste in der Presse hervorgerufen hat, sodass diese Pläne aufgegeben wurden -, trug das ihre dazu bei. Diese im Diskurs des deutschen Nationalismus verankerte Tendenz, im Speziellen die chinesischen Arbeiter und Semantiken des Ostens ganz generell mit der Empfindung des Bedroht-Seins zu beschreiben, ist ein elementarer Bestandteil des transnationalen Phänomens der »Gelben Gefahr«:

Man verstand unter »Gelber Cefahr« eine Drohung, die von Chinesen oder Japanern oder beiden zusammen gegen die weißen Völker ausgehen sollte. Die Art und Weise der Cefährdung wurde verschieden aufgefaßt. Einmal fürchtete man in der Arbeiterschaft weißer Länder den Kuliwettbewerb, die Unterbietung durch billige Arbeitskräfte mit minimalem Lebensstandard. Zum anderen ängstigten die Wirtschaft Europas und Amerikas die Erfolge

mit der Angst vor dem >Osten « und >Asien«. Vgl. Sebastian Conrad: Globalization effects. Mobility and nation in Imperial Cermany. 1880-1914. In: Journal of Clobal History 3 (1), 2008, 52-55.

50 Collwitzer: Die gelbe Gefahr, 30.

51 Diese Angst ist, zumindest in Bezug auf China, nie wirklich begründet gewesen, wie Jürgen Osterhammel ausführt. »Niemals ging von China eine weiträumige, den Charakter von Grenzsicherung und Grenzlandkolonisation überschreitende Expansionsbewegung aus«. Jürgen Osterhammel: China und die Weltgesellschaft. Vom 18. Jahrhundert bis in unsere Zeit. München: Beck (1989), 6. Die im weiteren Verlauf des Kapitels erläuterte »Gelbe Gefahr«, im Rahmen derer eine solche Angst prävalent wurde, ist ein kumulativer Effekt vieler Vorkommnisse des frühen 20. Jahrhunderts, und nicht die Reaktion auf eine wahrscheinliche und konkrete Gefahr. 
der japanischen Produktion. Von weitergehenden Befürchtungen hinsichtlich der Industrialisierung des Fernen Ostens war bereits die Rede. Drittens entwarf man das Zukunftsbild auch vollständiger politischer Emanzipation der großen gelben Nationen, die sich, ausgerüstet mit moderner Bewaffnung, erheben, aufgrund ihrer zahlenmäßigen Überlegenheit die Europäer und Amerikaner aus Ostasien entfernen und die Vorherrschaft in Asien, vielleicht sogar die Weltherrschaft, erringen könnten. ${ }^{52}$

Im Deutschen Reich (wie in anderen Ländern) wurde also eine dreifach motivierte Angst geschürt: die, im eigenen Land von eingewanderten billigen Gastarbeitern vom Arbeitsmarkt gedrängt zu werden; die, gesamtwirtschaftlich von Ländern aus dem Osten übertrumpft zu werden; und letztlich die, den neu formierten Kräften in Asien politisch zu unterliegen. Diese zeitgenössischen, in der deutschen Presse vieldiskutierten Ängste bezüglich China und Japan fließen mit in den Zauberberg ein. Darin mischen sich ebenfalls Visionen einer »weltgeschichtliche[n] Opposition von untergehendem Abendland und anbrechender Herrschaft des Ostens «, ${ }^{53}$ die Oswald Spengler in Vorausblick einer Hochphase der russischen Kultur prophezeit. ${ }^{54}$

\section{Collwitzer: Die gelbe Gefahr, $19 f$.}

53 Barbara Beßlich: Faszination des Verfalls. Thomas Mann und Oswald Spengler. Berlin: Akademie (2002), 55. Beßlich ist der Meinung, dass sich diese Opposition eben in der Konfrontation zwischen Castorp und Chauchat spiegele. Der Einfluss Spenglers auf Thomas Mann in den Jahren nach dem Ersten Weltkrieg ist gut dokumentiert. Vgl. hierzu beispielsweise Roger A. Nicholls: Thomas Mann and Spengler. In: The German Quarterly 58 (3), 1985, 361-374.

54 Vgl. hierzu ebenfalls Beßlich: Faszination des Verfalls, 73-80. Zum Verständnis der Beziehung zwischen dem Zauberberg und Spenglers Ceschichtsphilosophie wäre eigentlich noch eine handlungsorientierte Analyse erforderlich. Beßlich argumentiert, der Zauberberg zeichne »den Wechsel vom faustisch, aktiv, emporstrebenden zum russisch, passiv, in die Weite blickenden Leben nach « (77). Für Spengler ist diese Verteilung aber gar nicht so statisch: Er ist ja gerade der Meinung, dass das »faustische Weltgefühl der Tat, wie es von den Staufen und Welfen bis auf Friedrich den Großen, Goethe und Napoleon in jedem großen Menschen wirksam war, [...] zu einer Philosophie der Arbeit« verflachte, und dass die exzessive Hinwendung zur Arbeit den Untergang des Abendlandes geradezu befeuere. Oswald Spengler: Der Untergang des Abendlandes. Umrisse einer Morphologie der Weltgeschichte. Bd. 2. München: Beck (1979), 454. Die ,faustische Tatenfreude ist also bereits im Abendland nicht mehr möglich, und muss demnach, da Russland eine dem Abendland analoge, aber später einsetzende Entwicklung vollzieht, in der Zukunft zu einem russischen Charakteristikum werden. Mann mag also, wie Beßlich schreibt, den Zauberberg als Inszenierung eines endzeitlichen »formlose[n] 
Der historische Diskurs einer Angst vor der Stärke östlicher Gegner (d.i. der Aktivität) wird im Roman also aufgegriffen, und abgewandelt zu einer Angst vor ihrer Schwäche (d.i. der Inaktivität). ${ }^{55}$ Wie bereits in der Einführung $\mathrm{zu}$ diesem Kapitel skizziert, herrscht zwischen den widersprüchlichen Semantisierungen des asiatischen Raums ein Verhältnis der Projektion. Als psychoanalytisches Modell bedeutet Projektion einen Umgang mit Hassgefühlen, bei dem »the self projects all that is undesirable onto another, while concealing any traces of that projection «. ${ }^{56}$ Dieses Modell erklärt zum einen die Gefühlslage Settembrinis in der Diegese, der die >Ost</inaktiv->West</aktiv Opposition etabliert. Während sein höchstes Ideal die Tat ist, ist auch er im Sanatorium gefangen und so zur Untätigkeit verurteilt. Hans Wysling weist darauf hin, dass Settembrini zwar »die Wertewelt des Flachlands und des Westens: der Ratio und der Tätigkeit« vertrete, allerdings neige er nur, »in Worten[...] zum Aktivismus, zur Revolution «. ${ }^{57}$ Der Ärger über seine eigene Inadäquatheit äußert sich somit in der Projektion derselben auf die russischen Kurgäste, und den Osten im Allgemeinen. Die Bemühungen, Castorp zur Rückkehr ins Flachland und deshalb zur Tat zu überreden, sind ebenfalls Verlagerungserscheinungen; er will an der Figur Castorp das erreichen, was er will, aber selbst nicht kann. Zum anderen operiert die Projektion auch auf allegorischer Ebene: um den Misserfolg des kolonial eifrigen aber auf der Stelle tretenden Deutschen Reichs zu verarbeiten, wird die deutsche, also >westliche< Untätigkeit auf den erstarkenden Osten projiziert. ${ }^{58}$

Settembrini selbst ist sich seiner Projektion nicht bewusst - das Selbst verbirgt »any traces of that projection«, wie oben beschrieben. Sie zeigt sich al-

Felachenvolk[es]« (74) verstehen, doch der Übergang >West/aktiv zu >Ost//inaktiv findet eigentlich umgekehrt statt: Der nicht mehr zur Tat fähige >Westen< sieht dem sich neu zur Tat aufschwingenden >Osten< bei seinem Aufstieg zu.

Hermann Hesse drückt 1926 übrigens die gleiche Verwunderung aus: »Es herrscht bei uns, trotz jener jungen China-Begeisterung, noch immer in weitesten Kreisen die Meinung, die Seele des Chinesen sei der unseren doch eigentlich vollkommen fremd. Seine Tugenden, vor allem seine unermüdliche Geduld und sein stiller, zäher Fleiß, seien eigentlich mehr passiver Natur«. Hermann Hesse: Chinesisches. In: Ders.: Eine Literaturgeschichte in Rezensionen und Aufsätzen. Hg. v. Volker Michels. Frankfurt a.M.: Suhrkamp (1975), 28. Herv. meine.

Sara Ahmed: The Cultural Politics of Emotion. Edinburgh: UP (2014), 49. 
lerdings aus dem Widerspruch, in den seine Opposition mit anderen Verfahren des Romans tritt; die Uneindeutigkeit in der Zuordnung der Figuren zu den dergestalt semantisierten Räumen wurde bereits anhand des Verhältnisses von Castorp und Chauchat besprochen. Die Topographie des Romans, die Flachland und Bergwelt miteinander konfrontiert, deckt sich nicht mit Settembrinis Semantisierung der Welt als >westlichく tätig und ‘östlichく untätig. Denn in der Bergwelt herrscht ausnahmslos die Untätigkeit, obwohl sie von >westlichen` wie >östlichen « Charakteren bevölkert wird - so auch von Castorp und Settembrini. Das Sanatorium wird somit erst einmal zum Beobachtungsraum für die gefürchtete Kontamination des >Westens` mit der >östlichen Untätigkeit. Die Wirkmacht, die Settembrini dem `östlichen< Nichtstun zuschreibt, leitet sich aus dessen Kontaminationspotential her. Daran lässt sich ein weiterer Widerspruch erkennen, in diesem Fall sogar mit einer zuvor von Settembrini selbst getroffenen Aussage: Die Bedrohung durch den >Osten< im Roman (»Asien verschlingt uns. « $Z$ 366) wird nicht in Bezug auf seine möglicherweise überwältigende Stärke, sondern auf die Ansteckungsgefahr seiner Inaktivität zurückgeführt. So beschreibt Settembrini den >Osten einige Male als gefährlichen Virus, mit dem sich Hans Castorp trotz seiner vermeintlichen >westlichen< Überlegenheit infizieren könne:

»Wissen Sie nicht, daß es grauenhaft ist, wie Sie mit den Monaten herumwerfen? Grauenhaft, weil unnatürlich und Ihrem Wesen fremd, nur auf der Gelehrigkeit Ihrer Jahre beruhend. [...] Reden Sie nicht, wie es in der Luft liegt, junger Mensch, sondern wie es Ihrer europäischen Lebensform angemessen ist! Hier liegt vor allem viel Asien in der Luft, - nicht umsonst wimmelt es von Typen aus der moskowitischen Mongolei! Diese Leute - und Herr Settembrini deutete mit dem Kinn über die Schulter hinter sich - »richten Sie sich innerlich nicht nach ihnen, lassen Sie sich von ihren Begriffen nicht infizieren [Herv. meine], setzen Sie vielmehr Ihr Wesen, Ihr höheres Wesen gegen das ihre, und halten Sie heilig, was Ihnen, dem Sohn des Westens, des göttlichen Westens, - dem Sohn der Zivilisation, nach Natur und Herkunft heilig ist, zum Beispiel die Zeit! Diese Freigebigkeit, diese barbarische Großartigkeit im Zeitverbrauch ist asiatischer Stil, - das mag ein Crund sein, weshalb es den Kindern des Ostens an diesem Orte behagt. Haben Sie nie bemerkt, daß, wenn ein Russe >vier Stunden sagt, es nicht mehr ist, als wenn unsereins seine sagt? Leicht zu denken, daß die Nonchalance dieser Menschen im Verhältnis zur Zeit mit der wilden Weiträumigkeit ihres Landes zusammenhängt. Wo viel Raum ist, da ist viel Zeit, - man sagt ja, daß 
sie das Volk sind, das Zeit hat und warten kann. Wir Europäer, wir können es nicht. Wir haben so wenig Zeit, wie unser edler und zierlich gegliederter Erdteil Raum hat, wir sind auf genaue Bewirtschaftung des einen wie des anderen angewiesen, auf Nutzung, Nutzung, Ingenieur! Nehmen Sie unsere großen Städte als Sinnbild, diese Zentren und Brennpunkte der Zivilisation, diese Mischkessel des Gedankens! In demselben Maße, wie der Boden sich dort verteuert, Raumverschwendung zur Unmöglichkeit wird, in demselben Maße, bemerken Sie das, wird dort auch die Zeit immer kostbarer. Carpe diem! Das sang ein Großstädter. Die Zeit ist eine Göttergabe, dem Menschen verliehen, damit er sie nutze - sie nutze, Ingenieur, im Dienste des Menschheitsfortschritts.«(Z 368f.)

Der zitierte Passus legt offen, dass die Angst vor dem >Osten` auch eine Angst vor der gedanklichen Kontamination des >westlichen Nichtstuns ist, die das ökonomische Verhalten des Westens stören würden. Es ist m.E. aus diesem Zusammenhang ersichtlich, dass hier unter dem Leitmotiv der >Zeit das Thema Wirtschaft verdeckt diskutiert wird, im Gegensatz zu der häufig getätigten Beobachtung, Mann hätte diesen Bereich im Roman völlig außer Acht gelassen. ${ }^{59}$ Settembrini will sein Argument durch die angeblich unterschiedliche Quantifizierung von Zeit untermauern - und nimmt damit im Übrigen indirekt Bezug auf Nietzsche, der wiederholt von den großen Mengen Zeit spricht, die Russland zu seiner Verfügung hat. ${ }^{60} \mathrm{Im}$ Gegensatz zu Nietzsche allerdings, der in Russland eine zukünftige Macht erkennt, legt Settembrini die sgroße Zeit als einen Mangel aus, indem er auf die physikalische Größe der Leistung $(\mathrm{P})$ verweist, die sich aus dem Quotienten von Arbeit $(\mathrm{W})$ und Zeit $(\mathrm{t})$ ergibt: $\mathrm{P}=\mathrm{W} / \mathrm{t}$. Die sasiatische Leistung ist viel geringer als die >westliche<, weil sie ein Vielfaches an Zeit für die gleiche Arbeit braucht. Diese unwirtschaftliche Zeitnutzung (d.h. ein mangelhaftes Tätigsein) wird durch die Darstellung als Infektionsstoff in den KrankheitsTopos des Romans eingespeist. Settembrinis `Ost $<->$ West $<-$ Dualismus wird da-

59 Vgl. Zum Beispiel die Äußerung Michael Mindens über den Zauberberg: „What is odd about Mann's otherwise encyclopaedic novel is that there is one sphere which is conspicuous by its absence, namely the economic one. « Michael Minden: The German Bildungsroman. Incest and Inheritance. Cambridge: UP (1997), 243.

60 Dieser intertextuelle Nachweis wird überzeugend dargelegt im Kapitel »Über den asiatischen Umgang mit der Zeit in Thomas Manns `Zauberberg « in Helmut Koopmann: Der schwierige Deutsche. Studien zum Werk Thomas Manns. Tübingen: Niemeyer (1988), $17 f$. 
mit in mehrerer Hinsicht unterlaufen: (1) Zum einen suggeriert die Möglichkeit einer Ansteckungsgefahr - sowohl auf körperlicher wie auf geistiger Ebene -, dass es letztlich keinen essentiellen Unterschied zwischen >östlichen und `westlichen` Figuren gibt. Eine Anfälligkeit für ähnliches Verhalten lässt eben auf eine konstitutionelle Ähnlichkeit schließen. (2) Settembrinis Rede führt dies vor: die paradoxe Kraft, die er dem >Untätigkeits-Virus`zuschreibt, wird durch seinen Monolog selbst bewiesen. Er, der den >Asiaten im Vergleich zu den >Europäern`, einen vierfachen Zeitverbrauch vorwirft, erwähnt selbst den »Nutzen« ganze vier Mal, und performiert damit genau das, wovor er Angst hat: einen unökonomischen Umgang mit der Zeit. Settembrini verschwendet mit seinen Wiederholungen nicht weniger Zeit als die vermeintlich langsamen Asiaten. »Über die Materialität der Sprache wird Infektion zur Performanz «, ${ }^{61}$ schreibt Elisabeth Strowick zur Poetik der Ansteckung im Zauberberg: diese metaphorische Lesart des Krankheits-Topos im Roman zeigt mit besonderer Deutlichkeit die Kontamination des Nichtstuns auf der Ebene der Rede auf, und dekonstruiert so zusätzlich die >Ost</inaktiv->West</aktiv Opposition.

Settembrinis paradoxe Idee eines wirkmächtigen Nichtstuns greift auch die Angst vor Verbreitung einer >östlichen Philosophie des Nichtstuns auf. Im Deutschland des frühen 20. Jahrhunderts lässt sich zum Beispiel eine verhältnismäßig breite Lao-Tse-Rezeption nachweisen, und eine daraus sich ergebende wachsende Kenntnis des Daoismus. ${ }^{62}$ Diese fernöstliche Philosophie bzw. Religion geht von einer unabänderlichen kosmischen Ordnung aus, in die aktives Handeln - gerade im Verständnis Hannah Arendts, d.h. Handeln als das Tun von etwas Neuem $-{ }^{63}$ gar nicht einzugreifen vermag. Der Daoismus formuliert deswegen die >Handlungsmaxime< des Nichtstuns, das unter dem Schlagbegriff des »wu wei« bekannt ist. »Tao ist ewig Nicht-Tun, « ${ }^{64}$ heißt es bei Lao-Tse, und »Hohe Tugend (tut) Nicht-Tun,/und es ist ihr nicht ums

\footnotetext{
61 Strowick: Poetik der Ansteckung, 263.

62 Schon seit der zweiten Hälfte des 19. Jahrhunderts gibt es in Deutschland ein wachsendes Interesse am Daoismus. »Von der Konfuzius-Bewunderung der Frühaufklärung über die architektonischen und kunstgewerblichen Chinoiserien des Rokoko bis hin zur Rezeption des Daoismus in der exotisierenden Kulturkritik seit der letzten Jahrhundertwende hat sich Europa von China vielfältig anregen lassen«. Osterhammel: China und die Weltgesellschaft, 3.

$63 \mathrm{Vgl}$. den Abschnitt»Handlung und Geschichte « in diesem Buch.

64 Lao-tse: Tao-Tê-King, 104 (XXXVII).
} 
Tun. ${ }^{65}$ Der Gründertext des Daoismus, das Tao-Tê-King war zwar schon seit 1870 in der Erstübersetzung von Victor von Strauß in Deutschland erhältlich gewesen, hatte jedoch aufgrund der Neuübersetzung 1911 durch Richard Wilhelm erneut Beachtung gefunden. ${ }^{66}$ Der Daoismus, der im ausgehenden 19. Jahrhundert nur am Rande zum deutschen Bildungskanon gehörte, gewinnt, so Heinrich Detering, »schlagartig eine ganz neue Dringlichkeit. Nun wird die Frage nach der chinesischen Kultur von einem akademischen oder ästhetischen Sonderinteresse zu einer zentralen Frage von politischer Bedeutung. ${ }^{67}$ Nicht zuletzt aufgrund der relativ neuen kolonialen Herrschaft über die chinesischen Hafenstädte wurde asiatisches Wissen verfügbar und relevant für die Deutschen und fand Eingang in ihre Literatur. Dabei ist es vor allem die daoistische Maxime des Nichtstuns, die in dieser Rezeption den größten Raum einnimmt. Dies schlägt sich auch im Zauberberg nieder, wie sich an Settembrinis Einlassungen im Gespräch mit Castorp und Naphta über eben diesen Aspekt zeigt:

Der Osten verabscheut die Tätigkeit. Lao-Tse lehrte, daß Nichtstun förderlicher sei als jedes Ding zwischen Himmel und Erde. Wenn alle Menschen aufgehört haben würden, zu tun, werde vollkommene Ruhe und Clückseligkeit auf Erden herrschen. (Z 568f.)

Der Topos >Asien wird also sowohl mit fernöstlicher Philosophie, die das Nichtstun propagiert, als auch mit einer Gefahr für den Westen durch Einwanderung und ökonomische Unterwanderung assoziiert, sodass der 〉Osten im Roman nicht nur als materielle, sondern auch als eine spirituelle Bedrohung dargestellt wird. Diese Art der Angst vor einer spirituell-religiösen Revolution aus dem `Osten hatte im frühen 20. Jahrhundert ein Vorbild, und zwar

65 Lao-tse: Tao-Tê-King, 107 (XXXVIII).

66 Willy Y. Tonn: Vorwort. In: Lao-tse: Tao-Tê-King, 5, 10.

67 Heinrich Detering: Anfänge einer modernen China-Rezeption in deutschen Kulturzeitschriften um 1900. In: Perspektiven der Modernisierung. Die Pariser Weltausstellung, die Arbeiterbewegung, das koloniale China in europäischen und amerikanischen Kulturzeitschriften um 1900. Hg. v. Ulrich Mölk u.a. Berlin: De Gruyter (2010), 158. Die Tatsache, dass die von Maximilian Harden herausgegebene Zeitschrift Zukunft »für den am Grenzbereich von Literatur und Journalismus lebhaft interessierten jungen Thomas Mann ein erklärtes Vor- und Leitbild war « (ebd. 164), spricht für eine Auseinandersetzung Manns mit chinesischem Gedankengut, denn in Zukunft wurde wiederholt das mangelnde deutsche Verständnis gegenüber China thematisiert und Texte Lao-Tses in Auszügen abgedruckt, um eine tolerantere deutsche Politik zu propagieren. 
in der Furcht vor dem Pan-Islamismus, der im Osmanischen Reich als Reaktion auf europäisch-imperiale Präsenz entstanden war. Deutsche Orientalisten wie Carl Becker, die politisch engagiert waren, warnten vor der zunehmenden Macht der Islamischen Welt und sprachen Empfehlungen zur >Zähmung، ihrer Kräfte aus, die andernfalls das Deutsche Reich in seinem "quest for world power « behindern würden. ${ }^{68}$ Im Zauberberg wird impliziert, dass das daoistische Denken sich analog verbreiten ${ }^{69}$ und Europa so schwächen könnte - entweder, weil sich seine wachsende Anhängerschaft verbünden und in Konkurrenz zum europäischen Denken (und konsequenterweise auch zum Handeln) treten könnte, oder weil die Inhalte des Daoismus Leistungsschwäche propagieren, die der (vermeintlich genuin europäischen) protestantischen Arbeitsethik zuwiderlaufen. ${ }^{70}$ Max Webers Studie über die Wirtschaftsethik der Weltreligionen - die übrigens zwischen 1915 und 1919 erschien, während Mann am Zauberberg arbeitete - greift eben diesen letzten Gedanken auf. Von den Grundlagen der Religion auf das wirtschaftliche und politische Verhalten schließend attestiert Weber dem Daoismus minimale Leistungsfähigkeit, denn »das höchste Heil war auch bei Laotse eine seelische Zuständlichkeit, eine unio mystica, nicht aber ein aktiv handelnd sich bewährender Gnadenstand wie bei der Askese des Okzidents. ${ }^{71}$ Die damit assoziierten Begriffe der Leere, des Nichts, und des Nichtstuns schlagen sich,

68 Suzanne L. Marchand: Cerman Orientalism in the Age of Empire. Religion, Race, and Scholarship. Cambridge: UP (2009), 365.

69 Aus der Zwischenkriegsperspektive heraus lässt sich Hesse sogar zu der Behauptung hinreißen, es habe »auf die vom Krieg aufgewühlte studierende Jugend Deutschlands [...], nächst Dostojewski, « seit 1916 »gewiß kein anderer Geist so stark gewirkt wie Laotse«. Hesse: Chinesisches, 27. Thomas Mann, wenngleich kaum ıstudiert`, war davon ebenfalls betroffen.

70 Die Parallelen zwischen dem Denken Max Webers und Thomas Manns wurden extensiv von Harvey Goldman aufgearbeitet, der zum Beispiel bezüglich der protestantischen Arbeitsethik und der politischen Dominanz des Westens folgendes ausführt: »For Weber, the role of Puritanism in empowering the first entrepreneurs revealed a source of inner strength and power that helped make the Occident uniquely what it was and became the model for his own prescriptions. For Mann, the bourgeoisie, as the class »home « of the impulses of work, calling, and innovation, was the most important historical actor in the drama of the West's development of power«. Harvey Coldman: Politics, Death, and the Devil. Self and Power in Max Weber and Thomas Mann. Berkeley: University of California Press (1992), 5 f.

71 Max Weber: Studienausgabe der Max-Weber-Cesamtausgabe. Abt. I, Bd. 19. Die Wirtschaftsethik der Weltreligionen. Konfuzianismus und Taoismus. Schriften 1915-1920. Hg. v. Helwig Schmidt-Clintzer. Tübingen: Mohr Siebeck (1991), 162. 
so Weber, in einer Politik des Nichtintervenierens, oder vielmehr in "prinzipiellem Apolitismus « nieder. ${ }^{72}$

Ruft man sich nun noch einmal die eingangs zitierte Opposition Settembrinis ins Gedächtnis - »Europa war das Land der Rebellion, der Kritik und der umgestaltenden Tätigkeit, während der östliche Erdteil die Unbeweglichkeit, die untätige Ruhe verkörperte« (s.o., $Z$ 240) - so ist nun klar, dass der Roman diese Eigenschaften nur benennt, sie jedoch umgekehrt inszeniert. Es sind letztlich die vermeintlich >westlichen dem `Osten` wird unerwartet Stärke zugesprochen. Der Zauberberg stellt also keine seuropäische Überheblichkeit dar, sondern Angst vor dem `Ostenく bzw. >Asien<, und nimmt alle zeitgeschichtlich verfügbaren Diskurse her, um trotzdem Untätigkeit auf den `Osten zu projizieren. Diese rhetorische Entkräftung des faktisch wirtschaftlich und politisch erstarkenden >Ostens` dient der Verschleierung der Angst - vor der Stärke des `Ostens`, und der Schwäche des >Westens $<$. Das Motiv der Untätigkeit im Roman stellt so auch die Projektion einer wahrgenommenen eigenen seuropäischen` Handlungsunfähigkeit dar.

Doch es stellt sich heraus, dass Untätigkeit nicht nur eine Schwäche des >Ostens`, sondern auch eine Stärke ist: das Nichtstun ist Kernelement einer weit verbreiteten fernöstlichen Philosophie/Religion, die das >westliche Denken kontaminiert. Das Nichtstun ist im Kontext dieser Zeit eine philosophische und kulturelle Praxis, der ebenso viel Wirkungspotential zugeschrieben wird wie der >östlichen Wirtschaft und Politik. Durch die inhärente Widersprüchlichkeit dieser zwei Aspekte entfaltet der Zauberberg eine seiner schönsten Ironien: Das Nichtstun wird mit solcher Heftigkeit dem Anderen zugeschrieben, dass es sich als das Eigene entblößt; es steckt trotz seiner vermeintlichen Schwäche fast alle Patienten im Sanatorium an, und entwickelt sich zu einem der stärksten Motive im Roman. Der Zauberberg führt die Widersprüche des Diskurses über den >Osten` vor Augen, indem er die eine Angst - die vor Ansteckung - im Mantel der anderen Angst - die vor Einverleibung - im Raum des Literarischen experimentell zu Ende denkt. Der Berg ist eine Art Labor, in dem die Kontamination durch die fernöstliche Untätigkeit schon fortgeschritten ist. Settembrini führt durch seinen performativen Widerspruch den Beweis dafür, dass seine eigene Opposition zwischen >Ost//inaktiv und >Westen/aktiv nicht haltbar ist. Das ist die Strategie des Romans: bei jedem Ver- 
such, die als seuropäisch`wahrgenommene Schwäche der Zeit auszublenden, zeigt er gleichzeitig die Unmöglichkeit dieser Ausblendung auf.

In dieser ironischen Behandlung des Verhältnisses zwischen `Ost und >West mit der Projektion in ihrem Zentrum verweist der Zauberberg - ob mit oder ohne Vorsatz - auf den deutschen Orientalismus des 19. Jahrhunderts, dem man aus der historischen Distanz heraus ähnliche Projektions- und Kompensationsdynamiken nachweisen kann. Das Motiv der Untätigkeit hat im deutschen Orientalismus nämlich eine ganz besondere, sich vom Kontext anderer Nationen deutlich unterscheidende Stellung. Obwohl das Deutsche Reich, wie oben bereits ausgeführt, erst in den 1880er-Jahren kolonial aktiv wurde, begann die Publikation orientalistischer Schriften schon früher. Bemerkenswert dabei ist, dass diese Schriften, insbesondere im früheren 19. Jahrhundert und innerhalb der Religionswissenschaft und Geschichtsphilosophie, Untätigkeit zu einer zentralen Eigenschaft fremder, und speziell östlicher Völker deklarieren, obwohl das Deutsche Reich zu diesem Zeitpunkt noch gar keine unmittelbare Kolonialerfahrung hatte. Betonungen wie die einer historischen Stagnation des >Orients bzw. >Ostens`, wie sie in der Orientalismus-Einführung dieses Kapitels näher beschrieben wurden, sind den meisten kanonischen Texten des deutschen Orientalismus im 19. Jahrhundert gemein, und fast immer sind sie mit der Behauptung einer mangelhaften Handlungsbefähigung verknüpft.

Daran ist vor allem interessant, dass die Zuschreibung der Inaktivität bzw. Indolenz - gleich anderen Ablehnungsmotiven wie der oben beschriebenen Despotie und der Leidenschaftlichkeit - in den imperialen Praktiken anderer europäischer Großmächte »legitimatorischen Zwecken [diente], da [sie] die Unterwerfung und im nicht seltenen Extremfall die Ausrottung der fremden Kultur sanktionierte «. ${ }^{73}$ Doch im Fall des deutschen Orientalismus war das Ziel des Untätigkeits-Postulats nicht die Legitimierung kolonialer Unterwerfung, ${ }^{74}$ sondern die Etablierung einer intellektuellen Autorität. ${ }^{75}$ Im

73 Peter ]. Brenner: Der Reisebericht in der deutschen Literatur. Ein Forschungsüberblick als Vorstudie zu einer Cattungsgeschichte. Tübingen: Niemeyer (1990), 110.

74 Vgl. die Ausführungen zum Orientalismus zu Beginn dieses Kapitels und Punkt (3) in der Diskussion des Zusammenhangs zwischen kolonialem Begehren und der Zuschreibung der Inaktivität als Kerneigenschaft kolonisierter (bzw. zu kolonisierender) Völker im Abschnitt »Inaktivität begehren«.

75 »[W] hat German Orientalism had in common with Anglo-French and later American Orientalism was a kind of intellectual authority over the Orient within Western culture.«Edward W. Said: Orientalism. New York: Vintage (1979), 19. 
Gegensatz zu den orientalistischen Diskursen erfolgreicher Kolonialmächte ${ }^{76}$ erfüllt die Zuschreibung der Inaktivität hier also keinen praktischen Zweck im politischen Sinne. Es findet vielmehr eine Selbstaufwertung statt: der rhetorische Kniff der Untätigkeits-Behauptung kompensiert die Tatsache, dass es aufgrund der fehlenden deutschen Teilhabe im Kolonialgeschehen überhaupt keine Praxis im Sinne eines realen Eingreifens geben kann.

Die Abwertung des Fremden als indolent, die sich im deutschen Orientalismus des 19. Jahrhunderts festgesetzt hatte, kann wohlbemerkt nicht einem konkreten kolonialen Begehren angelastet werden, denn, wie Suzanne L. Marchand unterstreicht, »unquestionably, before the 1880s, the Reich did not have a >culture of empire «. «77 Dennoch ist die wiederkehrende Behauptung einer >östlichen` Tendenz zur Untätigkeit - und das gerade in dem Jahrhundert, das in Europa die rapideste Aufwertung der Arbeit als Tätigkeitsform mit sich brachte - kein Zufall. Sie mag vielleicht nicht einem Wunsch nach kolonialer Dominanz oder legitimer Inbesitznahme auf staatlicher Ebene Ausdruck verleihen, doch durch sie wird die kulturelle Vorherrschaft Deutschlands versichert - und damit ein Geltungsdrang artikuliert. Susanne Zantop hat deshalb dem deutschen Orientalismus im Allgemeinen den Charakter des >Handlungsersatzes« zugeschrieben: »[it] had a different function: to serve not so much as ideological smokescreen or cover-up for colonial atrocities or transgressive desires, but as Handlungsersatz, as substitute for the real thing, as imaginary testing ground for colonial action «. ${ }^{78}$ Es ist anzunehmen, dass der >Aktivitätsgrad der Ersatzhandlung sich umso höher ausnimmt, desto niedriger die Handlungsfähigkeit des Beschriebenen angesetzt ist. So könnte man auch Saids Kommentar zur Entstehung deutscher Orientalismus-Schriften deuten: "There is some significance in the fact that the two most renowned German works on the Orient, Goethe's Westöstlicher Diwan and Friedrich Schlegel's Über die Sprache und Weisheit der Indier, were based respectively on a Rhine journey and on hours spent in Paris

76 In Bezug auf orientalistische Untätigkeitsbehauptungen bezieht sich Said in seiner Studie zum Beispiel nur auf englische und französische, d.h. aus den größten europäischen Kolonialreichen stammende Quellen. Er nennt u.a. die Schriften William Robertson Smiths, Alphonse de Lamartines, und Élie Faures als Beispiele. Vgl. Said: Orientalism, 237, 178, 253.

77 Marchand: German Orientalism in the Age of Empire, 337.

78 Susanne Zantop: Colonial Fantasies. Conquest, Family, and Nation in Precolonial Germany, 1770-1870. Durham: Duke UP (1997), 6. 
libraries. ${ }^{79}$ Diese Schriften sind selbst aus Situationen relativer Inaktivität hervorgegangen - eine Reise zum Rhein steht nicht auf einer Stufe mit der französischen Besetzung von Réunion, die Anwesenheit in der Bibliothek ist nicht vergleichbar mit einer Präsenz der Briten in Westafrika. Die im Deutschen fehlende weitreichende Reisetätigkeit und Machtausübung, und der damit einhergehende Minderwertigkeitskomplex, liefern einen möglichen Grund, aus dem diese relative Untätigkeit auf die wissenschaftlichen Objekte projiziert werden. Dass sich die deutsche Orientalistik ihres dauerhaft fehlenden Zugangs zu ihren Studienorten- und objekten noch bis ins 20. Jahrhundert schmerzlich bewusst war, beweist auch die Aussage des Arabisten Georg Kampffmeyers, der 1913 die Gründung einer neuen Islamzeitschrift feierte, die eine neue, aktivere Ära der Orientalistik abbilden würde:

Irre ich nicht, so gehen wir in Deutschland einer teilweisen Umwandlung unserer orientalistischen Wissenschaft entgegen. Nicht mehr so weltfremd sitzen wir, bei einsamem Lämpchen, in unserem Studierkämmerlein; auch wir sind hinausgetreten und fühlen das in unserem Volksganzen pulsierende Leben. ${ }^{80}$

Dieser Hintergrund hat erhellende Wirkung für das `östlicheく Inaktivitätsmotiv im Zauberberg. Obwohl Settembrini als Figur keineswegs koloniale Unterdrückung propagiert, ja, vielmehr für Volksrevolution und Demokratie einsteht, ruft er durch die Opposition >Ost</Inaktivität und >West</Aktivität orientalistische wie koloniale Diskurse auf, die die fehlende koloniale Involviertheit Deutschlands als Mangel empfinden und deshalb den `Osten $<$ abzuwerten suchen. Hier wie dort hängt die Behauptung, das Fremde sei inaktiv, mit dem Bewusstsein der tatsächlich eigenen Inaktivität zusammen, das aus dem im 19. Jahrhundert abwesenden und im frühen 20 . Jahrhundert als eingeschränkt wahrgenommenen kolonialen Erfolg herrührt, ebenso wie aus dem gefühlten wirtschaftlichen und militärischen Erstarken des Ostens. Settembrinis Abwertung des >Ostens`, seine Lobreden auf den >Westen`, sein fast schon verzweifeltes Bemühen um Castorps Rückkehr ins Flachland - also topologisch in das dem >Westen eignende Gebiet der Aktivität - sind allesamt »Ersatzhandlungen« (s.o.) des Handlungsunfähigen. Die Romangeschichte im Ganzen entblößt diesen Ersatzcharakter von Settembrinis Aktivismus, indem sie

79 Said: Orientalism, 19.

80 Georg Kampffmeyer: Plane Perspicere. In: Die Welt des Islams 1 (1), 1913, 4. 
zeigt, dass er, Castorp und andere >Westler $<$ nicht weniger und vielleicht sogar in größerem Maße untätig sind als die `Ostlerく.

\section{Politiken des Nichtstuns}

Der Roman Der Zauberberg inszeniert mit dem Berghof einen Raum, in dem sich verschiedene europäische Diskurse über den 〉Osten` begegnen. Diesen Diskursen liegt, gemäß meiner Behauptung im einführenden Abschnitt dieses Kapitels, in jedem Fall das Motiv des Nichtstuns zugrunde; sie konnotieren sich gegenseitig. Der Vorwurf der Indolenz wird von der Figur Settembrini funktionalisiert, um dem Osten Fortschrittsfähigkeit abzusprechen und ihn dadurch abzuwerten. Die Leidenschaftlichkeit, mit der Castorp die passive Frau Chauchat begehrt, zeigt koloniales Begehren eines einnehmbaren, da passiven, Anderen an. Doch die Besonderheit dieses Romans liegt darin, dass er diese orientalistischen Diskurse nicht einfach reproduziert, sondern umdreht. Das Nichtstun sagt nicht nur etwas über den >Osten<, sondern auch den >Westen « aus: dass er die Passivität selbst begehrt statt ihrer Beherrschung, und dass der Indolenz-Vorwurf die Projektion der Unsicherheit über eine >westliche< Handlungsfähigkeit ist.

Der eingangs beschriebene Diskurs der Despotie erfährt eine ähnliche Behandlung. Im Gegensatz zu der von Montesquieu beschriebenen Figur des >orientalischen< Despoten, der nichts tut und deswegen politisch unfähig sein soll, wird im Zauberberg eine alternative Form der >östlichen` Regierung entworfen, deren politische Funktionalität nicht infrage gestellt, sondern sogar topologisch untermauert wird. Daraus ergibt sich auch in der konkreten Frage politischer Führung eine Übermacht des Ostens, in dem der >Westen $<$ weiter systematisch abgewertet wird. Aus dieser erneuten Umkehrung der Opposition >Osten $/$ inaktiv und >Westen/aktiv leitet Castorp schließlich eine Abwendung von den zwei dominanten politischen Ideologien des >Westens $<a b$, die im Roman beide als abhängig von der Arbeit beschrieben sind - vom konservativen Monarchismus auf der einen und der progressiven Demokratie auf der anderen - , und zwar zugunsten einer dem Nichtstun verschriebenen Gemeinschaftsform.

\section{»Regieren«: Herrschaft durch Nichtstun}

In den einführenden Bemerkungen $\mathrm{zu}$ diesem Kapitel, ebenso wie in den theoretischen Ausführungen zu Beginn dieses Buches habe ich die Verbindung zwischen Nichtstun und Herrschaft skizziert. Dies ist auch im orienta- 
listischen Kontext relevant, denn in der Despotie fallen diese beiden Themen zusammen, und sind außerdem >östlich konnotiert. Auch dieser orientalistische Diskurs wird im Zauberberg aufgegriffen, wenn auch in einer Variation und auf eine weniger offensichtliche Weise. Es ist nicht Montesquieus Despotie, die verhandelt wird, sondern die daoistische Idee des Herrschens durch ein Nichtstun. Sie findet Niederschlag in einer Praxis, die Castorp »Regieren" nennt. Die - wohlbemerkt einzige - Stelle im Roman, an der das Regieren beschrieben wird, lautet (in Gänze) wie folgt:

Das Hochgebild organischen Lebens, die Menschengestalt, schwebte ihm vor, wie in jener Frost- und Sternennacht anläßlich gelehrter Studien, und an ihre innere Anschauung knüpften sich für den jungen Hans Castorp so manche Fragen und Unterscheidungen, mit denen sich abzugeben der gute Joachim nicht verpflichtet sein mochte, für die aber er als Zivilist sich verantwortlich zu fühlen begonnen hatte, obwohl auch er im Flachlande drunten ihrer niemals ansichtig geworden war und vermutlich nie ansichtig würde geworden sein, wohl aber hier, wo man aus der beschaulichen Abgeschiedenheit von fünftausend Fuß auf Welt und Kreatur hinabblickte und sich seine Gedanken machte, - vermöge einer durch lösliche Cifte erzeugten Steigerung des Körpers auch wohl, die als trockene Hitze im Antlitz brannte. Er dachte an Settembrini im Zusammenhang mit jener Anschauung, an den pädagogischen Drehorgelmann, dessen Vater in Hellas zur Welt gekommen, und der die Liebe zum Hochgebild als Politik, Rebellion und Eloquenz erläuterte, indem er die Pike des Bürgers am Altar der Menschheit weihte; dachte auch an den Kameraden Krokowski und an das, was er seit einiger Zeit im verdunkelten Zimmergelaß mit ihm trieb, besann sich über das doppelte Wesen der Analyse und wie weit sie der Tat und dem Fortschritte förderlich sei, wie weit dem Grabe verwandt und seiner anrüchigen Anatomie. Er rief die Bilder der beiden Croßväter neben- und gegeneinander auf, des rebellischen und des getreuen, die Schwarz trugen aus unterschiedlichen Gründen, und erwog ihre Würde; ging ferner mit sich zu Rate über so weitläufige Komplexe wie Form und Freiheit, Ceist und Körper, Ehre und Schande, Zeit und Ewigkeit, - und unterlag einem kurzen, aber stürmischen Schwindel bei dem Gedanken, daß die Akelei wieder blühte und das Jahr in sich selber lief. Er hatte ein sonderbares Wort für diese seine verantwortliche Gedankenbeschäftigung am malerischen Orte seiner Zurückgezogenheit: er nannte sie »Regieren «, - gebrauchte dies Spiel- und Knabenwort, diesen Kinderausdruck dafür, als für eine Unterhaltung, die er liebte, obwohl sie mit Schrecken, 
Schwindel und allerlei Herztumulten verbunden war und seine Gesichtshitze übermäßig verstärkte. Doch fand er es nicht unschicklich, daß die mit dieser Tätigkeit verbundene Anstrengung ihn nötigte, sich der Kinnstütze zu bedienen, denn diese Haltung stimmte wohl mit der Würde überein, die das »Regieren« angesichts des vorschwebenden Hochgebildes ihm innerlich verlieh. (Z 588f., Herv. meine)

Hinter dieser großen und vielversprechenden Bezeichnung des »Regierens« versteckt sich scheinbar zunächst >nur das Verweilen an seinem Lieblingsort, einer »abgeschiedenen, wildwasserdurchrauschten Waldschlucht mit Steg und Ruhebank« ( $Z$ 584), wo er über all das nachdenkt, was er im Sanatorium Berghof erlebt hat - er denkt an Settembrini, den "pädagogischen Drehorgelmann«, den »Kameraden Krokowski«, an »Zeit und Ewigkeit« und an vieles mehr. Alles scheint darauf hinzudeuten, dass es sich beim Regieren um einen euphemistischen Ausdruck für Denken handelt. Schließlich bezeichnen die Verben in diesem Passus - vorschweben, denken, besinnen, Bilder aufrufen, Gedanken machen, erwägen - allesamt geistige Tätigkeiten ohne Eingriff in die Welt. Sie gehören in Hannah Arendts Vorstellung zur vita contemplativa. >Regieren` im konventionellen Sinne des >Herrschens` hingegen impliziert einen klaren Weltbezug, und gehört damit zur vita activa: wer regiert, der ist im »besitz der gewalt « über etwas, oder mit der »leitung der geschäfte « betraut. ${ }^{81}$ Die Kombination von körperlicher Untätigkeit und der Tätigkeit des Denkens kommt für Hannah Arendt im politischen Kontext einem Nichtstun gleich, das gerade nicht politisch sein kann, weil politisches Handeln eine soziale, und deswegen körperlich aktive Tätigkeit ist. ${ }^{82}$

Auch suggeriert der Rahmen der Zauberberg-Geschichte mit größter Emphase, dass Castorp weder Geschäft noch Gewalt im Sinn haben kann - das Sanatorium ist ja gerade ein Ort, der von der Welt, und damit auch von ökonomischen und politischen Realitäten abgeschottet ist. Die ausgeprägte Selbstbezüglichkeit der meisten Romanfiguren (Castorp miteingerechnet), scheint die Möglichkeit, dass er mit >Regieren tatsächlich

81 Regieren. In: Deutsches Wörterbuch von Jacob und Wilhelm Grimm. Quellenverzeichnis Leipzig (1854-1961). Leipzig: S. Hirzel (1971), Bd. 14, Sp. 528. Nachfolgend mit Sigle DWB abgekürzt.

82 »[S]o bedarf das Handeln und Sprechen der Mitwelt, an die es sich richtet. [...] das Handeln und Sprechen vollzieht sich in dem Bezugsgewebe zwischen den Menschen«. Arendt: Vita activa, 234. 
>über etwas herrschen berg-Interpretationen verweisen gerade deshalb auf die reflexive, d.h. Ichbezogene Form dieses Verbs - >sich selbst< regieren heißt »sich verhalten, sich gestalten $«-{ }^{83}$ und legen die politische Konnotation (des Regierens als >Herrschen`) als Metapher aus. So argumentiert Hans Wysling zum Beispiel, dass aus dem Topos des »Regierens « Castorps Bestreben gelesen werden kann, "sich eine Verfassung, eine Welt- und Werteordnung zu geben «. ${ }^{84}$ In dieser Auslegung wird die Spannung zwischen >Regieren als Herrschen >Regieren als Denken aufgelöst, indem >Herrschen` ins Innere des Subjekts verlegt und als rein geistiger Vorgang verstanden wird.

Tatsächlich passiert in diesem Abschnitt des Romans aber auch noch etwas Politisches, auch wenn es nicht sofort erkennbar ist: Hans Castorp spielt ein Spiel. Dass das »Regieren« als »Kinderausdruck«, »Spiel- und Knabenwort« (s.o., $Z$ 589) beschrieben wird, verdeutlicht, dass es sich hier um ein (Schau-)Spiel handelt - Castorp spielt einen Regenten, und zwar einen speziell `östlichen`Regenten. Die `östliche`Färbung seines Spiels verrät die Einleitung des Abschnittes, Castorps Nachdenken über das »Hochgebild organischen Lebens, [...] wie in jener Frost- und Sternennacht anläßlich gelehrter Studien« (s.o.), da diese direkt auf Castorps sexuelle Phantasie aus dem Kapitel »Forschungen« verweist - der einzigen beschriebenen »Frostnacht« $(Z$ 428) des Romans bis zu diesem Zeitpunkt. Wie oben bereits ausgeführt wurde, nimmt in der dort imaginierten Kuss-Szene der >westliche Castorp die passive, devote Rolle ein, die Settembrini (und dem Orientalismus-Diskurs) zufolge dem >Osten zugeschrieben ist. Aufgrund dieses Verweises sollte Castorps »Regieren « in diesem Licht gelesen werden: als eine passive, əöstliche Praxis.

Der Aspekt der Leidenschaftlichkeit aus der Frostnacht ist hier jedoch durch den der Politik ersetzt, denn Castorps »Regieren« stellt die experimentelle Ausführung einer >östlichen Herrschaftsform dar: der daoistischen, die sowohl das Nichtstun als auch das Denken in ihrem Zentrum hat. Beim TaoTê-King von Lao-Tse - dessen Erwähnung im Zauberberg (vgl. $Z$ 568) wurde

\footnotetext{
83 Regieren. In: DWB Bd. 14, Sp. 531.

84 Wysling: Der Zauberberg, 402. Herv. meine. Joachim Schoepf schlägt analog dazu vor, die politische Komponente des Regierens auszublenden (es sei doch ansonsten etwas »merkwürdig«) und es stattdessen im Sinne des Lenkens oder Führens zu verstehen, welche, so impliziert Schoepf, lediglich auf die Gedankengänge Castorps zu beziehen sind. Joachim Schoepf: Die pädagogischen Konzepte in Thomas Manns "Zauberberg und ihre Wirkung auf die Hauptfigur Hans Castorp. Marburg: Tectum (2001), 97.
} 
hier bereits kurz besprochen - handelt es sich nämlich nicht nur um einen philosophischen, sondern auch um einen politischen Text, eine HerrschaftsAnleitung, wie Hans-Georg Moeller ausführt: »[T]he Laozi was used by this group [the cultural elite] as a guideline for the exercise of social power ", und »[i]nsofar as the Laozi was a text about rulership, it was just as much a guidebook for political leaders as many other 'philosophical writings in China were at that point. ${ }^{85}$ Entgegen der westlichen Tradition ist in der Vorstellung des Tao der ideale Herrscher eine neutrale, interessenlose Person, die paradoxerweise regieren kann, ohne handeln zu müssen: »Tao ist ewig Nicht-Tun,/und doch bleibt nichts ungetan./Wenn Fürsten und Könige (es) zu halten vermögen,/werden alle Wesen von selbst sich umwandeln $«{ }^{86}$ Der Zweck dieser Regierungsform ist die Unterbindung eigennütziger politischer Aktivität, die Unruhe in die kosmische Ordnung bringen würde. So erklärt Moeller:

The ruler certainly does not encourage people to "participate in government." He himself has no intentions to actively govern and no ambitions to steer the people in a particular direction-and the last thing he wants is to encourage the people to become political agents themselves. The ideal of government is certainly not »democratic. « Even the ruler refrains from ruling and from forming a political will. One important function of his restraint is that it prevents his people from developing ambitions and the corresponding »political« means for getting their interests recognized at the cost of others. Once the political arena is opened, the scheming among the people will begin and they will use all sorts of cunning and deceitful behavior to gain power or influence. ${ }^{87}$

Castorp, der nur 20 Romanseiten vor der >Regierungs $<$-Episode von Settembrini erfahren hat, dass "Lao-Tse lehrte, daß Nichtstun förderlicher sei als jedes Ding zwischen Himmel und Erde« $(Z 568)$, probt hier die Rolle des daoistisch inspirierten Herrschers. Er bestätigt damit einmal mehr Settembrinis Furcht vor der Kontamination mit `östlichem` Gedankengut, die im vorherigen Kapitel ausführlich besprochen wurde. Nicht nur Settembrini ist mit der vermeintlich ıöstlichen< Ineffizienz infiziert, auch Castorp hat sich mit ıöstlichen Ideen angesteckt. Obwohl in der Episode über das Regieren das `östlicheく Motiv keine konkrete Erwähnung findet, so wird es trotzdem indirekt

85 Moeller: The Philosophy of the Daodejing, 2, 57.

86 Lao-tse: Tao-Tê-King, 104 (XXXVII). Vgl. den Abschnitt»Herrschaft « in diesem Buch.

87 Moeller: The Philosophy of the Daodejing, 61f. Herv. meine. 
verhandelt. Denn mit einer daoistischen Herrscherfigur verbindet Castorp viel: Auch er hat eigentlich »no intentions to actively govern « (s.o.) und bildet keinen konkreten »political will« (s.o.) aus. Außerdem ist der politische Führer in der daoistischen Konzeption absolut neutral, weil er über kein Wissen verfügt, das ihn leiten oder zu Entscheidungen verführen könnte. So heißt es bei Lao-Tse:

Die Menschen haben alle Überfluß:

Ich allein bin wie ausgeleert.

Oh, ich habe eines Toren Herz!,

ich bin so verwirrt!

Die gewöhnlichen Menschen sind sehr erleuchtet:

Ich allein bin wie verfinstert. ${ }^{88}$

Auch Castorp, der den »Tor« schon im Namen trägt, ist unwissend und über weite Strecken der Geschichte »verwirrt« (s.o.) und »verfinstert« (s.o.), während seine Gegenspieler Settembrini und Naphta »sehr erleuchtet« (s.o.) sind. Man erinnere sich an die Episode, in der Settembrini Castorp in seinem Zimmer besucht, um ihn mittels des Licht-Motivs saufzuklären<, während dieser sich der Aufklärung verweigernd - im Dunkeln liegt und sogar zum Sinnieren $\mathrm{zu}$ faul ist. Obgleich Castorp nicht gerade als »ausgeleert « (s.o.) bezeichnet werden kann - dafür konsumiert er einfach zu viel, sei es Essen, Trinken, Literatur, Musik usw. - so fühlt er sich der Leere doch zugeneigt. Seit seiner Kindheit neigt er zum »dösen«", d.h. dazu, »mit schlaffem Munde und ohne einen festen Gedanken ins Leere zu träumen« ( $Z$ 50), und ist mit $\mathrm{Zu-}$ friedenheit erfüllt, wenn »zwei leere und sicher gefriedete Stunden vor ihm lagen, diese durch die Hausordnung geheiligten Stunden der Hauptliegekur« ( $Z$ 158). Im daoistischen Denken besteht die Aufgabe des chinesischen Kaisers, so schreibt der Künstler und Philosoph Ernst Fuhrmann in einem 1921 erschienenen »Umriss « über China, darin, mittels dieser Leere eine andere Form des Wissens zu erlangen. Dieses Wissen wird allerdings nicht Mittel zu einem konkreten Zweck, und entfaltet gerade durch diese Zweckfreiheit ${ }^{89}$ seine Bedeutsamkeit:

dem Herrscher in China [bleibt] nach den rituellen Vorschriften fast nichts zu tun: In die Kleinigkeiten der praktischen Regierung soll er sich nicht ein-

88 Lao-tse: Tao-Tê-King, 80 (XX). Herv. meine.

89 Vgl. hierzu die im Abschnitt»Handlung und Ceschichte« ausgeführte Idee, dass Zweckfreiheit die Prämisse politischer Handlung ist. 
mischen, sondern er soll sich ins das tiefste Wissen der Zusammenhänge versenken, und es ist dem Orientalen dann sicher, daß das ganze Reich die wohltätigen Einflüsse dieses reinen Denkens und Lernens erfahren wird. ${ }^{90}$

Bei der Beschreibung des daoistischen Kaisers durch Ernst Fuhrmann ist die Unbeweglichkeit der Herrscherfigur mit einer intellektuellen Tätigkeit verbunden, dem Versenken in »das tiefste Wissen der Zusammenhänge«, dem "reinen Denken« (s.o.). Eine Verbindung, die im Übrigen auch der westlichen Philosophie nicht fremd ist: Hannah Arendt postuliert dieselbe Koinzidenz: beim Denken handele es sich um eine »reine Tätigkeit des Geistes in Verbindung mit völliger Unbeweglichkeit des Körpers «. ${ }^{91}$

Auch die Figur Castorp empfindet diese Koinzidenz als notwendige Voraussetzung für eine rege geistige Aktivität. So berichtet er (dessen »Regieren« wie bereits erwähnt in der Forschung sowieso schon als reines Denken verstanden wird), davon, nirgendwo seinen Geist so angestrengt zu haben wie auf seinem Liegestuhl - dem hauptsächlichen Thron-Möbel des Romans -, und zwar mit den Formulierungen, die er in der >Regieren`-Episode des darauffolgenden Kapitels fast Wort für Wort wiederholen wird:

[Castorp] äußerte ins Leere blickend:

Beschaulichkeit, Abgeschiedenheit. Es hat was für sich, es läßt sich hören. Wir leben ja ziemlich hochgradig abgeschieden, wir hier oben, das kann man sagen. Fünftausend Fuß hoch liegen wir auf unseren Stühlen, die auffallend bequem sind, und sehen auf Welt und Kreatur hinunter und machen uns unsere Gedanken. Wenn ich mir's überlege und soll die Wahrheit sagen, so hat das Bett, ich meine damit den Liegestuhl, verstehen Sie wohl, mich in zehn Monaten mehr gefördert und mich auf mehr Cedanken gebracht, als die Mühle im Flachlande all die Jahre her, das ist nicht zu leugnen. (Z 569)

Die Parallelität der Formulierungen - in der »Regieren«-Episode heißt es: "Wo man aus der beschaulichen Abgeschiedenheit von fünftausend Fuß auf Welt und Kreatur hinabblickte und sich seine Gedanken machte« ( $Z$ 588) zeigt auch die funktionelle Gleichwertigkeit der beiden Orte (Ruhebank in der Waldschlucht und Liegestuhl auf dem Balkon) auf. Castorp regiert auch

90 Fuhrmann: China, 15. Herv. meine.

91 Arendt: Vom Leben des Geistes, 127. 
während des Liegedienstes - unbewegt, ${ }^{92}$ mit Wissen erfüllt und doch »wie ausgeleert «; ${ }^{93}$ das Regieren selbst ist ein Liegedienst.

In der »Regieren«-Episode bewahrheitet sich, wie bereits gesagt, die Angst Settembrinis, Castorp könnte sich mit dem Virus eines >östlichen Denkens infizieren. Sie bespielt außerdem seine Angst, der >Westen< könnte vom `Osten vereinnahmt und dominiert werden. Zwar impliziert diese Episode, dass das »Regieren« nichts weiter ist als eine ironische Überhöhung eines untätigen Protagonisten - immerhin gibt er zu, dass es keine sernsthafteく Tätigkeit sei, sondern ein »Kinderausdruck [...] für eine Unterhaltung, die er liebte« (s.o., Z 589) - doch die Beschaffenheit der Diegese schwächt diese Implikation gleichzeitig ab. Denn obwohl das Denken ohne Handlung, das im Zentrum der daoistischen Herrschaft steht, dem >Westen konkret nichts anhaben zu können scheint, so passt doch die Topologie des »Regierens" im Roman $\mathrm{zu}>$ westlichen< Herrschaftsvorstellungen. Castorp befindet sich, so sagt er mehrmals, >oben` in »fünftausend Fuß« $(Z$ 588) Höhe, über dem Flachland >unten $\prec$. Diese Erhöhung ist auch in der Topologie des >westlichen Regierens enthalten, unter dem man gemeinhin »die Ausübung staatlicher Souveränität und Herrschaft von »oben nach unten« in territorial begrenzten Räumen « ${ }^{94}$ versteht. Hans Castorp sitzt auf dem Berg wie ein König auf dem Thron. In Anbetracht der vorhandenen Raumsemantisierungen im Zauberberg - der obige Berghof ist >östlichく, das untere Flachland ist >westlich <ergibt sich durch Castorps »Regieren« das Bild eines über den >Westen herrschenden >Ostens<.

Dieses >östlicheく Herrschaftsmotiv wird außerdem noch durch ein anderes Nichtstun untermauert, das eigentlich zum >westlichen Kolonialismus gehört: das vereinnahmende Sehen. Das Sehen ist integraler Bestandteil der Regierungs-Episode, immerhin findet diese an einem Ort statt, »wo man aus der beschaulichen Abgeschiedenheit von fünftausend Fuß auf Welt und Kreatur hinabblickte« ( $Z$ 588f., Herv. meine). Der Topos des Sehens ist ein beliebter Kunstgriff aus der Reiseliteratur des 18. und 19. Jahrhunderts: der Landschaftsbeschreibung von einer erhöhten Position aus, die Mary Louise Pratt

92 Fuhrmann schreibt über den taoistischen Herrscher, er könne »aus der völligen Unbewegtheit den ganzen Staat von sich aus lenken«. Fuhrmann: China, 15.

93 Lao-tse: Tao-Tê-King, $80(\mathrm{XX})$.

94 Brigitte Kerchner: Cenealogie und Performanz. Überlegungen zu einer kritischen Analyse des Regierens. In: Politisierung und Ent-Politisierung als performative Praxis. Hg.v. Detlef Ceorgia Schulze u.a. Münster: Westfälisches Dampfboot (2006), 58. Herv. meine. 
"promontory description « nennt. ${ }^{95}$ Solche Beschreibungen stellen Pratt zufolge das Kernelement spezifisch imperialer Reiseliteratur dar, das mittels der physischen Erhöhung des Beschreibenden dessen koloniale Übermacht vermittelt. Pratt gibt diesen Beschreibungen den Beinamen »the monarch-of-allI-survey scene $« .{ }^{96}$ Castorps Modus des »Regierens « schließt an diese literarische Strategie des >monarchischen< Überblickens an, und zwar auch aufgrund seiner körperlichen Passivität. Diese gehört nämlich Pratt zufolge zur Eroberungsdarstellung, stellt sogar ihren Höhepunkt dar. Denn die Passivität und das Nichtstun, wie in der theoretischen Einleitung zu Beginn dieser Arbeit bereits ausgeführt wurde, eignet auch im >westlichen se dem Monarchen. Nichtstun ist ein Zug des Adels, Tun hingegen gehört zum Leben des Untergebenen. Deswegen wurde das Sehen als passiver Akt in der literarischen Verarbeitung von Entdeckungs- oder Eroberungsreisen im Gegensatz zu den aktiveren Momenten der Unternehmung (dem Besteigen eines Bergs zum Beispiel) absolut privilegiert:

what actually constituted the heroic dimension of this kind of discovery, namely the overcoming of all the geographical, material, logistical, and political barriers to the physical and official presence of Europeans in places such as Central Africa [was set aside rather aggressively]. I wish to foreground the contradictions in the heroic perspective. In the end, the act of discovery itself, for which all the untold lives were sacrificed and miseries endured, consisted of what in European culture counts as a purely passive experience - that of seeing. ${ }^{97}$

Pratts Argument zeigt, dass auch der >westliche Imperialismus eine Passivität miteinschließt. Das ist eine wichtige Erkenntnis: Denn wenn nicht nur der ১Osten`, sondern auch der >Westen im Nichtstun, der Passivität ein Machtpotential erkennt, sind sie doch nicht so verschieden, wie Settembrinis Opposition suggeriert. Wie auch an anderen Stellen des Romans lässt die »Regieren«-Episode erkennen, dass die Topoi 〉Ost « und >West « nicht klar voneinander getrennt werden können, sondern sich stets und ständig überlappen,

95 Mary Louise Pratt: Imperial Eyes. Travel Writing and Transculturation. London: Routledge (1992), 202. »Promontory« lässt sich etwa mit »Cebirgsvorsprung« übersetzen, meint aber im Prinzip jede erhöhte Landmasse.

96 Pratt: Imperial Eyes, 201.

97 Pratt: Imperial Eyes, $203 \mathrm{f}$. 
indem sie Ähnlichkeiten aufweisen. Anstatt die Polarisierungen des orientalistischen Diskurses zu übernehmen, inszeniert sie der Zauberberg in einer oft nur schwer nachvollziehbaren Verstrickung. Eine Verstrickung, die einer eindeutigen Interpretation dieser Episode entgegensteht, denn die Gleichwertigkeit von 〉Ost $<$ und >West<, die sich durch die Gemeinsamkeit des Nichtstuns hier ergibt, kann verschieden interpretiert werden.

Einerseits kann man es als Aufwertung des >Ostens` lesen. Die Erkenntnis, dass Castorps Hinabblicken aus »fünftausend $F u ß «(Z 588)$ ein beliebtes, passives Moment europäischer Eroberungsnarrative zitiert, legt nahe, dass es wirklich eine >östliche Dominanz über den >Westen weil dies den Widerspruch zwischen dem >Westen $<$ und der >Passivität< aufhebt, und damit die Paradoxität eines politischen Nichtstuns liquidiert. Ganz zu schweigen von der Tatsache, dass `westliche`Vorstellungen von Macht ganz generell auch das Nichtstun zum Charakteristikum haben. So würde Castorps »Regieren« also Settembrinis Angst vor dem >Osten< bestätigen. Auf einem Berg zu sitzen und auf die umgebende Landschaft hinabzublicken, ist ein symbolischer Moment der Besitzergreifung - und ein rhetorischer Kniff des Romans, die Idee einer >östlichen< Herrschaft zu stärken. Wenn >westlicher Kolonialismus mit Passivität operiert, so lässt sich auch einer >östlichen Passivität ein kolonialisierendes, beherrschendes Potential zuschreiben. Die Verwendung des Wortes »Regieren« bedeutet eben nicht die ironische Überhöhung eines untätigen Protagonisten, sondern verweist auf eine politische Realität: Nichtstuer können auch Herrscher sein, egal ob im `Osten` oder im >Westen<.

Andererseits kann man die Gemeinsamkeit des Nichtstuns als Abwertung der Regierungspraktiken von sowohl >West < als auch >Ost<verstehen. Das würde heißen, das »Regieren« Castorps insgesamt als Ironie zu lesen. In dieser Lesart würde der `östliche` (in diesem Fall daoistische) Herrscherstil nicht nur zitiert, und könnte so als glaubhaft wirksam verstanden werden, sondern er wird parodiert: Der `östlicheく Herrscher versteht sich als der König, der über »Welt und Kreatur« $(Z$ 588) blickt und herrscht, ist aber tatsächlich machtlos, weil sein Nichtstun keine Weltwirkung entfalten kann. Denn auch wenn die Topologie des Romans eine Herrschaft von `Ost $<$ über >West $<$ nahelegt, so kann man Castorp selbst keine solche >Wirkung 'nachweisen. Der daoistische Kaiser, so Fuhrmann, »ist selbst ein Zentrum, das nun zentrifugal auf die Umwelt wirkt in kleinen oder großen Kreisen «. ${ }^{98}$ Doch das Gebiet >oben im Roman 
hat keine Verbindung zu dem Flachland, dem >Unten`, und Castorp kann diese Grenze nicht überschreiten und deshalb auch nicht "zentrifugal « auf seine Umwelt wirken. Er sagt selbst: »Ich habe gar keine Fühlung mehr mit dem Flachland, die ist mir abhanden gekommen.« (Z 898) Diese Lesart impliziert auch, dass ein 'westliches Regieren, das ein Nichtstun miteinschließt, ebenso unwirksam sei. Die Episode wirft überhaupt die Frage auf, ob Nichtstun Teil eines Regierens sein kann. Oder, wenn das Konzept von Herrschaft tatsächlich so eng mit dem Nichtstun verbunden ist, ob ein >richtiges« Regieren von dem »Regieren« Castorps eigentlich unterschieden werden kann. Vielleicht ist die Idee, die hier ironisiert wird, die, dass es eine aktive Regierung wirklich gibt.

Schließlich gibt die Tatsache, dass Castorp mit dem »Regieren« nur ein "Spiel« spielt, auch die Frage auf, ob er einen bestimmten Regenten dar- oder gar nachstellt. Die >östlichen< Konnotationen der Episode deuten auf einen `östlichen< Herrscher hin, einen Kaiser, vielleicht sogar einen Despoten. Doch wenn Nichtstun ein konstitutives Merkmal des Herrschens ist - egal ob ıöstlich oder 'westlich $<-$, dann kann sein Spiel auch als Imitation eines >westlichen $<$ Herrschers verstanden werden. Kaiser Wilhelm II. zum Beispiel - ihn parodierte er auch in seinem zweiten, dem Zauberberg vorangegangenen Roman Königliche Hoheit (1909). Wilhelm II. war zwar kein mächtiger Nichtstuer im Sinne eines erfolgreiches Kolonisators oder eines `östlichen« Herrschers, doch das nichtstuerische »Regieren« kann ja, wie gesagt, auch als Zeichen einer Ohnmacht verstanden werden.

Vielleicht verweist Castorps »Regieren«, den abwertenden Aspekt des Nichtstuns funktionalisierend, aus der Nachkriegsperspektive des Schriftstellers Thomas Mann auf den Niedergang des letzten deutschen Kaiserreiches. Vielleicht ist der Topos der Herrschaft durch Nichtstun eine Kritik des späteren Demokraten Mann an der überkommenen Monarchie - schließlich tat Montesquieu knapp 200 Jahre zuvor etwas ähnliches, als er über die Idee einer sorientalischen<, nichtstuerischen Despotie die Regierung der Bourbon Monarchie kritisierte. ${ }^{99}$ In dem Fall stellt das »Regieren « eine weitere Projektion dar: die vermeintlich `östliche` Untätigkeit verweist auf die Handlungsunfähigkeit des `Westens`.

Oder, in einer besonders amüsanten Variante der Überlappung zwischen

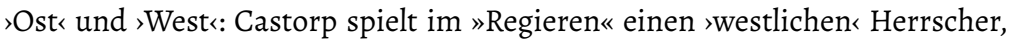

99 In De l'esprit de lois (1748) Montesquieu »used the threat of Oriental despotism to critique the perceived despotism of the Bourbon monarchy«. Dobie: Foreign Bodies, 37. 
der eigentlich ein `östlicher sein will. Genau diesen Wunsch attestiert Suzanne L. Marchand Wilhelm II. Sie berichtet, dass er sich gerne einbildete, ein >orientalischer< König zu sein:

[He] fancied himself as something of a reincarnated late Roman Emperor, tolerant and yet all-powerful, uniting in his person classical culture (without democracy), oriental kingship (without being an »oriental«), and Christian sacrality (without any actual Christian content). ${ }^{100}$

Vielleicht unterhält sich Castorp letztlich mit einem »Spiel«, in dem er ein 'westliches« Begehren des `Ostens`, das er selbst empfindet, an einer anderen Person durchspielt - und noch dazu an niemand geringerem als dem Staatsoberhaupt des Deutschen Reiches.

Der Zauberberg gibt keine Hinweise auf die >richtige< Lesart der »Regieren«-Episode, doch klar ist, dass sie ein Spiel mit verschiedenen Vorstellungen politischer Führung inszeniert. Der Topos des Nichtstuns steht im Zentrum dieser Inszenierung, und fungiert als Knotenpunkt des Spiels, der ১Ostく und >West $<$ zugleich trennt und verbindet. Auch hier wird der >Osten $<$ mit dem Nichtstun auf eine Art und Weise gekoppelt, die einen Kommentar über die mögliche Handlungsunfähigkeit des >Westens` suggeriert, während sie eine paradoxe Macht durch das Nichtstun im >Osten<impliziert. Die Tatsache, dass die Frage, welche Seite letztlich stärker und erfolgreicher ist, nicht beantwortet wird, zeigt auch beim »Regieren«, dass Settembrinis Opposition zwischen $>$ West $<$ und >Ost $<$ nicht haltbar ist.

\section{"Politischer Faktor « - Gemeinschaft statt Politik}

Der Zauberberg kreiert einen literarischen Raum, in dem unentwegt Gegensätze aufeinandertreffen. Die Opposition zwischen >Ost $<$ und >West $<$ als Verdeutlichung eines Gegensatzes zwischen Nichtstun und Handlung steht dabei im Zentrum. Doch dieser Opposition geht es wie den anderen im Roman: aus ihrer Konfrontation geht kein Gewinner hervor, auch wenn manche Figuren ebenso wie die Diskurse, die sie zitieren - sich bereits auf einen geeinigt hatten. Der >Westen « als Übermacht und Ort der Tat, der sich als dieser Gewinner abgezeichnet hatte, wird im Zauberberg jedoch abgesetzt. Der Roman zeigt im Gegenteil, dass diese Gegensätze nur scheinbar sind. In dem, was vermeintlich >westlich` ist, steckt `Östliches`, und andersherum. Was wie Nichtstun

100 Marchand: Cerman Orientalism in the Age of Empire, 341f. Herv. meine. 
aussieht, kann tatsächlich eine machtvolle Tätigkeit sein, die vormals einflussreiche Handlung als nichtig abwertet. Im Zauberberg werden nicht nur Gegensätze inszeniert, sondern auch ihre Aushebelungen.

Indem der Roman etablierte Polarisierungen - wie die zwischen 〉Ost $<$ und 'West<, oder die zwischen >Nichtstun $<$ und >Handlung $<$ - subvertiert, zeigt er Abweichungen von der Norm an. Zu diesem Zweck greift der Zauberberg auf das Genre des russischen Kurortromans aus dem 19. Jahrhundert zurück. Denn das dort entstandene »Kurortparadigma«, so Olga Kulishkina, ist ein Raum, der das Individuum aus »traditionellen alläglichen Daseinsformen " herauslöst und deshalb »antinormatives Verhalten « ${ }^{101}$ ermöglicht. Das Nichtstun stellt dabei sicherlich die größte Abweichung von der Norm dar, und außerdem eine häufig mit dem Topos des Kurorts assoziierte. Michel Foucault postuliert dies in seinen Überlegungen zur Heterotopie. Heterotopien sind in seinem Verständnis Räume, in denen außergewöhnliche Erfahrungen stattfinden, die vom Normalen abweichen. Das Sanatorium ist ein Ort des Müßiggangs, und deswegen eine typische »Abweichungsheterotopie« (Foucault nimmt als Beispiel das Erholungsheim), »da in unserer Gesellschaft $[. .$.$] der Müßiggang eine Art Abweichung ist { }^{102}$

Die Tatsache, dass das Sanatorium und das Nichtstun diskursiv miteinander verflochten sind, lenkt jedoch möglicherweise davon ab, dass es im Zauberberg nicht primär um das Nichtstun als Unterwanderung des Normativen geht. Denn das antinormative Verhalten, auf das der Roman fokussiert, besteht in der Infragestellung dessen, was als politischer Status quo gelten sollte: so zum Beispiel die bereitwillige Annahme eines >östlichen< Denkens durch Hans Castorp anstelle der Aufrechterhaltung der Vorstellung einer unhinterfragten >westlichen Dominanz. Die Bevorzugung des Nichtstuns im Berghof anstelle der Arbeit im Flachland vermittelt diese Präferenz lediglich; sie selbst ist nicht das Problem.

Über das Nichtstun also inszeniert der Roman einen Raum, der wie eine Abweichungsheterotopie nach Foucault aussieht. Doch da das Nichtstun nur als Medium für ein politisches Problem fungiert, ist das Sanatorium nicht

101 Olga Kulishkina: Walter Scotts »St Ronan's Well« und die Konstruktion des KurortDiskurses in der Russischen Literatur. In: Die Produktivität des Plagiats. The Productivity of Plagiarism. Hg. v. Charlotte Krauss u.a. Münster: LIT (2018), 124, 125. 
nur Ort einer Abweichung, sondern stellt die Bühne für eine politische Identitätskrise zur Verfügung. Deswegen erzählt Der Zauberberg stattdessen eine »Krisenheterotopie«, die den »Individuen vorbehalten [ist] [...], welche sich im Verhältnis zur Gesellschaft und inmitten ihrer menschlichen Umwelt in einem Krisenzustand befinden «. ${ }^{103}$ Dieser Krisenzustand betrifft sowohl Hans Castorp selbst als auch den >Westen<, dem er als Bürger des Deutschen Reiches zugehört, ihre Schicksale sind untrennbar miteinander verbunden. In der Zeit, in der Thomas Mann den Zauberberg schreibt, findet ein Umbruch im politischen System Deutschlands statt: das Kaiserreich wird nach dem Ersten Weltkrieg zur Weimarer Republik. Die Konkurrenz zwischen den Anhängern konservativer Monarchie und progressiver Demokratie, die sich schon lange vor dem Systemwechsel entwickelte, ist anhand der Figur Castorp im Roman abgebildet. Dieser wird zu Beginn der Geschichte als eine Art Prognoseinstrument beschrieben, als zukünftiger "politischer Faktor« (s.u.). Die Passagen, die im Flachland und in der frühen Kindheit Castorps spielen, zeigen nämlich nicht nur die Wichtigkeit der bürgerlichen Arbeit ${ }^{104}$ - die auch Settembrini bevorzugt aufruft (vgl. Z 92) -, sondern dass das dadurch seit Generationen gewonnene soziale Ansehen auch an die Erwartung eines politischen Engagements geknüpft ist:

Wenn er in den Ferien nach Hause kam, sehr sauber, sehr gut angezogen, mit einem kleinen rotblonden Schnurrbart in seinem schläfrigen jungen Patriziergesicht und offenbar auf dem Wege zu ansehnlichen Lebensstellungen, so sahen die Leute, die sich mit kommunalen Dingen befaßten, auch mit Familien- und Personalverhältnissen gut Bescheid wußten - und das tun die meisten in einem sich selbst regierenden Stadtstaat-, so sahen seine Mitbürger ihn prüfend an, indem sie sich fragten, in welche öffentliche Rolle der junge Castorp wohl einmal hineinwachsen werde. Er hatte ja Überlieferungen, sein Name war alt und gut, und eines Tages, das konnte beinahe nicht fehlen, würde man mit seiner Person als mit einem politischen Faktor [Herv. meine] zu rechnen haben. [...] Man konnte neugierig sein, wie er wohl einmal Partei bekennen würde, der junge Castorp. Äußerlichkeiten mochten

103 Foucault: Andere Räume, 40.

104 »Was dir gehört, liegt ja ganz gut und trägt dir was Sicheres. «- so spricht Castorps Onkel Tienappel zu ihm. »Aber von Zinsen zu leben, dabei ist heutzutage kein Spaß mehr, wenn man nicht wenigstens fünfmal so viel hat, wie du, und wenn du was vorstellen willst hier in der Stadt und leben wie du's gewohnt bist, dann mußt du ordentlich zuverdienen, das merk' dir lieber, min Söhn.« (Z 55) 
täuschen, aber eigentlich sah er ganz so aus, wie man nicht aussah, wenn die Demokraten auf einen rechnen konnten, und die Ähnlichkeit mit dem Großvater war unverkennbar. Vielleicht würde er ihm nacharten, ein Hemmschuh werden, ein konservatives Element [Herv. meine]? Das war wohl möglich - und ebensowohl auch das Gegenteil. Denn schließlich war er ja Ingenieur, ein angehender Schiffsbaumeister, ein Mann des Weltverkehrs und der Technik. Da konnte es sein, daß Hans Castorp unter die Radikalen [Herv. meine] ging, ein Draufgänger wurde, ein profaner Zerstörer alter Gebäude und landschaftlicher Schönheiten, ungebunden wie ein Jude und pietätlos wie ein Amerikaner, geneigt, den rücksichtslosen Bruch mit würdig Überliefertem einer bedächtigen Ausbildung natürlicher Lebensbedingungen vorzuziehen und den Staat in wagehalsige Experimente zu stürzen [Herv. meine],das war auch denkbar. (Z 58f.)

In dem Kapitel, aus dem diese Passage stammt, wird expliziert, dass die durch Arbeit erlangten »ansehnlichen Lebensstellungen« (s.o.) des Bürgertums nahelegen, dass Castorp zukünftig ein politisches Amt bekleiden wird - so wie auch Franco Moretti über den bürgerlichen Roman sagt: »work has become the new principle of legitimation of social power «, "the bourgeoisie [is] on its way to being the ruling class «. ${ }^{105}$ Dass Castorp in dieser »ruling class« einen Platz finden wird, nimmt die Flachland-Gesellschaft als gegeben hin. Die Frage ist nur, ob er »konservatives Element« (s.o.), d.h. kaisertreu wird bzw. bleibt, oder ob er sich den »Radikalen « (s.o.), d.h. den Demokraten anschließen wird. ${ }^{106}$

Castorp entzieht sich dieser Entscheidung, indem er im Bergsanatorium bleibt und nicht wieder ins Flachland zurückkehrt. Dies entspricht auch der Raumlogik im Roman: da das Flachland Arbeit und das Bergsanatorium

105 Moretti: The Bourgeois, 30, 74.

106 Auch hier ist die Parallele zu Manns eigener politischer Haltung offenbar. Der Umstand, dass eine radikale/demokratische Wendung des Protagonisten nicht nur die Kommunalpolitik, in der man ihn in der Zukunft vermutet, sondern gleich den ganzen Staat in »wagehalsige Experimente« stürzen würde, trägt dem Umstand Rechnung, dass es im Wilhelminismus eine ausgeprägte Angst vor politischen Querschlägern gab, wie Wolfgang Schivelbusch ausführt: »Die Vorstellung von einem inneren Feind, der nur darauf wartete, die herrschende Ordnung umzustürzen, und gegen den der Einsatz jedes Mittels gerechtfertigt war, gehört zum politisch-psychologischen Grundbestand des Wilhelminismus. Dieser Feind war die Sozialdemokratie. «Wolfgang Schivelbusch: Die Kultur der Niederlage. Der amerikanische Süden 1865, Frankreich 1871, Deutschland 1918. Berlin: Fest (2001), 245. 
Nichtstun impliziert, kann Castorp es durch den Rückzug ins Bergland vermeiden, sich politisch zu engagieren, so wie es eine bürgerliche Arbeit und Stellung im Flachland verlangen würden. Der weitere Romanverlauf macht klar, dass dies Castorps Wunsch entspricht. Er selbst hat nämlich keinerlei Interesse an politischen Fragen oder der Ausbildung einer politischen Haltung. Diese Interesselosigkeit - oder vielleicht kann man es auch Neutralität nennen - ist überhaupt einer der großen Witze des Romans. Der Zauberberg verhandelt Unmengen von Fakten, Thesen und Wissensbereichen, ohne jemals eine/n zu priorisieren oder $\mathrm{zu}$ einem Argument zu gestalten, und das trifft auch auf die im Roman diskutierten Politiken zu. Diese Ambivalenz wird besonders im rhetorisch-didaktischen Schussfeuer zwischen Settembrini und Naphta vorgeführt, die Castorp erfolglos mit zahllosen einander entgegengesetzten Meinungen und Haltungen konfrontieren. Dieser jedoch lässt sich nie überzeugen, und genießt stattdessen das gedankliche >Spiek mit all den unterschiedlichen Ideen, die sie vertreten. Die Losung »Placet experiri« (lat. für »es ist angenehm, zu experimentieren«, vgl. Z 150), unter der dieses `Spiek läuft, ist eine Metareferenz auf den Roman, der »the ironies, the ambivalence, the yes-and-no, as opposed to yes-or-no « zur Darstellung bringt. ${ }^{107}$

Diese Ambivalenz bildet den Kern der oben beschriebenen Krisenheterotopie. Einer der Gründe für Castorps überlangen Aufenthalt im Bergsanatorium ist sein Unwillen und seine Unfähigkeit, sich politisch festzulegen. Diese Stasis kennzeichnet die Unsicherheit der Zukunft der deutschen Politik. Doch auch wenn Castorp offensichtlich keine Anstalten macht, sich zwischen den beiden verfügbaren Positionen zu entscheiden, so haben doch die Ausführungen dieses Kapitels gezeigt, dass seine Praktiken des Nichtstuns politische Dimensionen eröffnen. Das oben diskutierte »Regieren« zum Beispiel hat eindeutig politische Bedeutung, die im Hinblick auf sowohl >östlicheく als auch >westliche< Herrschaftsformen gelesen werden kann - so auch auf verschiedene zeitgenössische Kaiserfiguren. Es ist möglich, dass Castorp hier nicht nur seine Infektion mit >östlicher Philosophie unter Beweis stellt, indem er einen daoistischen Kaiser mimt, sondern dass er im Rahmen des »Placet experiri« $\left(Z_{150}\right)$ in die Rolle des deutschen Kaisers Wilhelm II. schlüpft, um seine Neigung zur konservativen Kaisertreue zu testen. Das Ergebnis dieses Experiments offenbart sich schnell: nach nur wenigen Romanseiten beendet Castorp sein »Regieren«, weil es in ihm »stürmischen Schwindel« (s.o., Z

107 Irvin Stock: The Magic Mountain. In: Modern Fiction Studies 32 (4), 1986, 491. 
589) hervorruft. Darin deutet sich eine Abneigung gegenüber der Machtausübung an, die von der konservativen Politik einer Monarchie verlangt wird ein schwindelnder Herrscher hat nicht die notwendige Kontrolle, die er zum Regieren braucht. ${ }^{108}$

Der Abbruch des Regierens durch Castorp ist ein Hinweis darauf, dass er kein »konservatives Element « (Z 58f.) sein will, und die Tatsache, dass das Regieren im weiteren Romanverlauf kaum Erwähnung findet, bezeugt die Dauerhaftigkeit dieser Abneigung. Diese Abneigung kennzeichnet überhaupt die soziale Struktur der Gesellschaft im Sanatorium Berghof, die Roland Barthes zufolge von einer genuinen Machtferne gekennzeichnet ist. Barthes hat den Zauberberg, neben einigen anderen Romanen, zum Ausgangspunkt seiner Idee der Idiorrhythmie gemacht. Idiorrhythmie beschreibt eine Lebensweise, die zwischen Isolation und Rückkehr in die Gemeinschaft oszilliert. Es handele sich dabei um »eine auf geregelte Weise unterbrochene Einsamkeit«, in der jedes Subjekt jedoch grundsätzlich »seinem eigenen Rhythmus « folgt. ${ }^{109}$ Barthes bringt den Zauberberg mit dieser Idee in Verbindung, weil das Sanatorium eben diese Idiorrhythmie ermöglicht: $\mathrm{Zu}$ den Mahlzeiten können die Patienten zusammenkommen (Pflicht ist das jedoch nicht), während sie die »Liegekur $(Z$ 109) sowie ihre sonstige Freizeit (den sogenannten »dienstlichen Lustwandel«, $Z$ 484) selbst gestalten - und das meistens allein. Diese Form des individuell gestalteten Lebens weise, so Barthes, ein »negative[s] Verhältnis zur Macht« auf, denn

[w]as die Macht in erster Linie auferlegt, ist ein Rhythmus (von allem möglichen: des Lebens, der Zeit, des Denkens, des Diskurses). Die Forderung

108 Der Schwindel passt übrigens hervorragend in Pratts Narrativ der »the monarch-of-allI-survey scene«: Kathrin Maurer schreibt über den panoramatischen Blick (in den Orientalischen Briefen Ida von Hahn-Hahns), dieser involviere ein widersprüchliches » $\mathrm{Ne}$ beneinander von Erhabenheit und Schwindel «, womit auch impliziert ist, dass mit dem >Überblick`nicht nur Kontrolle über das Gesehene einhergeht, sondern dass diese Perspektive auch das eigene Gleichgewicht stören und so die Macht des Blickenden negieren kann. Kathrin Maurer: Der panoramatische Blick auf das Andere in Ida von HahnHahns Reisebericht >Orientalische Briefe (1844). In: The German Quarterly 83 (2), 2010, 154.

109 Barthes: Wie zusammen leben, 42f. Barthes beschreibt die Idiorrhythmie in Anlehnung an die Lebensweise der Koinobiten-Mönche der vorreformatorischen byzantinisch-orthodoxen Kirche, die ursprünglich in ablegenden Bergen lebten (vgl. ebd. 75) - wahrscheinlich eine topologische Verbindung zum Zauberberg. 
nach einem eigenen Rhythmus richtet sich immer gegen die Macht. [...] Idiorrhythmie = Schutz des rhythmos, das heißt eines geschmeidigen, anpassungsfähigen, beweglichen Rhythmus; flüchtige Form, aber doch Form. ${ }^{110}$

Es ist gerade die Abweichung vom Lebensrhythmus des Flachlandes, die Castorp interessant findet. Das Faszinierende an der »Kleingruppe«, so Barthes, sei eben ihre Autarkie, ihre "Selbstgenügsamkeit, Selbstzufriedenheit «. ${ }^{111}$ In der Autarkie, und das trifft auch auf das Sanatorium zu, gibt es eine "starke Intradependenz« und »keinerlei Extradependenz «. ${ }^{112}$ Das bedeutet auch, dass die im Flachland relevanten Politiken im Bergsanatorium für Castorp keine Relevanz haben, da er wie die meisten anderen Gäste auch vollkommen in dieser neuen sozialen Struktur aufgeht. Weder konservative noch progressive Tendenzen sind im Berghof wichtig. Im Gegensatz zum Flachland ist das Leben dort nämlich gar nicht politisch, weder im traditionserhaltenden Sinn, noch im progressiven Sinn, wie bei Hannah Arendt, die politische Handlung als "etwas Neues Anfangen « definiert. ${ }^{113}$ Das erklärt sich auch aus der dem Roman so häufig attestierten >zyklischen Zeit, die der Entwicklung seiner Geschichte zugrunde liegt. Die Zeit zeitige zwar Veränderung, doch das sei ein relativer Begriff: »Da aber die Bewegung, an der man die Zeit mißt, kreisläufig ist, in sich selber beschlossen, so ist das eine Bewegung und Veränderung, die man fast ebensogut als Ruhe und Stillstand bezeichnen könnte; denn das Damals wiederholt sich beständig im Jetzt, das Dort im Hier.« ( $Z$ 521) Die Zeitvorstellung, die im Roman entwickelt wird, beschreibt die ewige Regelmäßigkeit des Lebens im Berghof. Dort gibt es weder konservative noch progressive Haltungen, weil dort nichts bewahrt werden muss oder verändert werden kann. Alles, was es dort gibt, kommt von selbst wieder.

Die relevante soziale Dimension im Berghof ist nicht die Politik, sondern die Gemeinschaft. Sie ist, wie so häufig von Settembrini kritisiert wird, an der Nähe aller Bewohner zu Krankheit und Tod ausgerichtet. Die »Gemeinschaft Derer hier oben « $(Z$ 713) ist eine "Gemeinschaft mit den Leidensgenossen « $(Z$ 362). Castorp empfindet dies besonders stark, sucht die Nähe zu jenen, die bald sterben werden, oder zu den Hinterbliebenen der Verstorbenen. ${ }^{114}$ Diese aus dem geteilten Todes-Charakteristikum hervorgegangene Gemeinschaft

\footnotetext{
110 Barthes: Wie zusammen leben, 81.

111 Barthes: Wie zusammen leben, 82.

112 Barthes: Wie zusammen leben, 83.

113 Arendt: Vita activa, 215.

114 Vgl. zum Beispiel Castorps Besuch bei der Witwe des Herrenreiters (Z 441-445).
} 
wirkt morbid, dennoch zieht Castorp sie dem politischen Leben im Flachland vor. Auch dies folgt aus der Topologie des Romans: in dem semantischen Raum des Sanatoriums, in dem nicht Arbeit, sondern das Nichtstun die Norm ist, wird eine Gemeinschaft nicht 'gemacht<, sondern ergibt sich auf der Basis der Menschen die dort sind. Wie in den theoretischen Ausführungen $\mathrm{zu} B e-$ ginn dieser Arbeit beschrieben wurde, ermöglicht dieser Raum >oben in den Bergen die Existenz einer gewaltfreien Gemeinschaft, in der es keine Anpassung an Arbeitszwänge oder andere ideologische Produktionsnotwendigkeiten gibt - weil Arbeit und Produktion dort dem Nichtstun weichen müssen. Daraus ergibt sich, wie Maurice Blanchot in seiner Gemeinschaftsphilosophie postuliert, eine Reduktion der Gemeinschaft auf das, was wirklich allen Menschen von der Natur aus gemein ist: den Tod. Sich im Angesicht des Todes beizustehen wird zur einzigen Aufgabe:

Im Unterschied zu einer sozialen Zelle untersagt sie [die Gemeinschaft], ein Werk zu schaffen, und sie hat keinerlei Produktionswert zum Ziel. Wozu dient sie? Zu nichts, wenn nicht dazu, den Dienst am Anderen bis in den Tod hinein gegenwärtig zu halten, damit der Andere nicht einsam zugrunde geht. $^{115}$

Vor diesem Hintergrund kann man Castorps Neigung zum Tod in einem neuen Licht betrachten. Der Erzähler des Romans stellt mehrfach heraus, dass diese Neigung problematisch ist - er degradiert zum Beispiel Castorps Erzählen über die Vornehmheit des Todes als das »Gesellschaftsunfähige seiner Rede« ( $Z$ 699) - doch der Begriff der »Gesellschaft « bezieht sich in diesem Fall auf die Gesellschaft im Flachland. Im Bergsanatorium jedoch entwickelt sich mit der >Todesgemeinschaft ein Gegenentwurf zu dieser Gesellschaftsvorstellung, dessen soziale Kohäsion vielfach stärker ist. Castorp spricht davon, sich einer "gebundeneren Gemeinschaft zugehörig« ( $Z$ 714) zu fühlen. Diese durch das Nichtstun ermöglichte Gemeinschaft funktioniert grundlegend anders als die Gesellschaft des Flachlandes. Sie entbehrt vor allem der Polarisierungen, die die Politik im Flachland bestimmen: Sie kennt weder die hierarchisierte Opposition zwischen 〉Ost und `West für den Gegensatz zwischen konservativer und progressiver Politik, zwischen Monarchie und Demokratie. 
Der Zauberberg kreiert einen literarischen Raum, in dem Gegensätze aufeinandertreffen, um aufgelöst zu werden. Das Nichtstun, was den semantischen Raum des Berghofs bestimmt, übernimmt diese diegetische Auflösungsfunktion, indem es allen Romanfiguren eine gemeinsame Basis gibt, die Polarisierungen zwar nicht verhindert - Settembrini bleibt bei seiner Opposition - aber letztlich unhaltbar macht. 


\section{Indifferenz vs. Handlung}

Der dritte Topos dieses Buches hat viele Namen: Neutralität, Gleichgültigkeit, Indifferenz sind die geläufigsten. Ich verwende sie synonym, präferiere aber den Begriff >Indifferenz<, weil er das am konkretesten transportiert, was ihnen gemeinsam ist: die Abwesenheit eines Unterschieds, und, auf die Tätigkeit hin, das Nicht-Stattfinden einer Unterscheidung. Die Indifferenz ist genau deshalb eine Ausprägung des Nichtstuns, weil in ihr die Tätigkeit des Unterscheidens wegfällt, die Voraussetzung für jedes Urteil, und damit auch für menschliches Handeln ist. ${ }^{1}$ Sie zeigt so auch eine grundsätzliche Problematisierung des Verhältnisses zwischen Menschen und Welt, insofern der indifferente Mensch keinen verändernden Einfluss auf die Welt ausübt. »Der gleichgültige Mensch [...]«, so fasst es Manfred Geier, »verzichtet auf Proteste und hat der Welt seine leidenschaftliche Aufmerksamkeit entzogen. Teilnahmslos und indolent lebt er vor sich hin und verzichtet darauf, sich zu engagieren. ${ }^{2}$ Die Indifferenz, mehr als die anderen diese Arbeit dominierenden Themen, trägt eine deutlich anti-politische Konnotation. Das indifferente Individuum macht keine Unterschiede zwischen den Dingen und Ereignissen der Welt und steht allem in gleicher Weise gegenüber. Es hat keine Haltung. Dieser Begriff ist in Bezug auf das Nichtstun von größter Relevanz, denn eine Haltung lässt sich nur aus vorangegangen Handlungen ableiten. So wird der Begriff der Haltung (hexis) in der Nikomachischen Ethik als kumulatives Ergebnis menschlicher Einzelhandlungen definiert. ${ }^{3}$ Wer indifferent ist, hat gewissenmaßen nicht haltungsbildend gehandelt, hat nichts getan. Diese Bewegung

\footnotetext{
Vgl. Arendt: Vom Leben des Geistes, 77. Manfred Geier: Das Glückder Gleichgültigen. Von derstoischen Seelenruhe zur postmodernen Indifferenz. Reinbek bei Hamburg: Rowohlt (1997), 30. Herv. meine.

3 Vgl. z.B. Aristoteles: Werke. Bd. 6. Nikomachische Ethik. Übers. v. Franz Dirlmeier. Hg. v. Ernst Grumach. Berlin: Akademie (1956), 7of. [1119a-1120b]. Vgl. auch die kurze Notiz zum Begriff der Haltung im Kapitel »Cemeinschaft« in diesem Buch.
} 
gilt auch für Zukünftiges: Wer keine Haltung hat, der kann nur unbedeutendes tun, der kann nur Nichtstun. Das folgende Unterkapitel nimmt diesen Zusammenhang als Ausgangspunkt für eine weitergehende Betrachtung der Indifferenz. Die These lautet auch hier, dass Indifferenz, gerade im Bereich des Literarischen, nicht einfach da ist - sie wird durch Tätigkeiten und Worte erzählt, gezeigt, behauptet. Und weil sie kommuniziert werden muss, wird sie auch praktiziert, auf der Ebene des Erzählens wie in der Diegese selbst. In der Betrachtung der Indifferenz als Praxis des Nichtstuns, wie zu zeigen sein wird, ist sie letztlich gar nicht so handlungs- und haltungslos, wie sie wirkt und behauptet wird. So schreibt zum Beispiel Kathrin Glosch spezifisch über die französische Literatur des 20. Jahrhunderts, Apathie und Indolenz seien zwar »Spielarten« der Gleichgültigkeit, doch Indifferenz impliziere trotzdem »nicht notwendigerweise Handlungslosigkeit«; in der Literatur der Moderne fielen Indifferenz und Handlung nicht selten zusammen. ${ }^{4}$ Indifferenz mag ein Nichtstun zur Vorbedingung oder als Konsequenz haben, doch sie muss nicht darin verbleiben - sie kann auch eine Praxis ihrer selbst entwickeln, und sich aus dem indifferenten Nichtstun zur Handlung aufschwingen.

Es gibt einige Strömungen in der europäischen Ideengeschichte, die Gleichgültigkeit mit Handlung assoziieren. Die Stoa zum einen, und der Existentialismus zum anderen. Letzterer hat einen großen Eindruck in der Philosophie des 20. Jahrhunderts hinterlassen. Ein Kernmerkmal der existentialistischen Philosophie (besonders der Sartres), die sie jedoch mit ähnlichen Philosophien teilt, ist die Überzeugung, dass es in der Welt keine absoluten Werte gibt. So gibt es weder eine kosmische Ordnung, einen göttlichen Willen, noch entfaltet sich die Weltgeschichte nach einem bestimmten historischen Prinzip. All diese bis ins 19. Jahrhundert als sicher angenommenen Gegebenheiten geraten, spätestens mit Nietzsche, ins Wanken, und weichen der Vorstellung einer unendlich differenzierten Interpretierbarkeit: Die Bedeutung der Welt ist nicht gegeben, sondern vom Menschen konstruiert, und deshalb unsicher. Das ist ein ernstzunehmendes epistemisches Problem. Die Realisierung, dass man als Mensch nicht in einen bestimmten, sicheren Sinnzusammenhang eingebettet, sondern shaltlos $<$ in der Welt ist, wie Martin Heidegger es formuliert, kann angsteinflößend und lähmend sein. Diese Realisierung kommt Heidegger zufolge beispielsweise in der tiefen Langeweile zustande, die "alle Dinge, Menschen und einen selbst der französischen Literatur des 20. Jahrhunderts. Stuttgart: Metzler (2001), 1, 5. 
mit ihnen in eine merkwürdige Gleichgültigkeit zusammen[rückt]«. ${ }^{5}$ In einer Welt, in der es keinen absolut gesetzten Wert gibt, kann einem alles gleichgültig sein - zudem es ja auch impliziert, dass einem die Welt ebenso gleichgültig gegenübersteht wie man ihr. Natürlich stellt dieses Gleichgültigkeitsverhältnis auf den ersten Blick auch die Möglichkeit einer Ethik, und vielleicht auch des Handelns überhaupt, in Frage. Denn was sollte man angesichts dieser Sinnleere, die sich einem offenbart, noch tun können?

Aus der existentialistischen Perspektive kann man in dieser Situation durchaus viel tun. In einer Welt ohne absolute Bedeutung ist das Individuum frei, Bedeutung selbst zu kreieren. Die Erlangung dieser Freiheit hat zur Folge, dass man selbstverantwortlich handeln kann und muss. Befreit von konventionellen Entscheidungsmodellen, anerkannten Meinungen und vermeintlichen Objektivitäten kann man endlich eigene Werte kreieren und ihnen gemäß agieren. Es gilt also, Gleichgültigkeit als Freiheit zu deuten, wie es auch Albert Camus getan hat. Auf die selbstgestellte Frage, was es bedeute, in einem Universum zu leben, das man als absurd (d.h. eines absolut gesetzten Sinns ermangelnd) erkannt hat, antwortet er: "Nichts anderes zunächst als die Gleichgültigkeit einer Zukunft gegenüber «. ${ }^{6}$ Diese Gleichgültigkeit gebe dem Menschen seine »Handlungsfreiheit wieder und feiert sie«; statt einer Einschränkung bedeutet dieser »Verlust an Hoffnung und Zukunft [...] für den Menschen einen Zuwachs an Beweglichkeit. " ${ }^{7}$ Auch Heidegger betont den Gewinn einer neuen Handlungsfähigkeit, die für ihn in der Bewusstwerdung der zeitlichen Existenz des Menschen begründet liegt, die sich in der Gleichgültigkeit einstellt. Die Freisetzung seines Handlungspotentials beschreibt er als einen temporalen Bruch, den er >Augenblick nennt: »Es ist einem langweilig. Darin sagt die im Ganzen bannende Zeit sich selbst als das an, was gebrochen werden soll und einzig gebrochen werden kann im Augenblick, darin die Zeit selbst als das eigentliche das Dasein in seinem

5 Martin Heidegger: Was ist Metaphysik? Frankfurt a.M.: Klostermann (1992), 31.

6 Albert Camus: Der Mythos des Sisyphos. Übers. v. Vincent von Wroblewsky. Reinbek bei Hamburg: Rowohlt (2015), 73.

7 Camus: Der Mythos des Sisyphos, 70. Man muss kaum erwähnen, dass diese Vorstellung vielfach als anti-ethisch kritisiert wurde. Vgl. Mary Warnock: Existentialism. Oxford: UP (1970), 132. Das tut in diesem Kontext jedoch nichts zur Sache. Mein Anliegen ist es, zu zeigen, dass die Verbindung von Cleichgültigkeit und Handlung eine philosophische Tradition hat. 
Handeln Ermöglichende am Werk ist. ${ }^{8}$ Ausgehend von der Annahme, dass vor allem die Beziehung zur Zeit das Subjekt konstituiert, birgt die tiefe Form der Langeweile (eine Langeweile, die nicht durch einen Zeitvertreib verscheucht werden kann), die Möglichkeit, das Subjekt die zeitliche Bedingtheit seiner Existenz realisieren zu lassen. Durch das Langwerden der Zeit wird es vor seine Vergangenheit, Gegenwart und Zukunft (den dreifachen Zeithorizont) gestellt und eine Perspektive auf das Dasein eröffnet sich, die von der alltäglichen Geschäftigkeit normalerweise verschleiert wird. Kann der Mensch in der Regel auf solche Alltäglichkeiten nur reagieren, bringt die Langeweile eine »Entschlossenheit zum Handeln «" hervor, die ihm ermöglicht, zu agieren, d.h. aktiv zu handeln.

Selbst bei den Ausführungen zum Neutralen durch Maurice Blanchot, der einen viel weniger optimistischen Ton anschlägt, als es bei Heidegger der Fall ist, gibt es einen zumindest leisen Anklang einer solchen Handlungsmöglichkeit. Auch Blanchot spricht vom Neutralen, ähnlich wie Heidegger vom Nichts, als einer absoluten Unbestimmbarkeit, zu der man sich nicht verhalten kann. Man kann über das Neutrale (er nennt den Tod als ein Beispiel) nur sagen, »dass der Sinn nicht gesetzt wird, weder positiv noch negativ«, da er "außerhalb jeder Affirmation und Negation affirmiert ist ${ }^{10}{ }^{10}$ Doch während das Individuum unfähig ist, der Gleichgültigkeit, die es erfährt, etwas entgegenzusetzen, so kann er sie doch zumindest aushalten. So resümiert Alice Lagaay:

for Blanchot there still seems to be something of an imperative at work in the neutral. [...] it appears to result in a[n] [...] ethical appeal, an infinite responsibility even though this does not translate into action as such, but instead into a kind of radical withdrawal, a resistance to any kind of attempt (or temptation) to escape the night, nothingness, the neutral, in that the poet and philosopher explicitly choose not to turn towards the world, things and meaning[...]. ${ }^{11}$

8 Martin Heidegger: Cesamtausgabe. II Abt. Vorlesungen. Bd. 29/30. Die Grundbegriffe der Metaphysik. Welt- Endlichkeit-Einsamkeit. Hg. v. Friedrich-Wilhelm von Herrmann. Frankfurt a.M.: Klostermann (1983), 224.

9 Heidegger: Crundbegriffe der Metaphysik, 226.

10 Maurice Blanchot: Einklammerungen. In: Ders.: Das Neutrale. Schriften und Fragmente zur Philosophie. Übers. u. hg. v. Marcus Coelen. Zürich: Diaphanes (2010), 24.

11 Alice Lagaay: Sleepwalking Through the Neutral. In: Performance Research 21 (1), 2016, 41. 
Die Erfahrung des Neutralen und die Gleichgültigkeit, in die man dabei hineingerät, ist, so Lagaay, nicht passiv, sondern Ergebnis einer aktiven Entscheidung: Eine Entscheidung, die, auch wenn Lagaay sie nicht als Handlung (»action«) versteht, doch ein Urteil über richtige Verhaltensweisen miteinschließt. Nicht zuletzt setzt Blanchot das Neutrale auch immer in Bezug zum »literarische[n] Akt «. ${ }^{12}$ Er hört nie auf zu implizieren, dass die Erfahrung des Neutralen auch die Geburtsstunde der Literatur ist. Die Literatur kann eigentlich nur eines: das Neutrale erscheinen lassen. Das heißt natürlich auch, dass nur derjenige sie schriftstellerisch zu realisieren und produzieren vermag, der Neutralität schon erfahren hat. Sie ist also auch hier nicht etwa ein Zeichen von Indolenz, sondern Auftakt zu einem Schaffensakt.

Auch Roland Barthes' Verständnis des Neutralen fängt auf der sprachlichen Ebene an, und setzt sich auf der politischen fort. In seiner Vorlesung Le Neutre, die er 1977-78 am Collège de France hält, plädiert er dafür, die ausbleibende Sinnsetzung im Neutrum als bedeutsame Handlung zu verstehen, da sie eine Störung des Normativen hervorbringen kann. Er nennt das Neutrum »dasjenige, was das Paradigma außer Kraft setzt«, wobei er unter dem Paradigma strukturalistisch eine »Opposition zweier virtueller Terme« versteht, von denen im Sprechen (und nicht weniger im Handeln) immer einer der Terme aktualisiert, d.h. ein bestimmter Sinn hervorgebracht, während ein anderer zurückgewiesen wird. ${ }^{13}$ Das Neutrum verkörpert für Barthes einen dritten Term, der diesen »unerbittlichen Binarismus« außer Kraft setzt, und es so schafft, das Paradigma im Ganzen einfach zu vermeiden. ${ }^{14}$ Diese Vermeidung ist für Barthes alles andere als eine passive Leistung, er sieht darin eine »leidenschaftliche, inbrünstige Aktivität«. ${ }^{15}$ Darin zeigt sich die Umwertung der Gleichgültigkeit bei Barthes: sie bezeichnet nicht ein fehlendes, sondern ein anwesendes Engagement. Durch eine gleichgültige Haltung revoltiert sie gegen herkömmliche Wege des Revoltierens. Die Indifferenz reduziert den »Oppositionsgestus auf Null«, um eine neue Form der Opposition zu bilden. ${ }^{16}$

12 Blanchot: Einklammerungen, 25.

13 Roland Barthes: Das Neutrum. Vorlesung am Collège de France 1977-1978. Übers. v. Horst Brühmann. Hg. v. Éric Marty. Frankfurt a.M.: Suhrkamp (2005), 32.

14 Barthes: Das Neutrum, 33.

15 Barthes: Das Neutrum, 34.

16 Glosch: Cleichgültigkeit, 9. 


\section{PRÄTENTION in Un homme qui dort von Georges Perec, 1967}

Die Lektüre widmet sich der literarischen Darstellung von Indifferenz. Darin wird die These vertreten, dass Indifferenz eine Praxis des Nichtstuns darstellt, insofern sie einen Versuch unternimmt, übliche Tätigkeitsmuster zu durchbrechen und etwas Neues zu beginnen. Anhand von Georges Perecs Un homme qui dort (1967) wird dieser Versuch allerdings als Prätention entlarvt. Er nimmt zwar kurzzeitig die Form einer Handlung an, ist jedoch aufgrund der sozialen Isolation, die die Indifferenz bewirkt, auf Dauer nicht haltbar.

Das dritte Werk des französischen Schriftstellers Georges Perec, Un homme qui dort, ${ }^{17}$ setzt sich mit der Hoffnung auseinander, aus dem Gefühl der Indifferenz ein neues Handlungspotential schöpfen zu können. Die Romangeschichte handelt von einem Universitätsabbrecher, einem Studenten der Soziologie, der sein Abschlussexamen nicht ablegt und sich im Folgenden von der Hochschule und seinen Kommilitonen abschottet, um seine Zeit schlafend, liegend und durch Paris laufend zu verbringen. Das erste Unterkapitel (Rund um das Handlungsparadigma 1968) skizziert die Entstehungszeit des Romans. Darin wird die These vorgestellt, dass der Roman einen wichtigen Punkt der historischen Genese hin zum Ereignis der Pariser Revolten im Mai 1968 markiert und zwar nicht trotz, sondern wegen seiner Fokussierung auf das Nichtstun. Dieses Nichtstun wird vom Protagonisten aktiv gestaltet und damit zur Praxis erhoben. Zu Beginn des Romans wird er zunächst von einer umfassenden Indifferenz ergriffen, die ihn geradezu zwingt, nichts mehr zu tun. Doch schnell kommt es zu einer Umwertung: der Protagonist begrüßt seine Indifferenz und macht es sich zur Aufgabe, sie in vollem Umfang auszuleben. Die Strategien, mit denen er diese Mission realisiert, sind im zweiten Unterkapitel auf diegetischer und formaler Ebene beschrieben (Das Projekt Indifferenz). Derselbe Abschnitt widmet sich dem Erzählakt des Romans, der vom Protagonisten selbst ausgeführt wird, und der Paradoxität der Behauptung, indifferent zu sein. Die daraus mehrfach sich ergebene Vermutung, hinter der behaupteten und performierten Indifferenz könne etwa doch eine differenzierte

17 Georges Perec: Un homme qui dort. Paris: Éditions Denoël (1967). Wird nachfolgend mit der Sigle Hqd und der Seitenzahl im Text zitiert. Soweit nicht anders angegeben, beziehen sich die deutschen Zitate auf die Übersetzung Eugen Helmlés in Georges Perec: Ein Mann der schläft. Zürich: Diaphanes (2012). 
Haltung stecken, wird im dritten Unterkapitel (Handlung und geschichtsphilosophische Fremdbestimmung) bestätigt. Dort wird demonstriert, dass sich der Protagonist mit seinem Nichtstun tatsächlich gegen eine Geschichtsphilosophie des Fortschritts wendet, in der menschliche Handlung ihrer Kerneigenschaft - der Unvorhersehbarkeit ihrer Resultate - beraubt ist. Seine Praxis des Nichtstuns setzt der Heteronomie, die mit dieser Geschichtsphilosophie verbunden ist, eine Autonomie entgegen, in der der Protagonist eine alternative Geschichte entwirft - und somit, zumindest vermeintlich, handelt. Diese vermeintliche Handlung wird im zweiten Unterkapitel dieses Kapitels jedoch wieder demontiert, indem aufgezeigt wird, dass die neugefundene Selbstbestimmung zur megalomanen Herrschaftsphantasie auswuchert. In ihr und durch sie kommt dem Protagonisten zu Bewusstsein, wie sehr er an der Einsamkeit leidet, die mit seinem indifferenten Nichtstun einhergeht - und dass Handlung in Isolation unmöglich ist. Das letzte Unterkapitel (Aufgabe der Indifferenz und Rückkehr in die Gemeinschaft) widmet sich der Umwertung des Nichtstuns zum Ende des Romans: War es zunächst als mögliche Handlung gekennzeichnet, so stellt sich dies als Missverständnis heraus. Doch im Rückgriff auf die Historisierung zu Beginn des Kapitels lässt sich das Nichtstun zumindest als Auftakt für tatsächliche (d.h. unvorhersehbare, soziale, poli-

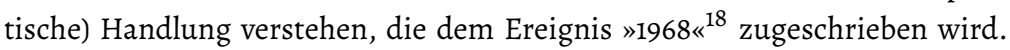
Und zwar, weil es genug Leid produziert, um seine eigene Überwindung in Form von Handlung herbeizuführen.

\section{Rund um das Handlungsparadigma 1968}

Un homme qui dort erscheint 1967, ein knappes Jahr vor den Studentenprotesten 1968. Diese zeitliche Nähe ist kein Zufall, denn zwischen der Geschichte des Romans und dem Mai '68 besteht ein direkter Zusammenhang. Beide haben als Ausgangspunkt die Institution der Universität, zudem sind die Akteure von 1968 Studierende, ebenso wie der Protagonist in Perecs Roman. Doch während erstere die Veränderung der Universität (und der Gesellschaft im Ganzen) anstreben, wendet sich der Protagonist Perecs von beidem ab und

18 Wie im wissenschaftlichen Diskurs über dieses Thema üblich geworden, markieren die Anführungszeichen, dass die Jahreszahl 1968 Chiffre für eine Vielzahl von Umbrüchen und heterogenen Bewegungen ist. Vgl. Wolfgang Kraushaar: 1968 als Mythos, Chiffre und Zäsur. Hamburg: Hamburger Edition (2000). Sie werden im Folgenden graphisch weggelassen, aber immer mitgedacht. 
tut nichts. Trotz dieser unterschiedlichen Haltung zur Universität zeigt sich in diesem Nichtstun der Romanhandlung eine ähnlich kritische Ausrichtung wie in den 68er Aufständen, und muss deshalb im Kontext dieses Ereignisses gelesen werden.

Auf den ersten Blick steht das Nichtstun im krassen Gegensatz zu dem >Ereignis 68<, das vielfach als Ergebnis genuin politischen Handelns verstanden wird. Dabei darf man nicht vergessen, dass vor 1968 die Vorstellung, Studierende könnten politisch bedeutsam handeln, vielfach unterminiert worden war. In den frühen und Mitt-1960er-Jahren bildete sich ein Diskurs heraus, der diese Möglichkeit explizit ausschloss. Und der damit in gewisser Hinsicht >Nichtstun $<$ als politische Handlungsunfähigkeit zur studentischen Eigenschaft deklarierte. Die Idee, dass Studierende wirklich handeln können, hat sich erst in Folge der Ereignisse 1968 wirklich ergeben. Erst nach den Aufständen schrieb Hannah Arendt, im Jahr 1968 sei »seit sehr langer Zeit zum ersten Mal eine spontane politische Bewegung entstanden, die nicht nur Propaganda treibt, sondern handelt, und zwar nahezu ausschließlich aus moralischen Motiven. «19 Auch Jacques Rancière attestierte den 68ern die »Wiederentdeckung grundlegender Eigenschaften der Politik«, ${ }^{20}$ und meint damit vor allem eine gesellschaftliche Re-appropriation des Handelns. Diese positive Haltung wird allerdings nicht von allen geteilt. Tatsächlich geriet die Bewegung vielfach in die Kritik, weil sie (unter anderem) keine langfristigen Veränderungen bewirken konnte (oder überhaupt wollte), was die Bedeutung ihrer Handlungen teilweise negierte. Dementsprechend kritisierte Theodor W. Adorno das Handeln von '68 als "Aktionismus", als "Scheinpraxis«, die keine Veränderung bedeutet, sondern den »alten gewalttätigen Gestus von Praxis ungebrochen übernehme ${ }^{21}$ Rancière hat solcher Kritik einen interessanten Einspruch entgegengesetzt: Die Besonderheit des Ereignisses 1968 ließe sich nicht an seinen Effekten beurteilen, sondern sollte auf seine Bedingungen hin untersucht werden. Denn den Ereignischarakter hätten die Unruhen nicht erhalten, weil sie eine positive und bleibende Veränderung geschaffen haben, sondern weil sie nicht erwartbar waren. Ein studentischer Aufstand war bis 1968 eine ungewöhnliche Idee. Die Studierenden konnten 1968 nur deshalb

19 Arendt: Macht und Gewalt, 108. Herv. vor dem letzten Komma meine, nach selbigem im Original.

20 Vortrag am Berliner Centre Marc Bloch am 19. Januar 2018: »Interpréter 68«.

21 Theodor W. Adorno: Marginalien zu Theorie und Praxis. In: Ders.: Cesammelte Schriften. Bd. 10.2. Kulturkritik und Gesellschaft II: Eingriffe. Stichworte. Anhang. Hg. v. Rolf Tiedemann. Frankfurt a.M.: Suhrkamp (1977), 762, 759. 
als Handelnde erscheinen, weil sie vorher als Nicht-Handelnde, als Nichtstuer verstanden worden waren.

Folgt man Rancières Forderung, nicht die Zeit nach, sondern vor $1968 \mathrm{zu}$ betrachten, so muss man sich mit dem Topos des Nichtstuns auseinandersetzen, der eben auch in Perecs Un homme qui dort verarbeitet wird. In der Tat hatte sich im Vorfeld der Proteste über etwas mehr als ein Jahrzehnt eine (vor allem akademische) Position entwickelt, die an der Idee eines politisch wirksamen Handels von Seiten der französischen Studierenden große Zweifel hatte. Viele dieser Einwände kamen aus dem Gebiet der Soziologie. So kommen Pierre Bourdieu und Jean-Claude Passeron 1964 in ihrer Studie des französischen Bildungssystems zu dem Schluss, dass dort gesellschaftliche Ungleichheit nicht abgebaut, sondern eher perpetuiert wird. Die Benachteiligung bildungsferner Schichten wird aufrechterhalten. Dies treffe insbesondere auf die Universität zu, zu deren Logik es zwar gehört, sich zu hinterfragen - nie aber in einem Modus, der sie wirklich abschaffen könnte. In Les héritiers: les étudiants et la culture heißt es:

Gehorcht nicht auch die Infragestellung der Universität und der von ihr vermittelten Bildung dem universitären Modell einer komplizenhaften und fiktiven Infragestellung der disputatio de quodlibet und dissertatio de omni re scibili, jenen hoch formalisierten Übungen, mit denen die Universität die unter Zwang stehende Übung intellektueller Freiheit lehrt? Wie kann man übersehen, dass die Revolte gegen das Bildungssystem und die Flucht in einen heterodoxen Enthusiasmus auf Umwegen letztlich die Zwecke der Universität verfolgt?22

Ein Zusammenhang zwischen Bildung und Emanzipation, so verdeutlichen Bourdieu und Passeron hier, sei illusorisch. Gerade Studierende der Fächer ohne klares Berufsziel identifizieren sich völlig mit der Universität und würden so »konformistische[...] Konsumenten« ihrer Lehrinhalte. ${ }^{23}$ Dass sie sich in der gegebenen Situation gegen diese Institution (ebenso wie gegen das ihnen bereits zugestandene Privileg der Aufnahme in dieselbe) auflehnen würden, um mehr Bestimmungsmacht über sie zu gewinnen und Bildungsressourcen gerechter zu verteilen, schien so in den Mitt-6oern immanent unwahrscheinlich.

22 Bourdieu u. Passeron: Die Erben, 64.

23 Bourdieu u. Passeron: Die Erben, 61. 
Neben der weitgehend neutralen Perspektive von Bourdieu und Passeron gab es innerhalb der Universität ebenfalls Stimmen, die die Möglichkeit studentischer Handlung aus politischen Gründen negierten. So zum Beispiel der konservative Raymond Aron, der von 1955-1968 Soziologie an der Sorbonne lehrte. Aron bezweifelte in den 1950er-Jahren das politische Handlungspotential linker Intellektueller, indem er in L'Opium des intellectuels behauptete, der Marxismus habe keine revolutionäre, sondern eine betäubende Wirkung (im Echo der Marx'schen Feststellung, Religion sei das Opium der Massen). ${ }^{24}$ In seiner Nachwirkung in den 1960er-Jahren diskreditierte diese These natürlich auch die Neue Linke, die mit den Studentenprotesten strukturell und ideologisch eng verbunden war. Auf die Ereignisse im Mai '68 reagierte Aron mit der Publikation der kurzen Abhandlung La Révolution introuvable noch im selben Jahr, in der er die angebliche Revolution der Studierenden für nichtig erklärte. Er greift dabei im Wesentlichen auf die Argumente aus L'Opium des intellectuels zurück, verweist so auf den Revolutionsmythos 1789, der dem französischen Volk, und vor allem der Linken, kontinuierlich aber fälschlich Hoffnung auf eine erneute Revolution gebe. ${ }^{25}$ Im Zuge dieser Argumentation führt er ebenfalls aus, dass die französischen Studierenden vor 1968 sehr unter einer allgemein verbreiteten Einsamkeit gelitten hätten. So heißt es in La Révolution introuvable:

les étudiants français, en particulier à Paris, constituent une foule solitaire. Nombre d'entre eux souffrent de la solitude, de l'absence de vie communautaire. Pas seulement de l'absence de contacts avec les professeurs lointains ce qui est souvent vrai - mais aussi d'absence de contacts avec leurs camarades. Et certaines enquêtes montrent que des étudiants, venus de la province, ont fait des années d'études à la Sorbonne sans vraiment appartenir à aucun groupe, sans avoir un cercle d'amis. Cette espèce de fraternité juvénile dans une communauté semi-délinquante, c'est la surcompensation de la solitude dans laquelle vivent ordinairement les étudiants français. ${ }^{26}$

Aron argumentiert hier, psychologisierend, dass die Unruhen 1968 nicht aus ideologischen Gründen stattgefunden hätten, oder um wirklich eine Verbes-

\footnotetext{
24 VgI. Raymond Aron: Opium für Intellektuelle oder Die Sucht nach Weltanschauung. Übers. v. Klaus Peter Schulz. Köln: Kiepenheuer \& Witsch (1957).

25 Raymond Aron: La révolution introuvable. Réflexions sur les événements de Mai. Paris: Fayard (1968), 31.

26 Aron: La révolution introuvable, 31.
} 
serung der Arbeits- und Studienbedingungen hervorzubringen, sondern weil die Studierenden einsam gewesen seien. Im Zusammenschluss zu einer großen Gruppe haben sie vor allem diese Einsamkeit kompensieren wollen (»c'est la surcompensation de la solitude«). Er impliziert damit, dass die Unruhen aus den >falschen (Gründen stattgefunden hätten, und delegitimiert sie zu Nicht-Handlungen ohne politische Tragweite. Darin zeigt sich, wie es um 1968 steht mit der Idee studentischer Handlung: Vor den Unruhen hielt man sie für unwahrscheinlich, im Moment ihrer Realisierung wird ihre Bedeutung untergraben, indem sie als > uneigentlich deklariert wird. Das sind die Bedingungen des Ereignisses '68, deren Untersuchung Rancière fordert. Ironischerweise gehört zur heutigen Betrachtung von 1968 als Geburtsstätte eines neuen, ereignishaften Handelns gerade das Element, was Aron zur Delegitimierung benutzen wollte: das Soziale. Denn der Standpunkt Hannah Arendts ist, dass es nur Handlung geben kann, wenn sie in der Gruppe stattfindet. Handeln »ist in Isolierung niemals möglich. «7

Zweifel an der studentischen Handlungsfähigkeit gab es ebenfalls innerhalb der kommunistischen Partei, durchaus von prominenter Seite. 1964 erschien das Essay »Problèmes étudiants«, in dem Louis Althusser den Studierenden, und vornehmlich den Studentenorganisationen der Neuen Linken, den Eingriff in die politische Praxis aufgrund ihrer fehlenden theoretischen Fundierung nicht zutraute. Damit wandte er sich konkret gegen das bereits in den früheren 6oer-Jahren begonnene studentische Bestreben, die Universität zu demokratisieren. Stattdessen sprach er sich explizit für die Lehrer/Schüler Hierarchie aus, da sie die effektivste Strategie für die Vermittlung wissenschaftlicher Inhalte sei. Nur richtig ausgebildete WissenschaftlerInnen könnten der Revolution dienlich sein, meinte Althusser: »la cause révolutionnaire est toujours indissolublement liée à la connaissance, c'est-à-dire à la science ${ }^{28}$ Die Möglichkeiten der Studierenden, sich gegen mangelhafte Wissensvermittlung an der Universität zu wehren, seien, so Althusser, auf ein Nichtstun beschränkt: »ils résistent par leur passivité«. ${ }^{29}$ Althusser impliziert hier, dass es zwei Formen des Widerstands gibt - den aktiven und dem passiven -, von denen die erste die Königsdisziplin darstelle, und die letzte nur die Anfängerliga. Im Gegensatz zu Bourdieu und Aron schreibt er Studierenden immerhin die Möglichkeit zur widerständigen Handlung zu - aber eben

27 Arendt: Vita activa, 234.

28 Louis Althusser: Problèmes étudiants. In: La Nouvelle Critique 152 (Januar), 1964, 94.

29 Althusser: Problèmes étudiants, 89. Herv. meine. 
snur in passiver Form, und bestenfalls als eine Vorstufe >richtigen stands. Im Kontext des französischen Universitätssystems der 1960er-Jahre kommt dieses Zugeständnis jedoch keiner Affirmation gleich, sondern einer Einschränkung.

Diese Beispiele weisen auf die Existenz eines wissenschaftlich und politisch geprägten Diskurses über studentische Handlungsunfähigkeit in den frühen 6oer-Jahren hin. Perec nimmt in Un homme qui dort auf diesen Diskurs Bezug, vor allem auf die von Althusser vorgestellte Idee eines passiven Widerstandes. In seinem Roman inszeniert Perec studentisches Nichtstun nicht als Fakt oder Resignation, sondern als Widerstand, als Streik und den Versuch zu handeln. Im Gegensatz zu dem eben referierten Diskurs wird dem Studenten bei Perec das Nichtstun jedoch nicht zugeschrieben, sondern er verordnet es sich selbst, um sich von den gesellschaftlichen Institutionen und Konventionen zu distanzieren, die er ablehnt. Dieses Nichtstun stellt so eine Praxis dar, die widerständig und kritisch ist, und damit wesentliche Charakteristika der '68er Revolten vorwegnimmt - wenn auch in ganz anderer Form. Die Ergebnisse unterscheiden sich wesentlich. So wird das Nichtstun im Roman dargestellt als eine Art Experiment - das Projekt >Indifferenz « - um aus der Ordnung auszutreten, das aber letzten Endes scheitert. Dennoch bezeichnet das Nichtstun bei Perec eben nicht nur eine Limitierung oder ein Unvermögen. Es ist ein Anfangspunkt, um die Frage zu verhandeln, wie politische Handlung überhaupt aussehen könnte.

\section{Das Projekt Indifferenz}

Perec nimmt in Un homme qui dort den Diskurs über die Handlungsunfähigkeit von Studierenden in den frühen 1960er-Jahren auf. Dies ist besonders zu Beginn der Geschichte der Fall, in dem die Universität eine Rolle spielt: Der Protagonist geht nicht zu seinem Abschlussexamen und bricht seine Ausbildung $a b$. Statt seinem ursprünglichen, konventionellen Lebensplan zu folgen (Studium, Beruf, Heirat usw.), tut er nichts. Er schläft viel, verlässt sein Zimmer kaum, trifft keine Freunde. Dann wieder läuft er nächtelang ziellos durch Paris. Dieses Nichtstun kann verschieden gedeutet werden. Gerade vor dem Hintergrund des oben beschriebenen Diskurses wirkt der Protagonist zum Beispiel wie ein Verlierer der zeitgenössischen akademischen Dynamiken. Er ist nicht nur unfähig zu einer emanzipatorischen Handlung, er kann nicht einmal sein Studium abschließen. Es ist jedoch ebenso möglich, dieses Nichtstun als einen Widerstand, einen Streik gegen die Institution der 
Universität zu deuten - man denke nur an Walter Benjamins These, die »Unterlassung von Handlungen, ein Nicht-Handeln« im Streik wende sich mit voller Kraft gegen die bestehende und als ungerecht empfundene Rechtsordnung. ${ }^{30}$ Der Romantext bestätigt allerdings weder die eine noch die andere Deutung. Er begegnet der Mehrdeutigkeit des Nichtstuns auf ungewöhnliche Weise: Der Protagonist, der zugleich der Erzähler der Geschichte ist, weist alle möglichen Deutungen zurück und behauptet, mit seinem Nichtstun gar nichts aussagen $\mathrm{zu}$ wollen. Er behauptet, vollkommen indifferent $\mathrm{zu}$ sein. Er sei »un dur noyau d'indifférence, un regard neutre« (Hqd 37) - »ein harter Kern aus Gleichgültigkeit, ein neutraler Blick« (23).

Diese Behauptung wiederholt sich im Laufe des Romans oft. Sie wird vom Protagonisten selbst artikuliert, der auch der Erzähler ist. Er erzählt in einem "self-to-self monologue«, ${ }^{31}$ in dem er sich selbst als Du (»tu«) anspricht. In dieser Sprecherrolle betont er immer wieder, dass er gegenüber seiner Umwelt vollkommen indifferent ist. Er tut dies, indem er behauptet, dass sein Nichtstun auf keine Art und Weise gedeutet werden kann:

Plus tard, le jour de ton examen arrive et tu ne te lèves pas. Ce n'est pas un geste prémédité, ce n'est pas un geste, d'ailleurs, mais une absence de geste, un geste que tu ne fais pas, des gestes que tu évites de faire. [...] Ton réveil sonne, tu ne bouges absolument pas, tu restes dans ton lit, tu refermes les yeux. (Hqd 23)

Später kommt der Tag deiner Prüfung, und du stehst nicht auf. Es ist kein vorbedachtes Handeln, es ist übrigens gar kein Handeln, sondern ein Nichthandeln, ein Handeln, das du unterlässt, das du vermeidest. [...] Dein Wecker läutet, du rührst dich überhaupt nicht, du bleibst im Bett liegen, du machst die Augen wieder zu. (14)

In diesem Passus besteht der Protagonist darauf, dass sein Fernbleiben von der Prüfung, das Unterlassen der Prüfungshandlung keine Geste (»geste«)

30 Benjamin: Gewalt, 184. Siehe Kapitel »Handlung und Geschichte in diesem Buch.

31 David Gascoigne: The Cames of Fiction. Georges Perec and Modern French Ludic Narrative. Bern: Peter Lang (2006), 132. Es gibt verschiedene Interpretationen dieser Erzählsituation; für eine nuancierte narratologische Analyse mit abweichenden Möglichkeiten vgl. Roman Kuhn: Zweite Person Singular Präsens. Überlegungen zu »Ein Mann der schläft« von Georges Perec. In: Der Präsensroman. Hg. v. Armen Avanessian u.a. Berlin: De Gruyter (2013), 210-217. 
darstelle. Er sagt es ganze fünfmal. Mit der Verwendung gerade dieses Begriffs verweigert er die Deutbarkeit seines Nichtstuns. Sowohl im Deutschen als auch im Französischen impliziert das Wort »Geste« eine Tat, die interpretierbar ist. Im Deutschen drückt die Geste eine »bestimmte innere Haltung« aus, ${ }^{32}$ und auch im Französischen bedeutet "geste « ein »[m]ouvement du corps (principalement des bras, des mains, de la tête) volontaire ou involontaire, révélant un état psychologique, ou visant à exprimer, à exécuter quelque chose ${ }^{33}$ Eine Geste ist eine körperliche Bewegung, die nicht für sich steht, sondern auf eine Haltung, einen bestimmten psychologischen Zustand hinweist. Sie enthüllt etwas (»révélant«), ist Ausdruck von etwas (»exprimer«), vollzieht etwas (»exécuter«). Sie ist ein lesbares Zeichen. Sie ist, wie Adam Kendon dargelegt hat, "visible action as utterance«, und hat so stets eine expressive oder repräsentative Funktion. ${ }^{34}$

Die unterlassene Handlung des Protagonisten erfüllt aber gerade diese kommunikative Funktion nicht, weil sie keine Geste ist - das behauptet der Erzähler-Protagonist. Denn anstelle der Artikulation einer Haltung strebt er eine Ent-Positionierung an. Er möchte nicht für oder gegen eine Institution eintreten, sondern verwehrt sich jeglicher Wertung und Meinung, die man aus einer von ihm stammenden Geste herauslesen könnte. Die Verneinung der >gestischen $<$ Qualität seines Nichtstuns ist Teil der Indifferenz.

Um dies zu verdeutlichen, verharrt der Protagonist, zumindest zu Beginn des Romans, in körperlicher Stasis - als ob man ihm keine Geste anhängen könnte, wo auch keine Bewegung stattfindet. Der oben zitierten Negation der Geste folgt die Behauptung körperlicher Immobilität auf dem Fuß: »tu ne bouges absolument pas« (Hqd 23), »du rührst dich überhaupt nicht« (14). Im unmittelbaren Anschluss an diese Stelle beschreibt der Erzähler-Protagonist seinen Körper, als wäre er ein fremdes Objekt, das er gar nicht kontrollieren könne. Er denkt zum Beispiel, nicht mit seinem Körper auf dem Bett zu liegen, sondern auf seinem Körper selbst: „tu es sur quelque chose de très mou qui es ton propre corps « (Hqd 17). ${ }^{35}$ Sein Körper stellt keine lenkbare Einheit dar, sondern »erstreckt sich in Wirklichkeit in alle Richtungen« (12), »le corps, à cet instant, ne présente plus du tout la belle unité de tout à l'heure, en fait,

Geste. In: Duden. Die deutsche Sprache. Bd. 2. Hg. v. Werner Scholze-Stubenrecht. Berlin: Dudenverlag (2014), 829.

33 Ceste. In: Le grand Robert de la langue française. Bd. 3. Hg. v. Alain Rey u.a. Paris: Dictionnaires Le Robert (2001), 1326. Herv. meine.

34 Adam Kendon: Gesture. Visible Action as Utterance. Cambridge: UP (2004), 2.

$35 »[D] u$ liegst auf etwas sehr Weichem, was dein eigener Körper ist « (Übers. meine). 
il s'étale dans tous les sens" (Hqd 18). Jede Beschreibung seines Körpers impliziert einen anderen Mangel. Mal ist der Körper nicht erreichbar, mal zu ausgeweitet, um ihn zu kontrollieren, mal scheinen ihm sowohl Knochen als auch Muskeln abhandengekommen zu sein - so schildert er die »l'impression doucereuse et étouffante d'être sans muscles et sans os « $(\mathrm{Hqd} 21)^{36}$ - sodass der Eindruck entsteht, ihm gehe jegliche Funktionalität ab. Dabei sind besonders die Körperteile, die in der obigen Definition des Robert die Bedeutungsträger der Geste darstellen - Arm, Hand, Kopf - , in Mitleidenschaft gezogen. So benutzt er zum Beispiel seine Hand nicht mehr zum Rauchen, die Zigarette verbrennt einfach von selbst: »une cigarette qui se consume« (Hqd 22). Er hat nurmehr eine abwesende Hand, eine »main absente« (Hqd 37) Überhaupt sind seine Glieder, Arme wie Beine, schwer (»lourdeur de tes membres«, Hqd 29) und steif (»tes jambes engourdies«, Hqd 23). Auch sein Kopf ist schwer (»[t]a tête est lourde«, Hqd 23), weil er in der Vorstellung des Protagonisten den Rest seines Körpers beherbergt: »Les trois quarts de ton corps se sont réfugiés dans ta tête $\left(\mathrm{Hqd}\right.$ 125). ${ }^{37}$ All diese Beschreibungen zeichnen das Bild eines Mannes, dessen körperliche Integrität fraglich geworden ist, und der keinerlei »mouvement« unternehmen kann, in dem man eine Geste vermuten könnte.

Doch die Beschreibung körperlicher Stasis kann letztlich nichts daran ändern, dass auch die Abwesenheit von Bewegung als Geste verstanden werden kann. Das zeigen Giorgio Agambens »Noten zur Geste«. Dort argumentiert Agamben entgegen der (beispielsweise von Adam Kendon vertretenen) konventionellen Bedeutung der Geste, dass diese eben nicht Teil eines Vermittlungs- und Kommunikationsprozesses sei, der interpretiert werden könne. Sie sei nicht Mittel zum Zweck der Kommunikation, sondern vielmehr reines Mittel ohne semantische Bestimmung. Er situiert die Geste zwischen den zwei aristotelischen Tätigkeitsformen der poiesis (ein Schaffungsprozess, der Mittel zum Zweck ist) und praxis (ein Handeln, das sein eigener Zweck ist). In Abgrenzung $z u$ diesen Handlungsformen sei die Geste hingegen weder Mittel noch Zweck, sie verweist lediglich auf ihr kommunikatives Potential: »Die Geste ist die Darbietung einer Mittelbarkeit [medialità], das Sichtbarmachen eines Mittels [mezzo] als solchem. [...] Die Geste ist in diesem Sinne Mitteilung einer Mitteilbarkeit. $" 38$ Diese Definition bezieht

36 Der »erstickende Eindruck, keine Muskeln und keine Knochen zu haben« (13).

37 »Dreiviertel deines Körpers sind in deinen Kopf geflüchtet« (76).

38 Agamben: Mittel ohne Zweck, 54f. 
sich vornehmlich auf ästhetische Gesten, wie Josef Früchtl argumentiert: »Eine ästhetische Geste, nicht die Geste überhaupt, hält dann die Mitte zwischen Mittel und Selbstzweck, Herstellung und Handlung, Referenz und Selbstreferenz. ${ }^{39}$

Daraus folgt, dass die Behauptung des Erzähler-Protagonisten, er führe keine Geste aus, ein Selbstwiderspruch ist. Die Behauptung selbst stell insofern eine Geste dar, als sie auf ihre eigene Mittelbarkeit verweist. Die vermeintliche Gestenlosigkeit ist selbst gestisch. Dieser literarische Sprechakt, der in Un homme qui dort vollzogen wird, ist eine ästhetische Geste. Sie hat allerdings auch eine politische Bedeutung. Dies ergibt sich aus einer strukturellen Analogie mit Hannah Arendts Verständnis von Politik. Diese zeichne sich Arendt zufolge dadurch aus, zuvorderst ein Mittel ohne konkreten Zweck zu sein (allerhöchstens ist der Zweck die Erlangung der Freiheit). ${ }^{40}$ Auch Agamben versteht die Geste als genuin politisches Phänomen. Er definiert sie als »Kreuzungspunkt zwischen Leben und Kunst, Akt und Potenz«, und damit als »reine Praxis «. ${ }^{41}$ Im Vorwort zu Mittel ohne Zweck findet sich gar der Vermerk, die Geste stelle die »eigentliche Sphäre der Politik« dar. ${ }^{42}$ Zieht man also in Betracht, dass Agambens Konzept der Geste, das die Situation im Roman einschlägig beschreibt, mit dem Handeln nach Arendt die sreine Mittelbarkeit als Gemeinsamkeit teilt, so ist es möglich, die sgestische Gestenlosigkeit ‘ in Un homme qui dort als politisch bedeutsam, und vielleicht sogar als Handlung $\mathrm{zu}$ begreifen.

Es gilt also, den Topos der Indifferenz dualistisch zu betrachten, d.h. zwischen Inhalt und Form der Erzählung zu unterscheiden. Auf der inhaltlichen Ebene ist die Indifferenz das dominante Motiv des Romans. Doch auf der formalen Ebene zeigt sich ein Widerspruch. Un homme qui dort bringt keineswegs reine Indifferenz zur Darstellung. Denn die Aussage, dem Nichtstun wohne keine Bedeutung inne, stellt trotzdem eine Verweigerung dar, ${ }^{43}$ - und ist da-

39 Josef Früchtl: Eine Kunst der Geste. Den Bildern Ceschichte und Bewegung zurückgeben. In: Ders.: Vertrauen in die Welt. Eine Philosophie des Films. München: Fink (2013), 155. Es spricht auch Agambens Verweis auf Kants ästhetisches Urteil (das sich auf die Zweckmäßigkeit ohne Zweck richtet) dafür, dass er hier eine Frage der Ästhetik adressiert.

40 Arendt: Was ist Politik?, 69.

41 Agamben: Mittel ohne Zweck, 70.

42 Agamben: Mittel ohne Zweck, 9.

43 Man ist unweigerlich an das Kommunikationsaxiom von Watzlawick u.a. erinnert, demzufolge man nicht nicht kommunizieren, also auch nicht nicht handeln könne. Vgl. Paul Watzlawick, Janet H. Beavin u. Don D. Jackson: Menschliche Kommunikation. For- 
mit bedeutsam. Der Protagonist verweigert sich der Interpretation: er will sie weder erfahren, noch ausführen. Die entschlossene Verweigerung einer Geste, wie sie im eingangs zitierten Passus zum Ausdruck kam, ist schließlich auch gestisch. Der folgende Abschnitt (Performativer Widerspruch) widmet sich der Analyse dieses performativen Widerspruchs, der für die Interpretation des Romans als Ganzem bedeutend ist. In Un homme qui dort, so lautet meine These, ist Indifferenz nicht theoretisch strikt ausexerziert und idealtypisch dargestellt, sondern ist ein kommunikatives Mittel, durch das Unzufriedenheit ausgedrückt wird. Die Indifferenz, die durch das Erzählen des Protagonisten entwickelt wird, ist also eine Prätention. Die vorgetäuschte, also prätentiöse Indifferenz ist das große Projekt des Protagonisten, seine Praxis des Nichtstuns. Er tut so, als wäre ihm alles gleich, doch tatsächlich versteckt und verweist diese Indifferenz auf eine ausgeprägt kritische Haltung. Der zweite Abschnitt dieses Unterkapitels (Indifferenz als Kritik) widmet sich dem kritischen Aspekt der Indifferenz. Insgesamt wirft dieses Unterkapitel einen genauen Blick auf die formale Darstellung der Indifferenz und ihrer semantischen Dissonanzen. Im weiteren Verlauf des Kapitels "Prätention« verschiebt sich der Fokus von einer kleinen, detaillierten Betrachtung textueller Strategien auf eine größere Ebene: der politischen Bedeutung der Indifferenz und des Nichtstuns in der Diegese. Beide Perspektiven tragen dazu bei, zu zeigen, dass die Performanz der Indifferenz eigentlich auf den Wunsch verweist, zu handeln. Ein Wunsch, der zwar letztlich scheitern wird, aber dessen Ausführung dennoch die Frage aufwirft, wie eine Handlung prinzipiell aussehen könnte.

\section{Performativer Widerspruch}

Der Protagonist in Un homme qui dort versteht sein Nichtstun nicht als Geste, es handele sich vielmehr um eine »absence de geste« (Hqd 23). Er behauptet so, seinem Tun bzw. Nichtstun läge keine sinnere Haltung`zugrunde. Im Roman gibt es einige Strategien, die diese Indifferenz >realisieren « sollen. Doch eben diese Strategien rufen Zweifel daran hervor, sodass eine Diskrepanz

men, Störungen, Paradoxien. Übers. v. Paul Watzlawick. Bern: Huber (1969). Es hat in meinem Argument allerdings keinen Platz, weil das literarische Material andere Deutungsvoraussetzungen hat. Da der Erzähler bereits kommuniziert, dass keine Kommunikation stattfinden soll, ist klar, dass es sich um Kommunikation handelt. Die Frage, ob man ohne den literarischen Vermittlungsakt das Verhalten das Protagonisten kommunikativ deuten könnte, stellt sich nicht. 
zwischen der Selbsteinschätzung des Protagonisten und der Wirkung seiner Selbst-Erzählung entsteht.

Eine zentrale Strategie der Indifferenz ist eine Sprachreduktion. Die Sprache ist zwar zentrales Erzählmedium, doch der Erzähler-Protagonist will sie von allen Elementen befreien, die eine Haltung zu den Dingen ausdrücken könnte, die sie bezeichnet. Er versucht, die Kategorie der Eigenschaftsbezeichnungen von ihr abzulösen. Das fällt besonders in seinem Konsumverhalten auf. Spricht der Protagonist zu Beginn des Romans über die Gegenstände seines Apartments durch Verweise auf Markenprodukte (»un bol de Nescafé« oder ein »cendrier publicitaire«, Hqd 22), so entfällt diese Spezifizierung im weiteren Verlauf des Romans. Der Protagonist trinkt zwar noch Kaffee, dieser jedoch - obwohl anfangs mehrmals durch die Nennung des Nescafés etabliert, der mit gesüßter Kondensmilch getrunken wurde - ist nunmehr geschmacklos (»sans goût«, Hqd 58). Diese Geschmacklosigkeit ist dabei keine Abwertung, sondern bezeichnet die neutralisierte, indifferente Wahrnehmung des Protagonisten: da es keinen Geschmack gibt, kann er ihn weder gut noch schlecht finden. Er hält sich, um Maurice Blanchot zu paraphrasieren, abseits von sowohl Affirmation als auch Negation; er ist neutral. Überhaupt macht sich im Erzählen von den Lebensmitteln des Protagonisten seine reduktionistische Indifferenz bemerkbar:

Mais ton estomac ne fait plus, s'il l'a jamais faite, la différence, et ton palais non plus. Le langage a été plus résistant : il t'a fallu quelque temps pour que la viande cesse d'être mince, coriace, filandreuse, les frites huileuses et molles, le vin poisseux ou acide, pour que ces qualificatifs éminemment dépréciateurs, porteurs au début de sens tristes, évocateurs de repas pour pauvres, de nourritures de clochards, de soupes populaires, de fêtes foraines de banlieue, perdent petit à petit leur substance, et pour que la tristesse, la pauvreté, la pénurie, le besoin, la honte qui s'y étaient inexorablement attachés - cette graisse devenue frite, cette dureté devenue viande, cette acidité faite vin - cessent de te frapper, de te marquer, de même qu'à l'opposé cessent de te convaincre les signes nobles, exacts envers de ceux-ci, de l'abondance, de la bombance, de la fête [...]. Nulle énergie sacrée, nul divin nectarn'emplissent désormais ton assiette et ton verre. Nul point n'accompagne tes repas. Tu manges de la viande et des frites, tu bois du vin. (Hqd 84f.)

Doch dein Magen macht keinen Unterschied mehr, wenn er je einen gemacht hat, und dein Gaumen ebenso wenig. Die Sprache ist widerstandsfä- 
higer gewesen: du hast einige Zeit gebraucht, bis das Fleisch aufhörte, dünn, zäh, faserig zu sein, die Fritten ölig und weich, der Wein trüb und sauer, bis diese ungeheuer abwertenden Eigenschaftswörter, anfänglich Träger trauriger Bedeutungen, Beschwörer von Armenmahlzeiten, von Nahrung für Clochards, von Volkssuppen, von Vorstadtkirmes, allmählich ihre Substanz verlieren, und damit auch die Traurigkeit, die Armut, das Elend, die Not, die Schande, die unauslöschlich damit verbunden waren - dieses zu Frittieröl gewordene Fett, diese Fleisch gewordene Zähheit, diese zu Wein gemachte Säure - aufhören, dich zu treffen, dich zu zeichnen, genauso wie umgekehrt die edlen Zeichen der Fülle, des Schlemmens, des Feierns, diese genauen Gegenstücke, aufhören, dich zu überzeugen [...] Keine heilige Energie, kein göttlicher Nektar füllen von nun an deinen Teller und dein Glas. Kein Ausrufezeichen begleitet deine Mahlzeiten. Du ißt Fleisch und Fritten, du trinkst Wein. (51f.)

Hier zeigt sich, dass der Protagonist - wohlbemerkt gegen einen Widerstand der Sprache (»[l]e langage a été plus résistant«) - seine Nahrung ent-charakterisiert hat. Die Pommes frites waren mal ölig und weich (»huileuses et molles«), das Fleisch war mal zäh (»coriace«), der Wein sauer (»acide«), und all diese Dinge waren auch mal auf symbolischer Ebene edel (»nobles«), doch nun sind sie eigenschaftslos: »Tu manges de la viande et des frites, tu bois du vin.« Der Protagonist strebt also eine semantische Verflachung an, weil ihm die differenzierende Funktion der Sprache sinnlos erscheint.

Dabei ist die Abwendung von der Handlung des Wählens ganz zentral. Dies ist vor dem Hintergrund der Romangeschichte besonders bedeutsam: der Protagonist charakterisiert die Gesellschaft, in der er lebt, als eine, in der sein Lebensweg bereits vorgezeichnet ist. Individuelle Entscheidungen, wie die eigene Zukunft gestaltet werden soll, gebe es darin nicht. In diesem Denken ist jede Handlung, die man vollzieht, und jede Wahl, die man trifft, nur eine Illusion. Sie sollen den Glauben an die eigene Handlungsfähigkeit erhalten, die man aber tatsächlich eingebüßt hat. Das Nichtstun des Protagonisten ist die Auflehnung gegen eine solche Illusion von Agens. Es ist ein Befreiungsversuch: Wenn jedes Sprechen, jedes Handeln auch bedeutet, sich Konventionen zu unterwerfen und in diesem Sinne fremdbestimmt zu werden, erscheint der Entzug in Form des Nicht-Handelns als letzter Ort der vermeintlichen Freiheit. Diese Idee gehört zu einer großen Tradition des abendländischen Denkens: Man wirft der »Spontanität des Handelns« vor, »daß sein Neuanfang ein Schein ist, der sich sofort in dem prädeterminierten Bezugs- 
gewebe verliert, in dem sich gerade der Handelnde verstrickt « - Freiheit, so scheint es, kann nur der bewahren, der sich des Handelns enthält «. ${ }^{44}$

Der Roman wird, analog zu Arendts Handlungstheorie, zeigen, dass diese Annahme falsch ist. Doch bis der Protagonist dies realisiert, ist die Verweigerung einer sprachlichen Präzisierung, der Wahl bestimmter Eigenschaften seine Strategie, um Freiheit zu erlangen. So heißt es später im Roman: »Lindifférence dissout le langage, brouille les signes[...] tu es libre et tu ne choisis pas« (Hqd 113, Herv. meine) - »Die Gleichgültigkeit löst die Sprache auf, verwischt die Zeichen[...] du bist frei, und du wählst nicht« (69, Herv. meine). ${ }^{45}$ Die Verweigerung der Wahl ist im Übrigen auch eine Funktion des Neutrums, wie Barthes es beschreibt: Im Paradigma beruht der Sinn auf »dem Konflikt (die Wahl des einen Terms und nicht des anderen)«, das Neutrum ist die Aufhebung der »drohende[n] Aufforderungen der Welt, »eine Wahl zu treffen« und die Bestrebung, den »Sinn [vom Paradigma] abzukoppeln. ${ }^{46}$

Die gewollte Reduktion der Ausdruckspalette teilt Un homme qui dort mit einem seiner wichtigsten Intertexte: »Bartleby, The Scrivener« von Herman Melville. ${ }^{47}$ Auch die Figur Bartleby ist absolut gleichgültig, was sie mit dem Ausspruch »I am not particular « ${ }^{48}$ ausdrückt - sie ist nicht wählerisch. Gilles Deleuze zufolge weist Bartleby so darauf hin, dass »alles weitere, was man ihm vorschlagen könnte, noch eine Besonderheit, eine Wahl wäre, die ihrerseits noch in den Bereich der großen, unbestimmten Formel ICH MÖCHTE LIEBER NICHT fällt«. ${ }^{49}$ Diese vermeintlich der Indifferenz dienende Ablehnung

44 Arendt: Vita activa, 298. Es muss kaum erwähnt werden, dass dies nicht Arendts eigener Vorstellung entspricht.

45 Die Erwähnung der Freiheit ist auch ein Hinweis auf das existentialistische Fundament des Romans. Vgl. die Hinweise zum Thema Freiheit in der Einleitung dieses Kapitels.

46 Barthes: Das Neutum, 33.

47 Die folgende Stelle am Ende des Romans zeigt die intertextuelle Beziehung zwischen den beiden Geschichten auf: »]adis, à New York, à quelques centaines de mètres des brisants où viennent battre les dernières vagues de l'Atlantique, un homme s'est laissé mourir. Il était scribe chez un homme de loi. Caché derrière un paravent, il restait assis à son pupitre et n'en bougeait jamais. II se nourrissait de biscuits au gingembre.« (Hqd 171) Dt.: »Früher einmal, in New York, einige hundert Meter von den Felsenriffen entfernt, an die die letzten Wellen des Atlantiks schlagen, hat sich ein Mensch sterben lassen. Er war Schreiber bei einem Juristen. Hinter einem Wandschirm versteckt, blieb er an seinem Pult sitzen und verließ es nie. Er ernährte sich von Ingwerbiskuits. « (104) Herman Melville: Bartleby, The Scrivener. In: Amerikanische Meistererzählungen/Famous American Short Stories. Köln: Anaconda (2013), 158. 
des Wählens enthält einen Hinweis darauf, dass der Protagonist nicht ganz indifferent, sondern vielmehr ebenso kritisch und radikal eingestellt war wie die Studierenden 1968. Denn der Unwille zur Wahl rekurriert implizit auch auf die von Raoul Vaneigem ebenfalls 1967 publizierte Schrift Traité de savoirvivre à l'usage des jeunes générations. Vaneigem, ein anarchistischer Kulturkritiker mit einigem Einfluss auf die 68er, bringt dort das in der Kapitalismuskritik häufig wiederholte Argument vor, dass die >Wahk in der Konsumgesellschaft keine eigenständige Handlung, sondern ideologische Untergebenheit sei. "L'outil dans la production, le choix conditionné dans la consommation deviennent les supports du mensonge«, schreibt er, »les médiations qui, incitant l'homme, producteur et consommateur, à agir illusoirement dans une passivité réelle «. ${ }^{50}$ Liest man Perecs Roman aus dieser Perspektive, so lässt sich seine Indifferenz ohne weiteres als Versuch einer tatsächlichen Handlung lesen (nur eben ohne die terroristische und emotionale Tendenz, wie sie von Vaneigem propagiert wird). Die Erzählung laboriert im Großen und Ganzen an eben dieser Idee: dass was man üblicherweise als Handlung begreift ein Sich-Entscheiden, Urteilen, zur Prüfung gehen, arbeiten - illusorisch ist. Dass, in Folge, nichts zu tun bedeutet, zu handeln.

Die Indifferenz des Protagonisten kommt nicht nur in der sprachlichen Verflachung zum Ausdruck. Sie wird auch durch die wiederholten Behauptungen performiert, indifferent zu sein. ${ }^{51}$ Der Protagonist, der im Modus des "tu« sich selbst anspricht, betont immer wieder, wie egal ihm alles ist, und wie gleichgültig er der Welt gegenübersteht. Variationen dieser Erklärung sind in fast jeden Abschnitt des Textes eingewebt. Bei dieser Strategie fallen zwei Dinge auf: Zum einen wiederholt sich der Protagonist diesbezüglich sehr häufig, und zum anderen benutzt er sehr viele verschiedene Ausdrücke - zu viele eigentlich, in Anbetracht der Neutralitäts-Strategie der Sprachreduktion.

50 Raoul Vaneigem: Traité de savoir-vivre à l'usage des jeunes générations. Paris: Gallimard (1967), 85.

51 Auch de Chalonge stellt fest, dass im Roman Indifferenz nicht nur thematisch, sondern auch wörtlich bestimmend ist. Florence de Chalonge: Stylistique de l'indifférence. Un homme qui dort. In: Georges Perec. Artisan de la Langue. Hg. v. Véronique Montémont u.a. Lyon: Presses Universitaires (2012), 146. 
Tabelle: Ausgewählte Ausdrücke und Häufigkeit ihres Auftretens

\begin{tabular}{|l|l|}
\hline nul bzw. nulle & 47 \\
\hline detaché (3), l'indifférent (8), ignorant (5) & 16 \\
\hline inerte (3), immobile (12) & 15 \\
\hline creuse (1), vide (13), peu importante (1) & 15 \\
\hline neutre & 8 \\
\hline absurde (2), inutile (5) & 7 \\
\hline faible & 5 \\
\hline
\end{tabular}

Die Häufigkeit und Varianz der Neutralitätsbehauptungen lassen sich auch hier besonders anschaulich im Vergleich mit dem Intertext »Bartleby, The Scrivener« darstellen. Der Unterschied zwischen dem Protagonisten Perecs und seinem Melville'schen Vorbild ist quantitativ greifbar: verwendet Bartleby (in einem Werkumfang von ca. 15000 Wörtern) seine Formel 12-mal in exakt dem gleichen Wortlaut, so enthält Un homme qui dort (bei ungefähr 35000 Wörtern) eine ungleich stärkere Gleichgültigkeits-Isotopie ${ }^{52}$ mit ca. 100 Erwähnungen vieler verschiedener Schlüsselbegriffe wie »'indifférent«, »ignorant « und »inutile« (siehe Tabelle) und doppelt so vielen gleichsam gefluchteten Negationen - »tu n'as plus besoin d'excuses, de regrets, de nostalgies. Tu ne rejettes rien, tu ne refuses rien« $(H q d \text { 32f. })^{53}$ oder »que tu n'entreprends plus jamais de les [tes repas] varier « (Hqd 110). ${ }^{54}$

Die Anzahl der neutralen bzw. negierenden Aussagen ist bei Perec also achtfach größer als bei Melville, und um ein Vierfaches größer, wenn man den größeren Werkumfang einkalkuliert. ${ }^{55}$ Wie aber wirkt dieser quantitative Unterschied? Die Meinungen in der Forschung sind zweigeteilt. Die einen nehmen die Proklamation der Indifferenz ernst - Kathrin Glosch zum Beispiel hält den Roman für eine genuine »Odyssee der Indifferenz«, da alle

52 Ich verwende den Isotopie-Begriff nach Greimas. Vgl. Algirdas ]. Greimas: Strukturale Semantik. Methodologische Untersuchungen. Übers. v. Jens Ihwe. Wiesbaden: Vieweg (1971), 45f., 6of.

53 »[D]u brauchst keine Entschuldigungen, keine Reue, keine Sehnsüchte mehr. Du verwirfst nichts, du lehnst nichts ab.« (20)

54 »[D]u unternimmst nie mehr den Versuch, sie [deine Mahlzeiten] zu variieren« (67).

55 Nicht zuletzt vielleicht deshalb, weil der Protagonist im Gegensatz zu Bartleby auch der Erzähler ist, und deshalb die Geschichte beeinflussen, seine Meinungen freier artikulieren kann. 
"Momente der Sinnstiftung « ausgeschlossen werden. ${ }^{56}$ Auch Robert Stockhammer ist dieser Meinung. Er bezeichnet gleichermaßen das Verhalten des Studenten als Verfahren, das $\gg z u$ einem Indifferenzpunkt führen [soll], an dem das menschliche Subjekt die Massen von Informationen [...] verarbeitet, oder eher durch sie hindurch passieren lässt, als sei es eine IT-Maschine. «57 Andere WissenschaftlerInnen, und dazu gehöre auch ich, bezweifeln, dass im Roman reine Indifferenz erzählt wird. Klar ist, dass der Protagonist indifferent werden will. Deshalb spricht er davon als von etwas, das noch nicht ist, aber was er lernen muss: »Tu as tout à apprendre, tout ce qui ne s'apprend pas: la solitude, l'indifférence, la patience, le silence« (Hqd 68) - »Du musst alles lernen, alles, was man nicht lernen kann: die Einsamkeit, die Gleichgültigkeit, die Geduld, das Schweigen« (41). Vor diesem Hintergrund ist jedoch die ständige Behauptung des Protagonisten, indifferent $\mathrm{zu}$ sein, keinesfalls wörtlich $\mathrm{zu}$ verstehen - >indifferent s sagen hat schließlich eine andere Bedeutung als >indifferent sein. Dass er es sich ständig sagt, kann viele andere Gründe haben: Vielleicht handelt es sich dabei um Beschwörungen einer noch nicht eingetretenen Indifferenz, die mittels der performativen Macht der Sprache zur Tatsache werden soll. Vielleicht kompensiert er dadurch seine Unfähigkeit, wirklich indifferent zu sein. Vielleicht ist er trotzig, oder obsessiv. Wie dem auch sei: Die Frequenz der Erwähnung suggeriert, dass er seinen Anspruch per definitionem unterläuft. Seine Indifferenz ist prätentiös. So schreibt auch David Gascoigne: »In a sense, a struggle for indifference can never be won, for struggle itself contravenes indifference. ${ }^{58}$ Indem der Student seine Indifferenz zum dominanten Thema seiner Erzählung macht, drückt er eine Neigung aus, die von diesem Thema eigentlich logisch ausgeschlossen ist.

\section{Indifferenz als Kritik}

Im Topos der Indifferenz ist ein performativer Widerspruch enthalten, der signalisiert, dass der Erzähler-Protagonist gar nicht indifferent, sondern vielmehr kritisch ist. Das sieht man in der Perec-Forschung zumeist anders, was vor allem an einem kurzsichtigen Verständnis des Neutralitäts-Topos liegt. Der Umstand, dass der Erzähler-Protagonist sein Nicht-Tun nicht als Geste verstanden wissen will, scheint die Möglichkeit einer kritischen Intention vermeintlich von vornherein auszuschließen. Leonhard Fuest nimmt in seiner

56 Closch: Gleichgültigkeit, 210, 211.

57 Robert Stockhammer: 1967. Pop, Grammatologie und Politik. Paderborn: Fink (2017), 170.

58 Gascoigne: The Games of Fiction, 135. 
Studie Poetik des Nicht(s)tuns (2008) gerade diese Abwesenheit einer kritischen Intention zum Anlass, dem Erzähler-Protagonisten die Kritikfähigkeit gleich ganz abzusprechen. Anstatt in der Art der Artikulation von Indifferenz eine Kritik zu sehen, sucht Fuest sie abseits von ihr, in den Lerninhalten des aufgegebenen Soziologiestudiums (Erwähnung finden Aron, Tocqueville, Marx, Weber und Lukács). Weil diese Positionen nur erwähnt, aber nicht verarbeitet werden, unterstellt Fuest dem Roman, das darin gegebene gesellschaftskritische Potential nicht auszuschöpfen:

Wäre aus dieser Themenstellung nicht eine treffliche politische Unterfütterung der Verweigerung zu ziehen? Müßte nicht über Industrialisierung und Entfremdung, über Ausbeutung, über die Verkürzung der Arbeitszeit, vielleicht noch unter Hinzuziehung von Lafargues Recht aufFaulheit, gesprochen werden? [...] Und obwohl der Student die damit einhergehenden »frommen Lügen« (»pieux mensonges«) durchschaut, entzündet sich hieran kein kritischer Funke, kein Widerstand [...]. ${ }^{59}$

Fuests Interpretation zeigt ein Unverständnis des historischen Kontexts, in dem Perecs Roman situiert ist. Die Tatsache, dass der Erzähler-Protagonist die von der Universität bereitgestellten ökonomischen und soziologischen Theorien nicht als Werkzeug einer Gesellschaftskritik zur Hand nimmt, spiegelt die oben von Bourdieu und Passeron umrissene Feststellung, dass die französische Universität jedes systemkritische Verhalten unterbindet, das auch ihr selbst schaden könnte. Die neutrale Distanz zu den Theorien, die Fuest zufolge »eine treffliche politische Unterfütterung der Verweigerung« (s.o.) abgeben würden, zeigt an, dass der Protagonist innerhalb dieses Diskurses und mit diesem Material eben keine Möglichkeit (mehr) sieht, sich kritisch zu äußern.

Die Indifferenz im Roman wird auch aus epistemologischen Gründen als unkritisch wahrgenommen. Robert Stockhammer zum Beispiel hält Indifferenz in Un homme qui dort für historisch >nachvollziehbar<, weil in den späten 6oer-Jahren eine Art Relativitäts-Bewusstsein entstanden sei, das die Möglichkeit von Kritik überhaupt in Frage stellt - indifferent zu sein bedeute in dem Fall, dies zu akzeptieren. Stockhammer meint, die Verlagerung vom einen in das andere Episteme - von der Möglichkeit zur Unmöglichkeit der Kritik - an Perecs Werk ablesen zu können. In seinem ersten Roman Les Choses (1965) habe es so noch Artikulationen von Kritik gegeben, zum Beispiel

59 Fuest: Poetik des Nicht(s)tuns, 245. Herv. meine. 
eine Ablehnung des sogenannten »Coca-Cola-way-of-life«, der »nicht bloß den Konsum bestimmter typischer Waren, sondern den konsum-geprägten Lebensstil überhaupt « problematisiert. ${ }^{60}$ In Un homme qui dort sei es jedoch anders. Zwar gebe es auch hier eine Abwendung von Markennamen (z.B. Nescafé) und eine Entdifferenzierung von Sprache, die auf die Unterschiedslosigkeit materieller Waren hinweise. Doch dadurch werde keine Kritik formuliert. Es handele sich vielmehr um Verfahren, die zu einem »Indifferenzpunkt führen « sollen, ${ }^{61}$ um die eigene Kritikunfähigkeit anzunehmen:

Die Auseinandersetzung mit der Warenkultur entzieht sich im Paradigma 67 der Alternative von Kritik und Affirmation schon deshalb, weil bemerkenswert viele Teilnehmer an dieser Warenkultur selbstreflexiv genug geworden sind, um zu wissen, dass sie keinen archimedischen Punkt der Kritik von außen mehr beziehen könnten. ${ }^{62}$

Die Indifferenz von Perecs Protagonisten ist, so impliziert Stockhammer, die logische Folge der Einsicht, dass man gar nicht mehr >objektiv< kritisieren kann. Diese Auslegung lässt jedoch eine wichtige Frage offen. Und zwar, ob die Indifferenz auch affirmativ ist, oder ob sie nicht vielmehr als Resignation, und damit auch als Geste des Bedauerns oder gar der Verzweiflung gelesen werden kann, in der auch kritisches Potential verborgen liegt. Die Tatsache, dass der Protagonist unter seiner Indifferenz leidet und sie letztlich aufgibt, spricht für letzteres. Die Indifferenz des Protagonisten ist nämlich nicht einfach eine bereitwillige Anpassung an die Gegebenheiten seiner Zeit, es ist die Zurschaustellung des Nicht-Kritisieren-Könnens als ein Problem.

Die Indifferenz in Un homme qui dort wurde in der Forschung bisher zu Unrecht als unkritisch betrachtet. Im Roman wird nämlich doch Kritik geübt, und zwar im Sinne Michel Foucaults. Foucault versteht Kritik als eine »besondere Haltung neben dem großen historischen Prozeß der Regierbarmachung der Gesellschaft «, die sich gegen diese >Regierbarmachung< wendet. ${ }^{63}$ Kritik sei damit, so Foucault, „die Kunst nicht dermaßen regiert zu werden. ${ }^{64}$ So verstanden bedeutet Kritik also ein Hinterfragen von Macht, Gesetz und Wahrheit, und beschreibt sie als »Funktion der Entunterwerfung «. ${ }^{65}$

60 Stockhammer: $1967,67$.

61 Stockhammer: 1967, 170.

62 Stockhammer: $1967,70$.

63 Michel Foucault: Was ist Kritik? Übers. v. Walter Seitter. Berlin: Merve (1992), 16f., 12.

64 Foucault: Was ist Kritik?, 12.

65 Foucault: Was ist Kritik?, 15. 
Auf den ersten Blick könnte man indessen meinen, dass eine derart negative Haltung zur Norm in der Indifferenz prinzipiell nicht gegeben ist. Indifferenz ist, um noch einmal Blanchots einschlägige Gedanken zum Neutralen zu zitieren, »weder Affirmation noch Negation« zuzuordnen. ${ }^{66}$ Indifferentes Sprechen schließt so eigentlich die Möglichkeit von Kritik aus, da es keinerlei Urteil zulässt, weder Zustimmung noch Ablehnung. Doch tatsächlich bezeichnet dieser Unwille zum Urteil ebenfalls eine Abwendung von der Macht: der Macht des Urteils. Die »Erfahrung des Neutralen«, führt Blanchot aus, bedeutet ja gerade,

in jene Verantwortung des Sprechens einzutreten, welches spricht, ohne irgendeine Form der Macht auszuüben, selbst diejenige Macht, die sich vollzieht, wenn wir blicken, da wir, wenn wir blicken, dasjenige und denjenigen, der sich vor uns befindet, innerhalb unseres Horizonts und unseres Sichtkrei$\operatorname{ses}^{67}$

halten. Eben diese >Machtferne< findet sich in Un homme qui dort. Sie findet Ausdruck im Plan des Protagonisten, nicht zu wählen, nicht zu interpretieren und auch nicht interpretierbar zu sein. Er möchte der Macht, also der Interpretation des dominanten Diskurses, weder unterliegen noch sie unterstützen. Seine Indifferenz ist Ausdruck dieser >Entunterwerfung < insofern sie eine Weigerung darstellt, diese Macht durch ein affirmatives oder negierendes Verhalten als gegeben zu akzeptieren und damit zu legitimieren. In der gleichen Art und Weise, wie der proletarische Generalstreik bei Benjamin das bestehende Recht weder erhalten noch ersetzen, sondern abschaffen will, um die ihm inhärenten Fehler nicht zu reproduzieren, ${ }^{68}$ so ist auch das Ziel der Indifferenz nicht ein bloß >legitimierendes Verhalten zu Bestehendem, sondern eine Unterbrechung. Eine Unterbrechung, die sich auf ein ablehnendes Urteil stützt, ohne jedoch in den Mechanismen partizipieren zu wollen, in denen eine Ablehnung üblicherweise ausgedrückt werden kann. Es ist demnach ein Urteil, das sich nicht als solches ausdrückt - eine Kritik ohne Kritik, ein Nichtstun. Darin liegt die Befreiung, die die Indifferenz zu leisten vermag. Roland Barthes schreibt in Le Degré zéro de l'écriture (1953) dem Neutrum eben

\footnotetext{
66 Blanchot: Einklammerungen, 25.

67 Blanchot: René Char und das Denken des Neutralen. In: Ders.: Das Neutrale, 21. Herv. meine.

68 Vgl. Kapitel »Handlung und Ceschichte« in diesem Buch.
} 
diese Funktion auf der Ebene der Sprache und der Literatur zu: »In dem Streben nach Befreiung der literarischen Sprache hier eine andere Lösung: eine neutrale Schreibweise schaffen, die von aller Unterwerfung unter eine gekennzeichnete Ordnung der Sprache befreit ist. « ${ }^{69}$

Diese sprachliche >Entunterwerfung findet in Perecs Roman statt und verweist darüber hinaus auch auf die Ebene des Politischen. Die Indifferenz seines Protagonisten bedeutet, im Foucault'schen Sinn, eine Unzufriedenheit mit der Art und Weise, wie er >regiert $<$ wird. Diese >Regierung < bezieht sich im Roman vornehmlich auf die Geschichtsphilosophie des Fortschritts und den Wert, den sie auf die Idee eines aktiven, zielgerichteten und strebsamen Menschen legt. Indem er nichts tut, unterminiert er die Werte dieser >Regierungく. Die Performanz der Indifferenz ist also ein Hinweis auf Systemkritik, und das nächste Unterkapitel (Handlung und geschichtsphilosophische Fremdbestimmung) widmet sich der Analyse ihrer Inhalte. Dort wird argumentiert, dass die in der Indifferenz entwickelte Praxis des Nichtstuns einen Versuch darstellt, aus der bestehenden bestimmten Gesellschaftsordnung auszutreten. Was dieser Austritt für den Protagonisten bedeutet, verändert sich im Laufe des Romans. Während es zunächst den Anschein erweckt, er würde dadurch im Sinne Hannah Arendts handeln, so wendet sich dies zum Ende der Geschichte. Die neugewonnene Kontrolle des Protagonisten über sein Leben steigt ihm zu Kopf und entwickelt sich zu einer unhaltbaren Herrschaftsphantasie. Mit ihrem Zusammenbruch endet auch das Nichtstun.

\section{Handlung und geschichtsphilosophische Fremdbestimmung}

Der Topos des Nichtstuns ist im Roman Un homme qui dort auch auf einer politischen Ebene bedeutsam. In ihm äußert sich eine bestimmte Gesellschaftskritik, und zwar eine Ablehnung der Geschichtsphilosophie des Fortschritts. Die Idee eines solchen Fortschritts, wie sie im folgend zitierten Abschnitt umrissen wird, ist in der Wahrnehmung des Protagonisten kausal an menschliche Handlung geknüpft. Diese Kausalität wird, ebenso wie die Möglichkeit eines verändernden Tuns überhaupt, im Roman geleugnet.

autour de toi tu as vu, de tout temps, privilégier l'action, les grands projets,

l'enthousiasme : homme tendu en avant, homme les yeux fixés sur l'hori-

69 Roland Barthes: Am Nullpunkt der Literatur. Übers. v. Helmut Scheffel. Frankfurt a.M.: Suhrkamp (1985), 88. Herv. meine. 
zon, homme regardant droit devant lui. Regard limpide, menton volontaire, démarche assurée, ventre rentré. La ténacité, l'initiative, le coup d'éclat, le triomphe tracent le chemin trop limpide d'une vie trop modèle, dessinent les sacro-saintes images de la lutte pour la vie. Les pieux mensonges qui bercent les rêves de tous ceux qui piétinent et s'embourbent, les illusions perdues des milliers de laissés-pour-compte, ceux qui sont arrivés trop tard, ceux qui ont posé leur valise sur le trottoir et se sont assis dessus pour s'éponger le front. (Hqd 32, Herv. meine)

[D]u hast zu allen Zeiten um dich herum gesehen, dass man der Tat, den großen Plänen, der Begeisterung den Vorzug gab: dem nach vorne strebenden Menschen, mit dem Blick auf den Horizont, dem geradeaus schauenden Menschen. Klarer Blick, willensstarkes Kinn, sicherer Gang, eingezogener Bauch. Hartnäckigkeit, Initiative, Clanzleistung, Triumph, zeichnen den allzu überschaubaren Weg eines allzu beispielhaften Lebens, zeichnen die sakrosankten Bilder vom Kampf ums Dasein. Die frommen Lügen, die die Träume all derer einlullen, die sich abstrampeln und im Dreck steckenbleiben, die verlorenen Illusionen der Tausenden, die den Anschluss verpasst haben, derer, die zu spät gekommen sind, derer, die ihren Koffer auf den Bürgersteig gestellt und sich draufgesetzt haben, um sich die Stirn abzuwischen. (20, Herv. meine)

In diesem Abschnitt wird durch die Verwendung von Formulierungen wie »nach vorne strebend« (»en avant«), »geradeausschauend« (»regardant droit devant lui«), »sicherer Gang« (»démarche assurée«), »Glanzleistung« (»coup d'éclat«) und »Triumph« (»triomphe«), sowie den »allzu überschaubaren Weg eines allzu beispielhaften Lebens « (»le chemin trop limpide d'une vie trop modèle«) das Konzept einer garantiert positiven Progression des menschlichen Lebens evoziert. Die Tat (»'action«) hat in dieser Idee eine privilegierte Stellung: das geplante, enthusiastische Tun könne angeblich den Fortschritt garantieren. Dies gelte für das Leben des Individuums ebenso wie für die Gesellschaft im Ganzen bzw. die Menschheitsgeschichte, darauf verweist die Verwendung des Plurals in der zweiten Hälfte des Abschnitts (»tous ceux«, »des milliers«). Der >Triumph ist dabei Zeichen eines im 20. Jahrhundert vorherrschenden Geschichtsoptimismus, der sich in liberal-wirtschaftlichen Vorstel- 
lungen eines unendlichen Wachstums oder der epistemologischen Perfektionierung im Bereich der Naturwissenschaften manifestiert. ${ }^{70}$

Im zweiten Teil des zitierten Abschnittes wird dieser Fortschrittsoptimismus demontiert: Es handele sich bei dieser Vorstellung um fromme Lügen (»pieux mensonges«), Träume (»rêves«) und verlorene Illusion (»illusions perdues«), da diejenigen, denen der Triumph versprochen wurde, im Dreck steckenbleiben (»s'embourbent «), wenn sie in der Chronologie dieses Fortschreitens etwas falsch gemacht haben. Sie werden abgehängt und zurückgelassen (»laissés-pour-compte«), weil sie zu spät gekommen sind (»sont arrivés trop tard«). Der Protagonist macht mehrmals deutlich, dass ihm diese geschichtsphilosophische Sichtweise sein Leben lang aufgedrängt wurde. Sein Austritt aus der Universität, und das damit einsetzende Nichtstun, sind Zeichen für das Ende seiner Bereitschaft, an dieses Konzept zu glauben:

rien ne reste de cette trajectoire en flèche, de ce mouvement en avant où tu as été, de tout temps, invité à reconnaître ta vie, c'est-à-dire son sens, sa vérité (Hqd 28, Herv. meine).

nichts bleibt von dieser pfeilförmigen Flugbahn, von dieser Vorwärtsbewegung, in der du von jeher aufgefordert worden bist, dein Leben zu erkennen, das heißt, seinen Sinn, seine Wahrheit (17, Herv. meine)

Diese Aussage impliziert, dass der Protagonist dieser Ideologie eigentlich nie, höchstens zum Schein, ${ }^{71}$ gefolgt ist. Heißt es doch, dass er immer aufgefor-

70 Vgl. hierzu David Engels Ausführungen: »Der Aufschwung der frühneuzeitlichen Staatenwelt, der Einfluß der Reformation und der großen Entdeckungsfahrten und schließlich die beginnende Industrialisierung des 18. Jahrhunderts sollten dann den Clauben an einen uneingeschränkten »Fortschritt « für lange Zeit zur leitenden Doktrin der abendländischen Ceschichtsphilosophie erheben.« David Engels: Biologistische und Zyklische Geschichtsphilosophie. Ein struktureller Annäherungsversuch. In: Von Platon bis Fukuyama. Biologistische und zyklische Konzepte in der Ceschichtsphilosophie der Antike und des Abendlandes. Hg. v. Dems. Brüssel: Éditions Latomus (2015), 42. In seiner ideengeschichtlichen Aufarbeitung stellt Engels fest, dass sich immer wieder »grundlegende Zweifel an der Natur jenes »Fortschritts « offenbaren sollten«, so zum Beispiel bei Giambattista Vico und Oswald Spengler, von denen dieser Fortschritt »eher als wesentlich spätzeitliche und ephemere Besonderheit der europäischen Kultur empfunden wurde« (ebd. 42f.). Protagonisten, der Soziologie, zusammenhängen. So schreiben Bourdieu und Passeron: »Die geisteswissenschaftliche Fakultät mit ihren Disziplinen wie Soziologie, Psy- 
dert worden war (»invité à reconnaître«), in der Vorwärtsbewegung (»mouvement en avant «) sein Leben zu erkennen, nicht jedoch, dass er es wirklich auch erkannt habe. Die Konsequenz, die er aus dieser Absage zieht, ist das Kernelement des Fortschritts, d.h. die Handlung (»l'action«) zu verweigern. Diese Entscheidung ist insofern hochinteressant als sie der Strategie der 68er diametral entgegengesetzt ist - obwohl auch sie die Idee des Fortschritts als gefährlich und verantwortungslos anprangerten. So merkte Hannah Arendt an, dass der Zweifel an den positiven Effekten eines solchen Fortschrittdenkens die Studentenbewegung der späten 1960er-Jahre als Ganze charakterisiere:

[W]enn man fragt, was denn nun eigentlich diese gänzlich unvorhergesehene Entwicklung an den Universitäten in der ganzen Welt ausgelöst hat, kann man nicht gut übersehen, daß eine Erfahrung dieser Generation in der Tat überall gemeinsam ist, die überdies ohne Beispiel und ohne Analogie istdie Erfahrung, daß gerade der »Fortschritt« in mancherlei Hinsicht das Leben auf der Erde katastrophal bedroht [...]. Mit diesen »Fortschritten«, bzw. ihren wissenschaftlichen Grundlagen, werden sie an den Universitäten vertraut gemacht, und was sie dabei lernen, ist unter anderem auch, daß die Wissenschaften nicht nur unfähig scheinen, die verhängnisvollen Folgen ihrer eigenen Technik rückgängig zu machen, sondern daß man nun nachgerade das Stadium erreicht hat, »where there's no damn thing you can do that can't be turned into war «. ${ }^{72}$

Perecs Ablehnung eines progressiven Geschichtsdenkens ist ein Vorläufer der von Arendt den 68ern attestierten Angst, dass es keine Absicherung für das Fortbestehen der Welt gibt. Die unterschiedliche Reaktion auf diese gemeinsame Angst verweist auf die Verschiedenheit der Einschätzungen in Bezug auf das Wirkpotential von Handlung. Arendt attestierte den Studierenden eine »Lust am Handeln«, die sich erklärt aus einem »noch nicht aufgebrauch-

chologie oder Sprachen kann solchen Studenten aus dem Bildungsbürgertum als ein Refugium dienen, die sich gesellschaftlich zu einem Hochschulstudium »verpflichtet«, ohne rechte Neigung diesen Fächern zuwenden, um zumindest den Schein sozialer Vernunft zu wahren.«Bourdieu u. Passeron: Die Erben, 17.

72 Arendt: Macht und Gewalt, 20. Am Schluss zitiert Arendt Jerome Lettvin vom M.I.T. in The New York Times Magazine vom 18. Mai 1969. Auch Stephen Spenders Augenzeugenbericht des Mai 1968 in Paris gibt einige Hinweise auf die Fortschrittsskepsis der Bewegung, z.B.: "Students, refuse categorically the ideology of >output< [rendement], of ' progress and such-called pseudo-forces. «Stephen Spender: The Year of the Young Rebels. London: Widenfeld and Nicolson (1969), 45. 
ten Vorrat an Vertrauen in die Möglichkeit, durch Handeln die Welt zu verändern «. ${ }^{73}$ Perecs Protagonist hingegen hat dieses Vertrauen verloren:

quoi que tu fasses, où que tu ailles, tout ce que tu vois n'a pas d'importance, tout ce que tu fais est vain, tout ce que tu cherches est faux. ( $\mathrm{Hqd} 140$ )

was du auch tust, wohin du auch gehst, alles, was du siehst, ist ohne Bedeutung, alles, was du tust, ist sinnlos, alles, was du suchst, ist falsch. (86)

Doch der Protagonist hält nicht nur sein eigenes Tun für sinnlos, sondern auch das seiner Mitmenschen. Diese, so suggeriert er, glaubten weiterhin an den Fortschritt und agierten diesen aus. Allerdings scheint gerade die ideologische Zugehörigkeit, in der es einen Glauben daran gibt, durch Handlung den Fortschritt voranzutreiben, aus der Sicht des Protagonisten den Wert ihres Tuns aufzuheben, wie im folgenden Passus dargelegt wird:

Tu ne sais rien des lois qui font se rassembler ces gens qui ne se connaissent pas, que tu ne connais pas, dans cette rue où tu viens pour la première fois de ta vie, et où tu n'as rien à faire, sinon regarder cette foule qui va et vient, se précipite, s'arrête : ces pieds sur les trottoirs, ces roues sur les chaussées, que font-ils tous ? Où vont-ils tous? Qui les appelle? Qui les fait revenir? Quelle force ou quel mystère les fait poser alternativement le pied droit puis le pied gauche sur le trottoir avec, d'ailleurs, une coordination qui saurait difficilement être plus efficace? Des milliers d'actions inutiles se rassemblent au même instant dans le champ trop étroit de ton regard presque neutre. ( $\mathrm{Hqd}$ 73)

Du weißt nichts von den Gesetzen, nach denen diese Leute, die sich nicht kennen und die du nicht kennst, in dieser Straße zusammenkommen, in der du zum ersten Mal in deinem Leben bist, in der du eigentlich nichts zu tun hast, höchstes diese Menge anzuschauen, die kommt und geht, sich beeilt, stehenbleibt: diese Füße auf dem Bürgersteig, diese Räder auf der Fahrbahn, was machen sie nur alle? Wo wollen sie hin? Wer ruft sie? Wer lässt sie zurückkommen? Welche Kraft oder welches Mysterium lässt sie abwechselnd den rechten, dann den linken Fuß mit einer Koordination übrigens, wie sie

73 Arendt: Macht und Gewalt, 19. Herv. meine. 
kaum wirksamer sein könnte, auf den Bürgersteig setzen? Tausende sinnloser Handlungen kommen im selben Augenblick im allzu engen Sehfeld deines fast neutralen Blicks zusammen. (44f.)

Der Protagonist sieht die anderen Menschen um sich herum nicht als eigenständige Akteure, sondern stilisiert sie zu Puppen an einem Strang, die von einer mysteriösen Kraft gelenkt werden - eine "force ou [un] mystère les fait poser alternativement le pied droit puis le pied gauche sur le trottoir«. Die Begriffe Kraft (»force«), Mysterium (»mystère«) und vor allem Gesetz (»lois«) zu Beginn des Absatzes verweisen auf die geschichtsphilosophisch prävalente Idee, dass die Ausbildung der Geschichte nach einem bestimmten Formprinzip, einem Gesetz, von statten geht. Die Vorstellung dabei ist, dass im Verlauf der Geschichte die »bestimmung einer höheren macht « erkennbar ist, ${ }^{74}$ bzw. dass aufgrund einer Kenntnis dieser Bestimmung die zukünftige geschichtliche Entwicklung vorhergesagt werden kann.

Diese Vorstellung bringt eine Komplikation der Handlungsverantwortlichkeit mit sich. Glaubt man an die geschichtliche Lenkung durch eine höhere Macht - Arendt nennt den göttlichen Drahtzieher Platos oder Adam Smiths »unsichtbare Hand « als Beispiele - so macht man damit einen übermenschlichen »Jemand« für die »sich ergebende Geschichte verantwortlich «. ${ }^{75}$ Was in der Folge bedeutet, dass dem Menschen die historische Verantwortlichkeit für sein Handeln entzogen und so auch die Motivation zur Handlung genommen wird. ${ }^{76}$ Der Erzähler-Protagonist in Un homme qui dort ruft eben dieses Problem auf, indem er nicht nur die Existenz eines geschichtlichen Gesetzes evoziert, sondern die Kraft dieses Gesetzes sogar personifiziert: "Qui les appelle? Qui les fait revenir? « (Herv. meine). Durch den Rückgriff auf das passive Element des geschichtsphilosophischen Determinismus stellt der Protagonist das Leben als Spiel dar, in dem der Mensch nur eine Spielfigur ist, nie aber der eigenverantwortliche Spieler. Die Konsequenz daraus ist, dass der Protagonist den Verlauf seines zukünftigen Lebens schon vor sich ausgebreitet sieht, allerdings ohne Möglichkeit, darin einzugreifen:

\footnotetext{
74 Cesetz. In: DWB Bd. 5, Sp. 4071.

75 Arendt: Vita activa, 230.

76 Die mögliche Verleitung zur Apathie ist der zentrale Grund für Arendts Ablehnung deterministischer Geschichtsphilosophie. »[D]eterminism[...] can be construed as relieving human beings of responsibility for their actions, «schreibt Kang. Taran Kang: Origin and Essence: The Problem of History in Hannah Arendt. In: Journal of the History of Ideas 74 (1), 2013, 143.
} 
Tu n'as que vingt-cinq ans, mais ta route est toute tracée. Les rôles sont prêts, les étiquettes : du pot de ta première enfance au fauteuil roulant de tes vieux jours, tous les sièges sont là et attendent leur tour. Tes aventures sont si bien décrites que la révolte la plus violente ne ferait sourciller personne. Tu auras beau descendre dans la rue et envoyer dinguer les chapeaux des gens, couvrir ta tête d'immondices aller nu-pieds, publier des manifestes, tirer des coups de revolver au passage d'un quelconque usurpateur, rien n'y fera : ton lit est déjà fait dans le dortoir de l'asile, [...]. Tout est prévu, tout est préparé dans les moindres détails : les grands élans du cœur, la froide ironie, le déchirement, la plénitude, l'exotisme, la grande aventure, le désespoir. (Hqd 53f., Herv. meine)

Du bist erst fünfundzwanzig Jahre alt, aber dein Weg ist fertig vorgezeichnet. Die Rollen sind verteilt, die Etikette liegen bereit: vom Topf deiner frühen Kindheit bis zum Rollstuhl deiner alten Tage stehen alle Sitze da und warten, bis sie dran sind. Deine Abenteuer sind so genau beschrieben, dass der gewaltigste Aufruhr niemanden mit der Wimper zucken ließe. Selbst wenn Du auf die Straße läufst und den Leuten die Hüte herunterschlägst, wenn du deinen Kopf mit Kehricht bedeckst, barfuß gehst, Manifeste veröffentlichst, mit dem Revolver aufirgendeinen Usurpator schießt, es wird sich nichts daran ändern: dein Bett im Schlafsaal des Altersheims ist bereits gerichtet, [...]. Alles ist vorhergesehen, alles ist bis auf die kleinsten Einzelheiten vorbereitet: die großen Regungen des Herzens, die kalte Ironie, die Zerrissenheit, die Fülle, das Fremdartige, das große Abenteuer, die Verzweiflung. (33, Herv. meine)

Diese Vorstellung des Lebens, das wie eine Straßenbahn in fest eingestellten Schienen auf ein längst festgelegtes Ziel zufährt - »ta route est toute tracée« - , bedeutet die radikale Unterminierung jeglicher Kontingenz. Darin drückt sich ebenfalls ein verlorener Glaube an das Ereignis aus. Das Ereignis ist ein Vorfall, der nicht vorauszusehen ist, weil er aus der bekannten Ordnung fällt - eine "rupture in the normal run of things «, wie Slavoj Žižek sagt. ${ }^{77}$ Ereignisse sind, Hannah Arendt zufolge, an die Bedingung des menschlichen Handelns geknüpft. Denn zu handeln heißt, etwas Neues anzufangen und damit ein Ereignis auszulösen. ${ }^{78}$ Doch der Erzähler-Protagonist schließt Handlung

77 Žižek: Event, 38.

78 Vgl. Arendt: Vita activa, $215 f$. 
und Ereignis kategorisch aus. Die Gesellschaft, in der er lebt, hat paradoxerweise bereits vorgefertigte Ideen von Ereignissen - »les grands élans du cœur, la froide ironie, le déchirement, la plénitude, l'exotisme, la grande aventure, le désespoir « - die dem Individuum nicht unerwartet zustoßen, sondern ihm wie nach Plan erscheinen. Ereignisse, die die bestehende Ordnung verändern, sind so undenkbar. Nicht zufällig werden in obigem Passus auch Handlungen/Ereignisse erwähnt, die konventionell mit dem Herbeiführen einer politischen Veränderung assoziiert werden - »la révolte la plus violente«, "publier des manifestes «, »tirer des coups de revolver au passage d'un quelconque usurpateur « -, nur um ihnen dann ihre Ereignishaftigkeit, d.h. ihr Veränderungspotential abzusprechen: »rien n'y fera«. Dabei ist es die Konventionalität der Maßnahme, die einer möglichen Ereignishaftigkeit im Wege steht. Das Ereignis bestehe aber darin, so Derrida, »das Unmögliche zu tun «. ${ }^{79}$ Doch der Protagonist nimmt seine Umwelt als eine wahr, in der nur das Mögliche getan, und deshalb auch nicht gehandelt werden kann.

Der Erzähler-Protagonist zeigt damit den statischen Charakter einer Gesellschaft auf, die substanzielle Veränderungen verhindert. So bilden sich im Roman zwei verschiedene Formen des Nichtstuns heraus:

(1) Zum einen die Handlungsunfähigkeit aller Gesellschaftsmitglieder, die vielleicht meinen, wirklich zu handeln, aber tatsächlich der Handlungsillusion der Fortschrittsideologie unterliegen. Johanna-Charlotte Horst argumentiert analog, der Einzelne wäre in diesem System »zwar zu Aktionismus, aber zu keinem selbstständigen Handeln getrieben« - diese »Art von Praxis ließe sich als passive Aktivität beschreiben, in der Tätigkeiten zwar stattfinden und auf bestimmte Ziele gerichtet sind, allerdings auf radikal heteronome, die den Handelnden zum bloß Ausführenden degradieren «. ${ }^{80}$

(2) Zum anderen das reaktive Nichtstun des kritisch indifferenten Protagonisten, der diese Handlungsillusion aufgegeben hat und direkt, quasi ohne Umschweife, nicht handelt. Der Effekt, der sich daraus ergibt, steht in direktem Gegensatz zu dem Motiv des Protagonisten. „Dem willenlosen Funktionieren als passive Aktivität stellt der indifferente Protagonist eine Haltung entgegen«, so meint wiederum Horst, »die entsprechend als passive Aktivität

79 Jacques Derrida: Eine gewisse unmögliche Möglichkeit, vom Ereignis zu sprechen. Übers. v. Susanne Lüdemann. Berlin: Merve (2003), 30.

80 Johanna-Charlotte Horst: Perecs Erbschaften. Zur Poetik der oulipotischen Freiheit. Dissertation. München: Ludwig-Maximilians-Universität (2017), 103. 
beschrieben werden kann. ${ }^{81}$ Der Protagonist tut durch sein Nichtstun etwas genuin Unerwartetes, und wird somit nicht nur aktiv, sondern scheint sogar zu handeln. Die noch so vehement verleugnete Möglichkeit, dass sich in der Indifferenz des Protagonisten ein Protest, ein Streik verbergen könnte, wie er zu Beginn der Arbeit im Anschluss an Benjamin und Hamacher beschrieben wurde, bestätigt sich - zumindest vorerst.

Das Nichtstun ist zu einer lesbaren Geste geworden, die auch, aber nicht nur auf ihre eigene Mittelbarkeit verweist. Sondern auf die Bedingungen ihrer Entstehung. Daraus ergibt sich die Möglichkeit, auf eine neue Art und Weise zu handeln, die jedoch im Verlauf der weiteren Geschichte außer Kontrolle gerät. Der einsame Protagonist steigert sich in eine Herrschaftsphantasie hinein, die seine Praxis des Nichtstuns als unhaltbar offenbart und zu einem Ende bringt. Seine Indifferenz, die von Beginn an nicht secht<, sondern prätentiös war, unterliegt dem Druck ihrer eigenen Täuschung, und verschwindet.

\section{Nichtstun als geschichtliche Selbstbestimmung}

Die im vorherigen Abschnitt erörterte Ablehnung des Fortschritts als dominanter Geschichtsphilosophie liefert die Begründung für das Nichtstun, und den Widerwillen gegenüber der Interpretation und die Indifferenz des Protagonisten. Er verweigert sich der Handlung (»l'action«), weil sie in dieser Ideologie das antriebstechnische Kernelement darstellt (= Nichtstun). Er verweigert sich ebenso einer Rationalisierung seines Verhaltens durch die epistemische Brille dieser Ideologie (= Interpretationswiderwillen). Schließlich will er $\mathrm{zu}$ ihr in keinerlei Verhältnis stehen, nicht mal in einem ablehnenden (= Indifferenz). Er will stattdessen Distanz zwischen sich und der Macht - der Geschichte, der Interpretation - etablieren.

Das heißt vor allem, sich ihrem geschichtlichen `Gesetz‘ nicht mehr länger zu unterwerfen. Zur Kritik gehört nämlich auch, so Foucault, der einen, dominanten Geschichte eine individuelle entgegenzusetzen, sich »seine eigene Geschichte zu machen ${ }^{82}$ Roland Barthes hat in Comment vivre ensemble die Emanzipation von der Konvention und ihren Gesetzmäßigkeiten mithilfe des Rhythmus-Begriffes umrissen: »Was die Macht in erster Linie auferlegt, ist ein Rhythmus (des Lebens, der Zeit, des Denkens, des Diskurses usw.). Die Forderung nach einem eigenen Rhythmus richtet sich immer gegen die

81 Horst: Perecs Erbschaften, 103.

82 Foucault: Was ist Kritik?, 26. 
Macht. ${ }^{83}$ Der Protagonist tut also genau dies, und zwar in zweifacher Hinsicht. Zum einen fungiert er selbst als Erzähler der Romangeschichte und übt so narrative Kontrolle aus. Indem er dabei sich selbst anspricht, koppelt er sich vom Rest der Gesellschaft $a b$. Zum anderen schreibt er durch sein Nichtstun eine Alternative zu der omnipräsenten Geschichte der Handlung und des Fortschritts. Diese alternative Geschichte zeichnet sich unter anderem durch Wahllosigkeit aus, die auch schon die Sprachreduktion zu Beginn des Romans bestimmte. Er kreiert einen neuen Lebens- und vor allem auch Tages-Rhythmus, der weder Konvention, noch individuellen Wünschen folgt, d.h. weder Anpassung (Folge leisten) noch Individualisierung (eigene Wahl treffen) ist. Er will eine ganz andere Geschichte erzählen, die gar nicht mehr verstanden, nicht mehr interpretiert werden kann. Denn, wie Barthes ebenfalls (etwas eigentümlich) formuliert: »Den "großen Brauch « abschütteln wird dann zu einer unverständlichen (unlesbaren) Handlung. ${ }^{84}$

Der Protagonist wendet sich also gegen das Gesetz der Geschichte, gegen den Rhythmus der Konvention. Zu diesem Zweck erfindet er für sich einen neuen Rhythmus. Dieser besteht in einer alternierenden Abfolge von (1) Phasen der Isolation und körperlicher Stasis, während derer er in seiner Mansarde ist, und (2) langen Spaziergängen durch die Stadt. Was wie ein durchaus normaler Rhythmus klingt, ist tatsächlich etwas ungewöhnlich, weil die Tageszeiten, in denen diese Tätigkeiten normalerweise passieren - Stillstand in der Nacht, Bewegung am Tag - umgedreht sind:

Tu ne sors qu'à la nuit tombée, comme les rats, les chats et les monstres. Tu traînes dans les rues, tu te glisses dans les petits cinémas crasseux des Grands Boulevards. Parfois, tu marches toute la nuit ; parfois, tu dors tout le jour. (Hqd 31)

Du gehst erst bei Einbruch der Nacht aus dem Haus, wie die Ratten, die Katzen und die Ungeheuer. Du läufst ziellos durch die Straßen, du schleichst dich in die kleinen, schmuddeligen Kinos an den Grands Boulevards. Manchmal läufst du die ganze Nacht hindurch; manchmal schläfst du den ganzen Tag. (19)

Der Protagonist unterwandert die Konvention, indem seine Aktivität in die Zeit fällt, in der dezidiert nicht andere Menschen, sondern Tiere und Phanta-

83 Barthes: Wie zusammen leben, 81.

84 Barthes: Wie zusammen leben, 197. 
siewesen aktiv werden (»les rats, les chats et les monstres«). Während andere Menschen schlafen, läuft er durch die Nacht (»tu marches toute la nuit«) und schläft dafür dann, wenn sie wach sind. Neben dieser Inversion setzt er dem `Gesetz der Geschichte < eine Reihe selbsterfundener Regeln entgegen, die die Rückgewinnung von Kontrollierbarkeit anzeigen. Die Regeln lassen »Heteronomie in Autonomie umschlagen «. ${ }^{85}$ Auch außerhalb seiner Mansarde, wenn er durch die Pariser Straßen läuft, sind seine Routen streng reglementiert:

Avec une rigueur louable, tu règles tes itinéraires. Tu explores Paris rue par rue, du Parc Montsouris aux Buttes-Chaumont, du Palais de la Défense au Ministère de la Guerre, de la Tour Eiffel aux Catacombes. (Hqd 150)

Du ordnest deine Wege mit einer lobenswerten Strenge. Du kundschaftest Paris Straße um Straße aus, vom Parc Montsouris bis zu den ButtesChaumont, vom Palais de la Défense bis zum Kriegsministerium, vom Eiffelturm bis zu den Katakomben. (92)

Ihm gelingt ein, so Horst, »reibungslos funktionierendes Selbstreglement, dessen Ziel nicht bloße Freiheit von konformistischen Handlungsweisen ist, sondern vielmehr die Bestimmung einer befreienden Ordnung «. ${ }^{86}$ Von besonderer Relevanz dabei ist die klare Absage an ein bestimmtes Ziel oder eine Richtung. Der Protagonist erkundet nicht bestimmte Straßen, sondern alle. Die Eckpunkte, die er nennt (Parc Montsouris usw.), sind lediglich Beispiele, nicht aber Andeutungen einer weiteren Teleologie. Er gleicht in dieser Hinsicht den interesselosen und erschöpften Figuren, die Deleuze in seiner Analyse der Fernsehfilme Becketts beschrieben hat: er hat »auf alle Bedürfnisse, Vorlieben, Ziele oder Sinngebungen verzichtet « und muss deshalb »wohl oder übel die Projekte durch sinnlose Tabellen und Programme ersetzen «. ${ }^{87}$ Das Motiv der "gleichgültige[n] Richtungslosigkeit ", ${ }^{88}$ in den Worten Manfred Geiers, deutet auf eine nihilistische Haltung hin, die weder Wert noch Ideal kennt. Sie ist Indikator für eine absolute Freiheit, die Camus zufolge dem Menschen auch die "Handlungsfreiheit « wiedergibt. ${ }^{89}$

85 Horst: Perecs Erbschaften, 102.

86 Horst: Perecs Erbschaften, 108.

87 Gilles Deleuze: Erschöpft. In: Ders.: He, Joe, Quadrat I und II, Nacht und Träume, GeisterTrio: Filme für den SDR. Übers. v. Erika Tophoven. Frankfurt a.M.: Suhrkamp; Absolut Medien (2008), 8.

88 Geier: Das Glück der Gleichgültigen, 23.

89 Camus: Der Mythos des Sisyphos, 70. Vgl. die Einleitung dieses Kapitels. 
Beide Elemente dieses neuen Rhythmus, sowohl die Stasis als auch die Bewegung, tragen dazu bei, dass der Protagonist durch indifferentes Handeln eine neu geordnete Geschichte entwerfen kann. Michel de Certeau greift in Arts de faire (1980) in Bezug auf die Benutzung des urbanen Raums auf die Metapher des Geschichtenerzählens zurück. Dabei sei es möglich, sowohl im (1) Stillstand als auch in (2) Bewegung eine Distanz zur >allgemeinen Geschichte zu etablieren. (1) So ist es auch mit dem Aufenthalt des Protagonisten in seiner Mansarde. Vom Dachgeschoss aus kann er auf die Stadt hinunterschauen. Mag er sich auch nicht ganz so weit oben befinden wie de Certeau - der steht auf dem World Trade Center - so macht die räumliche Distanz ihn dennoch unabhängig. Bei de Certeau heißt es:

emporgehoben zu sein, bedeutet, dem mächtigen Zugriff der Stadt entrissen zu werden. Der Körper ist nicht mehr von den Straßen umschlungen, die ihn nach einem anonymen Gesetz drehen und wenden; er ist nicht mehr Spieler oder Spielball und wird nicht mehr von dem Wirrwarr der vielen Cegensätze [...] erfaßt. ${ }^{90}$

Auch de Certeau erkennt in den städtischen Straßen ein »anonyme[s] Gesetz«, das die Körper der Fußgänger »dreh[t] und wende[t] « - dieses räumliche Gesetz funktioniert analog zu dem geschichtlichen Gesetz, das Leute auf einer Straße zusammenkommen lässt, und das der Protagonist nicht versteht. ${ }^{91}$ (2) Doch auch das Laufen in der Stadt sei de Certeau zufolge eine urbane Praxis, die mit den theoretischen Möglichkeiten der Begehbarkeit des städtischen Raums stets und ständig bricht. Im eigenwilligen Laufen durch die Stadt ist man ein "praktisch Handelnde[r]«, der je nach Gelegenheit sein »eigenes Spiel« spielt und dabei »überall wieder die Undurchsichtigkeiten der Geschichte « einführt. ${ }^{92}$ Auf dieselbe Weise versucht der Protagonist, sich aus dem Gesetz (der Anderen) herauszuhalten und gleichsam ein neues zu erfinden, nach dem er - und nur er allein - sich richten kann. Form und Bedeu-

90 Michel de Certeau: Kunst des Handelns. Übers. v. Ronald Voullié. Berlin: Merve (1988), 180.

91 Vgl. die Ausführungen des vorherigen Abschnitts zu dieser Stelle: »Tu ne sais rien des lois qui font se rassembler ces gens qui ne se connaissent pas, que tu ne connais pas, dans cette rue où tu viens pour la première fois de ta vie« ( Hqd 73). Dt.: »Du weißt nichts von den Gesetzen, nach denen diese Leute, die sich nicht kennen und die du nicht kennst, in dieser Straße zusammenkommen, in der du zum ersten Mal in deinem Leben bist« (44f.).

92 De Certeau: Kunst des Handelns, 184. 
tung dieser neuen Geschichte weichen natürlich wesentlich von ihrem herkömmlichen Erscheinungsbild und Bedeutungshorizont ab. Die alte Version von `Geschichte - individuelle Selektion möglicher Handlungen, die zu einem vor-definierten Ziel führen - wird abgelöst von einer >neuen $<$ Geschichte, in der nichts mehr selektiert wird, weil einfach alles gemacht wird, und das ohne jegliches Ziel. Dieser Prozess gleicht, um noch einmal auf Deleuzes Urteil über Becketts Fernsehfilme zurückzukommen, einer kreativen Erschöpfung - ein scheinbarer Widerspruch, der jedoch schon in der Etymologie des Begriffs angelegt ist. Das Grimm'sche Wörterbuch führt zwei Bedeutungen für sie auf: »creatio« auf der einen Seite - »für des menschen erschöpfung «und »exinanitio « (Leere) auf der anderen - »erschöpfung der kräfte«. ${ }^{93}$ Deleuze beschreibt dabei ein genuin Beckett'sches Phänomen: Dessen Charaktere handeln nicht, da ihre Tätigkeiten nichts verändern. Vielmehr wiederholen sie, mit nur kleinsten Variationen, ständig dieselben Handgriffe oder Wortgruppen. Deleuze betont, dass diese Wiederholungs-Reihen (»exhaustive Serien $\ll)^{94}$ keine Inhalte transportieren, sondern vielmehr, durch den metareferentiellen Verweis auf ihre Form, die Abwesenheit von Inhalt anzeigen. ${ }^{95}$ Doch auch diese vermeintliche Inhaltslosigkeit, die auch der Protagonist realisieren will, ist kreativ und zeichenhaft. Sie zeigt die Störung konventioneller Sinnproduktion an.

Der Prozess, eine konventionelle Regel gegen eine selbstgewählte zu tauschen, erinnert nicht zufällig an die Methoden der Schriftsteller-Gruppe Oulipo, der Perec 1967 (allerdings erst nach der Publikation von Un homme qui dort) beitrat. Stockhammer betont die Signifikanz der Programmatik: Der Roman

93 Erschöpfung. In: DWB Bd. 3, Sp. 969.

94 Deleuze: Erschöpft, 21.

95 Deleuze verwendet für diese Art von erschöpfter Kunst den Begriff des BilderRitornells - eine sich wiederholende (it. ritornello $=$ Wiederkehr) Bewegung, die sich aus der Aneinanderreihung statischer Bilder ergibt, die weder semantisch noch narrativ wirken kann, und die metareferentiell auf genau diesen Mangel hinweist. So heißt es: „Das Bild läßt sich nämlich nicht durch das Erhabene seines Inhalts definieren, sondern durch seine Form, das heißt durch seine »innere Spannung«, oder durch die Kraft, die es weckt, um eine Leere zu schaffen oder Löcher zu bohren, die Umklammerung der Worte zu lösen, das Hervorsickern von Stimmen zu ersticken, um sich vom Gedächtnis und der Vernunft zu befreien, ein kleines alogisches Bild, gedächtnislos, beinahe sprachlos, bald im Leeren schwebend, bald zitternd im Offenen.« Deleuze: Erschöpft, 16. 
folge zwar noch keinem »oulipotischen Programm, handelt aber von jemandem, der nach einem selbstentwickelten Programm lebt. ${ }^{96}$ Auch Gascoigne spricht von einer »systematic [...] cultivation of a flat, uncontoured degré zéro of existence «. ${ }^{97}$ Die Parallele zur oulipotischen Schreibstrategie, auch wenn sie in Un homme qui dort nicht offensichtlich erscheint, liegt darin, dass dieser Regel-Ersatz »Möglichkeiten aktualisiert, die bis dahin von der Konvention verdeckt worden sind. ${ }^{98}$ Es geht in den Neuregelungen des Protagonisten, wie schon vielfach beschrieben wurde, natürlich um eine Verflachung - Stockhammer spricht zum Beispiel von einem Versuch, alle Erfahrung durch »Ent-Wertung und De-Funktionalisierung « zu neutralisieren. ${ }^{99}$ Aber der letztendliche Zweck aus der Sicht des Protagonisten ist doch, mit dieser Verflachung etwas Neues zu tun, eben eine Möglichkeit für ein Handeln zu entdecken, das bisher »von der Konvention verdeckt« war.

In der neugefundenen Selbstbestimmung findet der Protagonist zunächst vor allem eine Routine, die ihm das Gefühl von Sicherheit gibt - „Vie sans surprise. Tu es à l'abri. Tu dors, tu manges, tu marches, tu continues à vivre« (Hqd 117, Herv. meine) ${ }^{100}$ - in ganz ähnlicher Weise, wie der konventionelle Lebenslauf (Ausbildung, Familie, Arbeit) Sicherheit bieten kann, auch wenn er beim Protagonisten nur Entfremdung hervorgerufen hat. Die Sicherheit der Selbstbestimmung, die der Protagonist im reglementierten und erschöpfenden Nichtstun findet, steigert sich jedoch im Laufe des Romans, bis sie sich mit überraschender Plötzlichkeit zu einer Herrschaftsphantasie transformiert.

\section{Kontrollverlust und Herrschaftsphantasie}

Der Entwurf einer eigenen Geschichte, die sich aus der Praxis des Nichtstuns ergibt, markiert so einen Höhepunkt in der Autonomie des Protagonisten. Endlich, so scheint es, hat er sich von der festgefahrenen und handlungslähmenden Struktur seines bisherigen Lebens verabschiedet. In dieser Entwicklung scheint er die ethischen Anforderungen existentialistischer Philosophie,

\footnotetext{
96 Stockhammer: $1967,170$.

97 Gascoigne: The Games of Fiction, 134.

98 Anita Miller: Georges Perec. Zwischen Anamnese und Struktur. Bonn: Romanistischer Verlag (1996), 70.

99 Stockhammer: 1967, 171.

100 »Leben ohne Überraschung. Du bist geschützt. Du schläfst, du isst, du gehst, du lebst weiter vor dich hin« (72).
} 
wie sie im einführenden Abschnitt dieses Kapitels umrissen wurden, zu bestätigen: Er hat sich der Indifferenz gestellt und eigene Werte geschaffen. Doch im weiteren Verlauf des Romans entpuppt sich die Handlung, die er zu vollziehen hoffte, als Illusion.

Durch den Entwurf einer alternativen Geschichte wird in Un homme qui dort nach und nach die Möglichkeit aktualisiert, Kontrolle auszuüben. Diese Art des Agens war für den Protagonisten zuvor unvorstellbar. Dass er nun doch gewissermaßen handlungsfähig geworden ist, liegt nicht zuletzt an seinem Bestreben, neue Regeln und Gesetze für sich zu erfinden. Schließlich, so betont auch Roland Barthes in Comment vivre ensemble, ist das Erfinden von Regeln alles andere als eine passive Tätigkeit: »Regeln heißt der Idee nach = lenken, führen, steuern: die Zeit, die Begierden, den Raum, die Objekte «. ${ }^{101}$ Doch den Wechsel von der zunächst so stark empfundenen Handlungsunfähigkeit hin zu dieser Rückgewinnung von Kontrolle und Handlungspotential findet beim Protagonisten keinen gemäßigten Ausdruck. Zum einen wirken seine eigenen Regeln, die ihn von denen der Gesellschaft befreien sollten, eben nicht nur befreiend, sondern zum Teil auch einschränkend. So versucht der Protagonist eine Zehe oder seinen Daumen zu bewegen, scheitert aber, weil er sich nicht an eine bestimmte Regel erinnern kann (»il y a une règle que tu oublies«, Hqd 18). ${ }^{102}$ Zum anderen, und dies wirkt noch schwerer, schlägt sein neugewonnenes Kontrollgefühl in einen Wahn um. Plötzlich stilisiert er sich zur Herrscherfigur:

Parfois, maître du temps, maître du monde, petite araignée attentive au centre de ta toile, tu règnes sur Paris: tu gouvernes le nord par l'avenue de l'Opéra, le sud par les guichets du Louvre, l'est et l'ouest par la rue SaintHonoré. (Hqd 67, Herv. meine)

Manchmal, Herr der Zeit, Herr der Welt, eine kleine, aufmerksame Spinne in der Mitte ihres Netzes, herrschst du über Paris: du regierst den Norden über die Avenue de l'Opéra, den Süden über die gewölbten Durchgänge des Louvre, den Westen und den Osten über die Rue Saint-Honoré. (41, Herv. meine)

In diesem Abschnitt hallen die von Barthes beschrieben Kontrollmechanismen des Regelns ziemlich genau wider: Der Protagonist meint, sowohl die Zeit (»maître du temps«) als auch den Raum (»maître du monde«) als ihr >Herr

101 Barthes: Wie zusammen leben, 194. Herv. meine.

102 »[A]ber jedes Mal gibt es da eine Regel, die du vergisst.« (12) 
zu steuern. Dieses Gefühl von Kontrolle artikuliert der Protagonist mithilfe eines politischen Vokabulars: er herrscht (»tu règnes sur Paris«) und regiert (»tu gouvernes le nord«) nicht nur über Paris, sondern über die ganze Welt und in alle Himmelsrichtungen. Diese Ausweitung der Kontrolle sei, so Roland Barthes, eben auch in der Tätigkeit des Regulierens angelegt: »Die Regel: Funktion und Instrument von Herrschaft. « ${ }^{103}$ Noch konkreter als bei Hans Castorps >Regieren $<$ in Thomas Manns Der Zauberberg $(1924)^{104}$ ermöglicht die Isolation bei Perecs Protagonisten eine megalomane Herrschaftsphantasie. Darin bewahrheitet sich Hannah Arendts Diktum, Freiheit und Souveränität seien nicht dasselbe. Souveränität, also »unbedingte Autonomie und Herrschaft über sich selbst « sei unmöglich. ${ }^{105}$ Kein Mensch wäre souverän, weil er in allen seinen Unternehmungen von anderen Menschen abhängig sei. Bei dem Versuch, Freiheit zu erlangen, indem man die Abhängigkeit von anderen Menschen überwindet, bindet man sich nur wieder an die Welt und die Gesellschaft - nicht jedoch im sozialen oder welterhaltenen Sinn. Es würde dabei "nicht so sehr eine souveräne Herrschaft über sich selbst als eine willkürliche Herrschaft über andere herauskommen «. ${ }^{106}$ So ist es auch in der Imagination und Selbsterzählung des Protagonisten von Un homme qui dort. Er stilisiert sich zum Hobbes'schen Leviathan, der als absoluter Souverän nicht nur über sich, sondern über den gesamten Globus herrscht - deswegen wird auch das französische »maître« nicht mit dem milderen »Herr«, sondern dem stärkeren »Herrscher« übersetzt. Man sieht, dass sich das Körpergefühl des Protagonisten im Laufe der Romangeschichte vollkommen wandelt: der bewegungslose, dysfunktionale Körper wird nicht nur kontrollierbar, sondern hat vermeintlich auch die Fähigkeit, seine Umwelt zu kontrollieren. In seiner Einsamkeit interpretiert der Protagonist die neugewonnene Kontrolle über seinen Körper, den er mithilfe seiner Verhaltensregeln durch ganz Paris bewegt, als Regierungsleistung. Damit findet, ähnlich wie in Robert Walsers Der Gehülfe (1907), eine Umkehrung der bekannten Metapher statt, nach der die Funktionsweise eines Staates am Beispiel des menschlichen Körpers erklärt wird (im Kopf sitzt die Regierung etc.) ${ }^{107}$ Bei Perec stellt nicht der Körper

\footnotetext{
103 Barthes: Wie zusammen leben, 194.

104 Siehe Abschnitt »Regieren«: Herrschaft durch Nichtstun« in der Zauberberg-Analyse dieses Buches.

105 Arendt: Vita activa, 299.

106 Arendt: Vita activa, 299.

107 Vgl. den Abschnitt »Unverhältnismäßigkeiten der Arbeit« im Kapitel zu Walsers Der Gehülfe.
} 
die Metapher für den Staat, stattdessen steht der Staat metaphorisch für den Körper. Das Subjekt regiert sich selbst, wie ein Leviathan in einer menschenleeren Welt.

Dieses Motiv der Eigen-Regierung durch Selbstregulation wird auf narrativer Ebene in erster Linie durch die bereits erwähnte Spaltung der Erzählinstanz erzeugt, in der "Protagonist und Erzähler identisch und zugleich in ein Distanzverhältnis zueinander gesetzt sind «. ${ }^{108}$ Denn auch wenn der Roman von nur einer Person handelt, gibt es in dieser Art des Erzählens immer zwei >Figuren : den Sender und den Empfänger. Entweder der Erzähler spricht zum Protagonisten, oder der Protagonist spricht mit sich selbst und nimmt so in einer Art Verdoppelung beide Rollen ein; und natürlich könnten sie jeweils auch zum Leser sprechen. In diesem Erzählen ist demnach die Anwesenheit von nicht einer, sondern zwei Personen impliziert. Das ermöglicht die Entstehung der Subjekt-Objekt Struktur, die ein direktes Herrschaftsverhältnis voraussetzt. Was der Protagonist selbst nicht reflektieren kann, ist jedoch, dass er beide Seiten dieses Herrschaftsverhältnisses bedienen muss. Er kann nicht nur der Herrscher sein, er muss ebenso die passive Rolle des Beherrschten einnehmen. Daraus folgt, dass er nicht allmächtig ist und sein neugewonnener Agens einer Beschränkung unterliegt, und zwar einer sozialen. Er kann keine Verbindung zu anderen Menschen außer sich selbst eingehen und leidet unter Einsamkeit.

Die Herrschaftsphantasie ist für den Protagonisten deshalb auf Dauer nicht tragbar, sie wird zum Ende des Romans aufgelöst. Ihre positive Konnotation schlägt in eine negative um, als der Protagonist bemerkt, dass er zwar Kontrolle zurückgewonnen hat, aber auch einsam ist. Der folgende Romanausschnitt exemplifiziert dies:

Maintenant tu es le maître anonyme du monde, celui sur qui l'histoire n'a plus de prise, celui qui ne sent plus la pluie tomber, qui ne voit plus la nuit venir. Tu ne connais que ta propre évidence : celle de ta vie qui continue, de ta respiration, de ton pas, de ton vieillissement. Tu vois les gens aller et venir, les foules et les choses se faire et se défaire. [...] tu passes ton chemin : tu es inaccessible. (Hqd 120, Herv. meine)

Du bist jetzt der anonyme Herr der Welt, der, über den die Ceschichte keine Macht mehr hat, der, der den Regen nicht mehr fallen spürt, der die Nacht 
nicht mehr kommen sieht.

Du kennst nur deine eigene Cewissheit: die deines Lebens, das weitergeht, deines Atems, deines Schrittes, deines Alterns. Du siehst die Leute kommen und gehen, siehst die Menge und die Dinge sich bilden und sich auflösen. [...] du gehst deinen Weg: du bist unzugänglich.« (73, Herv. meine)

Hier zeigt sich der Zusammenhang zwischen Herrschaftsphantasie und Isolation. Der »Herr der Welt« ist, im Gegensatz zur typischen Herrscherfigur, nicht bekannt oder verehrt, sondern anonym - »tu es le maître anonyme du monde«. Er hat sein Ziel erreicht, die Geschichtsvorstellung der Anderen, und damit die empfundene Fremdsteuerung, hinter sich zu lassen (»l'histoire n'a plus de prise [sur lui]«), und hat damit auch die Scheinhaftigkeit ihres Tuns überwinden können. Doch der Preis, den er dafür zahlt, ist die völlige soziale Abkoppelung. Wenige Seiten vor dem obigen Zitat heißt es, er sei frei - »tu es libre (Hqd 113) - und nachfolgend kommt zum Vorschein, wie umfassend diese Freiheit tatsächlich ist: Als anonymer Herrscher ist er namenlos, und damit unerkennbar. Er ist nicht Teil der Menschenmenge in der Großstadt, sondern sieht sie nur an sich vorbeiziehen (»[t]u vois les gens aller et venir, les foules et les choses se faire et se défaire«). Ein Kontakt zwischen ihm und anderen Menschen ist unvorstellbar (»tu es inaccessible«). Er hat das Gefühl völliger körperlicher Losgelöstheit von der Materialität der Welt, denn er spürt nicht einmal mehr den Regen fallen (»[tu] ne sen[s] plus la pluie tomber«).

In dieser Überzeichnung von Freiheit und Selbstbestimmung steckt auch eine in den 1960ern erstarkende Liberalismus-Kritik. Dies wird im Rückgriff auf John Stuart Mills Essay On Liberty (1859) realisiert, in dem Mill fordert, staatliche Eingriffe in das Leben des Individuums auf ein Minimum zu beschränken. Er betont besonders, dass weder Konvention noch Moral dafür genutzt werden können, dem Individuum den Willen eines anderen aufzuzwingen. So könne die Etablierung eines passiven, durch den Staat bestimmten Objekts zugunsten eines aktiven Subjekts verhindert werden, das sein eigener Herr ist: "In the part which merely concerns himself, his independence is, of right, absolute. Over himself, over his own body and mind, the individual is sovereign. ${ }^{109}$ Der Roman hinterfragt diese These, indem er zeigt, dass die Freiheit des so über sich herrschenden Protagonisten auch Probleme mit

109 John S. Mill: On Liberty. And Considerations on Representative Government. Hg. v. Ronald B. McCallum. Oxford: Blackwell (1948), 9. 
sich bringt: zum Beispiel die Unfähigkeit politisch zu handeln. Denn die Isolation, die diese Freiheit fordert, schließt auch das aus, was das Politische konstituiert: Gemeinschaft. Hannah Arendt, die sich in ihrer Politischen Philosophie vornehmlich an republikanischen bzw. demokratischen Ideen und Idealen abarbeitet, unterstreicht, dass Politik auf der Tatsache der »Pluralität der Menschen « beruhe: »der Mensch ist a-politisch ${ }^{110}$ Das Regieren als Tätigkeit braucht gemeinschaftliches Handeln, so Arendt. Eine Regierung könne sich erst ergeben, wenn man es schafft »sich mit anderen zusammenzuschließen und im Einvernehmen mit ihnen zu handeln. "111 Vor diesem Hintergrund hebt die Beschreibung des Protagonisten als "maître« und ihre Assoziation mit Mills Vorstellung des Individuums als »sovereign« lediglich seine einsame Isolation hervor. Der Roman im Ganzen stellt so die Perversion des liberalen Individualismus-Denkens heraus, die die Idee eines gemeinschaftlichen Handelns negiert. Denn »die Gemeinschaft ist nicht der Ort der Souveränität«, schreibt gleichermaßen Maurice Blanchot in Die uneingestehbare Gemeinschaft, ${ }^{112}$ und wer in ein soziales Netz eingebunden sein will, der kann kein Souverän sein. Die Fokussierung des liberalen Denkens auf das angeblich unabhängige Individuum allein, so Blanchot, ist fehlerhaft: »das isolierte Wesen ist das Individuum, und das Individuum ist nur eine Abstraktion, die Existenz, wie die schwachsinnige Auffassung des geläufigen Liberalismus sie sich vorstellt. «113 Der Mensch existiert nur in Beziehung zu anderen Menschen. Was von ihm übrigbleibt, wenn man diese Beziehung ausklammert, ist nicht mehr lebensfähig: Die Idee des Individuums, so argumentiert Blanchot, ist nichts weiter als ein Phantasma. Diese Kritik an der Priorität des unabhängigen Individuums wird im Roman außerdem durch die Darstellung einer in sich kollabierenden Despotie ${ }^{114}$ fortgeführt.

Indem der Roman zeigt, dass ein kompletter Rückzug in die eigene Existenz zwar Selbstbestimmung bedeutet, aber auch megalomane Einsamkeit zur Folge hat, kritisiert er die Zentralität des Individuums im Denken des Liberalismus. Er ruft damit ebenfalls das Problem der studentischen Einsamkeit im französischen Universitätssystem auf, das Raymond Aron 1968 in La Révolution introuvable beschrieben hatte: »Et certaines enquêtes montrent que

110 Arendt: Was ist Politik?, 9, 11.

111 Arendt: Macht und Gewalt, 45.

112 Blanchot: Die uneingestehbare Gemeinschaft, 26.

113 Blanchot: Die uneingestehbare Gemeinschaft, 37.

114 Die ideengeschichtliche Verbindung des Nichtstuns mit der Despotie wurde bereits beschrieben, vgl. Abschnitt »Herrschaft« in diesem Buch. 
des étudiants, venus de la province, ont fait des années d'études à la Sorbonne sans vraiment appartenir à aucun groupe, sans avoir un cercle d'amis. « ${ }^{115} \mathrm{Der}$ Protagonist ist der Prototyp eines solchen verlassenen Studenten. Perec, der Geschichte und Soziologie an der Sorbonne studierte, kreiert in ihm ein Alter Ego, das ebenfalls vom Land kommt (aus der Nähe von Auxerre, vgl. Hqd 45), das zwar Bekannte hat, jedoch niemanden, der es aus seiner Einsamkeit holen könnte.

Dass die selbstgewählte Isolation für ihn zum Problem wird, zeigt sich vornehmlich an der despotischen Ausprägung seiner Herrschaftsphantasie. Die Despotie, wie sie von Montesquieu in De L'esprit des Lois (1748) beschrieben wurde, ist ja gerade aufgrund der Isolation des Despoten eine heikle Herrschaftsform. Da der Despot sich nämlich vor seinen Subjekten ebenso fürchtet wie diese sich vor ihm, lebt er "ganz eingeschlossen « und ohne Kontakt zur Öffentlichkeit. ${ }^{116}$ Diese Abschottung bewirke eine Erhöhung des Ich, die in einem untätigen Solipsismus kulminiere. So sei der »naturgemäß faul[e]« Despot ein Mensch, »dem seine fünf Sinne unaufhörlich sagen, er sei alles und alle anderen nichts «. ${ }^{117}$ In der Hochphase seiner Herrschaftsphantasie ist bei Perecs Protagonisten eben dieser Solipsismus sehr ausgeprägt. Er hält sich auch für den einzigen, allmächtigen Akteur in der Welt, auch wenn er nur über sich selber herrschen kann. Dieser Zustand währt jedoch nicht lange. Der Umschwung, d.h. der Niedergang dieser Herrschaftsphantasie, kündigt sich durch eine Wiederaufnahme von Interpretation und Interpretierbarkeit an. Denn im Unterschied zum Montesquieu'schen Despoten ist er nicht vollkommen abgeschottet: er ist nicht in einem Serail isoliert, sondern in einer kleinen Mansarde mit dünnen Wänden oder auf den Straßen von Paris inmitten von Menschenmengen. Seine fünf Sinne werden ohne Pause stimuliert. Die Herrschaftsphantasie endet in dem Moment, in dem er auf diese Stimuli wieder reagiert.

Doch bevor sie endet, steigert sich die Herrschaftsphantasie auf einen Höhepunkt. Denn mit dem weiteren Voranschreiten seines EinsamkeitsExperiments beginnt er, andere Menschen wieder wahrzunehmen. Nicht jedoch, um sich $\mathrm{zu}$ resozialisieren, sondern um sie in seine Herrschaftsphantasie zu integrieren. So beginnt er, zu imaginieren, das Leben seines

115 Aron: La révolution introuvable, 31. Vgl. auch die Ausführungen im Abschnitt »Rund um das Handlungsparadigma 1968«.

116 Montesquieu: Vom Ceist der Cesetze, 86 (5/14).

117 Montesquieu: Vom Ceist der Cesetze, 31 (2/5). 
Nachbarn bestimmen zu können. Sie sind sich nie begegnet, nur ihre Zimmer grenzen aneinander. Und der Protagonist, noch überzeugt davon, »er sei alles und alle anderen nichts« (s.o.), glaubt, zumindest manchmal, der allmächtige und gefürchtete Herrscher dieses Nachbarn zu sein:

Pourtant, parfois, sa vie t'appartient, ses bruits sont à toi, puisque tu les écoutes, les attends[...]. Il t'importe peu que tu te trompes, ou interprètes, ou inventes. [...] Il vit la mince vie que tu lui laisses vivre, s'évanouissant à peine sorti du champ de ta perception, mort dès que le sommeil te gagne[...] II peut seulement déceler ta présence, et, s'il y est attentif, c'est qu'il a peur, c'est que tu l'inquiètes: il est comme ce vieux blaireau dans son terrier jamais trop bien protégé[...]. Il cherche à se protéger, il tente maladroitement de te tendre des pièges, de te faire croire qu'il est puissant, qu'il ne te craint pas, qu'il ne tremble pas [...].

II ne te déplaît pas, imbécile, de croire parfois que tu le fascines, qu'il a vraiment peur : tu t'efforces de rester silencieux le plus longtemps possible; ou bien tu grattes avec un bout de bois, une lime, un crayon, le haut de la cloison qui sépare vos deux chambres, produisant un bruit minuscule et énervant. (Hqd 159-162, Herv. meine)

Und doch gehört dir manchmal sein Leben, seine Ceräusche sind dein, weil du ihnen lauschst, auf sie wartest[...]. Es ist dir ziemlich gleichgültig, ob du irrst oder deutest oder erfindest. [...] Er lebt das unbedeutende Leben, das du ihn leben lässt und verschwindet, kaum dass er aus deinem Blickwinkel geraten ist, ist tot, sobald der Schlaf dich übermannt[...]. Er kann deine Gegenwart nur ahnen, und wenn er darauf achtet, so deshalb, weil er Angst hat, weil du ihn beunruhigst: er ist wie dieser alte Dachs, der in seinem Bau nie genügend geschützt ist[...]. Er versucht sich zu schützen, er versucht ungeschickt, dir Fallen zu stellen, dich glauben zu machen, dass er mächtig ist, dass er sich nicht fürchtet, dass er nicht zittert [...]!

Es missfällt dir nicht, du Dummkopf, manchmal zu glauben, dass du ihn faszinierst, dass er wirklich Angst hat: du bemühst dich, so lange wie möglich still zu bleiben; aber du kratzt mit einem Stück Holz, einer Feile, einem Bleistift oben an der Wand, die eure beiden Zimmer voneinander trennt, ein winziges, nerventötendes Ceräusch dabei erzeugend. (98f., Herv. meine)

In diesem Passus kündigt sich eine Peripetie der Roman-Handlung an, denn hier zeigt sich mit aller Deutlichkeit, dass der Protagonist seine Interpreta- 
tionsverweigerung ${ }^{118}$ aufgegeben hat. In diesem Moment befindet sich die Herrschaftsphantasie in ihrem Zenit, zeigt aber auch Zeichen einer Abnahme, denn die Indifferenz, die den Protagonisten in diesen Zustand versetzt hat, ist in ihrer Überwindung begriffen. Er interpretiert die Aktivitäten seines Nachbarn und möchte selbst auch von ihm interpretiert werden. Noch tut er dies im Rahmen seiner Herrschaft. Er produziert ein kleines, aber nervtötendes Geräusch (»un bruit minuscule et énervant«), das die Angst des Nachbarn schüren soll - und Angst (»il a peur«, »tu l'inquiètes«) ist Montesquieu zufolge die Grundhaltung des Despotismus. Das Auditive nimmt eine besondere Stellung in der Herrschaftsphantasie ein. Der Protagonist hält nämlich seine Hör-Wahrnehmung nicht nur für einen rezeptiven Prozess, sondern glaubt an dessen vereinnahmende Wirkung. Es heißt: »sa vie t'appartient, ses bruits sont à toi, puisque tu les écoutes « - das Leben des Nachbarn gehöre ihm, weil er ihm zuhört. Seine Sinne sagen ihm nicht nur, »er sei alles und alle anderen nichts«, sondern auch, dass alles von ihm sinnlich Wahrgenommene in seinen Besitz fällt. Die Macht des Protagonisten äußert sich in einer Art extremem Konstruktivismus, der Vorstellung also, die Wirklichkeit durch seine Wahrnehmung und seine Interpretation der Dinge überhaupt erst zu konstituieren - »Il vit la mince vie que tu lui laisses vivre«.

Ein weiterer Indikator für den Niedergang der Herrschaftsphantasie liegt im Element der Angst. Im zitierten Abschnitt heißt es, es würde dem Protagonisten gefallen, seinem Nachbarn Angst einzujagen - ihn einzuschüchtern, wie es der Herrscher mit dem Beherrschten tut. Das Problem, das in der limitierten Perspektive des Protagonisten gar nicht erst zur Reflexion kommt, ist allerdings, dass der Protagonist weiterhin in der Spaltung der Erzählinstanz gefangen ist, und deshalb nicht nur Herrscher, sondern immer auch Beherrschter ist. Wenn er einem Beherrschten Angst einjagt, so heißt das, dass auch er selbst Angst empfindet. Darauf verweist der implizite Vergleich mit Franz Kafkas Kurzgeschichte »Der Bau«. ${ }^{119}$ Der Nachbar, so der ErzählerProtagonist, verhalte sich ebenso paranoid wie das Tier in dieser Geschichte, das sich ständig bedroht fühlt, »il est comme ce vieux blaireau dans son terrier jamais trop bien protégé «. ${ }^{120}$ Doch die Angst des vermeintlichen Dachs-

118 Vgl. Abschnitt »Performativer Widerspruch« in diesem Kapitel.

119 Franz Kafka: >Bau<-Konvolut. [Der Bau]. In: Ders.: Schriften, Tagebücher, Briefe. Kritische Ausgabe. Nachgelassene Schriften und Fragmente II. Hg. v. Jürgen Born u.a. Frankfurt a.M.: Fischer (1992).

Der Protagonist sieht sich als Ursache dieser Bedrohung. Der Witz an der Ceschichte Kafkas besteht jedoch darin, dass es diese Bedrohung gar nicht gibt. Sie existiert nur in 
Nachbarn ist eigentlich seine eigene - einmal aufgrund der Spaltung in der Erzählinstanz, und außerdem, weil der Protagonist genauso ein Phantast ist wie das Tier (er imaginiert, eine Bedrohung zu sein ebenso wie das Tier imaginiert, bedroht zu werden). Dass er dennoch den Nachbarn für das Tier und sich selbst für eine Bedrohung hält ist eine Übertragung, die sich aus seiner Einsamkeit ergibt. Tatsächlich hat der Protagonist in seiner Isolation regelrechte Angst von seinen Mitmenschen entwickelt. Sowohl jene, die nach den Idealen leben, die er ablehnt - »les malins, les contents-d'eux« (Hqd 146) ${ }^{121}$ als auch diese, die ähnlich wie er aus der Ordnung fallen - »les brutes, les vieillards, les idiots « $(\mathrm{Hqd} 143)^{122}$ sind ihm zuwider:

tu les hais: monstres tapis dans leurs chambres de bonne, monstres en chaussons qui traînent leurs pieds près des marchés putrides, [...] monstres aux gestes mécaniques, monstres radotants. [...] Ils sont venus à toi, ils t'ont agrippé par le bras. [...] comme si, solitaire, tu voyais fondre sur toi tous les autres solitaires. (Hqd 143f.)

du hasst sie: in ihren Dachkammern sitzende Ungeheuer in Socken, die ihre Füße über angefaulte Stufen schleppen, [...] Ungeheuer mit mechanischen Gebärden, Unsinn redende Ungeheuer. [...] Sie sind zu dir gekommen, sie haben dich am Arm gekrallt. [...] als ob du, ein Einsamer, alle anderen Einsamen auf dich zustürzen sähest. (87f.)

Der Protagonist hasst sie alle (»tu les hais«), fühlt sich von ihnen angegriffen (»ils t'ont agrippé par le bras«) und fürchtet, von ihnen überwältigt zu werden (»tu voyais fondre sur toi tous les autres solitaires«). So geht sein Experiment mit einem letzten Haltungswechsel zu Ende: Indifferenz wird durch die Praxis des Nichtstuns zur Überlegenheit, welches erst von Hass, dieser dann von Angst abgelöst wird. Genau diese Angst versucht er zu kompensieren, indem er sie auf seinen Nachbarn überträgt. Auch David Gascoigne mutmaßt, der »invisible neighbour could be understood as an 'alter ego', a mirror-image

der Imagination des Tiers und nährt sich an seiner paranoiden Angst. Es ist kein Zufall, dass der Erzähler-Protagonist unter allen (literarischen oder anderen) Bedrohungsszenarien gerade ein solches herausgreift, in dem es keine materielle, keine personifizierte Gefahr gibt, sondern eine imaginierte. Dies reflektiert den wahnhaften Zustand des Protagonisten.

$121 »[D]$ ie Schlauen, die Selbstzufriedenen« (89).

122 »[D]ie Hohlköpfe, die Greise, die Idioten« (88). 
of himself«. ${ }^{123}$ Der minimalistische >Gewaltakt des An-die-Wand-Kratzens, um dem Nachbarn Furcht einzuflößen, ist ebenfalls Ausdruck eines erneuten Kontrollverlustes. Despotie und jede andere Form der Gewaltherrschaft gehen ja letztlich nicht aus Stärke hervor, so argumentiert auch Hannah Arendt, sondern sind Antworten auf ein Gefühl von Ohnmacht. ${ }^{124}$ Das gilt auch für die unscheinbarsten Tätigkeiten, solange ihnen die Intention innewohnt, gewaltig zu wirken und Angst zu produzieren.

Diese Überlagerung von Macht und Ohnmacht kommt in der Motivgeschichte des Nichtstuns immer wieder vor. Komik wie Tragik des Motivs sind in dieser Verschränkung angelegt. So auch bei Samuel Beckett, von dem Perec stark beeinflusst worden ist. Das Paradox, welches entsteht, wenn Charaktere in einer handlungsfeindlichen Welt plötzlich einen Kontrollzwang entwickeln, weil ihnen Handlung verwehrt ist, hat Theodor W. Adorno an der Figur Hamm aus Becketts »Endspiel« (1956, uraufgeführt 1957) beschrieben, der ähnlich ragiert wie der Protagonist in Un homme qui dort. Hamm lebt mit seinen Eltern in einer Wohnung, draußen geht trostlos die Welt unter. Obwohl es klar scheint, dass sie alle bald sterben werden, verwehrt er seinen Eltern den Zugang zur Speisekammer und hält den Schlüssel dafür unter Verschluss. Er übt die letztmögliche Kontrolle über sein Leben aus, dessen Umrisse sich bereits nahezu vollständig aufgelöst haben. Er ist damit, so Adorno, »Schlüsselgewaltiger und ohnmächtig in eins«, ein »König, um den alles sich dreht und der selber nichts vermag ${ }^{125}$ Die Parallelen zu Un homme qui dort sind frappierend. Doch Perec, der intertextuelle Referenzen bekanntermaßen verwendet, um Unterschiede zu literarischen Vorgängern zu markieren, ${ }^{126}$ reproduziert die Beckett'sche Schwermut nur zum Teil. Denn immerhin ist die Praxis des Nichtstuns, wie der Protagonist sie lebt, nicht gesetzt, sondern selbst gewählt und geschaffen. Er kann sie jederzeit unterbrechen. Und tatsächlich tut er

123 Gascoigne: The Games of Fiction, 136.

124 Arendt: Macht und Gewalt, 55.

125 Theodor W. Adorno: Versuch, das Endspiel zu verstehen. In: Ders.: Cesammelte Schriften. Bd. 2. Noten zur Literatur. Hg. v. Rolf Tiedemann. Frankfurt a.M.: Suhrkamp (1974), 312, 316.

126 »For him [Perec] the task is not to insert new books into shelves which are already full, so as to provoke a thoroughgoing rearrangement, but to discover gaps between existing books and to fill them. «Chris Andrews: Puzzles and Lists: Georges Perec's »Un Homme qui dort«. In: MLN 111 (4), 1996, 776. Vgl. auch Gascoigne: The Games of Fiction, 144-146. 
das. Anstatt folgenlos im Nichts zu verlaufen bildet die despotische >Gewalt<Herrschaft des Protagonisten einen Auftakt zur Kommunikation, in dem sich eine endgültige Zäsur der vermeintlich gleichgültigen Inaktivität ankündigt. Der folgende und letzte Absatz der Nachbars-Sequenz zeigt dies:

Ou bien, au contraire, pris d'une sympathie soudaine, tu as presque envie de lui envoyer des messages salutaires, en frappant du poing contre la cloison, un coup pour A, deux coups pour B... (Hqd 162).

Oder du möchtest ihm, von einer plötzlichen Sympathie ergriffen, plötzlich heilsame Botschaften hinüberschicken, mit der Faust an die Wand pochen, ein Schlag für A, zwei Schläge für B ... (99).

Bereits der >Gewalt<-Akt des Kratzens, der diesem Passus vorangeht, hatte eine kommunikative Funktion, die nun ausgeweitet wird. Nicht nur Angst und Furcht könnte er verbreiten, sondern seinem Nachbarn eine aufmunternde Nachricht übermitteln (»tu as presque envie de lui envoyer des messages salutaires«). Beide Kommunikationsimpulse - das angsteinflößende Kratzen wie das wohlwollende Klopfen - markieren eine Abwendung von der eingangs beschriebenen Neutralität, die der Protagonist durch sein Nichtstun ausagieren wollte. Außerdem zeigen sie eine rudimentäre, da zunächst auf einzelne Buchstaben beschränkte, Rückwendung zur Sprache an (»un coup pour A, deux coups pour $\mathrm{B}$ «). Besonders signifikant dabei ist, wie viel mehr physische Kraft der positiven Botschaft zukommt: Das angsteinflößende Geräusch ist winzig (»minuscule«) und leise, die heilsame Botschaft wird laut mit der Faust an die Wand gepocht (»en frappant du poing contre la cloison«). Der Protagonist will ihm unbedingt eine Botschaft senden. Auch, weil er eigentlich selbst wieder eine empfangen möchte. Schon einige Seiten vor dem obigen Zitat beschreibt der Erzähler-Protagonist den erhebenden Effekt des einfachsten menschlichen Kontakts:

les garçons de café, les ouvreuses, les caissières des cinémas, les marchands de journaux, les receveurs d'autobus, [...] Ills t'identifient, ils te reconnaissent. Ils ne savent pas que ces simples saluts, ces seuls sourires, ces signes de tête indifférents sont tout ce qui chaque jour te sauve (Hqd 148).

die Kellner, die Platzanweiserinnen, die Kassiererinnen an den Kinokassen, die Zeitungsverkäufer, die Busschaffner[...]. Sie identifizieren dich, sie erkennen dich wieder. Sie wissen nicht, dass diese einfachen Grüße, dieses Lächeln 
nur, dieses gleichgültige Kopfnicken genau das ist, was dich jeden Tag rettet (91).

So kündigt sich also das Ende des Nichtstuns als Praxis an. Der ursprüngliche Plan für die Realisierung der Neutralität beinhaltete die Abschaffung von Erkenntnis und Interpretation. Er wollte selbst nichts mehr erkennen und suchte auch von anderen keine Zeichen des Erkennens mehr (»signes de reconnaissance«, Hqd 70). Die Tatsache, dass er nun wieder von anderen Menschen erkannt wird (»[i]ls t'identifient, ils te reconnaissent«), ja dass er diese Würdigung sogar braucht, weil sie ihn rettet (»ces signes de tête indifférents sont tout ce qui chaque jour te sauve«) - all das markiert eine Rückwendung zu einem Willen, einer Meinung, einer Haltung. Dabei ist zentral, dass er den Blick der anderen wieder zulässt. Darin steckt auch ein Hinweis auf die von Jean-Paul Sartre geschilderte Szene im Park aus Lêtre et le néant (1943). Dort hält sich dieser solange für den >Herrn` des Parks, seines visuellen Königreichs (über das er seinen Blick schweifen lassen und es so passiv >besitzen kann), ${ }^{127}$ bis das Eintreten eines anderen, der Blick eines Zweiten, ihn aus dieser solipsistischen Phantasie reißt. ${ }^{128}$ Dass der Protagonist aus Un homme qui dort diesen Blick wieder zulässt, signalisiert das Ende seiner Herrschaftsphantasie, seinen Austritt aus der Isolation und nicht zuletzt eine mögliche Rückkehr in die Gesellschaft. Der später folgende kommunikative Impuls, an die Wand seines Nachbarn zu klopfen, zeigt auch, dass er nicht mehr nur in seiner Passivität erkannt werden will, sondern als aktiv Kommunizierender. Die Episode mit dem Nachbarn, um noch einmal Gascoignes Position zu zitieren, zeugt so von seinem »desire for contact as the mark of a yearning for a reintegration of the self, a closing of the 'je-tu' gap. ${ }^{129}$ Das Regelsystem

127 Vgl. hierzu die im vorangegangen Orientalismus-Kapitel beschriebene »monarch-ofall-I-survey scene«, in der koloniale Besitzansprüche durch die Darstellung passiven Sehens vermittelt werden. Pratt: Imperial Eyes, 202-204.

Norman Bryson fängt eben diesen herrschaftlichen Modus in seiner Beschreibung dieser Szene aus L'être et le néant ein: »[E]verything in the park is there for him to regard from an unchallenged center of the visual field. All of the park unfolds before this absolute center of a lived horizon: the subject resides at the still point of the turning world, master of its prospects, sovereign surveyor of the scene. In this initial exhilaration of self-possession, nothing threatens the occupancy of the self as focus of its visual kingdom. « Norman Bryson: The Gaze in the Expanded Field. In: Vision and Visuality. Hg. v. Hal Foster. Seattle: Bay Press (1988), 88.

129 Gascoigne: The Games of Fiction, 136. 
des Protagonisten überkommt sich selbst, es ist gescheitert: »Vielleicht verwandelt sich jede Regel, selbst wenn sie eine innere ist, nach einer gewissen (geschichtlichen, lebensgeschichtlichen) Zeit in Mißbrauch? Vielleicht muss man in bestimmten Momenten seine eigene Regel abschütteln? «30

\section{Aufgabe der Indifferenz und Rückkehr in die Gemeinschaft}

Die zu Beginn des Romans vom Protagonisten angenommene Indifferenz, und die daraus resultierende Praxis des Nichtstuns, markierten zunächst den Anfang einer neuen Selbstbestimmung. Die Unterwanderung des dominanten Handlungs- und Geschichtsparadigmas durch das Nichtstun hatte eine Weile lang den Anschein einer Handlung, scheitert jedoch am Ende des Romans. Seine Strategie entpuppt sich als reines Nichtstun, ohne den erhofften praktischen und ethischen Effekt:

Tu n'as rien appris, sinon que la solitude n'apprend rien, que l'indifférence n'apprend rien : c'était un leurre, une illusion fascinante et piégée. [...] L'indifférence est inutile. Tu peux vouloir ou ne pas vouloir, qu'importe! Faire ou ne pas faire une partie de billard électrique, quelqu'un, de toute façon, glissera une pièce de vingt centimes dans la fente de l'appareil. Tu peux croire qu'à manger chaque jour le même repas tu accomplis un geste décisif. Mais ton refus est inutile. Ta neutralité ne veut rien dire. (Hqd 177, Herv. meine)

Du hast nichts gelernt, höchstens, dass die Einsamkeit nichts lehrt, dass die Cleichgültigkeit nichts lehrt: es war ein Köder, eine faszinierende Illusion voller Fallen. [...] Die Gleichgültigkeit ist sinnlos. Du kannst wollen oder nicht wollen, was liegt schon daran! Du kannst eine Partie Flipper spielen oder nicht, irgendjemand wird auf jeden Fall ein Zwanzigcentimestück in den Schlitz des Apparats stecken. Du magst glauben, dass du eine entscheidende Tat vollbringst, wenn du täglich die gleiche Mahlzeit zu dir nimmst. Aber deine Weigerung ist sinnlos. Deine Neutralität hat nichts zu sagen. (107f., Herv. meine)

Hier wird das schon mehrfach beschriebene Konzept eines Handelns durch Nichtstun ganz konkret artikuliert. Der Protagonist hatte geglaubt, durch die Etablierung neuer Regeln zu handeln und eine ganz eigene Geschichte zu entwerfen, die ihn von den Fesseln der Konvention befreit: »Tu peux croire qu'à manger chaque jour le même repas tu accomplis un geste décisif.« Doch nun

130 Barthes: Wie zusammen leben, 197. 
wird ihm klar, dass diese versuchte Unterminierung bedeutungslos ist: »Mais ton refus est inutile. Ta neutralité ne veut rien dire.« Man sieht hier, wie sich der am Anfang des Romans etablierte Wunsch der Undeutbarkeit in sein Gegenteil verkehrt. Wollte der Protagonist zu Beginn des Indifferenz-Projekts nicht interpretierbar, nicht gestisch sein, so stellt sich nun heraus, dass all dies doch eine Geste sein sollte. Sein Nichtstun war nicht nur Selbstzweck, sondern sollte auch auf einer höheren Ebene Bedeutung erlangen und etwas aussagen (»dire«). Dadurch wird die Sprachreduktion und sein isolations-bedingtes Schweigen im Nachhinein als Fehler markiert. Es gibt, so argumentiert auch Arendt, kein Handeln ohne ein Sprechen, das erklärend mit ihm einhergeht. ${ }^{131}$ Dass er ein historisch bedeutungsvolles Handeln ohne den vollen Einsatz der Sprache erreichen konnte, stellt sich also als Irrtum heraus. Er habe sich, so gibt er zu, von einer Illusion fehlleiten lassen (»c'était un leurre, une illusion fascinante et piégée«). Dieses Scheitern war im Text von vornhinein angelegt, der ja auch nichts anderes als Sprache ist und so den Anspruch des Erzähler-Protagonisten von Anfang an unterminiert hat.

Auch hierin transzendiert Perec ein Stück Samuel Becketts, das noch wesentlich mehr Ähnlichkeit zu Un homme qui dort aufweist, als das darin referenzierte En attendant Godot (1949, uraufgeführt 1953). ${ }^{132}$ In dem frühen Stück Eleutheria (geschrieben 1947, uraufgeführt 2005), dessen altgriechischer Titel übersetzt >Freiheit $<$ bedeutet, reagiert Beckett kritisch auf die im Nachkriegsfrankreich prävalente Philosophie des Existentialismus. ${ }^{133}$ Das Stück, eine Parodie des im 19. Jahrhundert populären naturalistischen Theaters im Stile Ibsens, handelt von Protagonist Victor, der seit Jahren in einem Zustand anhaltender »inertie sordide ${ }^{134}$ verweilt, und seiner bürgerlichen Familie, die sich um seine Zukunft sorgt. Die Parallelen zur Handlung von Un homme qui dort, auch wenn Perec Eleutheria nicht gekannt haben mag, sind auffallend. ${ }^{135}$ Besonders die ihnen gemeinsame Gleichsetzung des Nichtstuns mit

131 Vgl. Arendt: Vita activa, 213-217.

132 Der Erzähler-Protagonist spricht von den »deux vieux acteurs de seconde zone« (Hqd 173), und meint damit die Figuren Didi und Cogo.

133 Leeder bezeichnet, Nicholas Hewitt zitierend, den Existentialismus im Post-WWII Frankreich als »the sofficial philosophy of the Fourth Republic«. Natalie Leeder: Freedom and Negativity in Beckett and Adorno. Something or Nothing. London: Rowman \& Littlefield International (2017), 10.

134 Samuel Beckett: Eleutheria. Paris: Éditions de Minuit (1995), 33.

135 Beide Protagonisten verbringen, von den Eltern finanziert und ihren Bekannten abgeschottet, den größten Teil ihrer Zeit in einem winzigen Ein-Zimmer-Apartment, in dem sich nicht viel mehr als ein Bett befindet. In der Beschreibung dieser Wohnung tre- 
Freiheit - auch Victor spricht von seiner »inertie« als seiner »liberté[...] [p]our rien faire «, ${ }^{136}$ die sich bei beiden aus der Folie der Sartre'schen Philosophie speist. In Eleutheria verarbeitet Beckett satirisch Sartres Idee der Freiheit, indem er sie auf ihren absurden Kern reduziert: Die absolute Gleichgültigkeit gegenüber und den Rückzug von aller Konvention. Diese Art der Freiheit, die sich durch eine Praxis des Nichtstuns realisieren will, so impliziert Beckett, ist aber weder wirklich frei (da sie immer in der Negation zur Norm und damit in einem Abhängigkeitsverhältnis verbleibt), ${ }^{137}$ noch vermag sich in ihr ein neuer, existentialistischer Ethos zu entwickeln. ${ }^{138}$ Das Nichtstun (»rien faire«) gibt Victor ja gerade nicht die »Handlungsfreiheit wieder und feiert sie«, wie Camus das Leben im Absurden definiert hatte; Nichtstun bedeutet keinen "Zuwachs an Beweglichkeit «, sondern vielmehr einen Verlust. ${ }^{139}$ Der markante Unterschied zwischen Un homme qui dort und Eleutheria liegt schließlich darin, dass sich Victor seiner falschen Freiheit nie bewusst wird, während Perecs Protagonist seinen Irrtum erkennt. Victor bleibt nur am Erhalt, nicht aber an der Überwindung des Nichtstuns interessiert. Als seine Verlobte Mademoiselle Skunk versucht, ihn an sein aktives Leben vor der Trägheit zu erinnern, verwirft Victor dies als Täuschung (»bluff«):

MLLE SKUNK. - [...] Tu travaillais. Tu blaguais avec ton père. Tu voyageais. Tu...

VICTOR. - C'était du bluff. Et puis, assez ! Va-t'en. ${ }^{140}$

ten in beiden Fällen die Socken in den Vordergrund. Victor ist» [s]ordidement vêtu, en chaussettes« (Beckett: Eleutheria, 71) und auch der Student erwähnt gleich am Anfang des Romans, und im Folgenden immer wieder, seine eingeweichten Socken - „Dans une bassine de matière plastique rose, tu mets à tremper trois paires de chaussettes « (Hqd 25). Dt.: »In einer rosa Plastikschüssel weichst du drei Paar Socken ein.« (15) Die Socke ohne Schuh, und Schuhe ohne Socken: In beiden Texten ist die mangelhafte Ausstattung zum Gehen ein Symbol der Fortschrittsverweigerung. Für Victor in Eleutheria bedeutet diese Verweigerung eine Befreiung. Beckett: Eleutheria, 90.

137 Bei Leeder heißt es über die frühen Texte Becketts: »For all their obsession with freedom, neither Murphy nor Eleutheria sufficiently transfigure or reconstellate the content that they lift from empirical reality. They are tied to the traditional even as they mock it." Leeder: Freedom and Negativity, 20. only self-deceptive but fundamentally unethical «. Leeder: Freedom and Negativity, 16.

139 Camus: Der Mythos des Sisyphos, 70. Vgl. die Ausführungen zu Beginn dieses Kapitels. 
$\mathrm{Zu}$ Beginn von Un homme qui dort war auch der Protagonist dieser Meinung. Nichtstun war für ihn eine Praxis: eine Befreiung von rigiden Handlungsnormen und Geschichtsparadigmen. Er betrachtete die Bevorzugung der konventionellen Tat - "privilégier l'action« (Hqd 32) - als eine Lüge: »pieux mensonges « (Hqd 32). ${ }^{141}$ Am Ende des Romans hat sich das Blatt gewendet. Er konnte durch sein Nichtstun keine entscheidende Tat vollbringen (»accomplis un geste décisif«, Hqd 177). Im Gegensatz zu Victor hält er nun nicht mehr die Phase vor und außerhalb der Inaktivität für einen »bluff«, sondern sie selbst die ihr zugrundeliegende Indifferenz, die er durch das Nichtstun ausleben wollte, sei vielmehr die Täuschung gewesen (»une illusion fascinante et piégée«, Hqd 177). Obwohl der Protagonist diese Täuschung erst spät erkennt, so war sie doch grundlegend für das Projekt Indifferenz als Praxis des Nichtstuns. Indifferenz sollte Kritik üben, eine Handlung darstellen, etwas Neues beginnen im Trott der gesellschaftlichen Erwartung konventioneller Handlung. Doch ihr Fundament war nie sechte< Indifferenz, sondern Prätention. Die Sprache der Erzählung hat schon früh gezeigt, dass sich hinter der Sprachreduktion und der Ent-differenzierung der Sprache eigentlich eine Agenda verbirgt. Die Indifferenz war ein Projekt, das vielleicht hätte funktionieren können, wenn es nicht einen unerfüllbaren Anspruch erhoben hätte. Was sich am Ende des Romans enthüllt, ist also nicht, dass das Nichtstun keine Handlung sein kann, sondern dass ein auf prätentiöser Indifferenz aufbauendes Nichtstun keinen Bestand haben kann.

Mit dem Zusammenbruch der Indifferenz geht natürlich auch die Hoffnung unter, durch das Nichtstun frei sein und handeln zu können. Un homme qui dort überwindet damit auch die Form des Absurden, die Adorno Becketts späteren Theaterstücken zusprach. In ihnen würde, so Adorno, das "nichts Bedeuten [...] zur einzigen Bedeutung. ${ }^{142}$ Auch der Protagonist Perecs hatte ursprünglich dieses Ziel: die Nichtbedeutung zur einzigen Bedeutung zu machen, vielleicht mit einer ähnlich mystischen Motivation, wie sie Beckett zugeschrieben wird. ${ }^{143}$ Am Ende des Romans wandelt sich diese reduktionis-

141 Vgl. den Abschnitt »Handlung und geschichtsphilosophische Fremdbestimmung in diesem Kapitel.

142 Adorno: Versuch, das Endspiel zu verstehen, 305.

143 Dem Werk Becketts wurden solche Bedeutungsstiftungen zum Beispiel auch durch Analogie zur Negativen Theologie attestiert. So schreibt Marius Buning: »Beckett's work might be considered in the light of and analogous to the via negativa of classic negative or apophatic mysticism. Predicated on systematic and indeed obsessive negation on both sentence and word level, the via negativa (a term coined by 
tische Einstellung um in die Hoffnung, mehr zu erreichen als Nichtbedeutung, und zwar doch Bedeutung zu schaffen, eine sinnvolle Weigerung zu erreichen. Seine Indifferenz soll etwas aussagen, sein Nichtstun einen semantischen Gewinn produzieren. Er schließt das Experiment mit der Erkenntnis $a b$, dass Bedeutungslosigkeit eben dies nicht leisten kann. Gleichgültigkeit ist sinnlos (»indifférence est inutile«), Nichtbedeutung ist und bleibt nur Nichtbedeutung. Das unterwirft auch seine Praxis des Nichtstuns einer neuen Bewertung. Nichtstun heißt doch nicht handeln im Sinne eines (bedeutsamen) Tuns durch (unbedeutendes) Nichtstun. Sondern nur, Unbedeutendes zu tun, Bedeutendes nicht zu tun.

Die vom Protagonisten erhoffte Transzendenz stellt sich letztlich noch ein, nur transzendiert er nicht das Denken der Anderen, gegen das er rebelliert hatte, sondern seine eigene, nichtstuerische Rebellion. In den letzten Absätzen des Romans macht er das deutlich, indem er seine Herrschaftsphantasie und seine Unzugänglichkeit für überwunden erklärt:

C'est un jour comme celui-ci, un peu plus tard, un peu plus tôt, que tout recommence, que tout commence, que tout continue. [...] Non. Tu n'es plus le maître anonyme du monde, celui sur qui l'histoire n'avait pas de prise, celui qui ne sentait pas la pluie tomber, qui ne voyait pas la nuit venir. Tu n'es plus l'inaccessible, le limpide, le transparent. Tu as peur, tu attends. Tu attends, place Clichy, que la pluie cesse de tomber. (Hqd 181f.)

Es ist ein Tag wie dieser hier, ein wenig später, ein wenig früher, an dem alles neu beginnt, an dem alles beginnt, an dem alles weitergeht. [...] Nein. Du bist nicht mehr der anonyme Herr der Welt, der, über den die Ceschichte keine Macht hatte, der, der den Regen nicht fallen spürte, der die Nacht nicht kommen sah. Du bist nicht mehr der Unzugängliche, der Reine, der Durchsichtige. Du hast Angst, du wartest. Du wartest an der Place Clichy, dass der Regen aufhört zu fallen. (110)

Hier kehren zwei Formeln, die früher im Roman, auf dem Höhepunkt der Isolation, vorkamen, in negierter Form zurück. Sagte er da, er sei der anony-

Thomas Aquinas) emphasises dispossession, self-annihilation, solitude, silence - in short >nothingness or the void - as prerequisites for the mystical experience, that is, the union between immanence and transcendence. « Marius Buning: The »Via Negativa « and Its First Stirrings in »Eleutheria«. In: Beckett and Religion. Beckett/Aesthetics/Politics. Hg. v. Dems. u.a. Amsterdam: Rodopi (2000), 44. 
me Herr der Welt - »tu es le maître anonyme du monde« (Hqd 120) - so ist er es nun nicht mehr: »Tu n'es plus le maître anonyme du monde«. Er spürt den Regen auch wieder fallen, er lässt sich wieder >berühren $<$. Aus »tu es inaccessible« (Hqd 120) wird »[t]u n'es plus l'inaccessible«.

Das Romanende lässt offen, ob und wie der Protagonist wieder handeln wird. Klar ist nur, dass er wieder in die Gesellschaft zurückgekehrt ist. So lässt sich das »tout« aus dem obigen Zitat als »Gesamtheit« oder »Totalität» übersetzen, in die der Protagonist nach seiner langen Isolation wieder eintritt. Was für Tätigkeiten er von nun an ausführen wird, ist jedoch unklar. Doch eben in dieser Kombination - dem Eintritt in die Gesellschaft und einer ungewissen Zukunft - liegt ein möglicher Auftakt für neue Handlung, die ja nicht nur eine soziale, sondern auch eine unplanbare Praxis ist. Obwohl der Protagonist gegen die Konvention und die dominante Ordnung handeln wollte, hat sich herausgestellt, dass seine Methode fehlerhaft war. Handeln heißt eben, das Unmögliche zu tun - aber nicht nur einmal, sondern immer wieder. Indem der Protagonist sich durch sein Nichtstun dem gesellschaftlichen Aktionismus entzogen hat, hat er es einmal geschafft. Die Regeln, die er sich zu dieser Realisierung auferlegt hatte, helfen ihm zwar dabei, diesen Ausstieg durchzuhalten, aber sie laufen stets auf dasselbe Ziel hinaus, was er schon längst erreicht hat. Der Erfolg seiner Handlung ist von kurzer Dauer. Die folgende Praxis des Nichtstuns zermürbt sich, und kann das Erfolgshoch nicht aufrechterhalten. Nicht zuletzt deshalb, weil ihr Fundament prätentiös war. Eine im Roman unausgesprochene Konsequenz dieser Geschichte ist dann auch, dass die Vorherbestimmung eines konkreten Ziels einer Tätigkeit ihren Handlungscharakter hemmt: Auf seine absolute Neutralität hinzusteuern stellt dann, kontextunabhängig, ebenso wenig eine Handlung dar wie seinem sicheren Hochschulabschluss oder der eigenen Hochzeit entgegenzuarbeiten. Die Offenheit des Romanendes scheint gerade diese Erkenntnis zu performieren - und impliziert damit auch eine Korrelation mit dem Handlungsbegriff, der um das Paradigma 68 herum formuliert wurde. Denn dort ging es, das hat die französische Philosophie zuhauf affirmiert, um die Auflösung von Kausalität, die Entpragmatisierung menschlichen Handelns, um das Ende der Klaffung von Theorie und Praxis, wie es bei Nancy heißt:

Das mehr oder weniger klare Verlangen, die Dehiszenz [zwischen Theorie und Praxis] zu überwinden und in gewisser Weise die Wahrheit in actu - in der Entelechie, sagt Husserl - einer praktischen Vernunft, oder wie man es nennen will [...] zu bekräftigen, dieses Verlangen hat sich um 1968 aufgelöst. 
Vielleicht kann man sogar sagen, dass die eigentliche Triebfeder von 68 auf der Ebene des Denkens eine Spannung war, die an die Grenze dieses Verlangens ging, hinausging über das Streben nach einem theoretischen Ziel durch eine daran orientierte Praxis, hinausging über alle Ebenen der Strategie, der Politik und zu einer eigentümlichen Praxis gelangte: der eines kompromisslosen Hic et nunc. ${ }^{144}$

Was 1968 stattfand, und was auch den Grund für seine anhaltende mythische Kraft darstellt, ist ein plötzlich auftretender Wille, nicht die Zukunft planvoll zu gestalten, sondern die Gegenwart spontan zu bestimmen. Hic et nunc: hier und jetzt, dort und da ist aus lockeren Impulsen und Ideen etwas entstanden, was erstmal nichts außer sich selbst realisieren wollte. Das, so argumentiert auch Hannah Arendt, ist das Wesen des Handelns, und nur so entsteht Gemeinschaft. Die entscheidende Bedeutung des Sozialen für die '68er belegt auch das folgende Fazit Blanchots:

Der Mai 68 hat gezeigt, daß sich ohne Projekt, ohne Verschwörung, mit der Plötzlichkeit eines glücklichen Zusammentreffens eine explosive Kommunikation affirmieren konnte (jenseits der gewohnten Formen der Affirmation) [...]. Im Gegensatz zu den »herkömmlichen Revolutionen« handelte es sich nicht darum, nur die Macht zu ergreifen, um sie durch eine andere zu ersetzen, [...] sondern es ging darum, außerhalb jedes Nutzenkalküls eine Möglichkeit des Zusammenseins sich manifestieren zu lassen[...]. ${ }^{145}$

Da der Protagonist am Ende des Romans seine Indifferenz und die zu ihr gehörigen Regeln aufgibt und sich in einer Pariser Menschenmenge wiederfindet, ermöglicht er prinzipiell die Annahme der von Nancy und Blanchot diagnostizierten Kernelemente der 68er Ereignisse. Sein ganz eigener Protest, den er im Rahmen einer Praxis des Nichtstuns veranstaltete, richtete sich ja sowieso schon gegen dieselben Feinde, die '68 angeprangert wurden. Doch ironischerweise perpetuierte sein Nichtstun auch eine Isolation, und damit gerade einen der zentralsten Aspekte, gegen die sich die Studierenden 1968 richteten: Die Einsamkeit an der französischen Universität. Unabhängig davon, ob Perec diesen Effekt intendierte oder nicht, zeigt Un homme qui dort das desolate Resultat eines falschen Protests, der bestehende Mängel nur verschlimmert, statt sie aufzuheben.

144 Nancy: Was tun?, 61.

145 Blanchot: Die uneingestehbare Cemeinschaft, $54 \mathrm{f}$. 



\section{Sprechen vs. Handeln}

Das Sprechen ist, ebenso wie die Arbeit, ein paradoxes Paradigma des Nichtstuns, denn beide werden der Kategorie des Tuns, wenn nicht des Handelns zugeordnet. Die Zugehörigkeit des Sprechens zu dieser Kategorie ist dabei weniger eindeutig, als es bei der Arbeit der Fall ist, denn die Meinungen, ob Sprache nun >nur Wort oder >schon Tat sei, gehen je nach Fach und Perspektive auseinander. Aus sprachphilosophischer und literaturwissenschaftlicher Sicht besteht allerdings kein großer Zweifel mehr daran, dass Sprache auch Sprechakte, d.h. Handlungen, hervorbringt. Während die traditionelle Philosophie davon ausging, dass die Funktion der Sprache eine >nur beschreibende im Verhältnis zu den damit beschriebenen theoretischen oder praktischen Inhalten ist, wurde ihr im Zuge des linguistic turn auch eine performative, das heißt: weltbildende Funktion zugestanden. ${ }^{1}$ Auf einer der formalen Linguistik übergeordneten Ebene zeigt beispielsweise die Entwicklung des epistemologischen Diskursbegriffes durch Michel Foucault an, dass das Wirklichkeitsverständnis einer jeweiligen Epoche einerseits sprachlich hervorgebracht und geregelt ist, und dass andererseits Diskurse (und damit die >Wirklichkeit`) durch Sprache verändert werden können. Diese Vorstellung baut unter anderem auf den die Sprechakttheorie fundierenden Überlegungen J. L. Austins und John Searles auf, die zeigen, dass und wie durch sprachliche Äußerungen Handlungen vollzogen werden können. War Austin zunächst davon überzeugt, dass dies nur auf manche sprachlichen Äußerungen zutraf, so änderte

$1 \quad$ Sprache ist nunmehr, so lautet Christopher Fynsks einschlägiges Urteil, »no longer understood as an instrument in social practice, but rather as the site or 'ground for such practice«. Christopher Fynsk: Linguistic Turn. In: International Encyclopedia of the Social \& Behavioral Sciences. Bd. 14. Hg. v. James D. Wright. Amsterdam: Elsevier (2015), 199. 
er im Verlauf seiner Untersuchungen seine Auffassung und bestimmte alle Äußerungen als performativ. ${ }^{2}$

Linguistische Betrachtungsweisen der Frage, ob Sprache eine Handlung darstellt, setzen jedoch zumeist Konditionen voraus, die sie aus handlungstheoretischen Auseinandersetzungen in der analytischen Philosophie übernehmen. Donald Davidson zufolge ist Intentionalität das Distinktionsmerkmal der Handlung - "a man is the agent of an act if what he does can be described under an aspect that makes it intentional ${ }^{3}$ Ebenso werden in der Linguistik sprachliche Aktivitäten als kommunikative Handlungen verstanden, wenn »sie mit bestimmten Ergebnissen verbunden sind « und wenn ihnen für die »Erzielung dieser Ergebnisse und ihrer sonstigen Wirkungen (also der Folgen) bestimmte Intentionen « unterstellt werden können. ${ }^{4}$ Auch außerhalb der Sprachwissenschaft ist Intentionalität der zentrale Faktor, an dem das Handlungspotential von Sprache festgemacht wird. So geht Hannah Arendt davon aus, dass Handeln, d.h. politisches Agieren (die wichtigste Wirkungsweise des Menschen in der Welt), nicht ohne Sprechen auskommt:

Handeln und Sprechen sind so nahe miteinander verwandt, weil das Handeln der spezifisch menschlichen Lage, sich in einer Vielheit einzigartiger Wesen als unter seinesgleichen zu bewegen, nur entsprechen kann, wenn es eine Antwort auf die Frage bereithält, die unwillkürlich jedem Neuankömmling vorgelegt wird, auf die Frage: Wer bist Du? Aufschluß darüber, wer jemand ist, geben implizite sowohl Worte wie Taten; aber so wie der Zusammenhang zwischen Handeln und Beginnen enger ist als der zwischen Sprechen und Beginnen, so sind Worte offenbar besser geeignet, Aufschluß über das Wer-einer-ist-zu verschaffen, als Taten. Taten, die nicht von Reden begleitet sind, verlieren einen großen Teil ihres Offenbarungscharakters, sie werden »unverständlich « [...]. ${ }^{5}$

Vgl. Austin: How to do Things with Words. Diese Entwicklung kann von der ersten (vgl. 6f.) bis zur letzten Vorlesung nachvollzogen werden (147f.).

3 Donald Davidson: Agency. In: Ders.: Essays on Actions and Events. Oxford: Clarendon Press (2002), 46.

4 Klaus Baumgärtner: Einleitung. In: Sprachliches Handeln. Hg. v. Dems. Heidelberg: Quelle \& Meyer (1977), XI. Herv. meine. Baumgärtner paraphrasiert an dieser Stelle einen Ansatz Rudi Kellers, doch seine Zusammenfassung Kellers ist auch nach dem heutigen linguistischen Wissensstand repräsentativ. In der analytischen Handlungsphilosophie hat das Sprechen kein gesondertes Interesse hervorgerufen, wahrscheinlich, weil es einfach als ein Ereignis unter vielen betrachtet wurde.

5 Arendt: Vita activa, $217 \mathrm{f}$. 
Die hier erörterte Position weicht von der oben beschriebenen, linguistisch motivierten signifikant ab: Sprache und Handlung sind nicht miteinander identisch, sondern formal voneinander getrennt. Das Sprechen fungiert als unterstützendes Werkzeug, das die Intention des Handelns verständlich machen soll. Dieses Modell ist repräsentativer für das allgemeine, alltägliche (d.h. unwissenschaftliche) Verständnis von Sprache, welches sie im Verhältnis zur Handlung als mindestens sekundär, wenn nicht als minderwertig betrachtet. John Haiman verweist zur Unterstützung dieser Behauptung auf populäre Sprichwörter aus dem Englischen, zum Beispiel >talk is cheap « und sactions do speak louder than words ‘, ${ }^{6}$ die man um viele weitere ergänzen könnte. ${ }^{7}$ Diese Einschätzung ist adäquat für eine Weltanschauung, in der Veränderungen nur in materieller Form auch als Veränderungen anerkannt werden. Arendts Einschätzung ist, wie bereits in der theoretischen Einführung dieser Arbeit beschrieben wurde, dass in der Moderne vorrangig die Tätigkeiten wertgeschätzt werden, die Mittel zum Zweck sind, und damit ein Produkt vorweisen können. ${ }^{8}$ Der Grund für die relative Abwertung der Sprache innerhalb dieses Ideologems ist also ihre Distanz von der materiellen Welt. Und selbst wenn Äußerungen materielle Änderungen bewirken können, so Haiman, so könne dies trotzdem nicht direkt, sondern nur über Vermittlungswege passieren: »It is only after the message is interpreted and voluntarily obeyed that the physical and social transformations which it "performs « are effected in the real world. [...] Unlike physical action, then, talk is displaced or removed from the world. «9

Für die literaturwissenschaftliche Betrachtung des Nichtstuns ist die Frage, ob Sprache als Handlung verstanden werden kann oder nicht, von großer Bedeutung. Denn betrachtet man Sprache von vornherein als einen der Handlung fremden Prozess, so ist sie umgekehrt de facto repräsentativ für das Nichtstun an sich. Diese These vertritt Leonard Fuest, und bezieht sie insbesondere auf die Sprache der Literatur. In seiner einschlägigen Arbeit zur Poetik des Nicht(s)tuns (2008) behauptet er, dass Literatur sich von der »Arbeitssprache « abwendet und das Nichtstun deswegen nicht nur thematisieren, sondern auch verkörpern könne: »Die Literatur bietet diese Sprache. Sie John Haiman: Talk Is Cheap. Sarcasm, Alienation, and the Evolution of Language. Oxford: UP (1998), 3.

7 Zum Beispiel: »One needs to walk the walk, not just talk the talk«; im Deutschen: »Taten sagen mehr als Worte«.

8 Vgl. hierzu die Ausführungen in »Handlung und Geschichte« in diesem Buch.

9 Haiman: Talk Is Cheap, 4. 
ist müßig, faul, träge, indolent, passiv, aber auch aggressiv, launisch, unwillig unwirsch. ${ }^{10}$ Mit dieser Verknüpfung von poetischer Sprache und Nichtstun will Fuest der Literatur und der Sprache im Allgemeinen jedoch nicht die Wirkmacht in der Welt absprechen. Sie produziere vielmehr Störungen, sowohl im Text als auch in der Ökonomie des Marktes, und wirke, so die Implikation, sehr wohl auf die Welt ein. ${ }^{11}$ In Anlehnung an diese Position glaube ich, dass Sprache (und Literatur) eine Handlung im Sinne Arendts (und dieser Arbeit) darstellen kann, wenn sie als Störung auftritt und zum Beispiel herkömmliche Zweck-Mittel-Kategorien überwindet. Die Sprache und Literatur, die sich mit dem Nichtstun auseinandersetzt, hat in dieser Hinsicht ein besonderes Wirkpotential: sie kann nicht nur eine Handlung darstellen, wo man keine vermutet, sondern lässt die Grenzen zwischen Handlung und Nichtstun verschwimmen, indem sie sie in ein dynamisches Verhältnis setzt. Man kann und sollte sie vor dem Hintergrund dessen verstehen, was Jacques Rancière als das ästhetische Regime der Kunst bezeichnet, und zwar die Fähigkeit der Kunst, die Konstitution der Politik grundlegend zu verändern womit Rancière auch das Verhältnis von Aktiv und Passiv miteinschließt. Die Kunst könne, meint er, diese traditionelle Unterscheidung ganz aufheben, und die Tätigkeiten, die vormals Gegensätze waren, gleichwertig machen. ${ }^{12}$ In Le partage du sensible (2000) schreibt Rancière:

literarische Aussagen wirken sich auf die Realität aus, und sie definieren Modelle des Sprechens oder des Handelns [...]. Sie zeichnen Karten des Sichtbaren, ziehen Bahnen zwischen Sicht- und Sagbarem und stellen Beziehungen zwischen Seinsweisen, Tätigkeitsformen und Redeweisen her. $^{13}$

Dieses Bewusstsein des Stör -, Veränderungs- und Wirkpotentials der Sprache, und im Speziellen der Literatur über das Nichtstun, ist der europäischen Motivgeschichte des Nichtstuns eingeschrieben. Es äußert sich in einem generellen Unbehagen, die Nichtstuer selbst sprechen zu lassen - aus Angst, dass sich das von ihnen Gesprochene irgendwie verselbstständigen und die Realität verändern könne. Das, was vom Nichtstuer gesprochen wird, kann und darf nicht für sich stehen, es muss in bereits bestehende Diskurse integriert werden. Geschichten über das Nichtstun brauchen deshalb einen Er-

\footnotetext{
10 Fuest: Poetik des Nicht(s)tuns, 12.

11 Vgl. Fuest: Poetik des Nicht(s)tuns, 24-26.

12 Rancière: Aufteilung des Sinnlichen, 15.

13 Rancière: Aufteilung des Sinnlichen, 62.
} 
zähler, der Verantwortung für sie übernimmt, und zwar indem er die diegetische Handlungslosigkeit durch die eigene Handlungsbereitschaft kompensiert.

Die kanonischen Untätigkeitserzählungen des 19. Jahrhunderts weisen nicht selten Erzähler auf, die in der Diegese als fleißige Arbeiter beschrieben werden, und gerade deswegen die Aussagen nichtstuerischer Protagonisten irgendwie sgeraderücken oder sausbalancieren wollen. In Melvilles »Bartleby« wird das Nichtstun des Protagonisten immer wieder durch den Erzähler, Bartlebys Vorgesetzten, zum unhaltbaren Zustand erklärt und Handlung gefordert - "Now one of two things must take place. Either you must do something or something must be done to you ${ }^{14}{ }^{14}$ und da sich bis zuletzt keine Handlung einstellt, wird diese Leerstelle durch die Geschichte des Erzählers gefüllt. Die bereits erwähnte Formel, die der Protagonist selbst zu dieser Erzählung beiträgt, und deren große philosophische Resonanz im 20. Jahrhundert ihrem Wirkpotential Rechnung trägt, wird ignoriert. Er wird stattdessen als jemand beschrieben, »of whom nothing is ascertainable, except from the original sources, and in his case those are very small - und dass wegen dieses Informationsmangels keine Biographie von Bartleby angefertigt werden kann, nennt er »an irreparable loss to literature ${ }^{15}$ Deswegen schreibt er sie selbst.

In Iwan Gontscharows Oblomow spricht der Protagonist zwar mehr, doch auch da wird das erzählte Geschehen in eine Rahmenhandlung eingebettet, deren Erzähler implizit darauf verweist, dass die traurige Geschichte eines nichtstuerischen Landadligen nur unter dem Vorzeichen der Warnung erzählt werden kann. So spricht Stolz - der sich ganz gegenteilig verhaltende, da handlungsfreudige und arbeitsame Freund Oblomows - die letzten Sätze des Romans über Oblomows Geschichte zu einem befreundeten Schriftsteller: "Das werde ich Dir gleich erzählen; laß mir nur Zeit, meine Gedanken und Erinnerungen zu sammeln. Und schreibe es dann auf, vielleicht nützt es jemand. Und er erzählte ihm das, was hier steht. «" ${ }^{16}$ Die Erzähler in Bartleby und in Oblomow sind hart arbeitende Figuren, die sich vermeintlich zum Erklären des Nichtstuns besser eignen als die Nichtstuer selbst, da sie selbst im Zeitalter der Arbeitsglorifikation gesellschaftlich höher geschätzt werden. Dahinter verbirgt sich jedoch auch eine Angst vor der Wirkmacht des Nichtstuns:

14 Melville: Bartleby, 158.

15 Melville: Bartleby, 80.

16 Gontscharow: Oblomow, 648. 
sie müssen anstelle der Nichtstuer sprechen, um eine mögliche revolutionäre Wirkung ihrer Geschichten und Sprechakte zu verhindern.

\section{KOMPENSATION in Bombel von Mirosław Nahacz, 2004}

Die letzte Lektüre widmet sich einer zentralen Praxis des Nichtstuns, die auch in den vorangegangenen Analysen immer wieder von Bedeutung war: dem Sprechen und dem Erzählen. Darin wird die These vertreten, dass das Sprechen eine Kompensation der gesellschaftlichen Verurteilung des Nichtstuns darstellt. Anhand von Mirostaw Nahaczs Bombel (2004) wird gezeigt, dass das gesellschaftskritische Erzählen die soziale Funktionslosigkeit eines Arbeitslosen kompensieren soll, und dass es dem Nichtstun zu einem öffentlichen Erscheinen verhilft, während dieses normalerweise höchstens gesehen, aber selten gehört wird.

Der zweite Roman des jungen Autors Mirosław Nahacz, Bombel, ${ }^{17}$ spielt im Polen des frühen 21. Jahrhunderts. Im ersten Unterkapitel (Dorf und Bushaltestelle: Räume praktischen Nichtstuns) wird ausgeführt, dass darin aus der Perspektive eines Arbeitslosen das Bild eines Dorfes gezeichnet wird, in dem es keine (soziale) Mobilität, keine Unterhaltungsmöglichkeiten und fast keinen öffentlichen Raum gibt. Anhand des Topos der Bushaltestelle wird in diesem Kapitel gezeigt, wie diese Mängel durch das Nichtstun kompensiert werden. Im zweiten Unterkapitel (Erzählen) werde ich auf das Erzählen als Praxis des Nichtstuns eingehen, die den gesellschaftlichen Ausschluss des arbeitslosen Protagonisten (und einige andere Umstände) im Erzählen zu kompensieren versucht. Der nichtstuende Erzähler ist zwar als `wahnsinnigく konnotiert, schafft es aber dennoch - oder vielleicht gerade deswegen - literarisch produktiv zu sein, und so auch politisch relevante Aussagen zu tätigen. So kritisiert er über das Motiv der Arbeit gesellschaftliche Missstände (Arbeit, eine Lüge) und zeigt, dass der Glaube an den gesellschaftlichen Fortschritt eine Illusion darstellt (Fortschrittsillusion). Der Erzähler-Protagonist Bombel problematisiert zudem, so demonstriert das dritte Unterkapitel (Biopolitik vs.

17 Mirosław Nahacz: Bombel. Wołowiec: Wydawnictwo Czarne (2004). Wird nachfolgend mit der Sigle B und der Seitenzahl im Text zitiert. Soweit nicht anders angegeben, beziehen sich die deutschen Zitate auf die Übersetzung Renate Schmidgalls in Mirosław Nahacz: Bombel. Frankfurt a.M.: Weissbooks (2008). 
Organische Gemeinschaft), die biopolitische Kontrolle seines inaktiven Körpers (Kontrolle des inaktiven Körpers), und überwindet diese Kontrolle in der Imagination einer Gemeinschaft von Nichtstuern (Gemeinschaft der Nichtstuer).

\section{Dorf und Bushaltestelle: Räume praktischen Nichtstuns}

Mirosław Nahaczs Bombel (2004) handelt von einem arbeitslosen Alkoholiker, der am frühen Morgen an einer dörflichen Bushaltestelle sitzt und dort ohne Unterlass spricht; die gut 150 Seiten lange Romangeschichte besteht ausschließlich aus diesem Monolog. Der Protagonist Bombel erzählt unter anderem von der Arbeitslosigkeit auf dem Land. Das Leben dort, so Bombel, sei trist - "nie ma u nas na wsi miejsc pracy i po prostu szarość życia ( $B$ 116); »bei uns auf dem Land gibt es keine Arbeitsplätze, das Leben ist grau« (128). Damit greift der Roman ein Problem seines Entstehungkontextes auf, als das polnische Dorf hauptsächlich mit Arbeitslosigkeit assoziiert und damit zum Inbegriff gesellschaftlicher Stagnation wurde. Der junge polnische Autor Nahacz, der in den 1980er-Jahren in der ländlichen Umgebung Krakaus aufgewachsen ist, lässt diese Geschichte im postsozialistischen Polen der frühen 200oer-Jahre spielen, kurz vor dessen Eintritt in die Europäische Union. Die Wirkung des Aufnahmeprozesses in die EU auf die Dritte Polnische Republik war signifikant. Dieser Prozess prägte das Land nicht nur nachhaltig mit westlich-liberalen Werten, sondern gab auch ungewollt einem langanhaltenden innerpolnischen Konflikt neues Futter: der kulturellen Abwertung des Ländlichen. Der Ursprung dieser Abwertung liegt in der langen Geschichte der Leibeigenschaft, die über Jahrhunderte hinweg eine Spaltung zwischen Bauerntum und Adelskultur provoziert hat. Da das Land noch bis ins spätere 20. Jahrhundert eine Agrargesellschaft war, ist diese Spaltung in Polen heute deutlicher als in anderen europäischen Ländern. Die Adels- und Gutsherrenkultur, die heute mit dem Leben in der Stadt gleichgesetzt wird, war und wird als überlegen angesehen (die meisten Polen sollen sogar glauben, selbst adeliger Abstammung zu sein), ${ }^{18}$ während die in der polnischen $\mathrm{Kul}$ tur tief verwurzelte Verachtung des bäuerlichen Dorfs« immer noch virulent

18 Magdalena Marszałek: Dörfliches Coming-out. Autobiographische Stimmen aus dem Dorf in der polnischen Cegenwartsliteratur. In: Über Land. Aktuelle literatur- und kulturwissenschaftliche Perspektiven auf Dorf und Ländlichkeit. Hg. v. Ders. u.a. Bielefeld: transcript (2018), 213. 
sei, so Magdalena Marszałek. In der polnischen Literatur, und nicht weniger im polnischen Film, wird das Dorf deshalb meist als Anti-Idylle dargestellt. Diese negative Ästhetik ist als künstlerischer Zugang zum Thema >Dorf< etabliert und stellt seit dem 19. Jahrhundert eine ästhetische Konstante dar, die sporadisch durch konkrete gesellschaftliche Notlagen aktualisiert wird. ${ }^{19}$

Eine solche Aktualisierung findet in Bombel durch den Topos des Nichtstuns statt, den der arbeitslose Protagonist Bombel symbolisiert. Er ist ein Vagabund, ein aus der Arbeitsgemeinschaft Ausgeschlossener. ${ }^{20}$ Er gehört zu den in Polen sogenannten »menele« (dt.: Penner), die vor Lebensmittelläden, unter Brücken oder an Bushaltestellen herumlungern, und sich dadurch auszeichnen, »[że] nic nie robią«. ${ }^{21}$ Im frühen 21 . Jahrhundert sind das in Polen besonders problematische Figuren. Da die EU im Vorfeld des Beitritts in Polen unter anderem die gestiegene Arbeitslosigkeit und die rückschrittliche Landwirtschaft bemängelt hatte, ${ }^{22}$ wurden Land und Dorf erneut als Problem wahrgenommen, weil sie der Weiterentwicklung Polens vermeintlich im Wege standen. ${ }^{23}$ Es kommt zu dieser Zeit zur Herausbildung einer

19 Vgl. hierzu Magdalena Marszałek: Das Dorf als Anti-Idylle: Polnische literarische und filmische Narrative des Verdrängten. In: Imaginäre Dörfer. Zur Wiederkehr des Dörflichen in Literatur, Film und Lebenswelt. Hg. v. Werner Nell u.a. Bielefeld: transcript (2014), 428431.

Vgl. Robert Castel: Die Metamorphosen der sozialen Frage. Eine Chronik der Lohnarbeit. Übers. v. Andreas Pfeuffer. Konstanz: UVK (2000). Der Vergleich Bombels mit einem Vagabunden ist strenggenommen nicht ganz korrekt, da Bombel z.B. örtlich gebunden ist, während Vagabunden auf der Suche nach Arbeit durch das Land ziehen. Ich benutze diesen Vergleich dennoch, da die Ausschlussmechanismen, die Castel beschreibt, auch auf Bombel zutreffen. Wie Michel Foucault auch, zeigt Castel, dass sehr unterschiedliche Arten von Abweichungen denselben gesellschaftlichen Ausschluss (Marginalisierung, Internierung usw.) hervorrufen, sodass diese verschiedenen Abweichungen (durch den Arbeitslosen, den Vagabunden, den Wahnsinnigen etc.) hinsichtlich ihrer Problematisierung analog sind. Der Vagabund als Figur ist sicherlich anachronistisch (eigentlich nimmt inn Castel nur als Prototyp), doch der Modus des sozialen Ausschlusses ist es nicht - und die Erklärung Castels passt genau auf die Situation von Nahaczs Protagonisten.

21 »[Dass] sie nichts tun « (Übers. meine). So Natalia Słowiak in ihrer soziologischen Studie über die Figur des Säufers bzw. ,Vagabunden` am Fallbeispiel der südlich von Krakau gelegenen Kleinstadt Stróże. Natalia Słowiak: Menele. Subkultura o tożsamości dewiacyjnej. Krakau: Oficyna Wydawnicza Impuls (2009), 74.

22 Vgl. hierzu Roland Freudenstein u. Henning Tewes: Wem die Glocken läuten. Ist Polen auf den Beitritt zur EU vorbereitet? In: KAS-Auslandsinformationen, 17 (5), 2001, $103 \mathrm{f}$.

23 In der polnischen Soziologie wird um die Jahrtausendwende eben dieses dörfliche Nichtstun als politisches Problem identifiziert. Zum einen weil es der >westlichen< Ar- 
Topologie, die Dorf und Untätigkeit miteinander verschränkt, und zugleich mit (vor allem im Hinblick auf die EU-Mitgliedschaft) einer eindeutig negativen Konnotation versieht. Sie bestätigt die populäre Meinung, das Ländliche im Allgemeinen und das Dorf im Speziellen seien der Ursprung und Ort des Schlechten. Früher war der Grund dafür ein Zuwenig an Zivilisation, das sich in verbrecherischem Verhalten äußerte, in den 2000er-Jahren ist es eine durch Untätigkeit begründete Ausbremsung politischen und wirtschaftlichen Fortschritts.

Der Roman bezieht sich explizit auf diesen Diskurs, ohne ihn allerdings zu reproduzieren. Er konstruiert zwar das Dorf als einen Ort der Untätigkeit, fügt ihm jedoch ein produktives Element hinzu: einen Erzähler. Der narrative Aspekt in der Geschichte hat von Anfang an eine starke Präsenz, beginnt der Roman doch mit den Worten: »No więc cześć i strzałka. Jestem Bombel na przystanku, bo siedzę właśnie tu, i dlatego na przystanku« (B 5); »Hallihallo und hi! Ich bin Bombel von der Haltestelle, hier sitze ich nämlich, deshalb von der Haltestelle« (9). Die Tatsache, dass der dörfliche Nichtstuer als zwar arbeitslos, aber zumindest sprechend aktiv dargestellt wird, weist den Roman als zu einem Gegendiskurs zugehörig aus, der zu der eben beschriebenen Abwertung des Ländlichen in Opposition steht. Er verleiht dem Dorf, das im öffentlichen Diskurs meist nur besprochenes Objekt, selten aber ein sich selbst artikulierendes Subjekt ist, eine Stimme. Damit weicht der Roman in zweierlei Hinsicht von dem dominanten Diskurs ab: Zum einen zeigt er Aktivität innerhalb eines vermeintlich nichtstuerischen Raums, zum anderen verleiht er einem Phänomen Sichtbarkeit, dem Repräsentation häufig verweigert wird.

beitsethik entgegenstehe (deren Nachahmung als der Aufnahme in die EU zuträglich wahrgenommen wird), zum anderen sollen aus ihm noch andere politische Probleme entspringen. Wenn z.B. Stadt und Land dadurch voneinander getrennt sind, dass erstere Arbeitnehmer, letzteres aber nur Arbeitslose (d.h. Sozialhilfeempfänger) beheimatet, dann bildet sich eine Zweiklassengesellschaft; infolge dessen ist die Landbevölkerung neben ihrer geographischen Marginalisierung auch noch sozial und wirtschaftlich abgeschottet und wird dadurch zur Brutstätte fremdenfeindlicher, spezifisch anti-europäischer Phobien. Vgl. Maria Hirszowicz: Spory o przyszłość. Klasa, polityka, jednostka. Warschau: Wydawnictwo IFiS PAN (1998), 124. Außerdem Lucjan Kocik: Trauma ieurosceptycyzm polskiej wsi. Krakau: Universitas (2001). Und Eugeniusz Kośmicki u.a. (Hgs.): Problem barier świadomościowych na wsi wobec integracji Polski z Uniq Europejskq. Poznań: AR (2000). In dieser Betrachtung wird der oben beschriebene Abwertungsmechanismus durch den Topos des Nichtstuns aktualisiert. 
Beides zeigt sich in besonderer Weise an dem Setting der Romanhandlung: der Bushaltestelle. ${ }^{24}$ Sie wird bereits im zweiten Satz des Romans zum zentralen Zuordnungsmerkmal des Protagonisten-Erzählers Bombel, schließlich beschreibt er sich selbst als »Bombel von der Haltestelle«. Diese Verquickung zwischen dem Nichtstuer und dem Ort der Bushaltestelle ist kein Zufall. Die Funktion der Haltestelle besteht üblicherweise darin, einen Raum bis zu dem Beginn einer Reise bereitzustellen, in dem lediglich gewartet werden soll, nichts sonst. Marc Augé nennt solch einen spezifisch mit dem Reisen verknüpften Raum (dazu gehören auch Autobahnen, Flughäfen, Hotels etc.) deshalb einen >Nicht-Ort<, weil er sich dadurch auszeichnet, kein »Ort der Tätigkeit« zu sein. ${ }^{25}$ Man kann dort nichts tun, weil das primäre Ziel immer ist, von dort weg und zu einem Ort (d.i. einem Raum) zu gelangen, an dem man wieder tätig sein kann. ${ }^{26}$ Auch in Michel de Certeaus Raumtheorie ist die Unterscheidung zwischen Ort und Raum durch die Anbzw. Abwesenheit von Handlung geregelt - ein Ort verweist »auf das Dasein von etwas Totem « und ist »im Abendland [...] immer durch einen reglosen Körper definiert «. ${ }^{27}$ Der Raum hingegen ist ein Ort, »mit dem man etwas macht «, seine Erzeugung ist »durch eine Bewegung bedingt «. ${ }^{28}$

Doch in Bombel weicht die Bushaltestelle von diesem konventionellen Verständnis ab: obwohl es sich um einen Nicht-Ort (Augé) bzw. einen Ort (de

24 In diesem Zusammenhang ist auch auf den kürzlich erschienenen Bildband zu verweisen, der den ungewöhnlich hohen ästhetischen Aufwand bei der architektonischen Gestaltung sowjetischer Bushaltestellen darlegt; Christopher Herwig: Soviet Bus Stops. London: FUEL (2015). Indessen handelt es sich bei der polnischen Bushaltestelle, um die es im Folgenden gehen soll, um einen anderen Topos. Architekten der Sowjetzeit haben die notwendige Fügung in die von der Politik vorgegebenen künstlerischen Richtlinien durch die phantastische Gestaltung alltäglicher Cebäude wie Bushaltestellen kompensiert. In Polen hingegen (das in Herwigs Bildband nicht mit Beispielen vertreten ist) gibt es kein vergleichbares architektonisches Phänomen. Die Bushaltestelle steht hier, so kann der Darstellung in Bombel entnommen werden, im Zentrum einer zeitgenössischen Topologie des Nichtstuns, die ebenso Rückschlüsse auf den politischen Kontext zulässt, der sich jedoch von dem sowjetischen maßgeblich unterscheidet.

Marc Augé: Orte und Nicht-Orte. Vorüberlegungen zu einer Ethnologie der Einsamkeit. Frankfurt a.M.: Fischer (1994), 80.

26 Ähnlich wie in der Theorie Michel de Certeaus entstehen in der Raumkonzeption Augés anthropologische Orte (d.h. Räume) erst durch soziales Handeln - nie andersherum. Vgl. Augé: Orte und Nicht-Orte, 63-67.

27 De Certeau: Kunst des Handelns, 219. Herv. meine.

28 De Certeau: Kunst des Handelns, 218, 219. Herv. meine. 
Certeau) handelt, findet dort Tätigkeit statt. Darin zeigt sich, dass die kausale Verknüpfung zwischen Bushaltestelle und Nichtstun auch umgekehrt funktioniert: Bombel sucht die Bushaltestelle bewusst auf, um dort nichts zu tun, weil es der Ort des Nichtstuns ist. In Weiterführung von Augés Gedanken lässt sich feststellen, dass solche Nicht-Orte das Nichtstun nicht unbedingt als Effekt produzieren, sondern dass sie kulturell so stark als >untätigく konnotiert sind, dass sie gerade deswegen von Nichtstuern aufgesucht werden, weil sie dem Nichtstun einen geeigneten, in gewissem Sinne sogar einen legitimen Raum bieten. Wenn die Bushaltestelle so zum Ort nichtstuerischer Praxis wird, findet eine Verwandlung des Ortes in einen Raum statt, ${ }^{29}$ der nichtsdestotrotz die Konnotation der Untätigkeit weiterträgt. Dabei lassen sich drei verschiedene ländliche Praktiken des Nichtstuns isolieren: die Ersatz-Reise (1), die Suche nach Unterhaltung (2), und der Versuch, sich öffentlichen Raum anzueignen (3).

(1) Reise: Zum ersten steht die Haltestelle stellvertretend für den Topos des Reisens, und der Aufenthalt in ihr funktioniert als Ersatz-Reise. In Polen war und ist dieser synekdochische Gebrauch eine kulturelle Praxis, die sich aus der stationären Lebensweise der Landbevölkerung ableitet. Im Gegensatz zu seinen westlichen Nachbarn waren in Polen bis ins späte 20. Jahrhundert mehr Menschen in der Landwirtschaft als in jedem anderen Sektor beschäftigt, was Ortgebundenheit auf der einen und ein oft geringes Einkommen auf der anderen Seite mit sich bringt und Mobilität einschränkt. Zeit an der Bushaltestelle zu verbringen bedeutet vor diesem Hintergrund, zumindest die Spur dieser Mobilität zu lesen und erleben, und die Hoffnung zu nähren, die sich damit verbindet: auf Anderes und auf Besseres. Bombel sucht die Bushaltestelle auf, um dem für ihn unerschwinglichen Luxus des Reisens näher zu sein. »Wchodzimy do autobusu, ja i Pietrek, skromni, ale dumni, [...] jest pięknie i nikomu nie przeszkadza, że nie mamy biletów«, träumt er, »[m]ogłoby tak być« (B 26). ${ }^{30}$

(2) Unterhaltung: In Abwesenheit konventioneller Vergnügungsmöglichkeiten wie dem Kino, einer Kneipe, oder zumindest einer Bibliothek war (und ist) in vielen polnischen Dörfern die Bushaltestelle, oder auch die Telefonzelle, der interessanteste Ort für diejenigen, die freie Zeit zur Verfügung ha-

29 Eine Arbeit, die de Certeau zufolge typischerweise von Erzählungen geleistet wird. Vgl. De Certeau: Kunst des Handelns, 220.

30 »Wir steigen in den Bus ein, ich und Pietrek, bescheiden, aber stolz, [...] es ist wunderschön, und keinen stört es, daß wir keine Fahrkarten haben. So könnte es sein.« (33) 
ben. Auf der Suche nach Abwechslung trifft man dort Gleichgesinnte, sodass auch beim Ausbleiben der Unterhaltung von außerhalb sich die Gemeinschaft durch ihr Zusammenkommen selbst unterhalten kann. Während Augé behauptet, Nicht-Orte würden Einsamkeit schaffen und »keinerlei organische Gesellschaft « beherbergen können, ${ }^{31}$ so ist die polnische Bushaltestelle im Gegenteil ein sozialer Raum. Er bleibt jedoch >zweitklassig<, da er nur von Subjekten aufgesucht und realisiert wird, die nicht schon anderweitig sozial eingebunden und damit auch tätig sind (z.B. durch Familie oder Beruf). Deshalb sitzt Bombel dort: Er hofft, dass sich in seiner Not (er braucht Zigaretten und Alkohol) "pojawi [się] jakiś zapomniany kolega« (B 8), ${ }^{32}$ der ihm aushelfen kann, und vertraut dabei auf die >Gemeinschaft der Trinker $<{ }^{33}$ die sich regelmäßig an diesem Ort bildet. Die Haltestelle dient als >Rettungsboot für die Zeiten, in denen aus eigener Kraft nichts für die Sucht getan werden kann: Die >Gemeinschaft der Trinker versteckt dort Weinflaschen, und auch Bombel hat zwischen den Balken eine Zigarette deponiert, für schlechte Zeiten. ${ }^{34}$

(3) Öffentlichkeit: Bombel hält sich an der Bushaltestelle auf, weil er für sich ein Stück des öffentlichen Raums reklamieren will. Das Nichtstun ist, wie bereits mehrfach besprochen wurde, oft in einem Kampf um sein eigenes Erscheinen begriffen, denn eine »Distanzierung vom Handeln ${ }^{35}$ zieht Hannah Arendt zufolge »Unsichtbarkeit « ${ }^{36}$ nach sich. Um in der Öffentlichkeit $\mathrm{zu}$ erscheinen, setzt sich Bombel an die wahrscheinlich einzige öffentliche Sitzgelegenheit im Dorf, die sich an der Bushaltestelle befindet - deswegen zieht er auch die Bank an der Bushaltestelle der von seinem Großvater geschnitzten, sprivaten Bank in seinem Garten vor (B 57). Anstatt, wie in der modernen Gesellschaft üblich, seine »soziale Zugehörigkeit« durch »Berufsarbeit « auszuweisen, ${ }^{37}$ definiert sich Bombel durch seinen öffentlichen Ort des Erscheinens: »Jestem Bombel na przystanku, bo siedzę właśnie tu« (s.o.,

31 Augé: Orte und Nicht-Orte, 131.

32 »I]rgendein vergessener Kumpel auftaucht« (13).

33 Siehe den Abschnitt »Cemeinschaft der Nichtstuer« später in diesem Kapitel.

34 »[S]chowałem kiedyś na tym przystanku papieroska na czarną godzinę, czyli na teraz.« (B 24); »[I]ch [hab] an dieser Haltestelle mal eine Zigarette für eine schwarze Stunde versteckt [...], das heißt, für jetzt.«(28)

35 Arendt: Vom Leben des Geistes, 97.

36 Arendt: Vom Leben des Geistes, 77.

37 Aßländer u. Wagner: Einführung: Arbeit und Philosophie, 11. 
B 5); »Ich bin Bombel von der Haltestelle, hier sitze ich nämlich, deshalb von der Haltestelle« (9). Er eignet sich diesen Raum mittels seiner Inaktivität an.

Diese drei Praktiken des Nichtstuns haben alle kompensatorischen Charakter: Bombel ist an der Bushaltestelle, um seine fehlende Mobilität, seine einsame Langeweile, und seine fehlende öffentliche Erscheinung imaginativ $\mathrm{zu}$ kompensieren. Neben diesen an den Ort der Bushaltestelle gebundenen Praktiken widmet sich der Protagonist noch einer weiteren Kompensation: dem Erzählen.

\section{Erzählen}

Das Erzählen im Roman Bombel ist in vielerlei Hinsicht eine kompensatorische Tätigkeit. Der Protagonist Bombel wartet in der Haltestelle darauf, dass jemand dort vorbeikommt. Die Langeweile, die er beim Warten empfindet, versucht er, der Benjaminschen Erzähler-Konzeption entsprechend, durch das Erzählen zu bannen. ${ }^{38}$

Doch dem Erzähler-Protagonisten Bombel ist nicht nur langweilig, er leidet auch an seiner Alkohol- und Nikotinsucht. Er sitzt an der Bushaltestelle, weil er darauf hofft, dort jemanden zu treffen, der ihm eine Zigarette oder einen Schluck Alkohol spendieren kann: »chce mi się pić dzisiaj[...]. Jeśli się nie wydarzy, nie pojawi jakiś zapomniany kolega[...]. Gorzej, jak nie« (B 8f.); »ich will heute trinken[...]. Wenn nichts passiert, wenn nicht irgendein vergessener Kumpel [...] unverhofft kommt[...][,] siehts übel aus« (12f.). Seine Trinksucht bereitet ihm Schmerzen und körperliches Unwohlsein - ihm ist kalt ( $B$ 8), seine Innereien scheinen zu jucken (B 59), er hat das Gefühl, sein Bauch könnte sich ausstülpen (B 99). Dieses Unwohlsein sucht der Protagonist durch das Erzählen auszugleichen. Das zeigt sich mit besonderer Deutlichkeit in der Abfolge von Bombels Erzählinhalten: der Beschreibung seines geplagten Kör-

38 Benjamin begreift das Erzählen als repetitives Handwerk und behauptet, dass sich im Zustand der Langeweile - dem Höhepunkt geistiger Entspannung - die gehörten Ceschichten einprägen, die dann während der Ausführung eines (ebenfalls repetitiven) Handwerks wiedererzählt werden. Benjamins Begründung, der Rhythmus der Arbeit wirke induktiv und sentfache`so das Erzählen, müsste man eigentlich auch um das Gegenteil erweitern: Wenn man in der Langeweile keinem Rhythmus ausgesetzt ist, so erzeugt man ihn im Erzählen. Walter Benjamin: Der Erzähler. In: Ders.: Erzählen. Schriften zur Theorie der Narration und zur literarischen Prosa. Hg. v. Alexander Honold. Frankfurt a.M.: Suhrkamp (2007), 111. 
pers folgt fast immer eine narrative Metabeobachtung, wie zum Beispiel in der folgenden Passage:

już nawet czuję w sobie te anomalia, jak we mnie drążą [sic!] i się wwiercają, jak kłóci się wszystko we mnie, żołądek ze śledzioną, jak prawe płuco razem z lewym wspólnie napadają z bronią w ręku na serce, jak mi się wszystko przewraca i nazywa nie tak, jak powinno. Tak więc, żeby umilić sobie czas, opowiem sam do siebie[...].(B 119, Herv. meine)

ich spüre die Anomalie sogar schon in mir, wie sie bohrt und sich hineinfrißt, wie alles in mir sich streitet, der Magen mit der Milz, wie die linke und die rechte Lunge mit der Waffe in der Hand zusammen über das Herz herfallen, wie alles durcheinanderkommt und nicht mehr heißt, wie es heißen soll. Also erzähle ich mir selbst was, um mir die Zeit angenehmer zu gestalten[...]. (131f., Herv. meine)

An dieser Abfolge, die sich im Roman oft wiederholt, zeigt sich die schmerzlindernde und sogar aufheiternde Funktion des Erzählens; eine Eigenschaft, die auch in der narratologischen Forschung etabliert ist. ${ }^{39}$ Bombel kompensiert also durch das Erzählen sein Unwohlsein, das sein Nichtstun begleitet.

Doch das Erzählen in Bombel ist nicht nur die Kompensation einer körperlichen Befindlichkeit, sondern auch der Stellung des Protagonisten im sozialen Abseits. Robert Castel hat die >Ausgeschlossenheit als zentrales Merkmal des Vagabunden beschrieben. Beim Vagabundendasein handele es sich, so Castel, um den »Grenzfall eines Entkoppelungsprozesses«, d.h. einer Losgelöstheit von konventionellen sozialen Bindungen, die sich »aus der Instabilität des Verhältnisses zur Arbeit und der Brüchigkeit der Gemeinschaftsnetzwerke speist «. ${ }^{40}$ Diese Entkoppelung hat eine wichtige sozial-phänomenologische Folge: der aus der Gemein- und Gesellschaft ausgeschlossene Arbeitslose verschwindet aus der Wahrnehmung der meisten anderen Menschen, die weiterhin arbeiten. Er wird nicht mehr gehört und nicht mehr gesehen. Der so >Verschwundene möchte gegen diese Unsichtbarkeit ankämpfen, er möchte wieder in den »Erscheinungsraum« treten, der Hannah Arendt zufolge entsteht, »wo immer Menschen handelnd und sprechend miteinander um-

39 Formenti schreibt: »Words and stories have the power to [...] heal, to soothe«. Laura Formenti: Auto/Biography. A Relational Journey. In: Constructing Narratives of Continuity and Change. Hg. v. Hazel L. Reid u.a. London: Routledge (2016), $12 f$. 
gehen ${ }^{41}{ }^{11} \mathrm{Da}$ ihnen zur Handlung - oder zu der Tätigkeit, die sozial am meisten wertgeschätzt wird - jedoch Ressourcen fehlen (aus welchem Grund auch immer), konzentrieren sich solche >unsichtbaren ₹iguren auf erreichbare Erscheinungen: das Sitzen in der Öffentlichkeit, und das Sprechen. Das entspricht auch der öffentlichen Wahrnehmung. Die Soziologin Natalia Słowiak, die eine Gruppe »menele« (dt.: Penner) in Südpolen in den späten 200oerJahren untersucht, berichtet, dass ihren Umfragen zufolge "menele« allgemein als besonders redselig ("gadatliw[i] «) gelten. ${ }^{42}$ Sie gibt außerdem an, dass Passanten gefühlt wesentlich häufiger in ein Gespräch verwickelt werden, als um Geld gebeten. ${ }^{43}$ Der Protagonist Bombel ist eben so eine redselige Figur, die das, was ihr widerfährt, allen ihren Mitmenschen erzählen muss. Dies reflektiert er schon vor dem Erzählen seiner ersten Geschichte zu Beginn des Romans: „No wieć pamiętam taką jedną rzecz, która mi się przytrafiła, już wszystkim ją opowiedziałem « (B 10); »Ich erinnere mich also an eine Sache, die mir widerfahren ist, ich habe sie schon allen erzählt« (14). Bombel, der in seinem Nichtstun weder durch Arbeit, Familie noch durch politisches Wirken eine gesellschaftliche Rolle einnimmt, kompensiert seine soziale Funktionslosigkeit also durch das Erzählen. Es bringt ihn mit anderen Menschen in Kontakt, und manchmal kann er sich damit bei Touristen sogar ein Bier serkaufen< (B 10)

Doch das Sprechen und das Erzählen des Protagonisten, obwohl aus dem Nichtstun heraus motiviert, hat gerade aufgrund des Nichtstuns des Erzählers keine hohe Wahrscheinlichkeit, gehört zu werden. Das liegt an der allgemein negativen Wahrnehmung des öffentlichen Nichtstuns, ${ }^{44}$ durch die ein diskursiver Ausschluss des nichtstuerischen Sprechens begründet wird. Das bestätigt auch die Studie Natalia Słowiaks: die Mehrzahl der von Słowiak befragten Passanten (71,9\% von 64 Befragten) geben an, so zu tun, als hörten sie die "menele« nicht. ${ }^{45}$ Eine solche, auf der Ebene der Sprache realisierte, gesellschaftliche Delegitimierung - sowie der damit einhergehende räumliche Ausschluss - trifft in der Regel die Individuen, die sich normativen Handlungszwängen nicht unterwerfen. Michel Foucault hat dieses Phänomen in Fo-

41 Arendt: Vita activa, 251

42 Słowiak: Menele, 77.

43 Słowiak: Menele, 78.

44 >Vagabunden wahrgenommen: »Ogólne ustosunkowanie społeczności lokalnej do badanej grupy »meneli«jest [...] negatywne«. Słowiak: Menele, 73.

45 Słowiak: Menele, 78. 
lie et déraison (1961) für den Wahnsinn beschrieben. Aus seiner Arbeit lässt sich Ähnliches über das Nichtstun ableiten. Das Nichtstun sei nämlich eine Folge des Wahnsinns, schreibt er: der »Wahnsinn in seiner allgemeinsten aber konkretesten Form « sei »das Fehlen einer Arbeit «. ${ }^{46}$ Foucault weist also den Wahnsinn auch als eine Form des Nichtstuns aus. In Anbetracht der Tatsache, dass sowohl der Wahnsinn als auch das Nichtstun Normabweichungen darstellen, kann man vermuten, dass sich diese Begriffe auch gegenseitig konnotieren, d.h. dass das Nichtstun an sich auch einer Bestimmung als >wahnsinnigく unterliegt, ebenso, wie der Wahnsinn >nichtstuerisch ‘ wirkt. Foucaults Folie et déraison impliziert ja gerade, dass Mechanismen gesellschaftlichen Ausschlusses nicht zwischen verschiedenen Arten der Normunterwanderung unterscheiden, sondern mit allen gleich verfahren. ${ }^{47}$

Diese gegenseitige Konnotation - deren wissenschaftliche Annahme übrigens auch in Polen nachgewiesen werden kann $-{ }^{48}$ ist in Nahaczs Roman

46 Michel Foucault: Wahnsinn und Gesellschaft. Eine Geschichte des Wahns im Zeitalter der Vernunft. Übers. v. Ulrich Köppen. Frankfurt a.M.: Suhrkamp (1989), 11. Herv. meine.

47 Vgl. Foucault: Wahnsinn und Cesellschaft, 71.

48 Im polnischen Kontext scheint Kausalität allerdings eine größere Rolle zu spielen als bei Foucault. Der polnische Psychiater Jerzy Strojnowski hat in einer medizingeschichtlichen Arbeit (ebenfalls aus den 1960er-Jahren) festgestellt, dass (zumindest im späten 18. Jahrhundert) Müßiggang - und, nebenbei bemerkt, Alkoholismus - als Auslöser für Psychopathologien verstanden wurde. In seinen Ausführungen zur polnischen Psychiatriegeschichte zitiert Strojnowski aus der von Ludwik Perzyna 1793 publizierten Abhandlung Lekarz dla wtościan, in der die Korrelation von Müßiggang und Wahnsinn vor allem für Frauen geltend gemacht wird: »Lekarze oświecenia dopatrywali się związku między pewnymi dolegliwościami nerwowo-psychicznymi a takim trybem życia; posłuchajmy np. Perzyny: 34: »Maciczne dolegliwości bywają dwojakie, jedne prawdziwe, [...] drugie [...] niby maciczne [...] takowe [...] najczęściej trafiać się zwykło kobietom próżnowanie lubiącym, zbytecznie się objadającym [...] miłośnicom trunków i pijaczkom [...] na bajkach życie trawiącym [...]. Najprzód: wszystkie ciotki, kumy [...] powyganiać na zawdy trzeba, wódki się wyrzec statecznie, ująć się roboty«. Dt.: »Die Ärzte der Aufklärung vermeinten einen Zusammenhang zwischen gewissen neuropsychologischen Befindlichkeiten und einem solchen Lebenswandel auszumachen. So hören wir von Perzyna: Uteröse Beschwerden gibt es zweierlei, die einen wahrhaftig ... die anderen ... angeblich uterös ... befallen am häufigsten Frauen, die dem Müßiggang frönen, sich üppig ernähren, alkoholische Trünke lieben, Trinkerinnen, die das Leben in Märchenwelten vergeuden. Zuallererst: ]egliche Tanten und Kumpaninnen auf Nimmerwiedersehen verscheuchen, dem Wodka standhaft entsagen und an die Arbeit machen.«(Übers. meine) Jerzy Strojnowski: Polska psychiatria społeczna w ujęciu historycznym. In: Roczniki Filozoficzne 15 (4), 1967, 51. Für die Ausführungen zum >polnischen< Alkoholproblem vgl. $49 f$. 
ebenfalls präsent. Die motivgeschichtliche Tendenz zur Pathologisierung des Nichtstuns adaptierend, zeigt Bombel nicht nur einen körperlich kranken (da an Alkoholsucht leidenden), sondern auch einen geistig nicht ganz gesunden Nichtstuer. Bombel gibt an, »Schikanen« mit dem »Kopf« zu haben - »mam nie ten tego z głową, jakieś takie szmery-bajery« $\left(B\right.$ 6), ${ }^{49}$ sie sollen ihn zum Sozialhilfeempfang berechtigen, der seinen Unterhalt garantiert. Er bezeichnet sich selbst mehrmals als Verrückten:

Jezu, tak mówię do siebie i nie poznaję tych słów, które wychodzą z mojej gęby. Gadam jak nienormalny, bo tylko tacy do siebie mówią[...]. (B 24)

Jesses, ich rede mit mir selber und erkenne gar nicht wieder, was da aus meinem Maul kommt. Ich quatsche wie ein Verrückter, denn nur die quatschen mit sich selber [...]. (28)

Der Wahnsinn, der sich aus Bombels >Kopferkrankung^ergibt, findet auch auf der Ebene der Erzählung deutlichen Niederschlag. Er äußert sich in einem Sprechen, das, Foucaults Charakterisierung des wahnsinnigen Sprechens gemäß, »außerhalb des reflektierten Schweigens der Vernunft endlos seinen Lauf nimmt «. ${ }^{50}$ Zum einen benutzt er am laufenden Band Schimpfworte, zum anderen verliert er ständig den Faden seiner eigenen Erzählung, über die er keine konstante Kontrolle auszuüben scheint. Obwohl er behauptet, ein selbstbestimmter Erzähler zu sein, der sich das Thema seiner Geschichte selbst aussucht und diese, seinem eigenen Willen nach, wiedergibt - er will unbedingt "mówić [...] tylko na właściwy temat, który sam ustaliłem, bo jestem wolnym człowiekiem w wolnym kraju« (B 33, Herv. meine $)^{51}$-, berichtet er vielfach von narrativem Kontrollverlust. Mehrmals behauptet er, gerade etwas gesagt zu haben, was er eigentlich gar nicht sagen wollte, was seine erzählerische Selbstbestimmtheit ebenso wie die mögliche Unterstellung einer Intention des Sprechens, ${ }^{52}$ in Zweifel zieht. Im folgenden Passus zu Beginn

\footnotetext{
49 "Denn ich hab da irgendwelche Schikanen, was mit dem Kopf « (10). Bombel umschreibt das mehrmals als den Besitz >gelber Papiere« (»żółte papiery« B 21). Michel Foucault: Der Wahnsinn, Abwesenheit eines Werks. In: Ders.: Schriften zur Literatur. Übers. v. Hans-Dieter Gondek. Hg. v. Daniel Defert u.a. Frankfurt a.M.: Suhrkamp (2003), 182.

$51 \gg$ [I]ch sollte [...] [nur] zum eigentlichen Thema [reden], das ich selbst bestimmt habe, weil ich ein freier Mensch in einem freien Land bin.« (39, Herv. meine)

52 Vgl. die Einleitung in diesem Kapitel.
} 
des Romans zeigt sich stattdessen, dass Bombel eine fiktive, andere Person erfindet, der er die Verantwortung für das von ihm Geäußerte zuschreibt:

Mówiłem o czym innym, ale zauważyłem, że jak tak mówię do siebie i mówię, to w pewnym momencie nawet nie wiem, co mi wychodzi i aż sam jestem ciekaw, co powiem, słucham uważnie i czuję, jakby to mówił jakiś inny Bombel, jakiś taki mniejszy, ale trochę mądrzejszy ode mnie, czyli Bombla większego, i jak gdyby on siedział w środku i wymyślał to wszystko, może nawet to ten sam, co mnie ssie, jak chce mi się palić. Tak więc to, że zaczynam i czasem nie kończę, to zasługa tego, że kiedy mówię, to nie myślę, tylko liczę na tego we mnie, a on mnie czasami zdradziecko okłamie. (B 9)

Ich wollte eigentlich was anderes sagen, aber ich merke, wenn ich so mit mir rede und rede, weiß ich manchmal gar nicht, was dabei raus kommt, und ich bin selbst gespannt, was ich sagen werde, ich hör mir aufmerksam zu und hab das Cefühl, da redet ein anderer Bombel, bißchen kleiner, aber bißchen gescheiter als ich, als der große Bombel, und es ist, als würde der in mir drin sitzen und sich das alles ausdenken, vielleicht ist es sogar derselbe, der an mir saugt, wenn ich Lust aufs Rauchen hab. Wenn ich also manchmal anfange und nicht fertigrede, dann kommt das daher, daß ich, wenn ich rede, nicht denke, sondern mich auf den in mir drin verlasse, und der legt mich manchmal ganz fies rein. (13f.)

Aussagen dieser Art, er habe sich »etwas vergaloppiert « (»trochę się zapętliłem«, B 11) - die eigentliche Übersetzung von »zapętlić« lautet eigentlich: sich endlos wiederholen, wie eine Schallplatte, die hängt -, oder wolle gar nicht über diese, sondern eine andere Sache sprechen (»nie o tym mam mówić«, B 16), ${ }^{53}$ stellen Bombel als unvernünftigen, unkontrollierten Erzähler heraus. Diesen Kontrollverlust möchte er durch die Metapher einer Persönlichkeitsspaltung (»jakiś inny Bombel, jakiś taki mniejszy, ale trochę mądrzejszy«, Herv. meine) erklären, was den Eindruck seiner Unkontrolliertheit allerdings noch verstärkt. Die Unfähigkeit, eine kohärente, vernünftige Erzählung zu produzieren, spiegelt die von Foucault in Bezug auf die Arbeit ebenso wie auf die Sprache getätigte Feststellung der »Unvereinbarkeit von Werk und Wahnsinn «.54 So führt der Roman den Grund für den diskursiven Ausschluss von Bombel, und von Nichtstuern, »menele«, im Allgemeinen

53 »N]icht darüber wollte ich reden« (20).

54 Foucault: Der Wahnsinn, 183. 
vor, indem er ihr Sprechen als >wahnsinnig<, und damit als einen Sprechakt markiert, der nicht ernst genommen werden kann und muss.

Doch während der Roman die Unkonventionalität eines nichtstuerischen Sprechens, und damit die Gründe für seinen diskursiven Ausschluss hervorhebt, zeigt er zugleich seine literarische Produktivität an. Die dargestellte Tätigkeit Bombels werde vielleicht von der Gesellschaft als mangelhaft empfunden, doch, so die Implikation, aus künstlerischer Perspektive sei sie durchaus wertvoll. Und zwar nicht trotz, sondern wegen ihrer Normabweichung. Denn die von der Gesellschaft entkoppelte Figur Bombel kann gerade deswegen sprechen und erzählen, weil sie nicht von konventionellen Tätigkeiten in Anspruch genommen wird. Zwar kann sie aufgrund ihrer Stellung als Außenseiter eigentlich keinen Sprechakt ausführen, weil ihr Sprechen außerhalb der diegetischen Konvention stattfindet. ${ }^{55}$ Extradiegetisch betrachtet vollzieht sich allerdings das genaue Gegenteil: Die Unkonventionalität der Sprechsituation legitimiert den Sprechakt als genuin literarischen. Denn obwohl Bombel durch seine Arbeitslosigkeit geltende Normen unterwandert, so zeigt doch schon allein die Tatsache, dass Nahacz mit diesem fiktiven Selbstgespräch einen ganzen Roman füllt, die künstlerische Qualität dieses Sprechens an. Sein Nichtstun, und damit seine soziale Funktionslosigkeit, ist eine Voraussetzung für das Entstehen von Kunst, ganz gemäß der Feststellung Terry Eagletons: "The function of art [...] is not to have a function «. ${ }^{56}$ In diesen Bahnen bewegt sich auch das Denken von Shoshana Felman, die, von den Thesen Foucaults ausgehend, die Literarizität des unkontrollierten, wahnsinnigen Sprechens herausstellt:

As opposed to the subject of logos, the subject of pathos is a subject whose position with respect to fiction (even when he is the author) is not one of mastery, of control, of sovereign affirmation of meaning, but of vertige, of loss of meaning. It could then be said that madness (as well as pathos and, perhaps, literature itself) is the non-mastery of its own fiction; it is a blindness to meaning. ${ }^{57}$

55 So schreibt John L. Austin: »There must exist an accepted conventional procedure having a certain conventional effect, that procedure to include the uttering of certain words by certain persons in certain circumstances «. Austin: How to do Things with Words, 14.

56 Terry Eagleton: The Event of Literature. New Haven: Yale UP (2012), 24.

57 Shoshana Felman: Madness and Philosophy or Literature's Reason. In: Yale French Studies 52, 1975, 221. 
So betrachtet ist das nichtstuerische Sprechen Bombels zwar unkontrolliert, aber trotzdem und deswegen literarisch, denn »literature itself[...] is the nonmastery of its own fiction «. Nahacz rückt diese Perspektive weiterhin in den Vordergrund, indem er Bombel als einen Unterhaltungskünstler darstellt. Dies ist schon am Beginn des Romans durch Bombels Selbstverständnis als eine Art Schauspieler augenfällig, der sich vor einem vorgestellten Publikum inszeniert. Um die Langeweile in der Bushaltestelle zu bannen, gibt er vor, Teilnehmer einer Talkshow im Fernsehen zu sein:

No więc ma być ekspozycja i w jej ramach coś o sobie, jak w teleturniejach, mam pięćdziesiąt pięć lat, emeryt elektryk, dwie córki i żonę, które teraz gorąco pozdrawiam poprzez machanie im do kamery. Ale na poważnie, bez żartów, to wcale nie mam pięćdziesięciu lat i chyba się skapnęliście, że tylko tak powiedziałem, żeby się nudno nie zrobiło. (B 5)

Also: Das soll eine Art Einleitung sein, das heißt, etwas über mich, wie im Fernsehquiz: Ich bin fünfundfünfzig, pensionierter Elektriker, zwei Töchter und eine Frau, ich grüße sie herzlich und winke in die Kamera. Aber im Ernst, ohne Quatsch: Ich bin nicht fünfundfünfzig [sic!], sicher habt ihr kapiert, daß ich das bloß gesagt habe, damit's nicht langweilig wird. (9)

An dieser Aussage Bombels wird erkennbar, dass er nicht nur für sich selbst erzählt, sondern zu einem imaginären Publikum spricht. Diese Inszeniertheit seines Sprechens stellt notwendig seinen Status als Wahnsinniger in Frage, da er die Vermutung zulässt, dass auch die Behauptung, verrückt zu sein, eben nur behauptet und nicht wahr ist. Betrachtet man nochmals Bombels Reflexionen über seinen Kontrollverlust beim Sprechen, so scheint sich diese Vermutung zu bestätigen. Dort behauptet er, er würde eigentlich ganz "gern« und absichtlich abschweifen, weil es »angenehm« sei, »den Moment hinauszuzögern, bevor man zum Kern der Sache kommt und dann das Wichtigste sagt« (18f.). Damit suggeriert er, Kontrolle über die Abschweifung, den Kontrollverlust ausüben zu können. Das polnische Original dieser Stelle unterstützt diesen Eindruck, dort heißt es nämlich: »Pozwolę sobie na dygresyjkę, bo przyjemnie jest tak oddalać ten moment, kiedy dojdę do sedna sprawy i będę mógł powiedzieć o tym najważniejszym« (B 14, Herv. meine). Die wörtliche Übersetzung des ersten Teilsatzes lautet »ich erlaube mir eine Abschweifung«, nicht, wie in Renate Schmidgalls Version, »ich schweife gern ein bisschen $a b$ « (18f., Herv. meine). Da mit dieser semantischen Vermischung von Agens und 
Passivität unsicher ist, ob man Bombel glauben kann oder nicht, erweist er sich als unzuverlässiger Erzähler.

Die Verbindung zwischen Nichtstun und einem unzuverlässigen IchErzähler, die sich in Mirosław Nahaczs Roman abzeichnet, hat eine lange Tradition, an die der Roman offensichtlich anknüpft. So weist Bombel besonders viele Parallelen zum pikaresken Roman des 16. Jahrhunderts auf. ${ }^{58}$ Auch der pícaro (Schelm) zeichnet sich dadurch aus, dass er nie arbeitet ${ }^{59}$ um trotzdem zu überleben, nutzt er Betrug, Lüge und Rollenspiel, die seiner Erzählung in ihrer Glaubwürdigkeit schaden. ${ }^{60}$ Wie auch im (fiktiven) autobiographischen Roman, wie der Schelmenroman ihn exemplifiziert, berichtet der Erzähler in einem Moment der Ruhe ${ }^{61}$ von früher stattgefundenen Ereignissen im Modus des erlebenden Ichs (Bombel alterniert zwischen dem Erzählen von seiner Bushaltestellen-Inaktivität und seinen vergangenen Erlebnissen, die auch an anderen Orten stattfinden). Im Schelmenroman ist der picaro typischerweise arm und bewegt sich - als Gauner, oder als Diener - in der untersten Gesellschaftsschicht, und berichtet deshalb auch

58 Dass die Literatur und Kunst im Osteuropa der zweiten Hälfte des 20. Jahrhunderts einige »Spielarten des Schelms « beheimatet, bemerken auch Kliems und Cölz. Christine Cölz u. Alfrun Kliems: Vorwort. In: Spielplätze der Verweigerung. Cegenkulturen im östlichen Europa nach 1956. Hg. v. Dens. Köln: Böhlau (2014), 9. Magdalena Marszałek stellt diese Verwandtschaft auch bei der zeitgenössischen Dorfprosa Zbigniew Masternaks in der Trilogie Księstwo (2006-08) fest. Die Rückschlüsse, die sie daraus zieht, behandeln die Distanzierungsmechanismen polnischer Erzähler von ihren Heimatdörfern, während in Bombel im Gegenteil eine enge Bindung an das Dorf betont wird. Marszatek: Dörfliches Coming-out, 220.

Joseph V. Ricapito definiert ihn als eine Figur »[who] has no particular profession and is incapable of sustained effort or purpose«, »avoids work«, und » has a general disdain for manual labour «. Joseph V. Ricapito: Toward a Definition of the Picaresque. A Study of the Evolution of the Genre. Dissertation. Los Angeles: UCLA (1966), 631f.

60 Riggan zufolge ist die narrative Situation des pícaro »a ready-made one for unreliable narration«. William Riggan: Pícaros, Madmen, Naïs, and Clowns. The Unreliable FirstPerson Narrator. Norman: University of Oklahoma Press (1981), 43.

61 Martinez und Scheffel deuten an, dass diese Form der Ich-Erzählung (nicht nur der Schelmenroman) mitunter durch einen inaktiven Ausgangspunkt motiviert ist, aus dem heraus erzählt wird, wie die Bushaltestelle ihn darstellt. Defoes Protagonist Robinson Crusoe erzähle so die Geschichte seiner Jugend, weil er »gegen Ende seines Lebens zur Ruhe gekommen ist « und der Erzähler Oskar Matzerath aus Günther Grass' Die Blechtrommel (1959) »nutzt seine Zeit als Insasse einer Heil- und Pflegeanstalt, um die Ceschichte seines Lebens zu erzählen«. Matias Martinez u. Michael Scheffel: Einführung in die Erzähltheorie. München: Beck (2007), $72 f$. 
»von unten« aus seinem Leben, und zwar »rückblickend mit der Erfahrung eines Wissenden und Geläuterten. ${ }^{62}$ Aus dieser Position sprechend, zeigt sich in der Erzählung eine privilegierte Einsicht in die höhere Gesellschaft trotz und aufgrund der narrativen Unzuverlässigkeit des Erzählers, der ohne >Filter und Angst vor Schäden durch Dritte frei und, so die Annahme, >wahr spricht. Diese höhere Gesellschaft, so geht in der Regel die Geschichte, hält den picaro aufgrund seiner sfalschen Herkunft, Haltung und Handlung sunten<, während ihr eigenes Verhalten den von ihnen proklamierten moralischen Standards ebenso wenig entspricht wie das seine.

Im Fall Bombels verhält es sich ähnlich. Indem der Roman den ErzählerProtagonisten Bombel als verrückt und unkontrolliert sprechend darstellt, entspricht er der gesellschaftlichen Erwartung der Verbindung zwischen Nichtstun und Wahnsinn. Doch indem er zugleich die Figur Bombel seine eigene Verrücktheit reflektieren wie inszenieren lässt, subvertiert er subtil diese gesellschaftliche Erwartung: Bombel wird dadurch im Roman ein Agens zugesprochen, das ihm ermöglicht, auch etwas Vernünftiges zu artikulieren, Kritik zu üben, und Wissen weiterzugeben. In Anbetracht von Bombels marginalisierter gesellschaftlicher Stellung kann man von seiner Erzählung als von einem "Aufstand des sunterworfenen Wissens« im Sinne Michel Foucaults sprechen, ${ }^{63}$ d.h. dem Sichtbarwerden von nicht-institutionalisierten Wissensformen, das "Dinge, Institutionen, Praktiken, Diskurse in einem ungeheuren und ausufernden Maße kritisierbar « macht. ${ }^{64}$ In Polen war diese Form der Kritisierbarkeit, deren Beginn Foucault auf die 1960erJahre datiert, für den Großteil des 20. Jahrhunderts nicht möglich gewesen. Zwar gab es seit dem Arbeiteraufstand 1956 (Poznański Czerwiec) immer wieder Kritik an der Staatsführung in Form von Protesten und versuchten Revolten, doch erst 1989 konnte mit dem Ende der Zensur die akademische Arbeit, und ebenso die Kunst, ihr kritisches Potential voll entwickeln. In den 1990er Jahren beginnt in der polnischen Literatur die Diskursivierung dessen, was Foucault »unterworfenes Wissen« nennt, indem über lange Zeit tabuisierte Themen wie Homosexualität, Kriminalität und natürlich

62 Hans C. Rötzer: Der europäische Schelmenroman. Stuttgart: Reclam (2009), 12. Mit der Formulierung »vvon unten« markiert Rötzer den Unterschied zum höfischen Idealroman.

63 Michel Foucault: [Von der Souveränität zur Disziplin]. Vorlesung vom 7. Januar 1976. In: Ders.: Kritik des Regierens. Schriften zur Politik. Übers. v. Hans-Dieter Gondek. Hg. v. Ulrich Bröckling. Berlin: Suhrkamp (2010), 11.

64 Foucault: [Von der Souveränität zur Disziplin], 12f. 
auch verschiedene Formen des Nichtstuns literarisch verarbeitet werden. ${ }^{65}$ Den Fußfesseln des polnischen Schriftstellerverbandes und der Doktrin des Sozialistischen Realismus entledigt begann man, "alles gesellschaftlich Etablierte in möglichst provozierender Weise in Frage zu stellen ${ }^{66}{ }^{6}$ Diese Infragestellung hatte zwei Effekte, die sich im Werk Mirosław Nahaczs, und besonders in Bombel niederschlagen: Zum ersten ist das Nichtstun, das im Rahmen sozrealistischer Erwartungen subversiv war und deshalb kaum thematisiert wurde, offen zur Darstellung gekommen und konstituiert damit ein neues literarisches Wissen. Andererseits zeigt die Erzählung der Figur Bombel die Existenz eines umfangreichen individuellen Wissens innerhalb des Nichtstun-Phänomens an - über die Geschichte des Dorfes, den persönlichen Blick auf europäische Politik und die Einschätzung der lokalen Regierung -, welches in den üblichen Institutionen, die Wissen organisieren, keinen Platz findet. Das Nichtstun als literarischer Topos in Nahaczs Bombel schafft also den Raum für eine Erzählung, die man sonst nicht hören würde, und im Ergebnis entbirgt es das »lokale, diskontinuierliche, disqualifizierte, nicht-legitimierte Wissen« des Erzählers. ${ }^{67}$

Wer den Roman genau liest, wer dem Sprechen des vermeintlich Verrückten lange genug zuhört, der wird auch - ebenso wie bei Lazarillo de Tormes, oder der Figur des sweisen Narren im Werk Bohumil Hrabals - ein desengaño beobachten können, eine »Entlarvung des gesellschaftlichen Scheins «. ${ }^{68}$ Mit dieser Aufdeckung artikuliert der Erzähler nicht nur eine aktive kritische Haltung, die ihm durch sein Nichtstun ermöglicht wird, sondern er vollzieht

65 Zum Beispiel etabliert sich eine schwule Literatur durch Werke wie Zakazana miłość von Tadeusz Gorgol (1990) oder Marcin Krzeszowiecs Ból istnienia (1992); die Romane Janusz Leon Wisniewskis und Anna Boleckas inszenieren eine explizite Erotik; Andrzej Stasiuk legte mit Mury Hebronu (1992) den Grundstein für ein introspektives Schreiben über die Kriminalität; Jerzy Pilchs Pod Mocnym Aniołem (2000) und Tomasz Piąteks Heroina (2002) brachten Sucht- und Rauschphänomene ins Zentrum der Aufmerksamkeit. Zudem schreibt sich seit einigen Jahren, in klarer Abgrenzung zum Sozrealismus, eine problematisierte Haltung gegenüber der Erwerbsarbeit im neuen Polen ein - die Werke Sławomir Shutys sind exemplarisch für diesen Trend. Für einen Überblick vgl. Lila Zarnowski: A simple question. An overview of new Polish literature. In: New Zealand Slavonic Journal 39, 2005, 121-138. Jochen-Ulrich Peters: Enttabuisierung und literarischer Funktionswandel. In: Enttabuisierung. Essays zur russischen und polnischen Gegenwartsliteratur. Hg. v. Dems. u.a. Bern: Peter Lang (1996), 11.

67 Foucault: [Von der Souveränität zur Disziplin], 15.

68 Rötzer: Der europäische Schelmenroman, $9 f$. 
durch sein künstlerisches Sprechen auch einen politischen Akt, eine - mit Jacques Rancière gesprochen - Neu-»Aufteilung des Sinnlichen «. ${ }^{69}$ Denn Bombel, der eigentlich der gesellschaftlichen Kategorie derer zugehört, »die man nicht sieht«, und "von denen es keinen Logos gibt«, tritt in diesem und durch diesen Roman heraus und gehört damit zu denen, »die wirklich sprechen «. ${ }^{70}$

\section{Arbeit, eine Lüge}

Im Roman Bombel wird ein desengaño, wie es dem Schelmenroman eigen ist, über den Topos der Untätigkeit und in Bezug auf die Arbeit vollzogen. Im Polen der frühen 2000er-Jahre wurde, im Einklang mit vielen westlichen Stimmen, der hohe gesellschaftliche Stellenwert der Arbeit kritisiert. Dies geschah zum Beispiel in der Künstlergruppe, die unter dem Namen »Generacja Nic« (Generation Nichts) bekannt geworden ist, und der auch Mirosław Nahacz zugerechnet wird. Die Gruppe übernahm als ihren Namen den Titel eines 2002 erschienenen Essays des Musikers Kuba Wandachowicz, der dort unter anderem auch gegen die Dominanz der Arbeit in der Lebensphilosophie der Polen polemisiert:

Problem bezrobocia, który stał się obecnie osią wszelkich niepokojów spotecznych, w zestawieniu ze społeczno-ekonomicznym boomem wczesnych lat 90. jawi się jako dodatkowy, jeżeli nie główny katalizator ogólnego rozprzężenia charakteryzującego pokolenie dzisiejszych dwudziesto- i trzydziestolatków. Jeżeli bowiem sytuacja rynku pracy przypomina $w$ istocie rzeczywistość postnuklearną, to niejako na mocy najpierwotniejszych praw »dżungli« oczywiste jest, że każdy z trudem zdobyty etat będzie broniony z ponoszeniem coraz to większych poświęceń[...]. [...] zarabianie pieniędzy to w naszych czasach niezwykle wielki przywilej! Wmawia się nam, że już sam fakt posiadania pracy powinien wystarczać za realizację największych życiowych aspiracji, i my się tak czujemy. ${ }^{71}$

Das Problem der Arbeitslosigkeit, welches zur Drehachse jeglicher gesellschaftlicher Unruhen wurde, im Vergleich zum sozial-ökonomischen Boom der frühen 9oer, erscheint als zusätzlicher, wenn nicht gar hauptsächlicher Katalysator der allgemeinen Entkopplung der Generation der heutigen

69 Jacques Rancière: Das Unvernehmen. Politik und Philosophie. Übers. v. Richard Steurer. Frankfurt a.M.: Suhrkamp (2002), 36.

70 Rancière: Das Unvernehmen, 34.

71 Kuba Wandachowicz: Generacja Nic. In: Gazeta Wyborcza, 05.09.2002. 
Zwanzig- und Dreißigjährigen. Wenn nämlich die Situation des Arbeitsmarktes wesentlich an eine postnukleare Realität erinnert, so ist es doch auf Grund der ursprünglichsten Gesetze des »Dschungels« offenbar, dass jede mit Mühe ergatterte Planstelle unter Inkaufnahme immer größerer Opfer verteidigt wird[...]. [...] Geldverdienen ist in unserer Zeit ein ungewöhnlich großes Privileg. Man redet uns ein, dass allein die Tatsache, dass wir eine Arbeit haben, hinreichen müsste als Verwirklichung der höchsten Bestrebungen im Leben, und wir fühlen uns [auch tatsächlich] so. (Übers. meine)

Wandachowicz lamentiert, dass durch den freien Markt auf der einen, und die Arbeitslosigkeit auf der anderen Seite, der Wert der Arbeit enorm angestiegen sei, was wiederum jegliche anderen Werte aus dem kulturellen Bewusstsein verdrängt hätte. Bombel knüpft an diese Kritik von Nahaczs Kollegen Wandachowicz an. Als Protagonist verschließt sich Bombel gegenüber den »Systemansprüchen«; als Erzähler entlarvt Bombel die Art und Weise, in der dominante polnische Ideologeme zu Unrecht mit einer Arbeitserwartung verschränkt sind, die ihn als Nichtstuer benachteiligt, und legt so Aussage zum »Zustand der Nation« ab. ${ }^{72}$ Er hinterfragt die Verschränkung in ihrer Notwendigkeit und stilisiert sie in Folge zur Lüge. Im Zentrum dieser Aufdeckungsstrategie stehen vor allem die katholische Kirche (1) und die postsozialistische Politik in Polen (2).

(1) Kirche: Für den polnischen Katholizismus hat die Arbeit einen besonders hohen Stellenwert, der in der Amtszeit des Papstes Jan Paweł II in seiner dritten Enzyklika Laborem exercens (1981) Ausdruck gefunden hat. Darin wird die Arbeit als Kerndimension im Leben des religiösen Menschen dargestellt. Die im Kapitel »Zwiastowanie« dargestellte Marienerscheinung vermittelt eben dieses Bild. Maria, die dem volltrunkenen Bombel erscheint, fordert ihn dazu auf, seinen Rausch auszuschlafen, um am nächsten Tag arbeiten zu können:

A Ona mi powiedziała, że to nie tak, żebym nie bił się w piersi, tylko położył na łóżku, bo najważniejsze wstać i wydoić wszystkie krowy, i nawrzucać im siana, i w ogóle zrobić ze wszystkim porządek, włączając w to siebie. (B 19f.)

Sie sagte, so wär das ja gar nicht, ich soll mir nicht an die Brust schlagen, 
sondern mich ins Bett legen, denn das Wichtigste ist, daß ich schlafen gehe und zu Kräften komme, damit ich morgen so früh wie möglich aufstehen und die Kühe melken kann, ihnen Heu geben und überhaupt alles in Ordnung bringen, einschließlich mich selber. (24)

Indem Maria Bombel dazu auffordert, sich auszuruhen, damit er am nächsten Tag »die Kühe melken« und »überhaupt alles in Ordnung bringen« kann, übernimmt sie die zwei Funktionen, die ihr durch die polnische Verehrungsgeschichte überantwortet werden: Als Heerführerin »Hetmanka« (als die sie 1655 in der Schlacht bei Chęstochowa den Polen zum Sieg über die protestantischen Schweden verhalf) ${ }^{73}$ motiviert und ermutigt sie; als Frau und insbesondere als Mutterfigur repräsentiert und fordert sie Arbeitsamkeit. ${ }^{74}$

Doch im Roman wird die normative Kraft dieses religiösen Wertes herabgesetzt: Nachdem Bombel Marias Aufforderung zunächst Folge leistet und sich um seine Wirtschaft kümmert (»mam gospodarkę na głowie«, B 20), ${ }^{75}$ vollzieht er eine blasphemische Kehrtwende. Er verkauft sein gesamtes Vieh, zieht seinen besten Anzug an - falls Maria ihn nochmal besuchen kommt und betrinkt sich mit der Begründung, dem Pfarrer wäre Wein ja ebenfalls erlaubt: "pomyślałem, że jak ksiądz pije wino, to jak ja się trochę napiję, nie będzie grzechu« (B 21). ${ }^{76}$ Durch die Auflösung der Wirtschaft wird die religiöse Arbeitsaufforderung aktiv negiert, und im gleichen Zug die Institution der Kirche (die Alkoholismus verurteilt, aber Pfarrern Wein erlaubt) als heuchlerisch denunziert. Auch die von der Kirche oktroyierte Koppelung von Religiosität und Arbeit stellt Bombel damit in Frage. Aus seiner Erzählung geht hervor, dass er an Gott glaubt, doch dieser Glaube existiert unabhängig von seiner Arbeitsleistung, und damit auch von der Institution der Kirche. Deshalb trägt er seinen Sonntagsanzug auch nicht für den Kirchgang, sondern, um Maria zu imponieren. Das von der Kirche vorgeschriebene Tätig-

Auch Bombel bemerkt eine Wunde im Gesicht der Jungfrau, deren Ursprung er in eben der Schlacht bei Chęstochowa festlegt (B17). Für die ausgezeichnete Aufarbeitung dieser Verehrungsgeschichte vgl. Brian Porter: Hetmanka and Mother: Representing the Virgin Mary in Modern Poland. In: Contemporary European History 14 (2), 2005, 151-170. Papst Jan Paweł II brachte dies prägnant zum Ausdruck: »In the light of Mary, the Church sees in the face of women [...] limitless fidelity and tireless devotion to work«. Zit. n. Stephen Benko: The Virgin Goddess. Studies in Pagan and Christian Roots of Mariology. Leiden: Brill (1993), 227. Herv. meine.

75 Wörtlich: »ich bin für die Wirtschaft verantwortlich«(Übers. meine).

76 »[I]ch dachte mir, wenn der Pfarrer Wein trinkt, dann kann das keine Sünde sein, wenn ich ein Schlückchen trinke« (25). 
keitsmodell - viel Arbeit, wenig Hedonismus - funktioniert für ihn nur mit vertauschten Vorzeichen. Das daraus resultierende `Zuwenig` an Arbeit (um davon zu leben) und `Zuviek an Hedonismus (um zu überleben) führt letztlich zu Bombels Tod, den er allerdings der kirchlichen Heteronomie vorzieht.

(2) Politik: Die an der Kirche geübte Kritik wiederholt sich auch in Bezug auf die polnische Politik dort, wo diese Arbeit (vermeintlich) unnötig aufwertet. Im ideologischen Wechsel 1989 hat sich der polnische Blick auf die Arbeit in mehrfacher Hinsicht geändert. War im Realsozialismus Arbeit einerseits ein gewöhnlicher und systemischer Teil des Lebens, so avanciert sie in den 1990er-Jahren zum Topos individueller Selbstverwirklichung. ${ }^{77}$ Andererseits war die Arbeit bis 1989 eine nationale Frage gewesen, doch seit dem Beginn der EU-Beitrittsverhandlungen war sie in den Fokus internationalen Interesses gerückt, insbesondere, da eine der Auflagen die Senkung der Landarbeitslosigkeit darstellte. ${ }^{78}$ Vor diesem Hintergrund schafft Nahaczs Roman mit seiner Hervorhebung der Arbeitslosigkeit und Untätigkeit einen scharfen Kontrast zu dem Ideal, das in Polen angestrebt wurde. In seiner Erzählung verweist die arbeitslose Figur Bombel mehrmals auf diesen Europa-Diskurs, und impliziert, dass das Ideal eines arbeitsamen Polens die Realität der anhaltenden Landarbeitslosigkeit nicht nur verdrängen, sondern vertuschen soll. Das zeigt sich an der Episode mit dem Gerichtsvollzieher, der aufgrund ausgebliebener Alimente Bombels Nutztiere pfänden will. Weil Bombel die Tiere verkauft (und den Erlös vertrunken) hat, gibt er vor, niemals solche Tiere gehabt zu haben, woraufhin ihm der Gerichtsvollzieher vorwirft, kein >ordentlicher Bauer zu sein - obwohl er ihm die Grundlage für das landwirtschaftliche Arbeiten in jedem Fall entzogen hätte. Diese Ironie knüpft an einen Diskurs an, der im Sozialismus bereits in den 1980er-Jahren Konjunktur hatte: Die Vorstellung, dass man in Polen auch ohne die Abdeckung der Grundbedürfnisse volle Arbeitsleistung bringen könne - und eine darüber entrüstete Bevölkerung. ${ }^{79}$ Arbeit wird so als ein unrealistisches Ideal dargestellt, was

77 Für die Haltungsveränderungen der Polen gegenüber der Arbeit vgl. Martyna Śliwa: Is Poland a Country of Roman Catholic Work Ethics? In: Journal of Management, Spirituality \& Religion 4 (4), 2007, 499.

$78 \mathrm{Vgl}$. hierzu den vorhergehenden Abschnitt in diesem Kapitel.

79 Vgl. zum Beispiel Krauzes Karikaturen aus den 1970er-Jahren, in denen u.a. die Rationierung von Lebensmitteln kritisiert wird, die mit der Erwartung, damit könne ganztags harte, körperliche Arbeit verrichtet werden, unvereinbar ist. Andrzej Krauze: Lubta mnie. Wybór rysunków z lat 1976-78. Warschau: Czytelnik (1980), 74. 
weiterhin durch die absurde Idee bekräftigt wird, ein Bauer sollte eigentlich im Anzug Traktor fahren, weil das noch besser aussähe:

On mi nie uwierzył i się wkurwił, bo powiedział, że z władzy kpić nie można. I że nie można się tak zachowywać, bo rolnik powinien być ucywilizowany, bo idziemy do Unii Europejskiej, a tam rolnicy jeżdżą traktorami w garniturach. Ja mu na to, że traktora nie mam, więc mimo najszczerszych chęci nic z tego, ale mógł przyjść przedwczoraj, bo też chodziłem w garniturze po ojcu, Panie świeć nad jego duszą [...]. (B 22)

Er hat mir nicht geglaubt und ist stinksauer geworden, weil man sich über die Behörden nicht lustig macht, hat er gesagt. Und daß man sich so nicht benimmt, daß der Bauer sich zivilisiert benehmen muß, weil wir in die EU eintreten, und da fahren die Bauern im Anzug Traktor. Darauf ich, ich hätte keinen Traktor, das geht also beim besten Willen nicht, aber wenn er vorgestern gekommen wäre, hätte ich den Anzug von meinem Vater angehabt, Gott hab ihn selig [...]. (26f.)

Die im Passus (im Rahmen von Bombels Nacherzählung) formulierte Hyperbel des im Anzug arbeitenden Bauern zeigt eine Engführung der landwirtschaftlichen Arbeit mit dem Topos des Kostümierens. In Bombels Wahrnehmung ist der Gerichtsvollzieher, der den Staat repräsentiert, mehr darauf bedacht, Arbeit zu inszenieren als sie tatsächlich zu ermöglichen. Durch seine sarkastische Bereitschaft, zumindest die Kostümierung leisten zu können, zeigt er - der ja ohne Arbeit ist -, dass das Kostüm gerade nicht zur Arbeitsausstattung gehört. Was dabei zum Ausdruck kommt, ist keine Kritik an der Arbeit an sich, sondern an der Politik, die sie dazu benutzen will, die Schwachstellen in Polens Reformplan zu kaschieren. Obwohl zur Figur des arbeitslosen Bauern in dieser Zeit eine anti-europäische Einstellung passen würde, ${ }^{80}$ ist Bombels Habitus kein europafeindlicher, sondern ein ganz

80 Wie zuvor schon kurz angedeutet wurde, ist der seit 1989 stattfindende Prozess des Übergangs in eine demokratische Zivilgesellschaft und hin zu einem freien Markt in urbanen Cebieten besser gelungen als auf dem Land. Vgl. Izabella Bukraba-Rylska: Polish Countryside in Times of Transition. Myths and Reality. In: Polish Sociological Review $168,2009,575$. Neben zahlreichen positiven Effekten hat der Balcerowicz-Plan, der den Übergang in eine kapitalistische Marktwirtschaft regelte, in den 1990er-Jahren einen Anstieg der Arbeitslosenquote auf $20 \%$ ausgelöst, da viele der staatlichen Agrarwirtschaftsbetriebe geschlossen wurden. Vgl. Władysław Kwaśniewicz: Between a PostFeudal and a Post-Industrial Model. Polish Society in the 2oth Century. In: Polish Soci- 
allgemein veränderungsunwilliger, der die Transformationslust seines Landes über den Gegensatz Arbeit/Nicht-Arbeit kritisiert. Die Fähigkeit, trotz und gerade wegen seiner Außenseiterposition als Arbeitsloser Systemkritik zu üben, verweist erneut auf die Verwandtschaft mit der Gattung des Schelmenromans. Während der pícaro im Lazarillo de Tormes die Machtgier des Klerus aufdeckt, stilisiert Bombel die Politik zu einer äußerlich auf Arbeit bedachten Anpassungsmaschinerie.

\section{Fortschrittsillusion}

Neben der Kritik an mit Arbeit verschränkten Ideologemen des zeitgenössischen Polens stellt der Erzähler Bombel durch sein Nichtstun auch noch einen anderen, im Westen weit verbreiteten Glauben in Frage: den des Fortschritts. Für diese Kritik wird das Motiv der Bewegungslosigkeit Bombels funktionalisiert: Die Tatsache, dass sich der Protagonist über 151 Textseiten nicht von der Stelle bewegt, obwohl er sich an einer Bushaltestelle befindet, steht einerseits symbolhaft für die oben erwähnte allgemeine Stagnation, die dem polnischen Dorf vorgeworfen wird, und andererseits für den nach dem Regimewechsel ausgebliebenen Fortschritt, der doch vermeintlich mit dem Kapitalismus einhergehen soll. Analog dazu stellt der Erzähler fest, dass im Bereich rund um die Bushaltestelle die Zeit stehen geblieben ist. Bombel, der sich über die anhaltende Ereignislosigkeit wundert, vergleicht die Haltestelle mit einer Maschine, die nicht mehr weiterlaufen kann, weil in ihr das Öl eingefroren ist. Dieses Sinnbild bringt gleichermaßen Bombels Nutzlosigkeit und einen zeitlichen Stillstand zum Ausdruck, und suggeriert so eine korrelative Beziehung zwischen ihnen:

wtedy można się znajdować ciągle w tym samym miejscu, wskazówka może i niby pokazuje, że idzie, że pcha dalej swoją siłą wszystko dookoła, ale takie ręczne zegarki ruszają tylko gdzieś tak na kilka metrów kwadratowych, niby wokoło się coś dzieje, można liczyć sekundy, ale ciągle jest to samo, słońce w tym

ological Review 144, 2003, 395. Die dadurch befeuerten fremdenfeindlichen Ressentiments waren um die Jahrhundertwende gerade auf dem Land besonders stark: »[S]eit den Parlamentswahlen vom Herbst 2001 stellen die EU-feindlichen politischen Kräfte [...] eine feste Größe im Sejm dar. [...] [D]ie Quelle[...] der EU-kritischen Kräfte in Polen [...] [ist] der Ärger über die ungleiche Förderung der Landwirtschaft in alten und neuen EU-Staaten und die Angst vor einem weiteren Niedergang des ländlichen Raumes«. Andrea Gawrich: Vor dem Referendum in Polen. In: Internationale Politik 1 (Januar), 2003, $19 f$. 
samym miejscu i chmury też. Że dzień nie ma zamiaru stać się nocą. (B 125, Herv. meine)

dann kann es sein, daß man sich immer am gleichen Ort befindet, der Zeiger zeigt zwar scheinbar, daß er geht, daß er mit seiner Kraft alles ringsum weiterschiebt, aber diese Armbanduhren bewegen sich nur auf einigen Quadratmetern, scheinbar geschieht etwas ringsum, man kann die Sekunden zählen, aber es ist immer das gleiche, die Sonne an der gleichen Stelle und die Wolken auch. Der Tag hat nicht die Absicht, zur Nacht zu werden. (137f., Herv. meine)

Die Idee einer unendlich verfließenden Zeit kann in diesem Kontext verschieden interpretiert werden: Einerseits liegt darin ein Vorwurf des fortschrittlich orientierten Polens an die veränderungsunwillige Landbevölkerung, und schließt so an die oben beschriebene Dynamik an. Andererseits evoziert das Bild des zeitlichen Stillstands eine motivische Verbindung zum Posthistoire, d.h. dem Denken einer Zeit, in der sich der Fortschritt überschlagen hat und deshalb zum Stillstand gekommen ist. So ist im vorangegangenen Abschnitt des Romans die Rede von einer eingefrorenen, kristallisierten Zeit - "czas wokół przystanku jest teraz kryształem « (B 124, Herv. meine $)^{81}$-, was ein Echo der Metapher Arnold Gehlens ist, der das Posthistoire als »kulturelle Kristallisation« bezeichnet. ${ }^{82}$ Dabei klingt weniger das von Gehlen formulierte (Problem-)Bewusstsein einer allgemeinen modernen Handlungsblockade an (die sich aus einer Verfestigung verschiedener operativer Systeme wie Bürokratie und Wissenschaft ergibt) ${ }^{83}$ als vielmehr eine Skepsis gegenüber dem geschichtsphilosophischen Wechsel von einer sozialistischen Utopie hin zum Glauben an einen durch den liberalen Kapitalismus angetriebenen Fortschritt.

$81 》[$ D]ie Zeit um die Haltestelle herum [ist] jetzt ein Kristall« (136, Herv. meine).

82 Cehlen: Über kulturelle Kristallisation, 312.

83 Cehlen erklärt die nunmehr erreichte Unveränderlichkeit der zivilisierten Cesellschaft durch einen nicht verwertbaren Informationsüberfluss. Dem Individuum sei zwar nicht die Möglichkeit zum Handeln überhaupt genommen, doch die Vorherbestimmtheit aller Handlungsziele und Problemfolgen habe eine lähmende Wirkung auf den Menschen. Vgl. Arnold Gehlen: Ende der Ceschichte? In: Ders.: Gesamtausgabe. Bd 6. Die Seele im technischen Zeitalter und andere sozialpsychologische, soziologische und kulturanalytische Schriften. Frankfurt a.M.: Klostermann (2004), 350. 
Eine solche skeptische Haltung charakterisiert wiederum auch die Werke der »Generacja Nic«. Kuba Wandachowicz bringt seine Zweifel an der Effektivität des ideologischen Wechsels zum Ausdruck: »Wir dachten, dass die Realität des neuen Polen uns 20-jährigen erlauben würde, eine irgendwie spektakuläre Existenz zu beginnen. Wir haben uns sehr geirrt« schreibt er, und verweist ebenfalls wiederholt auf die intellektuelle und seelische Leere des Kapitalismus. ${ }^{84}$ In diesem Sinne thematisiert auch die junge polnische Prosa der folgenden Jahre die Tatsache, dass es keine serfolgreiche «Adaption an die post-sozialistische Wirklichkeit « geben könne, ${ }^{85}$ weil ihr zufolge deren Prämissen - Freiheit und Fortschritt - nur hohle Schlagwörter seien. ${ }^{86}$

Der Roman Nahaczs bringt diese Kritik mit der polnischen (Literatur-)Geschichte in Verbindung. Das Setting der Bushaltestelle, in der die Zeit stehen geblieben ist, zitiert implizit das Werk Marek Hłaskos. Hłasko beschreibt das in staatlich kontrollierten Bahnen verlaufende Leben der Arbeiterklasse während der Tauwetterperiode, welche auf Veränderung hofft, die sich allerdings nie einstellt. Zur Darstellung dieser Hoffnungslosigkeit wird ebenfalls der Topos des Wartens an einer Haltestelle funktionalisiert, wie im folgenden Kneipengespräch aus Ósmy dzień tygodnia (Der achte Tag der Woche, 1957) geschildert wird:

Hast du dir manchmal Gedanken darüber gemacht, wie Polen aussieht? [...] So ein Lackel [Tölpel] in einer Tennismontur für 600 Zloty [sic!]. Ein bißchen beschwipst. In einem riesengroßen Wartesaal. Ohne Fahrplan. Um das Bild komplett zu machen, könnte er in der linken Hand den Königsgeist halten [mystisch-philosophisches Werk des romantischen Dichters Juliusz Słowacki]. Und in der rechten - nur wegen des Cleichgewichts - eine Flasche. Sehr blöd? ${ }^{87}$

84 »Myśleliśmy, że rzeczywistość nowej Polski pozwoli nam 20-latkom jakoś spektakularnie zaistnieć. Myliliśmy się bardzo.«Wandachowicz: Ceneracja Nic. Übers. meine.

85 Matthias Schwartz: Karrieren des Scheiterns. Verweigerungsgesten in junger polnischer Cegenwartsliteratur. In: Die Welt der Slaven 58, 2013, 155.

86 Wandachowicz äußert sich wie folgt: „Wolność w naszych czasach zaczęła oznaczać intelektualną pustkę ludzi młodych, którzy nie chcą uczestniczyć w żadnym dyskursie - społecznym, politycznym czy jakimkolwiek innym. « Wandachowicz: Generacja Nic. Dt.: »In unseren Zeiten erhielt Freiheit die Bedeutung intellektueller Leere bei jungen Menschen, die an keinem Diskurs teilnehmen wollen - ob gesellschaftlich, politisch, oder irgendwie anders. « Übers. meine.

87 Marek Hłasko: Der achte Tag der Woche. Übers. v. Vera Cerny. München: DTV (1962), 68. 
Nahaczs Roman transportiert diese vermeintlich genuin polnische Stimmung in die frühen 2000er-Jahre, in denen individuelle Selbstverwirklichung und neue Zukunftsperspektiven zwar möglich sein sollen, es aber tatsächlich nicht sind. Es gibt eine teure »Tennismontur für 600 Zloty«, die vielversprechend ist, doch man sitzt letztlich doch in einem »riesengroßen Wartesaal«, »[o]hne Fahrplan«, und wartet, anstatt Tennis zu spielen. Für all die Menschen, die unter den veränderten Bedingungen keine Arbeit finden können, dauert die staatliche Abhängigkeit in neuer Form an - das politische System ist ein anderes, das Problem bleibt gleich. In Analogie zu Hłaskos Metapher des Wartesaals beherbergt in Bombel die Bushaltestelle den Wartenden, der - in Anlehnung an Juliusz Słowackis mystisches Theorem der kontinuierlichen materiellen Progressivität - ebenso hoffnungslos auf fortschrittliche Veränderung hofft wie der Sozialist auf den Kommunismus. Im Vergleich dieser beiden fiktionalen Situationen zeigt sich eine bittere Ironie: So wie der Alkohol in Hłaskos Darstellung (die Flasche) als illusionsbildende Substanz fungiert, die dem unwahrscheinlichen Glauben auf Veränderung Nahrung gibt, so soll er auch in Nahaczs Text über die Enttäuschung des Ideologiewechsels 1989 hinweghelfen. Doch da Bombel aufgrund seines Nichtstuns mittellos ist, liegt die Verdrängung durch einen Rausch außerhalb seiner finanziellen Möglichkeiten. So bleibt auch die illusionsbildende Wirkung aus - und der Kapitalismus erscheint vielleicht noch aussichtsloser, als es der reale Sozialismus war.

Der paradoxe Topos der Bushaltestelle, von der man nicht wegkommt, suggeriert somit den möglichen Illusionscharakter des Fortschrittsdenkens »scheinbar geschieht etwas ringsum, [...] aber es ist immer das gleiche« (137f., Herv. meine) -, der auch die Untätigkeit des Individuums in ein neues Licht rückt. Bombel unterlässt es nicht etwa, sich zu bewegen und weiterzuentwickeln (z.B. indem er in den Bus einsteigt) - ihm fehlt überhaupt erst die Möglichkeit dazu (da gar kein Bus kommt). Ebenso verhält es sich mit der Untätigkeit auf dem Dorf im Ganzen: das Herumlungern an der Bushaltestelle bezeichnet eben nicht die Verweigerung einer Teilhabe am gesellschaftlichen Fortschritt. Es zeigt vielmehr den praktischen Umgang mit der Tatsache, dass den Bewohnern ländlicher Gegenden die Vorteile des vermeintlich sich bereits im Gange befindlichen Fortschritts (Reisen, Vergnügungsstätten, benutzbarer öffentlicher Raum) unzugänglich bleiben. Auch hier zeigt sich, dass die Figur des Nichtstuers, dem Prototypen des picaro gleich, trotz und gerade wegen ihrer Außenseiterposition einen Fehler im System entdeckt. Als derjenige, der sich nicht bewegt, verweist der Nichtstuer darauf, dass sich auch 
in der dominanten Anwesenheit des Fortschrittsglaubens nicht alles bewegt, und schon gar nicht nach >Vorneく.

\section{Biopolitik vs. Organische Gemeinschaft}

Das vorhergehende Unterkapitel hat gezeigt, dass Bombels Erzählen als eine Praxis des Nichtstuns eine kritische Funktion erfüllt, und damit andere vermeintliche Unzulänglichkeiten kompensiert. In dem vorliegenden Unterkapitel wird dieses Argument ausgeweitet: wo zuvor Bombels Kritik an der Idealisierung der Arbeit und des Fortschritts analysiert wurde, wird hier nun Bombels Kritik an der Politik beschrieben, die Nichtstuer wie ihn ausschließen und aus dem Bereich des Sichtbaren entfernen will. Außerdem wird gezeigt, dass Bombel einen Gegenentwurf zu dieser Politik vorstellt: Eine Gemeinschaft der Nichtstuer.

Um diese Kritik und die alternative Politik nachzuvollziehen, ist es wichtig, festzustellen, dass der Roman mit zwei unterschiedlichen NichtstunIsotopien arbeitet, die in einem agonalen Verhältnis zueinander stehen: Die eine Isotopie setzt das Primat der >Arbeit und des Fortschritts und bewertet das Nichtstun negativ. Dies ist im Roman stets die Meinung der >Anderen und entspricht implizit dem diegetisch als stärker wahrgenommenen Diskurs. Die zweite, für den Charakter Bombel bedeutsamere Isotopie ist ein positiv konnotiertes Nichtstun, das mit keiner Institution assoziiert (d.h. machtlos) ist, dafür aber eine sechte Gemeinschaft bezeichnet. In seinem Erzählen inszeniert Bombel den Konflikt zwischen diesen beiden Isotopien und ihren Agenten. Die unterschiedlichen Einschätzungen des Nichtstuns und der Probleme, die sich bei ihrem Aufeinandertreffen ergeben - sind mit verschiedenen politischen Modellen verbunden. Die Politik, die das Nichtstun strikt ablehnt, wird als aggressive, biopolitische Maschine dargestellt, ${ }^{88}$ als die »Organisation der Mächte«, die Jacques Rancière »Polizei« nennt (mehr dazu später), ${ }^{89}$ während diejenige, die sie affirmiert, als romantische und organische Gemeinschaft figuriert (wie im letzten Abschnitt dieses Kapitels ausgeführt wird).

88 Mit dem von Michel Foucault entwickelten Begriff der Biopolitik ist, in den konzisen Worten Ciorgio Agambens, die »wachsende Einbeziehung des natürlichen Lebens des Menschen in die Mechanismen und das Kalkül der Macht«gemeint. Agamben: Homo sacer, 127.

89 Rancière: Das Unvernehmen, 39, 40. 
Bombel vollzieht in seinem Erzählen dieses agonale Verhältnis. Im folgenden Passus stellt er die ihm zufolge im Sozialismus etablierte, lockere Einstellung zur Arbeit und eine angespannte, kapitalistische Obsession mit der Arbeit nebeneinander. Er identifiziert hier nochmals die zeitgenössische gesellschaftliche Fokussierung auf die Arbeit, der scherzhafte Ton vom Beginn des Romans weicht allerdings einer aggressiven Sprache:

wszyscy mieli pracę, pieniądze były, każdy miał swoje miejsce na świecie, każdy był potrzebny państwu, nie takjak teraz, że zdychajcie, a co nas, kurwa, obchodzicie, jak nic nie umiecie [sic!], [...] na wino jakoś macie, a na jedzenie nie starcza, do roboty, pedały, jest dla każdego, tylko musicie ruszyć swoje przyrośnięte dupy do miasta do urzędu, [...] na wino macie, a na bilety autobusowe nie macie, najlepiej siedzieć a narzekać, czekać, aż ktoś wam da za darmo! (B 8of.)

[als] alle Arbeit hatten und Celd da war; jeder hatte seinen Platz in der Welt, und der Staat brauchte jeden, nicht wie jetzt: Verreckt doch alle, was geht uns das an, wenn ihr nichts könnt, [...] für Wein habt ihr immer Geld, aber für Essen nicht, an die Arbeit, ihr schwulen Schweine, es reicht für alle, aber ihr müßt euren festgewachsenen Arsch hochkriegen, in die Stadt, zum Amt, [...] für Wein reicht's, aber für Busfahrkarten nicht, am liebsten sitzt ihr da und jammert und wartet, bis euch jemand was umsonst gibt! (90)

Konkret das Problem der Landarbeitslosigkeit und der Spaltung zwischen Arbeitnehmer und Sozialhilfeempfänger thematisierend, imitiert Bombel in seinem Sprechen zwei unterschiedliche politische Positionen. Im ersten Teil dieses Zitats summiert der Erzähler die nostalgischen Erinnerungen der arbeitslosen Dorfbewohner an den Sozialismus: alle hätten Arbeit und Geld gehabt, »jeder hatte seinen Platz in der Welt, und der Staat brauchte jeden«. Diese Harmonie wird im zweiten Teil des Zitats von einem beunruhigenden Bild abgelöst. Dort imaginiert Bombel den Staat als zurechtweisend sprechende Person, ${ }^{90}$ deren Aggression er in seinem Erzählen abbildet. Bis »teraz« (»jetzt«) spricht Bombel direkt aus der Position des Dorfbewohners, danach beginnt ein an die Dorfbewohner gerichtetes Sprechen. Der Umstand, dass der Wechsel von der einen in die andere Perspektive im Original nicht

90 Zum Thema eines Politischen Imaginären vgl. Albrecht Koschorke u.a. (Hgs.): Der fiktive Staat. Konstruktionen des politischen Körpers in der Ceschichte Europas. Frankfurt a.M.: Fischer (2007), 10f. 
angezeigt wird (im Deutschen wird er durch den Doppelpunkt markiert), zeigt die von Bombel empfundene Diskrepanz dieser beiden Inhalte - d.h. zwischen Vergangenheit und Gegenwart, und zwischen dem Arbeitslosen und der Polizei -, zwischen denen es keine vermittelnde Instanz gibt.

Diese Diskrepanz ist auch sprachlich realisiert: in den ersten anderthalb Zeilen des zitierten Passus findet sich eine grammatisch korrekte Aufzählung, die ohne Flüche auskommt und in der der romantische Gedanke an eine vergangene Welt entwickelt wird, in der das Leben vermeintlich besser und man mit der Welt auf eine ursprüngliche Weise verankert war. ${ }^{91}$ Dieser Modus wird jäh mit dem Imperativ »zdychajcie« (»verreckt«, ohne Ausrufungszeichen) abgebrochen, und durch eine mit Schimpfworten gespickte Verurteilung des Bombel'schen Lebensstils (trinken, aber nicht arbeiten) fortgeführt. Durch diese sprachlich sehr pointierte Zäsur wird die als aggressiv empfundene Haltung des Staates (in Gestalt eines sicherlich sehr realen Staatsdieners) gegenüber dem Schicksal der Nichtstuer (d.h. der Unangepassten) zum Ausdruck gebracht. Bombel kritisiert, indem er das zitiert, was er selbst von dieser Instanz zu hören bekommen hat und was ihm von anderen zugetragen wurde; er kritisiert, indem er wiedergibt, Zeugnis ablegt. Die Verwendung von Vulgärsprache ist dabei besonders relevant. Sie wurde in der polnischen Literatur der 1990er und 2000er-Jahre häufig als Zeichen einer Überwindung sprachlicher Tabus im postsozialistischen Polen gelesen, ${ }^{92}$ doch in Bombels Fall drückt sie keine positiv konnotierte Freiheit von Systemzwängen aus. In Bombel wird diese sprachliche Zwanglosigkeit gegen den Staat gerichtet, der an Stelle der alten Zwänge neue eingerichtet hat, unter denen AußenseiterFiguren mehr leiden als zuvor. Dass Bombels Sprache nicht prinzipiell vulgär ist, sondern Vulgarität als kritisches Mittel einsetzt, erkennt man daran, dass sie vornehmlich in Momenten des Ärgers und Schmerzes eingesetzt wird und immer dann, wenn es um die offizielle Politik, die Polizei im Sinne Jacques Rancières geht. Seine Empfindung von gemeinschaftlichen und schönen Dingen hingegen wird durch einen zarteren, sogar liebevollen Ausdruck vermittelt.

91 Die nostalgisch anmutende Feststellung, früher hätten alle Arbeit gehabt, ist nicht als Aufwertung der Arbeit selbst zu verstehen. Sie dient nur als Referenzpunkt einer Zeit, in der Arbeit kein fetischisierter Aspekt des kapitalistischen Marktes war, sondern ein normaler, vergleichsweise unproblematisierter Teil des Lebens.

92 Vgl. Małgorzata Warchoł-Schlottmann: Polnische Sprache nach der Wende 1989. Frankfurt a.M.: Peter Lang (2009), 112-115. 
Diese beiden Positionen werden im Folgenden näher im Hinblick auf ihre Politiken beleuchtet. Der negative Eindruck von der Polizei, die sich im aggressiven Verhältnis der biopolitischen Politik zum Körper des Nichtstuers Bombel ausdrückt, wird einer positiven, durch das Nichtstun sich neu konstituierenden politischen Gemeinschaft gegenübergestellt.

\section{Kontrolle des inaktiven Körpers}

Bombels Kritik an der Politik bzw. der Polizei wird über Körperlichkeit kommuniziert. Zu diesem Zweck wird der Körper doppelt als Zeichen funktionalisiert: Zum einen beschreibt Bombel seinen Körper als ein Objekt, mit dem biopolitisch verfahren, und der als eine Art gesellschaftlicher Fremdkörper behandelt wird (1). Zum anderen wird das Politische im Ganzen über eine Körper-Metapher, die an Bombel selbst realisiert wird, gespiegelt und kommentiert. In anderen Worten: Der Zustand der Politik wird mit dem Zustand gleichsetzt, in dem sich Bombels Körper befindet (2).

(1) Der Erzähler artikuliert seine Skepsis gegenüber der bestehenden Politik im Allgemeinen, weil ihre biopolitischen Praktiken mit dem Wohlbefinden seines nichtstuenden Körpers kollidieren. Als inaktive Figur fühlt sich Bombel der Macht politischer Institutionen (das sind in seiner Vorstellung nur mehr abstrakte Vorstellungen und bezeichnen alles von lokalen Behörden bis zu internationalen Bündnissen) körperlich ausgeliefert. Dieser Aspekt wird in der folgenden Passage sehr deutlich, die anhand der Marginalisierung des Nichtstuns auch grundsätzlich die Funktionsweise der Politik infragestellt:

Bo już mam niemal pewność, że wczoraj, jak spałem w dzień, to jeździł wóz z sanepidu z zamontowanym głośnikiem na pace, i puszczali najpierw dyskotekowe rytmy, żeby ludzie słuchali, a potem nagle przerywali muzyczną imprezę i włączali gościa, co czyta z kartki i ani razu sie nię myli, że jutro od rana zabrania się chodzenia po wsi, bo prowadzone są obowiązkowe natryskiwania gleb z powodu osiedlających się wszędzie zarazków wścieklizny, które roznoszą lisy z lasu poprzez gryzienie naszych domowych psów, i od tego nasze dzieci się mogą wściec, płakać na widok wody i gryźć niczego niepodejrzewających rodziców. I ta bakteria jest rozniesiona na wszystkich wiejskich powierzchniach, i można się jej pozbyć tylko za sprawą obecnego wójta, który dziękując za poparcie udzielone w wyborach, wezwał sanepid, który będzie opryskiwał gratis te zaraski, żeby je pozabijać na miejscu, a opryskiwanie będzie szkodliwe i może śmiertelne dla żywych ludzi, nawet w ubraniach, bo ten środek przeżre każdą wełnę i wniknie do skóry, powo- 
dując paraliż górnych dróg oddechowych i w rezultacie śmierć w drgawkach i kałuży krwi. A rejony najbardziej narażone na skażenie to między innymi przystanek autobusowy, gzie poziom zarazków jest o dwadzieścia osiem i pół raza wyższy od europejskich standardów[...]. No i na pewno tak tam mówili i mnie czeka śmierć od tych natrysków, już nawet czuję w sobie te anomalia, jak we mnie drążą i się wwiercają, jak kłóci się wszystko we mnie, żołądek ze śledzioną, jak prawe płuco razem z lewym wspólnie napadają z bronią w ręku na serce[...]. (B 118f.)

Denn ich bin mir fast sicher, daß gestern, als ich tagsüber schlief, ein Wagen vom Gesundheitsamt mit einem Lautsprecher auf dem Kasten vorbeifuhr; zuerst spielten sie Diskorhythmen damit die Leute zuhören, und dann unterbrachen sie die Musikveranstaltung plötzlich und brachten einen Typ, der vom Blatt liest und sich kein einziges Mal vertut, daß es morgen von früh an verboten ist, durchs Dorf zu gehen, weil ordnungsgemäß der Boden gespritzt wird, aufgrund der ausgedehnten Ansiedlung von Tollwuterregern, die von kranken Füchsen aus dem Wald verbreitet werden, indem sie unsere Haushunde beißen, und davon können unsere Kinder wütend werden, beim Anblick von Wasser weinen und ihre nichtsahnenden Eltern beißen. Diese Bakterien sind auf allen Flächen des Dorfes verbreitet, und man kann sie nur mit Hilfe des amtierenden Bürgermeisters loswerden, der als Dank für die Unterstützung bei den Wahlen das Gesundheitsamt geschickt hat, das gratis diese Erreger besprühen wird, um sie an Ort und Stelle zu töten, und das Sprühen ist für Menschen schädlich oder sogar tödlich, sogar in Kleidern, denn dieses Mittel frißt jede Wolle durch, dringt in die Haut ein und bewirkt eine Lähmung der oberen Atemwege und im Endeffekt den Tod unter Krämpfen und in einer Blutlache. Und zu den am meisten verseuchten Gebieten gehört unter anderem die Haltestelle, wo das Niveau der Erreger um 28,5 mal höher ist als im europäischen Durchschnitt[...]. Das haben sie ganz deutlich gesagt, und mich erwartet jetzt der Tod durch dieses Sprühzeug, ich spüre die Anomalie sogar schon in mir, wie sie bohrt und sich hineinfrißt, wie alles in mir sich streitet, der Magen mit der Milz, wie die linke und die rechte Lunge mit der Waffe in der Hand zusammen über das Herz herfallen[...]. (130f.)

Dieser Monolog wird von Bombel selbst als möglicher Traum (»spałem w dzień«) oder Wahn markiert, kann deshalb vielleicht nicht als Bericht einer wahren Begebenheit, aber dennoch - und vielleicht gerade deshalb - als Aus- 
druck eines genuinen Gefühls gelesen werden. Bombel fühlt sich hier als Subjekt, das aufgrund seines Nichtstuns durch den politischen Modus Operandi wesentlich gefährdet zu sein scheint - und damit zum Objekt wird. Der Umstand, dass die Bushaltestelle von der Seuche in besonderem Maße ergriffen ist, steht sinnbildlich für die Inkompatibilität des inaktiven Körpers und dem body politic im Ganzen. Er impliziert, dass sein Tod als möglicher Kollateralschaden in Kauf genommen wird; vielleicht ist die Tollwut nur das vorgeschobene Zeichen für eine Operation, die eine andere >Krankheit $<$ - das Nichtstun - beseitigen soll. Das Leben Bombels ist, zieht man die von Agamben re-etablierte Aristotelische Unterscheidung heran, reines, nacktes Leben (zoé) und nicht (mehr) politisches Leben (bíos). ${ }^{93}$ Die Figur Bombel entpuppt sich so als homo sacer, der aus der Gesellschaft ausgeschlossen und dennoch von ihr - auf Leben und Tod - kontrolliert wird. »Der Körper des homo sacer selbst ist [...]«, schreibt Agamben, »das lebende Pfand seiner Unterwerfung unter eine Macht über den Tod«. Die Metapher der Atemwegs-Lähmung drückt eben diese »engste Symbiose mit dem Tod [...], ohne aber bereits der Welt der Verstorbenen anzugehören «, ${ }^{94}$ aus, die Agamben meint. Nicht zufällig sind gerade die Körperteile betroffen, an denen die Genussmittel des Nichtstuns den deutlichsten Schaden anrichten - die Lunge wird durch das Rauchen angegriffen, Milz und Magen durch den Alkohol. An der Darstellung ihrer Zersetzung offenbart sich die körperliche Schwäche des Nichtstuers in vollem Umfang, die jedoch keine Schutz- sondern eine Strafreaktion hervorruft.

Die Beschreibung dieser >Strafe folgt im Text einer Ankündigung Bombels, seinen Durst durch einen Diebstahl zu stillen, ${ }^{95}$ was den Eindruck erweckt, dass diese Transgression schon vor ihrer Realisierung biopolitisch abgestraft wird. Dass durch den Angriff auf die Lunge auch das organische Instrument seines Erzählens in Mitleidenschaft gezogen wird, trägt der biopolitischen Kontrolle in einem weiteren Aspekt Rechnung: das dysfunktionale, nichtstuende Individuum soll noch seiner letzten aktiven Funktionalität, des Sprechens, beraubt werden. "Der Wahnsinn muss zum Schweigen gebracht werden«, schreibt Michael Foucault, und so verhält es sich auch mit

\footnotetext{
93 Agamben: Homo sacer, 11.

94 Agamben: Homo sacer, 109.

95 »No ale jak ten wspomniany stan będzie jeszcze trwał, to nie wiem, w celu uzyskania pomocy pójdę kraść« (B 117). Dt.: »Tja, aber wenn der erwähnte Zustand anhält, ich weiß nicht, dann werde ich wahrscheinlich stehlen, um mir zu helfen« (129f.).
} 
dem Nichtstun. ${ }^{96}$ Bombel wird durch die Angst vor dem Verlust dieser Fakultät zur manischen Berichterstattung angetrieben.

Die Tatsache, dass Bombel von der Existenz einer staatlichen Hilfsaktion überzeugt ist, die für die Bewohner des Dorfes zwar anscheinend wichtig, doch für sowieso schon marginalisierte Figuren gefährlich oder gar lebensbedrohlich sein könnte, verweist auf den schwierigen Stand des Staates im politischen Imaginären des Erzählers Bombel. Es kommt so das Bild eines Staates zustande, der in Ausübung seiner Aufgaben einigen seiner Subjekte die Lebensgrundlage entzieht - eine Tendenz des ideologisch motivierten Ausschlusses, den Geoffroy de Lagasnerie liberalen Demokratien der jüngeren Zeitgeschichte zuschreibt, die in Bedrohungsmomenten spontan absolutistische Regierungsformen ausbilden. ${ }^{97}$ In Bombels Vorstellung herrscht zwischen ihm und der Politik ein Kampf, in dem er zwar durch sein Erzählen einen Agens bekommt, doch in dem er letztlich der schwächere Gegner ist. Da die Bushaltestelle der einzig mögliche Aufenthaltsort für einen Nichtstuer wie ihn darstellt, müsste er sich selbst aus dem öffentlichen Raum entfernen und ins Private flüchten, um nicht der >verseuchten Bushaltestelle zu erliegen. In der Diegese fühlt er sich als jemand, den jeder »erschlagen kann, ohne einen Mord zu begehen«, und dessen "ganze Existenz auf ein nacktes, aller Rechte entkleidetes Leben reduziert « ist. ${ }^{98}$

Damit weist Bombel die Brutalität des politischen Systems aus, in dem er lebt. Gleichzeitig impliziert er, dass die polnische Politik leere, semantisch ausgehölte Handlungen produziert. Durch die oben zitierte Parodisierung einer humanitären Krise definiert Bombel die Politik als solipsistisches Unternehmen, dessen Abläufe rhetorisch kalkuliert, aber inhaltsleer sind: sie erregen die Aufmerksamkeit der Bevölkerung durch dramatische Mittel (»dys-

96 Foucault: Wahnsinn und Cesellschaft, 159.

97 Im Hinblick auf den politischen Aktivismus im Internet-Zeitalter schreibt dieser, Judith Butler rezipierend: »Inasmuch as it is haunted by a certain ideology of the nation or of its national identity, every nation-state has the innate propensity to create individuals who are expelled because they do not match the idea, the unity, and/or the definition of the nation, and therefore also to deprive them of the legal protections that states are supposed to afford; these are the refugees, exiles, and the stateless. "Ceoffroy de Lagasnerie: The Art of Revolt. Snowden, Assange, Manning. Übers. v. Erik Butler. Redwood City: Stanford UP (2017), 34. Damit spiegelt er im Wesentlichen das Argument Agambens in Homo sacer: die Normalisierung einer Ausnahmesituation (vermeintlich zum Schutz des Staates), infolge derer es zur biopolitischen Umwertung von politischem Leben in >nacktess, entrechtetes Leben kommt. Vgl. Agamben: Homo sacer, 98, $179 f$. Agamben: Homo sacer, 192. 
kotekowe rytmy«), bringen Lösungen für erfundene Probleme vor (Kinder, die »mogą [...] płakać na widok wody«), um sich selbst zu stärken (die Bakterien kann man »tylko za sprawą obecnego wójta« loswerden, Herv. meine). Bombel, der finanziell vom Staat abhängig ist, zeigt eindrücklich, dass dieser nicht verlässlich ist, da er mit Täuschungen operiert: indem amtierende Politiker Interesse am Gemeinwohl vortäuschen, während sie eigentlich nur auf die eigene Wiederwahl hinarbeiten. ${ }^{99}$ Der politische Raum ist kein Entstehungsort menschlichen Handelns im Sinne Hannah Arendts, sondern nur eine opportunistische Arena, in der mit scheinbaren Werten gehandelt wird.

(2) Aufgrund des Todes des Protagonisten (Bombel stirbt auf der letzten Seite) kann man Bombel als posthistorische Ausdeutung eines Dekadenzromans verstehen. Der Roman macht explizit, dass dieser Tod nicht individuell verschuldet, sondern gesellschaftlich bedingt ist. Robert Castel beschreibt, dass die meisten Gesellschaftsformen Außenseiter-Typen wie den Vagabunden herausbilden, die durch ihr Anderssein sozial abgekoppelt sind und daran ernsthaften körperlichen Schaden nehmen. Über den Vagabunden als Außenseiter in der Arbeitnehmergesellschaft schreibt er: "Sein Körper ist sein einziges Hab und Gut, sein einziger Bezugspunkt, den er bearbeitet, genießen läßt und in einer Explosion von absolutem Individualismus zerstört. « ${ }^{100}$ Genau diesen Eindruck erhält man auch von Bombel, der die Destruktion seines Körpers mit akribischer Genauigkeit in seiner Erzählung festhält. So be-

99 Hier greift Hannah Arendts Feststellung der frühen 1970er-Jahre, die heute zum Korpus des selbstverständlichen Wissens über das Politische zählt, dass sich die Politik zunehmend um PR und Image-Optimierung kümmert, anstatt materielle Ziele zu verfolgen. In Bezug auf den Vietnam-Krieg formuliert sie die prägnante Feststellung über die USA: »Image-Pflege als Weltpolitik - nicht Welteroberung, sondern Sieg in der Reklameschlacht um die Weltmeinung «. Arendt: Wahrheit und Lüge, 19. In diesem Paradigma spolitisch zu handeln heißt dann auch, Entscheidungen vor allem in Hinsicht auf die nächste Wahl zu treffen (vgl. ebd. 21). Überhaupt hält sie Täuschung an sich für ein fundamentales politisches Problem. In ihren Überlegungen zu den PentagonPapieren schreibt sie: »Ceheimhaltung nämlich und Täuschung - was die Diplomaten Diskretion oder auch die arcana imperii, die Staatsgeheimnisse, nennen -, gezielte Irreführungen und blanke Lügen als legitime Mittel zur Erreichung politischer Zwecke kennen wir seit den Anfängen der überlieferten Geschichte. Wahrhaftigkeit zählte niemals zu den politischen Tugenden« (ebd., 8). Analog hierzu heißt es bei Stephen Greenblatt über die Darstellung des Politischen bei Shakespeare: »[T]he word >politician, for Shakespeare, was virtually synonymous with hypocrite. « Greenblatt: Tyrant, 32.

100 Castel: Die Metamorphosen der sozialen Frage, 408. Herv. meine. 
hauptet er, obwohl er schon lange nicht gegessen hat, sein Bauch wäre zum Bersten voll, nur nicht mit Nahrung, sondern mit Schlamm (vgl. B 53). Er fürchtet, dass seine Atemwege zu kollabieren drohen (vgl. B 119). Er fühlt ein Beißen und Jucken an seinen inneren Organen, das er durch Kratzen nicht zu stillen vermag - „drapanie przez skórę nie działa, nie pasuje, nie da się tak po prostu« (B 60). ${ }^{101}$ Sein Hunger produziert in ihm gleichzeitig das Gefühl statischer Dichte - »wszystkie flaki razem sklejają i strajk generalny mam w sobie« $(B \text { 99 })^{102}$ - und plötzlicher Weite, als wäre sein Körper mit Leere ausgefüllt: »czuję, że [...] może mnie wzdąć od niejedzenia [...] po prostu pustka mie wypełni« (B 99). ${ }^{103}$

Bombels Körper erscheint maximal handlungsunfähig. Er wird als dysfunktional beschrieben, und durch die Beschreibung von Wucherungen, Dehnungen und Kompressionen poetisch verformt, sodass man letztlich gar nicht mehr daran glauben kann, dass Bombel seine Organe und Gliedmaßen überhaupt zu einer koordinierten Aktion bringen könnte. Dennoch darf man diese Beschreibungen nicht missverstehen: Bombel wirkt zwar wie ein passives, bewegungsunfähiges Opfer, doch dieser Eindruck kann erst durch sein Erzählen als Praxis des Nichtstuns hervorgebracht werden. Als Erzähler inszeniert er sich als dieses Opfer, auch, um erneut Systemkritik zu üben. Der chaotische $\mathrm{Zu}$ stand innerhalb seines Körpers reflektiert nicht nur das individuelle destruktive Verhalten Bombels, sondern auch den Zustand des politischen Kontextes, der diese Zerstörung überhaupt erst ermöglicht hat. In diesem Verständnis ist es nicht Bombels Bauch, sondern der Staat, der mit Leere (»pustka«) ausgefüllt ist, und dessen Inneres geöffnet und richtiggestellt werden muss, so wie Bombel sich das Jucken seiner Innereien (»flaki«) wegkratzen möchte. Indem er von seinen körperlichen Problemen berichtet, die er nicht in den Griff bekommt, erzählt er auch von den Mängeln des politischen Systems. Joachim Helfer zufolge gehören Metonymien, die den Staatsverfall durch Körperpathologien darstellen, zur Strategie der Dekadenzliteratur:

Aufbauend auf der alten Versinnbildlichung des Staates als einem menschlichen Körper, versucht der Dekadenzbegriff, die vielfältigen und oftmals

101 »[D]as Kratzen auf der Haut hilft nichts, das paßt nicht, das funktioniert einfach nicht.» (68)

$102 »[M]$ ir kleben [...] alle Kutteln zusammen, in mir ist Ceneralstreik« (111).

103 »[Mir] schwant«, »[d]aß es mich vielleicht blähen könnte von diesem Nicht-Essen [...] es ist einfach so, daß die Leere mich ausfüllt« (111f.). 
widersprüchlichen Vorgänge, die zum Untergang geschichtlicher Reiche geführt haben, nach dem leichter faßlichen Vorbild des Schwach- und Schlaffwerdens unserer Leiber zum Tode hin zu fassen. ${ }^{104}$

Die Körper-Staat-Metapher lässt sich an der Beschreibung des Bombel'schen Körpers erkennen, der über den ganzen Roman hinweg als dysfunktionales Konglomerat von Organen beschrieben wird, deren - anatomisch notwendige - Harmonie untereinander aufgelöst worden ist. Helfer stellt weiterhin fest, dass der Vorwurf der Dekadenz immer auf bestimmte Körperstellen gerichtet ist: »entweder auf den Bauch, also auf Völlerei und Trägheit - oder aber unter die Gürtellinie. ${ }^{105}$ Der Roman Nahaczs greift diese Topoi auf und wandelt sie ab. So ist Bombel nicht träge, weil er etwa zu viel, sondern zu wenig gegessen hat. Auch die Funktionalität seines Geschlechts wird ständig in Frage gestellt. Nicht nur spricht er die ganze Zeit über Sex, ohne je welchen zu haben, er ist sich auch nicht sicher, ob er den Akt überhaupt vollziehen könnte. Das wird durch eine, die verquere körperliche Konstitution Bombels noch verstärkende Metaphorologie deutlich gemacht. Im Kapitel »Podwójne duble« wird so zum Beispiel die Kastration eines Schafbocks im Detail nacherzählt, auch, dass aus der »eingeschnittenen Stelle« »nichts Rundes« fällt, sondern dass es aussieht, "als hätte sich da Eiter gesammelt, als wäre der Bock krank« - woraufhin Bombel zur Sicherheit kontrolliert, ob seine eigenen »Juvenalien« noch physisch intakt sind (B 101f.). Diese Dysfunktionalitäten stellen auch den Staat im Ganzen in Frage.

\section{Gemeinschaft der Nichtstuer}

Dieser ungenügenden und gefährlichen Politik wird eine vereinfachte Form der Gemeinschaft entgegengesetzt, die ausschließlich >Nichtstuer< als Mitglieder hat: eine Familie der Ausgestoßenen. ${ }^{106}$ Die Sehnsucht nach Gemeinschaft entwickelt sich aus der Isolation heraus, die häufig mit dem Nichtstun einhergeht (und die zum Beispiel in der Analyse von Georges Perecs Un homme qui dort gezeigt wurde). ${ }^{107}$ Robert Castel hat diese Isolation zum zen-

104 Joachim Helfer: Unter der Cürtellinie. Von den Ordnungen des Ceschlechtlichen. In: Merkur 61 (700), 2007, 860.

105 Helfer: Unter der Gürtellinie, 860.

106 Vgl. hierzu Deleuzes Ausführungen zur Bruderschaft der Ausgestoßenen im Kapitel »Gemeinschaft« in diesem Buch.

107 Vgl. den Abschnitt »Kontrollverlust und Herrschaftsphantasie« im betreffenden Kapitel. 
tralen Merkmal des Vagabunden erhoben. Beim Vagabundendasein handele es sich, so Castel, um den »Grenzfall eines Entkoppelungsprozesses«, d.h. einer Losgelöstheit von konventionellen sozialen Bindungen, die sich »aus der Instabilität des Verhältnisses zur Arbeit und der Brüchigkeit der Gemeinschaftsnetzwerke speist «. ${ }^{108}$ Diese Instabilität habe sich aus der modernen Transformation von der Gemeinschaft zur Gesellschaft ergeben, die den biopolitischen Ausschluss des Vagabunden (heute: des Arbeitslosen) befördert habe. ${ }^{109}$ Diese Isolation ist hier, im Gegensatz zu der Ausgangssituation in Un homme qui dort, jedoch ein ungewollter Zustand. Bombel sitzt ja gerade an der Bushaltestelle, um jemanden zu treffen. Die variiert immer wiederkehrende Formel »Jeden Moment kommt Pietrek «"10 ist nicht nur der Lust auf Alkohol und Zigaretten, sondern der Sehnsucht nach Gemeinschaft geschuldet. ${ }^{111}$ Tatsächlich sind diese beiden S(ehns)üchte nicht voneinander zu trennen, denn die Gemeinschaft, die Bombel sich vorstellt, setzt sich aus all den NichtstuerInnen zusammen, die er - hauptsächlich vom gemeinsamen Trinken - kennt. Im Gegensatz zu der aggressiven und schonungslosen Politik ist diese Gemeinschaft altruistisch, einer Familie gleich - was Bombel bezeichnenderweise daran festmacht, dass sie immer ihren Alkohol miteinander teilen: »bo wszyscy jesteście dla mnie bardziej niż rodzina, jesteście moimi ojcami i matkami, moimi braćmi i siostrami, i dlatego stawiam każdemu z was po winie« (B 119). ${ }^{112}$ Diese Art der Gemeinschaft ergibt sich aus der Affirmation der Mängel, die im Bereich des Politischen nicht auf Nachsicht, sondern auf Ablehnung stoßen: des Nichtstuns und des Alkoholismus. In direkter Anlehnung an ältere Staatstheorien wie Hobbes' Leviathan nimmt diese Gemeinschaft in der Vorstellung des Erzählers die Form eines gemeinsamen Kollektivkörpers an:

I kiedy Pietrek sobie uzmysławia, jak on też nas kocha, że chcemy tego samego i dla siebie, i dla niego, to wtedy opanowuje nas razem wspólnie ta siła,

108 Castel: Die Metamorphosen der sozialen Frage, 87.

109 Vgl. Castel: Die Metamorphosen der sozialen Frage, 401-406.

110 »Lada chwila przyjdzie Pietrek«(B 25).

111 Diese Formel gehört im Übrigen ebenso zum kompensatorischen Sprechen: Bombel kündigt an, dass sein Freund bald kommen wird, weil er im Moment noch einsam und allein ist. Das Sprechen sucht diesen sozialen Mangel auszugleichen.

112 »[D]enn ihr seid für mich alle mehr als Familie, ihr seid meine Väter und Mütter, meine Brüder und Schwestern, deshalb spendiere ich jedem von Euch eine Flasche Wein.« (132) Dieser Satz wird Pietrek zugeschrieben. 
nie że każdego osobno, tylko nasze głowy łączą się w jedną. A jak już jesteśmy wszyscy jedną wielką podpitą osobą, która ma te same problemy zdrowotne i rodzinne, łączymy się w coś ponad naszymi osobami i każdy wtedy przystaje i zastanawia się nad sobą i dochodzi do takiego samego wyniku, że jesteśmy dla siebie najlepsi na świecie, że kochamy się ponad naszę rodziny i życie. [...] to jakby człowiek dostał odpust zupełny od Pana Boga, jakby się wyspowiadał i od razu poszedł do komunii, żeby nie zdążyć czasami zgrzeszyć. (B 120)

Und wenn Pietrek sich klarmacht, wie er uns liebt, daß wir das gleiche wollen, für uns und für ihn, dann beherrscht uns zusammen diese Kraft, nicht jeden einzeln, sondern alle zusammen, und unsere Köpfe verbinden sich zu einem einzigen. Und wenn wir dann alle eine einzige betrunkene Person sind, die die gleichen Probleme mit der Familie und mit der Cesundheit hat, vereinigen wir uns zu etwas, was unsere Personen übersteigt, und dann hält jeder inne, denkt über sich nach und kommt zu dem gleichen Ergebnis, daß wir füreinander das Beste auf der Welt sind, daß wir uns mehr lieben als unsere Familien und unser Leben. [...] dann ist das, als hätte man die Absolution vom lieben Cott persönlich erhalten, als hätte man gebeichtet und wäre gleich darauf zur Kommunion gegangen, um nicht zufällig zwischendurch zu sündigen. (132)

Diese Textstelle bezeugt die Wertschätzung und Sehnsucht nach einer Gemeinschaft, die die gesellschaftliche Ausgeschlossenheit kompensiert, indem sie den Grund für ihren Ausschluss - das Nichtstun - affirmiert. Darin vollzieht sich das, was Jacques Rancière als den Grund für die Existenz von Politik ansieht: »Es gibt Politik, weil diejenigen, die kein Recht dazu haben, als sprechende Wesen gezählt zu werden, sich dazuzählen und eine Gemeinschaft dadurch einrichten, dass sie das Unrecht vergemeinschaften ${ }^{113}$ Dass es sich bei der Gemeinschaft um einen Zusammenschluss von Zechbrüdern- und schwestern handelt, deutet eine Aufwertung der Verliererseite in der sozialen Spaltung Polens an. Sie mögen ihre Arbeit verloren haben, doch unter ihnen herrscht der humanere Zusammenhalt, abgebildet durch die Metapher eines (zwar alkoholkranken aber in der Solidarität hochgesunden) Kollektivkörpers. Bombel bestätigt so die Auslegung Castels, transzendiert sie aber auch. Die

113 Rancière: Das Unvernehmen, 38. 
Entkoppelung des Protagonisten von der Gesellschaft ist nicht nur das Resultat einer brüchigen, sondern auch der Anfang einer neuen Gemeinschaft, die sich jenseits von Arbeit, Produktivität und gesellschaftlich legitimer Aktivität situiert. ${ }^{114}$ Die Verwendung der Körper-Metapher in der Vereinigung der einzelnen TrinkerInnen zu einer großen, betrunkenen Person im Roman"jesteśmy wszyscy jedną wielką podpitą osobą (B 120) -, kopiert eine gängige europäische Staatsfiktion. ${ }^{115}$ Damit wird in dem von Bombel erzählten Gegendiskurs die Formierung einer Alternativgemeinschaft zum Staat angezeigt.

In Anbetracht der Tatsache, dass die Metapher des politischen Körpers in demokratischen Regierungsformen, wie das postsozialistische Polen sie darstellt, schon längst keine Verwendung mehr findet, ${ }^{116}$ kann ihr Auftauchen an dieser Stelle als Ausdruck einer Sehnsucht nach einer organischen Gemeinschaft gelesen werden (im Gegensatz zu einer als >mechanisch fundenen Gesellschaft). ${ }^{117}$ Damit wird auch die Ende des 19. Jahrhunderts von Ferdinand Tönnies aufgestellte (und vielfach reproduzierte) Opposition - Gemeinschaft als »lebendiger Organismus«, Gesellschaft als »ein mechanisches Aggregat und Artefact « - ${ }^{118}$ aufgerufen. Bei Tönnies ist diese Unterscheidung auch eine topographische: Die Gesellschaft ist der Stadt, die Gemeinschaft

114 Vgl. Kapitel »Gemeinschaft« in diesem Buch. Diese Tendenz zur Gruppenbildung bei den »menele« behauptet übrigens auch Słowiak. Über die Landstreicher der Cegend, in der Bombel spielt, schreibt sie: „Wyizolowani ze społeczeństwa alkoholicy organizują się często w charakterystyczne grupy na różnych jednostkach terytorialnych «. Słowiak: Menele, 10. Allerdings legen ihre empirischen Untersuchungen eine weitaus weniger emphatische Gruppenidentität in der Selbstwahrnehmung der Landstreicher nahe, als es in Bombel der Fall ist. Für eine summative Beschreibung der Gruppenidentität siehe 123-125.

115 Vgl. Ethel Matala de Mazza: Der verfaßte Körper. Zum Projekt einer organischen Gemeinschaft in der politischen Romantik. Freiburg i.Br.: Rombach (1999).

116 Claude Lefort spricht in diesem Zusammenhang von einer >Leerstelle der Macht, die keine repräsentative Funktion mehr hat und deshalb auch keine `Gestalt annehmen könne. Vgl. Claude Lefort: Die leere Mitte. Essays 1945-2005. Frankfurt a.M.: Suhrkamp (2009).

117 Diese `Gestaltlosigkeit « moderner Regierungsformen ist aufs Engste mit der Metapher der Cesellschaft als >Maschine < verbunden, der im Zuge des in der Moderne entstandenen Entfremdungsphänomens die Cemeinschaft als organisches Cebilde entgegengesetzt wurde.

118 Ferdinand Tönnies: Cemeinschaft und Cesellschaft. Abhandlung des Communismus und des Socialismus als empirischer Culturformen. Leipzig: Fue's Verlag (1887), 5. 
hingegen dem Leben auf dem Land zugeordnet. Diese topographische Unterscheidung ist auch im Roman relevant. Für Bombel ist die Stadt negativ konnotiert, da sie als Ort der Arbeit charakterisiert wird, und da sich dort auch das Kontrollorgan >Amt <efindet (»urząd«, B 81). Im Gegensatz dazu sind Land und Dorf für Bombel nicht nur mit dem Nichtstun verschränkt, sondern werden von ihm auch als Orte genuiner Schönheit verstanden. In der Stadt könnte er deshalb nicht leben:

próbowałem mieszkać w mieście, ale to nie dla mnie, bo ja jestem jak te góry i łąky razem wzięte, że po prostu mam już je w swojej duszy i jak musiałbym mieszkać nie w górach, to ona by uschła z tęsknoty za pięknem. (B 65)

[Ich] habe [versucht], in der Stadt zu wohnen, aber das wäre nichts für mich gewesen, denn ich bin wie die Berge mitsamt den Wiesen, ich habe sie einfach in der Seele, und wenn ich woanders als in den Bergen wohnen müßte, würde die Seele aus Sehnsucht nach dem Schönen vertrocknen. (73)

Bombel ruft also den Topos der Gemeinschaft auch deshalb auf den Plan, um damit seine Wertschätzung für das Ländliche in seiner kontemporären Form in Polen auszudrücken, und zwar indem er behauptet, >wahre` Gemeinschaft könne nur dort und nur von solchen Individuen gebildet werden, die während der Transformation Polens auf der Strecke geblieben sind: den Nichtstuern. Diese Verknüpfung stellt einen Rückgriff auf die Romantik dar, ${ }^{119}$ nicht zuletzt, weil sie aufgrund der Hervorhebung des Genuss-Faktors an Friedrich Schillers Konzeption des ästhetischen Staates erinnert. ${ }^{120}$

Schiller, der ebenfalls die Metapher des Mechanischen in der Beschreibung des Staates verwendete, hatte vornehmlich in der ersten Fassung der Ästhetischen Erziehung, den Augustenburger Briefen, ein klassisches Humanitätsideal entworfen, welches die Wertschätzung des Schönen als zentralen Schritt zu einem friedlichen Zusammenleben beinhaltet, das die grobe Gewaltherrschaft des >normalen Miteinanders transzendiert. Wolfgang Düsing fasst diese Idee sehr konzise zusammen, weshalb ich seinen einschlägigen Kommentar hier zitiere:

119 Vgl. hierzu den kurzen Kommentar zu der Korrelation zwischen Nichtstun und Cemeinschaft im Kapitel »Cemeinschaft « in diesem Buch, und außerdem Matala de Mazza: Der verfaßte Körper.

120 Vgl. hierzu auch Rancière: Aufteilung des Sinnlichen, 40f. 
Nicht mehr Stärke und Cewalt regeln das alltägliche Miteinander, sondern der Wunsch zu gefallen. Mit dem Ästhetischen wird etwas entdeckt, das über den Nutzen und das Notwendige hinausgeht, ein erster Spielraum für Freiheit und Humanität eröffnet sich. Man kann noch einen Schritt weiter gehen und annehmen, daß bei einem Menschen, dem das Schöne um seiner selbst willen gefällt, eine Einstellung vorbereitet wird, die auch den andern um seiner selbst willen respektiert und in ihm nicht mehr ein Objekt für egoistische Ziele sieht. ${ }^{121}$

Auch in Bombel wird die Gemeinschaft der Nichtstuer als eine auf dem Land, in der Nähe von natürlicher Schönheit, realisierte entworfen, die sich von der »Stärke und Gewalt« abwendet, die die Stadt, die Arbeit und die Politik bestimmt. Die Hinwendung zum Schönen und dem, was »über den Nutzen und das Notwendige hinausgeht « (d.h. zur Zweckfreiheit), ${ }^{122}$ findet in der Gemeinschaft, die sich Bombel ausmalt, über die Nähe zu Natur einerseits, und das Nichtstun andererseits statt. Wie zu Beginn dieser Arbeit ausgeführt wurde, kann die Transzendenz der politischen Gewalt durch die Aufhebung des Zweck-Mittel-Verhältnisses im Nichtstun als Streik, und damit als Handlung betrachtet werden. Bombels Erzählung des familiären Kollektiv-Körpers stellt eine solche Handlung dar, indem sie die Gewalt der Polizei im Sinne Rancières überwindet und eine neue Gemeinschaft konstituiert, die sich unabhängig von gängigen Tätigkeitserwartungen realisiert.

Doch auch diese Gemeinschaft ruht auf einem prekären Fundament. Denn der Kollektivkörper, den Bombel imaginiert, mag den höchsten humanistischen und solidarischen Idealen entsprechen, doch er ist auch offensichtlich krank. Nahacz unterwandert die Staatsmetapher des Leviathan von Hobbes, ${ }^{123}$ indem die Mitglieder in Bombels Gemeinschaft zwar einen gemeinsamen Körper bilden, es diesem jedoch an einem klaren Kopf ("podpitą osobą«), und deshalb an souveräner Führung und, leider, auch an Überlebensfähigkeit fehlt. Die bittere Ironie liegt darin, dass diese Gemeinschaft nicht von Dauer sein kann. Wenn die anderen >Körperteile solidarischen Körpers genauso krank sind wie Bombel, dann sind sie dem Tod auch ebenso nah wie er. Bombel bringt diese Metapher kurz von seinem

121 Wolfgang Düsing: Friedrich Schiller. Über die ästhetische Erziehung des Menschen in einer Reihe von Briefen. Text, Materialien, Kommentar. München: Hanser (1981), 132.

122 Vgl. Kapitel »Handlung und Geschichte in diesem Buch.

123 Vgl. hierzu die im Abschnitt »Unverhältnismäßigkeiten der Arbeit« beschriebene Umkehrung der staatsmetaphorischen Hierarchie in Walsers Cehülfen. 
Tod auf, die Gemeinschaft der nichtstuenden Trinker in seinem eigenen Schwanengesang idealisierend.

Doch weder Erzähler noch Roman suggerieren, dass darin ein Grund zum Verzweifeln besteht, vielmehr steht die Vermutung im Raum, dass Gemeinschaft nur unter diesen prekären Bedingungen stattfinden kann. ${ }^{124}$ Im >Außen stimmter »Freiraum«, so Ethel Matala de Mazza und Uwe Hebekus, »in dem Gemeinsam-Sein als unmögliche Einheit « erfahren werden kann. ${ }^{125}$ Als solche ist Gemeinschaft in gewisser Hinsicht unmöglich, und kann nicht dauerhaft bestehen. Das besagt auch die Gemeinschaftstheorie Maurice Blanchots, in der die >Werklosigkeit< (désœuvrement) den Kern der Gemeinschaft bildet, die also in Opposition zur Arbeitsgesellschaft definiert ist. Eine Gemeinschaft könne nicht durch Arbeit gemacht oder produziert werden, sondern ergibt sich spontan im Angesicht des Todes:

Im Unterschied zu einer sozialen Zelle untersagt sie [die Gemeinschaft], ein Werk zu schaffen, und sie hat keinerlei Produktionswert zum Ziel. Wozu dient sie? Zu nichts, wenn nicht dazu, den Dienst am Anderen bis in den Tod hinein gegenwärtig zu halten, damit der Andere nicht einsam zugrunde geht $[\ldots]{ }^{126}$

Die Alkoholkranken und Ausgeschlossenen werden in dieser Auslegung zum Gemeinschafts-Körper ad mortem, dessen Tod allerdings weniger schmerzhaft ist als das Leben, das sie führen. In Bombels Vorstellung ist der Tod die Erfüllung seiner Wünsche, denn, so stellt er sich vor, »für Bombel werden sie einen Wagen schicken, noch dazu einen frisch lackierten blauen Metallic « (170), ${ }^{127}$ in dem er ganz ohne Fahrkarte endlich den Vergnügungen entgegenfahren kann, von denen er so lang nur träumen konnte.

124 Das ist es auch, was sie von den nostalgischen Gemeinschaftsvorstellungen unterscheidet, die Jean-Luc Nancy kritisiert. Vgl. das Kapitel »Cemeinschaft« in diesem Buch.

125 Ethel Matala de Mazza u. Uwe Hebekus: Einleitung. Zwischen Verkörperung und Ereignis. Zum Andauern der Romantik im Denken des Politischen. In: Das Politische. Figurenlehren des sozialen Körpers nach der Romantik. Hg. v. Dens. u.a. München: Fink (2003), 14. Jacques Rancières Theorie des Politischen weist Ähnlichkeiten zu dieser Position auf.

126 Blanchot: Die uneingestehbare Cemeinschaft, 25.

127 »[P]o Bombla wyślą wielki czterodrzwiowy samochód, do tego świeżo polakierowany na niebieski metalik« (B 155). 


\section{Fazit und Ausblick}

Wie zu Beginn dieses Buches ausgeführt wurde, lassen sich in der Handlungsphilosophie Hannah Arendts zwei Formen des Nichtstuns isolieren: die geistige Tätigkeit des Denkens und der passive Widerstand. ${ }^{1}$ Während Arendt den passiven Widerstand gleich nach seiner ersten Erwähnung den »aktivsten und wirksamsten Formen des Handelns « zuordnet, ${ }^{2}$ und ihn damit zu einem Teil der Vita activa erhebt, verfährt sie mit dem denkenden Nichtstun anders. Sie kommt in Vita activa nur marginal darauf zu sprechen, um dann aber das Werk mit einer bemerkenswerten Ausführung über das Denken abzuschließen. Das Denken sei zwar »niemals als eine Tätigkeit der Vita activa verstanden worden «, dennoch, vermutet Arendt, würde das »reine Denken alle Tätigkeiten [der Vita activa] an schierem Tätigsein übertreffen «. ${ }^{3}$ Im letzten Satz dieses Abschnittes verweist sie auf einen Spruch Catos: Niemals ist man tätiger, als wenn man dem äußeren Anschein nach nichts tut, niemals ist man weniger allein, als wenn man in der Einsamkeit mit sich allein ist. $\aleph^{4}$ Dieser Satz versinnbildlicht das Ergebnis der vorliegenden Untersuchung. ${ }^{5}$ Er kann für die Praxis des Nichtstuns stehen, die aus philosophischen, politischen und literarischen Texten herausgeschält worden ist.

Niemals ist man tätiger, als wenn man dem äußeren Anschein nach nichts tut.

1 Vgl. das Kapitel »Handlung und Geschichte« in diesem Buch. Hinzu kommt noch Arendts Form der Herrschaftskritik (vgl. das Kapitel »Herrschaft« in diesem Buch), die hier jedoch außer Acht gelassen wird.

2 Arendt: Vita activa, 253.

3 Arendt: Vita activa, 414.

4 Arendt: Vita activa, 415.

5 Dies ist wohlbemerkt metaphorisch gemeint, denn, wie bereits in der Einleitung gesagt wurde, wird in dieser Arbeit nicht die Form des Nichtstuns untersucht, die als Denken stattfindet. 
Dieses Buch hat gezeigt, dass das Nichtstun als eine Tätigkeit, und vielleicht sogar als eine Handlung verstanden werden kann. Die Grundlage für diese These lieferte Hannah Arendts Konzept des passiven Widerstands und Walter Benjamins Streik-Konzept. Beide argumentieren, dass eine gewaltvolle Politik transzendiert werden kann, wenn man die Logik des Handelns von der Zweck-Mittel-Relation befreit - und zwar in einem Nichtstun. ${ }^{6}$ Die Überwindung dieser Relation durch ein Nichtstun ist vor allem in der Lektüre von Georges Perecs Un homme qui dort (1967) in Erscheinung getreten. Der ErzählerProtagonist zieht sich ohne Ziel und Agenda aus der Welt des Handelns zurück und behauptet, vollkommen indifferent zu sein. Er sei »un dur noyau d'indifférence, un regard neutre« (Hqd 37) - »ein harter Kern aus Gleichgültigkeit, ein neutraler Blick« (23). Er schafft es so, das ihm sinnlos erscheinende dominante Tätigkeitsparadigma seiner Umwelt zu überwinden, und schüttelt durch sein - zum Teil systematisches - Nichtstun die historische Heteronomie, die Vorherbestimmung seines Lebensverlaufs ab. In dieser Praxis des Nichtstuns übt er nicht nur politische Kritik, sondern fängt etwas Neues an, und bringt ein Ereignis hervor, eine Handlung im Sinne Arendts. ${ }^{7}$

Nicht weniger eindrücklich zeigt sich das Nichtstun als Tätigkeit in Mirosław Nahaczs Bombel (2004). Der Roman Nahaczs fokussiert einen Arbeitslosen, der an einer Bushaltestelle sitzt, und skizziert damit - zumindest vordergründig - ein Bild völliger Untätigkeit. Doch dieses Bild ist nur vordergründig statisch; es entpuppt sich als eine dynamische Inszenierung: Wie ein Schauspieler im Fernsehen (»jak w teleturniejach«, B 5) unterhält der Erzähler-Protagonist Bombel ein abwesendes Publikum mit seinen Geschichten. Dies versinnbildlicht die Strategie des Romans: die Bushaltestelle ist eine Art öffentliche Bühne, und der arbeitslose Protagonist tritt auf ihr durch sein Sprechen in Erscheinung. Damit schließt der Roman an eine von Hannah Arendt genutzte Metapher für das Handeln an: Der handelnde Mensch ist jemand, der »vor der Allgemeinheit erscheint «, ${ }^{8}$ indem er »auf die Bühne der Welt « tritt. ${ }^{9}$ Der Protagonist ist zwar veränderungsunwillig und will den Ort der Bushaltestelle nicht verlassen, aber er handelt dennoch, indem er sich durch sein Sprechen wahrnehmbar macht und so den Status des homo sacer laut Agamben revidiert. Seine selbstzweckhafte Praxis des Nichtstuns steht im

Arendt: Vita activa, 291; Benjamin: Cewalt, 184.

Handeln heißt, »etwas Neues Anfangen«. Arendt: Vita activa, 215.

Arendt: Vita activa, 63. Herv. meine.

Arendt: Vita activa, 219. 
völligen Gegensatz zu der biopolitischen Gewalt, die ihn zu kontrollieren versucht. Der Roman enthält die subtile Hoffnung, dass sein öffentliches Erscheinen diese Gewalt nicht nur aufzeigen, sondern auch beenden könnte.

An Thomas Manns Der Zauberberg (2004) konnte die Analyse die reflexive Funktion der Praxis des Nichtstuns zeigen. Indem der Roman die Opposition >Osten/Inaktivität und >Westen/Aktivität (durch die Figur Settembrini) zwar behauptet, aber umgekehrt darstellt, weist er sie als arbiträr und projiziert aus - ebenso wie die mit ihr einhergehende Hierarchie, die eine Überlegenheit des >Westens` aufgrund seiner Aktivität voraussetzt. Während Perecs Un homme qui dort und Mirosław Nahaczs Bombel individuelle Erfahrungen der Figuren innerhalb eines bestimmten politischen Systems in den Blick nehmen, reflektiert Der Zauberberg makropolitische Zusammenhänge, indem er mehrere Charaktere in eine entsprechende Konstellation bringt. Über den Topos einer `östlichen< Inaktivität zeigt er, den orientalistischen Diskurs des 19. Jahrhunderts spiegelnd, ein koloniales Begehren des Deutschen Reiches an. Die deutschen (und allgemein die swestlichens) Figuren stecken sich mit dieser >östlichen< Inaktivität an, werden gar von ihr vereinnahmt - »Asien verschlingt uns « warnt Settembrini Castorp (Z 366). So schreibt der Roman durch ihre Perspektive, zeitgenössische Diskurse aufgreifend, dem `Osten« semantisch Stärke zu. Dies wird verstärkt, indem das dem >Osten zugeschriebene Nichtstun mit einer potentiell machtvollen, əöstlichen Die Infragestellung der Opposition >Osten//Inaktivität und >Westen/Aktivität in der Praxis des Nichtstuns, die der Roman seine Figuren ausüben lässt, spielt so mit den realen politischen Gegebenheiten des frühen 20. Jahrhunderts, und reflektiert Prozesse politischer Macht- und Ohnmachtszuschreibung. Castorps idiosynkratische Variante des $>$ Regierens $\triangleleft$ versinnbildlicht das von Cato formulierte Paradoxon: Wenn er am wenigsten zu tun scheint, übt er die scheinbar souveränste, wirkungsvollste Tätigkeit aus.

In Robert Walsers Der Gehülfe zeigt sich eine inverse Variante von Catos Paradoxon: Die Figur Marti ist zwar dem äußeren Anschein nach im Rahmen ihrer Arbeit als Gehilfe überaus tätig, während sie tatsächlich keiner Tätigkeit nachgeht - zumindest keiner wirklichen Arbeit (im Sinne einer zur Lebenserhaltung dienenden Erwirtschaftung von Lohn). ${ }^{10}$ Marti widmet sich vielmehr der Simulation von Arbeit; sie ist einerseits müßiges Spiel und legitimiert andererseits den Vollzug einer reinen Muße, da die Simulation von Arbeit die

10 Arendt zufolge bedeute Arbeit »Lebensnotwendigkeiten herbeizuschaffen«. Arendt: Vita activa, 101. 
Muße wie serarbeitet « wirken lässt. Ähnlich wie Manns Zauberberg reflektiert Walsers Roman durch die gleichzeitige Abbildung vermeintlich gegensätzlicher Vorgänge gesellschaftliche Prozesse des frühen 20. Jahrhunderts, und zwar klassenspezifische Identitäts- und Tätigkeitsdynamiken. Der Gehülfe bildet so über das Nichtstun Wünsche des Bürgertums ab, der Aristokratie anzugehören, und wiederum die Sehnsucht der Klasse der Angestellten nach einer Teilhabe am relativen Luxus des Bürgertums. Sowohl der Angestellte als auch der Bürger leben ihren Wunsch nach sozialem Aufstieg über ostentative Muße aus, die allerdings, wie es ihre gesellschaftliche Position verlangt, nicht nur an Arbeit gekoppelt sein muss, sondern auch mit der Verehrung der Arbeit zusammenfallen soll: "Es ist eine Ehre, es sich auch ein bißchen sauer zu machen.«(G 55f.) Die Praxis des Nichtstuns zeigt im paradoxen, gleichzeitigen Vollzug von Muße und Arbeit die Arbitrarität der Koppelung von gesellschaftlichen Klassen-Identitäten mit bestimmten Tätigkeiten auf, und kritisiert implizit die hohe Wertschätzung der Arbeit in der Moderne.

Niemals ist man weniger allein, als wenn man in der Einsamkeit mit sich allein ist.

All diese Werke zeigen insbesondere, dass das Nichtstun wesentlich mit Fragen der Gemeinschaftsbildung verknüpft ist. Denkend nichts zu tun bedeutet Arendt zufolge, Heidegger zitierend, sich »außer der Ordnung« zu befinden, weil dadurch »jedes Tun, jede normale Tätigkeit « unterbrochen würde. ${ }^{11}$ Dieses Aus-der-Ordnung-fallen beschreibt das Nichtstun im Allgemeinen. Da sich Gemeinschaft im 20. Jahrhundert wesentlich als über die Tätigkeit der Arbeit gestiftete Gemeinschaft definiert, zieht ein Heraustreten aus dieser Ordnung in diesem Diskurs angeblich zwangsläufig Einsamkeit nach sich. Die vorliegende Untersuchung hat jedoch demonstriert, dass das Nichtstun zwar mit sozialem Ausschluss einhergeht, aber auch, dass gerade dieser Ausschluss und das Aus-der-tätigen-Ordnung-fallen zur neuen Prämisse einer Gemeinschaftsbildung werden kann. Was anhand der Gemeinschaftsphilosophien von Jean-Luc Nancy, Maurice Blanchot, Giorgio Agamben und auch Gilles Deleuze - und ihrem Rückgriff auf Herman Melvilles Figur Bartleby theoretisch nachvollzogen wurde, zeigt sich in verschiedener Ausprägung in den Lektüren.

In Walsers Der Gehülfe sucht der Protagonist Marti so nach einer Gemeinschaft, die sich nicht durch Arbeit, sondern durch Muße und Spiel auszeichnet. Er sehnt sich nach einem familiären Zusammenhalt, in dem er, »Spiele 
erfindend und betreibend« ( $G$ 100), sein Glück finden kann. Die Vorstellung einer Gemeinschaft durch Arbeit, wie sie im Roman zum Beispiel durch den Sozialismus skizziert ist, wird von Marti abgelehnt. Der Roman impliziert, dass sich Marti in einer Masse arbeitender Menschen einsamer fühlt als in einer kleinen Gruppe von Untätigen, dass also Gemeinschaft nur innerhalb eines überschaubaren sozialen Nichtstuns zustande kommen könne. Die Idee, eine Gemeinschaft durch Arbeit zu bilden, wird kritisiert, während das Gegenteil (die Gemeinschaft der Nichtstuer) jedoch als wirtschaftlich unhaltbar herausgestellt wird.

Der Topos der Gemeinschaft von Nichtstuern ist auch in Thomas Manns Der Zauberberg präsent. Die Topographie des Romans stellt das aktive Unten des Flachlands dem inaktiven Oben des Sanatoriums gegenüber; zwischen ihnen gibt es eine klar markierte Abgrenzung. Die Patienten im Sanatorium verwenden wiederholt die Formel »wir hier oben $(Z$ 569) im Gegensatz zum "Flachlande drunten " $(Z$ 588) und bilden so über das gemeinsame Nichtstun einerseits, und die geteilte Krankheit andererseits, eine der Gesellschaft im >Flachland entgegengesetzte Gruppe mit starker sozialer Bindung. So wird die im Roman zunächst als `Schwäche` ausgelegte pathologische Untätigkeit gerade durch »das negative Verhältnis zur Macht «, ${ }^{12}$ wie Roland Barthes sagt, umgewertet: Weil es dominanten Diskursen fern ist, die Aktivität, Arbeit und bestimmte Formen der Politik voraussetzen, kann es gemeinschaftsstiftende Wirkung jenseits dieser Formen entfalten.

Mirosław Nahaczs Bombel zeichnet ebenfalls ein bemerkenswertes Gemeinschaftsbild. Der arbeitslose Protagonist imaginiert in Abgrenzung $\mathrm{zu}$ einer als aggressiv und gewalttätig wahrgenommen Politik eine Gemeinschaft von Nichtstuern, die, in Anlehnung an die Staatsmetapher des Hobbes'schen Leviathan, zusammen "jedną wielką podpitą osobę" (B 120) darstellen - »eine einzige betrunkene Person" (132). In dieser Gemeinschaft sind die Probleme, die gesellschaftlich einen Ausschluss oder biopolitische Kontrolle herbeiführen, gerade die Grundlage für eine - ebenfalls als familiär konnotierte - humanistische Ethik des Miteinanders. Diese ist, im Gegensatz zu der im Roman als wertvoll definierten Arbeit, kein "product of the working community«, wie Jean-Luc Nancy sagt. ${ }^{13}$ Sie ergibt sich in und aus einer Gemeinschaft jenseits der totalitären Gleichmachung durch Arbeit, weil sie Unterschiede und Singularitäten nicht problematisiert, sondern akzeptiert.

12 Barthes: Wie zusammen leben, 81.

13 Nancy: The Inoperative Community, xxxviiif. 
Die Tatsache, dass auch diese Gemeinschaft eigentlich homogen ist - alle sind arbeitslos und betrunken - kann allerdings gar nicht erst zu einem neuen Problem werden, da die Gemeinschaft nicht lange genug bestehen kann, um möglicherweise eine eigene aus der Homogenität und den daraus folgenden uniformierenden Kräften gespeiste Gewalt zu entwickeln. Der Tod der Figur Bombel kündigt allerdings auch die Vergänglichkeit der Gemeinschaft an; das Prekariat, aus dem sie entsteht, ist auch ihr Todesurteil.

Die Gemeinschaft, die sich in dem und durch das Nichtstun bildet, ist in all diesen Fällen nicht von Dauer. Die Lektüren erweisen die soziale Komponente des Nichtstuns als genussvoll, freundschaftlich und loyal, aber unbeständig, in ständiger Nähe zum wirtschaftlichen Ruin (Walser) oder dem Tod (Mann, Nahacz). In Perecs Un homme qui dort stellt sie sich gar nicht erst ein: Der Protagonist ist der einzige Nichtstuer, der tatsächlich einsam bleibt. Er findet eine andere Lösung aus seiner sozialen Ex-bzw. Inklusion: er spricht mit sich selbst wie mit jemand anderem; er teilt sich, um mit jemandem zu sein, auch wenn dieser jemand nur er selbst ist. Doch obwohl auch diese `Zweisamkeitく im Nichtstun am Ende der Erzählung aufhört, so geht damit keine generelle Abwertung des gemeinschaftlichen Nichtstuns einher. Eine Gemeinschaft von Nichtstuern, so zeigt der Roman, müsste allerdings lernen, sich dem Anderen - hier dem Nachbarn - erneut und ergebnisoffen anzunähern. Das hieße, sich nicht jeglicher Deutbarkeit zu verweigern - eine generelle »absence de geste« (Hqd 23) zu behaupten -, wie der Protagonist es lange tut, sondern alle Deutungen zuzulassen.

Das Nichtstun stellt so in jeder der Erzählungen eine Erleichterung dar, und fungiert zunächst als Ruhepause von einer anstrengenden, leistungsund fortschrittsfokussierten Gesellschaft, die über ihre Obsession durch Aktivität und Arbeit individuelle Bedürfnisse auf der Strecke lässt. Das Nichtstun verbirgt hinter sich eine ebenso relevante alternative Tätigkeit, welche Individualität zulässt und so rechte Gemeinschaft möglich macht.

Dieses Buch hat versucht zu zeigen, dass die literarische Darstellung von Nichtstun sich an einem philosophischen und politischen Diskurs über Handlung und Untätigkeit in ihr eigener Weise beteiligt. Ob dies auf eine eigene, aktive politische Praxis der Literatur verweist, wäre noch zu erforschen. Bezieht man Hannah Arendts Metapher des Theaters auf Literatur selbst, so könnte man sie auch als ein Erscheinen auf der Bühne der Welt betrachten, als »representation that simultaneously supplements or improves [...] poli- 
tics ${ }^{14}{ }^{14}$ wie Richard Halpern über Arendts Theater-Konzept bemerkt. Literarische Praktiken des Nichtstuns, die die Opposition zwischen Handlung und Nicht-Handlung aufheben, könnten so Teil von deren Infragestellung auch auf gesellschaftlicher Ebene sein. Für die Kunst im Allgemeinen hat Jacques Rancière diese Möglichkeit immerhin schon postuliert:

Die Politik der Kunst beruht innerhalb des ästhetischen Regimes der Künste auf dem grundlegenden Paradox dieser »Freiheit der Cleichgültigkeit«, die die Identität von Arbeit und Untätigkeit, von Bewegung und Unbeweglichkeit, Aktivität und Passivität, Einsamkeit und Cemeinsamkeit bedeutet. ${ }^{15}$

\section{Ausblick}

In diesem Buch wurde eine Frage ausgespart, die für eine weitere Untersuchung der literarischen Darstellung des Nichtstuns fruchtbare neue Wege weist. Mit Blick auf das Potential von literarischen Praktiken des Nichtstuns, gesellschaftspolitische Diskurse zu reflektieren und deren Grundoppositionen in Bewegung zu versetzen, ließe sich weiter fragen, inwiefern das Phänomen des Nichtstuns, wie es in der europäischen Literatur zur Darstellung kommt, einem gendering unterworfen ist. Sicher ist, dass die ausgewählten Romane die Konformität ihrer Protagonisten mit einem existierenden männlichen Rollenbild in Frage stellen. Ebenso wie die semantische Nähe des Nichtstuns zum Tod ist die Unfähigkeit zur sexuellen Erfüllung, in manchen Fällen sogar ihre Asexualität, typisch für die Literatur über das Nichtstun im 20. Jahrhundert.

Man kann und muss deshalb auch fragen, welche Rolle Weiblichkeit in den älteren wie neueren Untätigkeitsdiskursen spielt. Franziska Schößlers rezente Monographie über die Verschränkung von Geschlecht und Arbeitsvermögen in der europäischen und amerikanischen Literatur hat ergeben, dass sich eigentlich fast immer eine »Desemantisierung weiblicher Arbeit ${ }^{16}$ feststellen lässt. Weibliche Arbeit ist so entweder im häuslichen, emotionalen oder ästhetischen Bereich verortet - und demnach weder professionalisiert noch als lebenserhaltend konnotiert. Später, besonders ab der Literatur der Neuen Sachlichkeit, wird Frauen zwar ein Platz in der Arbeitswelt eingeräumt, doch

\footnotetext{
14 Richard Halpern: Theater and Democratic Thought: Arendt to Rancière. In: Critical Inquiry 37 (3), 2011, 549.

15 Rancière: Aufteilung des Sinnlichen, 83.

16 Franziska Schößler: Femina Oeconomica. Arbeit, Konsum und Ceschlecht in der Literatur. Von Goethe bis Händler. Frankfurt a.M.: Peter Lang (2017), 287.
} 
weibliche Arbeit bleibe »bis in die Gegenwart hinein auf Körperlichkeit und Sexualität fixiert «. ${ }^{17}$ Solche und andere Untersuchungen, mögen sie auch historisch und geographisch disparate Phänomene untersuchen, bestätigen eigentlich einen Trend, der sich schon lange in den Gender Studies gezeigt hat: Den Ausschluss der Frau aus machtvollen Diskursen, in diesem Fall dem seit der Moderne hochgeschätzten Diskurs der Arbeit, und die Eingeschränktheit ihrer Integration in demselben.

Dieser Ausschlussmechanismus ist nicht nur mit Bezug auf einen neuzeitlichen Begriff von Arbeit, sondern auch in Bezug auf Tätigkeit im Allgemeinen beschrieben worden. In Das andere Geschlecht (1949) legt Simone de Beauvoir die Inferiorisierung der Frau mit besonderem Fokus auf die Ebene des Handelns dar. Die Frau werde vom Mann der Faulheit bezichtigt - eine Einschätzung, die Beauvoir bestätigt, jedoch nicht ohne die männlich bestimmte Organisation der Gesellschaft dafür verantwortlich zu machen. De Beauvoir nimmt an, dass die räumliche und intellektuelle Einschränkung der Frau dazu beigetragen habe, dass diese sich nicht als handlungsfähiges Individuum begreife. Sie fühle sich vielmehr für die von Männern bestimmte Welt überhaupt nicht verantwortlich, sondern »erfaßt [...] sich als passiv angesichts der Götter mit menschlichem Antlitz, die Zwecke und Werte definieren. ${ }^{18}$ Die Frau wisse nicht, "was eine wirkliche Handlung ist, durch die man die Welt verändern kann ${ }^{19}{ }^{19}$ »so ist es denn nur natürlich, daß sie selbst wiederholt, von vorn beginnt, ohne je Neues zu erfinden, daß die Zeit sich für sie im Kreis zu drehen scheint, ohne irgendwohin zu führen. Sie beschäftigt sich, ohne je etwas zu tun. ${ }^{20}$ De Beauvoir betont die Abwesenheit des Tuns deshalb so eindringlich, weil es einerseits die sichtbarste Manifestation ihrer vermeintlichen Minderwertigkeit ist, und andererseits der folgenreichste Grund für ihre weiter anhaltende gesellschaftliche Hintanstellung. Und wenn Sara Ahmed in Willful Subjects (2014) schreibt, dass »[t]o become woman is to submit to a weakening of the will ${ }^{(87)},{ }^{21}$ dann schlägt sie in dieselbe Kerbe wie Simone de Beauvoir. Eigenwilligkeit ist als Eigenschaft für Frauen ein größeres

17 Schößler: Femina Oeconomica, 286.

18 Simone de Beauvoir: Das andere Geschlecht. Sitte und Sexus der Frau. Übers. v. Uli Aumüller u.a. Reinbek bei Hamburg: Rowohlt (1995), 748.

19 De Beauvoir: Das andere Geschlecht, 750.

20 De Beauvoir: Das andere Geschlecht, 755.

21 Sara Ahmed: Willful Subjects. Durham: Duke UP (2014), 87. Ich entnehme dieses Zitat Ahmeds Analyse von George Eliots Daniel Deronda, da es ihr Hauptargument wiederspiegelt. 
Problem als für Männer, weil der Wille Voraussetzung für das Handeln, und Handeln wiederum die Voraussetzung für die Handhabe von Macht ist.

Es ist demnach auffällig, dass die Literatur nicht mehr untätige Frauen darstellt, obwohl diese durch ihren Ausschluss aus der Welt der Arbeit ja prädestiniert sein müssten für diesen Topos. Doch bestätigt es im Grunde die Reichweite des gender bias: Wenn die männlichen Protagonisten, die nichts tun, eben doch tätig sind - ist diese uneigentliche Tätigkeit dann nicht trotzdem einzig Männern zuzuschreiben? Oder ist der Ausschluss der Frau aus dem Bereich der als einzig wertvoll fetischisierten Arbeit ein Zeichen für die Möglichkeit, dass dieser Ausschluss selbst - wie in den analysierten Praktiken des Nichtstuns - den Weg zu einer alternativen Ermächtigung weisen könnte, zumindest im Literarischen?

Die Überlegungen dieses Buches in eine solche Richtung fortzuführen, scheint mir gerade heutzutage von großer Relevanz. Denn zum einen findet mehr denn je ein reger gesellschaftlicher Austausch über die überkommenen Arbeitsparadigmen statt, die das Nichtstun in umgekehrter Wertung als Unterbrechung von Überlastung und Stress idealisieren. Zum anderen entstehen immer wieder Romane, die gerade nichtstuende Protagonistinnen vor diesem Hintergrund inszenieren und die mögliche Idealisierung des Nichtstuns dabei kritisch reflektieren. Das eher >männliche` Untätigkeitsnarrativ des 20 . und 21. Jahrhunderts wird nun durch mehr und mehr weibliche Stimmen ergänzt. Von Lisa Owens zum Beispiel, die mit Not Working (2016) ${ }^{22}$ einen Roman über eine junge Frau vorlegte, die ihren Marketing-Job freiwillig aufgegeben hat, um einen Beruf aufzugreifen, der sie wirklich glücklich macht. Da sie allerdings nicht weiß, was das sein könnte, lässt sie sich monatelang treiben und registriert sich online bei Werbe-Gewinnspielen. In diesem Roman kollabieren gesellschaftlich gefestigte Ideale einer wahrhaft erfüllenden Arbeit wie eines heilsamen Nichtstuns. Seine LeserInnen sind dazu herausgefordert, diese Konzepte neu zu evaluieren.

Eine Lähmung beschreibt auch Roja von Rönne in ihrem ersten Roman Wir kommen (2016), in der die Protagonistin Nora nie weiß, was sie tun soll, weil sie sich nicht für die >beste< Tätigkeit entscheiden kann. »Ich könnte ein Crowdfunding-Projekt ins Leben rufen. Mich in Stand-up-Comedy versuchen. Mal wieder meine Großmutter anrufen. Meinem Bruder ein Geschenk 
kaufen $\ll^{23}$ - so listet sie mögliche Tätigkeiten auf (im Roman sind es noch viel mehr). Doch

in dem Moment, in dem ich dem einen Gefühl folgen wollte, schaltete sich schon etwas anderes ein, drehte und wendete das Gefühl, hinterfragte die Konsequenzen und die Motive des ersteren und machte es mir unmöglich, mich zu entscheiden. ${ }^{24}$

Die durch Entscheidungsunfähigkeit hervorgerufene Stasis ist, auch ganz abgesehen von Diskursen über Gender, ein auffälliges Merkmal zeitgenössischer Literatur. "Ich wollte es allen recht machen, « schreibt so zum Beispiel Karl Ove Knausgård, "aber $\mathrm{ab}$ und zu tauchten nun einmal Situationen auf, in denen ich wählen und handeln musste, und dann litt ich Höllenqualen, denn das gehörte zum Schlimmsten, was mir überhaupt passieren konnte. « ${ }^{25}$ Die ethische Last der Folgen, die sich aus dem eigenen Handeln ergeben, ist auch in Leif Randts zweitem Roman Schimmernder Dunst über Coby County (2011) präsent, wird jedoch satirisch umgewertet. Der Protagonist Wim denkt:

Manchmal erstaunt es mich, dass mein vom Dasitzen und Lesen dominierter Alltag trotzdem ständig Risiken bereithält. Jede Entscheidung kann falsch sein, jede Formulierung gefährlich, jede Email verletzend. In den seltenen Augenblicken, in denen mir das schlagartig bewusst wird, komme ich mir handlungsunfähig vor. Aber dann handle ich meistens trotzdem, indem ich weiter auf den Bildschirm blicke und lese und irgendwann Grußformeln und Sätze eintippe. Zu dieser Art von Aktion bin ich bislang immer fähig geblieben, selbst wenn mir Sprechen schon unmöglich erschien. ${ }^{26}$

Der Roman erzählt die Stasis der Handlungsunfähigkeit als etwas >Unechtes‘, das vom Protagonisten überwunden werden kann. Die Tatsache jedoch, dass diese Überwindung im Schreiben von Emails bestehen soll, deutet darauf hin, dass das Handeln an sich in der Erzählung nicht mehr ernstgenommen wird obwohl, so impliziert der Roman, es wieder ernstgenommen werden sollte. Eine wirkliche Handlungslähmung gibt, auch wenn sie unangenehm ist, $\mathrm{zu}$ mindest wieder Anlass für die Frage, die Jean-Luc Nancy angesichts desselben

23 Ronja von Rönne: Wir kommen. Berlin: Aufbau (2016), $93 f$.

24 Von Rönne: Wirkommen, 199.

25 Karl Ove Knausgård: Lieben. Übers. v. Paul Berf. München: btb (2013), 415.

26 Leif Randt: Schimmernder Dunst über Coby County. München: Berlin Verlag (2017), 113f. 
Problems jüngst formuliert hat: Was tun ${ }^{27}$ So könnte das Nichtstun auch in der rezenteren Literatur des 21. Jahrhunderts eine neue Grundlage für ein ethisches oder politisches Handlungsbewusstsein zu schaffen beginnen.

27 Vgl. Nancy: Was tun?. 



\section{Literaturverzeichnis}

Adorno, Theodor W. (1974): Versuch, das Endspiel zu verstehen. In: Ders.: Gesammelte Schriften. Bd. 2. Noten zur Literatur. Hg. v. Rolf Tiedemann. Frankfurt a.M.: Suhrkamp, 281-321.

Adorno, Theodor W. (1977): Marginalien zu Theorie und Praxis. In: Ders.: Gesammelte Schriften. Bd. 10.2. Kulturkritik und Gesellschaft II: Eingriffe. Stichworte. Anhang. Hg. v. Rolf Tiedemann. Frankfurt a.M.: Suhrkamp, 769-782. Agamben, Giorgio (1999): Bartleby, or On Contingency. In: Ders.: Potentialities. Collected Essays in Philosophy. Hg. v. Daniel Heller-Roazen. Stanford: UP, 243-271.

Agamben, Giorgio (1999): On Potentiality. In: Ders.: Potentialities. Collected Essays in Philosophy. Hg. v. Daniel Heller-Roazen. Stanford: UP, 177-184.

Agamben, Giorgio (1999): The Messiah and the Sovereign: The Problem of Law in Walter Benjamin. In: Ders.: Potentialities. Collected Essays in Philosophy.

Hg. v. Daniel Heller-Roazen. Stanford: UP, 160-174.

Agamben, Giorgio (1999): Walter Benjamin and the Demonic: Happiness and Historical Redemption. In: Ders.: Potentialities. Collected Essays in Philosophy. Hg. v. Daniel Heller-Roazen. Stanford: UP, 138-159.

Agamben, Giorgio (2002): Homo sacer. Die souveräne Macht und das nackte Leben.

Übers. v. Hubert Thüring. Frankfurt a.M.: Suhrkamp.

Agamben, Giorgio (2003): Die kommende Gemeinschaft. Übers. v. Andreas Hiepko. Berlin: Merve.

Agamben, Giorgio (2006): Mittel ohne Zweck. Noten zur Politik. Übers. v. Sabine Schulz. Zürich: Diaphanes.

Agethen, Matthias (2018): Vergemeinschaftung, Modernisierung, Verausgabung.

Nationalökonomie und Erzählliteratur in der zweiten Hälfte des 19. Jahrhunderts.

Göttingen: V\&R unipress.

Ahmed, Sara (2014): The Cultural Politics of Emotion. Edinburgh: UP.

Ahmed, Sara (2014): Willful Subjects. Durham: Duke UP. 
Althusser, Louis (1964): Problèmes étudiants. In: La Nouvelle Critique 152 (Januar), 80-111.

Ammann, Ludwig (1989): Östliche Spiegel. Ansichten vom Orient im Zeitalter seiner Entdeckung durch den deutschen Leser, 1800-1850. Hildesheim: Georg Olms.

Andrews, Chris (1996): Puzzles and Lists: Georges Perec's »Un Homme qui dort«. In: MLN 111 (4), 775-796.

Arendt, Hannah (1998): The Human Condition. Chicago: University of Chicago Press.

Arendt, Hannah (2013): Vom Leben des Geistes. Das Denken, Das Wollen. Übers. v. Hermann Vetter. Hg. v. Mary McCarthy. München: Piper.

Arendt, Hannah (2015): Was ist Politik? Fragmente aus dem Nachlaß. Hg. v. Ursula Ludz. München: Piper.

Arendt, Hannah (2016): Vita activa oder Vom tätigen Leben. München: Piper.

Arendt, Hannah (2016): Wahrheit und Lüge in der Politik. Zwei Essays. München: Piper.

Arendt, Hannah (2017): Macht und Gewalt. Übers. v. Gisela Uellenberg. München: Piper.

Argast, Regula (2007): Staatsbürgerschaft und Nation. Ausschließung und Integration in der Schweiz 1848-1933. Göttingen: Vandenhoeck \& Ruprecht.

Aristoteles (1956): Werke. Bd. 6. Nikomachische Ethik. Übers. v. Franz Dirlmeier. Hg. v. Ernst Grumach. Berlin: Akademie.

Aristoteles (1991): Werke. Bd. 9. Politik. Übers. v. Eckart Schütrumpf. Hg. v. Hellmut Flashar. Berlin: Akademie.

Aristoteles (2003): Metaphysik. Übers. v. Hans Günter Zekl. Würzburg: Königshausen \& Neumann.

Aron, Raymond (1957): Opium für Intellektuelle oder Die Sucht nach Weltanschauung. Übers. v. Klaus Peter Schulz. Köln: Kiepenheuer \& Witsch.

Aron, Raymond (1968): La révolution introuvable. Réflexions sur les événements de Mai. Paris: Fayard.

Aßländer, Michael S.; Wagner, Bernd (2017): Einführung: Arbeit und Philosophie. In: Philosophie der Arbeit. Texte von der Antike bis zur Gegenwart. Hg. v. Michael S. Aßländer u. Bernd Wagner. Berlin: Suhrkamp, 11-26.

Assmann, Aleida (2000): Die Einsamkeit des Bösen. In: Einsamkeit. Hg. v. Aleida u. Jan Assmann. München: Fink, 129-144.

Augé, Marc (1994): Orte und Nicht-Orte. Vorüberlegungen zu einer Ethnologie der Einsamkeit. Frankfurt a.M.: Fischer.

Austin, John L. (1962): How to do Things with Words. The William James Lectures delivered at Harvard University in 1955. Oxford: Clarendon Press. 
Bachelard, Gaston (1960): La Poétique de la Rêverie. Paris: Presses Universitaires de France.

Banuls, André (2001): Thomas Mann und die französische Literatur. In: Thomas-Mann-Handbuch. Hg. v. Helmut Koopmann. 3., aktualisierte Aufl. Stuttgart: Kröner, 212-229.

Barthes, Roland (1985): Am Nullpunkt der Literatur. Übers. v. Helmut Scheffel. Frankfurt a.M.: Suhrkamp.

Barthes, Roland (2005): Das Neutrum. Vorlesung am Collège de France 1977-1978. Übers. v. Horst Brühmann. Hg. v. Éric Marty. Frankfurt a.M.: Suhrkamp. Barthes, Roland (2007): Wie zusammen leben. Simulationen einiger alltäglicher Räume im Roman. Vorlesung am Collège de France 1976-1977. Übers. v. Horst Brühmann. Hg. v. Éric Marty. Frankfurt a.M.: Suhrkamp.

Baruzzi, Arno (1996): Machbarkeit. Perspektiven unseres Lebens. Freiburg i.Br.: Alber.

Bataille, Georges (1975): Die Aufhebung der Ökonomie. Übers. v. Gerd Bergfleth. München: Rogner und Bernhard.

Bataille, Georges (1994): Die Erotik. Übers. v. Gerd Bergfleth. Berlin: Matthes \& Seitz.

Baudrillard, Jean (1981): Simulacres et simulation. Paris: Galilée.

Baudrillard, Jean (1982): Der Symbolische Tausch und der Tod. Übers. v. Gerd Bergfleth, Gabriele Ricke u. Ronald Voullié. München: Matthes \& Seitz.

Baudrillard, Jean (1990): Das Jahr 2000 findet nicht statt. Übers. v. Peter Geble u. Marianne Karbe. Berlin: Merve.

Bauer, Manuel (2016): Ökonomische Menschen. Literarische Wirtschaftsanthropologie des 19. Jahrhunderts. Göttingen: V\&R unipress.

Baumgärtner, Klaus (1977): Einleitung. In: Sprachliches Handeln. Hg. v. Klaus Baumgärtner. Heidelberg: Quelle \& Meyer, X-XV.

Beauvoir, Simone de (1995): Das andere Geschlecht. Sitte und Sexus der Frau. Übers. v. Uli Aumüller u. Grete Osterwald. Reinbek bei Hamburg: Rowohlt.

Beckett, Samuel (1995): Eleutheria. Paris: Éditions de Minuit.

Benjamin, Walter (1977): Zur Kritik der Gewalt. In: Ders.: Gesammelte Schriften. Bd. 2,1. Hg. v. Rolf Tiedemann u. Hermann Schweppenhäuser. Frankfurt a.M.: Suhrkamp, 179-203.

Benjamin, Walter (2007): Der Erzähler. In: Ders.: Erzählen. Schriften zur Theorie der Narration und zur literarischen Prosa. Hg. v. Alexander Honold. Frankfurt a.M.: Suhrkamp, 103-128. 
Benko, Stephen (1993): The Virgin Goddess. Studies in Pagan and Christian Roots of Mariology. Leiden: Brill.

Berman, Nina (1997): Orientalismus, Kolonialismus und Moderne. Zum Bild des Orients in der deutschsprachigen Kultur um 1900. Stuttgart: Metzler.

Bernstein, Richard J. (1971): Praxis and Action. Contemporary Philosophies of Human Activity. Philadelphia: University of Pennsylvania Press.

Beßlich, Barbara (2002): Faszination des Verfalls. Thomas Mann und Oswald Spengler. Berlin: Akademie.

Blanchot, Maurice (2007): Die uneingestehbare Gemeinschaft. Übers. v. Gerd Bergfleth. Berlin: Matthes \& Seitz.

Blanchot, Maurice (2010): Einklammerungen. In: Ders.: Das Neutrale. Schriften und Fragmente zur Philosophie. Übers. u. hg. v. Marcus Coelen. Zürich: Diaphanes, 23-30.

Blanchot, Maurice (2010): René Char und das Denken des Neutralen. In: Ders.: Das Neutrale. Schriften und Fragmente zur Philosophie. Übers. u. hg. v. Marcus Coelen. Zürich: Diaphanes, 15-21.

Blum, Bianca E. (2019): »Meiden Sie Untätigkeit, sie ist die Mutter aller Laster..."$\mathrm{Zu}$ Muße und Weiblichkeit in der russischen Literatur des 19. Jahrhunderts. Hamburg: Kovac.

Böhme, Hartmut (1988): Natur und Subjekt. Frankfurt a.M.: Suhrkamp.

Bon, Gustave Le (1953): Psychologie der Masse. [Übers. v. Rudolf Eisler.] Stuttgart: Kröner.

Boone, Joseph A. (2015): The Homoerotics of Orientalism. New York: Columbia UP.

Bordt, Michael (2011): Why Aristotle's God is Not the Unmoved Mover. In: Oxford Studies in Ancient Philosophy 40, 91-109.

Bourdieu, Pierre; Passeron, Jean-Claude (2007): Die Erben. Studenten, Bildung und Kultur. Übers. v. Stephan Egger u. Eva Kessler. Konstanz: UVK.

Brenner, Peter J. (1990): Der Reisebericht in der deutschen Literatur. Ein Forschungsüberblick als Vorstudie zu einer Gattungsgeschichte. Tübingen: Niemeyer.

Brokoff, Jürgen (2002): Die apokalyptische Vernichtung des Rechts. Zur politischen Theologie Walter Benjamins. In: Apokalypse und Erinnerung in der deutsch-jüdischen Kultur des frühen 20. Jahrhunderts. Hg. v. Jürgen Brokoff u. Joachim Jacob. Göttingen: Vandenhoeck \& Ruprecht, 39-57.

Bryson, Norman (1988): The Gaze in the Expanded Field. In: Vision and Visuality. Hg. v. Hal Foster. Seattle: Bay Press, 87-108.

Bukraba-Rylska, Izabella (2009): Polish Countryside in Times of Transition. Myths and Reality. In: Polish Sociological Review 168, 575-594. 
Buning, Marius (2000): The »Via Negativa« and its First Stirrings in »Eleutheria«. In: Beckett and Religion. Beckett/Aesthetics/Politics. Hg. v. Marius Buning, Matthijs Engelberts u. Onno Kosters. Amsterdam: Rodopi, 43-54.

Busch, Kathrin (2013): Elemente einer Philosophie der Passivität. In: Theorien der Passivität. Hg. v. Kathrin Busch u. Helmut Draxler. München: Fink, 1431.

Camus, Albert (2015): Der Mythos des Sisyphos. Übers. v. Vincent von Wroblewsky. Reinbek bei Hamburg: Rowohlt.

Castel, Robert (2000): Die Metamorphosen der sozialen Frage. Eine Chronik der Lohnarbeit. Übers. v. Andreas Pfeuffer. Konstanz: UVK.

Certeau, Michel de (1988): Kunst des Handelns. Übers. v. Ronald Voullié. Berlin: Merve.

Chalonge, Florence de (2012): Stylistique de l'indifférence. Un homme qui dort. In: Georges Perec. Artisan de la Langue. Hg. v. Véronique Montémont u. Christelle Reggiani. Lyon: Presses Universitaires, 145-153.

Conrad, Sebastian (2008): Deutsche Kolonialgeschichte. München: Beck.

Conrad, Sebastian (2008): Globalization effects. Mobility and nation in Imperial Germany. 1880-1914. In: Journal of Global History 3 (1), 43-66.

Dahrendorf, Ralf (2006): Homo Sociologicus. Wiesbaden: VS Verlag für Sozialwissenschaften.

Davidson, Donald (2002): Agency. In: Ders.: Essays on Actions and Events. Oxford: Clarendon Press, 43-61.

Deich, Werner (1974): Der Angestellte im Roman. Zur Sozialgeschichte des Handlungsgehilfen um 1900. Köln: Grote.

Deines, Timothy J. (2006): Bartleby the Scrivener, Immanence and the Resistance of Community. In: Culture Machine 8.

Deleuze, Gilles (1994): Bartleby oder die Formel. Übers. v. Bernhard Dieckmann. Berlin: Merve.

Deleuze, Gilles (2008): Erschöpft. In: Ders.: He, Joe, Quadrat I und II, Nacht und Träume, Geister-Trio. Filme für den SDR. Übers. v. Erika Tophoven. Frankfurt a.M.: Suhrkamp; Absolut Medien, 5-41.

Derrida, Jacques (2003): Eine gewisse unmögliche Möglichkeit, vom Ereignis zu sprechen. Übers. v. Susanne Lüdemann. Berlin: Merve.

Desmarais, Jane (2001): Preferring not to. The Paradox of Passive Resistance in Herman Melville's »Bartleby«. In: Journal of the Short Story in English 36 (Spring), 25-39 [Online Absatzzahlen 1-22].

Detering, Heinrich (2010): Anfänge einer modernen China-Rezeption in deutschen Kulturzeitschriften um 1900. In: Perspektiven der Modernisierung. Die 
Pariser Weltausstellung, die Arbeiterbewegung, das koloniale China in europäischen und amerikanischen Kulturzeitschriften um 1900. Hg. v. Ulrich Mölk, Christoph Jürgensen u. Heinrich Detering. Berlin: De Gruyter, 155-170.

Dischner, Gisela (2014): Melancholie und Müßiggang - Eine Zustandsbeschreibung. In: Ökonomie des Glücks. Muße, Müßiggang und Faulheit in der Literatur. Hg. v. Mirko Gemmel u. Claudia Löschner. Berlin: Ripperger \& Kremers, 7-15.

Dobie, Madeleine (2001): Foreign Bodies. Gender, Language, and Culture in French Orientalism. Stanford: UP.

Düsing, Wolfgang (1981): Friedrich Schiller. Über die ästhetische Erziehung des Menschen in einer Reihe von Briefen. Text, Materialien, Kommentar. München: Hanser.

Eagleton, Terry (2012): The Event of Literature. New Haven: Yale UP.

Ehrenberg, Alain (2004): Das erschöpfte Selbst. Depression und Gesellschaft in der Gegenwart. Übers. v. Manuela Lenzen u. Martin Klaus. Frankfurt a.M.: Campus.

Eickhoff, Hajo (2014): Thronen als Denken und Meditieren. Die Medialität von Thron und Stuhl. In: Möbel als Medien. Beiträge zu einer Kulturgeschichte der Dinge. Hg. v. Sebastian Hackenschmidt u. Klaus Engelhorn. Bielefeld: transcript, 33-45.

Engelberg, Edward (1999): Ambiguous Solitude. Hans Castorp's Sturm und Drang nach Osten. In: A Companion to Thomas Mann's The Magic Mountain. Hg. v. Stephen D. Dowden. Columbia: Camden House, 95-108.

Engels, Johannes (2006): Merces auctoramentum servitutis - Die Wertschätzung bestimmter Arbeiten und Tätigkeiten durch antike heidnische Philosophen. In: Arbeit im Mittelalter. Vorstellungen und Wirklichkeiten. Hg. v. Verena Postel. Berlin: Akademie.

Engels, David (2015): Biologistische und zyklische Geschichtsphilosophie. Ein struktureller Annäherungsversuch. In: Von Platon bis Fukuyama. Biologistische und zyklische Konzepte in der Geschichtsphilosophie der Antike und des Abendlandes. Hg. v. David Engels. Brüssel: Éditions Latomus, 8-46.

Engler, Wolfgang (2005): Bürger, ohne Arbeit. Für eine radikale Neugestaltung der Gesellschaft. Berlin: Aufbau.

Erwig, Andrea (2018): Waiting Plots. Paderborn: Fink.

Esposito, Fernando; Gumbrecht, Hans U. (2017): Posthistoire Then. Ein Gespräch mit Hans Ulrich Gumbrecht über »unsere breite Gegenwart«. In: Zeitenwandel. Transformationen geschichtlicher Zeitlichkeit nach dem Boom. Hg. v. Fernando Esposito. Göttingen: Vandenhoeck \& Ruprecht, 255-278. 
Fähnders, Walter (2015): »Generalstreik das Leben lang!«. Arbeit, Arbeitsverweigerung und Vagabondage. In: Arbeit und Protest in der Literatur vom Vormärz bis zur Gegenwart. Hg. v. Iuditha Balint u. Hans-Joachim Schott. Würzburg: Königshausen \& Neumann, 65-87.

Felman, Shoshana (1975): Madness and Philosophy or Literature's Reason. In: Yale French Studies 52, 206-228.

Finkin, Matthew (2007): Arbeit, Arbeitsrecht und Wissenschaft. Webers Frage. Übers. v. Rudolf Buschmann. In: Arbeit und Recht 55 (12), 409-412.

Finlay, Christopher J. (2009): Hannah Arendt's Critique of Violence. In: Thesis Eleven 97 (1), 26-45.

Fischer, Annalisa (2018): Preface. In: Faking, Forging, Counterfeiting. Discredited Practices at the Margins of Mimesis. Hg. v. Daniel Becker, Annalisa Fischer u. Yola Schmitz. Bielefeld: transcript, 7-10.

Flaßpöhler, Svenja (2011): Wir Genussarbeiter. Über Freiheit und Zwang in der Leistungsgesellschaft. München: DVA.

Flaubert, Gustave (1980): Die Erziehung des Herzens. Geschichte eines jungen Mannes. Übers. v. Emil Alphons Rheinhardt. Zürich: Diogenes.

Formenti, Laura (2016): Auto/Biography. A Relational Journey. In: Constructing Narratives of Continuity and Change. A Transdisciplinary Approach to Researching Lives. Hg. v. Hazel L. Reid u. Linden West. London: Routledge, 11-24.

Foucault, Michel (1989): Wahnsinn und Gesellschaft. Eine Geschichte des Wahns im Zeitalter der Vernunft. Übers. v. Ulrich Köppen. Frankfurt a.M.: Suhrkamp. Foucault, Michel (1992): Andere Räume. In: Aisthesis. Wahrnehmung heute oder Perspektiven einer anderen Ästhetik. Übers. v. Walter Seitter. Hg. v. Karlheinz Barck. Leipzig: Reclam, 34-46.

Foucault, Michel (1992): Was ist Kritik? Übers. v. Walter Seitter. Berlin: Merve. Foucault, Michel (2003): Der Wahnsinn, Abwesenheit eines Werks. In: Ders.: Schriften zur Literatur. Übers. v. Hans-Dieter Gondek. Hg. v. Daniel Defert u. François Ewald. Frankfurt a.M.: Suhrkamp, 175-185.

Foucault, Michel (2010): [Von der Souveränität zur Disziplin]. Vorlesung vom 7. Januar 1976. In: Ders.: Kritik des Regierens. Schriften zur Politik. Übers. v. Hans-Dieter Gondek. Hg. v. Ulrich Bröckling. Berlin: Suhrkamp, 9-26.

Freud, Sigmund (2009): Das Unbehagen in der Kultur. Und andere kulturtheoretische Schriften. Frankfurt a.M.: Fischer.

Freudenstein, Roland; Tewes, Henning (2001): Wem die Glocken läuten. Ist Polen auf den Beitritt zur EU vorbereitet? In: KAS-Auslandsinformationen 17 (5), 95-108. 
Früchtl, Josef (2013): Eine Kunst der Geste. Den Bildern Geschichte und Bewegung zurückgeben. In: Ders.: Vertrauen in die Welt. Eine Philosophie des Films. München: Fink, 149-163.

Fuest, Leonhard (2008): Poetik des Nicht(s)tuns. Verweigerungsstrategien in der Literatur seit 1800. München: Fink.

Fuhrmann, Ernst (1921): China. Das Land der Mitte. Ein Umriss. Bd. 1. Hagen i.W.: Folkwang-Verlag.

Fynsk, Christopher (2015): Linguistic Turn. In: International Encyclopedia of the Social \& Behavioral Sciences. Bd. 14. Hg. v. James D. Wright. Amsterdam: Elsevier, 199-201.

Gamper, Michael (2007): Masse lesen, Masse schreiben. Eine Diskurs- und Imaginationsgeschichte der Menschenmenge 1765 - 1930. München: Fink.

Garcia, Tristan (2018): Wir. Übers. v. Ulrich Kunzmann. Berlin: Suhrkamp.

Gascoigne, David (2006): The Games of Fiction. Georges Perec and Modern French Ludic Narrative. Bern: Peter Lang.

Gawrich, Andrea (2003): Vor dem Referendum in Polen. In: Internationale Politik I (Januar), 19-20.

Gehlen, Arnold (1963): Über kulturelle Kristallisation. In: Ders.: Studien zur Anthropologie und Soziologie. Neuwied: Luchterhand, 311-328.

Gehlen, Arnold (2004): Ende der Geschichte? In: Ders.: Gesamtausgabe. Bd. 6. Die Seele im technischen Zeitalter und andere sozialpsychologische, soziologische und kulturanalytische Schriften. Frankfurt a.M.: Klostermann, 336-351.

Geier, Manfred (1997): Das Glück der Gleichgültigen. Von der stoischen Seelenruhe zur postmodernen Indifferenz. Reinbek bei Hamburg: Rowohlt.

Gimmel, Jochen (2019): Zum Begriff des Nicht/Handelns und der Hoffnung, Geschichte zum Stillstand bringen zu können. In: Zwischen Handeln und Nichthandeln. Unterlassungspraktiken in der europäischen Moderne. Hg. v. Theo Jung. Frankfurt a.M.: Campus, 293-317.

Gimmel, Jochen; Keiling, Tobias (2016): Konzepte der Muße. Tübingen: Mohr Siebeck.

Glosch, Kathrin (2001): „Cela m'était égal«. Zu Inszenierung und Funktion von Gleichgültigkeit in der französischen Literatur des 20. Jahrhunderts. Stuttgart: Metzler.

Goldman, Harvey (1992): Politics, Death, and the Devil. Selfand Power in Max Weber and Thomas Mann. Berkeley: University of California Press.

Gollwitzer, Heinz (1962): Die gelbe Gefahr. Geschichte eines Schlagworts. Studien zum imperialistischen Denken. Göttingen: Vandenhoeck \& Ruprecht. 
Gölz, Christine; Kliems, Alfrun (2014): Vorwort. In: Spielplätze der Verweigerung. Gegenkulturen im östlichen Europa nach 1956. Hg. v. Christine Gölz u. Alfrun Kliems. Köln: Böhlau, 9-22.

Gontscharow, Iwan (2009): Oblomow. Roman in vier Teilen. Übers. v. Clara Brauner. Frankfurt a.M.: Fischer.

Graeber, David (2018): Bullshit Jobs. A Theory. London: Allen Lane (Penguin).

Greenblatt, Stephen (2018): Tyrant. Shakespeare on Power. London: The Bodley Head.

Greimas, Algirdas J. (1971): Strukturale Semantik. Methodologische Untersuchungen. Übers. v. Jens Ihwe. Wiesbaden: Vieweg.

Greven, Jochen (2009): Existenz, Welt und reines Sein im Werk Robert Walsers. Versuch zur Bestimmung von Grundstrukturen. Paderborn: Fink.

Gronau, Barbara; Lagaay, Alice (2008): Performanzen des Nichttuns. Wien: Passagen.

Gumbrecht, Hans U. (2016): Präsenz. Hg. v. Jürgen Klein. Berlin: Suhrkamp.

Haiman, John (1998): Talk Is Cheap. Sarcasm, Alienation, and the Evolution of Language. Oxford: UP.

Halpern, Richard (2011): Theater and Democratic Thought: Arendt to Rancière. In: Critical Inquiry 37 (3), 545-572.

Hamacher, Werner (1994): Afformativ, Streik. In: Was heißt »Darstellen«? Hg. v. Christiaan L. Hart Nibbrig. Frankfurt a.M.: Suhrkamp, 340-371.

Hamann, Richard; Hermand, Jost (1976): Epochen deutscher Kultur von 1870 bis zur Gegenwart. Bd. 2. Naturalismus. München: Nymphenburger Verlagshandlung.

Han, Byung-Chul (2010): Müdigkeitsgesellschaft. Berlin: Matthes \& Seitz.

Haus Bartleby (Hg.) (2015): Sag alles ab! Plädoyers für den lebenslangen Generalstreik. Hamburg: Edition Nautilus.

Hegel, Georg W. F. (1970): Werke. Bd. 12. Vorlesungen über die Philosophie der Geschichte. Hg. v. Eva Moldenhauer u. Karl Markus Michel. Frankfurt a.M.: Suhrkamp.

Heidegger, Martin (1983): Gesamtausgabe. II Abt. Vorlesungen. Bd. 29/30. Die Grundbegriffe der Metaphysik. Welt - Endlichkeit - Einsamkeit. Hg. v. Friedrich-Wilhelm von Herrmann. Frankfurt a.M.: Klostermann. Heidegger, Martin (1992): Was ist Metaphysik? Frankfurt a.M.: Klostermann. Helfer, Joachim (2007): Von den Ordnungen des Geschlechtlichen. Unter der Gürtellinie. In: Merkur 61 (700), 860-869.

Herwig, Christopher (2015): Soviet Bus Stops. London: FUEL. 
Hesse, Hermann (1975): Chinesisches. In: Ders.: Eine Literaturgeschichte in Rezensionen und Aufsätzen. Hg. v. Volker Michels. Frankfurt a.M.: Suhrkamp, 25-40.

Hill, Leslie (2018): Nancy, Blanchot. A Serious Controversy. London: Rowman \& Littlefield International.

Hirszowicz, Maria (1998): Spory o przyszłość. Klasa, polityka, jednostka. Warschau: Wydawnictwo IFiS PAN.

Hłasko, Marek (1962): Der achte Tag der Woche/Die Friedhöfe. Übers. v. Vera Cerny (Der achte Tag der Woche) u. Maryla Reifenberg. München: DTV.

Hole, Kristin (2013): The Ethics of Community: Nancy, Blanchot, Esposito. In: Angelaki 18 (3), 103-118.

Holona, Marian (1980): Arbeit, Mediocritas, Müssiggang. Zur Sozialethik in Robert Walsers Kleinprosa. Warschau: Wydawnictwa Uniwersytetu Warszawskiego.

Hong, Kil-Pyo (2002): Selbstreflexion von Modernität in Robert Walsers Romanen »Geschwister Tanner«, »Der Gehülfe« und »Jakob von Gunten«. Würzburg: Königshausen \& Neumann.

Honneth, Axel (2010): Das Ich im Wir. Studien zur Anerkennungstheorie. Berlin: Suhrkamp.

Horst, Johanna-Charlotte (2017): Perecs Erbschaften. Zur Poetik der oulipotischen Freiheit. Dissertation. München: Ludwig-Maximilians-Universität.

Hulme, Peter (1985): Polytropic Man. Tropes of Sexuality and Mobility in Early Colonial Discourse. In: Europe and Its Others. Proceedings of the Essex Conference on the Sociology of Literature, July 1984. Hg. v. Francis Barker, Peter Hulme, Margaret Iversen u. Diana Loxley. Colchester: University of Essex, 17-32.

Huysmans, Joris-Karl (2015): Gegen den Strich. Übers. v. Brigitta Restorff. München: DTV.

Jaeggi, Rahel (2008): Wie weiter mit Hannah Arendt? Hamburg: Hamburger Edition.

Jameson, Fredric (1991): Postmodernism, or, The Cultural Logic of Late Capitalism. Durham: Duke UP.

Jochum, Georg (2010): Arbeit als Grundlage menschlicher Existenz: Zur historischen Entwicklung des Verständnisses von Arbeit. In: Handbuch Arbeitssoziologie. Hg. v. Fritz Böhle, G. Günter Voß u. Günther Wachtler. Wiesbaden: VS Verlag für Sozialwissenschaften, 81-125.

Jung, Theo (2019): Einleitung. Bartleby und das Unterlassen: Elemente einer historischen Praxeologie des Nicht/Handelns. In: Zwischen Handeln und 
Nichthandeln. Unterlassungspraktiken in der europäischen Moderne. Hg. v. Theo Jung. Frankfurt a.M.: Campus, 9-39.

Kafka, Franz (1992): >Bau<-Konvolut. [Der Bau]. In: Ders.: Schriften, Tagebücher, Briefe. Kritische Ausgabe. Nachgelassene Schriften und Fragmente II. Hg. v. Jürgen Born, Gerhard Neumann, Malcolm Pasley u. Jost Schillemeit. Frankfurt a.M.: Fischer, 575-632.

Kafka, Franz (2012): Das Schloß. Frankfurt a.M.: Fischer.

Kampffmeyer, Georg (1913): Plane Perspicere. In: Die Welt des Islams 1 (1), 1-6.

Kang, Taran (2013): Origin and Essence: The Problem of History in Hannah Arendt. In: Journal of the History of Ideas 74 (1), 139-160.

Kantorowicz, Ernst H. (1957): The King's Two Bodies. A Study in Mediaeval Political Theology. Princeton: UP.

Kendon, Adam (2004): Gesture. Visible Action as Utterance. Cambridge: UP.

Kennedy, Paul M. (1982): The Rise of the Anglo-German Antagonism. 1860-1914. London: George Allen and Unwin.

Kerchner, Brigitte (2006): Genealogie und Performanz. Überlegungen zu einer kritischen Analyse des Regierens. In: Politisierung und Ent-Politisierung als performative Praxis. Hg. v. Detlef Georgia Schulze, Sabine Berghahn u. Frieder Otto Wolf. Münster: Westfälisches Dampfboot, 58-81.

Kittstein, Lothar (2003): Politik im Zeitalter der Revolution. Untersuchungen zur preußischen Staatlichkeit 1792-1807. Stuttgart: Steiner.

Knauer, James T. (1980): Motive and Goal in Hannah Arendt's Concept of Political Action. In: American Political Science Review 74 (3), 721-733.

Knausgård, Karl Ove (2013): Lieben. Übers. v. Paul Berf. München: btb.

Koch, Manfred (2012): Faulheit. Eine schwierige Disziplin. Springe: zu Klampen. Kocik, Lucjan (2001): Trauma i eurosceptycyzm polskiej wsi. Krakau: Universitas. Kojève, Alexandre (1947): Introduction à la lecture de Hegel. Hg. v. Raymond Queneau. Paris: Gallimard.

Kontje, Todd (2004): German Orientalisms. Ann Arbor: University of Michigan Press.

Koopmann, Helmut (1988): Der schwierige Deutsche. Studien zum Werk Thomas Manns. Tübingen: Niemeyer.

Koschorke, Albrecht; Lüdemann, Susanne; Frank, Thomas; Matala de Mazza, Ethel (Hgs.) (2007): Der fiktive Staat. Konstruktionen des politischen Körpers in der Geschichte Europas. Frankfurt a.M.: Fischer.

Kośmicki, Eugeniusz; Czaja, Zdzisław; Janik, Wojciech (Hgs.) (2000): Problem barier świadomościowych na wsi wobec integracji Polski z Unią Europejską. Poznań: AR. 
Kracauer, Siegfried (1971): Die Angestellten. Aus dem neuesten Deutschland. Frankfurt a.M.: Suhrkamp.

Kracauer, Siegfried (1977): Die kleinen Ladenmädchen gehen ins Kino. In: Ders.: Das Ornament der Masse. Essays. Frankfurt a.M.: Suhrkamp, 279-294. Krause, Robert (2018): Muße und Moderne. Zur Einführung. In: Muße und Moderne. Hg. v. Tobias Keiling, Robert Krause u. Heidi Liedke. Tübingen: Mohr Siebeck, 1-6.

Kraushaar, Wolfgang (2000): 1968 als Mythos, Chiffre und Zäsur. Hamburg: Hamburger Edition.

Krauze, Andrzej (1980): Lubta mnie. Wybór rysunków z lat 1976-78. Warschau: Czytelnik.

Kristiansen, Børge (1978): Unform - Form - Überform. Thomas Manns Zauberberg und Schopenhauers Metaphysik. Kopenhagen: Akademisk Forlag.

Kuechler Williams, Christiane (2001): Die Entdeckung des erotischen Paradieses. Eine Untersuchung der europäischen Südseerezeption im 18. Jahrhundert. Dissertation. Evanston: Northwestern University.

Kuhn, Reinhard C. (2017): The Demon of Noontide. Ennui in Western Literature. Princeton: UP.

Kuhn, Roman (2013): Zweite Person Singular Präsens. Überlegungen zu »Ein Mann der schläft« von Georges Perec. In: Der Präsensroman. Hg. v. Armen Avanessian u. Anke Hennig. Berlin: De Gruyter, 210-223.

Kulishkina, Olga (2018): Walter Scotts »St Ronan's Well« und die Konstruktion des Kurort-Diskurses in der russischen Literatur. In: Die Produktivität des Plagiats. The Productivity of Plagiarism. Hg. v. Charlotte Krauss, Christine Baron u. Larissa Polubojarinova. Münster: LIT, 117-128.

Kurbacher, Frauke A. (2017): Zwischen Personen. Eine Philosophie der Haltung. Würzburg: Königshausen \& Neumann.

Kwaśniewicz, Władysław (2003): Between a Post-Feudal and a Post-Industrial Model. Polish Society in the 2oth Century. In: Polish Sociological Review 144, 387-397.

Lagaay, Alice (2016): Sleepwalking Through the Neutral. In: Performance Research 21 (1), 37-41.

Lagasnerie, Geoffroy de (2017): The Art of Revolt. Snowden, Assange, Manning. Übers. v. Erik Butler. Redwood City: Stanford UP.

Lave, Jean; Wenger, Etienne (1991): Situated Learning. Legitimale Peripheral Participation. Cambridge: UP.

Lao-tse (1959): Tao-Tê-King. Übers. v. Victor von Strauß. Hg. v. Willy Y. Tonn. Zürich: Manesse. 
Lederer, Emil (1912): Die Privatangestellten in der modernen Wirtschaftsentwicklung. Tübingen: Mohr Siebeck.

Leeder, Natalie (2017): Freedom and Negativity in Beckett and Adorno. Something or Nothing. London: Rowman \& Littlefield International.

Lefort, Claude (2009): Die leere Mitte. Essays 1945-2005. Frankfurt a.M.: Suhrkamp.

Lenin, Vladimir I. (1971): Was tun? Brennende Fragen unserer Bewegung. Berlin: Dietz.

Lepenies, Wolf (1998): Melancholie und Gesellschaft. Mit einer neuen Einleitung: Das Ende der Utopie und die Wiederkehr der Melancholie. Frankfurt a.M.: Suhrkamp.

Lillge, Claudia; Unger, Thorsten; Weyand, Björn (2016): Arbeit und Müßiggang in der Romantik. Eine Einführung. In: Arbeit und Müßiggang in der Romantik. Hg. v. Claudia Lillge, Thorsten Unger u. Björn Weyand. Paderborn: Fink, 11-36.

Locke, John (1952): The Second Treatise of Government. With an Introduction by Thomas P. Peardon. Hg. v. Thomas P. Peardon. New York: Liberal Arts Press. Loomba, Ania (2015): Colonialism/Postcolonialism. Abingdon, Oxon: Routledge. Lotman, Jurij M. (1972): Die Struktur literarischer Texte. Übers. v. Rolf-Dietrich Keil. München: Fink.

Mann, Thomas (2002): Der Zauberberg. Große kommentierte Frankfurter Ausgabe. Bd. 5,1. Hg. v. Heinrich Detering, Eckhard Heftrich, Hermann Kurzke u.a. Frankfurt a.M.: Fischer.

Marchand, Suzanne L. (2009): German Orientalism in the Age of Empire. Religion, Race, and Scholarship. Cambridge: UP.

Marszałek, Magdalena (2014): Das Dorf als Anti-Idylle: Polnische literarische und filmische Narrative des Verdrängten. In: Imaginäre Dörfer. Zur Wiederkehr des Dörflichen in Literatur, Film und Lebenswelt. Hg. v. Werner Nell u. Marc Weiland. Bielefeld: transcript, 425-438.

Marszałek, Magdalena (2018): Dörfliches Coming-out. Autobiographische Stimmen aus dem Dorf in der polnischen Gegenwartsliteratur. In: Über Land. Aktuelle literatur- und kulturwissenschaftliche Perspektiven auf Dorf und Ländlichkeit. Hg. v. Marc Weiland, Magdalena Marszałek u. Werner Nell. Bielefeld: transcript, 211-225.

Martinez, Matias; Scheffel, Michael (2007): Einführung in die Erzähltheorie. München: Beck. 
Marx, Karl (1844): Zur Kritik der Hegelschen Rechtsphilosophie. In: DeutschFranzösische Jahrbücher. Hg. v. Karl Marx u. Arnold Ruge. Paris: Bureau der Jahrbücher, 71-85.

Marx, Karl; Engels, Friedrich (1970): Historisch-Kritische Gesamtausgabe. 1. Abt., Bd. 5. Deutsche Ideologie. Hg. v. Vladimir Adoratskij. Glashütten: Auvermann.

Matala de Mazza, Ethel (1999): Der verfaßte Körper. Zum Projekt einer organischen Gemeinschaft in der politischen Romantik. Freiburg i.Br.: Rombach.

Matala de Mazza, Ethel; Hebekus, Uwe (2003): Einleitung. Zwischen Verkörperung und Ereignis. Zum Andauern der Romantik im Denken des Politischen. In: Das Politische. Figurenlehren des sozialen Körpers nach der Romantik. Hg. v. Ethel Matala de Mazza, Uwe Hebekus u. Albrecht Koschorke. München: Fink, 7-22.

Matthes, Joachim (Hg.) (1983): Krise der Arbeitsgesellschaft? Verhandlungen des 21. Deutschen Soziologentages in Bamberg 1982. Frankfurt a.M.: Campus.

Maurer, Kathrin (2010): Der panoramatische Blick auf das Andere in Ida von Hahn-Hahns Reisebericht `Orientalische Briefe`(1844). In: The German Quarterly 83 (2), 153-171.

McClintock, Anne (1995): Imperial Leather. Race, Gender and Sexuality in the Colonial Contest. New York: Routledge.

McCormick, John (2008): Review: Ambiguous Immediacy. The Assistant by Robert Walser. In: The Sewanee Review 116 (4), lxxxviii-xc.

Melville, Herman (2013): Bartleby, The Scrivener. In:Amerikanische Meistererzählungen/Famous American Short Stories. Zweisprachige Ausgabe. Köln: Anaconda, 80-173.

Mill, John S. (1948): On Liberty. And Considerations on Representative Government. Hg. v. Ronald B. McCallum. Oxford: Blackwell.

Miller, Anita (1996): Georges Perec. Zwischen Anamnese und Struktur. Bonn: Romanistischer Verlag.

Minden, Michael (1997): The German Bildungsroman. Incest and Inheritance. Cambridge: UP.

Moeller, Hans-Georg (2006): The Philosophy of the Daodejing. New York: Columbia UP.

Montesquieu (1951): Vom Geist der Gesetze. Bd 1. Übers. v. Ernst Forsthoff. Tübingen: H. Laupp'sche Buchhandlung.

Moretti, Franco (2014): The Bourgeois. Between History and Literature. London: Verso. 
Murti, Kamakshi P. (2001): India. The Seductive and Seduced »Other" of German Orientalism. Westport: Greenwood.

Musil, Robert (2014): Der Mann ohne Eigenschaften. Erstes und zweites Buch. Hg. v. Adolf Frisé. Reinbek bei Hamburg: Rowohlt.

Naguib, Nagi (1969): Studien zu den Romanen Robert Walsers. München: Fink.

Nahacz, Mirosław (2004): Bombel. Wołowiec: Wydawnictwo Czarne.

Nahacz, Mirosław (2008): Bombel. Übers. v. Renate Schmidgall. Frankfurt a.M.: Weissbooks.

Nancy, Jean-Luc (1991): The Inoperative Community. Übers. v. Peter Connor, Lisa Garbus, Michael Holland u. Simona Sawhney. Hg. v. Peter Connor. Minneapolis: University of Minnesota Press.

Nancy, Jean-Luc (2017): Was tun? Übers. v. Martine Hénissart u. Thomas Laugstien. Zürich: Diaphanes.

Nancy, Jean-Luc (2018): Von einer Gemeinschaft, die sich nicht verwirklicht. Übers. v. Esther von der Osten. Wien: Turia + Kant.

Nicholls, Roger A. (1985): Thomas Mann and Spengler. In: The German Quarterly 58 (3), 361-374.

Nietzsche, Friedrich (1964): Sämtliche Werke. Bd. VII. Jenseits von Gut und Böse. Zur Genealogie der Moral. Stuttgart: Kröner.

O'Connor, Brian (2018): Idleness. A Philosophical Essay. Princeton: UP.

Osterhammel, Jürgen (1989): China und die Weltgesellschaft. Vom 18. Jahrhundert bis in unsere Zeit. München: Beck.

Owens, Lisa (2017): Not Working. London: Picador.

Perec, Georges (1967): Un homme qui dort. Paris: Éditions Denoël.

Perec, Georges (2012): Ein Mann der schläft. Übers. v. Eugen Helmlé. Zürich: Diaphanes.

Peters, Jochen-Ulrich (1996): Enttabuisierung und literarischer Funktionswandel. In: Enttabuisierung. Essays zur russischen und polnischen Gegenwartsliteratur. Hg. v. Jochen-Ulrich Peters u. German Ritz. Bern: Peter Lang, 7-17.

Porter, Brian (2005): Hetmanka and Mother: Representing the Virgin Mary in Modern Poland. In: Contemporary European History 14 (2), 151-170.

Pratt, Mary Louise (1992): Imperial Eyes. Travel Writing and Transculturation. London: Routledge.

Proust, Marcel (1997): Auf der Suche nach der verlorenen Zeit. In Swanns Welt. Übers. v. Eva Rechel-Mertens. Frankfurt a.M.: Suhrkamp.

Rancière, Jacques (2002): Das Unvernehmen. Politik und Philosophie. Übers. v. Richard Steurer. Frankfurt a.M.: Suhrkamp. 
Rancière, Jacques (2008): Die Aufteilung des Sinnlichen. Die Politik der Kunst und ihre Paradoxien. Übers. v. Jürgen Link. Hg. v. Maria Muhle. Berlin:b_books.

Randt, Leif (2017): Schimmernder Dunst über Coby County. München: Berlin Verlag.

Reinhardt, Volker (2014): Geschichte der Schweiz. München: Beck.

Ricapito, Joseph V. (1966): Toward a Definition of the Picaresque. A Study of the Evolution of the Genre. Dissertation. Los Angeles: UCLA.

Rifkin, Jeremy (1995): The End of Work. The Decline of the Global Labor Force and the Dawn of the Post-Market Era. New York: G. P. Putnam's Sons.

Riggan, William (1981): Pícaros, Madmen, Naïfs, and Clowns. The Unreliable FirstPerson Narrator. Norman: University of Oklahoma Press.

Rölli, Marc (2004): Einleitung: Ereignis auf Französisch. In: Ereignis auf Französisch. Von Bergson bis Deleuze. Hg. v. Marc Rölli. München: Fink, 7-40.

Rönne, Ronja von (2016): Wir kommen. Berlin: Aufbau.

Rötzer, Hans G. (2009): Der europäische Schelmenroman. Stuttgart: Reclam.

Rubiés, Joan-Pau (2005): Botero to Montesquieu: Oriental Despotism and European Orientalism. In: Journal of Early Modern History 9 (1), 109-180.

Rüsch, Lukas (1983): Ironie und Herrschaft. Untersuchungen zum Verhältnis von Herr und Knecht in Robert Walsers Roman »Der Gehülfe«. Königstein/Ts.: Forum Academicum.

Said, Edward W. (1979): Orientalism. New York: Vintage.

Schaffner, Anna K. (2016): Exhaustion. A History. New York: Columbia UP.

Schivelbusch, Wolfgang (2001): Die Kultur der Niederlage. Der amerikanische Süden 1865, Frankreich 1871, Deutschland 1918. Berlin: Fest.

Schlegel, August W. (1812-13): Über das Mittelalter. Eine Vorlesung, gehalten 1803. In: Deutsches Museum. Bd. 2. Hg. v. Friedrich von Schlegel. Wien: Camesina, 432-462.

Schlegel, Friedrich (1975): Über die Sprache und Weisheit der Indier [1808]. In: Ders.: Kritische Friedrich-Schlegel-Ausgabe. Bd. 8. Studien zur Philosophie und Theologie. Unter Mitarbeit v. Jean-Jacques Anstett u. Hans Eichner. Hg. v. Ernst Behler u. Ursula Struc-Oppenberg. München: Ferdinand Schöningh, 105-433.

Schlegel, Friedrich (1980): Lucinde. Mit: Friedrich Schleiermacher. Vertraute Briefe über Schlegels >Lucinder. Hg. v. Ursula Schröder. Frankfurt a.M.: Ullstein.

Schnabel, Ulrich (2010): Muße. Vom Glück des Nichtstuns. München: Blessing.

Schoepf, Joachim (2001): Die pädagogischen Konzepte in Thomas Manns »Zauberberg« und ihre Wirkung auf die Hauptfigur Hans Castorp. Marburg: Tectum. 
Schößler, Franziska (2017): Femina Oeconomica. Arbeit, Konsum und Geschlecht in der Literatur. Von Goethe bis Händler. Frankfurt a.M.: Peter Lang.

Schwartz, Matthias (2013): Karrieren des Scheiterns. Verweigerungsgesten in junger polnischer Gegenwartsliteratur. In: Die Welt der Slaven 58, 152-183.

Serres, Michel (1987): Der Parasit. Übers. v. Michael Bischoff. Frankfurt a.M.: Suhrkamp.

Shakespeare, William (2002): King Richard II. Arden Shakespeare Third Series. Hg. v. Charles R. Forker. London: Bloomsbury.

Sieber, Jan (2013): Schweigen, Streiken, Vergessen. Zur Aktivierung durch Passivierung bei Walter Benjamin. In: Theorien der Passivität. Hg. v. Kathrin Busch u. Helmut Draxler. München: Fink, 217-235.

Śliwa, Martyna (2007): Is Poland a Country of Roman Catholic Work Ethics? In: Journal of Management, Spirituality \& Religion 4 (4), 486-504.

Słowiak, Natalia (2009): Menele. Subkultura o tożsamości dewiacyjnej. Krakau: Oficyna Wydawnicza Impuls.

Smith, Adam (2007): An Inquiry into the Nature and Causes of the Wealth of Nations. Hg. v. Jonathan B. Wight. Petersfield: Harriman House.

Spender, Stephen (1969): The Year of the Young Rebels. London: Widenfeld and Nicolson.

Spengler, Oswald (1979): Der Untergang des Abendlandes. Umrisse einer Morphologie der Weltgeschichte. Bd. 2. München: Beck.

Spitta, Juliane (2013): Gemeinschaft jenseits von Identität? Über die paradoxe Renaissance einer politischen Idee. Bielefeld: transcript.

Stock, Irvin (1986): The Magic Mountain. In: Modern Fiction Studies 32 (4), 487520.

Stockhammer, Robert (2017): 1967. Pop, Grammatologie und Politik. Paderborn: Fink.

Strässle, Thomas (2013): Gelassenheit. Über eine andere Haltung zur Welt. München: Hanser.

Straub, Eberhard (2004): Vom Nichtstun. Leben in einer Welt ohne Arbeit. Berlin: Wjs.

Strojnowski, Jerzy (1967): Polska psychiatria społeczna w ujęciu historycznym. In: Roczniki Filozoficzne 15 (4), 39-56.

Strowick, Elisabeth (2009): Sprechende Körper-Poetik der Ansteckung. Performativa in Literatur und Rhetorik. München: Fink.

Thomas von Aquin (1934): Summa theologica. Die deutsche Thomas-Ausgabe. Bd. 1. Gottes Dasein und Wesen. Übers. v. Dominikanern u. Benediktinern 
Deutschlands u. Österreichs. Hg. v. Katholischen Akademikerverband. Salzburg: Anton Pustet.

Thum, Gregor (2006): Ex Oriente lux - ex Oriente furor. Einführung. In: Traumland Osten. Deutsche Bilder vom östlichen Europa im 20. Jahrhundert. Hg. v. Gregor Thum. Göttingen: Vandenhoeck \& Ruprecht, 7-15.

Tonn, Willy Y. (1959): Vorwort. In: Lao-tse: Tao-Tê-King. Übers. v. Victor von Strauß. Hg. v. Willy Y. Tonn. Zürich: Manesse, 5-10.

Tönnies, Ferdinand (1887): Gemeinschaft und Gesellschaft. Abhandlung des Communismus und des Socialismus als empirischer Culturformen. Leipzig: Fues's Verlag.

Trojanow, Ilija (2015): Der überflüssige Mensch. München: DTV.

Vaneigem, Raoul (1967): Traité de savoir-vivre à l'usage des jeunes générations. Paris: Gallimard.

Veblen, Thorstein (1934): The Theory of the Leisure Class. An Economic Study of Institutions. New York: Random House.

Volkening, Heide (2016): Über Europäische Arbeit und die Orientalische Kunst der Passivität. Friedrich Schlegels »Idylle über den Müßiggang«. In: Arbeit und Müßiggang in der Romantik. Hg. v. Claudia Lillge, Thorsten Unger u. Björn Weyand. Paderborn: Fink, 115-128.

Wagner, Karl (1980): Herr und Knecht. Robert Walsers Roman »Der Gehülfe«. Wien: Wilhelm Braumüller.

Walser, Robert (1985): Der Gehülfe. Sämtliche Werke in Einzelausgaben. Bd. 10. Hg. v. Jochen Greven. Zürich: Suhrkamp.

Wandachowicz, Kuba (2002): Generacja Nic. In: Gazeta Wyborcza, 05.09.2002, http://wyborcza.pl/1,75410,10939975,Generacja_Nic.html?disableRedirect $s=$ true [zuletzt besucht am 11.04.2021].

Warchol-Schlottmann, Małgorzata (2009): Polnische Sprache nach der Wende 1989. Frankfurt a.M.: Peter Lang.

Warnock, Mary (1970): Existentialism. Oxford: UP.

Wasihun, Betiel (2017): Nichtstun und dennoch Haltung beobachten - Robert Walser und Samuel Beckett. In: Muße-Faulheit-Nichtstun. Fehlende und fehlschlagende Handlungen in der russischen und europäischen Literatur seit der Aufklärung. Hg. v. Sonja Koroliov u. Andrea Zink. Wiener Slawistischer Almanach, Sonderband 91. Frankfurt a.M.: Peter Lang, 217-238.

Watzlawick, Paul; Beavin, Janet H.; Jackson, Don D. (Hgs.) (1969): Menschliche Kommunikation. Formen, Störungen, Paradoxien. Übers. v. Paul Watzlawick. Bern: Huber. 
Weber, Max (1991): Studienausgabe der Max-Weber-Gesamtausgabe. Abt. I, Bd. 19. Die Wirtschaftsethik der Weltreligionen. Konfuzianismus und Taoismus. Schriften 1915 - 1920. Hg. v. Helwig Schmidt-Glintzer. Tübingen: Mohr Siebeck.

Weisinger, Kenneth (1999): Distant Oil Rigs and Other Erections. In: A Companion to Thomas Mann's The Magic Mountain. Hg. v. Stephen D. Dowden. Columbia: Camden House, 177-220.

Wysling, Hans (2001): Der Zauberberg. In: Thomas-Mann-Handbuch. Hg. v. Helmut Koopmann. 3., aktualisierte Aufl. Stuttgart: Kröner, 397-422.

Zantop, Susanne (1997): Colonial Fantasies. Conquest, Family, and Nation in Precolonial Germany, 1770-1870. Durham: Duke UP.

Zarnowski, Lila (2005): A simple question. An overview of new Polish literature. In: New Zealand Slavonic Journal 39, 121-138.

Žižek, Slavoj (2014): Event. Philosophy in Transit. London: Penguin.

\section{Abbildungen}

Abbildung 1. Jan van der Straet (Stradanus): Allegory of America, ca. 1587-89. Maße: 19 x 26.9cm. Bildquelle: The Metropolitan Museum of Art.

\section{Bibel}

Die Bibel nach der Übersetzung Martin Luthers. Berlin: Evangelische HauptBibelgesellschaft zu Berlin (1968).

\section{Filme/Serien}

The Crown. Staffel 1, Episode 4: Act of God. Regie: Julian Jarrold. Drehbuch: Peter Morgan. GB/USA: Left Bank Pictures/Sony Pictures Television (2016): Fassung: Netflix 2016.

\section{Wörterbücher}

DWB. Deutsches Wörterbuch von Jacob und Wilhelm Grimm. Quellenverzeichnis Leipzig (1854-1961). Leipzig: S. Hirzel (1971).

Duden. Die deutsche Sprache. Wörterbuch in drei Bänden. Hg. v. Werner ScholzeStubenrecht. Berlin: Dudenverlag (2014).

Le grand Robert de la langue française. Bd 3. Hg. v. Alain Rey u. Paul Robert. Paris:

Dictionnaires Le Robert (2001). 


\section{Literaturwissenschaft}

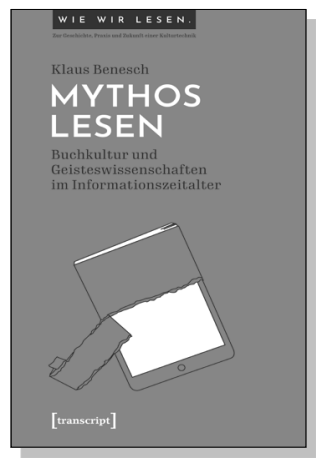

Klaus Benesch

\section{Mythos Lesen}

Buchkultur und Geisteswissenschaften

im Informationszeitalter

März 2021, 96 S., Klappbroschur, Dispersionsbindung 15,00€ (DE), 978-3-8376-5655-8

E-Book:

PDF: $12,99 €$ (DE), ISBN 978-3-8394-5655-2

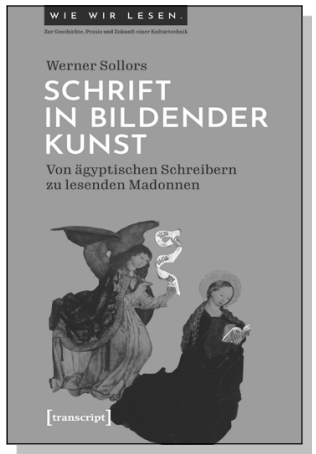

Werner Sollors

\section{Schrift in bildender Kunst}

Von ägyptischen Schreibern zu lesenden Madonnen

2020, 150 S., kart., Dispersionsbindung,

14 Farbabbildungen, 5 SW-Abbildungen

$16,50 €(D E), 978-3-8376-5298-7$

E-Book:

PDF: 14,99 € (DE), ISBN 978-3-8394-5298-1

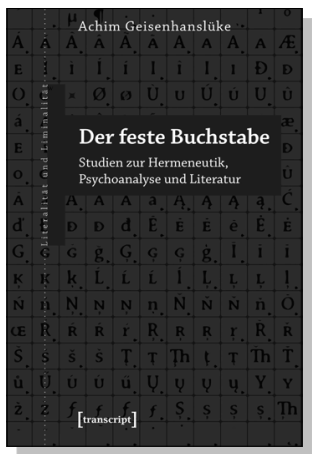

Achim Geisenhanslüke

\section{Der feste Buchstabe}

Studien zur Hermeneutik, Psychoanalyse und Literatur

Januar 2021, 238 S., kart.

$38,00 €(D E), 978-3-8376-5506-3$

E-Book:

PDF: 37,99€ (DE), ISBN 978-3-8394-5506-7 


\section{Literaturwissenschaft}

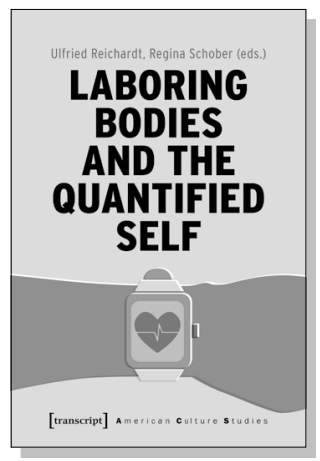

Ulfried Reichardt, Regina Schober (eds.)

Laboring Bodies and the Quantified Self

2020, 246 p., pb.

$40,00 €(D E), 978-3-8376-4921-5$

E-Book:

PDF: $39,99 €$ (DE), ISBN 978-3-8394-4921-9

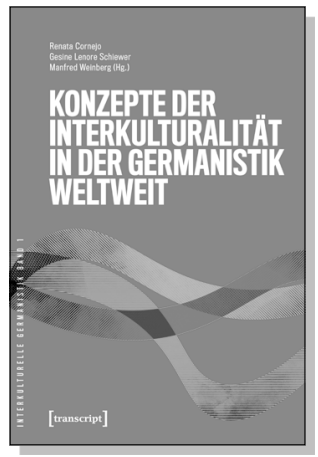

Renata Cornejo, Gesine Lenore Schiewer,

Manfred Weinberg (Hg.)

Konzepte der Interkulturalität

in der Germanistik weltweit

2020, 432 S., kart., Dispersionsbindung, 6 SW-Abbildungen

50,00€ (DE), 978-3-8376-5041-9

E-Book: kostenlos erhältlich als Open-Access-Publikation

PDF: ISBN 978-3-8394-5041-3

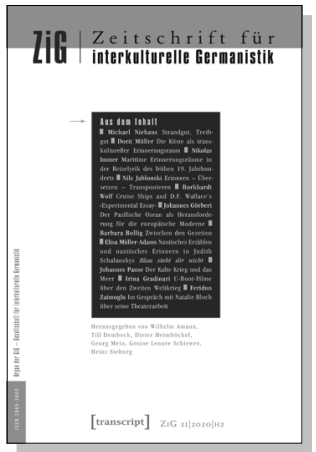

Wilhelm Amann, Till Dembeck, Dieter Heimböckel, Georg Mein, Gesine Lenore Schiewer, Heinz Sieburg (Hg.)

\section{Zeitschrift für interkulturelle Germanistik}

11. Jahrgang, 2020, Heft 2:

Das Meer als Raum transkultureller Erinnerungen

Januar 2021, 258 S., kart., Dispersionsbindung,

25 SW-Abbildungen

12,80€ (DE), 978-3-8376-4945-1

E-Book: kostenlos erhältlich als Open-Access-Publikation

PDF: ISBN 978-3-8394-4945-5 
